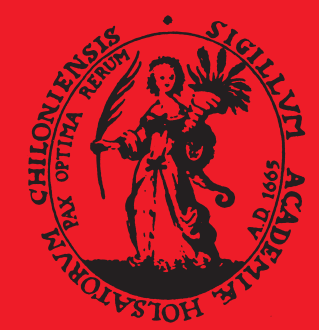

\title{
Kieler Werkstücke Reihe D:
}

Beiträge zur europäischen Geschichte des späten Mittelalters

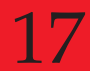

Sonja Dünnebeil (Hrsg.)

Die Protokollbücher des Ordens vom Goldenen Vlies

\section{Teil 4:}

Der Übergang an das Haus Habsburg (1477 bis 1480) 
Das 4. Protokollbuch des Ordens vom Goldenen Vlies berichtet in französischer Sprache über die Aktivitäten des Ordens zwischen 1477 und 1480. Höhepunkt dabei ist das prachtvolle Fest in Brügge im Frühjahr 1478: Hier wurde der neue Herzog von Burgund, der Habsburger Maximilian I., zum neuen Souverän eingesetzt, womit der Beginn einer neuen Ära im krisengeschüttelten Burgund symbolisiert werden sollte. Mit den präzisen Angaben über Ort der Versammlungen, Teilnehmer, Tagesordnungspunkte, Beschlüsse, Neuwahlen und Zeremonien bietet die Edition der Protokolle nicht nur eine bisher unbeachtete Quelle zur Ordensgeschichte, sondern eröffnet auch einen interessanten Blick auf die kritische Zeit Burgunds, denn sie berichtet auch von Identität, Sozialkontrolle sowie von Treue und Verrat.

Sonja Dünnebeil ist für das Historische Seminar in Kiel, das Deutsche Historische Institut in Paris und das Institut für Mittelalterforschung der Österreichischen Akademie der Wissenschaften wissenschaftlich tätig. 
Die Protokollbücher des Ordens vom Goldenen Vlies 


\section{Kieler Werkstücke}

Reihe D:

Beiträge zur europäischen Geschichte des späten Mittelalters

Herausgegeben von Werner Paravicini

Band 17 
Sonja Dünnebeil (Hrsg.)

Die Protokollbücher des Ordens

\title{
vom Goldenen Vlies
}

\author{
Teil 4: \\ Der Übergang an das Haus Habsburg \\ (1477 bis 1480)
}

Vorwort von Werner Paravicini 


\title{
Bibliografische Information der Deutschen Nationalbibliothek
}

Die Deutsche Nationalbibliothek verzeichnet diese Publikation in der Deutschen Nationalbibliografie; detaillierte bibliografische Daten sind im Internet über http://dnb.d-nb.de abrufbar.

Umschlagabbildung:

Siegel der Christian-Albrechts-Universität zu Kiel.

Die Universität trägt ihren Namen nach ihrem Gründer, dem Herzog Christian Albrecht von Schleswig-Holstein-Gottorf, der sie im Jahre 1665 - nur siebzehn Jahre nach dem Ende des Dreißigjährigen Krieges - für sein Herzogtum ins Leben rief. An diese Zeit erinnert auch ihr Siegel: Es zeigt eine Frauengestalt mit einem Palmzweig und einem Füllhorn voller Ähren in den Händen, die den Frieden versinnbildlicht. Das Siegel trägt die Unterschrift: Pax optima rerum (Frieden ist das höchste Gut).

Abdruck mit freundlicher Genehmigung der Christian-Albrechts-Universität zu Kiel.

Dieses Buch ist eine Open Access Publikation und ist auf www.oapen.org und www.peterlang.com verfügbar. Es wird auf der Basis der Creative Commons Attribution Noncommercial, No Derivatives (CC-BY-NC-ND) Lizenz verbreitet.

\author{
ISSN 0936-4161 \\ ISBN 978-3-631-66678-4 (Print) \\ E-ISBN 978-3-653-06144-4 (E-Book) \\ DOI 10.3726/978-3-653-06144-4 \\ (C) Peter Lang GmbH \\ Internationaler Verlag der Wissenschaften \\ Frankfurt am Main 2016 \\ Alle Rechte vorbehalten. \\ Peter Lang Edition ist ein Imprint der Peter Lang GmbH. \\ Peter Lang - Frankfurt am Main · Bern · Bruxelles · New York · \\ Oxford $\cdot$ Warszawa $\cdot$ Wien \\ Das Werk einschließlich aller seiner Teile ist urheberrechtlich \\ geschützt. Jede Verwertung außerhalb der engen Grenzen des \\ Urheberrechtsgesetzes ist ohne Zustimmung des Verlages \\ unzulässig und strafbar. \\ Diese Publikation wurde begutachtet. \\ www.peterlang.com
}




\section{Inhalt}

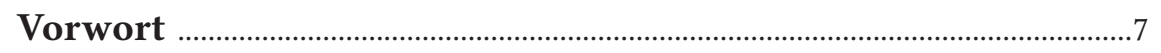

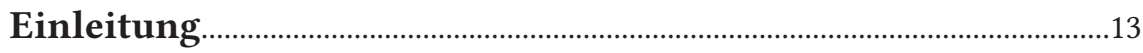

I. Die Übernahme der Ordenssouveränität..........................................................15

A. Die Legitimierung Herzog Maximilians .....................................................16

B. Die Vorbereitungen für die Festlichkeiten................................................19

C. Der Festakt der Inauguration........................................................................20

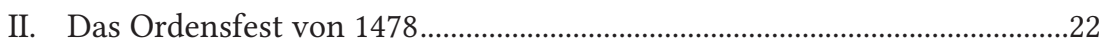

A. Ablauf des Ordensfestes...............................................................................22

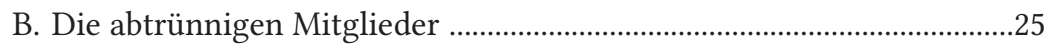

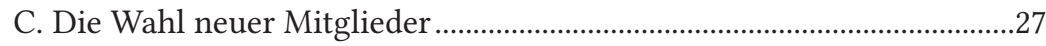

D. Das Wiederaufleben des internen Schiedsgerichts....................................31

III. Die Ordensangelegenheiten zwischen 1478 und 1480 ................................32

A. Das für 1479 geplante Ordensfest............................................................32

B. Die Ordenstreffen am St. Andreas-Tag......................................................33

C. Die Planung des Ordensfestes von 1481....................................................34

IV. Neubesetzungen unter den Amtsträgern des Ordens .....................................34

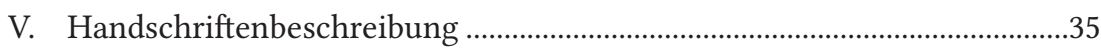

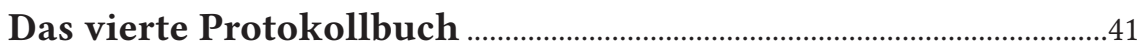

Teil 1: Die Übergabe des Ordens an Herzog Maximilian ...............43

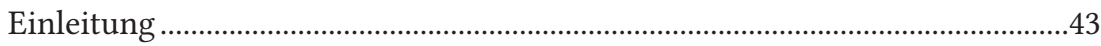

18. bis 23. August 1477 in Gent …………………………………………….....

17. Dezember 1477 in Brüssel ……………………………………………....57

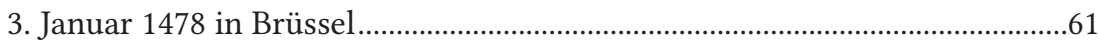

28. April 1478 in Brügge …………………………………………………....6

29. April 1478 in Brügge .................................................................................64

30. April 1478 in Brügge ..................................................................................

Teil 2: Das Ordensfest 1478 in Brügge .................................................. 105

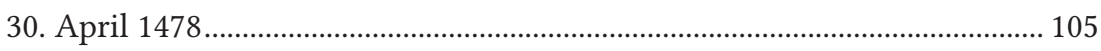

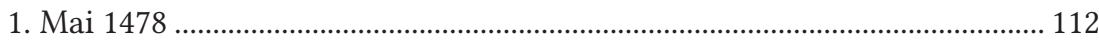




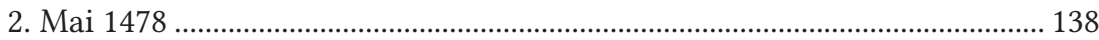

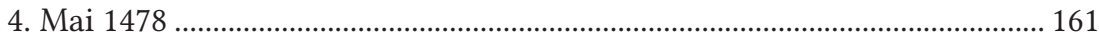

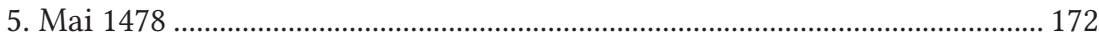

Teil 3: Die Versammlungen zwischen 1478 und 1480 .................. 175

9. September 1478 in Brüssel ............................................................................ 175

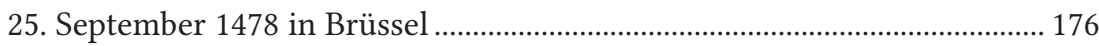

9. Oktober 1478 in Brüssel..................................................................................... 181

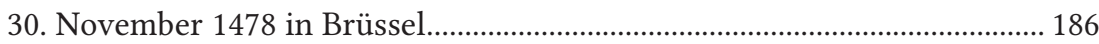

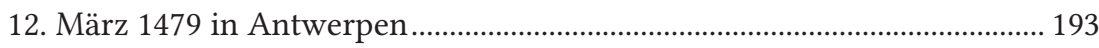

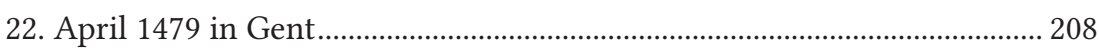

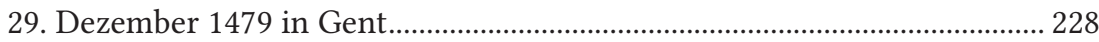

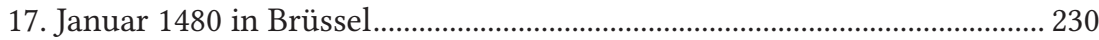

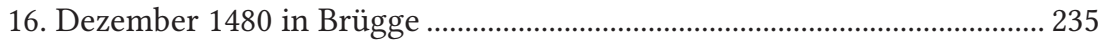

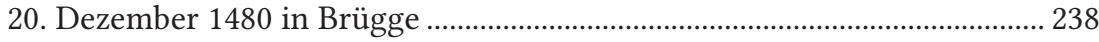

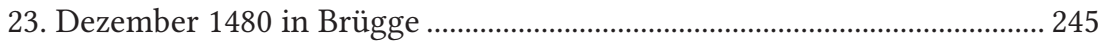

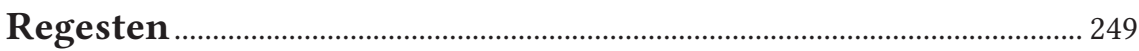

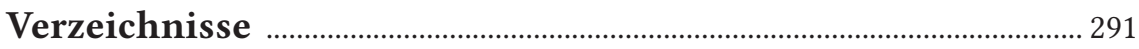

I. Verzeichnis der Feste und Mitglieder des Ordens vom Goldenen Vlies $(1430-1478)$.............................................................................................. 291

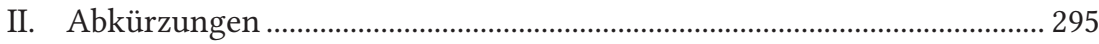

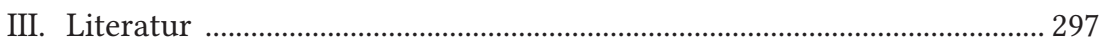

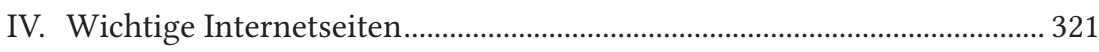

V. Archivalienverzeichnis ..................................................................................... 322

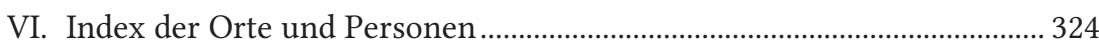




\section{Vorwort}

Allzu oft brechen Quellenveröffentlichungen und Darstellungen zu „Burgund” mit dem Jahre 1477 ab. Glücklicherweise setzt Sonja Dünnebeil ihre Edition der Protokollbücher und Regesten des Ordens vom Goldenen Vlies fort, desjenigen ordre de chevalerie (§ 163), der, wie der englische Hosenbandorden, bis in unsere Tage fortbesteht. Die Forschung fördert er nicht nur passiv, indem er diese Edition erlaubt, sondern seit einigen Jahren auch aktiv, durch wissenschaftliche Tagungen, die er anlässlich seiner Kapitelsitzungen an verschiedenen Orten veranstaltete. ${ }^{1}$ War in Band 3 der Höhepunkt der Regierungszeit Karls des Kühnen im Ordensfest von 1473 in Valenciennes zu beobachten, so ist es jetzt die Krise des burgundischen Staates nach dem Tod des Herrschers am 5. Januar 1477. Posthum erhielt Herzog Karl noch einmal hohes Lob: liberal et magnifique moult singulierement aimant et favorisant justice sei er gewesen; en toute magnificence et vaillance a esté renommé singulierement entre les autres princes de son temps, heißt es ganz richtig in $\S 124$, wobei darauf zu achten ist, was nicht gelobt wurde. Denn von seinem Vater, le bon duc Phelippe, wird in ganz anderem Ton gesagt, dass er amé et tresamé de tous gewesen sei, par la bonté et doulceur qui estoit en lui (§ 126). Jetzt drohte der Orden sich aufzulösen: Dreizehn Mitglieder waren gestorben, fünf hatten die Partei Ludwigs XI. ergriffen, der Herzog von Kleve reagierte nicht auf die Einladung, verstimmt darüber, dass die Hand Marias von Burgund nicht seinem Sohn gegeben worden war, was eine diplomatische Krankheit zur Folge hatte, wie aus der Marginalie zu § 9 zu ersehen ist (und aus $\S 209$ und 228-232). Der englische König hatte aufgehört die Ordenskette zu tragen (§ 201, 268), nur fünf altgediente Mitglieder versammelten sich um Maximilian Ende April 1478 in Brügge, und der musste erst noch zum Ordenssouverän gemacht werden und zum chevalier, denn bislang hatte er den Ritterschlag, den er sich von seinem Vater, dem Kaiser wünschte, noch gar nicht erhalten. Wie er dann Ritter wurde, ist hier ausnahmsweise einmal ganz genau beschrieben (§ 54).

Zweieinhalb Jahre später hatte sich die Situation nicht wirklich gebessert (§ $265 \mathrm{f}$.), und sie tat es auch nicht wesentlich bis zum Friedensschluss von Arras im Jahre 1482. War der Mann der Erbin Maria überhaupt berechtigt, die Ordensleitung zu übernehmen? Ludwig XI. bestritt dies: Da nunmehr er im Besitz des Herzogtums Burgund sei, unterstehe der Orden ihm. Dies wurde ausgesprochen, als die abgefallenen bzw. gefangenen Mitgliedern - Anton, der Große Bastard von Burgund, Jacques de Luxembourg-Richebourg, Philippe Pot, Philippe de Crèvecœur (beide Patenkinder Herzog Philipps des Guten), Jean de Damas-Clessy, Jean de Neufchâtel-Montaigu - aufgefordert wurden, auf dem nächsten Fest zu erscheinen und sich zu rechtfertigen. Die Schilderung, wie der Herold Fusil in Poitiers vor den versammelten Hof tritt und seine Schreiben übergeben will, wie Ludwig XI. antwortet und nach ihm, offensichtlich peinlich berührt (er trägt den

1 Das Haus Österreich und der Orden vom Goldenen Vlies, hg. von der Ordenskanzlei. Beiträge zum wissenschaftliche Symposium am 30. November und 1. Dezember 2006 in Stift Heiligenkreuz, Graz/Stuttgart 2007. - Fondation et rayonnement de l'Ordre de la Toison d'or. Colloque organisé à l'occasion du chapitre de la Toison d'or, Dijon, 30 novembre $-1^{\text {er }}$ décembre 2007, par l'Académie des sciences, arts et belles-lettres de Dijon (Mémoires de l'Académie des sciences, arts et belles-lettres de Dijon, $142^{\text {bis }}$ ), Dijon 2008. 
königlichen Michaelsorden), der Herr von Richebourg, gehört zu den kostbaren Texten dieses Bandes (§ 29, Reg. 75-79, 100). Richebourg, seit 1475 in französischer Gefangenschaft und vom König davon befreit, will doch noch nicht ganz brechen, nimmt das Schreiben entgegen, antwortet, dass er kommen wolle (Reg. 99), tut es aber schließlich doch nicht. Um Clessy zu erreichen, reist ein anderer Herold, Ferrette, nach Mâcon, wo Clessy als von Ludwig XI. bestätigter Amtmann tätig war, und musste erleben, wie dort seine traditionelle Immunität ihm nichts nützte, er gefangengenommen wurde, man ihm den Wappenrock zerreißt und ihn all seiner Briefschaften beraubt (§ 119). Der Abfall vom Haus Burgund, auch in den Hofordnungen derselben Zeit aufscheinend, ${ }^{2}$ noch nie zusammenfassend untersucht, ${ }^{3}$ war in der Mehrzahl der Fälle unumkehrbar. ${ }^{4}$ Ludwig XI. zahlte mit Bedacht sehr gut: Zu den 16 größten Pensionsempfängern des Jahres 1481 (die Höchstsumme, für Pierre de Bourbon, betrug $20.000 £$ von Tours) zählten auch der Große Bastard Anton und Philippe de Crèvecœur, beide mit $12.000 £$, und Richebourg mit $10.000 £$, ebensoviel wie Johann von Burgund, Graf von Nevers, doch kamen noch $2.000 £$ für Richebourgs Frau hinzu. Jean de Damas wurde mit $5.000 £$ ausgestattet, ${ }^{5}$ Philippe Pot mit 4.000 £. Jean de Neufchâtel-Montaigu erhielt $1.200 £$. Zum Vergleich: Philippe de Commynes, auch er ein Patenkind Herzog Philipps des Guten wie Crèvecœur und Pot, strich $6.000 £$ ein, ebensoviel ein weiterer burgundischer Bastard, Baudouin; dessen Kompagnon Jean d'Arson kam immer noch auf $1.200 £ .^{6}$

Lebenswirkliche Details dieser Art enthält der Text an vielen Stellen. Wo wohnten die Ordensritter? Ludwig von Brügge, Herr von Gruuthuse, stets auch als Graf von Winchester bezeichnet, hatte sein Quartier im Genter Hof van de Walle sur la porte (§ 10). Auch Philipp de Croy-Chimay verfügte in der Residenz zu Brügge und zu Brüssel über ein Zimmer oder eher Appartement, das ihm als Erstem Kammerherrn zustand (§ 21, 22, 196, 206 219, 263). Adolf von Kleve-Ravenstein logierte in Brügge bei ihm (§ 196), in Brüssel aber besaß er seine eigene Stadtresidenz, das Hôtel Ravenstein, das sogar bis in unsere Tage erhalten ist; auch dort versammelte man sich, en sa petite chambre (§ 16). Maximilian beriet sich mit den Ordensrittern in der chambre de son retrait ( $\$ 260$, 269), der chambre de son petit retrait (§ 220), einer chambrette (§ 277), also im privaten Bereich der größten Nähe. Welche Phasen ein Briefentwurf durchlaufen musste, bis er ausgefertigt und versandt wurde, lehren die $\S 14-19$. Wie bezeugt man einander amour und benivolence? Mit Kuss und Hand: levé par la main, baillé la main oder touchié de la main (§ 61-65), was dann nicht möglich ist, wenn der Betreffende den Arm in einer Schärpe tragt, der Gicht wegen, unter der nicht nur Adolf von Kleve-Ravenstein litt, sondern auch Saint-Pol (§ 222, 237, 269). Da musste dann die Umarmung ausreichen

2 Die Veröffentlichung der Hofordnungen Marias, Maximilians und Philipps des Schönen, hg. v. Valérie Bessey, Jean-Marie Cauchies und Werner Paravicini, ist für 2017 vorgesehen, ebenfalls in der Reihe der Kieler Werkstücke.

3 Siehe aber STERCHI, Überläufer, 2003, worin mehrere ihrer Briefe gedruckt sind. Material für die Zeit vor 1477 wird der von Valérie Bessey und Werner Paravicini herausgegebene Band „La Guerre des Manifestes” bieten, dessen Erscheinen bei der Académie des Inscriptions et Belles-Lettres, Paris, für 2016 geplant ist.

4 Hugues de Châlon, Herr von Châtelguyon, blieb dem Hause Burgund hingegen treu, s. $\S 134,221,235$.

5 Chevaliers de la Toison d'or, ${ }^{2} 2000$, S. 155.

6 Dauphant, 700 pensionnaires, 2015, hier S. 29, 43-50 sowie (in der Reihenfolge der obigen Erwähnungen) Nr. 4, 503, 671, 22, 300, 637, 242, 15, 66, 299 und 511. 
(§ 237, 261). Zwar waren alle Ordensmitglieder chevaliers freres und haulz, nobles et puissans messeigneurs (§ 239), dazu mehr oder minder fiktive cousins des Ordenssouveräns. Auch fällte dieser keine Entscheidung, ohne alle oder wenigstens die in seiner Nähe befindlichen befragt zu haben. Aber wenn man ihn anspricht, dann stets auf Knien, a genoulx humblement et reverenment (z.B. § 237). Nur Ferry de Clugny als neuernannter Kardinal von S. Vitale, obschon noch Ordenskanzler, kniete nicht (§ 276); als Bischof von Tournai hatte er es noch getan (§ 53). Die Ordensbrüder waren dennoch untereinander nicht gleich: ${ }^{7}$ Den Königen gebührte die Anrede treshault et trespuissant, bei Herzog Albrecht von Sachsen aber entfiel das tres (§ 154), die Prinzen aus dem Hause Kleve und Savoyen waren treschier et tresamé, ihnen schrieb Maximilian in erster Person, den geringeren treschier et feal im Pluralis majestatis; auch die Form von Über- und Unterschrift brachte Standesunterschiede zum Ausdruck (§ 254f.). Eine Sonderstellung nimmt der Herr von Egmond ein, der mit tres chier et amé angeredet wurde (§ $252 \mathrm{f}$.). Als jüngerer Bruder und präsumtiver Nachfolger des Herzogs Arnold von Geldern war er ein Prinz. Aus der kleinen Abweichung spricht aber der nunmehr habsburgische Anspruch auf das Herzogtum Geldern. Köstlich ist die Instruktion für den Gesandten zu König Eduard IV. (Anrede: Sire): Sie enthält sogar die Worte, die er sprechen sollte, um quasi unbemerkt dem König eine Erklärung dafür zu entlocken, weshalb er aufgehört hatte, die Ordenskollane zu tragen (§ 201).

In den vier Jahren, die der Band behandelt, kommt es zwar zu vielen Versammlungen der vorhandenen Ordensritter mit und ohne Maximilian, aber nur zu einem einzigen Ordensfest, das auch noch verkürzt werden musste: Mehr als drei Tage lang konnte der von den Aggressionen Ludwigs XI. getriebene Fürst in Brügge nicht bleiben. Der Krieg ist das leise oder lautere, immer vorhandene Hintergrundgeräusch in diesem Band. Ludwig XI. als vorgeblicher Gesamterbe Karls des Kühnen bemächtigt sich des Herzogtums Burgund und seiner Nebenländer, greift die Franche-Comté an, rückt im Hennegau ein, bedroht Flandern und schließt zwar einen Waffenstillstand, nachdem er bei Enguinegatte südlich Thérouanne im Artois am 7. August 1479 eine heftige Niederlage erlitten hatte. Aber er bricht ihn wieder, als es ihm nützlich zu sein erscheint. Die kriegserfahrenen Ordensritter raten zu grenznahen Versammlungsorten, Saint-Omer, Lille, Douai, auch Valenciennes und Ypern, weniger zum entfernten Brüssel (§ 233, 267, 271, 273). Maximilian hält dagegen, dass gerade diese Stadt im Mittelpunkt der Niederlande liege und er dort am schnellsten von überallher Nachrichten erhalten könne (§ 223) - ein Stück Zentralitätstheorie: Brüssel wird sich auf lange Sicht als Residenz und Hauptstadt durchsetzen. Aber es stellt sich immer wieder heraus, dass das nächste Ordensfest ohnehin verschoben werden muss, erst 1481 kommt es wieder dazu. Dies wird im 5. Band, der weit fortgeschritten ist, beschrieben werden. Ungern beugte man sich derweil der Kraft der Verhältnisse und fürchtet den Spott der Franzosen (§ 240) oder deren Angriff, wenn man den Ort bekanntgäbe (§ 271, 273). Von besonderem Interesse ist ein innenpolitisches Argument, das bei den Beratungen eine bedeutende Rolle spielt, nämlich das Murren, der Unmut des flandrischen Volkes (le peuple) angesichts solch unnützen Zeitaufwands und großer Ausgaben: ce pays de Flandres murmure ja fort, heißt es. Man fürchtet während der Feierlichkeiten militärische Rückschläge zu erleiden, die dem Fürsten und seinen Räten angerechnet werden könnten (§ 239, 244, 264). Öffentliche Meinung gilt etwas, öffentliche Rituale

7 Vgl. unten Anm. 236 zu § 253 und Anm. 1 zu Reg. 1. 
(hier mehrfach als mistere bezeichnet, so z.B. § 1, 6, $37 \mathrm{f} ., 45$ oder $101,{ }^{8}$ oder auch als les louables et honnestes ceremonies, § 220), sind nicht immer angebracht.

Trotz der stets prekären Lage bestehen die wenigen noch vorhandenen Ordensmitglieder auf statutengemäßem Vorgehen (§ 130, 132f., 178). Die vier goldenen Ordenskollanen, die in der Schlacht von Enguinegatte verloren gegangen waren (man trug sie also wirklich im Kampf), ersetzt Maximilian (§ 262 und Reg. 129 und 137-139), obwohl er kaum noch Juwelen besaß, um ehrenvoll damit aufzutreten (§ 264). Die Geheimhaltung der Statuten, der Wahlen, der Beratungen soll unter allen Umständen gewahrt werden (§ 11,101, 188, 197-200). Desto größer die Bestürzung, als es heißt, der Herr von Croy sei von einem Ordensmitglied von seiner (gar nicht erfolgten) Wahl unterrichtet worden (§ 210, 221). Friedrich III. soll den vorgeschriebenen Hand-Eid leisten, den er gar nicht schwören darf (§ 207, 234). Maximilian kennt die üblichen Verfahren nicht und auch nicht die Leute (§ 266), er muss sich erst unterrichten. Französisch versteht er nicht, also werden ihm die Statuten ins Lateinische übersetzt (§ 12, 60, 159, 190f.), dessen er offensichtlich mächtig ist. Andere, die Ordensritter werden sollen, können nicht einmal das, so Bartholomäus von Liechtenstein, Maximilians Hofmeister: point de françois et peu de latin (§ 157). Die Ordensmitglieder wählen ihn etwas unwillig, ebenso wie Herzog Albrecht von Sachsen (§ 132, 149-151): Man kennt den Kandidaten nicht, kann dessen Adel nicht beurteilen, die Wahl gehe auf Maximilians Gewissen (§ 133). Der kann nicht verhindern, dass der Orden seine Privilegien als Sondergruppe vermehrt (§ 172) und als allgemeines Schiedsgericht wieder auflebt, was uns Heutigen rare Einblicke in verdeckte Feindschaften, böswillige Verleumdungen und die Gefahr der division bei Hofe verschafft (§ 237 Croy-Chimay / Luxembourg-Sant Pol: les hayneux, und § 261 Savoyen-Romont / Burgund-Beveren). Die reglementären Sittenrügen, diesmal abgekürzt, geben andere Einblicke, hier in die Würfelpassion und die (übliche) eheliche Untreue des Ahnen des niederländischen Königshauses, Engelbert II. von Nassau (§ 104).

Dass Sprachenfragen noch öfter auftraten als sie es ohnehin zwischen der frankophonen Mehrheit und der germanophonen Minderheit taten, hängt mit dem verständlichen Wunsch Maximilians zusammen, seine Vertrauten auch in den Niederlanden um sich zu haben. Sogleich trennte man diejenigen de la langue franchoise von denjenigen de la nacion d'Alemaigne (§ 47), die überraschenderweise auch als Bavieres, Bayern bezeichnet werden (§ 95).

Wiederum sind die eingesandten Vorschlagslisten für die Neuwahlen aufschlussreich: Der König von Kastilien benannte mit Mathias Corvinus, dem König von Ungarn, und dem Herrn von Beveren zwei Personen, die tatsächlich gewählt wurden, daneben auch den Prinzen von Orange und den Papstnepoten Girolamo Riario und weiter ein Fülle von Leuten iberischer Herkunft (Reg. 31). Der König von Neapel favorisierte neben Mathias von Ungarn eine ganze Reihe deutscher Fürsten, auch Albrecht (Achilles) von Brandenburg und einen seiner wichtigsten neapolitanischen Räte, Diomede Carafa, Grafen von Maddaloni (Reg. 37). Die Liste des greisen, um 1396 geborenen Jean de Melun, der aus Altersgründen nicht mehr reisen kann, entsprach eher der Situation: Sechs oder gar sieben seiner Vorschläge (wenn der Herr von Becan, wie anzunehmen, mit Wolfart VI. von Borssele identisch ist) wurden angenommen, darunter auch Kaiser Friedrich III.; auch er hielt den beim Kaiser sehr einflussreichen Kurfürsten von Brandenburg für einen geeigneten Kandidaten (Reg. 46), zu dessen Wahl es aber nicht kam.

8 Vgl. Melville, Mystère, 2013, wo auf den Begriff allerdings nicht eingegangen wird. 
Deutlich treten die Funktionen der Ordensbeamten hervor: der Kanzler führt das Wort, auch für den Souverän (§ 237). Der Schatzmeister verwahrt das Ordensvermögen. Der Greffier ist das Gedächtnis des Ordens, nicht nur was den älteren Schriftverkehr angeht (§ 273), sondern auch was die Taten und Untaten der Mitglieder betrifft (§ 146): Leider sind diese Aufzeichnungen verloren. Der Wappenkönig Toison d'or vertritt den Orden und den Souverän nach Außen in dessen Personifikation als ranghoher Bote und als Unterhändler. Überhaupt kann man die Herolde bei der Arbeit beobachten, die manchmal im schieren Nichtstun besteht: Toison d'or muss mehr als drei Tage lang in Brüssel warten, ob nicht doch einer der vorgeladenen Abtrünnigen zum abgesagten Fest nach Brüssel kommt. Sein Bericht lässt miterleben, wie er sich von morgens bis abends spazierengehend (moy promenant) die Zeit in- und außerhalb des Palasts und seiner grant salle auf dem Coudenberg vertreibt, lediglich von Mahlzeiten und Gottesdiensten in Sainte-Gudule und Saint-Jacques unterbrochen (§ 256, Reg. 127). Solche Berichte bietet dieser Band mehrere: Fusil über seine Reise an den französischen Hof (§ 225, 227; Reg. 100); Riplemonde (Rupelmonde) über seine Mission nach Burgund (227, 240; Reg. 102); der Herold Ravenstein über seine Englandfahrt (§ 233, Reg. 104), zu der auch Orscamps aufbrach (Reg. 106). Im Übrigen bekräftigt der Herold Ferette (Pfirt) die Wahrhaftigkeit seines Berichts comme officier d'armes (§ 119), so wie der Edelmann sur sa foy et leaulté oder sur son honneur comme noble homme schwört (§ 237) und Maximilian in verbo principis verspricht (§ 59).

Alte Bekannte treten auf, darunter der Hofmeister und Memorialist Olivier de la Marche, der das Ordensfest zu Brügge organisierte (so wie er zehn Jahre zuvor die Hochzeit Karls des Kühnen ebendort gestaltet hatte) und für dasjenige zu Brüssel, das dann nicht zustande kam, vorgesehen war (§ 20, 225; Reg. 41 f., 105). So wird jeder, der diese Texte aufnimmt, ein Stück jener Menschen und jenes Lebens finden, das er sucht. Hier gebe ich nur hors d'œuvres als Einladung, diese Texte nicht nur als das zu lesen, was sie sein wollen, sondern gegen den Strich als wertvolle Quelle für vielerlei Fragen, von der Symbol- und Zeremonialgeschichte über die politische, kriegerische, ständische, kulturelle, weiter zum Thema Treue und Verrat, Persönlichkeit und Geschichte, Jugend und Alter, Anfang und Ende.

Da das Deutsche Historische Institut in Paris nicht dazu zu bewegen war, die im Jahre 2009 mit Band 18 eingestellte Buchreihe der „Instrumenta” wieder aufzunehmen, erscheint dieses Werk nicht mehr in blauem Gewand, sondern im rotem der Kieler Werkstücke. Das DHIP pflegt aber weiterhin das Internetportal „Prosopographia Burgundica”. ${ }^{9}$ Darin wird alsbald die pdf-Datei des vorliegenden Texts zusammen mit den ersten drei Protokollbüchern der gelehrten Welt zur Verfügung stehen. ${ }^{10}$ Die Arbeit an diesem Band finanzierte der Österreichische Wissenschaftsfond (FWF) und die Fondation pour la protection du patrimoine artisanal, historique et culturel in Lausanne, die auch noch die Druckkosten übernommen hat. Allen Mäzenen und Förderern sei hiermit der geziemende Dank gesagt.

Kronshagen bei Kiel, Pfingsten 2015

Werner Paravicini

9 http://www.prosopographia-burgundica.org/.

10 Gleichzeitig wird der Text dieses Protokollbuches auch auf der Seite des Peter LangVerlages unter http://www.peterlang.com/index.cfm?cid=902 abrufbar sein. 



\section{Einleitung}

Mit dem unerwartetem Tod Herzog Karls des Kühnen \{34\} von Burgund während der Schlacht von Nancy am 5. Januar $1477^{1}$ begann in dem Staatengebilde des burgundischen Herzogtums eine neue Ära, denn Karl hinterließ nur eine unverheiratete Tochter als Alleinerbin. Herzogin Maria $^{2}$ sah sich bald mit inneren und äußeren Angriffen konfrontiert und wählte zur Rettung ihres Erbes die Heirat mit Maximilian, dem Sohn Kaiser Friedrichs III. ${ }^{3}$

Im August 1477 traf dann Maximilian von Österreich als strahlender Held gefeiert in den Niederlanden ein und übernahm als Ehemann Marias die Herrschaftsansprüche seines verstorbenen Schwiegervaters Karls und damit auch die Souveränität über den Orden vom Goldenen Vlies. In dem vorliegenden 4. Protokollbuch wird ausführlich Maximilians erste Bewährungsprobe als Souverän des Ordens im Zeitraum zwischen 1477 und 1480 beschrieben. ${ }^{4}$ Dabei teilt sich die Handschrift in drei Teile:

Der erste Teil beschreibt auf 27 Folia den Weg bis zur Ordensübernahme von seiner Ankunft in den Niederlanden bis hin zur feierlichen, öffentlichen Einführung in den Orden in der Salvator-Kirche in Brügge am 30. April 1478. ${ }^{5}$

Im Anschluss daran schloss sich das erste Ordensfest unter seiner Führung an. Die Beschreibung dieses Festes bildet den zweiten Teil der Handschrift. Bedingt durch den

1 Zum Tod Karls des Kühnen vgl. die Angaben in § 2 mit Anm. 9.

2 Maria von Burgund (1457-1482) entstammt der zweiten Ehe Hz. Karls mit Isabella von Bourbon (1437-1465). Zur Person Marias vgl. u. a. MÜNCH, Maria und Margarethe, 1832; Hommel, Marie de Bourgogne, ${ }^{2} 1945$; Blockmans, Maria von Burgund, 1993; Bruges à Beaune, 2000; DünnEBEIL, Erbtochter, 2008; MARTI, Maria, 2008 mit Tafel $79 \mathrm{f}$. (Abb. von Porträts) sowie künftig der Tagungsband Mary of Burgundy: The Reign, the 'Persona' and the Legacy of a European Princess, Brussels and Bruges, hg. von Michael DePreter, Jonathan Dumont, Elizabeth L'EstAnge und Samuel MAREEL (in Vorbereitung).

3 Zur Person Maximilians vgl. u.a. Wiesflecker, Maximilian, 5 Bde., 1971-1986; Noflatscher, Maximilian, 2003; Hollegger, Maximilian I., 2005; Rapp, Maximilien, 2007; Hollegger, Persönlichkeit, 2012, aber auch DünnebeIl, Rolle Burgunds, 2012.

4 Die ersten drei Bände der Protokollbücher des Ordens vom Goldenen Vlies (= PB) behandeln die Zeit vor 1477: PB 1 (erschienen 2002): Herzog Philipp der Gute (14301467) [http://www.perspectivia.net/content/publikationen/instrumenta/duennebeil_ protokollbuecher-1]. PB 2 (erschienen 2003): Das Fest im Jahr 1468 unter Herzog Karl dem Kühnen [http://www.perspectivia.net/content/publikationen/instrumenta/ duennebeil_protokollbuecher-2]. PB 3 (erschienen 2009): Das Fest im Jahr 1473 in Valenciennes unter Herzog Karl dem Kühnen [http://www.perspectivia.net/content/ publikationen/instrumenta/duennebeil_protokollbuecher-3]. Diese drei Bände sind in der Reihe „Instrumenta“ des Deutschen Historischen Instituts in Paris beim ThorbeckeVerlag erschienen. Da diese Reihe jedoch nicht mehr weitergeführt wird, erscheint der vorliegende Band erstmals in der von Werner Paravcini herausgegebenen Reihe „Kieler Werkstücke, Reihe D: Beiträge zur europäischen Geschichte des späten Mittelalters" beim Peter Lang-Verlag. Alle vier Bände sollen jedoch online auf der Plattform „Prosopographia Burgundica” [http://www.prosopographia-burgundica.org/] vereint werden.

5 Dazu ausführlicher S. 15-22. 
französischen Einfall in den Hennegau nahm sich Maximilian jedoch nur knappe drei Tage Zeit, um den Orden und dessen wenige anwesende Mitglieder kennenzulernen. Die Zeit reichte jedoch aus, um die wichtigsten Gottesdienste zu absolvieren und die auf ein Drittel reduzierten Mitgliederzahl durch Neuwahlen zu ergänzen. Zahlreiche andere wichtige Agenden konnten jedoch nicht erledigt werden, deshalb beschlossen die versammelten Ordensmitglieder, dass im folgenden Jahr ein weiteres Ordensfest veranstaltet werden sollte. ${ }^{6}$

Der dritte Teil der Handschrift beschreibt die verschiedenen außerordentlichen Sitzungen zwischen Oktober 1478 und Dezember 1480, bei denen für die dringendsten Angelegenheiten des Ordens Lösungen gesucht wurden, das für 1478 geplante Fest vorbereitet und dann nach eingehender Diskussion aufgrund der politisch unsicheren Zeiten abgesagt wurde. Zuletzt legten die versammelten Mitglieder im Dezember 1480 fest, dass nun ein neues Ordensfest dringend notwendig sei, wofür sie die Einladungen versandten. ${ }^{7}$ Die Beschreibung der weiteren Vorbereitungen und dieses Festes selbst sind dann aber schon Bestandteil des 5. Protokollbuches, dessen Edition ebenfalls schon bald nach dem Erscheinen dieses Bandes erscheinen wird.

Auf insgesamt 89 Folia erfährt man durch das 4. Protokollbuch vieles über die Annäherung zwischen Herzog Maximilian und dem Orden vom Goldenen Vlies und dessen Mitgliedern. Einen Überblick sollen die folgenden Seiten der Einleitung geben, aber dort können nicht alle Facetten dieses beeindruckenden Textes berücksichtigt werden. Nach ausführlicher Beschreibung der Handschrift folgt dann die Edition der Handschrift, die sich nach den bewährten Vorgaben der ersten drei bereits veröffentlichten Protokollbücher richtet. ${ }^{8}$ Ergänzend wurde im Anhang ein Regestenverzeichnis aller bekannten und im Zusammenhang mit dem Orden bis zum Tode Herzog Karls des Kühnen stehenden Schriftstücke hinzugefügt. ${ }^{9}$ Ein Verzeichnis der Ordensmitglieder zwischen 1430 und 1478, ein Literaturverzeichnis sowie ein Archivalien-, Orts- und Namensindex sollen zur schnelleren Orientierung dienen.

Die Realisierung der vorliegenden Edition wurde dankenswerter Weise ermöglicht durch die finanziellen Unterstützung der Fondation pour la protection du patrimoine artisanal, historique et culturel in Lausanne und des Österreichischen Wissenschaftsfonds (Projekte FWF P 21478-G18: Der Orden vom Goldenen Vlies unter Maximilian I. [1477-1486] und P 25157-G18: Der Orden vom Goldenen Vlies zwischen Loyalität und Felonie [1484-1493]). Dem Kanzler des Ordens vom Goldenen Vlies, DI Alexander Pachta-Reyhofen, danke ich für die Erlaubnis für

6 Dazu ausführlicher S. 22-32.

7 Dazu ausführlicher S. 32-35.

8 Zur Anlage der Edition vgl. ausführlich PB 1, S. $24 \mathrm{f}$. Als Neuerung wurde mit diesem Band aber eingeführt, dass inserierte Briefe, Urkunden etc. durch eine kleinere Schriftart gekennzeichnet werden, wie z. B. in § 183-195.

9 Verzeichnet sind Schriftstücke, die zwischen 1477 und Dezember 1480 von Hz. Maximilian oder dem Orden verfasst wurden oder an den Orden oder dessen Souverän gerichtet waren. Dabei wurden in erster Linie die Stücke aus dem Ordensarchiv erfasst und gelegentlich durch Funde in anderen Archiven ergänzt. Bei letzteren wird jedoch kein Anspruch auf Vollständigkeit erhoben. Die tatsächlich durchgesehenen Bestände sind im Register S. 254f. mit einem Stern versehen. - Zur Systematik der Regestenerstellung vgl. PB 1, S. 322 f., wo auch ausführlich beschrieben wird, welche Stücke in den Archiven der Ordensmitglieder zu erwarten sind. 
die Benutzung des Ordensarchivs und die gute Zusammenarbeit. Meinem Lehrer Prof. Dr. Werner Paravicini, der auf vielfältige Art und Weise schon lange meine Arbeit unterstützt, diesen Band kritisch durchgesehen hat und ihn in seiner „wiederbelebten“ Reihe „Kieler Werkstücke, Reihe D: Beiträge zur europäischen Geschichte des späten Mittelalters" aufnimmt, möchte ich an dieser Stelle meine große Dankbarkeit ausdrücken. Bei einer Edition ist das Vieraugenprinzip äußerst wichtig und so danke ich Frau Dr. Andrea Berlin (Bochum/Hagen) für ihr Kollationieren der Handschrift. Besondere Aufmerksamkeit verlangte die lange lateinische Rede des Ordenskanzlers anlässlich Maximilians Einsetzung als Ordenssouverän: Frau MMag. Katharina Kaska (Wien) hat nicht nur den Text transkribiert, sondern auch soweit als möglich die klassischen Zitate identifiziert. Einige Hinweise dazu erhielt ich auch von Frau Dr. Anke Paravicini (Kiel) und Frau Dr. Giesela Naegle (Paris/ Gießen). Zahlreiche Hinweise und Hilfestellungen erhielt ich von Dr. Roland Forster (Eferding), Dr. Eva Helfenstein (ehemals Havard), Dr. Torsten Hiltmann (Münster), Dr. Renate Holzschuh-Hofer (Wien), Dr. Anne-Katrin Kunde (Wien/Luxembourg), Corinna Pichler, BA (Wien), Dr. Claudia Rotthoff-Kraus (Aachen), Marcus Stiebing (Jena) und vielen anderen. Mit meinen großen und kleinen Fragen zur Editionstechnik oder zum Textverständnis fand ich stets ein offenes Ohr bei meinen Kolleginnen und Kollegen der Abteilung Editionsunternehmen \& Quellenforschung / MIR des Instituts für Mittelalterforschung der Österreichischen Akademie der Wissenschaften in Wien, hier vor allem bei Dr. Renate Kohn, Mag. Gertrud Mras, Dr. Andrea Rzihacek, Dr. Kornelia Holzner-Tobisch, Dr. Manfred Hollegger und PD Dr. Andreas Zajic. Ihnen allen sei hier gedankt!

\section{Die Übernahme der Ordenssouveränität}

Der erste Teil der Handschrift beschreibt den Weg von Maximilians Ankunft in den Niederlanden im August 1477 und seiner Hochzeit mit Herzogin Maria von Burgund bis zu seiner feierlichen Inauguration als Souverän des Ordens vom Goldenen Vlies. ${ }^{10}$ Drei Tage nach der Hochzeit versammelten sich einige Mitglieder und Amtsträger des Ordens vom Goldenen Vlies, um über die Zukunft des Ordens zu beraten. Schnell sind sie sich einig, dass statutengemäß Maximilian die Ordenssouveränität zustehe. ${ }^{11}$ Dieses Anliegen unterbreiteten sie dem neuen Herzog in einer Audienz am 23. August 1477. ${ }^{12}$ Der Kanzler und Sprecher des Ordens Ferry de Clugny, Bischof von Tournai, trug nach einer langen Rede über die Vorzüge des Ordens Maximilian die Führung über den Orden vom Goldenen Vlies an. Maximilian ließ durch seinen Rat Dr. Wilhelm Maroltinger in einer lateinischen Rede für das Angebot danken, gab aber zu bedenken, dass ihm der Ritterschlag fehle. Zuletzt wurden die Vliesritter um eine lateinische Übersetzung der Ordensstatuten gebeten, damit Maximilian und seine Räte sich mit dem Orden vertraut machen könnten. Jedoch erst am 17. Dezember 1477 erhielten die Ordensmitglieder Maximilians Zusage, den Orden übernehmen zu wollen. Bei dieser Gelegenheit wurde dann auch beschlossen, die Ordensübernahme mit einem Ordensfest zu verbinden.

10 Vgl. § 1-69. Eine Zusammenfassung des Inhaltes bieten AOGV, Codex 34/1, S. 117-122; Reiffenberg, Toison d'or, 1830, S. 89-91.

11 Vgl. $§ 9$.

12 Vgl. § 10-12. 


\section{A. Die Legitimierung Herzog Maximilians}

Im ersten Teil des Protokolles finden sich neben den Schilderungen über Maximilians Annäherung an den Orden umfangreiche Eintragungen, die beweisen sollten, dass Maximilian auch tatsächlich der legitime Nachfolger Herzog Karls war. ${ }^{13}$ Dies erfolgte in zwei verschiedenen Argumentationssträngen, nämlich durch die Berufung auf die Erbfolgeregelung der Statuten des Ordens vom Goldenen Vlies einerseits und durch die Betonung, dass die Heirat nach dem Willen und Wunsch des verstorbenen Herzog Karl geschlossen worden war, andererseits.

In den Statuten wurde die Nachfolge in der Ordenssouveränität klar geregelt: ${ }^{14}$ Wenn der Souverän ohne männlichen Erben verstirbt, soll der Ehemann der Erbtochter den Orden vom Goldenen Vlies übernehmen. Des weiteren bestimmen die Statuten, dass bis zur Verheiratung der Erbtochter oder bis zur Volljährigkeit ihres Ehemannes oder des Erben, die Mitglieder aus ihren Reihen einen wählen sollen, der bis zur Volljährigkeit und bis zum Ritterschlag des designierten Nachfolgers die Ordensgeschäfte führen sollte.

Somit hatte Herzog Maximilian eindeutig durch seine Heirat mit Maria Anrecht auf die Souveränität über den Orden. Die einleitenden Eintragungen im Protokollbuch betonen des Weiteren, dass Maria die einzige Tochter und somit legitime Erbin Herzog Karls und dessen Herrschaften und Besitzungen war. ${ }^{15}$ Dem gegenüber hatte König Ludwig XI. von Frankreich behauptet, dass die französischen Kronlehen Burgunds als reine Mannlehen nicht an Maria übergehen könnten. Deshalb hatte er nach dem Tode Herzog Karls seine Truppen gegen das Herzogtum und die Freigrafschaft Burgund sowie gegen die nördlichen Grenzgebiete in die Pikardie und den Artois in Bewegung gesetzt. Darüber hinaus wählte er auch den gerichtlichen Weg und ließ im Frühjahr 1478 am Parlament von Paris einen Prozess gegen den verstorbenen Herzog Karl wegen Majestätsverbrechens eröffnen, um auf diesem Weg seine Rückforderung auf die burgundischen Gebiete zu untermauern. ${ }^{16}$ Mit der Begründung die Souveränität über den Orden vom Goldenen Vlies sei an das Herzogtum Burgund geknüpft, proklamierte Ludwig XI. Anfang Mai 1478 sich selbst zum Souverän des Ordens und verbot den an seinem Hof weilenden Vliesrittern, zu dem Ordensfest nach Brügge zu reisen, zu dem Herzog Maximilian eingeladen hatte. ${ }^{17}$

13 Vgl. dazu auch DünNeBEIL, Zeichen, 2012, S. $113 \mathrm{f}$.

14 Der entsprechende Paragraph der Statuten ist unten in $\S 3$ zitiert. Die vorliegende Edition richtet sich nach der Statutenedition in PB 1, S. 196-231; dort S. 189-195 zu Genese der Statuten, deren archivalische Überlieferung und Drucke. Zwischenzeitlich ist auch noch eine engl. Übersetzung der Statuten in Court and Civic Society, 2007, S. 137-155, erschienen. Zu den Statuten vgl. aber auch die Angaben in § 12, 62, Anm. 326 und § 190.

15 Vgl. § 2.

16 Vgl. dazu u.a. Lettres de Louis XI, 7, 1900, S. 53 ff., Nr. 1135 ff.; Kervyn De LetTenHove, Histoire de Flandre, V, 1850, S. 295; Hollegger, Maximilian I., 2005, S. 32 und 44 f.; Kintzinger, Caesar, 2010. S. 136 f.; Paravicini, Souverain seigneur, 2010, S. 45 f. Nach Bock, Maximilian, 1970, S. 41 war Hz.in Marias rechtliche Stellung als Erbin der Ländereien des burgundischen Gesamtstaates unangreifbar.

17 Davon berichtet der burgundische Herold Fusil am 19. Jan. 1479 nach seiner Rückkehr vom französischen Hof, wo er bei seinen Bemühungen, den dort weilenden Vliesrittern ihre Vorladungsschreiben für das 1479 geplante Ordensfest zu überbringen, auch ein Gespräch mit König Ludwig XI. hatte; vgl. Reg. 100. Fusil brachte auch einen Brief des 
Um ihr Erbe vor den äußeren Angriffen König Ludwigs XI., aber auch vor den inneren Angriffen und Unruhen zu schützen, wurde nach dem Tod Karls seine unverheiratete Erbin Maria von allen Seiten gedrängt, möglichst schnell zu heiraten. Kandidaten standen angesichts ihrer immensen Besitzungen und des sagenhaften burgundischen Reichtums mehrere zu Verfügung, allen voran der Kaisersohn Maximilian. In Frage kamen aber auch der achtjährige französische Dauphin Karl, Herzog Georg von Clarence und Anton Woodville, beide aus der Familie des englischen Königs Eduards IV., sowie mehrere am burgundischen Hof aufgewachsene Adlige, wie der Jungherzog Johann II. von Kleve, dessen Cousins Philipp von Kleve oder Adolf von Egmond. Bald zeigte sich eine Mehrheit für den Kaisersohn Maximilian, der seit 1463 immer wieder und mit wechselnder Intensität als einer der vielen möglichen Heiratskandidaten gehandelt worden war. Herzog Karl sah in der Verheiratung seiner einzigen Tochter ein Faustpfand zur Durchsetzung seiner ehrgeizigen Pläne ${ }^{18}$ und spätestens in den 1470er Jahren erhoffte er sich durch die Verheiratung seiner Tochter mit dem Sohne Kaiser Friedrichs III. die römisch-deutsche Königs- und Kaiserkrone zu erringen oder wenigsten ein (von Frankreich) unabhängiges Königreich zu erhalten. Diese Verhandlungen scheiterten während des großen Treffens in Trier zwischen ihm und Kaiser Friedrich III. im Herbst $1473 .{ }^{19}$ Überraschenderweise stimmte Karl dann aber nach seiner Niederlage bei Grandson am 6. Mai 1476 der Heirat zwischen Maximilian und Maria zu, ohne auf seinen bisherigen Forderungen zu bestehen. ${ }^{20}$ Der für den November 1476 geplante Hochzeittermin in Köln verstrich zwar, aber Karl, Maria und Maximilian tauschten in dieser Zeit mehrere Briefe und

Jacques de Luxembourg $\{61\}$ mit, in dem dieser ebenfalls Ludwigs Ansprüche unterstrich; vgl. Reg. 99. Auch die Mémoires de la Marche, 3, 1885, S. 249, beschreiben, dass es commune renommée gewesen sei, dass Kg. Ludwig XI. die Führung über den Orden vom Goldenen Vlies für sich beanspruchte. Vgl. dazu auch Roo, Annales rerum, 1592, S. 327; Roo, Annales rerum (dt.), 1621, S. 336; Fugger, Spiegel der Ehren, 1668, S. 881; Chroniques de Molinet, I, 1935, S. 249; Fichtenau, Maximilian, 1959, S. 35; Bock, Maximilian, 1970, S. 40 f.; DünnebeIL, Zeichen, 2012, S. 116 f.; vgl. dazu auch S. 27 mit Anm. 69.

18 Vaughan, Charles the Bold, 1973, S. 126 f. bezeichnete Maria als Karls "diplomatic weapon of universal value". Die burgundisch-habsburgische Heirat wurde in der Forschung vielfach thematisiert, deshalb sollen hier nur einige wenige Titel genannt werden: Rausch, Heirat, 1880; DíEz, Política matrimonial, 2004, S. 75-83; Blockmans, Maximilian, 2002, S. 52-54; HeInIG, Westpolitik, 2004, S. 59-69; Debris, Felix Austria, 2005, S. 191-194 und 576-582; Koller, Friedrich III., 2005, S. 198-203; Hollegger, Maximilian I., 2005, S. 29-37; Oschema, Freundschaft, 2006, S. 38-40; DünnebeIl, Erbtochter, 2008; KoHLER, Expansion, 2008, S. 327-333 („Der Konflikt um das burgundische Erbe“); Just, Burgund, 2009, S. 21-24; Haemers, Common Good, 2009, S. 18-21; DüNNEBEIL, Rolle Burgunds, 2012, S. 73-76 sowie künftig dies., Mary.

19 Zum Trierer Treffen vgl. die Angaben in § 4, Anm. 13.

20 Hz. Karls Zustimmung befindet sich im Or. im HHStA Wien, Familienurkunden, Nr. 727; Kop. (18. Jh.) ebd., Urkundenabschriften, Collationierte Urkunden, Karton 73, sub dato). Druck: Chmel, Aktenstücke, 1, 1854, S. 134f., Nr. 32. Dazu auch Rausch, Heirat, 1880, S. 222; Stein/Dünnebeil, Catalogue S. 580 f. Nr. 2325; Hollweg, Heßler, S. 29 und 41; Heinig, Westpolitik S. 68; DünNebeIL, Erbtochter, 2008, S. 174; Kat. Karl der Kühne, 2008, S. 348, Nr. 157 (mit Abb.). 
Urkunden aus, die ihre Freude an der bevorstehenden Hochzeit bekundeten. ${ }^{21}$ Die Ereignisse nach dem Tod Karls zeigen aber, dass dennoch auch andere Kandidaten noch Hoffnung auf eine Ehe mit Maria hatten. Nachdem Kaiser Friedrich III. Ende Januar 1477 von Karls Tod erfahren hatte, warb er einerseits in zahlreichen Briefen bei den wichtigsten burgundischen Amtsträgern, Städten und Ständen für die burgundisch-habsburgische Heirat und entsandte andererseits eine hochkarätige Gesandtschaft nach Burgund. ${ }^{22}$ Diese erwirkte, dass am 21. April 1477 die Heirat zwischen Maximilian und Maria per procuram geschlossen wurde. Im darauf folgenden August trafen die Brautleute zum ersten Mal zusammen und wurden am 19. August in Gent getraut. ${ }^{23}$

Im Protokollbuch wird eigens betont, dass über diese Heiratsverbindung schon während des Trierer Treffens und durch verschiedene Gesandtschaften verhandelt worden war und dass Herzog Karl noch vor seinem Tode die Heiratsverträge ausgestellt und besiegelt hatte. ${ }^{24}$ Johann Jacob Fugger geht in seinem „Spiegel der Ehren“ mit Herzog Karls Zustimmung für die burgundisch-habsburgische Heirat noch weiter, in dem er berichtet, dass Karl beim Besteigen seines Pferdes, um in die Schlacht von Nancy zu reiten, einem seiner Vertrautesten mündlich anbefahle, auch einen geschriebenen Zettel darüber zustellte, wie es mit seinen Landen nach seinem Tod gehalten und an wen seine Tochter Maria vermählt werden sollte. ${ }^{25}$

Neben Karls Zustimmung zur Heirat wurde im Protokollbuch aber auch erwähnt, dass nach seinem Tod eine kaiserliche Gesandtschaft bei Herzogin Maria und Karls Witwe Margarete erfolgreich für die Heirat geworben hatte. ${ }^{26}$

21 Vgl. dazu u.a. DünNEBEIL, Erbtochter, 2008, S. 175. Zuletzt hatte Maria am 26. März 1477 einen eindringlichen Brief an Maximilian geschrieben, in dem sie ihren Verlobten um eine rasche Heirat und um wirkungsvolle Unterstützung in Flandern bat; vgl. dazu zuletzt Kat. Karl der Kühne, 2008, S. 349, Nr. 159 (mit Abb.).

22 Ks. Friedrich III. stellte am 15. Febr. 1477 für diese Gesandtschaft einen Kredenzbrief aus. Am 14. April hielt sich die Gesandtschaft in Mecheln auf, wo sie mit Hz.in Margarete von Burgund zusammentraf. Zwei Tage später, am 16. April, trafen sie dann in Gent ein und wurde am 18. April von Hz.in Maria empfangen. Ergebnis der Verhandlungen war der Vollzug der Heirat per procuram am 21. April. Zahlreiche Schriftstücke im Zusammenhang von dieser Gesandtschaft druckt CHMEL, Aktenstücke, 1, 1854, S. 137-158, Nr. 35-48; vgl. dazu auch Mémoires de la MArche, 3, 1885, S. 242f.; Rausch, Heirat, 1880, S. 166-171; Wiesflecker, Maximilian, 1, 1971, S. 121-126; DüNNeBEIL, Erbtochter, 2008, S. $180 \mathrm{f}$.

23 Dazu auch $\S 6-8$.

24 Vgl. § 4.

25 Fugger, Spiegel der Ehren, 1668, S. 835; danach Wiesflecker, Maximilian, 1, 1971, S. 111 mit Anm. 46 auf S. 446.

26 Vgl. $§ 5$. 


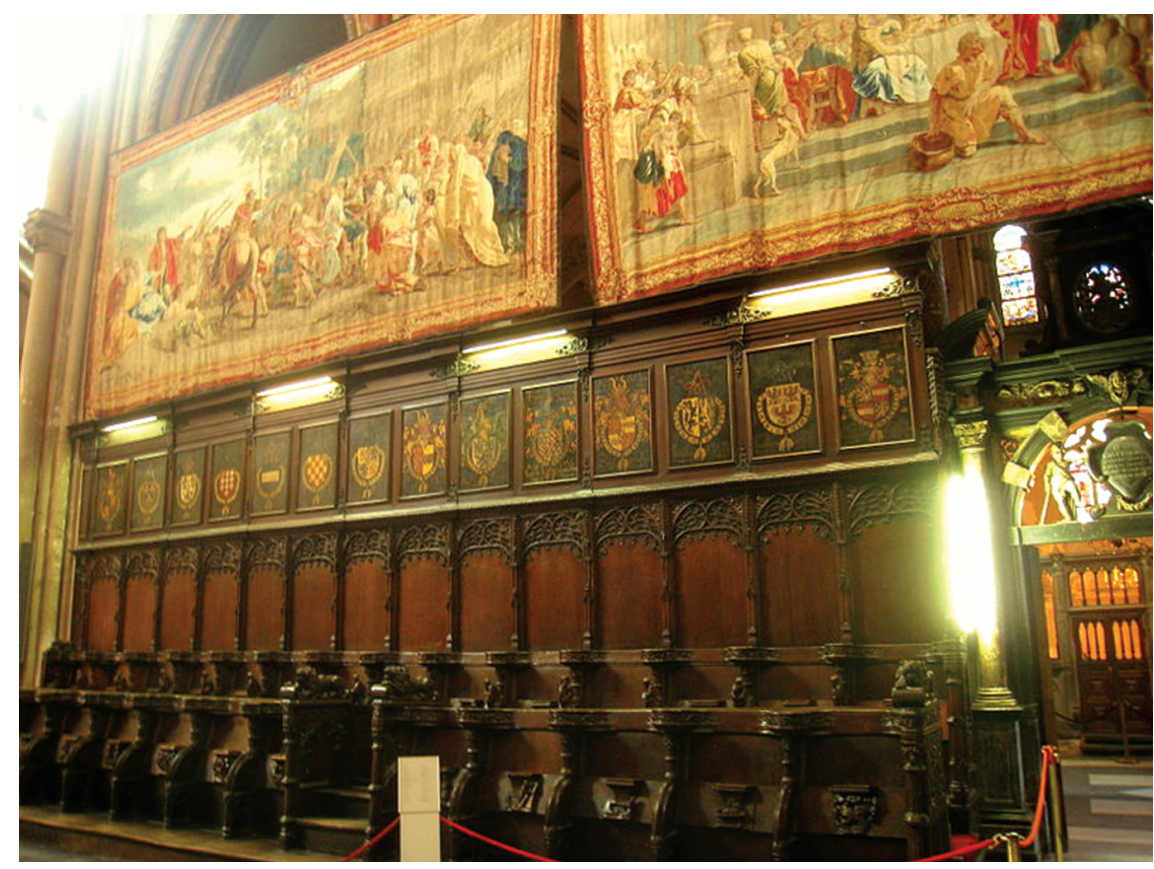

Abbildung 1 Die Wappentafeln von 1478 in der Salvatorkirche in Brügge

\section{B. Die Vorbereitungen für die Festlichkeiten}

Nachdem Maximilian am 17. Dezember 1477 zugestimmt hatte, die Ordenssouveränität anzunehmen, wurde mit der Planung des Festaktes, der öffentlich zelebriert werden sollte, und des daran anschließenden Ordensfestes begonnen.

Damit auch die weit entfernt lebenden Mitglieder rechtzeitig von den geplanten Ordensfeierlichkeiten erfuhren, wurden alsbald die Einladungsschreiben aufgesetzt. Man beschloss dazu zwei verschiedenen Schreiben zu verfassen: Im ersten Schreiben, das im Namen Maximilians verfasst und von diesem eigenhändig unterschrieben wurde, teilte Maximilian den Mitgliedern mit, dass er durch seine Heirat mit Maria von Burgund auch die Nachfolge als Souverän des Ordens vom Goldenen Vlies antreten werde. Dazu und zu dem daran anschließenden Ordensfest lud er die Mitglieder ein und wies sie darauf hin, dass sie im Falle des Nichterscheinens die entsprechenden Absageschreiben und Vorschläge zur Neubesetzung der zwölf vakanten Mitgliederplätze senden sollten. In einem zweiten Schreiben bestätigten die drei bei Maximilian weilenden Ordensritter, namentlich Adolf von Kleve $\{55\}$, Ludwig von Brügge $\{61\}$ und Philippe de Croy $\{74\}$, die Richtigkeit von Maximilians Einladungsschreiben. ${ }^{27}$

27 Die Einladungsschreiben Maximilian, die im internen Sprachgebrauch als lettres de l'intimacion et significacion bezeichnet wurden, erhielten bei verschiedenen Mitgliedern noch indivuiduelle Nachsätze; vgl. dazu Reg. 1-13 sowie in Reg. 14-25 die Schreiben der drei Ordensritter. Die verschiedenen Einladungsschreiben sind zwar mit dem 26. De- 
Dennoch wurde die Rechtmäßigkeit der Einladungen von zwei Seiten in Frage gestellt: Zum einen von König Ludwig XI. von Frankreich, der wie schon berichtet, selbst Anspruch auf die Ordenssouveränität erhob, und zum anderen von König Eduard IV. von England $\{63\} .^{28}$ Letzterer sandte zwar am 14. März 1478 einen Brief mit seiner Absage, verweigerte aber weitere Formalitäten, wie Ernennung eines Stellvertreters und Wahlvorschläge, da die Einladung seiner Meinung nach nicht von einem ordentlich eingesetzten Souverän erfolgt sei.

Wurde in den Einladungsschreiben als Austragungsort des Festes Mons in Aussicht gestellt, so fiel Anfang April die Entscheidung auf Brügge ${ }^{29}$ und für die Gottesdienste wurde die Salvatorkirche gewählt. ${ }^{30}$ Für diesen Anlass wurde die Kirche aufwändig umgestaltet und in der Mitte vor dem Chor wurde eine hölzerne Estrade (grant hourt spacieux) aufgebaut, in dem für alle gut sichtbar die Angehörigen des Ordens während der Gottesdienste sitzen sollten. Ausgeschmückt wurde diese Estrade mit Säulen, einer Galerie für die Herolde und zahlreichen Tapisserien. An zentraler Stelle befand sich der Sitz des Ordenssouveräns, von dem ausgehend jeweils links und rechts die Bänke für die Ordensritter aufgestellt waren. Entsprechend ihres Ranges innerhalb des Ordens waren die Sitzplätze für die einzelnen Ordensritter reserviert und über dem Platz hing das Wappen des jeweiligen Ritters (Abbildung 1). ${ }^{31}$ Aber auch die Plätze für die Damen des Hofes, die von den Herzoginnen Maria und Margarete angeführt wurden, und für die zahlreichen Ehrengäste, die im Kirchenschiff ihre Plätze einnahmen, wurden ausgeschmückt. ${ }^{32}$ Die letzten Feinheiten für den Ablauf der Inauguration Maximilians am 30. April wurden von den angereisten Ordensmitgliedern und Amtsträgern noch am 28. und 29. April geregelt. ${ }^{33}$

\section{Der Festakt der Inauguration}

Die Feierlichkeiten selbst wurden unter Einbeziehung des gesamten herzoglichen Hofes als Akteure und aller in Brügge anwesender Personen als Zeugen zelebriert. ${ }^{34}$

zember 1477 datiert, doch auch am 3. Januar 1478 wurde noch über Details diskutiert; vgl. dazu § 14-19.

28 Vgl. dazu S. 16f. (Ludwig XI.) und Reg. 29 (Eduard IV.).

29 Vgl. § 20. Der Ordenskanzler Ferry de Clugny und Olivier de la Marche wurde am 7. April 1478 beauftragt, in Brügge die Feierlichkeiten vorzubereiten; vgl. Reg. 41 und 42.

30 Schon früher war Brügge die Gastgeberstadt für den Orden gewesen, so bei der Ordensgründung 1431 und den Festen von 1432 und 1468.

31 Die Wappentafel sind noch heute in der Kirche vorhanden; vgl. dazu die Beschreibung im Protokoll in § 31-34 sowie die Anmerkungen in den Fußnoten 187, 190-195. Abbildung 1 wurde aus http://commons.wikimedia.org/wiki/File:Sint-Salvatorskathedraal_-_Bruges_-_IMG_4744.JPG (11.11.2015) entnommen. Zur Sitz- und Rangordnung der Mitglieder vgl. Tabelle 1.

32 Zur Gestaltung der Kirche vgl. § 36-38; dazu auch Verschelde, Feeste, 1873, S. 25 (nach Stadtbibl. Brügge, Historisch Fonds ms. 437 [Excellente Chronycke van Vlaanderen]); DünnebeIL, Order of the Golden Fleece, 2013, S. 60 f.; dies., Aufnahme, 2014, S. $81 \mathrm{f}$.

33 Vgl. § 21-35.

34 Zur Beschreibung des Festaktes vgl. § 39-68 sowie u. a. - wenn auch bei weitem nicht so detailliert - Toison d'or, 1689, 208-214; Fugger, Spiegel der Ehren, 1668, S. 881; Chroniques de Molinet, I, 1935, S. 250-253; Mémoires de la MARche, 3, 1885, S. 250 f.; Barante/Gachard, Histoire, II, 1838, S. 601 f.; Delepierre, Fête en 1478, 1842, S. 337- 
Auftakt des Festaktes war eine Prozession des „trauernden Hofes“, bei der die männlichen Mitglieder des burgundischen Hofes die Ordenskollane des verstorbenen Souveräns, Herzog Karl \{34\}, von der herzoglichen Residenz zur Salvatorkirche geleiteten. Alle Akteure waren in Trauer gekleidet und gingen in Zweierreihen zu Fuß; zuerst die Amtsträger, Diener und niedrigen Adligen, dann die Hofmeister und die Herolde in ihren jeweiligen Wappenröcken. Ihnen folgten zu Pferd die Mitglieder des Ordens vom Goldenen Vlies, erst die Amtsträger, dann die Vliesritter im aufsteigenden Rang. Höhepunkt und Mittelpunkt des Umzuges war ein prächtiger Schimmel, auf dessen Rücken auf schwarzem Untergrund die goldene Ordenskollane des verstorbenen Herzog Karls lag. Geführt wurde das Tier von Toison d'or, begleitet von vier weiteren Herolden. Dem „toten“ Herzog folgten dessen Blutsverwandte sowie hohe Adlige und burgundische Notabeln nun in absteigendem Rang. ${ }^{35}$ Nachdem alle ihre zugewiesenen Plätze in der Salvatorkirche eingenommen hatten, betrat Herzog Maximilian, anders als die bisherigen Akteure nicht in Trauer gekleidet sondern in mit Silber bestickter Kleidung, mit großem Gefolge die Kirche. Es folgte ein über drei Stunden dauernder Gottesdienst ${ }^{36}$, an dem auch der päpstliche Legat und zahlreiche Gesandte aus dem Reich, Vertreter der verschiedenen in Brügge residierenden Kaufleute, viele öffentliche Vertreter Brügges und Flanderns sowie die weiblichen Mitglieder des burgundischen Hofes teilnahmen. Nach einer langen lateinischen Rede über die Vorzüge des Ordens vom Goldenen Vlies erklärte der Ordenskanzler Maximilian zum rechtmäßigen Nachfolger in der Ordenssouveränität. ${ }^{37}$ Darauf zogen sich die Ordensmitglieder zurück und tauschten ihren schwarzen Ordensornat gegen ihren purpurfarbenen. Auch Maximilian wurde mit dem Ordensornat bekleidet. Nach ihrer Rückkehr in den Chor der Kirche wurde Maximilian vom ranghöchsten anwesenden Ordensritter Adolf von Kleve $\{55\}$ zum Ritter geschlagen. ${ }^{38}$ Anschließend nahm ihn das älteste anwesende Mitglied, Jean de Lannoy $\{50\}$, in den Orden auf, in dem er von Maximilian den Aufnahmeeid entgegennahm und ihm die von Karl dem Kühnen getragene Ordenskollane um den Hals legte. Als nächstes leisteten die Ordensmitglieder - sowohl die anwesenden Ritter als

339; Kervyn de Lettenhove, Histoire de Flandre, V, 1850, S. 290 f.; Verschelde, Feeste, 1873, S. 26 f. (nach Stadtbibl. Brügge, Historisch Fonds ms. 437: Excellente Chronycke van Vlaanderen); CARTon, Het boeck van Brugghe, 1859, S. 4 f.; Reiffenberg, Toison d'or, 1830, S. 91; Praet, Recherches, 1831, S. 20; Webern, Grafen von Nassau, 1978, S. 159 f.; SMedt, Jan van Lannoy, 1992, S. 73f.; Martens, Biografie, 1992, S. 30. Eine Beschreibung auf Grundlage des Protokollbuches und Überlegungen zu der damit verbundenen Propaganda bietet DünNeBEIL, Zeichen, 2012, S. 114-117; dies., Order of the Golden Fleece, 2013, S. $61 \mathrm{f}$. mit Abb. 7.

35 Zur Prozession und Maximilians Einzug in die Kirche vgl. § 45-47.

36 Die Zeitangabe nach CARTON, Het boeck van Brugghe, 1859, S. 5.

37 Die Rede des Ordenskanzlers ist in $\S 49 \mathrm{f}$. wiedergegeben.

38 Zum Ritterschlag vgl. § 54. Bis zuletzt hatte Maximilian gehofft, sich vor diesem Festakt noch mit seinem Vater Kaiser Friedrich III. \{94\} zu treffen und von ihm den Ritterschlag zu empfangen; vgl. u. a. § 13. 
auch die Amtsträger - Maximilian ihren Treueeid..$^{39}$ Danach wurde der Festgottesdienst fortgesetzt und zuletzt geleiteten die männlichen Hofmitglieder den Orden wieder zurück in die herzogliche Residenz, nur nahm dieses Mal Maximilian die Stelle des verstorbenen Karls im Zentrum des Umzuges ein. Als Abschluss der Feierlichkeiten wurde in der herzoglichen Residenz ein Festmahl eingenommen, an dem nicht nur die Ordensmitglieder sondern auch zahlreiche Ehrengäste teilnahmen.

\section{Das Ordensfest von 1478}

\section{A. Ablauf des Ordensfestes}

Aufgrund des Einmarsches französischer Truppen in burgundisches Herrschaftsgebiet beschlossen die anwesenden Mitglieder des Ordens, dass das Ordensfest möglichst kurz gehalten und nur die dringendsten Angelegenheiten geregelt werden sollten. ${ }^{40}$ Noch am Tag der Inauguration versammelte sie sich zu seiner ersten Sitzung und am Abend begab man sich zu dem ersten für die Ordensfeste vorgeschriebenen Gottesdienste ${ }^{41}$ bei denen die Ordensmitglieder in Begleitung des gesamten Hofes in einer Prozession von der Residenz zur Kirche gingen. Am folgenden Morgen, dem 1. Mai, wurde die große Messe zu Ehren des Ordenspatrons, dem Heiligen Andreas. Daran schloß sich Festmahl an. ${ }^{42}$ Es folgte am selben Abend die Totenvigil und am 2. Mai die Totenmesse, bei der die verstorbenen Mitglieder offiziell verabschiedet wurden. ${ }^{43}$

$39 \mathrm{Zu}$ diesem Teil des Zeremoniells vgl. § 58-65.

40 Vgl. § 69. - Die Beschreibung des Ordensfestes findet sich in § 70-196. Nachrichten über das Fest finden sich auch in Paris, BNF, ms. fr. 5046, fol. 127r-128v (zitiert bei Mémoires de la MArche, 3, 1885, S. 248 f., Anm. 316); AOGV, Codex 34/1, S. 122-147 (Türck'sche Inventar); Brüssel, BR, ms. 20.851 (F.J. de Bors d'Overen, Histoire chronologique de l'ordre de la Toison d'or, Bd. 1), fol. 179-231, hier vor allem fol. 182-187 (vgl. dazu Cat. mss. de BR, 12, 1936, S. 56-62, hier S. 59 f.); Mémoires de la MARCHE, 3, 1885, S. 248-251; Chroniques de Molinet, I, 1935, S. 249-255; Roo, Annales rerum, 1592, S. 327 f.; Roo, Annales rerum (dt.), 1621, S. 336; Fugger, Spiegel der Ehren, 1668, S. 879-881; Reiffenberg, Toison d'or, 1830, S. 92-97; Delepierre, Fête en 1478, 1842; Despars, Chronycke van Vlaenderen, 4, 1840, S. 167 f.; Barante/Gachard, Histoire, II, 1838, S. 601 f.; Kervyn de Lettenhove, Histoire de Flandre, V, 1850, S. 290 f. (mit Hinweis u. a. auf „Journal ms. [Bibl. de Bourgogne 13.169]“); Verschelde, Feeste, 1873 (mit Druck des Berichts über das Ordensfest in Stadtbibl. Brügge, Historisch Fonds ms. 437: Excellente Chronycke van Vlaanderen); WeBERn, Grafen von Nassau, 1978, S. 46 f. und 159 f.; Kuyer, Veertiende kapittel, 1981, S. 74-76; Smedt, Jan van Lannoy, 1992, S. 73-75; Bauchau, Jacques de Savoie, 1992, S. 138-142; DünnebeIL, Zeichen, 2012; dies., Order of the Golden Fleece, 2013. Kurze Erwähnungen des Ordensfestes finden sich u.a. auch bei Bock, Maximilian, 1970, S. 40 f.; WiEsflecker, Maximilian, 1, 1971, S. 142 mit Anm. 48 f. auf S. 456; Born, Lalaing, 1986, S. 184; Auer, Maximilian I ${ }^{\mathrm{er}}, 2008$, S. $58 \mathrm{f}$.

41 Vgl. § 70-79.

42 Vgl. § 81-97. Zu den verschiedenen Gottesdiensten, die im Verbindung mit den Ordensfesten standen, vgl. ausführlich PB 3, S. 17-19.

43 Zur Totenvigil vgl. § 98 f. und zur Totenmesse § 123-126 (Planung) mit Anm. 121 und § 140-146 (Durchführung). - Zum Zeremoniell des Verabschiedens vgl. auch DüNNEBEIL, Entwicklung, 2007, S. $30 \mathrm{f}$. 
Zwischen den Gottesdiensten regelten die anwesenden Mitglieder die dringendsten Angelegenheiten, wobei die Neuwahlen, die Korrektionen und die Diskussion über die weitere Vorgehensweise gegen die abtrünnigen Mitglieder die meiste Zeit vereinnahmten. $^{44}$

Die geringe Anzahl der Teilnehmer dürfte große Enttäuschung hervorgerufen haben. Zwar war die Zahl der Mitglieder aufgrund der unruhigen Zeiten der letzten Jahren um ein Drittel reduziert, es waren aber dennoch von den 21 lebenden Ordensrittern nur fünf anwesend..$^{45}$ Dass die vier königlichen Mitglieder zum Ordensfest anreisten, wurde nicht erwartet, und den fünf am französischen Hof befindlichen Mitgliedern wurde die Teilnahme durch König Ludwig XI. verboten. ${ }^{46}$ Danach verblieben noch drei weitere Mitglieder, deren Teilnahme erwartet wurde, von denen nur Jean de Melun $\{28\}$ sich ordnungsgemäß entschuldigte. ${ }^{47}$ Bei Philippe von Savoyen $\{68\}$ wusste man nicht, ob er die Einladung tatsächlich erhalten hatte, da diese bei der Gefangennahme des Herold Ferrette in Macon möglicherweise verloren gegangen war. Auch Johann, Herzog von Kleve $\{47\}$, sandte trotz zweiter Aufforderung, am Ordensfest teilzunehmen, keine Absage, aber mit einer Randbemerkung im Protokollbuch wurde angedeutet, dass Johann sich aufgrund der nichterfolgten Heirat seines Sohnes mit Maria von Burgund vom Ordensleben fernhielt. ${ }^{48}$ Und so nahmen nur fünf Ordensritter, nämlich Jean de Lannoy $\{50\}$, Adolf von Kleve $\{55\}$, Ludwig von Brügge $\{61\}$, Philippe de Croy $\{74\}$ und Engelbert von Nassau $\{77\}$, am Ordensfest teil.

Die sogenannte „correction“ mit der Prüfung jedes Mitglieder auf seine ritterlichtugendhafte Lebensweise hin wurde bei diesem Fest aus Zeitmangel nur bei den anwesenden Mitgliedern durchgeführt. ${ }^{49}$ Allen anwesenden Mitgliedern wurde Klugheit, Bedachtsamkeit und Tapferkeit bescheinigt. Ledig bei Engelbert von Nassau \{77\} wurde bemängelt, dass er es mit der ehelichen Treue nicht genau hielt und Umgang mit zwielichtigen Personen habe; dies wurde aber als jugendlicher Leichtsinn eingestuft. Herzog Maximilian brauchte sich dieses Jahr der Überprüfung nicht zu unterziehen und die Korrektur der abwesenden Mitglieder wurde auf das nächste Fest verschoben, das im kommenden Jahr abgehalten werden sollte.

44 Zur Neuwahl vgl. unten S. 27-31; zu den Korrekturen S. 23; zu den abtrüningen Mitglieder S. 25-27 und zum Ordensschiedsgericht S. $31 \mathrm{f}$.

45 Vgl. dazu Tabelle 1 sowie die Eintragungen in § 25-29.

46 Dazu mehr auf S. 25-27.

47 Vgl. Reg. 45 und 46.

48 Vgl. die Randbemerkung in $\S 9$.

49 Zur Korrektur der Mitglieder vgl. § 103-121 mit weiterführenden Angaben in Anm. 74. In den Protokollen wird dieses Verfahren als correction bezeichnet, in der deutschsprachigen Literatur wurde dazu gelegentlich die Begriffe Sittenrüge, Sozialkontrolle oder Evaluierung benutzt. 


\begin{tabular}{|ll|}
\hline \multicolumn{2}{|c|}{ Karl, Herzog von Burgund, Ordenssouverän $\{34\} \dagger^{50}$} \\
Maximilian $\{77 b\}$ A
\end{tabular}

Tabelle 1 Mitgliederspiegel zu Beginn des Festes im fahr 1478

Nachdem als weiterer wichtiger Tagungsordnungspunkt die Wahl der neuen Mitglieder, die einige Zeit in Anspruch nahm, durchgeführt worden war, ${ }^{51}$ wollte am Abend des 2. Mai 1478 Maximilian mit einem Teil der Ordensritter zur Front abreisen. ${ }^{52}$ Die in Brügge verbliebenen Mitglieder sowie die Amtsträger wurden beauftragt, die noch ausstehenden Gottesdienste $\mathrm{zu}$ absolvieren, über die wichtigsten noch ausstehenden Fragen zu beraten und vor allem für die Umsetzung der gefassten Beschlüsse zu sorgen. ${ }^{53}$ Bevor jedoch die Versammlung am Abend des 2. Mai aufgehoben wurde, baten die Anwesenden Maximilian um die Bestätigung von mehreren bestehenden Vorrechten. So bestätigte Maximilian die von Herzog Karl $\{34\}$ verliehene Einkünfte für den Ordenssekretär Martin Steenberch und den Wappenkönig Toison d'or, Gilles Gobet. ${ }^{54}$ Für die Mitglieder und die Amtsträger war aber die Bestätigung des von Herzog Karl im Jahr 1473 gewährten Privilegs

50 Vgl. auch die Aufstellung der Sitzordnung zu diesem Fest bei Verschelde, Feeste, 1873, S. 27 f.; Korteweg, Location, 1996, S. 218 f.; DünNeBeIL, Burgund und Österreich, 2006, S. $26 \mathrm{f}$. - In den Tabellen 1 und 2 werden folgende Abkürzungen verwendet: † verstorben; A anwesend; N Neuwahl.

51 Dazu ausführlicher auf S. 27-31.

52 Zusammen mit Maximilian verließen auch die Ordensritter Philippe de Croy $\{74\}$, Engelbert von Nassau $\{77\}$, Jakob von Savoyen $\{84\}$ und Bartholomäus von Liechtenstein $\{85\}$ Brügge. Dagegen verblieben zusammen mit den vier Amtsträgern die Ordensritter Jean de Lannoy $\{50\}$, Adolf von Kleve $\{55\}$, Ludwig von Brügge $\{61\}$, Pierre de Luxembourg $\{83\}$ und Josse de Lalaing $\{80\}$ in der Stadt.

53 Vgl. § $169 \mathrm{f}$.

54 Vgl. § 173 f. sowie Reg. $49 \mathrm{f}$. 
die wichtigste Errungenschaft. Mit diesem hatte Karl den Ordensrittern einen bevorzugten Rang innerhalb der burgundischen Hofhierarchie eingeräumt und den Rittern, Amtsträgern und deren Familien zahlreiche finanzielle Vorrechte gewährt. Auch stellte er sie unter seinen besonderen Schutz. Maximilian bestätigte nun dieses Privileg und erweiterte es durch eine allgemeine Zoll-, Maut- und Abgabenfreiheit. Die Urkunde wurde aber erst im Oktober 1478 ausgestellt, vermutlich in der Zeit als sich der Orden zu einer außerordentlichen Sitzung versammelt hatte. Doch scheint die Umsetzung nicht zur Zufriedenheit der Ordensmitglieder funktioniert zu haben, denn während des Festes von 1481 wurde Herzog Maximilian gebeten, dafür zu sorgen, dass der Inhalt des Privilegs jedem Amtsträger zur Kenntnis gebracht werde. ${ }^{55}$

Nach einem Tag Pause besuchten die zurückgebliebenen Ordensritter und Amtsträger die Marienmesse, danach setzten sie sich zu einer Beratung zusammen. Das Ergebnis wurde in einer langen Instruktion für Toison d'or notiert, der nach Abschluss dieser Sitzungen zu Maximilian gesandt wurde, um diesem die Ergebnisse der Beratungen und die daraus resultierenden Empfehlungen mitzuteilen. ${ }^{56}$ Zuletzt besuchten sie noch am 5. Mai die Messe zu Ehren des Heiligen Geistes. ${ }^{57}$ Damit enden die Eintragungen zum Ordensfest des Jahres 1478.

\section{B. Die abtrünnigen Mitglieder}

$\mathrm{Zu}$ den fehlenden Ordensrittern gehörten auch fünf Mitglieder, die sich am französischen Hof aufhielten, nämlich Anton, Bastard von Burgund \{54\}, Philippe Pot $\{60\}$, Jean de Damas $\{65\}$, Jacques de Luxembourg $\{67\}$ und Philippe de Crèvecœur $\{69\} .{ }^{58}$ Die beiden erst genannten kamen als Gefangene dorthin, gerüchteweise hatten sich aber alle fünf in die Gefolgschaft König Ludwigs XI. - au parti contraire - begeben und sogar dessen Michaelsorden angenommen, ohne die Mitgliedschaft im Orden vom Goldenen Vlies aufzukündigen. ${ }^{59}$ Deshalb erhielten sie für das für 1478 geplantes Ordensfest spezielle Einladungsschreiben, in den sie aufgefordert wurden, persönlich zu erscheinen, um ihr Verhalten zu rechtfertigen. ${ }^{60}$

Sie reagierten weder auf die Vorladungsschreiben noch reisten sie zum Ordensfest an, da König Ludwig XI. von Frankreich ihnen die Teilnahme verboten hatte. ${ }^{61}$ Da zumindest ein Teil der Öffentlichkeit wusste, dass diese fünf Ordensmitglieder, die zur Zeit Herzog Karls hohes Ansehen am burgundischen Hof genossen hatten, zur feind-

55 Vgl. § 172 und Reg. 74 (mit ausführlichen Angaben zu Karls Privileg und zur erneuten Verhandlung während des Festes von 1481).

56 Zur den Aktivitäten am 4. Mai vgl. § 177-195 sowie Reg. 51.

57 Vgl. § 196.

$58 \mathrm{Zu}$ den in Frankreich befindlichen Mitgliedern vgl. PB § 9, 26-29, 78, 122 f., 145, 225, 227 und 274. Zu ihrem Wechsel ins frz. Lager u. a. STERCHI, Umgang, 2005, S. 444-454 (zum Ausschlussverfahren) sowie S. 460-465 (zum weiteren Verlauf); Wiesflecker, Maximilian, 1, 1971, S. 115 f.; Haemers, Common Good, 2009, S. 103 f.; Dünnebeil, Zeichen, 2012, S. $121 \mathrm{f}$.

59 Vgl. dazu vor allem § $28 \mathrm{f}$. mit Anmerkungen zu den „abtrünigen“ Mitgliedern, zum Michaelsorden und dem Exklusivitätsgebot für die Vliesritter.

60 Vgl. Reg. 9-13 und 21-25.

61 Vgl. dazu S. 16f. mit Anm. 17. 
lichen Seite übergewechselt waren, wurde diese Abtrünnigkeit bei der öffentlichen Präsentation des Ordens zum Ausdruck gebracht. ${ }^{62}$ Ihre Wappen wurden zwar wie die aller anderen lebenden und verstorbenen Mitglieder in der Salvator-Kirche aufgehängt, sie wurden aber von den öffentlichen Opferhandlungen ausgeschlossen: Als der Wappenkönig Toison d'or im Laufe des Münz- und Kerzenopfers ein Mitglied nach dem andern aufrief, damit dieses am Altar eine Opferhandlung durchführte, änderte er dieses Zeremoniell für die fünf in Frankreich befindlichen Mitglieder dahingehend $\mathrm{ab}$, in dem er vor dem entsprechenden Wappenschild nur eine knappe Verbeugung machte und dann ohne ein Wort zu sagen zur Tafel des nächsten Mitglieds ging, um dieses aufzurufen. ${ }^{63}$ So sollte demonstriert werden, dass man die Mitgliedschaft der Fünf noch duldete, dass es aber ein schwebendes Verfahren über deren möglichen Ausschluss gab.

Schon früher wurden Ordensmitglieder von den Ordensfeierlichkeiten ausgeschlossen: 1468 wurden aufgrund der Differenzen Herzog Karls \{34\} mit der Familien Croy Antoine de Croy $\{15\}$, Jean de Croy $\{22\}$ und Jean de Lannoy $\{50\}$ ausgeschlossen; bei den Gottesdiensten wurden diese drei wie die anderen aufgerufen, nur führte Toison d'or stellvertretend die Opfergaben ohne weitere Erklärung durch. ${ }^{64} 1468$ wurde dann auch beim Münzopfer der öffentliche Ausschluss Johanns von Burgund \{53\} durchgeführt ${ }^{65}$ und 1473 wurde laut verkündet, dass der in burgundische Gefangenschaft befindliche Adolf, Herzog von Geldern \{58\}, sich geweigert habe, einen Stellvertreter für das Ordensfest zu benennen, und er deshalb vom Zeremoniell ausgeschlossen worden sei ${ }^{66}$ Im Laufe der Zeit hatte der Orden vom Goldenen Vlies die öffentliche Aufrufung der einzelnen Mitglieder während des Münzopfers also dazu genutzt, um zu zeigen, dass es innerhalb des Ordens einzelne Mitglieder gab, die sich nicht an die Ordensrichtlinien hielten. Im Jahr 1478 griff man nun diese Form der öffentlichen Zurschaustellung nicht konformer Mitglieder ebenfalls auf, verstärkte sie nun aber, in dem man die Delinquenten deutlich sichtbar überging.

Ihr Fehlen beim Ordensfest von 1478 hatte zur Folge, dass die anwesenden Mitglieder beschlossen, die fünf in Frankreich befindlichen Ordensmitglieder noch einmal zum nächsten Ordensfest vorzuladen. Denn ihr Fehlen und Parteiwechsel wurde als ein Akt der Felonie und somit Ausschließungsgrund angesehen ${ }^{67}$ Davor

62 Vgl. § 78, 123 und 145.

63 Vgl. dazu die Beschlussfassung in $\S 28$ f., 78 und 123 sowie die Durchführung in $\S 89-91$ und 145.

64 Vgl. dazu PB 2, S. 18-20, S. 82 f., § 49 und 53 sowie S. 87 f., § 61. Mit der „Causa Croy“ beschäftigte sich zuletzt Soen, La Causa Croy, 2012.

65 Vgl. dazu PB 2, S. 20 f. Mit dem Ausschluss Johanns von Burgund beschäftigt sich ausführlich Berlin, Aberglaube, 2012; dies., Familiy Politics, 2013; dies., Main, 2013.

66 Vgl. dazu PB 3, S. 34-40 und S. 48 f., § 36 und S. 50, § 58.

67 Gründe für einen Ausschluss aus dem Orden sind neben Verrat noch Ketzerei, Verirrungen im christlichen Glauben sowie Feigheit auf dem Schlachtfeld; so § 14-16 der Statuten (dazu S. 16, Anm. 14). Der letztgenannte Absatz regelt zudem noch die Verfahrensweise eines Ausschlusses, wonach jedes angeklagte Mitglied die Gelegenheit erhalten soll, sich vor dem Orden verteidigen zu können. - Zu § 16 der Statuten siehe auch die Angaben in $\S 9$, Anm. 44. 
sollten sie aber noch die Gelegenheit erhalten, sich vor dem versammelten Orden zu rechtfertigen. Entsprechende Vorladungsschreiben wurden für das geplante Ordensfest von 1479 ausgestellt und der mit der Überbringung beauftragte Herold mit den entsprechenden Begleitbriefen ausgestattet. ${ }^{68}$ Fusil reist zwar an den französischen Hof, konnte aber nur Jacques de Luxembourg \{67\} die Vorladung persönlich übergeben. Er erhielt von Jacques auch ein Antwortschreiben, in dem er Ludwig XI. als den tatsächlichen Souverän des Ordens bezeichnet. ${ }^{69}$ Auch für das geplante Ordensfest von 1481 wurden wieder Vorladungsschreiben ausgestellt, die in ihrem Ton schon harscher ausfielen. Als sie wieder nicht zugestellt werden konnten, wurden sie in verschiedenen französisch-burgundischen Grenzstädten öffentlich verlesen, um so sicher zu stellen, dass die Delinquenten sich nicht herausreden konnten, sie hätten von dem Ordensfest nichts gewusst. Beim Fest im Mai 1481 wurden dann auch Philippe Pot $\{60\}$, Philippe de Crèvecœur $\{69\}$, Jacques de Luxembourg $\{67\}$ sowie Jean de Neufchâtel $\{52\}$, der sich spätestens im Sommer 1479 ebenfalls in französische Dienste begeben hatte ${ }^{70}$ aus dem Orden ausgeschlossen. Jean de Damas und Anton von Burgund entgingen diesem Urteil, da man gerüchteweise von ersterem gehört hatte, er sei verstorben, und von zweiterem, dass er trotz königlichem Verbotes am französischen Hof weiterhin selbstbewusst die Kette des Ordens vom Goldenen Vlies trug. Die Ereignisse von 1481 sind im 5. Protokollbuch ausführlich beschrieben und sollen deshalb dort ausführlicher behandelt werden. ${ }^{71}$

\section{Die Wahl neuer Mitglieder}

Seit dem letzten Ordensfest im Jahr 1473 war nicht nur Herzog Karl \{34\} sondern auch zwölf weitere Mitglieder verstorben, mehrere davon verloren ihr Leben bei den großen Schlachten Herzog Karls in Grandson, Murten und Nancy. ${ }^{72}$ Schon bei der ersten Sitzung des Ordens am 30. April wurden die Mitglieder aufgefordert, sich Gedanken über mögliche Kandidaten zu machen, obwohl die eigentliche Wahl erst nach Abschluss der correction erfolgen sollte. ${ }^{73}$

68 Vgl. § 122 und 209 sowie Reg. 75-80.

69 Vgl. dazu § 225 und 227, Reg. 99-100 sowie S. 16f. mit Anm. 17.

70 Vgl. dazu § 265 mit Anm. 300.

71 Vgl. Reg. 136 und vor allem PB 5.

72 Vgl. die Aufstellung des Mitgliederspiegels in Tabelle 1 sowie die Auflistung der verstorbenen Mitglieder mit Angaben zu ihrem Tod jeweils am Ende von § $26 \mathrm{f}$. - Mit den Neuwahlen dieses Ordensfestes beschäftigen sich u. a. FugGER, Spiegel der Ehren, 1668, S. 881; Reiffenberg, Toison d'or, 1830, S. 94 f.; Delepierre, Fête en 1478, 1842, S. 343; Despars, Chronycke van Vlaenderen, 4, 1840, S. 167 f.; Barante/Gachard, Histoire, II, 1838, S. 602; Kervyn De Lettenhove, Histoire de Flandre, V, 1850, S. 290 f.; VerschelDE, Feeste, 1873, S. 28; Webern, Grafen von Nassau, 1978, S. 159f; SmEdT, Orden vom Goldenen Vlies, 2003, S. 129f.; DünneBEIL, Burgund und Österreich, 2006, S. 22 und 27; Auer, Maximilian I Ir, 2008, S. 59; DünnebeIL, Zeichen, 2012, S. 118 f.; dies., Order of the Golden Fleece, 2013, S. $64 \mathrm{f}$.

73 Vgl. § $79 \mathrm{f}$. 


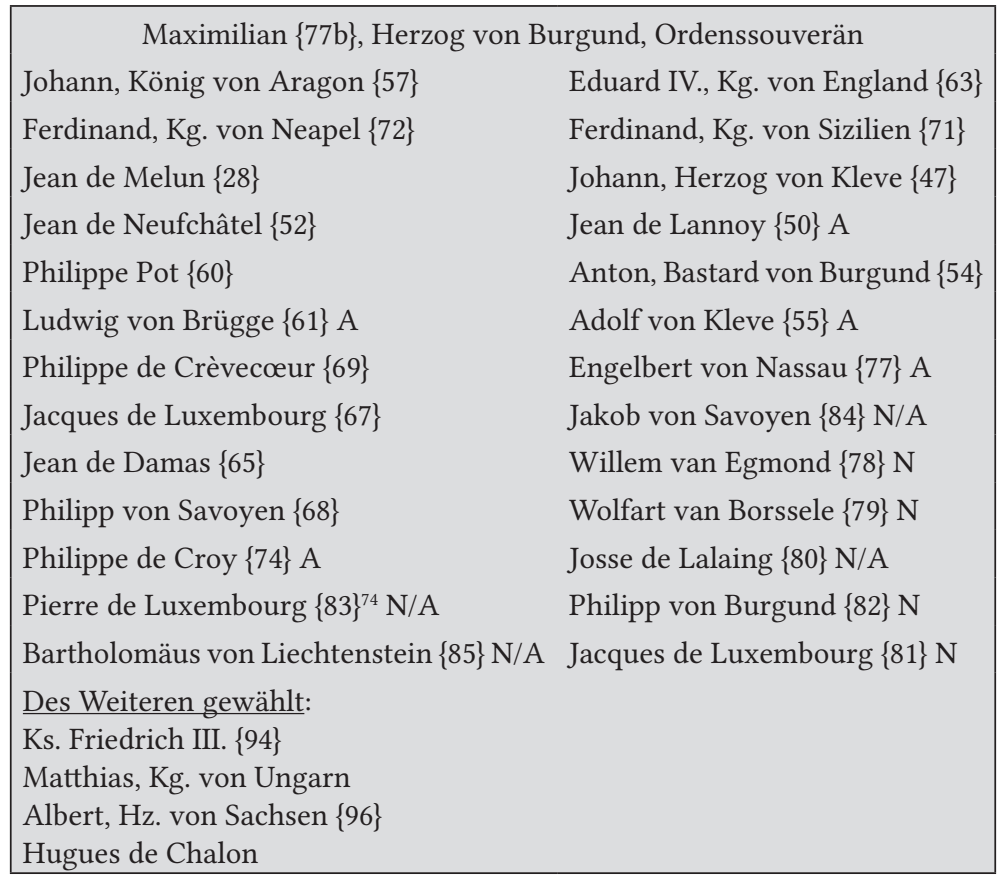

\section{Tabelle 2 Mitgliederspiegel nach den Neuwahlen}

Und somit begann das Wahlverfahren am 1. Mai 1478, ${ }^{75}$ das mit der Eidesleistung und der Ermahnung des Kanzlers eingeleitet wurde, bei der Wahl nicht persönliche Interessen, sondern nur die Interessen des Ordens zu berücksichtigen. Als erstes stelle Herzog Maximilian seine Kandidaten vor, nämlich sein Vater Kaiser Friedrich III. \{94\}, König Matthias von Ungarn, Herzog Albrecht von Sachsen \{96\} und seinen Hofmeister Bartholomäus von Liechtenstein $\{85\}$. Friedrich III. wurde sogleich einstimmig gewählt, war man sich doch dem Prestigezuwachs bewusst, der seine Mitgliedschaft mit sich führen würde. ${ }^{76}$ Auch Bartholomäus von Liechtenstein erhielt die Stimmenmehrheit, wenngleich die Mitglieder erst zögerten, da Bartholomäus am burgundischen Hof noch recht unbekannt war. ${ }^{77}$ Die Kandidatur von König Matthias von Ungarn und Herzog

74 Die Plätze von Pierre de Luxembourg und Bartholomäus von Lichenstein auf der rechten Seite und Jakob von Savoyen und Josse de Lalaing auf der linken Seite wurde ihnen am 2. Mai 1478 zugewiesen; vgl. § 167. Bei der Sitzverteilung während des Ordensfestes im Jahr 1481 sind rechts Pierre de Luxembourg und Jakob von Savoyen und links Willem van Egmond, Wolfart van Borssele, Josse de Lalaing, Philipp von Burgund, Jacques de Luxembourg und Bartholomäus von Lichenstein plaziert; vgl. PB 5, fol. 10v-13r. Demnach wurden die Seiten von Jakob von Savoyen und Bartholomäus von Lichenstein vertauscht.

75 Zum Wahlverfahren vgl. § 127-135, 138 f. und 149-154.

76 Vgl. § 129-131.

77 Vgl. § 133. 
Albrecht von Sachsen führte zu einer regen Diskussion: ${ }^{78}$ Einige Mitglieder wandten ein, dass mit Kaiser Friedrich III. und König Matthias die Anzahl der königlichen Mitglieder auf sechs steigen würde, aber Herzog Karl \{34\} beim Ordensfest von 1473 festgelegt hatte, dass dem Orden nur vier königliche Mitglieder angehören sollten. Auch gefiel den Mitgliedern Maximilians Ansinnen, die Aufnahme König Matthias und Herzog Albrechts von der Zustimmung seines Vaters abhängig zu machen nicht, denn dies entsprach nicht den Vorgaben der Statuten und würde die Unabhängigkeit des Ordens untergraben. Schließlich wurden sie aber doch noch gewählt.

Problemlos verlief die Neuwahl der „Burgunder“ und so wurden Philipp von Burgund $\{82\}$, Josse de Lalaing $\{80\}$, Pierre de Luxembourg $\{83\}$ und Hugues von Chalon am 1. Mai und Jacques de Luxembourg $\{81\}$, Wolfart van Borssele $\{79\}$, Willem van Egmond $\{78\}$ und Jakob von Savoyen $\{84\}$ am 2. Mai gewählt. ${ }^{79}$ Da sich die anwesenden Mitglieder nicht sicher waren, ob Jakob von Savoyen der Aufnahme in den Orden zustimmen würde, ernannten sie Claude de Toulongeon $\{93\}$ als Ersatzkandidaten. ${ }^{80}$

Jakob von Savoyen zeigte sich über seine Wahl in den Orden erfreut und wurde noch am selben Tag zusammen mit den ebenfalls in Brügge befindlichen Pierre de Luxembourg $\{83\}$, Josse de Lalaing $\{80\}$ und Bartholomäus von Liechtenstein $\{85\}$ in den Orden aufgenommen. ${ }^{81}$ Die Aufnahme von Philipp von Burgund \{82\}, Jacques de Luxembourg $\{81\}$, Wolfart van Borssele $\{79\}$ und Willem van Egmond $\{78\}$ erfolgte in den darauf folgenden Monaten. ${ }^{82}$

Hugues de Chalon befand sich zum Zeitpunkt seiner Wahl in französischer Gefangenschaft, deshalb beschlossen die Mitglieder, dass diese Wahl bis zu seiner Freilassung geheim bleiben sollte. Bei zwei Sondersitzungen des Ordens am 30. Nov. 1478 und am 12. März 1479 wussten die versammelten Ordensmitglieder gerüchteweise, dass Hugues wieder in Freiheit sei, man wollte aber erst genauere Auskünfte über die Umstände einholen, bevor man ihn über seine Wahl in den Orden informierte. Für die spätere Zeit gibt es dazu keine Einträge mehr, aber spätestens nach Hugues Heirat mit dem Mündel König Ludwigs XI., Louise von Savoyen, wurde dessen Hinwendung zum französischen König allgemein bekannt und damit sein Beitritt in den Orden hinfällig. ${ }^{83}$

Um die Aufnahme Kaiser Friedrichs III., Herzog Albrechts von Sachsen und König Matthias von Ungarn voranzutreiben, wurde im September 1479 eine Gesandtschaft unter der Leitung des neuen Ordensmitglieds Bartholomäus von Lichtenstein $\{85\}$ geplant. ${ }^{84}$ Bei einer Sitzung am 9. Oktober 1478 wurde zum ersten Mal darüber diskutiert, dass es bei der Aufnahme Friedrichs III. ein rechtliches Problem gab. ${ }^{85}$ Die

78 Vgl. § 132 und 149-151.

79 Vgl. § 134 und 138.

80 Auch schon bei früheren Ordensfesten wurden Ersatzkandidaten ernannt, wenn man sich bei einer Neuwahl nicht sicher war, ob die betreffende Person den Orden annehmen werde; vgl. u. a. PB 2, S. 23 und S. 127, § 146.

81 Vgl. § 155-167.

82 Vgl. dazu die Angaben in $§ 154$ sowie in Reg. 52 f. und 59.

$83 \mathrm{Zu}$ seiner französischen Gefangenschaft und zu seiner Heirat im Okt. 1479 vgl. die Angaben § 134, Anm. 160 sowie § 221 und 235.

84 Vgl. § 188 (Empfehlung), § 197-200 (Planung) und § 203 (Verschiebung). Vgl. dazu auch DünNEBEIL, Burgund und Österreich, 2006, S. $22 \mathrm{f}$.

85 Vgl. § 207. 
Ordensstatuten forderten, dass neue Mitglieder ihren Aufnahmeid unter Berühung des Schwurkreuzes oder eines anderen heiligen Gegenstandes leisten sollten. Es war aber gängige Praxis, dass die römisch-deutschen Könige nach ihrem Krönungseid keine weiteren persönlichen Eide mehr zu leisten brauchten, außer um vor dem Papst ihren Glauben zu rechtfertigen. ${ }^{86}$ Aus diesem Grund konnte der Kaiser den Aufnahmeeid in den Orden nicht in vorgeschriebener Weise leisten. Der Kaiser zeigte sich grundsätzlich bereit, dem Orden beizutreten, ${ }^{87}$ die Aufnahme erfolgte aber erst 1492. Dadurch verzögerte sich auch die Aufnahme Herzogs Albrechts von Sachsen, dessen Aufnahme mit der Kaiser Friedrichs III. verknüpft war. Das Verhältnis der Habsburger mit König Matthias von Ungarn - dessen Aufnahme ebenfalls nur mit Zustimmung des Kaisers erfolgen sollte, verschlechterte sich in den folgenden Jahren rapide, ${ }^{88}$ so dass schon beim Fest von 1481 von seiner Aufnahme keine Rede mehr war.

Für Aufregung sorgte, dass Philippe de Croy, Graf von Porcien, fälschlicherweise glaubte, er sei in den Orden gewählt worden. ${ }^{89}$ Möglicherweise entstand dieses Missverständnis durch seine Namensgleichheit mit seinem Vetter Philippe de Croy, Graf von Chimay \{74\}, der 1478 am Ordensfest teilnahm. Wegen seiner Verdienste am burgundischen Hof konnte der Graf von Porcien auf eine Aufnahme in den Orden hoffen und als ihm das Gerücht, er sei gewählt worden, zu Ohren kam, freute er sich nun vergeblich über seinen Eintritt in den elitären Kreis. Der normale Ablauf sah aber vor, dass die Namen der Neugewählten bis zu deren Zustimmung geheim gehalten wurden. ${ }^{90}$ Um dies wirklich zu gewährleisten, wurden die Kandidaten von einer Delegation des Ordens aufgesucht, die sie (unter Ausschluss Dritter) über die Wahl in den Orden unterrichten und über ihre Interesse an der Mitgliedschaft befragen sollten. Damit sollte verhindert werden, dass bei Ablehnung der Mitgliedschaft ein negatives Licht auf den Orden fiel. ${ }^{91}$

Die Geheimhaltungspflicht der neugewählten Mitglieder bis zu ihrem Beitritt führte aber auch dazu, dass die Bewegung der Ordensritter genauestens beobachtet und viel spekuliert wurde. Und so ist es nicht verwunderlich, dass die Gerüchteküche hin

86 Diese Rechtspraxis ist seit dem 12. Jh. belegt, in der Forschung wurde dies u.a. mit der höchsten Stellung des Königs bzw. Kaisers in der Lehenspyramide und in der Sakralität des Königsamtes begründet. Vgl. dazu u. a. EIchmanN, Kaiserkrönung, 2, 1942, S. 161-207; Schubert, König, 1979, S. 350-355; Colberg, Eid des Königs, 1983; SCHWEDLER, Herrschertreffen, 2008, S. 146-168. Die beiden letztgenannten zeigen jedoch an Beispielen, dass dieses Eidverbot aus politischem Kalkül und als Mittel der Diplomatie immer wieder umgangen wurde. Dazu auch künftig DüNNEBEIL, Suche (im Druck).

87 Vgl. § 234.

88 Vgl. dazu die Angaben in § 132, Anm. 140.

89 Vgl. § 210 und 221.

90 Aus diesem Grund wurden die Namen von Kaiser Friedrich III. \{94\}, Matthias Corvinus, Kg. von Ungarn, und Albrecht, Hz. von Sachsen \{96\}, in einer Instruktion für Toison d'Or von 1478 Mai 7 (Reg. 51) nicht namentlich genannt, sondern es war nur von aucuns grans personnaiges comme roys ou ducs die Rede; vgl. dazu § 188 mit Anm. 315.

91 So wurden die in Brügge weilenden Neugewählten einzeln von einer Ordensdelegation aufgesucht, die sie über die Wahl unterrichten sollte (§ 160ff). Auch wurde nach Beendigung des Ordensfest den abwesenden Mitgliedern nur die Namen der schon aufgenommenen neuen Mitgliedern mitgeteilt, vgl. dazu Reg. 66 und 67. Zu den Bemühungen um die Geheimhalten auch DüNnEBEIL, Entwicklung, 2007, S. 20. 
und wieder falsche Kandidaten „auskochte“. Auch die Berichterstatter über die Ordensfeste waren nicht immer darüber informiert, wer nun tatsächlich gewählt worden war. Teilweise wurden nur die tatsächlich aufgenommen neue Mitglieder aufgezählt, ${ }^{92}$ andere ergingen sich in falschen Spekulationen. Für 1478 zählt z. B. das Brügger Exemplar der „Chronycke van Vlaenderen“ folgende Neugewählte auf: De keyser van den Roomschen rycke, de conynck van hongheryen, de ryck hertoge van beyeren, de hertoghe van zassen, de markys van brandenborch, de markys van baden, de grave van Römondt, de grave van sint pol, de paelsgrave, de hofmeestre van den prinche, mer joos de la layn, de heere van fiennes. ${ }^{93}$

Der verkürzte Ablauf des Ordensfestes führte zu einem unerwarteten Problem: Normalerweise fand die Mitgliederwahl erst nach Beendigung der Pflichtgottesdienste statt, aber 1478 waren vier neue Mitglieder schon aufgenommen worden, bevor die Messen zu Ehren von Maria und dem Heiligen Geist stattgefunden hatten. Nun stellte sich die Frage, wo die neuen Mitglieder platziert werden sollten, denn für sie gab es ja noch keine Wappentafeln. Nachdem Maximilian und ein Teil der Ordensritter in den Krieg gezogen waren, beschlossen die ältesten anwesenden Mitglieder, dass die neuen Ritter sich in ihrer zugewiesenen Reihe auf die Plätze von abwesenden Rittern am unteren Ende setzen sollten. ${ }^{94}$

\section{Das Wiederaufleben des internen Schiedsgerichts}

Die Statuten des Ordens vom Goldenen Vlies sahen vor, dass Differenzen zwischen Mitgliedern oder mit Dritten während der Ordensfeste vor ein internes Schiedsgericht gebracht werden konnten, das sich um eine Lösung des Konfliktes bemühen sollte. ${ }^{95}$ Während der Souveränität Herzog Philipps $\{01\}$ wurde diese Möglichkeit der Streitschlichtung mehrfach in Anspruch genommen, aber Herzog Karl \{34\} beschränkte in einer seiner ersten Amtshandlungen als Ordenssouverän die Kompetenz der Schiedsgericht auf Frage der Ehre ein, alle anderen Differenzen sollten vor seiner herzoglichen Justiz verhandelt werden. Mit der Übernahme der Souveränität durch Herzog Maximilian scheint das Schiedsgericht seine alte Funktion zurückgefunden

92 So z. B. Fugger, Spiegel der Ehren, 1668, S. 881 und in der neueren Literatur BAUCHAU, Jacques de Savoie, 1992, S. $139 \mathrm{f}$.

93 Stadtbibl. Brügge, Historisch Fonds ms. 437, danach der Druck bei Verschelde, Feeste, 1873, S. 28. Gemeint sind dabei Ks. Friedrich III. \{94\}, Matthias Corvinus, Kg. von Ungarn, Ludwig, Hz. von Bayern, Albrecht, Hz. von Sachsen \{96\}, Albrecht, Mgf. von Brandenburg, Christoph I., Mgf. von Baden \{102\}, Jakob von Savoyen \{84\}, Gf. von Romont, Pierre de Luxembourg \{83\}, Gf. von Saint-Pol, Philipp, Pfalzgraf bei Rhein, Bartholomäus von Liechtenstein-Karneid \{85\} und Josse de Lalaing \{80\}. - Bei DesPars, Chronycke van Vlaenderen, 4, 1840, S. 167 und danach Kervyn de Lettenhove, Histoire de Flandre, V, 1850, S. 291, werden anstelle von Ks. Friedrich III., Albrecht von Sachsen und Hugues de Chalon als Neugewählte Ludwig, Hz. von Bayern, Albrecht, Mgf. von Brandenburg und Pierre de Hennin \{88\} genannt. Vgl. dazu auch die Angaben in $\S 154$, Anm. 208.

94 Vgl. dazu § $178 \mathrm{f}$.

95 Vgl. dazu § 8, 10, 80 (neu § 55) und 103 der Statuten; zur Tätigkeitkeit des Schiedsgerichtes PB 1, S. 38-41, 48-56, 58-60, 64-75, 77f., 87, 96 f., 108-110, 114f., 117-122 und PB 2, S. 171-180; dazu auch u. a. DünNEBEIL, Entwicklung, 2007, S. 24; dies., Beherrschung, 2010, S. 172. 
zu haben. Noch während des Ordensfestes im Mai 1478 bat Ludwig von Brügge $\{61\}$ den Orden bei seinen Differenzen zu dem neugewählten Josse de Lalaing $\{80\}$ zu vermitteln. ${ }^{96}$

Auch während der folgenden Sondersitzungen des Ordens wurde das Schiedsgericht mehrfach angerufen, so am 25. Sep. 1478 von Wolfart van Borselle \{79\}, der mit Jan van Wassenaar im Streit lag. ${ }^{97}$ Ausführlich beschrieben wird im 4. Protokollbuch die erfolgte Vermittlung zwischen Philippe de Croy $\{74\}$ und Pierre de Luxembourg $\{83\}$ während der Sitzung am 12. März 1479. Die beiden hatten sich gegenseitig der üblen Nachrede beschuldigt; zuletzt wurde der Konflikt beigelegt, in dem Herzog Maximilian sie aufforderte, zu beeiden, weitere Unterstellungen zu unterlassen, und sich die Hand zu geben. ${ }^{98}$ Die gleiche Lösung wurde für Jakob von Savoyen $\{84\}$ und Philipp von Burgund \{82\} gewählt, deren Differenzen auf der Sitzung am 17. Jan. 1480 verhandelt wurden. ${ }^{99}$

\section{Die Ordensangelegenheiten zwischen 1478 und 1480}

\section{A. Das für 1479 geplante Ordensfest}

Aufgrund der verkürzten Dauer des Festes von 1478 hatte man schon dort beschlossen, im darauffolgenden Jahr ein neues Treffen einzuberufen. Am 9. Oktober 1478 versammelten sich etliche Ordensmitglieder, um das neue Fest zu planen und die Einladungen auszustellen. ${ }^{100}$ Am 12. März wurde für das Ordensfest Brüssel als Austragungsort festgelegt und Olivier de la Marche wurde zusammen mit Philippe du Chesne dorthin geschickt, um Vorbereitungen zu treffen. ${ }^{101}$

Erst am 22. April entschied eine kleine Gruppe bei Herzog Maximilian versammelter Ordensritter, dass das für den 2. Mai geplante Ordensfest doch abgesagt werden sollte. Den Mitgliedern der näheren Umgebung sandte man sogleich die Nachricht mit der Absage. Um dennoch anreisende Mitglieder, deren Gesandte bzw. Absageschreiben in Empfang zu nehmen, wurde Toison d'or nach Brüssel gesandte. In einem an den Orden gerichteten Brief berichtet er, dass er zwischen dem 30. April und 4. Mai in Brüssel vergeblich auf anreisende Festteilnehmer gewartet habe. ${ }^{102}$

Auffällig ist, dass trotz der kurzfristigen Absage des Ordensfestes nur ein Absageschreiben im Ordensarchiv überliefert ist, während von anderen geplanten, dann aber doch abgesagten Feste mehrere Absagebriefe im Ordensarchiv aufbewahrt sind. 1478 hatten z.B. die weiter entfernt lebenden Mitglieder, wie z.B. Ferdinand \{72\}, Kg. von Neapel, Ferdinand $\{71\}$, Kg. von Kastilien, oder Johann \{57\}, Kg. von Aragon, schon im

96 Vgl. dazu § 111, 113 und 162-164. Diese Angelegenheit erwähnen Chevaliers de la Toison d'or, ${ }^{2} 2000$, S. 195; Cools, Mannen, 2000, S. 343; STERCHI, Umgang, 2005, S. 426.

97 Vgl. § 205.

98 Vgl. § $236 \mathrm{f}$.

99 Vgl. § 261.

100 Anwesend waren neben Hz. Maximilian $\{77 \mathrm{~b}\}$ Adolf von Kleve $\{55\}$, Ludwig von Brügge $\{61\}$, Philippe de Croy $\{74\}$, Engelbert von Nassau $\{77\}$, Wolfart van Borssele \{79\}, Philipp von Burgund \{82\} und Bartholomäus von Liechtenstein \{85\}. Zur Sitzung am 9. Okt. vgl. § 206-210 sowie Reg. 74-95.

101 Zur Sitzung am 12. März 1479 vgl. § 222-237 sowie Reg. 103-105.

102 Vgl. Reg. 127. 
März ihrer Absageschreiben verfasst. ${ }^{103}$ Es ist davon auszugehen, dass diese Könige auch für das 1479 geplante Ordensfest ihre Absageschreiben schon etliche Wochen vor dem eigentlichen Fest ausgestellt haben. Einzig von Jean de Neufchâtel $\{52\}$ ist die Absage vom 12. April überliefert, ${ }^{104}$ sie scheint aber Anfang Mai noch nicht in den burgundischen Niederlanden angekommen zu sein, denn Toison d'or berichtete dem Orden, dass er während seines Aufenthalts in Brüssel keine Briefe entgegengenommen habe.

\section{B. Die Ordenstreffen am St. Andreas-Tag}

Das Protokollbuch berichtet, dass am 30. November 1478, den Festtag des Ordenspatrons St. Andreas, Herzog Maximilian mit einigen Ordensmitgliedern und Amtsträger in der Kirche Sainte-Goudule in Brüssel eine Messe zu Ehren des hl. Andreas besuchte. ${ }^{105}$ Dabei wurden sie von Herzogin Maria, zahlreichen Mitgliedern des Hofes und Gesandten König Ferdinands von Neapel $\{72\}$ begleitet. Ähnlich wie bei den Ordensfesten im Mai gingen alle Teilnehmer in einem hierarchisch geordneten Prozessionszug zur Kirche. Und wie bei der Großen Messe zu Ehren des Ordensheiligen während des Ordensfestes am 1. Mai, ${ }^{106}$ rief Toison d'or während dieses Gottesdienstes die anwesenden Mitglieder namentlich auf, damit sie am Altar ein Münzopfer zu Ehren des hl. Andreas stiften konnten. Im Anschluss an den Gottesdienst gab es eine Mahlzeit und danach versammelte man sich zu einer außerordentlichen Ordenssitzung, um die dringlichsten Angelegenheiten des Ordens zu regeln. ${ }^{107}$

Hier im Jahre 1478 wird in den Protokollbüchern zum ersten Mal vermerkt, dass der Orden bzw. die zu dieser Zeit beim Souverän befindlichen Ordensmitglieder am AndreasTag gemeinsam eine Messe zu Ehren des Ordenspatrons besuchten. Ursprünglich sollten die Ordensfeste jährlich an diesem Festtag stattfinden, doch aufgrund der ungünstigen Wetterlage in dieser Jahreszeit und den dadurch erschwerten Reisebedingungen wurde bei der Statutenrevision im Winter 1445/46 der Termin für die Ordensfeste auf den 2. Mai verschoben. ${ }^{108}$ Seit dem darauffolgenden Ordensfest im Jahr 1451 wurden die Feste nun an diesem Frühjahrstermin abgehalten, wobei an diesem Tag auch die zu Ehren des Apostel Andreas zuhaltende große Messe besucht wurde. ${ }^{109}$

Für das Jahr 1468 wurde zwar vermerkt, dass sich die Mitglieder am Andreas-Tag zu einer Beratung getroffen hatten, von einer Messe war aber keine Rede. ${ }^{110}$ Spätestens mit 1478 setzte wohl eine neue Tradition ein und der Ordenssouverän und die bei ihm

103 Vgl. Reg. 30-38.

104 Vgl. Reg. 108-110.

$105 \mathrm{Zu}$ diesem Gottesdienst vgl. die Eintragungen in § 211-219; dazu auch Prizer, Brussels, 2001, S. 77-79.

106 Vgl. die Beschreibung in § 81-96.

$107 \mathrm{Zu}$ dieser Besprechung vgl. § $220 \mathrm{f}$.

108 Vgl. dazu u. a. § 47 (neu § 22) der Statuten (mehr zu diesem Statutenartikel findet sich unten in Anm. 323); zur Terminänderung u. a. auch DünnEBEIL, Entwicklung, 2007, S. $26 \mathrm{f}$.

109 Dies hatte Herzog Karl \{34\} während des Ordensfestes von 1473 so festgelegt; vgl. dazu PB 3, S. 21 (mit Hinweis auf die entsprechenden Stellen im Protokollbuch).

110 PB 2, S. 162 f., § 205. 
weilenden Mitglieder feierten das Andreasfest inklusive Messe. ${ }^{111}$ Reiffenberg spricht in diesem Zusammenhang davon, dass der Orden sich nach dem Gottesdienst „par forme de petit chapitre" versammelt habe. ${ }^{112}$ Für 1479 ist kein solches Treffen überliefert, aber auch 1480 haben sich die Mitglieder getroffen, wenngleich das Protokollbuch darüber schweigt. Aber kurz danach schrieb Herzog Maximilian an verschiedene Mitglieder, dass er sich am Andreas-Tag mit einigen Ordensmitgliedern versammelt habe, aber aufgrund der geringen Teilnehmerzahl seien sie nicht beschlussfähig gewesen. Deshalb befahl er ihnen, sich am 9. Dezember in Gent einzufinden, um die dringlichsten Ordensangelegenheiten zu regeln. ${ }^{113}$ Auch 1481 versammelte sich mehrere Ordensmitglieder zu gemeinsamer Messe und Besprechung. ${ }^{114}$

\section{Die Planung des Ordensfestes von 1481}

Nachdem das für 1479 geplante Ordensfest kurzfristig hatte abgesagt werden müssen, wurde sogleich angekündigt, dass das Fest nur um ein Jahr verschoben sei. Doch besserte sich die politische Lage nicht und so wurde bei zwei Sitzungen am 29. Dezember 1479 in Gent und am 17. Januar 1480 in Brüssel beschlossen, das Fest um weiteres Jahr zu verschieben. ${ }^{115}$ Bei den außerordentlichen Versammlungen in Brügge am 16., 20. und 23. Dezember 1480 wurde dann konkret mit der Planung eines neuen Festes im Mai 1481 begonnen. ${ }^{116}$ Auch hier wurde zuerst darüber diskutiert, ob die Situation es wirklich erlaube, ein Fest zu veranstalten. Mit dem Argument, dass Herzog Maximilian die Ordensmitglieder nur wenig kenne und auch etliche Mitgliederplätze unbesetzt seien, beschlossen die anwesenden Mitglieder, dass eine große Ordensversammlung notwendig sei. Sie setzten dann auch die entsprechenden Ein- und Vorladungsschreiben auf, wobei sie der Austragungsort aber erst kurzfristig bekannt gegeben werden sollte. ${ }^{117}$ Die weitere Planung sowie die Beschreibung des Ablaufes der Ordensversammlung im Mai 1481 ist Inhalt des 5. Protokollbuch und soll deshalb in der dortigen Edition im Detail beschrieben werden.

\section{Neubesetzungen unter den Amtsträgern des Ordens}

Die Zeit nach 1477 war eine Zeit des Umbruchs im Orden vom Goldenen Vlies, nicht nur weil ein neuer Souverän den Vorsitz übernahm und eine größere Zahl neuer Mitglieder aufgenommen wurde. Auch in den Reihen der Amtsträger gab es Veränderungen.

111 Mit der musikalischen Untermalung der Andreasmesse beschäftigen sich u. a. PrIzer, Brussels, 2001, S. $78 \mathrm{ff}$.

112 Reiffenberg, Toison d'or, 1830, S. 99; dazu auch Prizer, Music, 1985, S. 117 f.; ders., Brussels, 2001, S. 77.

113 sommes trouves si petitement accompaingnié de noz treschiers freres les chevaliers compaignons dudit ordre que bonnement selon les status n'avons peu besoingner ne conclure sur quelque affaire d'icellui ordre; so der Brief Maximilians an Josse de Lalaing \{80\} vom 1. Dez. 1480 in Reg. $133 \mathrm{f}$.

114 Vgl. PB 5, fol. 78r-80r.

115 Vgl. § 257-262.

116 Vgl. § 263-282.

117 Vgl. Reg. 136 mit weiterführenden Angaben. 
Schon im Laufe des Sommers 1477 wurde die Stelle des Trésoriers vakant, nachdem der bisherige Amtsinhaber, Guillaume de Clugny, nach den Ereignissen in Gent im Frühjahr 1477 die burgundischen Niederlande verlassen und sich an den Hof König Ludwigs XI. begeben hatte. ${ }^{118}$ Aufgrund der vielfältigen Aufgaben des Trésoriers, die neben der Finanzverwaltung auch die Aufbewahrung des Ordensschatzes, der Festgardrobe der Mitglieder und des Archivs umfasste, wurde wohl im November 1477 der ehmalige Audienzier Herzog Karls, Jean Gros, zunächst provisorisch zum Trésorier ernannt. Bei der ersten Sitzung während des eigentlichen Ordensfestes von 1478 wurde Jean Gros von Herzog Maximilian in einer seiner ersten Amtshandlungen als neuer Ordenssouverän in diesem Amt bestätigt. ${ }^{119}$ Jean Gros versah seine Aufgabe als Trésorier des Ordens vom Goldenen Vlies bis zum Sommer 1484, wo er nach freiwilligem Rücktritt durch Nicolas de Gondeval abgelöst wurde. ${ }^{120}$

Im Dezember 1480 wurde auch der Ordenskanzler ausgewechselt. ${ }^{121}$ Der bisherige Amtsträger, Ferry de Clugny, der im September 1473 von Herzog Karl in dieses Amt eingesetzt worden war, war am 15. Mai 1480 zum Kardinal ernannt worden. Aus Bedenken, dass mit dieser neuen Würde viele Reisen und neue Aufgaben auf ihn zukommen würden und er damit dem Haus Burgund und dem Orden vom Goldenen Vlies nicht in gebührender Weise würde dienen können, legte Ferry de Clugny sein Amt als Ordenskanzler nieder. Bei der außerordentlichen Sitzung am 20. Dezember 1480 , bei der wie schon erwähnt ein neues Ordensfest vorbereitet wurde, fand auch die Diskussion über die Neubesetzung des Kanzleramtes statt, wobei man sich schnell auf Jean de Lannoy, Abt von Saint-Bertin bei Saint-Omer, einigte. Bei der nächsten Sitzung des Ordens, am 23. Dezember 1480, wurde er in sein neues Amt eingesetzt, nachdem er seinen Aufnahmeeid geleistet hatte. Auch wurde ihm das Ordenssiegel übergeben, mit dem Auftrag, sogleich die Einladungs- und Vorladungsschreiben für das im Mai 1481 geplante Ordensfest auszufertigen.

\section{Handschriftenbeschreibung}

Wie schon die früheren Protokollbücher befindet sich das Original der hier edierten und beschriebenen Handschrift im Bestand „Akten (Burgundisch-Spanisches Archiv)“ des Archivs des Ordens vom Goldenen Vlies im Haus-, Hof- und Staatsarchiv in Wien. ${ }^{122}$ Eine Abschrift der Protokolle der Jahre 1477 bis 1486 aus dem 17. Jahrhundert ist Teil des Bestands »Handschriften und Bücher «. ${ }^{123}$

118 Dazu ausführlicher $\S 9$ mit Anm. 40.

119 Dazu und zu seiner Bestätigung am 30. April 1478 vgl. ausführlicher § 74 und Reg. 48.

120 Dazu ausführlicher PB 6, fol. 39r.

121 Vgl. dazu § 276-282 sowie Reg. 140.

122 Die genaue Signatur ist: AOGV, Akten, Karton 1. In diesem Karton befinden sich auch die Protokollbücher aus den Jahren 1431-1467, 1468, 1473, 1481 und 1491. - Zur Geschichte und zu den wichtigsten Archivbehelfen vgl. die Angaben in PB 1, S. 17.

123 AOGV, Codex 37, fol. 1r-146v. - Eine Überprüfung zeigt, dass es sich um eine wörtliche Abschrift handelt; der Band wurde deshalb nur herangezogen, wenn es galt, Leseprobleme zu lösen. 
Beim 4. Protokollbuch des Ordens vom Goldenen Vlies handelt es sich um einen auf Papier geschriebenen und in Pergament gebundener Band von 20 mm Dicke. ${ }^{124}$ Im Hochformat gehalten, misst er in der Breite vorne $240 \mathrm{~mm}$, hinten $250 \mathrm{~mm}$ und in der Höhe $300 \mathrm{~mm}$. Der Umschlag besteht aus einem rauen, harten und brüchigen Pergament, das auf der Rückseite um 90 mm verlängert ist, so dass es zum Schutz der Handschrift nach vorne unter den Deckel geschoben werden kann.

Im oberen Drittel des vorderen Einbanddeckels befindet sich folgende zeitgenössische Aufschrift:

$$
\text { XXJ FESTE }{ }^{125} \text { avoit a Bruges l'an lxxviij }{ }^{126}
$$

Registre des ceremonies et misteres gardees et observees quant treshault, tresexcellent et trespuissant prince monseigneur le duc Maximilian par la grace de Dieu archeduc, duc d'Austrice, de Bourgoingne, de Lothrijc, de Brabant, de Lembourg, de Luczembourg etc., conte de Flandres, de Tyroll, d'Arthois, de Bourgoingne etc. comme bail et mary de treshaulte, tresexcellente et trespuissante princhesse madame Marie duche[sse] et contesse desdis pays, sa tresnoble espeuse et compaingne, fille unique, naturelle ${ }^{127}$ et legitime et seule heritiere universele de feu treshault, tresexcellent et trespuissant prince monseigneur le duc Charles, jadis duc de Bourgoingne, de Lothrijc, de Brabant etc., conte de Flanderes, d'Artois, de Bourgoingne etc. de tresnoble memoire que Dieu absoille, en son viviant chief et souverain du noble ordre de la Thoyson d'or, darrenier deffunct, a relevé et receu ledit noble ordre comme chief et souverain d'icellui ou lieu dudit feu le duc Charles, son beaupere, ensamble les actes des xxjes feste et chappittre du mesme l'ordre, celebrez et tenus par mondit seigneur le duc Maximilian en ladite qualité avec messeigneurs les chevaliers freres et compaingnons dudit ordre pour ce convocuez et devers lui assamblez en sa ville de Bruges en Flanderes le darrenier jour du mois d'avril et es jours ensuivans l'an mil cccc et soixante dixhuit. ${ }^{128}$

\title{
Maistre Martin \\ Steenberch, greffier
}

Darunter steht von einer anderen Hand geschrieben 1478. Im linken, unteren Eck schrieb 1759/60 Türck $^{129}$ bei seiner Inventarisierung des Ordensarchivs noch seine Signatur dazu:

\author{
Premiere Partie \\ de l'Inventaire \\ N. $4^{\circ}$
}

124 Die Beschreibung der Handschrift lehnt sich an an Mazal, Praxis des Handschriftenbearbeiters, 1987, und die Richtlinien Handschriftenkatalogisierung, 1992.

125 Ms.: xxj feste ist in großen Buchstaben geschrieben, deshalb wurde in der Edition dafür die Schrifttype Kapitälchen verwendet. Der danach folgende Text ist dagegen in extrem kleinen Buchstaben geschrieben, so dass diese zeitgenössische Ergänzung fast zu übersehen ist.

126 Ms.: avoit a Bruges l'an lxxviij wurde in sehr kleiner Schrift nachgetragen.

127 Ms.: naturelle ist unterstrichen.

128 Ms.: Die Jahresangabe 1478 ist unterstrichen.

129 Emanuel Joseph Türck ordnete in der Mitte des 18. Jahrhunderts des Ordensarchiv und fertigte die ersten Inventare an; dazu ausführlicher LAURENT, Inventaire, 1996 und PB 1, S. 17, Anm. 47. 
Weiters hatte Türck auch noch an der Deckelinnenseite mit Siegellack einen kleinen, heute stark zerknitterten, Pergamentstreifen angebracht. Dessen beschrifteter Teil (Premiere Partie N. 4/Registre des actes du relievement ${ }^{130} /$ de l'ordre en 1478 et de la fete /4 ensuivie à Bruges) ist von außen zu lesen, wenn der Streifen heruntergeklappt ist.

Die Handschrift besteht aus drei Heften, die von Doppelblatt A (fol. 0 und 100) umfasst werden. Das erste Blatt ist unbeschrieben, deshalb wurde es bei der Foliierung, die kurz vor Beginn der Transkription von einem Archivmitarbeiter rechts unten im Eck mit Bleistift durchgeführt wurde, nicht berücksichtigt.

Heft 1 (fol. 1-28) beschreibt auf 14 Doppelblättern die Ereignisse des Ordens bis zum Festmahl nach Herzog Maximilians Einführung zum Ordenssouverän am 29. April 1478 und hat keine zeitgenössische Foliierung. ${ }^{131}$

Heft 2 (fol. 29-59) umfasst die Ereignisse des in Brügge veranstalteten Ordensfestes und der darauffolgenden Ereignisse bis zum Gottesdienst am St. Andreas-Tag, 30. November 1479. ${ }^{132}$ Mit Beginn dieses Heftes wurde von zeitgenössischer Hand rechts oben im Eck mit schwarzer Tinte eine römische Zählung der Folia durchgeführt; diese zeitgenössische Foliierung wird in der Edition ebenfalls ausgewiesen. ${ }^{133}$ Das Heft besteht aus 15 Doppelblätter, dazwischen befindet sich mit fol. 40 ein Einzelblatt. Darauf ist die Wahl Bartholomäus von Liechtenstein $\{85\}$ beschrieben, die Steenberch wohl zuerst vergessen hatte. ${ }^{134}$

Der Übergang zu Heft 3 ist fließend, sowohl im Erzählverlauf als auch bei der zeitgenössischen Foliierung. Dieses Heft geht von fol. 60 bis fol. 99, dem vorletzten Blatt der Handschrift. ${ }^{135}$ Das Heft wird von einer Lage A bestehend aus acht Doppelblättern (fol. 60-67 und 92-99) umfasst. Jedes der Doppelblätter hat unten rechts eine mit hellerer Tinte vorgenommene eigene zeitgenössische Zählung von 1 bis 8. Dazwischen liegen nebeneinander zwei Lagen B (fol. 69-78) und D (fol. 53-60). Lage B wird von einem Doppelblatt (fol. 68 und 83) umfasst und wird rechts unten zeitgenössisch mit 9 bezeichnet wurde. Dazwischen liegen eine aus fünf Doppelblättern bestehende Lage C (fol. 69-78), sowie zwei nebeneinander liegende Doppelblätter. Das erste umfasst fol. 79 und 80 und weist sowohl oben als auch rechts unten keine zeitgenössische Zählung auf. Das zweite Doppelblatt umfasst fol. 81 und 82 und trägt unten rechts die zeitgenössische Zahl 10 und führt auch oben rechts die zeitgenössische Foliierung weiter. Es scheint so, dass das erste Doppelblatt, das einen Bericht des Wappenkönigs Toison d'or enthält ${ }^{136}$, erst nachträglich eingelegt wurde. Einen Neuanfang der Eintragungen bildet Lage D, die aus vier Doppelblättern besteht und von fol. 84-91 geht. Nach einer Pause seit der letzten Sitzung im Januar 1480 traf sich nun der Orden im Dezember 1480 erneut, um Vorbereitung für ein neues Ordensfestes im Mai $1481 \mathrm{zu}$ treffen. ${ }^{137}$

130 Ms.: relievement ist unterstrichen.

$131 \S 1-69$.

$132 \S 70-213$.

133 In der Edition wurde folgende Darstellung gewählt: [fol. xxx/yyy], wobei die erste Ziffer der modernen Foliierung mit Bleistift und die zweite Ziffer der zeitgenössische Foliierung folgt, wobei statt der römischen Ziffern ebenfalls arabische Ziffern gewählt wurden.

$134 \S 133$; vgl. dazu auch die Angaben in Anm. 145 und 150.

$135 \S 214-282$.

$136 \S 256$.

137 § 263-282. 
Inhaltlich hätten diese Eintragungen fast besser in das 5. Protokollbuch gepasst, das das Fest von 1481 beschreibt. Das Schriftbild ist wesentlich kursiver und weist mehr Kürzungen auf. Es fehlt ab hier auch die zeitgenössische Folia-Zählung. Die letzten beiden Seiten dieser Lage sowie die fol. 92-100, die das Heft 3 zusammenhalten, sind unbeschrieben.

Der Band wird durch eine einfache Fadenbindung zusammengehalten. Da die Bindung noch gut erhalten und der Abstand zwischen dem Umschlag und den Papierlagen sehr klein ist, kann ohne ein Auseinandernehmen des Bandes die Bindung nicht genau gesehen werden. Sicher ist aber, dass die einzelnen Hefte und Lagen jeweils eine eigene Bindung haben. ${ }^{138}$ Am Buchrücken erkennt man, dass das Heft an mehreren Stellen mit dem Umschlag und dem Doppelblatt verbunden ist. Dafür wurde an verschiedenen Stellen, meist oben und unten, Fäden mit mehreren Einstichen durch das Pergament gezogen und außen mehrfach verknotet.

Das Protokollbuch ist eine schlichte, schmucklose Handschrift, die durchweg mit schwarzer Tinte geschrieben wurde. Die Eintragungen beginnen mit Beginn von Heft 1 auf fol. 1r und enden mit fol. 89r, der Rest ist unbeschrieben. Der Schriftraum, der durch Ritzungen im Papier begrenzt wurde, zeichnet sich vor allem durch einen breiten Rand unten $(60-80 \mathrm{~mm})$ und an der linken Seite $(50 \mathrm{~mm})$ aus. Der obere Rand ist dagegen kleiner $(35 \mathrm{~mm})$. Rechts wurde bis nahe an den Seitenrand geschrieben.

Die Handschrift weist eine Beschädigung auf und zwar am rechten oberen Rand (ca. $25 \mathrm{~mm}$ vom oberen und $15 \mathrm{~mm}$ vom rechten Rand entfernt) ein kleines Loch, das von einem spitzen Gegenstand von hinten fast durch die ganze Handschrift hindurch gebohrt wurde.

In der Handschrift lassen sich auf jedem Doppelblatt insgesamt drei verschiedene Wasserzeichen finden. ${ }^{139}$ Bei dem ersten handelt es sich um einen Einhorn mit Mähne und Streifen auf dem Horn, das quer zur Seite steht. ${ }^{140}$ Auch im 1. Protokollbuch ist an einer Stelle ein nahezu identisches Tier zu sehen. ${ }^{141}$ Einhörner waren beliebte Wasserzeichen, die sich in vielen Variationen finden lassen, sie sind aber vorwiegend in der 2. Hälfte des 15. Jahrhunderts im burgundisch-niederländischen Raum zu finden. ${ }^{142}$ Bei dem zweiten vorhandenen Wasserzeichen handelt es sich um einen achtstrahli-

138 Heft 1 wurde zwischen fol. 14 und 15 gebunden und durch einen schmalen Pergamentstreifen verstärkt. Desgleichen ist bei den Bindungen fol. 44 und 45 (Heft 2), fol. 73 und 74 (Heft 3) und fol. 87-88 (Lage D in Heft 3) zu sehen.

139 Lediglich das eingelegte (Einzel-)Blatt fol. 40 trägt kein Wasserzeichen, vermutlich hat sich dieses aber auf der abgeschnitten Seite befunden. - Bei den nun folgenden Aufzählungen wird als erstes die Blatthälfte mit dem Wasserzeichen und als zweites die leere Blatthälfte genannt (z. B. fol. 40/1).

140 Vorhanden im gesamten Heft 1 auf den Blättern 4/25, 6/23, 9/20, 10/19, 11/18, 13/16, 15/14, 17/12, 21/8, 22/7, 24/5, 26/3, 27/2 und 28/1, im gesamten Heft 2 auf den Blättern $29 / 59,33 / 55,35 / 53,38 / 50,41 / 48,42 / 47,44 / 45,46 / 43,49 / 39,51 / 37,52 / 36,54 / 34$, $56 / 32,57 / 31$ und 58/30 sowie in Heft 3, Lage C bei den Doppelblättern 73/74, 75/72, 76/71, 77/70 und 78/69. Dieses Wasserzeichen befindet sich auch in AOGV, Codex 45, z.B. auf fol. 54v, 74v, 75v, 81r und 83v (zu dieser Handschrift vgl. die Angaben in 15 , Anm. 90) sowie Akten, Karton 5, Fasz. 14 A (vgl. dazu die Angaben in § 239 mit Anm. 173).

141 PB 1, S. 20 (fol. 53).

142 Vgl. dazu das Wasserzeichen-Informationssystem (www.wasserzeichen-online.de), Referenznummer DE4500-PO-124648 (nach Picard). 
gen Stern mit einer darüber stehenden Krone. ${ }^{143}$ Vergleichbare Zeichen sind im gleichen Zeitraum für Troyes, Péronne, Paris und den niederländisch-rheinischen Raum nachgewiesen. ${ }^{144}$ Beim dritten vorhandenen Wasserzeichen handelt es sich um einen Schild mit Zwillingsschrägbalken, darüber ein Tatzenkreuz und darunter ein t. Dieses Zeichen ist in PB 4 nur dreimal vorhanden und zwar am Ende der Handschrift mit Eintragungen von 1480. ${ }^{145}$ Mit kleinen Variationen findet sich dieses Wasserzeichen auf zahlreichen Schriftstücken aus dem niederländisch-burgundischen Raum im Zeitraum zwischen 1480 und 1485, darunter auch auf einem Brief Maximilians von 1482. ${ }^{146}$

In der Regel sind die Anfangsbuchstaben jedes Abschnittes um einiges größer geschrieben als der übrige Text. Gelegentliche Randbemerkungen und Überschriften sollen auf besonders wichtige Stellen hinweisen. ${ }^{147}$ Das gesamte Schriftbild, die fließenden Übergänge zwischen den Lagen und kaum vorhandene Streichungen, Korrekturen und Leerstellen weisen darauf hin, dass das Protokollbuch in einem Durchgang, möglicherweise nach einer (nicht mehr erhaltenen) Vorlage niedergeschrieben wurde. Verfasser des 4. Protokollbuchs, wie auch schon des letzten Teils des ersten sowie des zweiten und dritten Protokollbuches war der Ordensgreffier Martin Steenberch, der dieses Amt seit 1461 innehatte. Zu Beginn des Ordensfestes von 1481 las Steenberch den versammelten Ordensmitgliedern das gesamte (4.) Protokollbuch vor und es wurde als genau und vollständig empfunden. ${ }^{148}$ Gelegentlich finden sich Randbemerkungen die von einer anderen Hand notiert wurden. Diese zeichnen sich durch eine stark kursive Schrift mit vielen Kürzungen aus; zur Unterscheidung von Steenberch wird sie mit „Hand s“ gekennzeichnet. Möglicherweise stammen sie von dem zwischen 1480 und 1492 amtierenden Ordenskanzler Jean de Lannoy, Abt von Saint-Bertin. ${ }^{149}$

143 Vorhanden auf dem Umschlagblatt 0/100 sowie bei bei Heft 3 bei den Doppelblättern 60/99, 61/98, 63/96, 65/94, 66/93, 67/92, 81/82, 83/68, 85/90, 89/86 und 95/64.

144 Vgl. dazu das Wasserzeichen-Informationssystem (www.wasserzeichen-online.de), u. a. die Referenznummern DE2730-PO-41681, DE2730-PO-41684, DE4500-PO-41689 und AT3800-PO-41686, Briquet, Filigranes, 1907, Nr. 6109f. und 615; danach http:// www.ksbm.oeaw.ac.at/_scripts/php/BR.php (11.11.2015).

145 Vorhanden am Ende von Heft 3 bei den Doppelblättern 79/80, 88/87 und 91/84.

146 Vgl. dazu das Wasserzeichen-Informationssystem (www.wasserzeichen-online.de), u. a. die Referenznummern AT3800-PO-24507, DE2040-PO-24514, DE4500-PO-24515, DE8100-PO-24506, DE8100-PO-24509, NL5325-PO-24510, NL8370-PO-24502, NL8370PO-24503 und NL8370-PO-24505.

147 Die entsprechenden Stellen sind in der Edition vermerkt.

148 PB 5, fol. 6v und 7r, § 16 und 21.

149 Vgl. seine eigenhändigen Briefe in AOGV, Akten, Karton 5, Fasz. 14 K. 


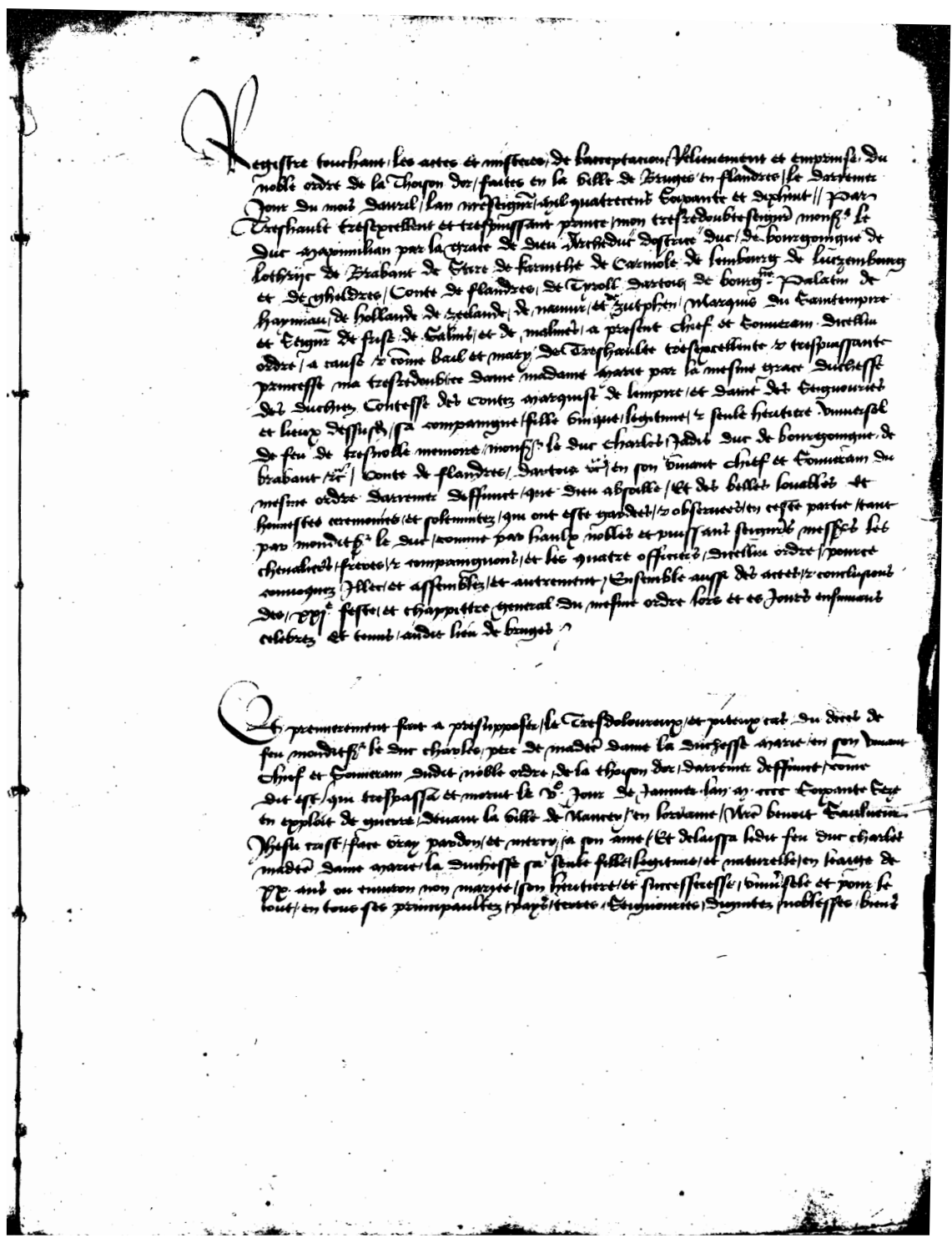

Abbildung 2 Die erste Seite des 4. Protokollbuches (fol. 1r) 


\section{Das vierte Protokollbuch}





\section{Teil 1: Die Übergabe des Ordens an Herzog Maximilian}

\section{Einleitung}

[fol. 1r] [1] [Berichtet wird von der Übernahme des Ordens durch Hz. Maximilian und
von dem darauf folgenden 21. Ordensfest.]

Registre touchant les actes et misteres de l'acceptacion relievement et emprinse du noble ordre de la Thoison d'or, faites en la ville de Bruges en Flandres le darrenier jour du mois d'avril l'an Nostre Seigneur mil quatrecens soixante et dixhuit, ${ }^{1}$ par treshault, tresexcellent et trespuissant prince mon tresredoubté seigneur monseigneur le duc Maximilian, par la grace de Dieu archeduc d'Ostrice, duc de Bourgoingne, de Lothrijc, de Brabant, de Stire, de Karinthe, de Carniole, de Lembourg, de Luczembourg et de Gheldres, conte de Flandres, de Tyroll, d'Artois, de Bourgoingne palatin, de Haynnau, de Hollande, de Zeelande, de Namur et $\operatorname{de}^{2}$ Zutphen, marquis du Saint Empire et seigneur de Frise, de Salins et de Malines, ${ }^{3}$ a present chief et souverain d'icellui ordre, a cause et comme bail et mary de treshaulte, tresexcellente et trespuissante princesse, ma tresredoubtee dame madame Marie, ${ }^{4}$ par la mesme grace duchesse des duchiez, contesse des contez, marquise de l'Empire et dame des seignouries et lieux dessusdites, sa compaingne, fille unique, legitime et seule heritiere universel de feu de tresnoble memoire monseigneur le duc Charles \{34\}, jadis duc de Bourgoingne, de Brabant etc., conte de Flandres, d'Artois etc. en son vivant chief et souverain du mesme ordre, darrenier deffunct, que Dieu absoille. ${ }^{5}$ Et des belles, louables et honnestes ceremonies et solemnitez, qui ont esté gardees et observees en ceste partie, tant par mondit seigneur le duc comme par haulx, nobles et puissans seigneurs messires les chevaliers, freres et compaingnons et les quatre officiers d'icellui ordre, pour ce convoquez illec

\section{April 1478. \\ Ms.: de steht über der Zeile.}

3 Die für Hz. Maximilian zu dieser Zeit gebräuchlichen Titelei lässt sich besonders gut ablesen in drei Belehnungsurkunden seines Vaters Ks. Friedrich III. \{94\}, ausgestellt am 19. April 1478 in Graz, worin er Maximilian, seine Frau Maria und deren Erben mit (1.) dem Hzt. Geldern und der Gft. Zutphen, (2.) mit allen zum Hlg.-röm. Reich gehörenden Herzogtümer, Graf- und Herrschaften Hz. Karls \{34\} und (3.) mit allen dessen Besitzungen inclusive der zu Frankreich gehörenden belehnt. Im Vergleich dazu fehlen aber bei den hier im Protokollbuch aufgezählten Titel mehrere habsburgische Haustitel, wie die Grafschaften Habsburg, Pfirt und Kyburg, die Landgrafschaft Elsaß und die Herrschaften der Windischen Mark und Portenau. Die ksl. Urkunden befinden sich im Or. im HHStA Wien, AUR 1478 IV 19; (unzureichend) gedruckt bei CHMEL, Aktenstücke, 2, 1855, S. 396-400, Nr. 88. Vgl. dazu u. a. HeINIG, Westpolitik, 2004, S. 69; Koller, Friedrich III., 2005, S. 200 f.; Böck, Herzöge, 2013, S. 562 f. sowie künftig die ausführlich kommentierten und mit Quellen- und Literaturangaben versehenen Regesten bei Regesten Friedrichs III., Heft AUR 1476-1479, sub dato.

4 Zur Person Maria von Burgund s. in der Einleitung S. 13, Anm. 2.

5 Zu seinem Tod vgl. die Angaben im folgenden Absatz mit Anm. 9. 
et assemblez et autrement, ensemble aussi des actes et conclusions des $\mathrm{xxj}^{\mathrm{e}}$ feste et chappittre general du mesme ordre ${ }^{6}$ lors et es jours ensuivans celebrez et tenus audit lieu de Bruges. ${ }^{7}$

\section{[2] [Der am 5. Januar 1477 gefallene Hz. Karl hinterlässt alle seine Rechte und Besitzungen seiner unverheirateten Tochter Maria.]}

Et premierement fait a presupposer le tresdoloureux et piteux cas du deces de feu mondit seigneur le duc Charles $\{34\}$, pere de madite dame la duchesse Marie, en son vivant chief et souverain dudit noble ordre de la Thoison d'or, darrenier deffunct comme dit est, qui trespassa et mourut le $\mathrm{v}^{\mathrm{e}}$ jour de janvier l'an $\mathrm{M}$ cccc soixante seze $^{8}$ en exploit de guerre devant la ville de Nancey en Lorraine, ${ }^{9}$ nostre benoit saulveur Jhesu Crist face vray pardon et merry a son ame. Et delaissa ledit feu duc Charles madite dame Marie la duchesse, sa seule fille legitime et naturelle en l'eaige de xx ans ou environ, non mariee, son heritiere et sucesseresse universele et pour le tout en tous ses principaultez, pays, terres, seignouries, dignitez, noblesses, biens [fol. 1v] prerogatives $^{10}$ et possessions quelzconques qu'il avoit et lui competoient au jour de sondit trespas.

\section{[3] [Die Bestimmungen der Statuten über die Nachfolge eines verstorbenen Sou- veräns.]}

Secondement fait a presupposer le $\mathrm{lxv}^{\mathrm{e}}$ article des status et ordonnances dudit noble ordre de la Thoison d'or parlant ainsi: «Item s'il avenoit que, apres le deces du souverain de l'ordre, son successeur en l'ordre fust moindre d'eaige, parquoy ne fust puissant de [de]mener les fais de l'ordre, voulons et ordonnons que, en ce cas, les freres et compaingnons de l'ordre facent ensemble une convocacion et assemblee et, par oppinions et le greigneur nombre de voix, eslisent l'ung d'entre eulx pour presider et demener les besoingnes de l'ordre ou lieu du mineur a ses despens jusques a ce qu'il sera en eaige et chevalier. Et se, du trespas du souverain, demouroit fille son heritier[e], non mariee, voulons et ordonnons que semblablement soit esleu ung des chevaliers de l'ordre pour conduire les fais de l'ordre jusques ladite fille heritiere soit mariee a chevalier en eaige d'emprendre et conduire la charge et le fait du souverain de l'ordre

6 Nach der Zählung der Protokollbücher, bei der auch einige ausgefallene Feste mitgezählt werden, war dieses das 21. Fest, das seit Gründung des Ordens gefeiert wurde. In der Literatur werden gerne nur die tatsächlich abgehaltenen Feste gezählt; danach ist das Fest von 1478 das 13. Fest des Ordens. - Eine Aufstellung der Feste findet sich unten auf S. 291-294.

7 Vgl. § $70 \mathrm{ff}$.

8 5. Januar 1477 (n.St.).

9 René II., Hz. von Lothringen (reg. 1473-1508) bemühte sich darum seine von Hz. Karl besetzten Länder, die eine Brücke zwischen den südlichen und nördlichen Gebieten der burgundischen Besitzungen bildeten, wieder zurückzuerobern. Dabei kam es am 5. Januar 1477 zur Schlacht vor Nancy, bei der Hz. Karl erschlagen und erst Tage danach identifiziert wurde. Kaum wurde Karls Tod bekannt, bemühten sich viele, aus dem entstandenen Machtvakuum des großen Burgunderreiches ihre Vorteile zu ziehen, allen voran Ludwig XI, Kg. von Frankreich. Zu Karls Tod vgl. u. a. Vaughan, Charles the Bold, 1973, S. 425-432; Brachmann, Tod, 2008; Brachmann, Karls Nachleben, 2010.

10 Ms.: prerogatives ist unterstrichen. 
dessusdit, et qu'il en ait fait le serment. Auquel ainsi esleu voulons et ordonnons, durant ledit temps, estre obey es besoingnes d'icellui ordre comme au souverain. ${ }^{11}$

\section{[4] [Hz. Karl hat die Verträge für eine Heirat zwischen dem Kaisersohn Maximi- lian und seiner Tochter Marie kurz vor seinem Tod unterschrieben.]}

Tiercement fait a presupposer que pieça paravant ledit deces de feu mondit seigneur le duc Charles \{34\}, pere de madite dame la duchesse, paroles avoient esté et ouvertures faites de bouche et autrement de la part de la souveraine maiesté imperial l'empereur de Rome Frederic $\{94\}$, tiers de ce nom, ${ }^{12}$ a feu mondit seigneur le duc Charles en la cité de Treves ${ }^{13}$ et autrepart pour le mariaige de mondit tresredoubté seigneur monseigneur le duc Maximilian, unique filz legitime et natural de ladite maiesté imperial, d'une part avec madite dame la duchesse d'autre. Et que du costé d'icelle maiesté par notables et grandes ambassades a ce auctorisees souffisamment avoit ceste matiere esté tellement poursuie, continuee, entretenue et conduite devers icellui feu monseigneur le duc Charles [fol. 2r] que pluseurs jours paravant sondit trespas le traictié dudit mariaige finablement avoit par et entre lesdis ambaxeurs et procureurs de l'empereur d'une part et feu mondit seigneur le duc Charles d'autre esté par meure et grande deliberacion accordé, conclut et fermé d'ung costé et d'autre ainsi que souffisamment depuis icellui trespas. Il est apparu par lettres et seellez qui en avoient esté fais, baillez et rendus d'une part et d'autre. ${ }^{14}$

\section{[5] [Ksl. Gesandte verhandeln mit Hz.in Maria und deren Stiefmutter Hz.in Margarete über die Heirat.]}

Quartement delaissees pluseurs autres belles et notables ambaxades qui de par l'empereur $\{94\}$ et de par mondit seigneur le duc Maximilian, son filz, apres le trespas de feu mondit seigneur le duc Charles $\{34\}$ ont esté envoyees devers madite tresredoubtee

11 Zitat von § 103 (neu § 65) der Statuten (dazu S. 16, Anm. 14); vgl. PB 1, S. 229.

12 Zur Person Ks. Friedrichs III. († 1493) vgl. u. a. Koller, Friedrich III., 2005; HeInIG, Friedrich III.; zu seiner Wahl in den Orden vom Goldenen Vlies unten $§ 129$ passim.

13 Im Herbst 1473 trafen sich Ks. Fridrich III. und Hz. Karl von Burgund mit großem Gefolge zwischen dem 30. September und 25. November in Trier. Offiziell wurde über eine burgundische Beteiligung an einem geplanten Kreuzzug gegen die Türken verhandelt, in Wirklichkeit ging es aber vor allem um die Verheiratung des Kaisersohns Maximilian mit Maria von Burgund. Karl forderte dafür die römische Königskrone oder ein neuzuschaffendes Königreich, erhielt aber tatsächlich nur eine Belehung mit dem Hzt. Geldern. Die Heiratsverhandlungen selbst kamen während der Trierer Verhandlungen zu keinem Ergebnis, erst 1476 stimmte Karl dieser zu. Zu den burgundisch-habsburgischen Heiratsanbahnung vgl. in der Einleitung S. 17 f. und zum Trier Treffen u. a. PARAvicini, Magnificences, 2001, S. 348-358 (mit zahlreichen Quellen- und Literaturangaben); EHM, Beobachtungen, 2002; Müller, Um 1473, 2005; Енм-Schnocks, Trier, 2008; MarTi, Treffen, 2008; Müller, Griff nach der Krone, 2010; DünnebeIl, Rolle Burgunds, 2012.

14 Das Original des Heiratsvertrages gilt als verloren. Eine frz. Version von Marias Ausfertigung druckt Chronique de Maximilien I, 1839, S. 447-449, Nr. 2 (ohne Quellenangabe). Eine lat. Version druckt Dumont, Corps universel diplomatique, III/2, 1726, S. 9 f., Nr. VIII; MÜNCH, Maria und Margarethe, II, 1832, S. 87-90, Nr. 3; eine dt. Übers. bietet Wiesflecker-Friedhuber, Quellen, 1996, S. 38 f., Nr. 6. Dazu auch Wiesflecker, Maximilian, 1, 1971, S. 133 f.; Oschema, Freundschaft, 2006, S. 40, Anm. 111. 
dame madame la duchesse Marie ${ }^{15}$ lors damoiselle orphenine, et devers ma dame la duchesse Margriete, vesve dudit feu le duc Charles, sa belle mere. ${ }^{16}$ Et mesmement des personnes de reverend pere en Dieu hault et puissant prince messire [...] evesque de Metz ${ }^{17}$ de hault et puissant prince messire Loys, duc en Baviere, ${ }^{18}$ et de reverend pere messire George Hezeler, docteur, lors prothonotaire du Saint Siege apostolique, ${ }^{19}$ et d'autres grans et notables personnaiges, tant pour obtenir l'aggreement et consentement de madite damoiselle et de madite dame la grant, ${ }^{20}$ sa belle mere, au fait dudit

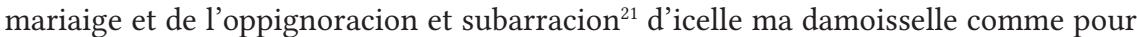
en avoir l'aggreement et consentement de messeigneurs les princes de son noble sang

15 Ms.: Marie steht über der Zeile.

16 Margarete von York (1446-1503), war die Schwester Eduards IV. \{63\}, Kg. von England, und heiratete $1468 \mathrm{~Hz}$. Karl \{34\}. Politisch trat sie in Erscheinung, in dem sie die Beziehungen zwischen Burgund und dem Hause York absicherte, aber sie leitete auch während der langen Abwesenheit ihres Mannes in den burgundischen Niederlanden die Verhandlungen mit den Ständen. Zu ihrer Stieftochter Maria, die nur wenige Jahre jünger als sie selbst war, hatte sie ein sehr enges Verhältnis, setzte sich gerade im Frühjahr 1477 für die burgundisch-habsburgische Heirat ein und übernahm nach Marias Tod die Erziehung von deren Kindern Philipp und Margarete. Zu ihrer Person vgl. MÜNCH, Maria und Margarethe, 1832; Blockmans, Margarete von York, 1993; Blockmans, Margret, 2005; Weightman, Margaret of York; Kat. Karl der Kühne, 2008, S. 177, Nr. 7 und Tafel 20 (Abb. ihres Porträts). - Zur kaiserlichen Gesandtschaft im Frühjahr 1477 vgl. die Angaben in der Einleitung S. 18 mit Anm. 22.

17 Georg von Baden $(†$ 1484) war von 1457 bis 1459 Koadjutor des Bf.s und dann selber Bf. von Metz. Wie andere Angehörige des Hauses Baden war er sowohl in Burgund als auch am ksl. Hof aktiv. Er erhielt den Bischofsstuhl von Metz mit Unterstützung Friedrichs III. und gegen den Widerstand der Burgunder, andererseits war er immer wieder als Rat und einflussreicher Gast am burgundischen Hof anwesend. Zu seiner Person vgl. u.a. Schneider, Georges de Bade, 1979; ChÂtellier, Georg von Baden, 1996; EhM, Burgund, 2002, S. 137 f.; HeInig, Akteure, 2006, S. 134.

18 Auch Fugger, Spiegel der Ehren, 1668, S. 854f. nennt ihn Herzog Ludwig von Bayern, der am 21. April als Stellvertreter Hz. Maximilians die Heirat mit Hz.in Maria per procuram vollzog. Es handelt sich dabei um Ludwig von Veldenz, Pfalzgraf und Hz. von Pfalz-Zweibrücken (1424-1489). Er traf am 1. Aug. 1477 in Aachen mit Maximilians Reisegesellschaft auf dem Weg nach Gent zusammen; vgl. dazu den Bericht der sächsischen Räte für die Zeit vom 4. Juli bis Ende Aug. 1477; gedruckt LANGENN, Albrecht der Beherzte, 1838, S. 529-538, Nr. 11, hier S. 532; nach dem Bericht gedruckt bei Lichnowsky, Geschichte, 7, 1843, Beilagen S. 497-501, Nr. 11. Zu seiner Person vgl. u. a. Rausch, Heirat, 1880, S. 169; WiLLE, Ludwig von Veldenz, 1884; HeInIG, Friedrich III., 1997, S. $416 \mathrm{f}$.

19 Georg Heßler (um 1427-1482) stand seit 1474 im Dienste Ks. Friedrichs III. \{94\}, gewann bald sein Vertrauen, diente ihm zeitweise als Kanzler und in zahlreichen diplomatischen Missionen. Da er längere Zeit am Erzstift Köln tätig gewesen war, war er Friedrich III. ein wichtiger Berater bei Angelegenheiten an der Westgrenze des Reichs und seit 1475 engagierte er sich sehr für die österreichisch-burgundische Heiratsverbindung. Als Dank dafür wurde Heßler am 13. Jan. 1478 die Kardinalswürde verliehen; vgl. Rausch, Heirat, 1880, S. 182. Zu seiner Person vgl. u. a. Hollweg, Heßler, 1907; Heinig, Friedrich III., 1997, S. 709-720; LEIDL, Heßler, 1996; DüNNEBEIL, Erbtochter, 2008, S. 173-175 und $180 \mathrm{f}$.

20 „Madame la Grande“ ist am burgund. Hof der offizielle Titel für die Herzogswitwen und wurde nach Hz.Karls Tod von dessen Witwe Margarete geführt; vgl. dazu u.a. Armstrong, Language, ${ }^{2} 1983$, S. 201, Anm. 5.

21 Ms.: l'oppignoraction et subarracion ist unterstrichen. 
et des estas de ses pays et seignouries comme aussi pour la garde et preservacion de sa personne. Et les diligences par eulx faites a ceste fin que sont hors de nostre propos et feroient trop longues a descripre.

\section{8. bis 23. August 1477 in Gent}

\section{[6] [Feierlicher Einritt Maximilians in Gent.]}

Fait aussi a presupposer que finablement mondit seigneur le duc Maximilian moult noblement et grandement accompaingnié, assavoir de tres reverend pere en Dieu monseigneur l'arcevesque de Treves, esliseur du Saint Empire, ${ }^{22}$ et de pluseurs autres notables prelas et grans princes, contes, barons, chevaliers, escuiers, clercs, notables et d'autres de divers estas, offices et condicions, est venu d'Austrice pardeça devers madite damoiselle, sa tresnoble espeuse, ${ }^{23}$ et saichant qu'elle estoit en sa ville de Gand, se y est venu rendre et y arriva a moult bel apparat le xviije jour du mois d'aoust l'an $\mathrm{M}$ cccc lxxvij, ${ }^{24}$ et au devant de lui approichant ladite ville de Gand alerent ledit jour apres disner au de hors de la porte [fol. 2v] tirant vers Tenremonde messeigneurs les princes du sang et avec eulx reverend pere en Dieu messire Ferry de Clugny, evesque de Tournay, chancellier, ${ }^{25}$ et messeigneurs les chevaliers freres dudit ordre de la Thoison d'or, messeigneurs les presidens et autres du grant conseil et les maistres d'ostel, chevaliers, escuiers, gentilz hommes et principaulx officiers des hostelz de madite damoiselle et de ma dame la grant, sa belle mere, $\mathrm{en}^{26}$ moult bel et grant apparat, y alerent aussi les prelas, baillis, eschevins et conseil, les grans doyens et ceulx des membres de ladite ville de Gand et des autres membres du pays de Flandres, en belle et notable compaignie tous a cheval, et arriva mondit seigneur le duc en ladite ville de Gand moult noblement et grandement accompaignié comme dessus environ quatre heures apres disner, et parmy la ville avoit es quarfours pluseurs et divers personnaiges et misteres par figures et autrement a l'onneur et reverence de lui et de sa joyeuse venue, et s'en vint descendre tout arivé en l'ostel de mondit seigneur l'evesque de Tournay, situé empres l'eglise parrochial de Saint Michel audit Gand.

22 Johann II., Mgf. von Baden (1430-1503), war seit 1456 Kurfürst und Erzbf. von Trier (1456-1503) und leitete im Frühjahr 1477 die ksl. Gesandtschaft, die in Burgund die Heiratsverhandlungen führte. Zu seiner Person vgl. u. a. SEIBRICH, Johann von Baden, 1996; Heinig, Friedrich III., 1997, I, S. 512 f.; Heinig, Akteure, 2006, S. 134.

23 Zeitgenössische Berichte über Maximilians Reise von Köln nach Burgund bieten u.a. Lichnowsky, Geschichte, 7, 1843, S. XXXXCVII-DI, Beilage Nr. 11; Chmel, Aktenstücke, 1, 1854, S. 159-164, Nr. 49; LANGENn, Albrecht der Beherzte, 1838, S. 529-538, Nr. 11; vgl. dazu aber auch u. a. Rausch, Heirat, 1880, S. 172-177; Priebatsch, Correspondenz, 2, 1897, S. 307 f.; Wiesflecker, Maximilian, 1, 1971, S. 129 f.; FichtenAu, Maximilian, 1959, S. 32f.; Noflatscher, Heuser, 2001, S. 37 mit Anm. 72 auf S. 46.

24 18. Aug. 1477. - Zu seinem Empfang in Gent vgl. u. a. LAngenn, Albrecht der Beherzte, 1838, S. 529-538, Nr. 11, hier S. 533 f.; Chronique de Maximilien I, 1839, S. 76-79; Wiesflecker, Maximilian, 1, 1971, S. 131 f.; Wiesflecker-Friedhuber, Quellen, 1996, S. 35-38, Nr. 5.

25 Zur Person des Ordenskanzlers Ferry de Clugny, der dieses Amt seit 1473 versah, vgl. die Angaben in § 276 mit Anm. 342.

26 Ms.: en steht am rechten Rand außerhalb des eigentlichen Textfeldes und wurde wohl noch während des Schreibens nachgetragen. 


\section{[7] [Am Abend veranstaltet Hz.in Margarete ein Festmahl für Hz, Maximilian.]}

Item et fait a presupposer en oultre que ledit xviije jour d'aoust l'an que dessus, ${ }^{27}$ environ six heures du vespres, mondit seigneur le duc Maximilian ala devers madite damoiselle lors son espeuse pour la veoir et visiter, comme il fist reverenment et moult honorablement. Et ce soir il souppa avec madite dame la grant que lui fist le banquet et la eubt grant joye, jeux de tous instrumens dausses apres soupper et autres esbattemens pluseurs. Mais le soir environ la my nuyt mondit seigneur s'en retourna et vint coucher en son logis, assavoir oudit hostel de mondit seigneur l'evesque de Tournay. ${ }^{28}$

\section{[8] [Die Hochzeit Maximilians und Marias.]}

Item et le lendemain que fut le xix ${ }^{\mathrm{e}}$ jour dudit mois d'aoust l'an que dessus, ${ }^{29}$ matin entre v et vj heures, mondit seigneur le duc Maximilian espousa selon l'ordonnance de Sainte Eglise nostredite damoiselle, a present madame la duchesse Marie de Bourgoingne, sa compaigne, ${ }^{30}$ en la chappelle de l'ostel d'icelle, [fol. 3r] appellé l'ostel de le Walle, ${ }^{31}$ et en la main de reverend pere en Dieu messire Lucas evesque Sibinicensis, orateur et ambasseur de nostre Saint Pere le pape Sixte iiij de ce nom, aiant puissance de legat du Saint Siege apostolique, ${ }^{32}$ par dispensacion ${ }^{33}$ souffisante dudit Saint Pere

27 18. Aug. 1477.

28 Zum abendlichen Empfang, bei dem sich das Brautpaar zum ersten Mal sah, vgl. auch Fugger, Spiegel der Ehren, 1668, S. 857 f.; Kervyn DE LetTenhove, Histoire de Flandre, V, 1850, S. 280 f.; Rausch, Heirat, 1880, S. 177 (mit weiteren Quellenangaben).

29 19. Aug. 1477.

30 Hz.in Maria wurde hierzu von den Vliesrittern Ludwig von Brügge $\{61\}$ und Jean de Lannoy $\{50\}$ zum Altar geführt; vgl. dazu u. a. Hommel, Marie de Bourgogne, ${ }^{2} 1945$, S. 308. Beschreibungen der Heiratsfeierlichkeiten bieten u. a. MüNCH, Maria und Margarethe, I, 1832, S. 189-196; Mémoires de la Marche, 3, 1885, S. 244 f.; Hommel, Marie de Bourgogne, ${ }^{2} 1945$, S. 308-310; Wiesflecker, Maximilian, 1, 1971, S. 134f.; CARon, Banquet, 2007, S. 11. Im HHStA Wien, AUR 1479 III 17, befindet sich dazu noch einen im März 1479 in Einsiedeln verfasster Bericht über die Hochzeitfeierlichkeiten; vgl. dazu Kat. Karl der Kühne, 2008, S. 350, Nr. 161.

31 Zur hzl. Residenz in Gent, auch Ten Walle oder Prinsenhof genannt, vgl. u. a. Boone/ Hemptinne, Espace urbain, 1997, S. 288-295; Hof ten Walle, 2000; Lievois/Haemers, Maria, 2014.

32 Lucas de Tolentis, Bf. von Šibenik (1470-1491), hielt sich als päpstlicher Gesandter zwischen 1462 und 1484 vornehmlich in den burgund. Niederlanden auf. Während des Festes des Ordens vom Goldenen Vlies 1473 in Valenciennes erhielt er eine Audienz vor dem Orden, bei der für einen Kreuzzug gegen die Türken und die Einrichtung einer spirituellen Bruderschaft warb (vgl. dazu PB 3, S. 128-130, § 201-203, S. 132-137, $\S 206-215)$. Auch zwischen 1477 und 1478 befand er sich in den Niederlanden; er wurde am 11. Sept. 1480 sogar zum Rat und maistre de requestes de l'hostel des Herzogenpaars ernannt. Zu seiner Person vgl. u. a. PAQuet, Tolentis, 1949, S. 31 ff.; Walsh, Coming of Humanism, 1976, 151 f.; Regesten Friedrichs III., Suppl. 1, 2008, S. 101 f., Nr. 103. Nach Wiesflecker, Maximilian, 1, 1971, S. 134, war der ausführende päpstliche Legat Julianus von Ostia.

33 Der päpstl. Heiratsdispens vom 1. Jan. 1477 (Druck: Bachmann, Urkundliche Nachträge, 1892, S. 391-393, Nr. 396) wurde von Lucas de Tolentis in die Niederlande gebracht. Am 30. Sept. 1477 stellte Hz. Maximilian eine Zahlungsanweisung aus, damit der Papst über Tolentis 3.000 écus für die Ausstellung des Dispens erhielt; vgl. dazu BARANTE/ Gachard, Histoire, II, 1838, S. 729; Paduet, Tolentis, 1949, S. 47 f. mit Anm. 3. Zum 
en tel cas pertinente, presens mondit seigneur l'archevesque de Treves, esliseur dudit Saint Empire,$^{34}$ messeigneurs les evesques de Mets et de Tournay et pluseurs haulx et puissans princes, marquis, contes, barons, prelas, chevaliers, escuiers et autres notables personnes de divers estas, condicions et nacions, menans grant joye et solas.

[9] [Diskussion der in Gent anwesenden Mitglieder des Ordens: Schnell stellen sie fest, dass Hz. Maximilian durch seine Hochzeit mit Maria statutengemäß der neue Ordenssouverän werden solle. Sie beschliessen mit einem dementsprechenden Ansuchen bei ihm vorzusprechen. Da bei dieser Sitzung nur vier Mitglieder anwesend sind, diskutieren sie auch noch darüber, ob sie angesichts der geringen Zahl für einen solches Vorgehen überhaupt beschlussfähig sind. Sie kommen zu einem positiven Ergebnis, denn der Orden hat nur noch wenige Mitglieder und von denen wohnen einige weit entfernt, sodass die Kontaktaufnahme zu ihnen zu viel Zeit in Anspruch nehmen würde und dadurch möglicherweise der weitere Bestand des Ordens gefährdet werde.]

$[a]^{35}$ Item le xxij jour dudit mois d'aoust l'an dessusdit, ${ }^{36}$ environ trois heures apres disner, pardevers hault noble et puissant seigneur messire Jehan de Melun, seigneur d'Anthoing \{28\}, chevalier frere et compaignon du noble ordre de la Thoison d'or et le plus anchien de ceulx dudit ordre, qui lors estoient en la ville de Gand, se assamblerent en son logis haulx nobles et puissans messires Loys, seigneur de Gruythuse $\{61\}$, conte de Wyncestre, Phelippe de Croy $\{74\}$, conte de Chimay, $<c>$ et Engelbert, conte de Nassauw $\{77\}$, seigneur de Breda, tous chevaliers freres et compaignons, reverend pere en Dieu messire Ferry de Clugny, evesque de Tournay, ${ }^{37}$ chancellier, M(artin) Steenberch, graffier ${ }^{38}$ et Thoison d'or, roy d'armes, ${ }^{39}$ officiers d'icellui ordre. Messire Guillaume prothonotaire de Clugny, lors tresorier dudit ordre,$^{40}$ empeschié et exusé qu'il n'y povoit estre.

Dispens vgl. u. a. auch Wiesflecker, Maximilian, 1, 1971, S. 111 mit Anm. 45 auf S. 445; Vaughan, Charles the Bold S. 421.

34 Zur Person Johanns von Baden, Ebf. von Trier, vgl. § 6, Anm. 22.

35 Ms.: Zur besseren Lesbarkeit dieses langen Paragraphen wurden Absätze und Unterpunkte eingefügt.

36 22. Aug. 1477.

37 Ferry de Clugny wurde im September 1473 zum Kanzler des Ordens ernannt; mehr Angaben zu seiner Person finden sich unten in § 276 mit Anm. 342.

38 Martin Steenberch (†9. Okt. 1491) wurde 1461 zum Greffier ernannt, vgl. PB 1, S. 123 f. § 3; zu seiner Person auch Koller, Service, 1971, S. 114; PB 2, S. 10-12; Cockshaw, Prosopographie, 2006, S. 92-94, Nr. 95 und HoorebeEck, Steenberch, 2006.

39 Gilles Gobet wurde 1468 zum Wappenkönig Toison d'or ernannt, vgl. PB 2, S. 26 f.; zu seiner Person vgl. Koller, Service, 1971, S. 140 f.; Gruben, Chapitres, 1997, S. 37 f.

40 Ms.: Guillaume prothontaire de Clugny, lors tresorier dudit ordre ist unterstrichen und zwar mit der gleichen Tinte, wie die zu diesem Absatz gehörigen Randbemerkung. Guillaume de Clugny, der auch apostolischer Protonotar und Archidiakon von Thérouanne war, wurde im April 1472 zum Trésorier des Ordens vom Goldenen Vlies ernannt und gehörte 1476 dem Regentschaftrat Hz. Karls \{34\} in den Niederlanden an. Während des Genter Aufstandes wurde er zusammen mit dem burgund. Kanzler Guillaume $\mathrm{Hu}-$ gonet und Guy de Brimeu \{76\} gefangengenommen, er entging aber einer Verurteilung 
[b] Et en ceste assamblee mondit seigneur l'evesque de Tournay, chancellier, par l'ordonnance de mesdis seigneurs les chevaliers freres de l'ordre mist en termes deux poins pour y avoir deliberacion et advis entre eulx.

[c] L'un des poins estoit: Se veu le mariaige lors parfait et consummé entre mondit tresredoubté seigneur monseigneur le duc Maximilian et madite dame la duchesse, sa compaigne, fille legitime et seule heritiere de feu mondit seigneur le duc Charles $\{34\}$, en son vivant chief et souverain dudit ordre de la Thoison d'or, darrenier deffunct ${ }^{41}$, il estoit expedient et temps oportun et convenable de parler a mondit seigneur le duc Maximilian du fait d'icellui ordre et de l'exhorter, prier et requerir qu'il lui pleust de relever, accepter et emprendre ledit ordre, pour le remettre sus selon les status et ordonnances d'icellui. Car a cause dudit trespas de feu mondit seigneur le duc Charles et depuis icellui l'ordre estoit demouré jusques a lors sans chief et fort diminué en nombre de personnes et autrement et seroit taillié de decliner [fol. 3v] de plus en plus et de faillir ou tumber de tous poins en brief temps, se pourveu n'y estoit. Et n'estoit loisible de le restaurer ou remettre sus, se non par moyen d'icellui monseigneur le duc, a cui comme a present bail et mary de madite dame la duchesse, fille et heritiere seule dudit feu monseigneur le duc Charles, darrenier chief et souverain d'icellui ordre, et a nul autre et competoit et appartenoit selon la forme desdis status et ordonnances du mesme ordre. ${ }^{42}$

[d] L'autre point fut: Se en cas que la deliberacion et conclusion de mesdis seigneurs les chevaliers freres de l'ordre illec assamblez porteroit et concluroit de faire lesdites remonstrances et requeste a mondit seigneur le duc Maximilian, ilz estoient en nombre competent pour ce faire, consideré que la matiere estoit grande et pesante et telle que bien requerroit plusgrant nombre des chevaliers que de ceulx qui la estoient se bonnement recouvrer se povoient.

[e] Sur lesquelz deux poins ainsi mis en termes une deliberacion et meur advis par mesdis seigneurs les chevaliers freres de l'ordre, veu et leu bien au long et examiné prealablement ledit $\mathrm{lxv}^{\mathrm{e}}$ article des status et ordonnances dudit ordre ${ }^{43}$, declairant amplement et ouvertement comment ceulx de l'ordre conduide se devroient en cas que le chief et souverain dudit ordre trespassast et ne laissast que fille son heritiere non mariee comme il s'estoit offert ou cas present. Veu que feu mondit seigneur le duc Charles a l'eure de son trespas n'avoit delaissié autre hoir de son corps que madite

aufgrund seines geistlichen Standes. Nachdem er am 14. Aug. 1477 Urfehde geschworen hatte, liessen ihn die Genter frei und er begab sich an den Hof Ludwigs XI., Kg. von Frankreich, wo er rasch Karriere machte; vgl. dazu u. a. PARAvicini, Guy de Brimeu, 1975, S. 485 f. mit Anm. 125. Infolgedessen wurde er in seinem Amt als Trésorier des Ordens vom Goldenen Vlies am 29. Nov. 1477 von Jean Gros abgelöst; vgl. dazu unten $\S 74$. Zur Person Guillaumes vgl. u. a. Koller, Service, 1971, S. 63 f.; Paravicini, Guy de Brimeu, 1975, S. 281 mit Anm. 108; Dykmans, Guillaume de Clugny, 1983; Eнм, Burgund, 2002, S. $241 \mathrm{f}$.

41 Ms.: deffunct wurde nachträglich über die Zeile geschrieben. Eine Marke zeigt auf die dafür vorgesehene Stelle im Text.

42 Der entsprechenden Artikel der Statuten (§ 103/neu § 65) wird in § 3 zitiert.

43 Wie Anm. 42. 
dame la duchesse, sa fille legitime et seule heritiere, lors non mariee comme dessus est dit. Veu aussi aucuns autres articles des status et ordonnances dudit ordre, servans au propos et la matiere bien debattue. ${ }^{44}$

[f] Finablement mesdis seigneurs les chevaliers freres de l'ordre illec assemblez ont deliberé et conclut d'un commun accord sur ledit premier point, que considerez les grans et estrois sermens qu'ilz avoient audit ordre, par lesquelz ilz et tous les autres chevaliers freres d'icellui estoient et sont obligez et astrains d'eulx emploier a leur povoir pour maintenir ledit ordre en estat et honneur et l'augmenter sans le souffrir decheoir ou amoindrir tant que remedier y puissent.

[g] Que besoing estoit et chose tresnecessaire d'en parler a mondit seigneur le duc et de le advertir et informer de la institucion dudit ordre, des status et ordonnances d'icellui, de l'estat, [fol. 4r] dignité et honneur, en quoy il a esté par cy devant et comment a present il est fort diminué et alant a declin. Et de l'en supplier par toute humilité que son plaisir soit de le relever et remettre sus. Et ont requis et ordonné mesdis seigneurs les chevaliers freres audit reverend pere en Dieu l'evesque de Tournay, chancellier de l'ordre, de parler pour eulx et faire a mondit seigneur le duc a la fin que dessus toutes bonnes honnestes, louables et raisonnables remonstrances qu' $\mathrm{il}^{45}$ advisera servir a ceste fin au bien de l'ordre. ${ }^{46}$

[h] Et quant audit second point, touchant le petit nombre de mesdis seigneurs qui la estoient pour executer et conduire ceste matiere, ja soit que la qualité d'icelle requeist plusgrant nombre et du moins jusques a six chevaliers freres. Toutevoie[s] consideré que en l'ordre avoit ja xiij lieux vacans par le deces de feu mondit seigneur le souverain et d'autres xij chevaliers freres y trespassez depuis la darreniere feste precedent ${ }^{47}$ et qu'il en avoit autres cinq en France ou parti contraire, assavoir deux prisonniers de guerre, comme monseigneur Anthoine, bastart de Bourgoingne $\{54\}$, et messire Jaques de Luczembourg $\{67\}$, seigneur de Richebourg. Et autres trois, assavoir messire Phelippe, seigneur de la Roiche de Nolay $\{60\}$, messire Phelippe de Crevecuer $\{69\}$, seigneur d'Escardes, et messire Jean de Damas $\{65\}$, seigneur de Clessey, qui se y estoient rendus comme l'en disoit. ${ }^{48}$ Lesquelz fa[i]soient ensemble le nombre de xviij chevaliers. Et quant aux quatres roys, comme le roy d'Arragon $\{57\}$, le roy d'Angleterre $\{63\}$, le roy de Castille $\{71\}$ et le roy de Naples $\{72\}$, freres dudit ordre, ilz estoient treslongtains et de tresdifficile acces pour les consulter sur ceste matiere. Et au regart de monseigneur le duc de Cleves $\{47\}$ et monseigneur Adolph \{55\}, son frere, seigneur de Ravestein, absens, par Thoison d'or, le roy d'armes de l'ordre, ilz avoient esté exhortez et requis de venir a Gand pour ceste matiere, mais mondit seigneur de Cleves pour empeschement

44 In $\S 16$ der Statuten wird z. B. angedeutet, dass in dringenden Fällen eine außerordentliche Sitzung des Ordens einberufen werden soll und dass dann die Stimmenmehrheit der anwesenden Mitglieder zu einem Beschluss führen kann. Zu diesem Statutenartikel vgl. auch die Angaben auf S. 26 mit Anm. 67.

45 Ms.: Am linken Rand der Zeile, die mit qu'il advisera beginnt, befindet sich ein senkrechter Doppelstrich.

46 Fortsetzung in $\S 10$.

47 Das im Mai 1473 in Valenciennes abgehaltene Ordensfest wird ausführlich in PB 3 beschrieben. Die seither verstorbenen Mitglieder werden unten in § $26 \mathrm{f}$. genannt.

$48 \mathrm{Zu}$ den in Frankreich weilenden Mitgliedern ausführlicher in $\S 28 \mathrm{f}$. 
de maladie ${ }^{49}$ et monseigneur de Ravestein par autre occupacion et affaires, dont il avoit commission et charge de par mondit seigneur, ${ }^{50}$ s'estoient excusez. Parquoy n'y restoient fors trois, assavoir messire Phelippe de Savoye $\{68\}$ estant es marches de Savoye, monseigneur de Montagu $\{52\}$ estant en Bourgoingne, qui sont aussi marches longtaines et de difficile acces pour l'eure et monseigneur de Lannoy $\{50\}$, qui s'estoit excusé par empeschement de grieve maladie, dont il estoit pressé et occupé [fol. 4v] pour ces regars et autres.

[i] Illec touchiez ont deliberé et conclut que, non obstant leur petit nombre, ilz le povoient et devoient faire, attendu mesmement que la matiere requeroit haste et ne povoit bonnement souffrir plusgrant delay, mais estoit besoing de l'avancer pour l'honneur et devoir dudit ordre. Car posé orres que apres et d'aventure en quelque autre lieu ou mondit seigneur le duc se peust retraire, l'on peusist finer de mondit seigneur le duc de Cleves ou de monseigneur de Ravestein, son frere, illec ne pourroit aler mondit seigneur d'Anthoing pour cause de sa viellesse et foiblesse, aussi consideree l'indisposicion du temps et qu'il est grant apparence ${ }^{51}$ de guerre ouverte, se pourroient ce pendant les chevaliers freres qui la estoient absenter et retraire en divers lieux par l'ordonnance de mondit seigneur, fust pour la garde des pays ou pour conduire les gens de guerre ou pour autres affaires d'icellui seigneur ou les leurs propres. Ouquel cas ilz seroient espars en divers lieux et seroit chose incertaine quant plus ilz se pourroient rassembler en tel nombre que la estoient, et n'estoit quelque apparence ou espoir de recouverer de cy a grant temps plusgrant nombre de mesdis seigneurs les chevaliers frerers de l'ordre pour l'execution de ceste matiere.

[j] Parquoy tout resolu mesdis seigneurs sont parseverez en leurdite conclusion et ont chargié messires de Gruythuse et de Chimay de demander et obtenir audience et heure et lieu a ce propices devers mondit seigneur le duc le plus tost que faire se pourroit a son noble plaisir.

[s] Messire Guillaume de Clugny, tresorier de l'ordre. ${ }^{52}$

[s] Si monseigneur de Cleves eust peu faire la mariaige de madame et de son filz, il

n'eust point esté malade. ${ }^{53}$

49 Wie die am Ende des Absatzes stehende Randbemerkung besagt, wurde seine Entschuldigung, er sei krank, nur als Vorwand angesehen. Hz. Johann hatte sich Hoffnung gemacht, dass Hz.in Maria seinen Sohn Johann II. (zu ihm Angaben in Reg. 37, Anm. 29) heiraten würde, und war nach deren Vermählung mit Hz. Maximilian verständlicherweise entäuscht. Vgl. dazu u.a. Chroniques de Molinet, I, 1935, s. 194; Glezerman/ Harsgor, Cleve, 1985, S. 209-212; Debris, Felix Austria, 2005, S. 581; Rapp, Maximilien, 2007, S. 68; DünNEBEIL, Erbtochter, 2008, S. 179. - Fortsetzung in 27 mit Anm. 157.

50 Im Juli 1477 war Adolf von Kleve zum burgund. Statthalter im Hennegau ernannt worden, vermutl. hielt er sich angesichts der frz. Bedrohung zu dieser Zeit dort auf. Zu seiner Ernennung vgl. u. a. Cools, Mannen, 2000, S. 336 f., Nr. 131.

51 Ms.: grant apparence steht über einer Radierung.

52 Ms.: Die Randbemerkung steht neben der Zeile, die mit den unterstrichenen Worten de Clugny, lors tresorier durdit ordre beginnt.

53 Ms.: Die Randbemerkung beginnt bei der Zeile, die mit den Worten de l'ordre ilz avoient esté exhortez anfängt. - Vgl. dazu die Angaben in Anm. 49. 
[10] [Die Ordensmitglieder erhalten eine Audienz bei Hz, Maximilian in Gegenwart von dessen privaten Rates und sie bitten ihn, die Souveränität über den Orden vom Goldenen Vlies zu übernehmen.]

$[a]^{54}$ Le sabmedi, xxiije jour dudit mois d'aoust l'an lxxvij dessusdites, ${ }^{55}$ environ quatre heure apres disner, heure a ce accordee et assignee par mondit seigneur le duc messeigneurs d'Anthoing $\{28\}$, de Gruythuse $\{61\}$, de Chimay $\{74\}$ et de Nassouw $\{77\}$, chevaliers freres de l'ordre dessus nommez, ensemble mondit seigneur l'evesque de Tournay, chancellier, le graffier et Thoison d'or, le roy d'armes, officiers dudit ordre, partans ordonneement de la chambre de mondit seigneur de Gruythuse, qui estoit sur la porte dudit hostel de la Walle, s'alerent devers mondit seigneur le duc Maximilian en sa chambre, ou ilz le trouverent en [fol. $5 \mathbf{r}$ ] conseil accompaignié de tresreverend pere en Dieu mondit seigneur l'archevesque de Treves, esliseur du Saint Empire, ${ }^{56}$ de monseigneur l'evesque de Mets, ${ }^{57}$ de monseigneur le jeune marquis de Bade $\{102\},{ }^{58}$ dudit messire George Hezeler, prothonotaire, ${ }^{59}$ de maistre Willame $[\ldots],{ }^{60}$ docteur, de messire Bertremy de Lichtestein $\{85\}$, grant maistre d'ostel d'Ostrice, ${ }^{61}$ de maistre

54 Ms.: Zur besseren Lesbarkeit dieses langen Paragraphen wurden Absätze und Unterpunkte eingefügt.

55 22. Aug. 1477.

56 Zur Person Johanns von Baden, Ebf. von Trier, vgl. die Angaben in § 6, Anm. 22.

$57 \mathrm{Zu}$ Georg von Baden, Ebf. von Metz, vgl. die Angaben in $§ 5$ mit Anm. 17.

58 Christoph, Markgraf von Baden (1453-1527), begleitete $1477 \mathrm{~Hz}$. Maximilian auf seiner Reise in die Niederlande. Dort spielte er bei den verschiedenen Feldzügen gegen Frankreich eine wichtige Rolle und wurde 1491 in den Orden aufgenommen. Aber schon 1478 wurde er als möglicher Aufnahmekandidat genannt (vgl. Reg. 37). Zu seiner Person vgl. u. a. Heinig, Friedrich III., 1997, S. 324; Cools, Mannen, 2000, S. 233 f., Nr. 4; Chevaliers de la Toison d'or, ${ }^{2} 2000$, S. 242-244, Nr. 102; HeInIG, Akteure, 2006, S. 135 f.; Cools, Quelques hommes, 2006, S. 165.

59 Zur Person Hesslers vgl. § 5, Anm. 19.

60 Ms.: Steenberch ließ nach Willame einen freien Platz, um nachträglich den Nachnamen eintragen zu können. In $\S 11$ bezeichnet er ihn als messire Guillaume [...], docteur, son conseillier. Vermutl. handelt es sich hier um Dr. Wilhelm Maroltinger $(\dagger 1482)$, der zur österreichischen Gesandtschaft gehörte, die im Juli 1477 am burgund. Hof über die Heiratsmodalitäten verhandelte. Über den Stand der Verhandlungen berichtet er Hz. Maximilian in einem Brief vom 30. Juli 1477; gedruckt bei LichnowsKy, Geschichte, 7, 1843, S. CCCCXCVI, Beilage Nr. 10; Chmel, Aktenstücke, 1, 1854, S. 157 f., Nr. 48. Am 13. März 1478 wurde er von Ks. Friedrich III. \{94\} aufgefordert, Hz. Maximilian zu empfehlen, aufgrund eines drohenden Krieges mit Frankreich sein Land nicht zu verlassen; vgl. Reg. bei Chmel, Aktenstücke, 1, 1854, S. 393, Nr. 84. Zu seiner Person auch Heinig, Friedrich III., 1997, 1, S. 456 f.

61 Bartholomäus von Liechtenstein-Karneid war im Laufe seiner politischen Karriere immer wieder für Ks. Friedrich III. \{94\} und Sigmund, Hz. von Österreich und Tirol, tätig. Zwischen 1473 und 1478 hatte er das Amt als Hz. Maximilians Hofmeister inne und nahm an dessen Seite am Treffen Ks. Friedrichs mit Hz. Karl \{34\} im Herbst 1473 in Trier teil und ging im Sommer 1477 dann mit ihm nach Burgund. Am 1. Mai 1478 wurde er während der Großen Messe des Ordens vom Goldenen Vlies von Hz. Maximilian zum Ritter geschlagen (§ 95) und noch am selben Tag zum neuen Mitglied des Ordens gewählt (§ 133). Zu seiner Person vgl. u. a. HeINIG, Friedrich III., 1997, S. 64; Pfeifer, Liechtensteiner, 1998, S. 88 f.; Noflatscher, Räte, 1999, S. 339 f. mit Anm. 51; Chevaliers de la Toison d'or, ${ }^{2} 2000$, S. 203 f., Nr. 85. 
Josse $[\ldots]^{62}$, son secretaire, et autres de son privé conseil jusques au nombre de vij ou viij personnes. ${ }^{63}$

[b] Et illec honneur et reverence deues par eulx faites et exhibees a mondit seigneur le duc, qui benignement les recueillit, mondit seigneur l'evesque de Tournay, chancellier, par l'ordonnance de mesdis seigneurs les chevaliers freres et de par l'ordre a exposé et declairé a mondit seigneur le duc Maximilian bien amplement et notablement la noble, religieuse et tresvertueuse institucion jadis faite dudit ordre de la Thoison d'or par feu de tresnoble memoire monseigneur le duc Phelippe $\{01\}$, que Dieu absoille, en son vivant duc de Bourgoingne et de Brabant, son penultime predecesseur, ayeul de par pere $\{34\}$ de madite dame la duchesse, sa compaigne, premier fondateur, chief et souverain d'icellui ordre, et les causes, raisons et consideracions qui l'avoient meu a en faire ladite fondacion et institucion.

[c] Apres a fait remonstrance sommiere de l'effect desdis status et ordonnances de l'ordre ensemble des condicions, dignitez, qualitez et merites de messeigneurs les chevaliers freres qui a ladite premiere institucion furent nommez et establis et de ceulx qui depuis par election avoient esté accompaignez oudit ordre, tant au regart des trespassez, comme des survivans et mesmement comment encores pour l'eure y avoit quatre roys tresexcellens et des plus puissans de la chrestienté, assavoir le roy Jehan, roy d'Arragon et de Navarre $\{57\}$, le roy Edouart, roy d'Angleterre et seigneur d'Yrlande $\{63\}$, le roy Fernande, roy de Naples et de Cecille $\{72\}$, et le roy Fernande, roy de Castille, de Leon et de Cecille $\{71\}$, et autres haulx et puissans princes et grans seigneurs portans le colier dudit ordre.

[d] Consequenment a remonstré mondit seigneur de Tournay l'estat dudit ordre et en quel honneur et magnificence il avoit esté maintenu et conduit dez sadite premiere fondacion et institucion par feu mondit seigneur le duc Phelippe, premier fondateur, premierement, et depuis par feu monseigneur le duc Charles, son filz, que Dieu absoille, qui tous deux successivement en avoient esté les chiefs et souverains leurs vies durant.

[e] A remonstré enoultre mondit seigneur le Tournay comment depuis $1 e^{64}$ lamentable deces de feu mondit seigneur le duc Charles, pere de madite dame, ledit ordre estoit demouré sans chief et fort diminué et decliné en ses honneurs et prerogatives et aussi en [fol. $\mathbf{5 v}$ ] nombre de personnes et seroit taillié de dimuner et decliner de plus en plus et de tumber et faillir ala parfin et briefment se obvié et pourveu n'y estoit.

[f] Et par ces raisons et remonstrances et mesmement consideré et attendu que selon lesdis status et ordonnances dudit ordre a cause du mariaige qui, l'a Dieu grace estoit nouvellement fait et consummé par et selon l'ordonnance de nostre mere Sainte Eglise entre mondit seigneur d'une part et madite dame, sa compaigne, seule fille legitime et heritiere universele et pour le tout dudit feu monseigneur le duc Charles, en son vivant duc de Bourgoingne, chief et souverain d'icellui ordre, darrenier deffunct, a mondit seigneur seul competoit et appartenoit a cause de madite dame, sa compaigne, de relever ledit ordre et d'en estre le chief et souverain pour et ou lieu de sondit feu beaupere.

[g] A finablement mondit seigneur de Tournay supplié, prié et requis treshumblement es noms que dessus mondit seigneur le duc, que son plaisir fust d'ensuir et entretenir ladite noble fondacion dudit ordre de la Thoison d'or a l'exemple de feuz mesdis seigneurs

62 Ms.: Steenberch ließ nach fosse einen freien Platz, um nachträglich den Nachnamen eintragen zu können, ohne den Mag. Josse nur schwer zu identifizieren ist.

63 Dieses Treffen erwähnt auch Barante/Gachard, Histoire, II, 1838, S. 601, Anm. 4.

64 Ms.: le wurde aus la verbessert. 
les ducx Phelippe et Charles, ses tresnobles predecesseurs, ayeul et pere de madite dame, de relever, pren[d]re et recevoir icellui ordre comme chief et souverain d'icellui et doresenavant le maintenir gouvernes et conduire selon les status et ordonnances du mesme ordre, ainsi comme mesdis seigeneurs ses feuz predecesseurs haultement, noblement, grandement et treshonnestement l'avoient fait tout leurdit vivant.

[h] En quoy il demonstreroit signé de parfait amour et honneur a madite dame, sa compaigne, et a sa tresnoble maison de Bourgoingne, que au moyen dudit ordre a esté et est moult grandement faicte par tout le monde exaultee, honnoree et decoree, feroit aussi grant honneur et plaisir au noble college dudit ordre souverainement le desirant et convoitant et par ce moyen acquerroit l'amour, faveur et assistence des tresexcellens roys, princes et autres grans seigneurs y accompaignez et donneroit singuliere consolacion a tout le peuple de tous les pays et seignouries de madite dame qu'il a acquis avec elle au moyen de sondit mariaige.

[11] [Dr. Wilhelm antwortet im Namen Hz. Maximilians: Er dankt für den Antrag der Mitglieder des Ordens vom Goldenen Vlies, gibt aber zu bedenken, dass Maximilian bisher noch nicht seinen Ritterschlag erhalten hat. Des Weiteren bittet er um ein Exemplar der Statuten in lateinischer Sprache, um sich mit dem Orden vertraut machen zu können. Da der Inhalt der Statuten nicht allgemein gekannt sein soll, einigt man sich schließlich darauf, dass der Ordenskanzler im Beisein von Protonotar Heßler Hz. Maximilian am folgenden Tag über den Inhalt der Statuten unterrichten soll.]

$[a]^{65}$ Apres ces remonstrances oyes et entendues mondit seigneur le duc s'est retrait avec son conseil d'ung costé et messeigneurs de l'ordre se sont tirez a part de l'autre costé en ladite chambre. Et petite deliberacion sur ce eue par mondit seigneur avec ceulx de sondit privé conseil il a fait dire a messeigneurs de l'ordre par [fol. 6r] ledit messire Guillame [...], ${ }^{66}$ docteur, son conseillier, qu'il avoit bien entendu les choses que reverend pere en Dieu monseigneur l'eveque de Tournay pour et ou nom de messeigneurs de l'ordre en latin moult notablement et elegamment lui avoit exposees et remonstrees touchant l'estat de disposicion et les affaires du noble ordre de la Thoison d'or. Et la requeste qu'ilz lui avoient faite et mesmement avoit il entendu par ledit propos qu'il fauldroit qu'il fust chevalier quant il recevroit l'ordre de la Thoison d'or, ce qu'il n'estoit par encoires et l'empereur $\{94\}$, son pere, lui avoit ordonné qu'il ne se feist chevalier que par sa main ou en exploit de guerre honnorable.

[b] Neantmoins la matiere estoit grande et pesante et a lui nouvelle et si avoit il pour l'eure d'autres grans affaires ausquelz mestier lui estoit de vaquer et entendre et ceulx de son conseil par aucuns jours, parquoy bonnement ne leur y povoit respondre pour celle fois. Mais il y auroit son advis et le plus brief qu'il pourroit bonnement leur y seroit response, priant que pour mieulx entendre la matiere et sur icelle deliberer plus seurement il pleust a messeigneurs de l'ordre de lui communiquer les status et ordonnances dudit ordre, car il desiroit de les veoir.

65 Ms.: Zur besseren Lesbarkeit dieses langen Paragraphen wurden Absätze und Unterpunkte eingefügt.

66 Ms.: Steenberch ließ nach Guillaume einen freien Platz, um nachträglich den Nachnamen eintragen zu können; in $\S 10$ bezeichnet er ihn als maistre Willame [...], docteur. Zu seiner Identifizierung vgl. ebd., Anm. 60. 
[c] Surquoy se retrahirent mesdis seigneurs de l'ordre en la mesme chambre et apres brieve deliberacion firent dire et remonstrer, que pour eulx acquiter du serment qu'ilz avoient fait d'eulx emploier a leur loyal povoir au bien honneur et pour leatretenement dudit ordre estant sans chief et souverain ilz lui avoient fait faire les remonstrances et requestes qu'il avoit oyes, car veue l'aliance par mariaige ja faite et consummee, l'a Dieu mercy, entre lui et madite dame la duchesse, sa compaigne, seule fille et heritiere unversele de feu mondit seigneur le duc Charles $\{34\}$, son beaupere, ilz ne se povoient selon lesdis status adreçer a autres prince du monde en ce cas, fors que a sa personne seulement, et qu'il estoit cellui seul qui povoit relever ledit ordre pour en estre le chief et souverain et le devoit faire, et si povoit prendre l'ordre de chevalerie et consequenment recevoir tantost apres le colier de la Thoison d'or toutes les fois qu'il plairoit, gardees aucunes solemnitez au cas requises sans qu'il fust besoing de pour ce faire connotacion de messeigneurs les chevaliers freres de l'ordre, fors de ceulx qui pour l'eure se trouveroient devers lui ne aussi d'attendre le chappittre de l'ordre. Ce que par cy devant depuis la premiere institucion des xxiiij premiers chevaliers dudit ordre ${ }^{67}$ jamais n'avoit esté fait ne faire se pourroit pour roy ou prince quelconque qu'il [fol. 6v] n'ait tousjours falu et faille que tous y soient appellez par vraye election du souverain et des chevaliers freres de l'ordre pour ce deuement convoquez et assamblez en leur chappittre. Et quant a la comunicacion desdis status de l'ordre que bien raison estoit que mondit seigneur en fust informé et adverti, mais que l'ordre estoit et est institué par forme de college et d'une noble compaignie, reglee et conduite par et soubz ordonnances et status especiaulx qui sont de leur secret ${ }^{68}$ et ne se doivent ne sont accoustumez communiquer au dehors dudit ordre, fors en cas de besoing et necessité et lors a ceulx tant seulement ausquelz la chose peult touchier.

Et pourtant liberalement ont consenti et accordé a mondit seigneur le duc ou de lui comuniquer et monstrer lesdis status et ordonnances de l'ordre par les mains d'aucuns chevaliers et officiers dudit ordre, que ad ce ilz depputeroient telz et toutes les fois qu'il lui plairoit. Ou de lui faire baillier de livre pour le veoir a son privé avec aucuns bien privez et secrets de son conseil telz que ad ce vouldroit appeller ou plus estroit nombre touvevoie que faire se pourroit bonnement, combien que vraissemblablement il povroit trop mieulx entendre et comprendre lesdis status par l'interpretacion et declaracion que de bouche lui en feroient ceulx de l'ordre que autrement. Neantmoins le tout remettoient a son noble plaisir.

[d] Sur ce a fait dire mondit seigneur le duc par ledit docteur Guillame accompaignié dudit prothonotaire docteur Hezeler ${ }^{69}$ que pour ledit jour et pour le lendemain ensuivant mondit seigneur avoit necessairement a besoingner en autres ses grans affaires, mais apres et le plus brief qu'il pourroit leur en feroit dire son plaisir.

\section{[12] [Steenberch erstellt eine lateinische Übersetzung der Statuten.]}

Depuis et peu de jours apres mondit seigneur le duc s'est declairé et a dit a aucuns de mesdis seigneurs les chevaliers freres et aussi a monseigneur le chancellier de l'ordre, qu'il desiroit avoir le livre desdis status de l'ordre pour le veoir a son privé et qu'il fust baillié a reverend pere en Dieu monseigneur l'evesque de Mets qui le lui communique-

67 Mit der Gründung des Ordens vom Goldenen Vlies ernannte Hz. Philipp im Jahr 1430 erst einmal 24 Ritter, die er in den Orden aufnehmen wollte; vgl. unten die Mitgliederliste auf S. 291.

68 Die Statuten des Ordens waren demnach nicht allgemein bekannt.

69 Zur Person Georg Hesslers vgl. § 5, Anm. 19. 
roit bien secretement. Et pour ce que lesdis status et ordonnances estoient en langaige [fol. 7r] françois, lequel point il ne entendoit, requist qu'ilz lui fussent translatez du françois en latin, afin qu'il les peust mieulx entendre, ce que lui a esté accordé par mesdis seigneurs les chevaliers freres, qui apres ce ont ordonné a moy, graffier, d'en faire ladite translacion du françois en latin, comme l'ay fait par leur ordonnance. ${ }^{70}$ Et ladite translacion faite, veue, examinee et corrigee par mondit seigneur l'evesque de Tournay, chancellier de l'ordre, et collationnee avec le françois au plus vray qu'il s'est peu faire, ay par l'ordonnance et adveu de mesdis seigneurs les chevaliers freres et en la presence de mondit seigneur le chancellier et de Thoison d'or, le roy d'armes de l'ordre, porté et baillié ledit livre desdis status et ordonnances de l'ordre en langaige françois avec ladite translacion sur ce faite en latin es mains de reverend pere en Dieu monseigneur l'evesque de Mets, qui les receut de moy et se chargea de les porter et baillier a mondit seigneur le duc en sa main si tost que bonnement il y pourroit entendre. ${ }^{71}$

[s] Translation des statuz de l'ordre de français en latin par le greffier Steenberge. ${ }^{72}$

\section{Dezember 1477 in Brüssel}

[13] [Die Ordensmitglieder wenden sich erneut an Hz. Maximilian, ob der bereit sei, die Souveränität über den Orden vom Goldenen Vlies zu übernehmen, und betonen, dass es dringend notwendig sei, ein neues Ordensfest einzuberufen. Hz. Maximilian stimmt beidem zu, sieht aber Probleme wegen seines fehlenden Ritterschlages und wegen des bevorstehenden Krieges.]

$[a]^{3}$ Le mercredi, xvije jour du mois de decembre l'an lxxvij dessusdit, ${ }^{74}$ mon tresdoubté seigneur monseigneur le duc Maximilian estant en sa ville de Brouxelles et devers lui assemblez a part en sa chambre ${ }^{75}$ messeigneurs de l'ordre, cy apres nommez. C'est assavoir messire Adolph de Cleves $\{55\}$, seigneur de Ravestein, messire Loys, seigneur de

$70 \mathrm{Zu}$ Steenberchs Sprachkenntnissen vgl. Hoorebeeck, Steenberch, 2006, S. 343.

71 In AOGV, Akten, Karton 4, Türck'sche Systematik $\S 1$, Nr. 2, befindet sich eine in der burgund. Kanzlei des 15. Jahrhunderts entstandene lateinische Fassung der Statuten. Es handelt sich dabei um eine schmucklose in rauhem Leder gebundene PergamentHandschrift mit der einleitenden Überschrift Translation faicte du françois en latin sur les status du noble ordre de la Thoison d'or. Möglicherweise handelt es sich um die aus diesem Anlass entstandene Statutenübersetzung. Auch bei der Aufnahme des Bartholomäus von Liechtenstein $\{85\}$ wurde ein lateinisches Statutenbuch benutzt; vgl. § 159. - In Brüssel, BR, ms. 12.648, befindet sich ein Statutenbuch in frz. Sprache, das sich in Maximilians Besitz befunden haben muss und das lt. einem Vermerk aus fol. 9r von Martin Steenberch geschrieben wurde; dazu u. a. LemaIRE, Considérations codicologiques, 1996; PB 1, S. 191; HoorebeEck, Steenberch, 2006, S. 314.

72 Ms.: Die Randmerkung steht zu Beginn von fol. 7r.

73 Ms.: Zur besseren Lesbarkeit dieses langen Paragraphen wurden Absätze und Unterpunkte eingefügt.

74 17. Dez. 1477. - Dieses Treffen erwähnen auch Barante/Gachard, Histoire, II, 1838, S. 601, Anm. 4; Regesten Friedrichs III., Suppl. 1, 2008, S. 57, Anm. 2 zu Reg. 29 (beide datieren Maximilians Zusage jedoch auf den 24. Dez. 1477, welches jedoch das Ausstellungsdatum der Einladungsschreiben ist; vgl. Reg. 1-6).

75 Zur (im 18. Jahrhundert zerstörten) Brüsseler Residenz der Herzöge von Burgund, auch Palais Coudenberg genannt, vgl. u. a. Segnave, Coudenberg, 1953; De Jonge, Paleis, 
Gruythuse $\{61\}$, conte de Wincestre, et messire Phelippe de Croy $\{74\}$, conte de Chimay, chevaliers freres, ensemble reverend pere en Dieu monseigneur Ferry, evesque de Tournay, chancellier, m(oy), greffier, et Thoison d'or, roy d'armes, officiers dudit ordre.

[b] Mondit seigneur de Tournay a par l'ordonnance de mesdis seigneurs les chevaliers reduit a la memoire de mondit seigneur le duc sommierement et en brief les remonstrances que aultre fois mesdis seigneurs de l'ordre lui avoient faites et fait faire en sa ville de Gand apres le mariaige, fait et confirmé entre lui et ma tresredoubtee madame la duchesse, sa compaigne, touchant la fondacion et institucion, l'estat et disposicion du noble ordre de la Thoison d'or. ${ }^{76}$ Et comment depuis le trespas de feu monseigneur le duc Charles $\{34\}$, son beaupere, qui en fut le chief et souverain, darrenier deffunct, ledit ordre estoit tousjours demouré sans chief, parquoy et mesmement attendu [fol. 7v] que selon les status dudit ordre ${ }^{77}$ aultre prince du monde, fors lui seul n'en povoit estre chief ne souverain, mais que a cause de madite dame, sa compaigne, seule fille et heritiere dudit feu monseigneur le duc Charles, lui competoit et qu'il estoit tenu de relever icellui ordre et d'en estre le chief et souverain, lui avoient deslors treshumblement supplié et requis que son plaisir fust de le faire.

[c] Autrement consideré le long temps couru depuis ledit trespas et que l'ordre estoit ja fort diminué en nombre de chevaliers freres et autrement et se diminueroit de plus en plus mesmement car les roys tresexecellens et autres princes accompaignez oudit ordre estans en longtaines marches, saichans ledit mariaige d'entre lui et madite dame, consummmé en cas que mondit seigneur ne relieveroit ledit ordre selon lesdis status ilz pourroient suspeçonner et doubter qu'il fust desert et habandonné, et le vouldroient mesmes delaisser et le collier d'icellui et consequenment seroit taillié de faillir totalement en brief temps ou par forsmorture de ceulx qui encoires en sont ou par habandon et delaissement de l'enseigne et collier d'icellui.

[d] Attendu ${ }^{78}$ que mondit seigneur estoit en eaige competent pour le relever et en estre le chief et faire le pourroit sans connotacion ou assemblee generale de ceulx de l'ordre sans election et hors chappittre toutes les fois qu'il lui plairoit comme dessus e esté touchié, mais aultre chevalier quelconque n'y pourroit estre esleu ne accompaignié, fors par connotacion et assemblee generale et en chappittre de l'ordre deuement signiffié et par temps competent selon les status dessusdites.

[e] Orres $^{79}$ avoit il passé pres de cinq ans que le darrenier chappittre de l'ordre avoit par feu mondit seigneur le duc Charles, son beaupere, esté tenu au lieu de Valenciennes, que fut en may l'an lxxxiij. ${ }^{80}$ S'il plaisoit a mondit seigneur de relever ledit ordre entre cy et le premier jour du mois de may prouchain venant, il pourroit aussi en ce cas concluire desmaintenant de tenir la feste et solemnité et le chappittre general dudit ordre audit premier jour de may prouchain et es jours ensuivans, et ainsi l'escripre [fol. 8r] et signiffier par tout a messeigneurs les chevaliers freres de l'ordre

1991; Gruben, Chapitres, 1997, S. 189-193; PARAvicini, Residenzen, ${ }^{2} 2002$, S. 480-482 sowie der Sammelband Coudenberpaleis, 2014.

76 Vgl. § 10.

77 Der entsprechenden Artikel der Statuten (§ 103/neu § 65) wird in § 3 zitiert.

78 Ms.: Am linken Rand der Zeile, die mit Attendu beginnt, befindet sich ein senkrechter Doppelstrich.

79 Ms.: Am linken Rand der Zeile, die mit Orres beginnt, befindet sich ein senkrechter Doppelstrich.

80 Eine Beschreibung des 1473 in Valenciennes abgehaltenen Festes bietet PB 3. 
pour les en advertir et afin qu'ilz y viennent et comparent au jour ou y envoyent leurs procuracions ensemble leurs cedules pour les elections a faire et remplir les lieux desdis trespassez vacans en l'ordre, comme il est accoustumé et se doit faire selon lesdis status et ordonnances. ${ }^{81}$ Et quant aux chevaliers freres estans ou parti contraire ${ }^{82}$ et autres notez ${ }^{83}$ l'on pourroit adviser et delibrer apres de la maniere comment a eulx se devroit faire ladite signifficacion ou par lettres patentes en placcart ou par lettres closes et par officier d'armes, comme il appartient en tel cas.

[f] Mais mondit seigneur avoit a deliberer et concluire prealablement, se son plaisir seroit de prendre l'ordre de chevalerie devant ledit temps qui est le prealable et sans lequel il ne pourroit estre receu oudit ordre, et en cas que si sur cest espoir faire faire ladite signifficacion des jour et lieu quant et ou lesdites futures feste et chappittre se devroient tenir.

[g] Et finablement a supplié mondit seigneur de Tournay ou nom que dessus mondit tresredoubté seigneur monseigneur le duc, que son plaisir fust de ainsi le faire et sur ces choses leur declairer son intencion et benigne vouloir et plaisir.

[h] Surquoy mondit seigneur le duc tout ouy benignement et bien au long a respondu: Que depuis que en sa ville de Gand ilz lui avoient parlé du fait de l'ordre et requis de vouloir, relever et recevoir ledit ordre et que a ceste fin lui avoient comuniqué le livre des status et ordonnances d'icellui, il avoit eu advis et deliberacion sur la matiere avec prelas, princes et autres ses parens et de son privé conseil et avoit veu lesdis status et ordonnances, et tout veu, tant pour consideracion et regart du saint et noble propos que avoit meu feu le duc Phelippe $\{01\}$, premier fondateur, a instituer tant noblement ledit ordre, dont moult il faisoit a recommander et les traces duquel souverainement il desiroit ensuir, comme pour satisfaire au tresnoble desir de la sacré maiesté l'empereur \{94\}, son pere, par l'ordonnance duquel il s'est ainsi alié a la noble maison de Bourgoingne et moult especialment lui avoit recommandé ledit ordre de la Thoison d'or et ordonné qu'il ne le laisast decheoir ou perir pour ces consideracions et autres raisonnables.

[i] Mesmement ${ }^{84}$ pour le vray amour qu'il avoit a madite dame la duchesse, sa compaigne, pour contemplacion aussi et faveur de la noble compaingnie dudit ordre et des excellens roys, princes et autres [fol. 8v] haulx nobles et vaillans seigneurs qui en sont ja long temps, il avoit desiré et moult desiroit d'y estre accompaingnié et y vouloit bien entendre le plus brief que possible lui seroit bonnement, mais il n'estoit encoires point chevalier ce que lui empeschoit.

[j] Toutevoie esperoit que l'empereur, son pere, seroit es marches depardeça devant l'entree du mois de may prouchain, ouquel cas il vouldroit recevoir de sa main l'ordre

81 Die zeitliche Abfolge der Ordensfeste und die damit verbundenen Einladungsschreiben sind in $\S 47$ (neu § 22) der Statuten geregelt, dazu ausführlicher unten in § 192, Anm. 323.

$82 \mathrm{Zu}$ ihnen ausführlicher in $\S 28 \mathrm{f}$.

83 Jean de Neufchâtel $\{52\}$ und Philipp von Savoyen $\{68\}$ erhielten gesonderte Einladung, mit der Aufforderung, zu den 1473 gegen ihn erhobenen Vorwürfe Stellung zu nehmen; vgl. dazu Reg. $7 \mathrm{f}$.

84 Ms.: Am linken Rand der Zeile, die mit mesmement beginnt, befindet sich ein senkrechter Doppelstrich. 
de chevalerie, car bien savoit que ainsi le desiroit. ${ }^{85}$ Autrement s'il ne venoit dedans ledit temps, il le prendroit par autre main honnestement ${ }^{86}$ a la fin d'avril, et consequenment recevroit lors l'ordre de la Thoison d'or le releveroit et en feroit la feste et tendroit le chappittre es jours ensuivans au plaisir Nostre Seigneur. Mais quant au lieu, veu ses affaires et l'apparence et doubte qui estoit de la guerre, il ne se povoit bonnement determiner encoires de lieu certain, comme il disoit. Si ordonna que les lettres de ladite signifficacion se feissent en bonne forme et diligenment et pour lieu nomma sa ville de Mons en Haynnau ou en autre de ses villes y voisines, la ou selon sesdites affaires il seroit lors en ses pays depardeça, car l'ordre il desiroit et vouloit maintenir honnorer et augmenter a l'exemple de sesdis predecesseurs de tout son pouvoir. ${ }^{87}$

\section{[14] [Die versammelten Mitglieder danken Hz. Maximilian für dessen Antwort und beschließen, ebenfalls den abwesenden Mitgliedern zu schreiben.]}

Ceste response de mondit seigneur le duc entendue par mesdis seigneurs les chevaliers freres de l'ordre, treshumblement l'ont remercié d'icelle. Et afin que messeigneurs les chevaliers freres absens auquelz mondit seigneur escriproit fussent plus entendans a la matiere et ne prenissent delay ou excuse de venir au jour ou d'en faire leurs devoirs, chascun a son endroit, a cause que mondit seigneur encoires n'avoit receu ledit ordre [fol. 9r] conclurent de leur escripre aussi par autres leurs lettres a part pour les advertir chascun de ladite conclusion de mondit seigneur et soubz le seel de l'ordre. ${ }^{88}$

\section{[15] [Die Briefe werden verfaßt, geprüft und in ein Register eingetragen.]}

Les lettres closes de ladite signifficacion ont esté pourjectees tant de par mondit seigneur le duc, comme de par messeigneurs de l'ordre. Et les minutes d'icelles ont esté veues par mondit seigneur le duc, par messeigneurs les chevaliers freres et par monseigneur le chancellier de l'ordre, corrigees et amendees et finablement accordees et conclues es formes et par la maniere declairees et contenues en aultre registre a ce servant, gardé devers le graffier dudit ordre pour memoire et souvenance en temps avenir. A aussi esté conclue la forme comment, tant monseigneur le duc comme messeigneurs de l'ordre, escriproient aux cinq chevaliers freres estans en l'obeissance de France et aux aultres notez, ${ }^{89}$ dont aussi les copies sont enregistrees oudit registre, parquoy icy je n'en fais aultre mencion pour cause de briefté. ${ }^{90}$

85 Nachdem Hz. Maximilian nach seiner Ankunft in den Niederlanden die schwierige Lage erfasst hatte, wandte er sich ab Oktober 1477 mehrfach an seinen Vater mit der Bitte um Hilfe und um persönliches Erscheinen. Anfang 1478 versuchte Ks. Friedrich III. ohne großen Erfolg im Reich gegen Ludwig XI., Kg. von Frankreich, zu mobilisieren. Vgl. dazu u. a. Kraus, Briefwechsel, 1875, S. $31 \mathrm{ff}$.; Bachmann, Reichsgeschichte, 2, 1894, S. 624 ff.; FichtenaU, Maximilian, 1959, S. 36f; Bock, Maximilian, 1970, S. 36 f.

86 Ms.: honnestement ist dünn unterstrichen.

87 Vgl. Reg. 1-6; zur Ausstellung der Einladungen auch in der Einleitung S. $19 \mathrm{f}$.

88 Siehe dazu Reg. 14-20. - Beschreibungen des Ordenssiegels, das seit 1468 in Gebrauch ist, bieten Laurent, Sceaux, I/1, 1993, S. 619, Nr. 58 mit Abb. in ebd. I/2, Tafeln 363 f.; LAUREnt, Sceaux, 1996, S. 24 f. mit Abb. 1.

89 Siehe dazu Reg. 7-13 und 21-25.

90 Verzeichnet sind die verschiedenen Einladungsschreiben in AOGV, Codex 45, fol. 28r-45r. Bei dieser Handschrift handelt es sich um ein Kopialbuch, in dem für den Zeitraum 1438 bis 1486 vor allem Einladungsschreiben zu den Ordensfesten eingetragen wurden. In PB 5, fol. 73v, wird diese Handschrift wie folgt beschrieben: registre collectaire des lettres 


\section{Januar 1478 in Brüssel}

\section{[16] [Hz. Maximilian unterschreibt seinen Teil der Briefe und die versammelten Mitglieder des Ordens diskutieren über weitere Formalia.]}

Le tiers jour du mois de janvier oudit an lxxvij que dessus, ${ }^{91}$ mondit seigneur le duc estant encoires en sadite ville de Brouxelles, lesdites lettres closes de mondit seigneur le duc signees de sa main et prestes pour cloire et expedier de la date du xxvje jour du mois de decembre darrenier passé, ${ }^{92}$ se sont du sceu et bon plaisir de mondit seigneur assamblez pardevers monseigneur Adolph de Cleves $\{55\}$, seigneur de Ravestein, en son hostel, illec en sa petite chambre environ ix heures du matin, messeigneurs de l'ordre cy apres nommez, assavoir messire Loys, seigneur de Gruythuse $\{61\}$, conte de Wincestre, messire Phelippe de Croy $\{74\}$, conte de Chimay, et messire Engelbert, conte de Nassouw $\{77\}$, chevaliers freres et compaignons de l'ordre, ensemble reverend pere en Dieu messire Ferry evesque de Tournay, chancellier, M(artin) Steenberch, graffier, et Thoison d'or, roy d'armes, officiers dudit ordre. Et illec en leur presence a presenté et exhibé ledit graffier lesdites [fol. 9v] lettres de mondit seigneur le duc, toutes signees et prestes pour cloire. A aussi illec apporté celles qu'il avoit faites pour et ou nom de mesdis seigneurs de l'ordre estans devers mondit seigneur audit Brouxelles pour en faire leur bon plaisir tant au regart de la subcripcion, signature et superscripcion comme du seeler d'icelles, requerant et demandant leur bonne ordonnance sur ce.

\section{[17] [Anweisungen zur Ausstellung der Einladungsschreiben.]}

Surquoy mesdis seigneurs les chevaliers freres de l'ordre estans quatre en nombre et considerans l'estat et disposicion de l'ordre et qu'il n'estoit apparant ne possible de povoir si tost jusques a long temps recouvrer et assembler plusgrant nombre des chevaliers freres pour entendre au fait de l'expedicion desdites lettres et que la matiere requeroit haste et celerité pour la briefté du temps qui restoit pour envoier lesdites lettres de ladite signifficacion a messeigneurs de l'ordre absens, espars en divers royaulmes et pays longtains, delibererent et conclurent par commun accord que moy, M(artin) Steenberch, graffier, signeroit lesdites lettres, faites ou nom de ceulx de l'ordre estans devers mondit seigneur, comme dit est, et que reverend pere en Dieu monseigneur l'evesque de Tournay, chancellier de l'ordre, les seeleroit du seel d'icellui ordre. Selon la conclusion aultre fois sur ce prinse devant mondit seigneur le duc, comme dessus est touchié, ${ }^{93}$ et ordonnerent et commanderent a chascun de nous de ainsi le faire par le devoir de noz offices que avions en l'ordre.

\section{[18] [Ausführung.]}

En ensuivant ladite conclusion et ordonnance lesdites lettres toutes grossoiees illec presentees devant mesdis seigneurs les chevaliers freres et par eulx veues et visitees l'une apres l'autre tant en forme comme en subscripcion et superscription a leur plaisir, je, graffier dessus nommé, les ay illec signees et closes une apres aultre. ${ }^{94}$ Et incontinent

closes et autres, touchans l'indiction, intimacion ou publicacion des festes et chappittres, gardé devers le graffe d'icellui ordre.

91 3. Jan. 1478 (n.St.).

92 26. Dez. 1477. - Vgl. Reg. 1-6.

93 Vgl. § $14 \mathrm{f}$.

94 Ms.: apres aultre ist unterstrichen. 
mondit seigneur de Tournay, illec en la presence et au veu de mesdis seigneurs a fait seeller toutes lesdites lettres une apres autre ${ }^{95}$ dudit seel de l'ordre que par leur ordonnance il y avoit apporté pour ceste cause, dont et mesmement de la conclusion et ordonnance que dessus mondit seigneur de Tournay a requis et demandé de moy, ledit graffier, acte ou que mencion expressé par moy en fust faire ou registre de l'ordre pour sa descharge et que mesdis seigneurs de l'ordre lui ont accordé et a moy commandé ainsi le faire.

[s] Comment les eust l'en signé et seellé ensemble d'une main et d'ung seel. ${ }^{96}$

\section{[fol. 10r]}

\section{[19] [Die Briefe werden durch verschiedene Wappenkönige und Herolde den Empfängern überbracht.]}

Toutes ces lettres ont esté expediees par la maniere dicte et baill(iees) et distribuees aux roys, heraulx et poursuivans d'armes, ordonnez et delivrez pour les porter, assavoir celles du roy d'Angleterre $\{63\}$ audit Thoison d'or, le roy d'armes de l'ordre; celles du roy de Naples $\{72\}$ au roy d'armes de Flandres $;{ }^{97}$ celles des roys d'Arragon $\{57\}$ et de Castille $\{71\}$ au roy d'armes de Haynnau; ${ }^{98}$ celles de monseigneur le duc de Cleves $\{47\}$ a Lembourg le herault, ${ }^{99}$ et celles de monseigneur Anthoine bastart de Bourgoingne $\{54\}$, de messire Jaques de Luxembourg $\{67\}$, de messire Phelippe Pot $\{60\}$, seigneur de la Roiche de Nolay, et de messire Phelippe de Crevecuer $\{69\}$, seigneur d'Escardes, a Namur le herault. ${ }^{100}$

[20] [Das kommende Fest soll in Brügge stattfinden. Der Kanzler wird gebeten, die entsprechenden Vorkehrungen zu treffen.]

Item mondit seigneur le duc estant a La Haye en Hollande ${ }^{101}$ et adverti que le temps approichoit fort pour faire sesdites emprinses ${ }^{102}$ et qu'il estoit besoing de concluire du lieu ou faire se devroient et tenir la feste dudit ordre pour y faire faire les apprestes a ce requises, il escrivit a mondit seigneur l'evesque de Tournay, chancellier de l'ordre, par ses lettres closes, datees du vije jour du mois d'avril l'an lxxviij apres Pasques, ${ }^{103}$ qu'il estoit deliberé et conclut de relever ledit ordre et faire la feste d'icellui ou mois de

95 Ms.: une apres autre ist unterstrichen.

96 Ms.: Die Randbemerkung beginnt bei der Zeile, die mit den Worten superscription a leur plaisir anfängt und wurde mit der selben Tinte geschrieben wie die Unterstreichungen in diesem Absatz.

97 Zwischen 1477 und 1483 ist Gilles Nokerscot als Herold Flandern belegt; vgl. DB Heraudica ID person 10 und 5.

98 Zwischen 1473 und 1488 ist Tristan Bolin als Wappenkönig Hennegau belegt; vgl. DB Heraudica ID person 22 und 6.

99 Zwischen 1473 und 1481 versah Colinet Rose das Amt des Herolds Limburg; vgl. DB Heraudica ID Person 2 und 21.

100 Vgl. Reg. 1-20. - Für das Jahr 1478 gibt es bisher keine namentliche Nennung der Person, die als Herold Namur am burgund. Hof tätig war. Davor wurde 1475 Guillaume de Loche in diesem Amt genannt und zwischen 1480 und 1482 Guillaume Peletier; vgl. DB Heraudica ID Person 25, 115 und 243. Zu den verschiedenen am burgund. Hof tätigen Herolde vgl. auch die Angaben in § 48 mit Anm. 212.

101 Hz. Maximilians Aufenthalt in Den Haag ist mit Unterbrechungen zwischen dem 25. März und 7. April 1478 belegt; vgl. VANDER Linden, Itinéraires, 1934, S. 31.

102 Ms.: emprinses ist unterstrichen.

103 7. April 1478. - Siehe Reg. 41. 
may lors prouchain ensuivant et darrenier passé en sa ville de Bruges en l'eglise Saint Saulveur illec. ${ }^{104}$ Parquoy lui manda que par messire Olivier, seigneur de la Marche, chevalier, son maistre d'ostel, auquel aussi sur ce il escrivit lors a celle fin, il feist faire et preparer diligenment les apprestes et preparatoires pour ce necessaires. ${ }^{105}$

\section{April 1478 in Brügge}

\section{[21] [Es wird über das Zeremoniell der Ordensübergabe diskutiert.]}

Le mardi, xxviije jour du mois d'avril l'an lxxviij, ${ }^{106}$ mon tresredoubté seigneur monseigneur le duc Maximilian, duc d'Austrice, de Bourgoingne, de Brabant etc., estant en sa ville de Bruges, se assemblerent en la court de mondit seigneur audit Bruges ${ }^{107}$ en la chambre de monseigneur le conte de Chimay $\{74\}$, son premier chambellan, illec messire Loys, seigneur de Gruythuse $\{61\}$, conte de Wincestre, et mondit seigneur le conte de Chimay, chevaliers freres, reverend pere en Dieu messire Ferry de Clugny, evesque de Tournay, maistre Jehan Gros, tresorier, ${ }^{108} \mathrm{M}$ (artin) Steenberch, graffier, et Thoison d'or, le roy d'armes de l'ordre de la Thoison d'or. Et eurent communicacion ensemble sur le fait des ceremonies a garder et observer tout par mondit seigneur le duc comme par messeigneurs les chevaliers freres comme aussi par les officiers dudit ordre et autrement et par chascun a son endroit a la solemnité des actes et misteres a faire tant pour creer mondit seigneur le duc chevalier comme pour par lui relever, accepter et emprendre ledit ordre de la Thoison d'or et l'estat et dignité du chief et souverain d'icellui ordre et des formes des seremens a faire par mondit seigneur a l'acceptacion et emprinse dudit ordre. Et equit(able ?) par messeigneurs les chevaliers freres et par les officiers dudit ordre a mondit seigneur comme chief et souverain du mesme ordre, toutes lesquelles ${ }^{109}$ [fol. 10v] ceremonies estoient ja conceues, redigees et mises par escript bien au long. Et ledit concept y fut veu, leu et visité et examiné

104 Brügge war ein beliebter Veranstaltungsort großer herzoglicher Feste, auch der Orden hatte sich dort schon 1430, 1432 und 1468 versammelt. Vgl. dazu u. a. DocQUIER, L'heure du légitime tribut, 2012; GoossenaERTs, Charles the Bold's Marriage Celebration, 2013.

105 Vgl. Reg. 42. - Olivier de la Marche (1426-1502) war unter Maximilian I. der erste Hofmeister (maistre d'hostel). Seit den 1450er Jahren war er immer wieder an der Organisation großer burgundischer Feste beteiligt und hier in diesem Protokollbuch erfahren wir nun, dass er auch das Ordensfest von 1478 organisiert hatte. Chroniques de Molinet, I, 1935, S. 249, bezeichnet Olivier de la Marche in seiner Chronik als principals conductuer des Festes. Zur Person Oliviers de la Marche und seinem Werk vgl. u. a. Gachard, Ordonnance 1477, 1857, S. 117 und 126; Vielliard, La Marche, 1991; Zingel, Historiographie, 1995, S. 195-222; Cools, Mannen, 2000, S. 363 f., Nr. 168; PrietZel, Imitation, 2004, S. 97.

106 28. April 1478.

107 Zur burgund. Residenz in Brügge, auch Prinsenhof genannt, vgl. u. a. Gruben, Chapitres, 1997, S. 143-146; Hillewaert, The Bruges Prinsenhof, 2013; eine Abb. der Residenz findet sich u. a. bei Kat. Karl der Kühne, 2008, S. 173 (nach Antonius SANDERUS, Flandria illustra, Köln 1641).

108 Ms.: maistre Jehan Gros, tresorier wurde von Hand s unterstrichen. - Zu seiner Ernennung zum Trésorier vgl. unten $\S 74$.

109 Ms.: Die letzten drei Zeilen dieser Seite kleiner, gedrängter und mit mehr Kürzungen als sonst geschrieben. 
bien au long. Et sur tout eue deliberacion et advis apres aucunes corrections y notees et adjoustees a esté tout continué et remis jusques au lendemain sur espoir de la venus de monseigneur de Lannoy $\{50\}$ et de monseigneur de Ravestein $\{55\}$, que l'on y attendoit pour le soir et des autres messeigneurs les chevaliers freres qui $\mathrm{v}$ [i]endroient a la feste de l'ordre.

[s] N(ota) Jehan Gros, tresorier. ${ }^{110}$

\section{April 1478 in Brügge}

\section{[22] [Versammlung der anwesenden Mitglieder am 29. April 1478.]}

Ledit lendemain, qui fut le xxix ${ }^{\mathrm{e}}$ et penultime jour dudit mois d'avril, ${ }^{111}$ devant disner, se assemblerent encore en la court en ladite chambre dudit monseigneur de Chimay $\{74\}$, premier chambellan, messire Jehan, seigneur de Lannoy, monseigneur Adolf de Cleves $\{55\}$, seigneur de Ravestein, messire Loys, seigneur de Gruythuse $\{61\}$, et messire Phelippe, conte de Chimay. <et> Messire Engelbert, conte de Nassouwe, y fut mandé, mais $<\ldots>^{112}$ obstant certaine autre occupacion ${ }^{113}<$ je $>$ il n'y vint point pour celle fois. ${ }^{114}$

[23] [Bei dieser Versammlung wird über das Zeremoniell und die Eidesleistungen bei Hz. Maximilians Annahme der Ordenssouveränität diskutiert.]

En ceste assemblee comparurent aussi reverend pere en Dieu messire Ferry, evesque de Tournay, chancellier, maistre Jehan Gros, tresorier, le graffier et Thoison d'or, le roy d'armes dudit ordre. Et y fut parlé et communiqué bien au long du fait desdites ceremonies et solemnitez a tenir aux misteres dessusdis. Et y fut leu de rechief, visité et examiné bien au long ledit concept desdites ceremonies ensemble les formes des sermens a faire, tant par monseigneur le souverain avenir a sa recepcion en l'ordre, comme aussi a lui par messeigneurs les chevaliers freres et lesdis officiers dudit ordre apres qu'il seroit receu a la dignité et estat du souverain d'icellui ordre, avec les corrections sur tout avisees le jour precedent, comme dessus est dit. Et tout resolu et conclut par mesdis seigneurs et en fut ordonné d'en faire ung brief extrait pour mondit seigneur le duc, pour le lui baillier afin qu'il le puist incorporer et mieulx estre de tout adverti. Ce que j'ay fait le lendemain ensuivant devant sa messe privee, dite en sa chapelle, comme cy apres sera dit. ${ }^{115}$

110 Ms.: Dieser Name steht am linken Rand bei der Zeile, in der Jean Gros ebenfalls genannt ist, und wurde gleichzeitig mit der Unterstreichung des Namens im Text eingefügt.

111 29. April 1478.

112 Ms.: Aufgrund der mehrfachen Streichung ist der ursprüngliche Text nicht mehr lesbar.

113 Ms.: obstant certaine autre occupacion steht am linken Rand und eine Marke vor der Strichung zeigt die dafür vorgesehene Stelle im Text. Sie wurde von Hand s geschrieben.

114 Ms.: Es folgt ein kleinerer Abstand zum nächsten Absatz als sonst üblich.

115 Zur Ausführung vgl. unten § 40-67. 
[24] [Es wird festgestellt, dass bisher nur zwei der nichtteilnehmenden Mitglieder einen Stellvertreter ernannt haben.]

Apres a esté parlé en ladite assamblee d'autres ceremonies a garder a l'offrande tant de la grant messe au jour de la feste comme le lendemain a la messe des trespassez pour donner ordre et savoir ceulx de messeigneurs les chevaliers freres presens qui garderoient et suppleeroient les lieux de messeigneurs les absens. Veu qu'ilz n'avoient que deux procuracions de deux absens, assavoir l'une du roy de Naples $\{72\}$ et l'autre de monseigneur d'Anthoing $\{28\} .{ }^{116}$ Et faisoit a doubter que pour celle foix plus nulles y vendroient a temps. ${ }^{117}$

\section{[25] [Zur geringen Teilnahme.]}

Et pour entendre la chose fait a savoir que pour l'eure n'avoit que dixhuit chevaliers freres survivans en l'ordre et xiij trespassez y comprins feu monseigneur le duc Charles $\{34\}$, en son vivant chief et souverain, darrenier deffunct, que Dieu [fol. 11r] absoille. De tous lesdis survivans n'avoit que cinq chevaliers freres, assavoir messeigneurs $<$ de ...by $>$ de Lannoy ${ }^{118}\{50\}$, de Ravestein $\{55\}$, de Gruythuse $\{61\}$, de Chimay $\{74\}$ et de Nassouwe $\{77\}$, presens et lesdis deux procuracions, assavoir celle pour le roy de Naples $\{72\}$ et l'autre pour mondit seigneur d'Anthoing $\{28\} .{ }^{119}$ Pour les autres xj absens n'y avoit procuracion, nulle venue ne lettre ou charge par cui leurs lieux garder et suppleer se devvoient tant en l'eglise comme en chappittre, parquoy la description et provision en fut faite telle que s'ensuit et par les assietes deues dez lez dextre et senestre. ${ }^{120}$ Et premierement au lez dextre:

[s] No(ta) que l'y se trouverent seullement $<\mathrm{cinq}^{121}<\mathrm{iiij}>\mathrm{v}$ chevaliers presens.

[26] [Des folgt eine Bestandsaufnahme aller Mitglieder; zuerst die der rechten Seite:]

Au lez dextre

Treshault et trespuissant prince don Jehan, roy d'Arragon et de Navarre etc. $\{57\}$, absent. ${ }^{122}$ Il n'a point de procuracion pour lui q(ue) soit venue a cognoissance, car le roy d'armes de Haynnau envoié devers lui a tout les lettres de l'intimacion et significacion de ceste feste ${ }^{123}$ n'estoit encore retourné. Parquoy a esté deliberé et ordonné

116 Vgl. Reg. 34-36 und 45.

117 Ms.: Es folgt ein kleinerer Abstand zum nächsten Absatz als sonst üblich.

118 Ms.: de Lannoy wurde von Hand s über der nicht lesbaren Streichung eingefügt.

119 Wie Anm. 116.

120 Vgl. dazu auch die Bestandsaufnahme der anlässlich des Ordensfest aufgehängten Wappen der Mitglieder in § 32-34. Eine Mitgliederliste des Jahres 1478 findet sich auch bei Chronique de Maximilien I, 1839, S. 293 f.; Chroniques de Molinet, I, 1935, S. 252f. (vgl. dazu die Angaben unten in Anm. 187).

121 Ms.: <iiij> $v$ steht über der ersten Streichung. - Die Randbemerkung steht zu Beginn von fol. $12 \mathrm{r}$.

122 Ms.: absent ist unterstrichen.

123 Vgl. Reg. 3 und 14. 
par messeigneurs que monseigneur de Ravestein $\{55\}$ gardera son lieu quant a ladite offrande. ${ }^{124}$

Treshault et trespuissant prince don Fernande, roy de Cecille et de Naples $\{72\}$, absent. ${ }^{125}$ Mais il a envoyé sa procuracion souffisante pour tenir son lieu et faire son excuse adreçee a monseigneur le conte de Chimay $\{74\}$, qui tendra son lieu tant en l'eglise comme ou chappittre en vertu et vigeur de sadite procuracion. ${ }^{126}$

Messire Jehan de Melun $\{28\}$, seigneur d'Anthoing, absent. ${ }^{127}$ Mais il a envoyé sa procuracion souffisante a mondit seigneur de Chimay, pour faire ses excuses et tenir son lieu tant en l'eglise comme en chappittre, parquoy mondit seigneur de Chimay sera pour lui. ${ }^{128}$

$<$ Messire Phelippe Pot, seigneur de Roy [!] de Nolay.>

Messire Jehan de Neufchastel $\{52\}$, seigneur de Montagu, absent. ${ }^{129}$ Il n'a point eu ses lettres de l'intimacion et significacion de ceste feste pour lui envoyees. ${ }^{130} \mathrm{Car}$ Ferrettes le herault d'armes qui avoit charge de les porter, afferme par son rapport, que lesdites lettres lui avoient esté ostees et tollues en la cité de Mascon avec autres adreçans a monseigneur de Clessy $\{65\},{ }^{131}$ qu'il lui cuida presenter audit lieu de Mascon. Et combien que mondit seigneur le duc depuis le departement dudit Ferrette eust escript audit monseigneur de Montagu autres lettres, le exhortant qu'il voulsist venir en personne et estre a ceste feste, ${ }^{132}$ toutevoye ces lettres secondaires de mondit seigneur estoient relatives desdites personnes et prinicpales, lesquelles il n'avoit point receues. Parquoy et tant pour la debilité de sa personne comme pour le dangier des chemins a cause de la guerre il s'en est execusé et n'a point envoyé de procuracion pour tenir son lieu. ${ }^{133}$ Neantmoins mesdis seigneurs les freres de l'ordre ont ordonné monseigneur de Gruythuse $\{61\}$, conte de Wincestre, pour suppleer son lieu quant a ladite offrande.

Messire Phelippe Pot $\{60\}$, seigneur de Roiche de Nolay, est en France ou parti contraire, absent, ${ }^{134}$ et n'a envoyé procuracion ne excuse. ${ }^{135}$

Messire Loys, seigneur de Gruythuse $\{61\}$, conte de Wyncestre, present. ${ }^{136}$

Messire Phelippe de Crevecuer $\{69\}$, seigneur d'Escardes, est en France ou parti contraire, absent et n'a envoyé procuraction ne excuse. ${ }^{137}$

$124 \mathrm{Kg}$. Johann hatte ein Entschuldigungsschreiben gesandt, das aber nicht rechtzeitig in Brügge ankam; vgl. Reg. 38.

125 Ms.: absent ist unterstrichen.

126 Vgl. Reg. 34-37. Auch Chroniques de Molinet, I, 1935, S. 254, berichtet, dass Philippe de Croy hier die Rolle des Stellvertreters übernommen hat.

127 Ms.: absent ist unterstrichen.

128 Vgl. Reg. 45 und 46.

129 Ms.: absent ist unterstrichen.

130 Vgl. Reg. 7 und 18. - Zu Ferrettes beschwerlicher Reise und Gefangennahme, bei der seine mitgeführten Briefe verloren gingen, vgl. die Angaben § 120 und Reg. 13.

131 Vgl. Reg. 13.

132 Vgl. Reg. 28.

133 Das Absageschreiben von Jean de Neufchâtel datiert vom 8. April 1478 und kam nicht mehr rechtzeitig in Brügge an; vgl. dazu Reg. 43. - Fortsetzung in § 119.

134 Ms.: absent ist unterstrichen.

135 Dazu mehr in $\S 28$.

136 Diese Wappentafel ist abgebildet bei Bergen-PAntens, Chapitres, 1980, S. 291, Nr. 7.

137 Zu Philippe de Crèvecœur, Jacques de Luxembourg und Jean de Damas mehr in § $28 \mathrm{f}$. 


\section{[fol. 11v]}

Monseigneur Jaques de Luxembourg \{67\}, seigneur de Richebourg, est en France ou parti contraire, prisonnier, absent.

Messire Phelippe de Croy $\{74\}$, conte de Chimay, present.

Messire Jehan de Damas $\{65\}$, seigneur de Clessy, est en France ou parti contraire et n'a envoyé procuracion ne excuse, absent.

Monseigneur Phelippe de Savoye $\{68\}$, conte de Baugey, seigneur de Bresse, absent. Il n'est point venu combien qu'il ait receu ses lettres de ladite intimacion et significacion de ceste feste. ${ }^{138}$ Mais Ferretes le herault, qui les lui avoit portees et $p$ (rese)ntees, certifié que par lui mesmes mondit seigneur de Bresse avoit fait response et escript a messeigneurs de l'ordre lettres aimables, ${ }^{139}$ lesquelles a Macson lui furent ostees et tollues par les François avec celles de mondit seigneur de Montagu, ${ }^{140}$ certiffié aussi que mondit seigneur de Bresse doulcement et benignement l'avoit traitié, dont faisoit plus a esperer de lui le bien que le mal. ${ }^{141}$ Parquoy mesdis seigneurs de l'ordre ont ordonné monseigneur Engelbert, conte de Nassouwe $\{77\}$, pour suppleer et tenir son lieu quant a l'offrande. ${ }^{142}$

A ce mesme lez dextre avoit quatre lieux vacans, assavoir les lieux de feu messire Anthoine, jadis seigneur de Croy $\{15\} ;{ }^{143}$ feu messire Loys de Chalon $\{64\}$, seigneur de Chasteauguion; ${ }^{144}$ feu messire Jehan de Reubempré $\{73\}$, seigneur de Bievre, ${ }^{145}$ et de feu monseigneur Jehan de Lucembourg $\{75\}$, jadis conte de Marle ${ }^{146}$, trespassez. ${ }^{147}$

\section{[27] [Die Mitglieder der linken Seite:]}

\section{$\mathrm{Au}$ lez senestre}

Treshault, tresexcellent et trespuissant prince le roy Eduard, roy d'Angleterre $\{63\}$, seigneur d'Yrlande, absent. ${ }^{148} \mathrm{Il}$ a rescript par forme d'excuse, ${ }^{149}$ mais il n'a point envoyé de procuracion, parquoy messeigneurs ont ordonné monseigneur de Gruthuyse $\{61\}$, conte de Wyncestre, pour suppleer et garder son lieu quant a l'offrande. ${ }^{150}$

Treshault, tresexcellent et trespuissant prince l'infant don Fernando $\{71\}$, roy de Castille, de Leon et de Secille etc., prince de Navarra, absent. ${ }^{151}$ Il n'a point envoyé de

138 Vgl. Reg. 8 und 17.

139 Vgl. Reg. 26.

140 Vgl. dazu die Angaben in Anm. 130.

141 Fortsetzung in $\S 119 \mathrm{f}$.

142 Auch Chroniques de Molinet, I, 1935, S. 254, berichtet, dass Engelbert von Nassau die Rolle des Stellvertreters übernommen hat.

143 Er verstarb am 21. Okt. 1474; vgl. Chevaliers de la Toison d'or, ${ }^{2} 2000$, Nr. 15.

144 Er fiel bei Grandson am 2. März 1476; vgl. Chevaliers de la Toison d'or, ${ }^{2} 2000$, Nr. 64.

145 Er fiel bei Nancy am 5. Jan. 1477; vgl. Chevaliers de la Toison d'or, ${ }^{2} 2000$, Nr. 73.

146 Er fiel bei Murten am 22. Juni 1476; vgl. Chevaliers de la Toison d'or, ${ }^{2} 2000$, Nr. 75. Nach PB 3 § 183 sollten Engelbert von Nassau \{77\} auf der rechten und Jean de Luxemburg auf der linken Seite sitzen.

147 Vgl. auch die Aufählungen der verstorbenen Mitglieder in § 27, $33 \mathrm{f}$. und 153.

148 Ms.: absent ist unterstrichen.

149 Vgl. Reg. 29.

150 Auch Chroniques de Molinet, I, 1935, S. 254, berichtet, dass Ludwig von Brügge als Eduards Stellvertreter tätig war.

151 Ms.: absent ist unterstrichen. 
procuracion que soit venue a cognoissance, car le roy d'armes de Haynnau qui estoit envoyé devers lui a tout les lettres de l'intimacion et significacion de ceste feste de l'ordre ${ }^{152}$ n'est pas encore retourné. Parquoy messeigneurs de l'ordre cy dessusnommez ont ordonné monseigneur de Lannoy $\{50\}$, pour suppleer et tenir son lieu quant a l'offrande. ${ }^{153}$

Hault et puissant prince monseigner Jehan, duc de Cleves $\{47\}$, conte de la Marke, absent. ${ }^{154} \mathrm{Il}$ a eu ses lettres de l'intimacion et significacion de ceste feste par Lembourg le herault, officier d'armes, qui encore la seconde fois a esté devers lui a tout lettres l'iteratives, ${ }^{155}$ mais il [fol. 12r] n'a rescript ne envoyé procuracion ou fait ${ }^{156}$ quelque excuse. ${ }^{157}$ Neantmoins messeigneurs ont ordonnee monseigneur de Ravestein $\{55\}$, son frere, pour suppleer et tenir son lieu quant a l'offrande.

Messire Jehan, seigneur de Lannoy $\{50\}$ present.

Messire Anthoine, bastart de Bourgoingne $\{54\}$, conte de la Roiche en Ardenne, absent, ${ }^{158}$ et est en France ou parti contraire, prisonnier. ${ }^{159}$

Monseigneur Adolff de Cleves et de la Marke $\{55\}$, seigneur de Ravestein, present.

Messire Engelbert, conte de Nassouwe $\{77\}$, seigneur de Breda, present. ${ }^{160}$

A ce mesme lez senestre avoit huit lieux vacans, assavoir les lieux de feu hault et puissant prince monseigneur Jehan, duc d'Alençon $\{39\}$, conte du Perce; ${ }^{161}$ de feu messire Bauduin de Lannoy $\{19\}$, dit le Begghe ${ }^{162}$, seigneur de Molembais; de feu messire Symon de Lalaing $\{26\}$, seigneur de Montigny; de feu messire Jehan, ber et seigneur d'Auxy $\{45\} ;{ }^{163}$ de feu messire Henry de Borssele $\{44\}$, seigneur de la Vere, conte de Grantpré, ${ }^{164}$ de feu mesire Regnault, seigneur de Brederode $\{43\} ;{ }^{165}$ de feu hault et puissant monseigneur Adolf de Ghelres et de Zuthphen $\{58\}^{166}$ et de feu messire Guy

152 Vgl. Reg. 4 und 16.

$153 \mathrm{Kg}$. Ferdinand hatte die entsprechenden Schreiben ausgestellt, sie kamen jedoch nicht rechtzeitig in Brügge an; vgl. Reg. 30-33. Chroniques de Molinet, I, 1935, S. 254, berichtet, dass Adolf von Kleve die Rolle des Stellvertreters übernommen hat.

154 Ms.: absent ist unterstrichen.

155 Vgl. Reg. 5, 19 und 39.

156 Ms.: fait wurde aus fais verbessert.

157 Fortsetzung in $\S 121$.

158 Ms.: absent ist unterstrichen.

159 Dazu mehr in $\S 28 \mathrm{f}$.

$160 \mathrm{Zu}$ seiner Reihung in der linken Seite vgl. die Angaben in Anm. 146.

161 Er verstarb am 8. Sept. 1476; vgl. Chevaliers de la Toison d'or, ${ }^{2} 2000$, Nr. 39.

162 Ms.: dit le Begghe steht über der Zeile und eine Marke zeigt die dafür vorgesehene Stelle im Text. - Er verstarb während des Jahres 1474; vgl. Chevaliers de la Toison d'or, ${ }^{2} 2000$, Nr. 19. Nach seinem Tod übergab sein Sohn Baudouin $\{89\}$ statutengemäß die Ordenskette Hz. Karl $\{34\}$ im Lager vor Neuss, der sie Guy de Brimeu $\{76\}$ anvertraute. Nach dessen Tod erhielt Baudouin die Kette wieder zurück und stellte dafür Jean du Chesne als Beautragtem der Witwe von Guy de Brimeu darüber an 7. Mai 1477 eine Quittung aus; dazu Paravicini, Guy de Brimeu, 1975, S. 337 f., Anm. 372c (mit Hinweis auf Brüssel, AGR, Fonds de Brimeu).

163 Er verstarb am 15. Aug. 1474; vgl. Chevaliers de la Toison d'or, ${ }^{2} 2000$, Nr. 45.

164 Er verstarb am 16. Okt. 1473; vgl. Chevaliers de la Toison d'or, ${ }^{2} 2000$, Nr. 44.

165 Er verstarb am 15. März 1474; vgl. Chevaliers de la Toison d'or, ${ }^{2} 2000$, Nr. 43.

166 Hz. Karl nahm Adolf von Egmond, Hz. von Geldern und Gf. von Zutphen, 1471 gefangen und verleibte sich im Sommer 1473 dessen Herzogtum gewaltsam ein (dazu ausführlicher PB 3, S. 34-37 § 11 und S. 94-97 § 138-143). Während des Trierer 
de Brimeu \{76\}, seigneur de Humbercourt, conte de Meghen, ${ }^{167}$ tous jadis chevaliers freres et compaingnons de cest ordre, trespassez depuis la darreniere feste dudit ordre tenue a Valenciennes l'an lxxiij. ${ }^{168}$

\section{[28] [Zur Nichtteilnahme von Philippe Pot, Philippe de Crèvecoeur und Jean de Damas.]}

\section{La Roiches, Esquerdes et Clessy ${ }^{169}$}

Et quant ausdis messire Phelippe Pot $\{60\}$, seigneur de la Roiche de Nolay, ${ }^{170}$ messire Phelippe de Crevecuer $\{69\}$, seigneur d'Escardes, ${ }^{171}$ et messire Jehan de Damas $\{65\}$, seigneur de Clessy, ${ }^{172}$ qui de leur volunté se sont tournez au parti contraire et n'ont

Treffens erhielt Karl am 6. Nov. 1473 eine entsprechende Belehnungsurkunde (vgl. Chmel, Regesta, 1838, Nr. 6815) und nach Karls Tod wurde Maximilian am 19. April 1479 u. a. mit dem Herzogtum Geldern und der Gft. Zutphen belehnt (vgl. oben $\S 1$, Anm. 3). Im Frühjahr 1477 wurde Adolf von Geldern freigelassen und erhob sogleich mit breiter Unterstützung der Einwohner von Geldern Anspruch auf seine entzogenen Herrschaftsrechte. Während der darauf folgenden kriegerischen Auseinandersetzungen fand er am 27. Juni 1477 den Tod (vgl. Chevaliers de la Toison d'or, ${ }^{2} 2000$, Nr. 58). Entsprechend ihrem Anspruch auf das Herzogtum Geldern und die Gft. Zutphen durch Hz. Karl und Hz. Maximilian wird Hz. Adolf hier, wie auch schon in PB 3, nur als Adolf von Geldern und Zutphen ohne Nennung des Herzogsbzw. Grafentitels genannt.

167 Er wurde während des Genter Aufstands am 3. April 1477 von den Aufständischen enthauptet; vgl. Chevaliers de la Toison d'or, ${ }^{2} 2000$, Nr. 76.

168 Vgl. zu diesem Fest Anm. 80 und zu den verstorbenen Mitglieder auch $\S 26,33 \mathrm{f}$. und 153.

169 Ms.: Diese Zwischenüberschrift wurde von anderer Hand s vor dem folgenden Absatz eingefügt. - Vgl. zu den in Frankreich befindlichen Mitgliedern in der Einleitung S. 25-27.

170 Philippe Pot genoss zu Lebzeiten Hz. Philipps $\{01\}$ und Hz. Karls $\{34\}$ ein hohes Ansehen am burgund. Hof, seit 1474 war er u. a. auch grant maître de l'hôtel Hz. Karls. Nach dessen Tod stelle er sich zunächst auf die Seite von Hz.in Maria, wechselte dann aber in die Dienste Kg. Ludwigs XI. Dieser ernannte ihn im Sept. 1477 zu seinem grand sénéchal von Burgund und ließ ihn in der hzl. Residenz in Dijon logieren. Auch wurde Philipp zum kgl. Rat und Kammerherr sowie zum „chevalier d'honneur du Parlement de Bourgogne" ernannt; vgl. dazu Chevaliers de la Toison d'or, ${ }^{2} 2000$, Nr. 60; zu seiner Person u. a. auch Varvre, Primitif tiré de l'oubli, 2005, S. 816-818 und S. 822-824.

171 Philippe de Crèvecœur diente den Hzz. Philipp $\{01\}$ und Karl $\{34\}$ von Burgund als deren Rat und Kammerherr. Darüber hinaus war er Bailli von Arras und Gouverneur der Pikardie und des Artois. Nach Karls Tod wurde er zu einem der Ehrenritter Hz.in Marias ernannt, aber am 5. März 1477 öffnete er den frz. Truppen die Tore von Arras, übergab Kg. Ludwig XI. die von ihm verwalteten Gebiete und trat in dessen Dienste ein; vgl. dazu Chevaliers de la Toison d'or, ${ }^{2} 2000$, Nr. 69; Cools, Mannen, 2001, S. 277 f., Nr. 55; Haemers, Common Good, 2009, S. 22 f.; Paravicini, Terreur royale, 2011, S. $554 \mathrm{f}$.

172 Nach dem Tod Hz. Karls \{34\} hatte Jean Damas den Mâconnais, den er seit 1467 als Gouverneur und Bailli innehatte, an Kg. Ludwig XI. ausgeliefert. Dieser ernannte ihn darauf hin zum Bailli und seinem lieutenant géneral dieser Gegend und zu seinem Kammerherrn. Darüber hinaus stattete Kg. Ludwig XI. Jean mit einer jährlichen Pension von 5.000 livres aus; vgl. dazu Chevaliers de la Toison d'or, ${ }^{2} 2000$, Nr. 65. 
point eu leur lettre de la significacion et intimacion de ceste feste, obstant que Namur, l'officier d'armes, qui avoit charge de les porter et semblablement audit monseigneur le bastart de Bourgoingne $\{54\}$ et a monseigneur Jaques de Luxembourg $\{67\}$ celles qui a eulx s'adreçoient, n'avoit peu passer ne parvenir a eulx et n'avoit baillié, fors celle de mondit seigneur Jacques de Luxembourg seulement. ${ }^{173}$ L'advis et deliberacion de mesdis seigneurs a esté: Que veu et consideré que de leur volonté lesdis trois chevaliers, assavoir seigneurs de la Roiche, d'Escardes et de Clessy, estoient et sont tournez audit parti contraire et ont delaissié le collier de l'ordre et prins et accepté aultre ordre, assavoir l'ordre du roy de France. ${ }^{174}$ Ce que faire ne povoient ne devoient selon les status d'icellui ordre de la Thoison d'or solemnellement par eulx jurez. ${ }^{175}$ Qu'ilz ne seront point appellez pour aler a l'offrande et que nul n'offrera pour eulx, soit le roy d'armes Thoison d'or ne autre. Mais ledit Thoison d'or, quant leur tour sera de les appeler, yra devant le lieu de leurs armes et en faisant maniere de la teste, passera oultre sans [fol. 12v] mot dire et sans offrir pour eulx comme dit est. ${ }^{176}$

[29] [Zur Nichtteilnahme von Antons, Bastard von Burgund, und facques de Luxembourg.]

Messire Anthoine bastart de Bourgoingne et messire Jaques de

Luxembourg - Ces deux avoient esté prisonniers, mais presens delivrees. ${ }^{177}$

Et au regart de monseigneur le bastart de Bourgoingne $\{54\}$ et de messire Jaques de Luxembourg $\{67\}$ combien qu'ilz fussent prisonniers et prins ou service <et> en et pour la querelle de feu monseigneur le duc Charles $\{34\}$, jadis souverain de cest ordre de ladite Thoison d'or, darrenier deffunct, parquoy ilz pourroient alleguer quelque excusé de leur costé. Toutevoie consideré qu'ilz ont delaissié le collier dudit ordre de la Thoison d'or et prins l'ordre du roy, ce que faire ne povoient comme dit est. Et si a ledit messire Jaques obtenu par don du roy les villes et seignories de Lens et de la

173 Vgl. Reg. 10-13, 24 und 21-25. Kg. Ludwig verbot den an seinem Hof weilenden fünf Vliesrittern die Teilnahme am Fest; vgl. dazu oben in der Einleitung, S. 16 f. mit Anm. 17.

174 Der genaue Zeitpunkt ihres Beitrittes in den von Ludwig XI. im Jahr 1469 gegründeten Michaels-Orden ist nicht bekannt; Colleville/Saint-Christo, Ordres, [1925], S. 68f., gibt an, dass die fünf Vliesritter vor 1479 bzw. 1480 aufgenommen wurden. Zur Geschichte dieses Ordens vgl. u. a. Contamine, L'ordre de Saint-Michel, 1978; VetTer, Ritterorden, 1979, hier S. 33 f. zur Mitgliedschaft dieser Vliesritter; Boulton, Knights of the crown, 1987, S. 427-447; Contamine, Michaelsorden, 1993; PARAViciNI, Schlichtheit, 2002, S. 67 f.; PB 2, S. 162, Anm. 723; VAIVRE, Primitif tiré de l'oubli, 2005, S. $824 \mathrm{f}$.

175 In $\S 2$ der Statuten (dazu S. 16, Anm. 14) wurde festgelegt, dass die Mitglieder des Ordens keinem anderen Orden angehören dürfen. Ausgenommen von dieser Bestimmung wurden Kaiser, Könige und Herzöge, die selbst Souverän eines Ordens waren. Bei ihrem Aufnahmeeid mussten alle Mitglieder beschwören, dass sie sich an den Inhalt der Statuten halten werden; so § 82 (neu § 57) der Statuten.

$176 \mathrm{Zu}$ ihrem Ausschluss vom öffentlichen Zeremoniell vgl. in der Einleitung S. 26 sowie die Fortsetzung in $\S 78$.

177 Ms.: Hand s fügte die Namen der beiden oberhalb des Absatzes ein und aus Platzgründen den restlichen Text am linken Rand daneben. 
Bassee et a fait guerre ouverté a madame la duchesse. ${ }^{178}$ Et mesmement a esté veu par freres chevaliers de cest ordre de la Thoison [d'or] portant ledit ordre du roy. Et qu'il est chosé toute notoire que semblablement mondit seigneur le bastart ait porté et porte ledit ordre du roy. ${ }^{179} \mathrm{~A}$ esté la deliberacion et conclusion de mesdis seigneurs pour ces regars, la matiere bien et meurement entre eulx disputee et debattué par diverses fois, que pareillement sera fait d'eulx deux quant a ladite offrande comme des autres trois dessus nommez. C'est assavoir qu'ilz ne seront point appellez par le roy d'armes pour aler a l'offrande, mais quant leur tour sera pour les y appeller, ledit roy d'armes Thoison d'or yra devant les lieux de leurs tableaux inclinant ung peu la teste sans parler mot ou faire offrande pour eulx, ains passera oultre, comme dessus est dit. ${ }^{180}$

[30] [Diskussion, wie mit dem Wappen des verstorbenen Souveräns, Hz. Karl, verfahren werden soll.]

Apres a esté parlé de l'assiete du blason des armes de feu mondit seigneur le duc Charles $\{34\}$, jadis chief et souverain de cest ordre de la Thoison d'or, darrenier deffunct, a faire en l'eglise sur le siege de monseigneur le duc a la prouchaine feste, ${ }^{181}$ quant il sera chief et souverain dudit ordre. Et oyé et entendue par mesdis seigneurs la maniere qui avoit esté tenue en l'assiete du blason des armes ${ }^{182}$ de feu monseigneur le duc Phelippe $\{01\}$, jadis premier fondateur, chief et souverain du mesme ordre et pere dudit feu monseigneur le duc Charles, lors que ledit blason dudit feu monseigneur le duc Phelippe avoit esté mis au dessus du tableau des armes d'icellui feu duc Charles, son filz, seul heritier et successeur etc., environ d'ung piet et demy de hault. ${ }^{183}$ A sam-

178 Jacques de Luxembourg geriet 1475 in frz. Gefangenschaft, etwa zur selben Zeit wie sein Bruder Louis de Luxembourg, der Konnetabel von Frankreich, wegen Verrat hingerichtet wurde. Jacques befand sich dort über 10 Jahre und konnte sich nur daraus befreien, in dem er in die Dienste Ludwigs XI. trat und auch den Michaelsorden (vgl. dazu Anm. 174) annahm; vgl. dazu u. a. Vaughan, Charles the Bold, 1973, S. 253; Chevaliers de la Toison d'or, ${ }^{2} 2000$, S. 158; PAviot, Jacques de Luxembourg, 2000, S. 336 f.; vgl. dazu auch Jacques Brief von [1478] Dez. 29 in Reg. 99.1481 wurde Jacques aus dem Orden ausgeschlossen; dazu mehr in PB 5; zu seiner vorgebrachten Verteidigung nach 1485 vgl. STERCHI, Umgang, 2005, S. $460 \mathrm{f}$.

179 Anton, Bastard von Burgund, war erster Kammerherr Hz. Karls und wurde während der Schlacht von Nancy gefangengenommen und von Hz. René von Lothringen an Kg. Ludwig XI. ausgeliefert. Dieser versuchte Anton auf seine Seite zu ziehen, in dem er ihm diverse Herrschaften und Auszeichnungen übergab. Am 15. Aug. 1477 legt Anton seinen Treueschwur auf Kg. Ludwig ab (gedruckt bei MüNCH, Maria und Margarethe, II, 1832, S. 266 f., Nr. 3). Am burgund. Hof bestand auch noch 1481 große Unsicherheit, für welche Seite Anton sich entschieden hatte. Später stellte er sich eindeutig auf die burgund. Seite und gehörte ab 1494 zum engeren Kreis Philipps des Schönen \{86\}; vgl. dazu Commies, Anton van Bourgondie, 1979, S. 64 f.; Clément, Antoine de Bourgogne, 1990, S. 177 f.; Cools, Mannen, 2000, S. 246-248, Nr. 24; Chevaliers de la Toison d'or, ${ }^{2} 2000$, S. 129-131, Nr. 54; PB 5, fol. 37r und passim.

180 Siehe $\S 28$. - Fortsetzung in $\S 78$.

181 Ms.: Bei der Zeile, die mit le duc a la prouchaine feste beginnt, fängt am linken Rand eine senkrechte, leicht geschlängelte Linie an, die über neun Zeilen geht.

182 Ms.: des armes steht über der Zeile und eine Marke weist auf die dafür vorgesehene Stelle im Text hin.

183 Beim Ordensfest von 1468 in Brügge, dem ersten unter Hz. Karl nach dem Tod Hz. Philipps, hing dessen Wappen über dem Sitz des Ordenssouveräns in der Kirche. Erst 
blé a mesdis seigneurs que ce n'estoit pas ${ }^{184}$ chose pareille, attendue que ladite assiete avoit esté du pere descendant au filz, mais ceste qualité n'estoit pas entre mondit seigneur le duc et feu monseigneur le duc Charles, parquoy leur deliberacion et advis a esté: Que l'assiete dudit blason des armes dudit feu monseigneur le duc Charles se feroit sans interstice ou moyen d'aucune vuyt gaires apparant droit au dessus du tableau des armes de mondit seigneur le duc. ${ }^{185}$

\section{[fol. 13r]}

\section{[31] [Zu den Wappen der übrigenen lebenden und verstorbenen Mitglieder.]}

Pour demonstrer evidement et plainement l'estat present de l'ordre de la Thoison d'or et la dignité et qualité de messeigneurs dudit ordre, tant survivans comme trespassez <en icellui> depuis la darreniere feste d'icellui ordre, tenue et faite en la ville de Valenciennes ou mois de may l'an lxxiij, ${ }^{186}$ s'ensuit icy l'ordre de l'assiete des tableaux des armes de messeigneurs les survivans et des blasons des trespassez, que Dieu absoille, et est telle: ${ }^{187}$

[Bestandsaufnahme: Zuerst das blason des verstorbenen Souveräns, Hz. Karl.]

$$
\text { Primo }^{188}
$$

Le blason des armes de feu treshault et trespuissant prince monseigneur Charles $\{34\}$, jadis duc de Bourgoingne, le Lothrijck, de Brabant etc., en son vivant chief et souverain dudit ordre, darrenier deffunct, sur le lieu du souverain, qui est en chief, au lez dextre:

[b] obiit - blason. ${ }^{189}$

bei der Totenmesse wurde das Wappen entfernt und der Ordenskanzler rief Hz. Karl offiziell als neuen Souverän aus; vgl. PB 2, S. 38 f., § 3-6 und S. 86 f., § 60 .

184 Ms.: pas steht über der Zeile und eine Marke weist auf die dafür vorgesehene Stelle im Text hin.

185 Zur Ausführung dieses Beschlusses vgl. § 76.

$186 \mathrm{Zu}$ diesem Fest vgl. Anm. 80.

187 Vgl. dazu auch die Bestandsaufnahme aller Mitglieder in $§ 26 \mathrm{f}$., wo auch die Sterbedaten genannt sind; die verstorbenen Mitglieder werden noch einmal in $\S 153$ aufgelistet. - Die Wappen wurden von den Hofmalern Jehan Hennekart oder Pierre Coustain hergestellt; dazu Welzel, Kunstproduktion, 1997, S. 142 mit Anm. 5 auf S. 152 (mit Hinweis auf Devliegher, Sint-Salvatorskatedraal, 1979, S. 209-211 und Abb. 290-317; Schouteet, Vlaamse Primitieven, 1989, S. 152-158). Abbildungen aller Wappen sind unter http://balat.kikirpa.be (Stichworte Pierre Coustain und 1478) abrufbar. Die Inschriften der Wappentafeln zitiert Chroniques de Molinet, I, 1935, S. $252 \mathrm{f}$. Heute hängen noch im Chor der Salvatorkirche in Brügge insgesamt 28 an dieses Fest erinnernde Wappentafeln über dem Chorgestühl. Wie schon 1478 sind die Wappentafeln in zwei Reihen gehängt, wenngleich die Reihenfolge nicht ganz der historischen Rangfolge der Mitglieder enstpricht. Es fehlten auch die Wappen von Hz. Karl von Burgund \{34\}, Hz. Maximilian, Johann, Kg. von Aragon \{57\}, Ferdinand, Kg. von Neapel \{72\}, Ferdinand, Kg. von Kastilien \{71\}, und Antoine de Croy $\{15\}$. Dagegen befinden sich unter den heutigen Wappentafeln zwei, die 1478 dort nicht vorhanden gewesen waren, nämlich die Tafeln von Jacques de Bourbon \{66\} und Claude de Montaigu \{70\}, die beide schon vor 1473 verstarben. Zu den Wappentafeln vgl. auch in der Einleitung S. 19f. mit Abbildung.

188 Ms.: primo ist unterstrichen.

189 Ms.: Dieser Vermerk, wie auch die der anderen bei den verstorbenen Mitglieder, stehen jeweils am linken Rand. 
Au lez dextre

Treshault, tresexcellent et trespuissant prince don Jehan $\{57\}$, par la grace de Dieu roy d'Arragon et de Navarre etc.

Treshault et trespuissant prince don Fernande $\{72\}$, par la grace [de] Dieu roy de Naples et de Secille etc.

Messire Anthoine, seigneur de Croy $\{15\}$, conte de Porcien - trespassé.

[b] obiit - blason.

Messire Jehan de Melun $\{28\}$, seigneur d'Anthoing.

Messire Jehan <seigneur $>$ de Neufchastel $\{52\}$, seigneur de Montagu.

Messire Phelippe Pot $\{60\}$, sire de Roiche de Nolay - absent, en France.

Messire Loys, seigneur de Gruythuse $\{61\}$, conte de Wyncestre. ${ }^{190}$

Messire Phelippe de Crevecuer $\{69\}$, sire d'Escardes - absent, en France. ${ }^{191}$

Messire Jaques de Lucembourg $\{67\}$, seigneur de Richebourg - absent, en France.

Messire Jehan de Damas $\{65\}$, sire de Clessy - absent, en France.

Messire Loys de Chalon $\{64\}$, seigneur de Chasteauguion - trespassé.

[b] obiit - blason.

Hault et puissant monseigneur Phelippe de Savoye $\{68\}$, conte de Baugey et seigneur de Bresse - absent. ${ }^{192}$

Messire Jehan de Reubempré \{73\}, seigneur de Bievre - trespassé.

[b] obiit - blason.

Messire Phelippe de Croy $\{74\}$, conte de Chimay.

Messire Jehan de Lucembourg $\{75\}$, conte de Marle - trespassé.

[b] obiit - blason.

[fol. 13v]

[34] [Die Wappen der Mitglieder der linken Seite:]

$\mathrm{Au}$ lez senestre

Treshault, tresexcellent et trespuissant prince Edouart $\{63\}$, par la grace de Dieu roy d'Angleterre, seigneur d'Yrlande [ - absent.$^{193}$

Treshault, tresexcellent et trespuissant prince infant don Fernande $\{71\}$, par la grace de Dieu roy de Castille, de Leon et de Secille, prince de Navarre [ - absent].

Hault et puissant prince monseigneur Jehan, duc d'Alençon $\{39\}$, conte du Perche trespassé.

190 Diese Wappentafel ist abgebildet bei Bergen-Pantens, Chapitres, 1980, S. 291, Nr. 7; Martens, Biografie, 1992, S. 23 sowie die Beschreibung auf S. 68f., Nr. 41.

191 Diese Wappentafel ist abgebildet bei Sterchi, Umgang, 2005, S. 771, Abb. 25.

192 Diese Wappentafel ist abgebildet unter https://commons.wikimedia.org/wiki/ File:Pieter_Coustens_-_Coat-of-Arms_of_Philip_of_Savoy_-_WGA05543.jpg (11.11.2015).

193 Sein Wappen ist abgebildet bei Martens, Biografie, 1992, S. 23 sowie die Beschreibung auf S. 70, Nr. 42; MirA, Busca, 2007, S. 39 sowie unter http://commons.wikimedia.org/wiki/File:Shield_of_Edward_IV_as_knight_of_the_Order_of_the_Golden_ Fleece.jpg (11.11.2015). 
[b] obiit - blason.

Messire Bauduin de Lannoy $\{19\}$, dit le Besgue, seigneur de Molembais [ - trespassé].

[b] obiit - blason.

Messire Symon de Lalaing \{26\}, seigneur de Montigny - trespassé.

[b] obiit - blason.

Messire Jehan, ber et seigneur d’Auxy $\{45\}$ - trespassé.

[b] obiit - blason.

Messire Henry de Borssele \{44\}, seigneur de la Vere, conte de Grantpré - trespassé.

[b] obiit - blason.

Messire Regnault, seigneur de Breederode et de Vyane $\{43\}$ - trespassé.

[b] obiit - blason.

Hault et puissant prince monseigneur Jehan, duc de Cleves $\{47\}$, conte de la Marke absent.

Messire Jehan, seigneur de Lannoy $\{50\}$.

Messire Anthoine, bastart de Bourgoingne \{54\}, conte de la Roiche en Ardenne - absent, en France prisonnier. ${ }^{194}$

Monseigneur Adolff $\{55\}$, frere de Cleves et de la Marke, seigneur de Ravestein.

Hault et puissant monseigneur Adolf de Gheldres et de Zuthphen \{58\} - trespassé.

[b] obiit - blason.

Messire Guy de Brimeu \{76\}, seigneur de Humbercourt, conte de Meghen - trespassé. ${ }^{195}$

[b] obiit - blason.

Messire Engelbert, conte de Nassouwe $\{77\}$, seigneur de Breda, etc.

\section{April 1478 in Brügge}

\section{[fol. 14r]}

[35] [Es folgt die Beschreibung der Feierlichkeiten anläßlich Maximilians Einführung in den Orden vom Goldenen Vlies: Als Erstes wird noch einmal das Procedere bis zu Maximilians Zusage rekapituliert.]

Cy apres s'ensuivent les ceremonies gardees a creer et faire chevalier monseigneur le duc Maximilian et au relievement par lui fait de l'ordre de la Thoison d'or

Pour entendre le mistere du relievement du noble ordre de la Thoison d'or fait en la ville de Bruges ou pays de Flandres, le darrenier jour du mois d'avril l'an mil quatrecens soixante dixhuit ${ }^{196}$ moult honnorablement et solemnellement par treshault et tresexcellent prince mon tresredoubté seigneur monseigneur le duc Maximilian, duc

194 Sein Wappen ist abgebildet unter https://commons.wikimedia.org/wiki/File:Pieter Coustens_-_Coat-of-Arms_of_Anthony_of_Burgundy_-_WGA05542.jpg (11.11.2015).

195 Diese Wappentafel ist u. a. abgebildet bei Paravicini, Guy de Brimeu, 1975, Abb. 11 (zwischen S. 400 und 411); dazu auch ebd. S. 427, Anm. 133.

196 30. April 1478. 
d'Austrice, de Bourgoingne, de Lothrijc, de Brabant, de Lembourg etc., comme bail et mary de treshaulte et tresexcellente princesse et ma tresredoubtee dame madame Marie, duchesse desdis pays, fille legitime, heritiere seule, universele et pour le tout de feu monseigneur le duc Charles \{34\}, jadis duc de Bourgoingne, de Lothrijc, de Brabant etc. et chief et souverain dudit ordre, darrenier deffunct, que Dieu absoille, lequel trespassa en exploit de guerre devant Nancy en Lorraine, le $\mathrm{v}^{\mathrm{e}}$ jour du mois de janvier l'an xiiij ${ }^{c}$ lxxvj dessusdit, ${ }^{197}$ depuis lequel temps jusques a l'eure dudit relievement ledit ordre de la Thoison d'or avoit esté sans chief pres de xvj mois continuellement. Presupposees les treshumbles remonstrances, exhortacions, prieres, requestes et grans devoirs qui par messeigneurs les chevaliers freres ensemble les chancellier et autres officiers dudit ordre, cy devant nommez, avoient esté faites et souvent reiterees et renouvellees a mondit seigneur le duc a celle fin dez la tiers jour apres la consummacion de son mariaige avec madite dame, sa compaigne, ${ }^{198}$ et les benignes responses de mondit seigneur sur icelles, et quant benignement, noblement et favorablement se y est accordé et a consenti de le faire et de prendre et recepvoir prealablement l'estat et ordre de chevalerie et consequenment apres le collier dudit ordre de la Thoison d'or et d'emprendre et relever icellui ordre comme chief et souverain, succedant au vray lieu dudit feu le duc Charles, son beaupere, selon les status et ordonnances du mesme ordre, ${ }^{199}$ et que pour ces choses executer tant par mondit seigneur le duc comme par messeigneurs dudit ordre, jour et lieu certains aient esté accordez et prins entre eulx et aussi signiffiez deuement par leurs lettres aux roys, princes et autres chevaliers freres et compaignons d'icellui ordre ${ }^{200}$ ou qu'ilz fussent si avant que possibile estoit de les trouver et avoir seur acces a eulx, comme il est devisé, contenu et declairé plus amplement cy dessus, font aussi a presupposer les aultres choses qui cy apres s'ensuivent.

[fol. 14v]

\section{[36] [Beschreibung der Ausschmückung der Brügger Salvatorkirche für die Or- densgottesdienste.]}

C'est assavoir premierement: Que en l'eglise parrochial de Saint Saulveur en ladite ville de Bruges qui est belle, notable ${ }^{201}$ et grande eglise et une des principales eglises dudit Bruges, devant le grant chœur entre les quatre principales ${ }^{202}$ pillers de la croisee de ladite eglise avoit fait et ediffié ung grant hourt spacieux tout de bois et d'asselles eslevé environ trois piez de terre, a tout appoix et barrieres dorserez darriere. Dedans lequel hourt avoit ung autre hourt plus estroit et plus eslevé environ cinq piez de hault alentour duquel par embas avoit une gallerie d'environ trois ou quatre piez de large tout alentour. Et aux deux grans pillers de ladite croisee vers la nef de ladite ${ }^{203}$ eglise avoit autres hours au dextre et au senestre, ung peu plus bas que cellui qui estoit eslevé dedans ledit grant hourt et avoit degrez devers west pour de la nef de ladite

197 5. Jan. 1477 (n.St.). - Vgl. dazu auch § 2 mit Anm. 9.

198 Vgl. § 10 und 13.

199 Vgl. § 14-18.

200 Vgl. Reg. 1-20.

201 Ms.: notable ist unterstrichen. - Vgl. dazu auch in der Einleitung S. 14.

202 Ms.: principales wurde von Steenberch am rechten Rand außerhalb des Schriftspiegels eingefügt.

203 Ms.: de ladite steht über der Zeile und eine Marke zeigt auf die dafür vorgesehene Stelle im Text. 
eglise monter esdis hours, et autres devers orient pour en partir et descendre devers ledit grant chœur a l'entree d'icellui. Et sur ledit plushault hourt avoit eslevé devers orient environ le milieu formé d'un petit autel, tout couvert de drap de veloir noir. Et au senestre costé dudit autel avoit une chayere honneste par forme de siege, toute couverte et paree de velou noir. Et au dextre et senestre d'icellui hourt avoit deux bancs a tout appoys pardevers assez pres de la haulteur dudit siege, seant audit costé senestre de l'autel et devers west au lez dextre joingnant l'entree dudit hourt avoit ung autre petit banc, aussi a tous appoy au dos ung peu plus bas des autres deux. Et tout ledit plushault hourt par embas ensemble tous lesdis bans ${ }^{204}$ seans sur icellui estoient parez et couvers de drap noirs de laine.

\section{[37] [Zur Ausstattung und Nutzung zweier Kapellen.]}

Faites aussi a presupposer que au lez dextre au dehors dudit grant chœur avoit par maniere de chambres de retraite deux chappelles tendues et parees moult richement de tappisserie, l'une pour y retraire mondit seigneur le duc et soy revestir et habiller selon l'exigence du mistere, et l'autre pour y retraire messeigneurs les chevaliers freres ensemble les officiers de l'ordre pour cas semblable.

[38] [Es gibt auch einen geschmückten Platz für Hz.in Maria und Hz.in Margarete sowie deren Damen. Des Weiteren sind in der Kirche zahlreiche Tapisserien $z$ u sehen.]

Item sur loxal ${ }^{205}$ dudit grant chœur avoit beaulx et riches paremens de tappisserie de soye et de laine et aucuns draps d'or et de velou noir [fol. 15r] pour y recevoir et logiez madite dame la duchesse d'Austrice et aussi madame la duchesse Margritte, vesve de feu mondit seigneur le duc Charles $\{34\},{ }^{206}$ sa belle mere, avec les dames et damoiselles de leurs hostelz quant elles vouldroient veoir ledit mistere. Et si estoit toute ladite eglise, assavoir alentour du chœur et aussi la nef d'icelle aux deux lez, moult richement paree et tendue de moult beaulx et riches draps de tapisserie de diverses histoires. ${ }^{207}$

\section{[39] [Zur Ausstattung des Kapitel-Saales in der hzl. Residenz.]}

D'autre part fait aussi a presupposer que en l'ostel de mondit seigneur le duc audit Bruges avoit ledit darrenier jour du mois d'avril dessusdit ${ }^{208}$ bien matin paree une belle chambre richement tendue regardant sur le gardin, ordonnee pour y tenir le chappittre

204 Lies: bancs.

205 Lies: local.

206 Zu ihrer Person vgl. die Angaben in § 5, Anm. 16 und 20.

207 Lt. Kervyn de Lettenhove, Histoire de Flandre, V, 1850, S. 290, wurden in der Kirche die Gideon-Tapisserien gezeigt. Die 1449 von Hz. Philipp \{01\} angeschafften Tapisserien standen in enger Verbindung mit dem von ihm gegründeten Orden vom Vlies und wurden immer wieder bei den Ordensfesten (so z.B. 1473) aber auch anderen wichtigen Festen der Burgunderherzöge und später von den Habsburgern gezeigt; zu ihnen vgl. die Angaben u. a. bei PB 3, S. 50 mit Anm. 121 f. (mit zahlreichen Literaturangaben). Einen Überblick über den Tapisserienbesitz der Burgunderherzöge bieten u. a. Cheyns-CondÉ, Tapisserie, 1985; EICHBERger, Tapestry production, 1992; Buren-Hagopian, Images monumentales, 1996; Franke, Tapisserie, 1997; Schnerb, État bourguignon, 1999, S. 359-363; RAPp BURI, STUCKY-SchürRER, Tapisserien, 2001; Ehm, Burgund, 2003, S. 155-158; Schmitz-von Ledebur, Textilien, 2009. 30. April 1478. 
de l'ordre de ladite Thoison d'or a la feste lors avenir. En laquelle chambre avoit ou milieu une haulte chayere eslevee toute paree a tout ciel et doussier couverte pour l'eure de drap de veloux noir et deux bancs aux deux costez, et a l'opposite de ladite chayere avoit une table et darriere ladite table ung autre petit banc, tout ordonné par maniere de consistoire en quature toutes parees d'autres tappisseries. ${ }^{209}$

\section{[40] [Morgens um 8 Uhr versammeln sich die anwesenden Mitglieder und vier officiers d'armes in der hzl. Residenz, alle in Trauerkleidung.]}

Ces choses ainsi presupposees pour venir a l'oeuvre et execution dudit mistere et a la declaracion des solemnitez et ceremonies y tenues et observees. Est vray que en ensuivant l'ordonnance et conclusion paravant sur ce prinse par mesdis seigneurs les chevaliers freres de l'ordre du bon gré et plaisir de mondit seigneur le duc, qui de tout plainement estoit informé et adverti par la maniere cy devant declaree, ledit darrenier jour du mois d'avril l'an lxxviij, environ l'eure de huit heures au matin, messeigneurs les chevaliers freres de l'ordre de la Thoison d'or, assavoir messire Jehan, seigneur de Lannoy $\{50\}$, monseigneur Adolph $\{55\}$, frere de Cleves et de la Marke $\{47\}$, seigneur de Ravestain, messire Loys, seigneur de Gruythuse $\{61\}$, conte de Wincestre, messire Phelippe de Croy, conte de Chimay $\{74\}$, et messire Engelbert, conte de Nassouw $\{77\}$, seigneur de Breda. Et semblablement reverend pere en Dieu messire Ferry, evesque de Tournay, chancellier, maistre Jehan Gros, tresorier, et M(artin) Steenberch, graffier dudit ordre, s'en alerent vers l'ostel de mondit seigneur le duc, tous revestus en deul et habillez de robes et chapperons de drap noir. ${ }^{210}$ Et illec arrivez l'ung apres autre s'assemblerent en une sallette, seant devant ladite chambre ordonnee pour ledit chappittre de l'ordre, pourveuz chascun de manteau noir de deul. La ou ilz ont trouvé quatre officiers d'armes, ${ }^{211}$ vestus et affulez de noir habis en deul, a tout leurs cottes d'armes armoiez aux armes dudit feu monseigneur le duc Charles $\{34\}$, assavoir le roy de Flandres, Lothrijc, herault, Saint-George, herault, et $[\ldots] .{ }^{212}$

209 Zur Ausschmückung des Festsaales vgl. auch § 97.

210 Bekannt ist der rote Ordensornat des Ordens vom Goldenen Vlies, das in vielen Abbildungen über den Orden zu sehen ist; vgl. dazu ausführlich unten Anm. 309. Für die Totenmessen und Trauergottesdienste besaß jedes Mitglied des Orden aber auch seinen schwarzen Mantel und eine schwarze Kappe; vgl. dazu § 52 (neu § 27) der Statuten (dazu S. 16, Anm. 14). Eine Darstellung der schwarzen Ordensmontur aus der Mitte des 16. Jahrhunderts befindet sich in AOGV, Codex 42, fol. 25v; abgebildet auf der Frontseite des Tagungsbandes Haus Österreich und der Orden vom Goldenen Vlies, 2007.

211 Kervyn de Lettenhove, Histoire de Flandre, V, 1850, S. 290 erwähnt in diesem Zusammenhang Toison d'or und drei weitere (namentlich nicht genannte) Wappenkönige.

212 Der Name des vierten officiers d'armes fehlt. In Maximilian Hofordung von Sept. 1477 werden vier Herolde genannte: Toison d'or, Fusil, Namur und Saint-George; vgl. Gachard, Ordonnance 1477, 1857, S. 123. Nach Vaughan, Charles the Bold, 1973, S. 193, waren unter Hz. Karl fünf Wappenkönige (Toison d'or, Brabant, Flandern, Artois und Hennegau), der Wappenmarschal von Brabant, sieben Herolde (Burgund, Franche-Comté, Salins, Limbourg, Luxembourg, Charolais und Lothier) sowie vier Persevante (Fusil, Chasteau Belin, Gorinchem, und Le Quesnoy) tätig. - Zu den Wappenröcken der Herolde dieser Zeit vgl. u. a. НАвLOt, Revêtir le prince, 2006. 


\section{[fol. 15v]}

[41] [Die Mitglieder des Hofes versammeln sich ebenfalls in Trauerkleidung. Ein
reichgeschmückter Schimmel wird bereitgestellt.]

A celle mesme heure et par ordonnance se sont assamblez aussi oudit hostel de mondit seigneur es autres salles et chambres et en la place, tant messeigneurs du sang comme les barons et autres nobles chevaliers, chambellans, maistres d'ostel, gentilz hommes et principaulx officiers. ${ }^{213}$ Et pareillement messeigneurs les presidens, conseilliers, secretaires et autres du conseil mesmement qui avoient esté de l'ostel et retenue dudit feu monseigneur le duc Charles \{34\}, ensemble ceulx des hostelz de mesdites dames trouvez au lieu de Bruges pour l'eure, tous vestus d'habis noirs en signe de deul sans manteaulx. A aussi esté illec amené ung cheval courssier de poil blanc a tout selle, bride et harnois doublez de drap de velou noir a frain et boistes d'or, tout couvert d'une houssure de semblable drap de velou noir large et plantureuse fachonnee selon ladite selle pendant jusques a terre. ${ }^{214}$

[42] [Die Ordensmitglieder begeben sich in den Kapitelsaal, in dem auf dem Thron das Kollier des Souveräns liegt, das von Toison d'or bewacht wird.]

Item tantost mesdis seigneurs de l'ordre ainsi assemblez se sont tous vestus de leurs manteaulx de deul fendus au costé dextre et sur iceulx ont mis leurs grans coliers de l'ordre, portans leurs chapperons de deul sur les espaulles et bonnets noirs en teste. Et ainsi revestus sont entrez ordonneement en ladite chambre, servant pour le chappittre de l'ordre. La ou ilz ont trouvé mis et couchié en ladite chayere du souverain ung collier d'or de l'ordre dessusdit, ${ }^{215}$ espandu sur ung beau coussin quarré, couvert de velou noir et la thoison dudit collier mise vers le milieu dudit coussin declinant a tout ledit coussin vers bas. Lequel collier gardoit Thoison d'or, le roy d'armes, vestu de robe noire longue jusques a terre, portant son chapperon de deul sur l'espaulle et a tour de son col le grant collier dudit ordre, armoyé des armes de messeigneurs les chevaliers freres d'icellui, servant pour son office. ${ }^{216}$

213 Namentliche Nennungen der nicht dem Orden vom Goldenen Vlies angehörigen Teilnehmer an den Feierlichkeiten finden sich in § 47, 68, 75 und 95.

214 Mit diesem Schimmel wurde dann die Ordenskette Hz. Karls in die Kirche gebracht; vgl. § 45; dies erwähnt auch Kervyn de Lettenhove, Histoire de Flandre, V, 1850, S. 290. SchwedLer, Herrschertreffen, 2008, S. 365-367, zeigt, dass weiße Pferde im Spätmittelalter vornehmlich vom Papst und von Königen geritten wurden und in der Forschung deshalb davon ausgegangen wird, dass damit ein symbolischer Herrschafts- und Souveränitätsanspruch zum Ausdruck gebracht wurde. Dazu auch Kintzinger, Reiter, 2003, S. 322-349; PARAvicini, Theatre, 2012, S. 44 f. und $52 \mathrm{f}$.

215 Eine Ordenskette aus dem 15. Jahrhundert befindet sich heute in der Schatzkammer des Kunsthistorischen Museums in Wien und war auch während der großen Karl der Kühne-Ausstellungen in Bern, Brügge und Wien zu sehen; vgl. dazu u. a. Kat. Karl der Kühne, 2008, S. 189, Nr. 16 mit Tafel 3 (hervorragende Abb.); Fillitz, Schatz, 2009, S. 40 f. mit Abb. 3. Dazu auch Müller, Orden, 2009, S. 5 mit Abb. Siehe auch die Datenbank des Museums unter http://bilddatenbank.khm.at/viewArtefact?id=100661 (11.11.2015).

216 Toison d'or trug in seinem Amt eine große Kette, die sogenannte Potence, an der jeweils die Wappen der aktuellen Mitglieder des Ordens hingen. Unter Karl V. \{108\} wurde 1516 eine Kette hergestellt, die heute noch erhalten und in der Schatzkammer 
[43] [Vor dem ausgelegten Kollier sollen die Mitglieder (stellvertretend) Abschied von dem verstorbenen Ordenssouverän nehmen. Danach wird das Kollier des Souveräns in die Kirche gebracht, wo es von Toison d'or bewacht wird. Die Mitglieder werden den neuen Herzog an der Pforte der Kirche empfangen und ihn hineingeleiten.]

Et a ladite entree, reverence faicte et honneur donné par messeigneurs de l'ordre au feu tresnoble prince, mondit seigneur le duc Charles \{34\}, jadis chief et souverain dudit ordre, darrenier deffunct, lequel representoit illec ledit collier ainsi mis en ladite chayere, et priere faite a Dieu pour l'ame du trespassé, se sont mesdis seigneurs les chevaliers freres mis a deviser ung peu ensemble des ceremonies a tenir [fol. 16r] a la venue de mondit seigneur le duc en l'eglise pour sçavoir se les aucuns d'eulx se tendroient par forme de garder deul oudit hourt d'alez ledit collier aux deux costez de l'autel, sur lequel illec il seroit mis, et les autres yroient au devant de mondit seigneur jusques a l'entree de ladite eglise, ensemble les officiers de l'ordre et les officiers d'armes pour honnorablement le recevoir et mener sur ledit hourt, ou se tous ensemble ilz yroient au devant de mondit seigneur, saulf le roy d'armes Thoison d'or seul qui demourroit sur ledit hourt pour ladite garde le temps pendant ou comment autrement ilz en feroient. Et la matiere debattue entre eulx et deliberee par opinions, ont conclut finablement par commun accord que Thoison d'or, le roy d'armes, seul demourroit sur le hourt pour la garde dudit collier d'or et que eulx tous les chevaliers freres ensemble les officiers de l'ordre avec les officiers d'armes yroient au devant de mondit seigneur le duc jusques aux portes de l'eglise. Et que illec a son entree, la reverence deue a lui faite, les deux plus anchiens chevaliers, assavoir monseigneur de Lannoy $\{50\}$ et monseigneur de Ravestain $\{55\}$, se mettroient au dextre et senestre de lui pour le amener et convoier sur ledit hourt jusques a son siege illec pour lui ordonné. Et les autres chevaliers, deux a deux selon leur ordre et maniere d'aler les suiveroient et consequenment les officiers dudit ordre par darriere.

[44] [Diskussion, ob das Mitglied mit dem höchsten Rang oder das älteste Mitglied Hz. Maximilian in den Orden aufnehmen soll.]

Et en parlant de ces matieres y est survenu l'incident d'une autre question ou demande, assavoir lequel d'entre eulx lesdis chevaliers freres bailleroit la colee a mondit seigneur le duc pour le creer et faire chevalier et lequel lui mettroit au col le collier dudit ordre de la Thoison d'or, quant il seroit heure de le faire. Et apres argumens fais d'une part et d'autre, aucuns disans que pour la dignité de la personne de mondit seigneur le duc le plus noble d'entre eulx, assavoir monseigneur de Ravestein $\{55\}^{217}$,

des Kunsthistorischen Museums in Wien zu sehen ist; vgl. dazu u. a. PB 2, S. 197 mit Anm. 26; НАвцот, Revêtir le prince, 2006, S. 767-771 (mit Abb.); Kat. Karl der Kühne, 2008, S. 190, Nr. 17 mit Abb. 73 auf S. 186; Fillitz, Schatz, 2009, S. 49 mit Abb. 1 und 8. Vgl. dazu auch die Datenbank des Museums unter http://bilddatenbank.khm. at/viewArtefact?id=100355 (11.11.2015).

217 Die Mutter von Adolf von Kleve, Herr von Ravenstein, war Maria von Burgund (1393-1463), Hz.in von Kleve und Schwester Hz. Philipps des Guten \{01\}. Somit war Adolf mütterlicherseits eng mit dem burgund. Herzogshaus verwandt und ein Onkel Hz.in Marias; vgl. dazu u. a. Cools, Mannen, 2000, S. 336 f., Nr. 131. 
le pourroit faire. Aultres disoient que selon les status de l'ordre ${ }^{218}$ le plus anchien frere en l'ordre le devroit faire, auquel honneur appartenoit devant les autres es actes dudit ordre. ${ }^{219}$ Et finablement, la chose bien debattue et les opinions demandees et oyees, la conclusion a esté de partir ces honneurs en ceste maniere: assavoir que monseigneur de Ravestein comme le plus noble bailleroit la colee a mondit seigneur et le feroit chevalier et que monseigneur de Lannoy $\{50\}$ comme le plus anchien oudit ordre recevroit mondit seigneur en l'ordre et lui mettroit au tour du col le collier d'or dudit ordre, en gardant par chascun d'eulx en son endroit les ceremonies et solemnitez au cas requises. Neantmoins en tant qu'il touchoit [fol. 16v] le mistere du bail de ladite collee, ilz s'en rapportoient a mondit seigneur le duc de nommer et choisir a ce cellui d'entre eulx que mieulx lui plairoit. ${ }^{220}$

[s] Qui fera monseigneur le duc chevalier et qui luy mettera a l'ordre au col. ${ }^{221}$

\section{[45] [Der erste Gang zur Kirche geschieht im Zeichen des Abschiednehmens von Hz. Karl.]}

Item pendant ces devises de mesdis seigneurs de l'ordre se sont en la court dudit hostel de mondit seigneur le duc par les maistres d'ostel dudit feu [duc Charles \{34\}] mis en ordonnance les chevaliers, chambellans et autres gentilz hommes et officiers d'icellui feu pour deux a deux prendre chemin et eulx en aler tous a piet vers l'eglise Saint Saulveur audit Bruges, la ou lesdis misteres faire se devoient. ${ }^{222}$ Et eulx ainsi mis en ordonnance ledit roy d'armes Thoison d'or, par l'ordonnance de mesdis seigneurs, a levé reverenment de ladite chayere et prins ledit collier d'or ainsi espandu sur ledit coussin et l'a porté a deux mains devant sa poitrine ladicte thoison gisant ou mileu dudit coussin et aucunement abaissant vers terre. Et tantost lesdis quatre officiers d'armes, vestus de leurdis cottes d'armes, alans devant et apres eulx les < graffier et>

$218 \S 21$ (neu § 18) der Statuten (dazu S. 16, Anm. 14) regelt, dass unter den Mitgliedern nicht deren Herkommen, Besitz oder Titel die Rangfolge bestimmen soll, sondern alleine die Länge ihrer Mitgliedschaft. Bei gleichzeitig aufgenommenen Mitgliedern wurde der Rang noch durch das Alter ihres Ritterschlages bestimmt.

219 Vermutlich wurde in den Protokollbüchern nachgeschaut, welches der anwesenden Mitglieder tatsächlich am längsten dem Orden angehörte; Jean de Lannoy wurde 1451 während des Ordensfestes in Mons gewählt; vgl. PB 1, S. 107, § 10. Nur der abwesende Jean de Melun $\{28\}$ gehörte dem Orden länger als Jean de Lannoy an, denn er wurde schon 1432 während des Ordensfestes in Brügge gewählt, vgl. PB 1, S. $38, \S 9$.

220 Fortsetzung in $\S 53$.

221 Ms.: Die Randbemerkung steht am Anfang des Absatzes.

222 Diesen prozessionsartigen Gang zur Kirche beschreiben auch Verschelde, Feeste, 1873, S. 26 (nach Stadtbibl. Brügge, Historisch Fonds ms. 437 [Excellente Chronycke van Vlaanderen]); Kervyn de Lettenhove, Histoire de Flandre, V, 1850, S. 290; DünNeBeIL, Zeichen, 2012, S. 114f.; Dies., Order of the Golden Fleece, 2013, S. $60 \mathrm{f}$. Vergleichbare Aufstellungen der beteiligten Personen sind auch schon von den Ordensfesten aus den Jahren 1468 und 1473 überliefert, vgl. PB 2, S. 77-80, § 45 f. und $\mathrm{PB} 3$, S. 37-39, § 12; mit der damit verbundenen öffentlichkeitswirksame Repräsentation des Ordens beschäftigt sich DünNEBEIL, Selbstdarstellung, 2003; DiEs., Innen und Außen, 2005, S. $252 \mathrm{f}$. 
tresorier et greffier ensemble $\mathrm{e}^{223}<$ apariez $>$ et mondit seigneur de Tournay, chancellier de l'ordre, seul. Et apres lui messire Engelbert $\{77\}$, conte de Nassouw, et messire Phelippe $\{74\}$, conte de Chimay, <apariez>. Item messire Loys $\{61\}$, conte de Wincestre, et monseigneur Adolph de Cleves $\{55\}$, deux a deux, et monseigneur de Lannoy $\{50\}$, le darrenier, seul tenant toutevoie son droit reng du lez senestre. ${ }^{24}$ Se sont mis a chemin partans ainsi ordonneement de ladite chambre, et pour le darrenier en ${ }^{225}$ est parti ledit roy d'armes Thoison d'or portant icellui collier d'or a tout ledit coussin, et ainsi sont descendus par la grant salle, et au montoir estoit prest et attenant ledit ${ }^{226}$ courssier houssé par la maniere dite, et messeigneurs les chevaliers freres ensemble lesdis trois officiers, assavoir les chancellier, tresorier et graffier d'icellui ordre, sont montez a cheval et ledit Thoison d'or, roy d'armes, a mis ledit collier de l'ordre a tout icellui coussin en ladite selle sur ledit courssier et tellement asseuré qu'il ne povoit cheoir. Et messeigneurs lesdis chevaliers freres ensemble lesdis trois officiers de l'ordre montez a cheval et mis en leur ordonnance les maistres d'ostel a tout les officiers, escuiers [fol. 17r] et gentilz hommes se sont mis a chemin, les moindres d'estat alans devant ordonneement et consequenment les autres et au darriere deux desdis maistres d'ostel. Apres lesquelz suivrent les communs officiers d'armes, vestus de leurs cottes d'armes, reservé les quatre dessusdit tous alans a piet deux a deux, et ainsi sont alez devers ladite eglise Saint Saulveur. Apres lesdis officiers d'armes suivrent a cheval lesdis trois officiers de l'ordre, assavoir $\operatorname{les}^{227}$ graffier et tresorier apariez et monseigneur de Tournay seul et consequenment messeigneurs les chevaliers freres gardans leur ordre et maniere d'aler celle que dessus. Apres lesquelz a suivy incontinent sans autre moyen ledit roy d'armes Thoison d'or, alant a piet et menant par la bride ledit courssier portant le collier d'or dessusdit ${ }^{228}$, honnoré et accompaignié desdis quatre officiers d'armes ${ }^{229}$, a tout leurs cottes d'armes alans aussi a piet, deux de chascun costé sans touchier toutevoie ledit courssier. ${ }^{230}$ Et apres icellui courssier suivoient a cheval messeigneurs du sang, messeigneurs les presidens du conseil, messeigneurs les chambellans et autres notables tant du conseil dudit feu comme autres notables, clercs, chevaliers, escuiers, gentilz hommes et autres de divers estas honnorans et accompaignans ledit collier pour la reverence du trespassé et de la compaignie.

\section{[46] [Toison d'or bringt das Kollier des toten Souveräns in die Kirche.]}

Item et par ceste ordonnance mavcerent mesdis seigneurs de l'ordre et s'en alerent devers ladite eglise Saint Saulveur en passant par le merchié et eulx arrivez et descendus devant le grant portal d'icelle, tantost a illec reprins ledit roy d'armes Thoison d'or

223 Ms.: et greffier ensemble wurde von Hand s am linken Rand eingetragen und eine Marke zeigt die dafür vorgesehene Stelle im Text an.

224 Ms.: le darrenier, seul, tenant toutevoie du lez senestre ist unterstrichen und zusätzlich mit einer geschlängelten, senkrechten Linie am linken Rand hervorgehoben.

225 Ms.: en steht über der Zeile und eine Marke zeigt die dafür vorgesehene Stelle im Text an.

226 Ms.: ledit steht über der Zeile und eine Marke zeigt die dafür vorgesehene Stelle im Text an.

227 Ms.: le wurde nachträglich zu les korrigiert.

228 Ms.: Thoison d'or, alant a piet ... portant le collier d'or dessusdit ist unterstrichen.

229 Zur Identifizierung der vier Herolde vgl. § 40.

230 Zu den Aufgaben und Funktionen von Herolden bei Leichenbegängnissen vgl. MELvilLE, Heroldwesen, 2002, S. 303. 
et levé reverenment ledit collier a tout ledit coussin honnestement, le portant a deux mains devant sadite poitrine. Et eulx mis en leur ordonnance sont entrez en ladite eglise, ledit roy d'armes alant le darrenier. Apres eulx a costé desdis quatre officiers d'armes qui accompaignié l'avoient au venir alans les deux au dextre et deux au senestre costez, comme devant. Et ainsi sont tant les officiers comme messeigneurs les chevaliers freres dudit ordre montez sur ledit hourt au plus hault et eulx illec arrivez et leur oroison faite a Dieu devant le crucifix et consequenment la reverence a madame la duchesse d'Austrice et a madame la Grant, ${ }^{231}$ estans sur loxal de l'entree dudit grant chœur moult noblement accompaignees, se sont alez mettre mesdis seigneurs les chevaliers aux deux lez dudit hourt devant leurs bancs illec pour eulx ordonnez, assavoir monseigneur de Lannoy $\{50\}$, monseigneur de Ravestain $\{55\}$ et monseigneur de Nassouw $\{77\}$ au lez dextre et monseigneur de Gruythuse $\{61\}$ et monseigneur de Chimay $\{74\}$ au lez senestre. Et lesdis trois officiers ou tiers petit banc pour eulx ordonné vers west. Et Thoison d'or, le roy d'armes, les a suivis portant ledit collier d'or par la maniere dite, auquel en passant tant mesdis seigneurs les chevaliers freres comme lesdis officiers ont fait reverence deue eulx enclinant [fol. 17v] devers icellui. Et ledit roy d'armes est alé mettre ledit collier a tout ledit coussin sur ledit autel, illec paré comme dessus a esté dit. ${ }^{232}$ Et la reverence par lui faicte audit collier s'est alé tenir droit au cornet senestre dudit autel par maniere de garde. Et lesdis quatre officiers d'armes qui l'avoient accompaignié sont demourez en la gallerie ou bas et mis aux quatre cornets d'icellui hourt eulx tenans tout droit. Et nulz aultres que ceulx de l'ordre sont pour celle foiz montez sur le hault d'icellui hourt. Et ce fait tant messeigneurs les chevaliers freres comme lesdis officiers se sont assis sur lesdis bancs abaissans leurs testes par maniere de deul, ${ }^{233}$ messeigneurs du sang et autres nobles et ceulx du conseil sont alez au devant de mondit seigneur le duc qui estoit demouré en sa court pour le amener et accompaigner en venant vers ladite eglise.

\section{[47] [Hz. Maximilian betritt mit großem Gefolge die Kirche.]}

Item et tantost apres est venu mondit seigneur le duc descendre devant ladite eglise, vestu d'une robe de drap brochetee d'argent moult riche, grandement et noblement, accompaignié assavoir de monseigneur l'evesque Sibinicensis, legat apostolique ${ }^{234}$, de monseigneur l'evesque de Metz ${ }^{235}$, du jeune marquis de Baden $\{102\}^{236}$, du conte de Saintpol et de Brienne $\{83\}^{237}$ et d'autres pluseurs haulx et puissans seigneurs, contes, barons, chevaliers, escuiers, prelas et autres gens de conseil et de divers estas, condicions et nacions le suivans pour veoir le mistere. Ce sachans mesdis seigneurs de l'ordre, ilz ensemble les officiers dudit ordre, reservé Thoison d'or qui demoura pour la garde dudit collier, incontinent ordonneement descendirent dudit hourt et alerent

231 Zu Herzogswitwe Margarete vgl. Angaben in § 5, Anm. 16 und 20.

232 Vgl. $§ 42$.

233 Ms.: les chevaliers freres comme lesdis officiers ... par maniere de deul ist unterstrichen.

$234 \mathrm{Zu}$ Lucas de Tolentis vgl. die Angaben in § 8 mit Anm. 32. - Zu den bei den Ordensfeierlichkeiten anwesenden Gästen vgl. auch § 41, Anm. 213.

$235 \mathrm{Zu}$ Georg von Baden, Bf. von Metz, vgl. die Angaben in $\S 5$ mit Anm. 17.

$236 \mathrm{Zu}$ ihm vgl. die Angaben in $§ 10$ mit Anm. 58.

237 Pierre de Luxembourg wurde während der folgenden Tage als neues Mitglied in den Orden vom Goldenen Vlies aufgenomen; vgl. § 134. - Zu seiner Person vgl. u. a. Chevaliers de la Toison d'or, ${ }^{2} 2000$, Nr. 83; Cools, Mannen, 2000, S. 361 f., Nr. 165. 
au devant de mondit seigneur jusques a l'entree d'icelle eglise. Et illec, honneur et reverence deues par eulx faites et exhibees a mondit seigneur, pour sadite entree se sont mis en tel ordre que les deux plus anchiens chevaliers freres de l'ordre se sont mis aux deux costez de mondit seigneur et les communs officiers d'armes et sergens a masse alans devant lui tout ainsi amené jusques au piet dudit hourt. Sur lequel mondit seigneur le duc est monté et les chevaliers freres dessusdis tenans leur ordre, tel que dit est, et au darrenier les officiers d'icellui ordre les suivans et l'ont ainsi convoyé jusques en son siege illec pour lui ordonné a la main senestre. Et mondit seigneur s'est mis en sondit siege et messeigneurs se sont remis et rassis sur leurs bancs et lesdis trois officiers ou leur. Et avec mondit seigneur le duc n'est autre de ses gens monté sur ledit [fol. 18r] hourt, fors messire Adolph, conte de Nassouw, ${ }^{238}$ son marischal d'Austrice, portant et tenant devant lui l'espee d'honneur, et maistre Jehan de le Bouvrie, seigneur de Wierres, president de $<\mathrm{u}>$ son conseil, ${ }^{239}$ qui pour lui devoit parler comme cy apres sera declairé. Et monseigneur l'evesque Sibinicensis, monseigneur l'evesque de Mets, le marquis de Bade et mondit seigneur de Saintpol, messire Bertremy de Lichtestein $\{85\}$, ${ }^{240}$ grant maistre d'ostel d'Austrice, et autres pluseurs grans seigneurs et prelas se mirent sur le hourt, fait au grant piller de la croisee du costé du nort. Et les contes, barons, chevaliers et escuiers, gens de conseil et autres officiers de mondit seigneur estans de la nacion d'Alemaigne se mirent sur l'autre hourt, fait a l'autre grant piller de ladite croisee devers le zuyt. En grant nombre soubz loxal devant le chœur estoient messire Jehan Carondelet, seigneur de Champvanx, ${ }^{241}$ president de Bourgoingne, maistre Anthoine Hanneron, prevost de l'eglise

238 Adolf, Gf. von Nassau-Wiesbaden (1443-1511) kam Anfang der 1470er Jahre an den Hof von Kaiser Friedrich III. \{94\}, machte dort Karriere und trat Ende 1473 in die Dienste Hz. Maximilians. Er begleitete ihn auf seiner Brautfahrt in die Niederlande, wurde 1479 zum Marschall von Geldern und Zutphen und im Jahr darauf als dortiger Generalstatthalter ernannt. 1493 wurde er als Maximilians Hofmeister bezeichnet. Er gehörte sicherlich zu den engsten Vertrauten Hz. Maximilians; zu seiner Person vgl. u. a. Webern, Grafen von Nassau, 1978, S. 29-132; Wiesflecker, Maximilian, 5, 1986, S. 46-49; Heinig, Friedrich III., 1997, S. 1184-1187; Cools, Mannen, 2000, S. 371 f., Nr. 186; HeInig, Akteure, 2006, S. 142 f.; dazu auch unten § 221, Anm. 84.

239 Jan van der Bouverien, Herr von Wiere († 1493) hatte unter Hz. Karl $\{34\}$ eine hohe und einflussreiche Position am Parlament von Mecheln inne. Im Mai 1477 erhielt er den Vorsitz im neugegründeten Großen Rat; zählte im Nov. 1477 zu den Räten und Kammerherren Hz. Maximilians und wurde 1481 zum Kanzler von Brabant ernannt. Während der Feierlichkeiten zur Übergabe der Ordenssouveränität, hielt er im Namen Maximilians eine an den Orden (und die Öffentlichkeit) gerichtete Rede (§ 51f.) und wurde im Anschluss des Zeremoniells von Maximilian zum Ritter geschlagen (§ 67). Vgl. zu seiner Person u. a. Cools, Mannen, 2000, S. 256f., Nr. 32. - Zu seiner Rede vgl. § 51 f.

$240 \mathrm{Zu}$ seiner Person vgl. § 10, Anm. 61.

241 Jean de Carondelet (1428/29-1501/02), Herr von Champvans, wurde unter Hz. Karl von Burgund \{34\} zum Vorsitzenden des Großen Rates und des Parlaments von Mecheln eingesetzt. Mit der Abschaffung des letzeren wurde er zum Präsident von beiden Parlamenten Burgunds ernannt und 1480 zum Kanzler. Sowohl unter Hz.in Maria, Hz. Maximilian und deren Sohn Philipp \{86\} ist er als Rats- und Kammerherr genannt; zu seiner Person vgl. u. a. Kerckhoffs-De Hey, Grote Raad 2, 1980, S. 41 f.; Cools, Mannen, 2000, S. 268-270, Nr. 43; Regesten Friedrichs III., Suppl. 1, 2008, S. 60, Reg. 34, Anm. 4. 
Saint Donas de Bruges, ${ }^{242}$ et les maistres d'ostel ${ }^{243}$ et pluseurs autres tant conseilliers comme secretaires et autres officiers des hostelz de mondit seigneur et de mesdites dames estans de la langue franchoise. A l'entree dudit principal hourt es deux costez vers west ou bas se tindrent les communs officiers d'armes, comme heraulx et poursuivans d'armes de divers seignories et pays, tous habillez de leurs cottes d'armes. Les trompettes et menestriers estoient devers les orgues de ladite eglise seans hault dessus la grant porte de l'entree d'icelle vers west. Et par bas aux deux costez dudit hourt vers nort et vers zuyt au dehors d'icellui avoit bancs et planciers ${ }^{244}$ eslevez de terre la ou se tindrent ceulx de la loy et autres notables de la bourgosie de la ville de Bruges et aussi les notables des nacions estrangieres estans demourans audit Bruges. Et par embas a terre es deux costez de ladite croisee de ladite eglise et en la nef par tout icelle avoit peuple innumerable d'hommes et femmes de toutes nacions, qualitez et condicions et si grant presse et foule qu'il ne se pourroit assez escripre, pour regarder et veoir les misteres qui faire illec se devoient.

\section{[48] [In einer langen Rede rekapituliert der Ordenskanzler die bisherige Ge- schichte des Ordens und bittet Hz. Maxilian im Namen aller Mitglieder, er möge als Ehemann Marias die Leitung des Ordens übernehmen.]}

Item tantost apres silence commandé pour cause du grant bruyt et des clameurs de la multitude du peuple qui la estoit, messeigneurs les chevaliers freres ensemble les officiers de l'ordre se sont levez et vers le milieu dudit hourt mis a genoulx reverenment et humblement devant mondit seigneur le duc. Et par la bouche dudit reverend pere messire Ferry, evesque de Tournay, chancellier dudit ordre, lui ont de rechief mesdis seigneurs fait exposer et remonstrer l'estat et dignité du noble ordre de la Thoison d'or, les causes et maniere de l'institucion d'icellui ensemble la qualité et condicion de ceulx qui depuis ladite institucion avoient esté oudit ordre et de ceulx qui encoires de present y estoient, et comment ledit ordre estoit sans chief et avoit esté depuis le trespas de feu [fol. 18v] mondit seigneur le duc Charles $\{34\}$, son beaupere, par l'espace de seze mois ou environ, et que a lui seul comme bail et mary de ma tresredoubtee dame madame la duchesse, sa compaigne, fille legitime et vraye heritiere seule et universele dudit feu mondit seigneur le duc Charles et a nul autre prince du monde competoit de relever et remettre sus ledit ordre pour en estre le chief et souverain ou lieu dudit deffunct, et qu'il estoit tenu de le faire mesmement selon les status et ordonnances d'icellui ordre. Et apres treshumble recommendacion faite de madite dame la duchesse

242 Als Vertrauter Hz. Karls \{34\} diente Antoine Haneron (ca. 1400-1490) diesem als Finanzfachmann und Diplomat. So war er auch an den Vorbereitungen des großen Treffens zwischen Kaiser Friedrich III., Hz. Maximilian und Hz. Karl 1473 in Trier sowie an den Verhandlungen um die burgundisch-habsburgische Heirat beteiligt. Während der Unruhen in Gent im Frühjahr 1477 wurde er von den Aufständischen gefangengenommen und am 14. Aug. 1477 gegen eine Lösegeldzahlung wieder freigelassen; danach scheint er aber seine aktive politische Laufbahn beendet zu haben; zu seiner Person vgl. u. a. Stein, Haneron, 1937; EhM, Burgund, 2002, S. 244-246; PrietZel, Imitation, 2004, S. 101.

$243 \mathrm{Zu}$ dieser Zeit waren Olivier de la Marche und Nicolas d'Aveluys die beiden Hofmeister unter Hz. Maximilian; vgl. GACHARD, Ordonnance 1477, 1857, S. 119. Zu den beiden vgl. die Angaben in § 20, Anm. 105 und § 95 mit Anm. 57.

244 Lies: planchers. 
et de sa noble maison de Bourgoingne ensemble des nobles et beaulx pays, belles et grandes seignouries, principaultez, vassaulx, subgiez et grant peuple qu'il avoit acquis a cause de madite dame au moyen de sondit mariaige, et mesmement ${ }^{245}$ aussi dudit ordre et de messeigneurs les chevaliers freres ensemble des officiers d'icellui, a exhorté en suppliant mondit seigneur esdis noms que son plaisir fust de relever et recevoir icellui ordre comme ja long temps paravant et dez tantost apres la consummacion de sondit mariaige avec madite dame supplié et requis lui avoient, car autrement ledit ordre lequel ja estoit fort diminué en nombre de personnes et autrement, tendroit a declin et pourroit tumber en brief temps s'il n'estoit relevé et remis sus pour pluseurs raisons sur ce alleguees. Et sur ce fist mondit seigneur de Tournay une moult belle proposicion concluant a la fin que dessus. De laquelle proposicion la teneur cy apres s'ensuit de mot a autre. Et est telle: ${ }^{246}$

[49] [Wörtliche Wiedergabe der Redes des Ordenskanzlers, in die er zahllose Anspielungen auf die Bibel sowie Werke verschiedener antiker Autoren und Kirchenväter einfliessen lässt. Er spricht ausführlich über die Ordensgründung durch Hz. Philipp und die glorreiche Entwicklung des Ordens unter dessen und Hz. Karls Führung. Danach preist er Hz. Maximilian, der als Gatte Hz.in Marias nach Burgund gekommen ist, als großen Fürsten, der künftig die Geschicke des Ordens leiten soll.]

C'est la proposicion ou oroison faite par monseigneur l'evesque de Tournay, pour et ou nom des messeigneurs les chevaliers freres du noble ordre de la Thoison d'or a monseigneur le duc Maximilian: ${ }^{247}$

$[a]^{248} \mathrm{Si}$ apud Homerum, illustrissime, excellentissime ac potentissime princeps, ille, cui Pallas familiare numen vires aspirabat the(ma)tus, expavit cum virtutis lumine fulgentem Nestorem alloqueretur? Si Demostenes, cuius eloquenciam universa decantat Grecia, ad Philippum regem magni Alexandri patrem verba facturus erubuit? Si apud

245 Ms.: Links vor der Zeile, die mit Et mesmement beginnt, befindet sich ein Doppelstrich.

246 Eine Zusammenfassung der Rede bieten Chroniques de Molinet, I, 1935, S. $250 \mathrm{f}$. Diese Rede erwähnen auch Mémoires de la MARche, 3, 1885, S. 250; BARANTE/GAChard, Histoire, II, 1838, S. 601; Delepierre, Fête en 1478, 1842, S. 337; Kervyn DE Lettenhove, Histoire de Flandre, V, 1850, S. 290. Nach Verschelde, Feeste, 1873, S. 26 (nach Stadtbibl. Brügge, Historisch Fonds ms. 437 [Excellente Chronycke van Vlaanderen]), dauerte diese Rede een heure lanc. Zur Rede als Form der burgund. Propaganda vgl. allgemein Prietzel, Rhetoric, 2006; Prietzel, Reden, 2008; zur Kenntnis klassischer Autoren vgl. u. a. Dumolyn, Justice, 2006. - Der Redner zeigt, dass er umfassende Kenntnisse in Theologie, Philosphie und in der klassischen lateinischen Literatur besitzt. Eine Reihe seiner Anspielungen und Zitate konnten wir verifizieren, eine eingehende Untersuchung würde jedoch den zeitlichen Rahmen sprengen und soll an anderer Stelle erfolgen.

247 Ms.: Diese Zwischenüberschrift wurde später mit dunklerer Tinte von Steenberch eingetragen.

248 Ms.: Zur besseren Lesbarkeit dieses langen Paragraphen wurden Absätze und Unterpunkte eingefügt. 
Iuvenalem ${ }^{249}$ bucce noscenda est mensura sue? Si apud Ciceronem ${ }^{250}$ in oratore perdifficile sit onus suscipere se omnibus silentibus esse unum in prestantissimorum virorum cetu audiendum. Et se totum eorum examini sententieque committere comparando maximum profecto et meis viribus impar onus dicendi coram te omnis virtutis decore splendente, magna procerum ac sapientissimorum stipante caterva a preclarissimis dominis aurei velleris fratribus et militibus impositum existit. Quod quidem michi in primis cogitanti non parvi tremor, pavor et rubor accedent nisi perspecta prope divina esse tua humanitas, caritas et benivolentia, quibus secundum Gregorum in Moralibus, si aliquando minus bene dicta [fol. 19r] accidunt, mitissime agis ad hocque pondus ipsorum dominorum fratrum praeceptum ac mei in eo ordine officii debitum, me astringerent, quibus id quamuis gravissimum suscipere ausim. Et maxime cum ea, que dicturus sum, de auctore ipsius Velleris Aurei ordinis dignissimo eiusve institutionis causis disciplina sive post de auctoris huiuscemodi sibi non inferiori successore dehinc de te optimo tuis moribus excellentisimis honoreque maximo eidem ordini a te impenso per se sint ornatissima et audiencium auribus, non hesitem, fore gratissima, ut igitur incipiam, supremi omnium domini ope confisus, qui Moysi Exodi x ac regine Hester xiij $56^{251}$ in ore verba sonancia posuit et qui hominum linguas facit esse disertas pro themate Gedeoni ab angelo dictum et Iudicum $\mathrm{vj}^{\circ}$ capitolo scriptum in medium ponam: »Dominus tecum virorum fortissime $\ll .{ }^{252}$

[b] Pro quibus verbis deducendis et huic rei applicandis, quibus enim de rebus loquimur, ut Boecius ${ }^{253}$ inquit cognatos oportet esse sermones divina in primis opera michi mente et cogitacione versanti hominis ipsius venit in mentem, cuius figura et composicio miro quodam modo excogitata adeo imprehensibilem creatoris sapienciam potestatem amoremque testatur, ut omnes humani ingenii vires superet. Contraria enim, que invicem pugnare seque mutuo solent interimere, rerum proprietatis libro primo perpulchre demonstrante, in homine speciosam effigiem et continuam, ut dixerim, conficiunt harmoniam. Quid tam contrarium, quam sempiternum corruptibile, inmortalitati mortalitas, terreno celeste, bruto racionale, hisce rebus hominem constare nemo est, qui nesciat tantum ille rerum opifex potuit, qui cum hominem id est sanctum et celeste in terris animal statuerit erectum fecit pronaque cum spectant teste Ovidio ${ }^{254}$ animalia cetera terram, os homini sublime dedit celumque videre iussit et erectos ad sydera tollere vultus, ut eloquencie parente in Tusculanis, Paradoxis et pulcherrime in Legibus edocente calcatis caducis omnibus virtutem ad quam natus est, suspiceret, originem monstraret, deum ipsum contemplaret et, cum reliqua sint hominis animalia, homo dei animal cognosceretur in quo quanto corruptibile ${ }^{255}$ mortali bruto terreno

249 Iuvenal, Saturae XI, 34.35.

250 Cicero, De oratore XXVI 116.

251 2. Buch Moses und Esther.

252 Ms.: Dominus tecum virorum fortissime ist unterstrichen. Es handelt sich dabei um das Bibelzitat Richter 6, 12, und wird während der Rede noch mehrfach wiederholt. Am linken Rand bei der Zeile, die mit fortissime. Pro quibus verbis beginnt, fügte Hand s thema ein. - Zur besseren Lesbarkeit dieses langen Paragraphen wurden Absätze eingefügt.

253 Boecius, Consolatio Philosophiae III, Pr. 12.38.

254 Ovid, Metamorphosen I 84-86.

255 Ms.: Am linken Rand neben der Zeile, die mit quo quanto corruptibile beginnt, notierte Hand s cor. 
sempiternum inmortali racionale celesti, maius est tanto, ornatior, preciosioror, carior excellentiorque super corpus ${ }^{256}$ habendus est animus.

[c] Eum ergo ipsum, si quis vite honestate, gestis preclaris bonisque virtutibus ornaverit, ad bene vivendum instituerit, ad id alios commoverit num amandus, num colendus, num doni munieris loco habendus et virorum fortissimus, cum quo dominus secundum thematis verba, vocandus est. Qualia equidem Macrobio teste sunt hominis excercicia, tales eorum esse mentes necesse est. Hic fuit profecto dive memorie dominus Philippus Burgundie Brabancieque dux $\{01\}$, cuius nobilitatem, corporis composicionem, potenciam, vitam, mores, gesta, famam, si contemplaremur, nulla eorum pars non admiranda cognoscetur. Namque fuit ex maiori et regio tam Francie quam Germanie genere ortus, ${ }^{257}$ corpore venustissimus, potencia maximus, vita splendissimus, fide, spe, caritate, prudencia, justicia, fortitudine, temperancia omnique virtute ornatissimus, gesta vero sua tanta et talia fuere quod si eorum partem attingere voluero ante diem [fol. 19v] clauso componet Vesper Olimpo ${ }^{258}$. Omittam igitur quomodo hic serenissimus dux Phelippus uno tempore, quod et si mirabile utique tamem verum est, Francie, Germanie et Anglie impetum repulerit. Tacebo quod eternam ad laudem $^{259}$ et merito Virgilius attribuit. Modo gravi, animo forti, ingenio dulci scivit regere imperium, bella ducere et paci imponere finem parcere subiectis et debellare $\operatorname{superbos}^{260}$ atque efferre bonos titulis opibusque fovere. Verum dicam ${ }^{261}$ et utinam digne dicere possim, quod eciam, ut premisi, res ipsa et actus ipse expostulant sua inter preclarissima hic dominus dux Philippus, princeps catholicus, anno xxix ${ }^{\circ}$ januarii decima die, qua quidem die ipsius domini Philippi et illustrissime domine Ysabellis, domini Portugalie regis filie, de uno et triginta militibus genere, nomine armis utroque ex parente clarissimus et macula carentibus notabili societatem ornatissimam, nobilissimam et dignissimam amoris, fraternitatis, dilectionis ac caritatis plenam et hinc ordinem laudabilem instituit. ${ }^{262}$ Quibus quatuor cancelarii, thesaurarii, secretarii et regis armorum officia adiecit, qua quidem die ipsius domini Philippi et illustrissime domine Ysabellis domini Portugalie regis filie decoratissime et domine imperatricis

256 Ms.: corpus steht über der Zeile und eine Marke zeigt auf die dafür vorgesehenen Stelle im Text.

257 Zu den Vorfahren Hz. Philipps des Guten und dessen Lebenswerk siehe u. a. VAUGHAN, Philip the Good, 1970. Vgl. die Würdigung von Hz. Philipp in PB 2, S. 90 f., § 63 sowie in Guillaume Fillastre, 1. Buch vom Goldenen Vlies; gedruckt bei Fillastre, Ausgewählte Werke, 2003, S. 268-202, Nr. VIII. Es ist vorstellbar, dass der Ordenskanzler Ferry de Clugny Fillastres Werk über den Orden vom Goldenen Vlies als Vorlage für seine Rede nutzte. Zu diesem Werk ausführlich Fillastre, Ausgewählte Werke, 2003, S. 42-62.

258 Vergil, Aeneis I 374.

259 Ms.: Am linken Rand bei der Zeile, die mit eternam ad laudem beginnt, notierte Hand s Virgilius. Hier beginnt auch eine über vier Zeilen gehende geschlängelte, senkrechte Linie.

260 Vergil, Aeneis VI $353 \mathrm{f}$.

261 Ms.: dicam steht über der Zeile und eine Marke zeigt auf die dafür vorgesehenen Stelle im Text.

262 Hz. Philipp gründete anlässlich seiner Hochzeit mit Isabella von Portugal († 1471), Tochter König Johanns I. († 1433), am 10. Januar 1430 (n.St.) in Brügge den Orden vom Goldenen Vlies; vgl. dazu u. a. PB 1, S. 29 mit Anm. 3; Court and Civic Society, 2007, S. 130-137; MüLLER, Orden, 2009. 
excellentissime matris, tue amite, hoc in opido Brugensi nupcie admodum solemnes celebrate fuerunt. ${ }^{263}$ Hunc autem ordinem Gedeonis signo et misterio praeallegato in septimo Iudicum capittulo a sanctis in divinis luminibus amplissime declarato sapienter ductus et fidei zelo succensus Aurei Velleris ordinem vocari voluit. ${ }^{264}$ Dices princeps graciosissime, quod signum est? Medius fidius nullum cum ipsius figura maius. Namque Gedeone a domino postulante ros in solo vellere fuit et in omni terra siccitas rursum vellus siccum et omnis terra rore madens.

[d] Quid ex hoc? Quid nempe? Non modo Gedeonis victorie parva manu contra Madianitas et liberationis Israhel, ut ibi habetur. Signum fuit verum prophete psalmo lxxj precinente »sicut pluvia in vellus « descendit, ${ }^{265}$ ulla sine corruptione verbi dei, Adonay, Emanuel, legifferi, regis nostri, iusticie solis, pacis auctoris, incorrupto virginali in utero conceptionem et hinc nostre salutis precium atque triumphum prefiguravit, vicit enim leo de tribu Iuda, qui sua ineffabili gracia, sicut Eusebius bellissime demonstrat, nos a vita alienos prodicionisque filios preterita utilitate deposita adoptivos filios nona dignitate ornatos efferit et, ut Augustinus in sermone [fol. 20r] loquitur, de morte triumphavit, quam cristiani nominis inimicus suas perastucias homini propinaverat. Queres deinde ordinis huius institucionis causas. Equidem et si multe sint, ne longiori tamen sermone te et hunc cetum tedio afficiam, tres minime principales commemorabo, que ipsum dominum Philippum principem cristianissimum commoverunt: ${ }^{266}$

[e] Primum ${ }^{267}$ dei nostri eiusque sancte genitricis ad honorem, laudem et sancte fidei orthodoxe exaltacionem. Cur ita? Quia sicuti in epistola inter claras de summa trinitatis codicis libro inserta et a sancto Thoma in libro primo De regimine principium traditur: nichil est quod munere clariori prefulgeat quam recta fides in principe. ${ }^{268} \mathrm{Id}$ eciam iuramenti lege veluti erga deum religio divini iuris est.

$[f]$ Secunda $^{269}$ vero istius ordine institucionis causa motiva fuit ecclesie sancte ac sedis apostolice ob tuicionem, quod est, ut Canones in capitulo boni xlvj ${ }^{\mathrm{a}}$ distinc-

263 Hz. Maximilians Mutter Eleonore $(† 1467)$ war die Tochter Kg. Eduards von Portugal $(†$ 1438), der ein Bruder von Hz.in Isabella von Portugal war; vgl. Stammbaum in Kat. Karl der Kühne, 2008, S. 20.

264 Vgl. in der Bibel Richter 6, 37-40. Zur Symbolik des Ordens vgl. u. a. das Vorwort zu Guillaume Fillastres erstem Buch vom Goldenen Vlies; gedruckt bei Fillastre, Ausgewählte Werke, 2003, S. 254-259, Nr. VI, hier S. 256 f. (zu diesem Werk vgl. die Angaben in Anm. 257); des Weiteren Boulton, Order of the Golden Fleece, 2006, S. 33 f.; Paviot, Emblématique, 2007, S. 12 f.; Müller, Orden, 2009, S. 5 f.

265 Tatsächlich handelt es sich um ein Zitat aus Psalm 72, 6.

266 Ms.: Am linken Rand bei der Zeile, die mit principem cristianissimum commoverunt beginnt, notierte Hand s cause institucionis ordinis principales.

267 Ms.: primum ist unterstrichen. Dazu hatte Hand s auch noch am linken Rand $p^{a}$ notiert.

268 Ms.: nichil est quod munere clariori prefulgeat quam recta fides in principe ist unterstrichen. Er bezieht sich dabei auf den Fürstenspiegel des Thomas von Aquin De regimine principum. Auch in der Einleitung der Statuten des Ordens wurde erwähnt, dass der Orden vom Goldenen Vlies zu Ehren der Mutter Gottes und zum Schutz der Kirche eingerichtet wurde; vgl. dazu u. a. PB 1, S. $196 \mathrm{f}$.

269 Ms.: Am linken Rand der Zeile, in der secunda steht, hatte Hand s auch noch $2^{a}$ notiert. 
tione et capitulo principes xxiij q.v. perpulchre declarant, ${ }^{270}$ boni principis officium et a Genove Philelpho ${ }^{271}$ doctissimo In Agezelai laudibus summopere commendatum. Hec autem non solum verbis non scriptis sed factis permaximis et pro aliis exemplis optimus ille dux commonstravit. Non certe longissimis itineribus, neque arduis laboribus, neque prorsus auri argentique dispendiis neque est dictum stupendius in tanto principe suis vel maxime vite periculis pro fide pepercit. Que voluntas, bone Ihesu, illi fuit, qui sumptus, que studia, ut catholica pro fide tuenda regum ac principum animos conciliaret, coadiuvaret, concitaret. Quis? Ille fideliori animo sancte matris ecclesie unitatem inconsutilemque christi tunicam impiis manibus abrumpere et lacerare conantibus obstiterit? Quis firmiori studio pro sedis apostolice conservacione contendeat? Quis constantiori mente summis pontificibus parverit legacionesque ampliores pro fide, ecclesia et sede apostolica miserit? Praetera nonne triremes septem et navem permaximam biennio sepe contra barbaros tenuit nonne bis urbi Rodiorum a paganis obsesse occeani ab extremis presidium opemque transmisit? ${ }^{272}$ Quibus profecto ymitatus est Gondigarium, Burgundie regem, ${ }^{273}$ qui Athilam ecclesie hostem et orbis flagellum, primus, ut Eutropius auctor est, bello temptavit, insuper Gocianum alterum Burgundie regem, quem ecclesie inimicis illata clades subtili gloria vixit, Sigismundum eciam Burgundie regem, qui Longobardos sancte ecclesie hostes acie vicit, castris exint sub iugo misit denique Burgundie alium regem Hugonem cuius ab Ytalis petita virtus Berengarii tyranni rabiem fregit, profligavit, expulsit ${ }^{274}$.

[g] Tercia ${ }^{275}$ deinde huius sacri ordinis institucionis causa fuit propter virtutum honorumque morum excitacionem atque, ut primo de officiis scribitur omnium societatum nulla clarior, nulla prestantior, nulla melior quam, quod boni viri moribus similes sint, amicicia, benivolencia et familiaritate coniuncti quodque hinc ipsos bonos ad mores excitentur. Id mirum in modum Valerius Maximus ${ }^{276}$ libro II, capitulo [fol. 20v] de antiquis constitutis commendat, qui refert, maiores natu, in conviviis adhibeas ${ }^{277}$ superiorum egregia opera carmine comprehensa pangere, quo ad ea imitanda iuvenum virtutes alacriores redderent. Inde oriebantur Camilli, Sanxiones ${ }^{278}$, Fabricii, Martelli, Fabii itaque non Athenam scolam, non alienigena studia huic domestice discipline prefert. Et certe nulla norma, excitatio, disciplina istius recti ordinis regulis est anteferenda, que, ut Plato stoicus admonet, cuius dictum Gracianus viij ${ }^{\mathrm{a}}$

270 Corpus Iuris Canonici, Decreti Prima Pars, Distincio XLVI sowie Decreti Secunda Pars, Causa III, Quest. V, c. 20 und c. 21; vgl. dazu die online-Edition http://geschichte. digitale-sammlungen.de/decretum-gratiani/online/ (Nov. 2015).

271 Es handelt sich wohl um den italienischen Humanisten Franceso Filelfo (1398-1481); vgl. Giustinani, Francesco Filelfo, 1989.

2721442 kam eine burgund. Flottilie den Johannitern auf Rhodos zur Hilfe; vgl. VAughaN, Philip the Good, 1970, S. 270 f.; PAviot, Politique navale, 1995, S. 108-111.; PB 1, S. 90 f., § 63 mit Anm. 307.

273 Zur Frühzeit Burgunds vgl. u. a. Richard, Burgunder, 1983; Schnerb, État bourguignon, 1999, S. 11-16; KaISER, Burgunder, 2004.

274 Ms.: Am rechten Rand außerhalb des Schriftfeldes vermerkt Hand s, dass richtigerweise expulit statt expulsit stehen sollte.

275 Ms.: Am linken Rand der Zeile, in der tercia steht, hatte Hand s auch noch $3^{a}$ notiert.

276 Valerius Maximus 2.1.10.

277 Lies: ad tibeas.

278 Ms.: Sanxiones ist unterstrichen. Am linken Rand vermerkt Hand s, dass es richtigerweise Scipiones heißt. 
distinctione magnifacit, nullos proprios habet affectus. ${ }^{279}$ Istius vero institucionis ordinacio fuit, quod decoris, quod honestatis, quod officii et hinc sancte sedis apostolice et sacri consilii auctoritate confirmati extitit. Propterea eiusdem principis tempore reges tres Arragonum ingentissime fame et glorie, Navarie, Cypry, ducesque quinque Aurelianenses, Britanie, Alenconii, Clivenses, Gueldrenses, comites tam ex Bourbonii, Sabaudie, de Fuxo, ${ }^{280}$ quam aliis regiis domibus plures barones multi hoc in ordine et societate preclarissimis fuerunt. Cicerone in Officiorum fine demonstrante, certis ampliorem transmisit, quibus omnibus nullus sane patrie locus, nullus externe, nullus denique temporum cursus ipsius domini Philippi ducis pene divinas virtutes laudesque permaximas conticescet, quorum omnium secum adiutor semper fuit altissimus. Inde convenienter ad ipsum thema prefatum applicari potuit »dominus tecum virorum fortissime $« .{ }^{281}$ Huic autem parenti eius filius unicus, dominus dux Karolus $\{34\}$ omni virtute preditus probe respondit, licet enim a patre decus maximum acceperit. Certe cum Proverbiorum $\mathrm{X}^{\circ}$ filius sapiens sit gloria patris, ${ }^{282}$ non minus decoris et glorie in ipsum patrem redundari fecit, unde sicut suetatis et nature iure $\mathrm{L}$ in suis et L fi $\mathrm{S}^{283}$ de impii declarato. Ita virtutis decore eadem persona censetur, huic dulcis pater, ut David de Salomone, eius filio, suam propter sapienciam $3^{\circ}$ re i egit, ${ }^{284}$ ipsum dominum Karolum suas vires gerere fecit, cuius postea magnificentissime in Francia, Leodio, Germania et aliis plerisque locis gesta non modo explicare verum attingere non esset operis mei, sed gestorum suorum splendor disseminatus in dies magis atque magis elucescit. Omissis igitur reliquis, que non solum orationem elegantissimam et longissimam verum historiam exposcerent inter cetera suarum virtutum insignia Gedonis $^{285}$ exemplo, una manu tulit lampadem sapiencie luce accensam, altera vero magne eloquencie et mire.

[h] [fol. 21r] In principe tu[r]bam distrinxit armaque non solum fuit supra modum decoratus verum, ut convenit principi, iusticie scuto mirum in modum coruscante armatus. Hanc quidem iusticie virtutem, ut Proverbiorum vj ${ }^{\circ}$ scribitur, ${ }^{286}$ virorum dei principium, vite lumen, sacrificio acceptabilior et quod [X]enofontus, Aristonis, Zenonis, Socratis, Platonis ac Aristotilis ${ }^{287}$ aliarum virtutum vexillum, publice rei leticie pro-

279 Corpus Iuris Canonici, Decreti Prima Pars, Distincio VIII; vgl. dazu die online-Edition http://geschichte.digitale-sammlungen.de/decretum-gratiani/seite/bsb00009126_00058 (Nov. 2015).

280 Gemeint sind damit Alfons, Kg. von Aragon \{41\}, Johann, Kg. von Aragon und Navarra \{57\}, Johann, Hz. von Coïmbra und Regent von Zypern\{56\}; Karl, Hz. von Orléans \{37\}; Johann, Hz. der Bretagne \{38\}, Johann, Hz. von Alençon \{39\}, Johann, Hz. von Kleve \{47\}; Adolf, Hz. von Geldern \{58\}; Jacques de Bourbon \{66\} (Aufnahme 1468), Philipp von Savoyen $\{68\}$ (Aufnahme 1468) und Mathieu de Foix $\{40\}$.

281 Ms.: dominus tecum virorum fortissime ist unterstrichen. Vgl. dazu die Angaben in Anm. 252.

282 Sprüche 10.

283 Ms.: $L$ in suis et $L$ fi $S$ konnten nicht aufgelöst bwz. identifiziert werden.

284 Sprüche 3?

285 Ms.: Bei der Zeile, die mit virtutum insignia Gedonis beginnt, fängt am linken Rand eine senkrechte, geschlängelte Linie an, die bis zum Ende der Seite und auf der folgenden Seite noch über weitere neun Zeilen reicht.

286 Sprüche 6.

287 Ms.: Das ursprüngliche Aristolis wurde in Aristotilis verbessert, in dem ti über die Zeile geschrieben und eine Marke auf die dafür vorgesehene Stelle gesetzt wurde. 
creatricem, principatus ac corporis mistici et politici conservatricem plane cognoscens, tamquam sydus illustrius pre ceteris extulit. Dehinc iste princeps dominus Karolus, ut Job viij capitolo loquitur, ${ }^{288}$ sicut sapiens consilio, ita fortis viribus continue corpus exercicio afferit, quatenus prout in officiis docetur negociis in conducendis et labore tollerando obedire obsequique posset. Preterea illustrissimam domum suam atque familiam tantis magnificencia, decore, munificencia splendore temperancia, ordine insignivit, quod alter Salomon, ad quem regina Sabba et principes plures propterea profecti sunt, ab omnibus haberetur. Denique hanc insignem Velleris Aurei ordinem non solum direxit, conservavit, verum auxit, ornavit, ampliavit, magnificavit, cui ordini suo tempore, Castelle $\{71\}$, Anglie $\{63\}$ et Neapolis $\{72\}$ reges, maximi adiuncti sunt. Et ne remorer nimium fando paucisque verbis multa complectar aliorum tamen principum pace dicam. Quis isto principe suo tempore animo forcior, audacior? Sane nemo. Quis iusticia fervencior, prudencior? Sane nemo. Quis fama preclarior, magnificencior? Sane nemo. E quibus omnibus thematis verba eciam sibi hec vidimus non audivimus non sepe, sed cotidie de quo inde communia verba dicere possumus. Tunc hominem cognoscimus, cum eum amisimus. Attribui potuerunt »virorum fortissime dominus tecum ${ }^{2}{ }^{289}$

[i] De hoc autem preexcelentissimo principe, veluti de sole luna oritur, domina ducissa Maria, ${ }^{290}$ gloria decore et omnii virtute plena prefatisque parentibus dignissima. Num acceptam, num illis lucem in splendorem convertam. Late disseminat tibi vero matrimonio iuncta ecclesie sponso opem ferente, pulchra te faciet prole parentem, cui domine Marie ducisse mirum in medium est profecto gratulandum, tale sibi omen evenisse, ut tantum coniugem habere meretur. Tum certe eciam dominiis nature ac suetatis iure sibi obvenientibus omnibusque populis subditis precipue vero huius sacri ordinis Aurei Velleris dominis fratribus et militibus ac eiusdem in officiis commissis est magnopere gratulandum, cuius ordinis institutis decretum exitit quod filie Burgundie ducisse coniunx sicuti dei gratia nunc est, ordinis ac fraterne societatis huiuscemodi caput esset et supremus itaque, si Ecechielem ${ }^{291}$ per [fol. 21v] prophetam dominus speciali pro munere principem equum et iustum populo dare pollicetur. Quoniam talis proner [!] terram erigit, ${ }^{292}$ si apud Senecam in epistola ad Lucillum sicut prima causa universo est necessaria corpori anima, anime nostre ratio, sic corporis mistici et politici monarcha recens. Deo immortales agere debemus gracias, qui nobis de tam bono, tam gravi, tam honesto duce providit, de quo dicere possimus omnes, quod de Iuda Machabeo $2^{\circ}$ Machabei $2^{\circ 293}$ populus dei exclamavit. Maximilianus fortis viribus a iuventute sua sit nobis princeps, pariter id, quod in Ecclesiastico xlvi ${ }^{294}$ scribitur. Eruditus est in iuventute sua et impletus, quasi flumen sapiencia. Sub te quidem, ut videmus sicuti ab Augustino xviij De civitate dei, Egidio et sancto Thoma De principum

288 Hiob 8.

289 Ms.: virorum fortissime dominus tecum ist unterstrichen. Vgl. dazu die Angaben in Anm. 252.

290 Zur Person Hz.in Marias vgl. die Angaben in § 1, Anm. 4.

291 Ms.: Das ursprüngliche Echielem wurde in Ecechielem verbessert, in dem ce über die Zeile geschrieben und eine Marke auf die dafür vorgesehene Stelle gesetzt wurde. Möglicherweise spielt er hier auf Hezekiel 3 an.

292 So z.B. Proverb 29,4: rex iustus terram erigit.

293 1. Makkabäer 2, 66.

294 Buch Jesus Sirach oder Ecclesiasticus 47, 15-16. 
regimine ${ }^{295}$ post prophetam docetus regale vero dispositum dominium, quodque principis est proprium, ut perpulchre viij Ethicorum et primo Politicorum a ${ }^{296} \mathrm{Philelpho}^{297}$ demonstratur, subditorum intendere utilitati conaris. Preterea, que principi maximo conveniunt, evidenter in te concurrunt. In primis utroque ex parente genus imperiale atque regale, quo nullum maius, corporis venustas, heroyca maiestas, gravitas elegantissima, anima non tabula rasa, sed plurimo ac vario virtutum et morum ornatu depicta es quippe maxime prudens, admodum circumspectus, fortis, magnanimus, iustus, verus, temperatus, liberalis, equus, rectus, affabilis, mansuetus et super omnes clemens, benignus, misericors et pius, quod certe in principe est omnii commendacione dignissimum, quoniam vero hoc pacto nam virtutis alie et si profecto precelse et omni bono ac recto principe conventissime tamen humane sunt, clemencia vero celestis et divina. Quo hec auditore, quia Ciceronis in oracione pro maiore Martello et fere omnium auctorum divinorum sentencia pium, mansuetum et clementem non cum summis comparat, sed deo similimum iudicat, unde, si in beati Petri canonica $2^{\circ}$ capitulo ducibus tamquam a deo missis obsequium honorque debeatur, si, ut est apud Valerianus libro $2^{\circ}$ capitulo ${ }^{298}$ De maiesta ad Scipionem Affricanum maiorem virtutis sue admiratores, conspectum atque maiestatem tanti viri quasi celeste beneficium exprecantes eciam extra confluxerunt, si Paulo alio Macedonie duces, Pubplio Rutilio Asie populus, Mario Monturmenses, Marco Porcio Cathoni totus senatus et dehinc universus populus Romanus, Harmogio Aristogitem ac $<$ Zencra $>$ Zenocrati Athenienses [fol. 22r] solis eorum maiestate, virtute et claritate capti honoris, reverencie ac amoris officia exhibuerunt, longemagis a nobis colendus es venerandus, amandus, observandus et toto pectore complectendus, qui non modo generis, virtutis, maiestatis, auctoritatis splendore illos antecellis, verum te principem dignissimum, rectorem, tutorem ac ductorem nostrum peroptimum animo, opera studio, factis ostendis, hec autem officia potissime ab istius Aurei Velleris ordinis dominis, fratribus et militibus et officiariis exhiberi debent. Quibus profecto ob domini ducis Karoli ordinis supremi obitum et longo tempore capitis, carenciam maximis laboribus afflictis et hinc habitu lugubri vestitis, tue gravissime maiestatis nunc presencia nil dulcius tua benivolencia, humanitate nil nil ${ }^{299}$ amenius illisque spe nil optacius, quam primum militaris, dehinc huius ordinis insignia suscipere ipsumque ordinem non solum tueri et servare, verum augere et ampliare studebis. Eya igitur clementissime princeps, eya nunc memor officii tui, memor erga dominam Mariam, ducissam nostram et coniugem tuam affectionis, memor populi tibi commissi ipsius in te amoris et tui in eos, memor tandem huius ordinis et dulcissime societatis et hanc illustrissimam et nobilissimam Burgundie domum, que usque adeo fama, gloria et auctoritate claruit, restaures, defendas ac

295 Verweis auf Augustinus, De civitate Dei, und auf die Fürstenspiegel (De regimine Principum) von Aegidius Romanus und Thomas von Aquin (zu letzterem vgl. auch Anm. 268).

296 Am Rand que principe.

297 Ms.: Am linken Rand vor der Zeile, mit a Philippo beginnt, fängt ein dicker über zwei Zeilen gehender senkrechter Strich an; bei der darauf folgenden Zeile beginnt eine über 15 Zeilen gehende senkrechte, geschlängelte Linie. Am Übergang der beiden Linien steht links von Hand s geschrieben que principe conveniunt.

298 Valerius Maximus, Li. II C X.

299 Ms: Das zweite nil ist überflüssig. Vermutlich entstand diese Wortverdopplung durch den Zeilenumbruch. 
conserves et ad ecclesie sancte et fidei nostre tuicionem anheles, quo in freta ${ }^{300}$ dum fluvii current, dum montibus umbre lustrabunt, convexa polus, dum sydera pascet, semper honos nomenque tuum laudesque manebunt et tibi merita applicari poterunt thematis verba, que premisi »virorum fortissime dominus tecum $\aleph^{301}$ qui sit sua gracia tecum sit et tu secum, ut cum te esse possis in tuum. Amen.

[50] [Zuletzt dankt er im Namen der Mitglieder Hz. Maximilian für seine Bereitschaft den Orden zu übernehmen.]

Illustrissime princeps tue maiestati, quanto devocius et humilius possunt, gracias agunt et habent suaque inter felicia deputant, quod tanto honore ordinem ipsum ac eos afficere ac decorare voluisti et tue, illustrissime domine, honoris, reverencie, venerationis, amoris, dedicionis, observancie officia puro, sincero et fideli animo exhibent. Te excipiunt, te laudant, te magnifaciunt, mandatis tuis, ut nervi in fidibus, parere et obsequi pollicentur quodque ipsos tibi fidelissimos et obsequentissimos semper invenies te suppliciter exorantes, quatenus tuis bonitate, caritate et amicicie lege ordinem ipsum ac eos pariter omnes amplecti digneris.

[fol. 22v]

[51] [Es folgt die von fean de la Bouverie vorgetragene Antwort Hz. Maximilians.]

Ceste proposition ainsi faite elegamment et treshumblement et par mondit seigneur oyé et entendue, mondit seigneur le duc a par ledit maistre Jehan de la Bouvrie, seigneur de Wierre, president de sondit grant conseil ${ }^{302}$, fait respondre a mesdis seigneurs de l'ordre en effect et substance telles parolles: ${ }^{303}$

[52] [Zum Inhalt der Antwort: Er bedankt sich beim Ordenskanzler für die vorgetragene Rede und bei den Ordensmitgliedern für die an ihn herangetragene Bitte, die Leitung über den Orden vom Goldenen Vlies zu übernehmen. Schon lange hege er den Wunsch, dem Orden anzugehören, leider fehle ihm dafür aber der Ritterschlag. Diesen wollte eigentlich ihm sein Vater, Kaiser Friedrich III, erteilen. Leider war es ihnen derzeit aber nicht möglich, sich zu treffen, und da es für den Fortbestand des Ordens wichtig ist, bald zu handeln, nimmt er das Angebot an, dass eines der Ordensmitglieder ihn zum Ritter schlägt. Danach werde er dem Orden beitreten.]

Assavoir que bien au long il avoit ouy et entendu les choses a lui proposees et remonstrees moult elegamment par l'evesque de Tournay pour et ou nom et de la part de messeigneurs les chevaliers freres du noble ordre de la Thoison d'or, tant touchant la noble fondacion et institucion et les status et ordonnances dudit ordre institué et fondé

300 Vergil, Aeneis I $657 \mathrm{ff}$.

301 Ms.: virorum fortissime dominus tecum ist unterstrichen. Vgl. dazu die Angaben in Anm. 252.

302 Zu Jan van der Bouverien, Herr von Wiere, vgl. die Angaben in § 47 mit Anm. 239.

303 Diese Rede erwähnen Chroniques de Molinet, I, 1935, S. 251; Verschelde, Feeste, 1873, S. 26 (nach Stadtbibl. Brügge, Historisch Fonds ms. 437 [Excellente Chronycke van Vlaanderen]); BARANTE/Gachard, Histoire, II, 1838, S. 601f.; Kervyn DE LetTenhove, Histoire de Flandre, V, 1850, S. 290. 
par feu le duc Phelippe $\{01\}$, jadis duc de Bourgoingne, ayeul de par pere de madame la duchesse sa compaigne, comme des condicions, dignitez et qualitez de ceulx qui a ladite premiere institucion par feu ledit fondateur y avoient esté establis ensemble de ceulx qui depuis par l'election du souverain et des chevaliers freres dudit ordre en leur chappittre successivement y estoient appellez et accompaignez, ensemble de ceulx qui encoires y sont de present, comme touchant la gloire et magnificence en quoy ledit ordre avoit esté conduit, gardé et maintenu par feuz ledit duc Phelippe en son temps et tousjours depuis par feu monseigneur le duc Charles $\{34\}$, son filz, beaupere de mondit seigneur, et jusques a son trespas, et de la diminucion que l'ordre souffroit de present en nombre des personnes et autrement par ce que dez ledit trespas il avoit jusques a lors esté sans chief, comment aussi autre prince du monde ne pourroit parvenir audit estat du souverain d'icellui ordre, fors lui seul a cause de madite dame la duchesse sa compaigne, seule fille et heritiere universel d'icellui feu duc Charles, jadis chief et souverain du mesme ordre darrenier deffunct, et qu'il lui competeroit et appartendroit de le relever et d'en estre le chief et souverain ou lieu dudit feu, mesmement en vertu des status dudit ordre sur ce alleguez. Avoit aussi bien entendu les prieres et requestes que pieça en la ville de $\mathrm{Gand}^{304}$ tantost apres le parfait du mariaige d'entre lui et madite dame et encoires depuis par diverses fois sur ce ilz lui avoient faites et fait faire et que encoires de rechief lui faisoient a ceste fin. Pour consideracion desquelles choses mondit seigneur le duc, tant pour le vray amour et affection qu'il porte a madite dame madame la duchesse sa compaigne, et a cause d'elle a sa noble maison de Bourgoingne a laquelle par l'ordonnance et bon plaisir de la souveraine et sacré maiesté l'empereur de Rome \{94\}, son pere, il s'estoit allié par marriaige, parquoy tout honneur et plaisir a lui possible leur vouldroit faire et demonstrer et aux nobles et beaulx pays, vassaulx et subgiez de madite dame, comme pour contemplacion et reverence de la noble [fol. 23r] compaignie dudit ordre, a laquelle il avoit ja longtemps paravant desiré d'estre assoié et accompaignié, leur a de rechief comme autre fois ottroyé et accordé leurdite requeste. Et pour ce que encoires il n'estoit chevalier, sans lequel estat il ne povoit estre receu oudit ordre, combien que ladite sacré maiesté imperial, son pere, lui eust ordonné de recevoir l'ordre de chevalerie par sa main ou en exploit d'armes honnerable en guerre et que ainsi l'eust desiré de faire. Neantmoins pour l'absence de ladite maiesté imperial estant en marche treslongtaine, attendue mesmement la grant necessité dudit ordre de la Thoison d'or qui tant longuement avoit esté sans chief et estoit diminué en nombre de personnes et autrement, parquoy plus ne povoit ainsi demourer sans chief qu'il ne fust en dangier de confusion et desclandre. En ensuivant sa conclusion autre fois avec eulx prinse en ceste partie et par ses lettres et les leurs signiffiee ausdis roys, princes et autres chevaliers freres dudit ordre ${ }^{305}$ encoires survivans comment il avoit deliberé et conclut de accepter l'ordre de chevalerie au darrenier jour d'avril, qui estoit huy, et consequenment de relever et recevoir ledit ordre de la Thoison d'or pour en estre le chief et souverain ou lieu de sondit feu beaupere et de en apres aussi tenir la feste et solemnité ensemble le chappittre d'icellui ordre. Sur espoir et confidence qu'il avoit en mesdis seigneurs les chevaliers freres de l'ordre et de leur bon ayde, confort, conseil et adreçe par l'ayde et grace de messeigneurs il estoit et seroit content de proceder et entendre a ce que dit est, soy offrant prest pour

304 Vgl. § 10.

305 Vgl. Reg. 1-20. 
recevoir prealablement l'ordre de chevalerie par la main de l'ung d'entre eulx que a ce ilz vouldroient ordonner et depputer.

[53] [Die Ordensvertreter freuen sich über Maximilians Antwort und schlagen vor, dass das folgende Zeremoniell von Jean de Lannoy als den Ältesten und von Adolf von Kleve als den Ranghöchsten des Ordens durchgeführt werden solle. Nach Maximilians Zustimmung wechseln die beiden und Toison d'or ihre Kleidung.]

Oyé laquelle response mesdis seigneurs les chevaliers freres ensemble les officiers dudit ordre de la Thoison d'or se sont remis a genoulx devant mondit seigneur le duc et par la bouche de mondit seigneur l'evesque de Tournay, chancellier de l'ordre, treshumblement et joyeusement par grande congratulacion ont remercié mondit seigneur le duc, lui rendant graces trescordiales de sa response tant liberale et benigne qu'il lui avoit pleu leur donner. Et quant a ce que par la conclusion de sadite response mondit seigneur le duc avoit fait dire qu'il estoit prest de prende l'ordre de chevalerie par la main de l'ung de mesdis seigneurs les chevaliers freres de l'ordre qu'il leur plairoit a ce deputter, lui firent dire qu'ilz lui en avoient mesmes baillié le chois, toutevoie puis que son noble plaisir estoit qu'ilz en depputassent l'ung d'eulx. Sur ce lui firent remonstrer et dire que au matin a leur premiere assemblee en la chambre ordonnee pour le chappittre ou estoit le collier d'or ilz avoient communiqué ensemble de ceste matiere. Et combien que selon les [fol. 23v] ordonnances et status de l'ordre les actes d'honneur en icellui ordre competent au plus anchien chevalier frere dudit ordre illec present et par ainsi competeroient a monseigneur de Lannoy $\{50\}$, qui est le plus anchien frere d'entre eulx oudit ordre, toutevoie, saulf le bon plaisir de mondit seigneur veu que pour le jour il auroit deux actes honnerables a faire en l'ordre, assavoir l'ung de baillier la collee et creer chevalier mondit seigneur, et l'autre de lui baillier le collier de l'ordre aux ceremonies et solemnitez en cel cas requises, ilz avoient distribué lesdis honneurs et ordonné monseigneur de Ravestein $\{55\}$, comme le plus noble, pour creer chevalier mondit seigneur le duc, et mondit seigneur de Lannoy, comme le plus anchien en l'ordre, pour lui baillier ledit collier ${ }^{306}$ de l'ordre quant le vendroit. ${ }^{307}$ De laquelle response et ordonnance mondit seigneur le duc a esté bien content. Et tantost apres messeigneurs de Lannoy et de Ravestein se sont levez de leurs lieux, et la reverence faite a mondit seigneur le duc et devers l'autel ouquel gisoit ledit collier de l'ordre, se sont partis ensemble et descendus dudit hourt et ledit roy d'armes Thoison d'or avec eulx pour les accompaigner, et en passant parmy le grant chœur sont alez au lez dextre dehors ledit chœur au lieu et retrait, illec a ce ordonné comme dessus a esté dit, ${ }^{308}$ pour eulx trois devestir des habis de deul et revestir des habis de l'ordre, chascun a son endroit, assavoir lesdis deux chevaliers de leurs robes, chapperons et manteaulx de velux cramoisy ${ }^{309}$ et ledit Thoison d'or de robe et chap-

306 Ms.: ledit collier steht über der Zeile und eine Marke zeigt auf die dafür vorgesehenen Stelle im Text.

307 Vgl. dazu die Beschlussfassung in § 44.

308 Vgl. § 37.

309 Während des Ordensfestes von 1473 hatte Hz. Karl \{34\} neue Ordensgewänder eingeführt, die bei großen Festveranstaltungen getragen werden sollten. Es handelt sich dabei um bodenlange purpurfarbene Samtmäntel mit weißem Damastfutter und aufwendiger Goldstickerei von Ordenssymbolen. Dazu passend trugen die Mit- 
peron semblables portant au tour de son col ledit grant collier de l'ordre, servant pour son office comme dessus est dit. ${ }^{310}$

\section{[54] [Hz. Maximilians Ritterschlag.]}

Item, mesdis seigneurs de Lannoy $\{50\}$ et de Ravestein $\{55\}$, ainsi revestus, se sont retournez parmy ledit chœur sur ledit hourt et illec revenus et la reverence faite comme devant, Thoison d'or s'est remis a sa premiere garde, monseigneur de Lannoy s'est remis en sa place premiere et monseigneur de Ravestein s'est tiré vers le milieu dudit hourt, soy offrant prest pour faire selon ladite ordonnance. Et incontinent mondit seigneur le duc s'est levé de son siege donnant signe a sondit marischal, ${ }^{311}$ qui tenoit devant lui l'espee d'honneur, qu'il s'approichast de lui a tout ladite espee, ce qu'il fist reverenment. Et mondit seigneur venu vers ledit milieu dudit hourt la ou <l'attendoit> mondit seigneur de Ravestein l'attendoit, demanda l'espee dudit marischal, qui la lui ${ }^{312}$ bailla a tout la gayne ung peu tyree en la baysant et reverenment soy engenoullant, et mondit seigneur la tyra hors ladite gayne et la bailla toute nue a mondit seigneur de Ravestein en requerant de lui l'ordre de chevalerie. Et monseigneur de Ravestein receut ladite espee reverenment et la baisa aussi soy enclinant jusques a terre et lui redrecié mondit seigneur le duc s'acclina bas de la teste nue et lors mondit seigneur de Ravestein lui bailla la collee a tout ladicte espee [fol. 24r] moult humblement et reverenment, en disant ces mots «Soiez chevalier a l'onneur et ou nom de Dieu, de Nostre Dame et de monseigneur Saint George. »Ce fait, il rebaisa ladicte espee et a mondit seigneur redrecié tout droit la bailla reverenment soy engenoullant et mondit seigneur le duc la reprint et rendit a sondit marischal soy retraiant devers son premier siege. Duquel acte firent grant joye tous ceulx qui la estoient. Et les trompettes sonnerent ung peu par forme de joye. ${ }^{313}$

\section{[55] [Die Ordensmitglieder ziehen sich zurück, um sich umzukleiden.]}

Item, tantost apres que mondit seigneur le duc fut ainsi fait chevalier, se leverent tous mesdis seigneurs les chevaliers freres ensemble lesdis officiers de l'ordre et se tirerent devers mondit seigneur lui remonstrant, que pour proceder ou fait du relievement de l'ordre de la Thoison d'or besoing estoit que lui et eulx tous se alassent habillier et vestir des habis dudit ordre. Ce oyant mondit seigneur le duc se leva de son siege et les trois officiers, premiers assavoir le tresorier et greffier ensemble, monseigneur de

glieder Kappen aus purpurfarbenem Samt. Auch die Amtsträger des Ordens hatten vergleichbare Gewänder, jedoch ohne Stickerei. Gleichzeitig wurde die Kleiderordnung bei den verschiedenen zu besuchenden Gottesdiensten definiert; vgl. dazu ausführlich in PB 3, S. 17-19 (mit Hinweis auf die Statuten und deren Ergänzung, mit Querverweisen auf die entsprechenden Stellen im Protokoll und auf Literatur). Zum schwarze Ornat vgl. die Angaben in $\S 40$ mit Anm. 210.

310 Zur Kette des Wappenkönigs vgl. die Angaben in § 42, Anm. 216.

311 Zu Adolf, Gf. von Nassau, vgl. die Angaben § 47 mit Anm. 238.

312 Ms.: lui steht über der Zeile und eine Marke zeigt auf die dafür vorgesehenen Stelle im Text.

313 Den Ritterschlag erwähnen u.a. Chroniques de Molinet, I, 1935, S. 251; Fugger, Spiegel der Ehren, 1668, S. 881; Barante/Gachard, Histoire, II, 1838, S. 602; DelePIERre, Fête en 1478, 1842, S. 337; Kervyn de Lettenhove, Histoire de Flandre, V, 1850, S. 290; Glezerman/Harsgor, Cleve, 1985, S. 213; Smedt, Jan van Lannoy, 1992, S. 73. Siehe dazu auch oben in der Einleitung S. 15. 
Tournay, chancellier, seul, et apres lui messire Engelbert, conte de Nassouw $\{77\}$ seul tenant son reng au dextre, apres lui monseigneur de Gruythuse $\{61\}$ et monseigneur de Chimay $\{74\}$ et les darrenieres monseigneur de Lannoy $\{50\}$ et monseigneur de Ravestein $\{55\}$, ja revestus desdis habis de l'ordre, deux a deux. Et mondit seigneur le duc alant entre lesdis seigneurs de Lannoy et de Ravestein, tous descendirent dudit hourt et se alerent habillier et vestir desdis habis de l'ordre, assavoir mondit seigneur en son retrait pour lui ordonné et messeigneurs de l'ordre ensemble lesdis officiers a l'autre pour eulx ordonné, ${ }^{314}$ ledit Thoison d'or, roy d'armes, demourant seul sur ledit hourt pour la garde dudit collier d'or.

\section{[56] [Schwurkreuz und Messbuch werden für den Eid bereitgestellt.]}

Item et ce pendant provision s'est faite d'une belle croix moult riche et d'un missel ${ }^{315}$ qui furent apportez et mis oudit hourt sur une schabelle illec paree et couverte de drap de veloux noir honnestement environ le milieu d'icellui hourt ladite croix couchee et ledit missel ouvert sur l'encommenchement du saint canon de la messe.

\section{[57] [Rückkehr des Herzogs und der Ordensritter im Ordensornat.]}

Item et mondit seigneur le duc et messeigneurs de l'ordre ainsi revestus de robes, manteaulx et chapperons dudit ordre, ilz sont tous retournez par l'ordonnance premiere vers ledit hourt. ${ }^{316}$

[fol. 24v]

[58] [Die Mitglieder und Amtsträger versammeln sich um Hz. Maximilian, der den Aufnahmeeid spricht.]

Item mondit seigneur le duc et messeigneurs les chevaliers freres ensemble lesdis officiers de l'ordre retournez sur ledit hourt, mondit seigneur se alla mettre devant la schabelle ouquel estoient lesdites crois et missel soy tenant droit. Et alentour de lui

314 Vgl. § 37.

315 Zum Zeremoniell des Aufnahmeeides aller Mitglieder, nicht nur der Souverän, gehörte es, dass sie beim Sprechen der Eidesformel das Schwurkreuz und das Meßbuch berührten; vgl. dazu auch das Zeremoniell der Neuaufnahmen in den folgenden Tagen in $§ 159$ und $166 \mathrm{f}$. sowie allgemein SchwedLER, Herrschertreffen, 2008, S. $154 \mathrm{f}$. Das Schwurkreuz befindet sich noch heute im Besitz des Ordens und findet dort auch heute noch bei Neuaufnahmen seine Verwendung. Außerhalb der Ordensfeste ist es in der Schatzkammer des Kunsthistorischen Museums in Wien zu sehen; vgl. dazu die Angaben in PB 1, S. 31, Anm. 18 sowie PB 3, S. 69, Anm. 205; Salet, Croix de serment, 1974. Das Schwurkreuz war auch bei den internationalen Karl der KühneAusstellungen in Bern, Brügge und Wien zu sehen, vgl. dazu Kat. Karl der Kühne, 2008, S. 182, Nr. 10 mit Tafel 1 (mit hervorragenden farbigen Abbildungen); Fillitz, Schatz, 2009, S. 49 mit Abb. 11. Vgl. dazu auch die Datenbank des Museums unter http://bilddatenbank.khm.at/viewArtefact?id=100333 (11.11.2015). - Über das Aussehen und den Verbleib des Meßbuches ist dagegen nichts bekannt, dazu ausführlicher PB 3, S. 69, Anm. 205.

316 Maximilians Inauguration ist in Brüssel, BR, ms. 13.073-74 (Excellente Chronycke van Vlaanderen), fol. 335v dargestellt; vgl. dazu Kat. Toison d'or, 1962, S. 131, Nr. 49; Smedt, Jan van Lannoy, 1992, S. 74, Abb. 6. Zu dieser Handschrift, die in einem zweiten Exemplar in Brügge, Stadtbibl., Historisch Fonds ms. 437, vorhanden ist, vgl. auch Kat. Karl der Kühne, 2008, S. 351, Nr. 162. 
se tenoient messeigneurs les chevaliers et officiers de l'ordre. Et incontinent Thoison d'or, le roy d'armes, a la lever dudit autel ledit collier et reverenment a deux mains espandu le bailla a monseigneur de Lannoy $\{50\}$ comme le plus anchien chevalier frere des presens. Et mondit seigneur le duc se mist a genoulx devant ladite croix et tous les chevaliers et officiers se mirent a genoulx pareillement autour de lui et mettant mondit seigneur l'une de ses mains sur ladite croix et l'autre sur le canon dudit missel, fist le serment a hault voix entendiblement en la forme que s'ensuit: ${ }^{317}$

\section{[59] [Nach seinem Eid wird Hz. Maximilian die Ordenskette um den Hals gelegt.]}

»Ego, Maximilianus, Dei gracia dux Austrie, Burgundie etc., caput ac supremus ordinis Velleris Aurei, promitto in verbo principis et juro ad hec sancta Dei Evangelia et super crucem sanctam, servare, intertenere atque adimplere deinceps perpetuo ac integre et inviolabiliter pro posse meo, statuta et ordinaciones dicti ordinis Velleris Aurei, juxta eorum forman et tenorem. ${ }^{318}$ Et a la fin dudit serment il baisa la croix reverenment et devotement. Apres ce serment ainsi fait, monseigneur de Lannoy $\{50\}$ s'est approiché de mondit seigneur le duc atout ledit collier lequel il baisa et mist au col de mondit seigneur moult reverenment en disant: »Domine mi, ordo Velleris aurei vos recipit in caput suum et supremum et in signum eius vobis presentat istud collare et Deus [velit] quod diu portare, dictoque ordini praeesse possitis ad laudem suam et servicium, ad exaltacionem ecclesie sue sancte, ad augmentacionem et honorem dicti ordinis meritorumque vestrorum et bone fame. In nomine Patris + et Filij + et Spiritus Sancti $+\ll^{319}$ A quod mondit seigneur respondit en disant »Amen. Deus hanc michi det

317 Die nun folgenden Eideszeremonie wird zitiert bei Toison d'or, 1689, S. 208-214 und ausführlich beschrieben bei Delepierre, Fête en 1478, 1842, S. 337-339. Dazu auch Verschelde, Feeste, 1873, S. 26 f. (nach Stadtbibl. Brügge, Historisch Fonds ms. 437 [Excellente Chronycke van Vlaanderen]); SMEDT, Jan van Lannoy, 1992, S. 73 f.

318 Die Eidesformel wird zitiert bei Toison d'or, 1689, S. 208. - Delepierre, Fête en 1478, 1842, S. 337 f., zitiert folgenden (frz.) Eid: Moi, Maximilien, par la grâce de Dieu, archiduc d'Autriche, duc de Bourgogne, comte de Flandre etc., chef et souverain de la Toison d'or, je promets sur ma parole de prince, et jure sur les saints Evangiles et sur la croix sainte, de maintenir les privilèges et d'observer inviolablement les statuts et ordonnances du dit ordre, selon leur forme et teneur.

319 Lannoy spricht hier den leicht abgewandelten Begrüßungsspruch, mit dem normalerweise der Souverän ein neues Mitglied nach seiner Eidesleistung im Orden willkommen heißt und von diesem mit der Fürbitte bei Gott erwidert wird; vgl. dazu den vorgeschriebenen Text in $\S 85$ (neu § 59) der Statuten (dazu S. 16, Anm. 14). Delegiere, Fête en 1478, 1842, S. 337, druckt die von Lannoy gesprochenen Worte in frz. Übersetzung. - Nach Chroniques de Molinet, I, 1935, S. 251, sagte Lannoy dagegen: Très hault et très puissant prince, pour le sens, preudhomie, vaillance, vertus et bonnes meurs que nous esperons estre en vostre très noble personne, l'ordre vous rechoit en son aimable compagnie; en signe de ce, je vous donne ce collier d'or. Dieu doint que le puissiez à la loenge et augmentation de vos merites. Danach auch BARANTE/ Gachard, Histoire, II, 1838, S. 602; Kervyn de Lettenhove, Histoire de Flandre, V, 1850, S. 290 f. Fugger, Spiegel der Ehren, 1668, S. 881 schreibt ihm folgende Worte zu: Durchleuchtigster Fuerst! Der Ritter Orden des Gueldnen Vlueß / das Gott begluecke! nimt E. Durchl. von wegen eurer hohen Tugend und Dapferkeit des Gemuets / mit welcher die Hoheit Eures Stammens und Glueckes sich vergleichet / in seine Genoßschaft an und auf / und bestaetigt hiemit E. Durchl. zu desselben Obristen Haupt / Vorsteher und Beschirmer. 
graciam.«Et ce fait, mondit seigneur le duc fut par messeigneurs mené et fait asseoir en une autre chayere richement paree de drap d'or et de coussin du mesme comme chief et souverain de l'ordre.

[b ?] Forma iuramenti domini supremi ordinis. ${ }^{320}$

[b ?] No(ta) hic verba misterii collacionis collaris ordinis Velleus Aurei. ${ }^{321}$

\section{[60] [fean de Lannoy leistet dem neuen Souverän seinen Treueeid.]}

Apres cela mesdis seigneurs les chevaliers de l'ordre se sont retrais en leurs lieux reverenment et monseigneur le chancellier est demouré [fol. 25r] d'alez mondit seigneur et Thoison d'or prinst le missel a tout ladite croix touchee sur ledit missel et les porta devers mondit seigneur et tint $<\mathrm{t}>$ devant lui. Et tantost ${ }^{322} \mathrm{~s}^{\prime}$ est levé de son lieu monseigneur de Lannoy $\{50\}$ et, venu mettre a genoulx devant mondit seigneur, et en mettant l'une de ses mains sur ladite croix et l'autre sur ledit canon du missel, a fait serment a mondit seigneur le duc comme chief et souverain dudit ordre en la forme que s'ensuit:

\section{[61] [Ihm folgen nacheinander alle anderen Mitglieder und jeder erhielt vom Sou- verän einen Kuss als Zeichen der brüderlichen Liebe.]}

« Ego, Johannes de Lannoy $\{50\}$, promitto et juro ad hec sancta Dei Evangelia et super crucem sanctam vobis, serenissimo principi domino Maximiliano Austrie et Burgundie duci, capiti ac supremo ordinis Velleris Aurei, reverenciam debitam et honorem vobisque in omnibus debitum et negocia dicti ordinis concernentibus ac respicientibus obedire secundum statuta et ordinaciones euisdem ordinis, quemadmodum articulos in mea ad ipsum ordinem recepcione solemniter juravi et promisi. ${ }^{323}$ Lequel serment ainsi fait, mondit seigneur le souverain l'a prins et levé par sa main et baisié a la bouche en signe d'amour perpetuelle et fraternelle que mondit seigneur vouloit et veult avoir et maintenir avec lesdis freres d'icellui ordre. ${ }^{324} \mathrm{Et}$ ce fait, mondit seigneur de Lannoy s'est alé remettre en son premier lieu. Apres s'est levé monseigneur Adolph de Cleves $\{55\}$, seigneur de Ravestein, chevalier frere de l'ordre, et alé mettre a genoulx semblablement devant mondit seigneur et mettant l'une de ses mains sur ladite < croix $>$ sainte croix et l'autre sur ledit canon du missel a fait serment semblable a mondit seigneur. Apres lequel serment par lui fait, mondit seigneur le souverain a aussi prins et levé par sa main mondit seigneur de Ravestein et baisié a la bouche en signe d'amour, comme dessus. Et tantost ledit monseigneur de Ravestein, la reverence faite a mondit seigneur

320 Ms.: Diese Randbemerkung, die links und rechts mit einer senkrechten geschweiften Linie umrahmt ist, steht am Anfang des Absatzes und ist wohl gleichzeitig entstanden.

321 Ms.: Diese Randbemerkung, die links und rechts mit einer senkrechten geschweiften Linie umrahmt ist, beginnt bei der Zeile, die mit Apres ce serment ainsi fait beginnt.

322 Ms.: Links vor der Zeile, die mit Et tantost beginnt, befindet sich ein Doppelstrich.

323 Die Eidesformel wird zitiert bei Toison d'or, 1689, S. 210. Delepierre, Fête en 1478, 1842, S. 338, zitiert folgenden (frz.) Eid: Moi, Jean de Lannoy, je promets et je jure sur les saints Evangiles et sur la croix sainte, respect et honneur au sérénissime prince Maximilien, archiduc d'Autriche, duc de Bourgogne, chef et souverain de la Toison d'or. fe lui jure obéissance en tout ce qui concerne les statuts et les ordonnances du dit ordre, ainsi que je l'ai solennellement juré et promis, lors de ma réception.

324 Zur Bedeutung des Bruderkusses vgl. Oschema, Freundschaft, 2006, S. 525-538. 
le souverain, s'est alé remettre en son lieu premier, dont il estoit parti. Pareillement et consequenment ont fait ledit serment l'ung apres [l']autre, messire Loys, seigneur de Gruythuse $\{61\}$, conte de Wincestre, messire Phelippe de Croy $\{74\}$, conte de Chimay, et messire Engelbert, conte de Nassouw $\{77\}$, seigneur de Breda, tous chevaliers freres de l'ordre, chascun commenchant par son propre nom et au sur plus le continuant de mot a autre selon la forme dessus contenue et mondit seigneur le souverain a prins et levé chascun d'eulx par la main et baisié a la bouche en la maniere devantdite.

[b ?] Forma iuramenti dominorum militum fratrum ordinis. ${ }^{325}$

\section{[fol. 25v]}

\section{[62] [Ferry de Clugny leistet als Ordenskanzler seinen Treueeid.]}

Et quant messeigneurs les chevaliers freres de l'ordre ont eu fait leurdis sermens l'ung apres autre gardant leur ordre accoustumé et les ceremonies cy dessus touchees, reverend pere en Dieu messire Ferry de Clugny, evesque de Tournay, chancellier dudit ordre, s'est mis a genoulx devant mondit seigneur et mettant l'une de ses mains sur la croix et l'autre sur ledit canon du missel a fait serment solemnel a mondit seigneur le souverain en la forme que s'ensuit: »Ego, Ferricus de Clugny, episcopus Tornacensis $<$ et $>$ cancellarius incliti ordinis Velleris Aurei, promitto et juro vobis seremissimo principi domino Maximiliano, Dei gracia Austrie et Burgundie duci, capiti ac supremo dicti ordinis Velleris Aurei, reverenciam debitam et honorem vobisque in hiis que prefatum ordinem ac debitum officii mei cancellariatus euisdem ordinis concernent ac respicient, obedire, secundum formam et tenorem ordinationum pro quatuor officiarijs ipsius ordinis ${ }^{326}$ factarum et sicut in mea ad officium huiusmodi recepcione pridem juravi et promisi. « ${ }^{327}$ Lequel serment fait, mondit seigneur print benignement et leva par la main mondit seigneur l'evesque de Tournay et le embrassant pour reverence de sa dignité episcopal, sans toutevoie le baisir.

[b ?] Forma juramenti quod prestitit reverendus in Christo pater dominus episcopus

Tornacensis cancellarius domino supremo ordinis. ${ }^{328}$

\section{[63] [fean Gros leistet als Trésorier seinen Treueeid.]}

Consequement s'est alé mettre a genoulx devant mondit seigneur le duc, chief et souverain de l'ordre, maistre Jehan Gros, tresorier dudit ordre, et, mettant l'une de ses mains sur ladite croix et l'autre sur ledit canon du missel, a promis et juré solem-

325 Ms.: Diese Randbemerkung, die links und rechts mit einer senkrechten geschweiften Linie umrahmt ist, steht am Anfang des Absatzes.

326 In der ursprünglichen Fassung der Statuten des Ordens vom Goldenen Vlies von 1431 waren die Bestimmungen für die Amtsträger des Ordens an verschiedenen Stellen der 103 Paragraphen verteilt, bei der Statutenrevision von 1445 wurden ihre Bestimmungen von denen der Ordensmitglieder getrennt und die Amtsträger erhielten ihre eigenen 28 Paragraphen umfassende Statuten; vgl. dazu PB 1, S. $194 \mathrm{f}$ und ebd. die Edition der ursprünglichen Fassung S. 195-231 sowie die Angaben oben S. 16, Anm. 14.

327 Die Eidesformel wird zitiert bei Toison d'or, 1689, S. 212.

328 Ms.: Diese Randbemerkung, die links und rechts mit einer senkrechten geschweiften Linie umrahmt ist, steht zu Beginn des Eides des Ordenskanzlers. 
nellement a mondit seigneur le duc, chief et souverain du noble ordre de la Thoison d'or, toutes honneur et reverence deues et es choses touchans et regardans ledit ordre et le devoir de son office lui obeir en ensuivant les ordonnances faites pour les quatre officiers du mesme ordre et ainsi que en sa recepcion audit office de tresorier il avoit juré et promis. Et ledit serment fait, mondit seigneur lui a baillié la main en signe de benivolence et amour.

[b ?] Forma juramenti quod thesaurarius, scriba et rex armorum ordinis fecerunt domino duci supremo eiusdem ordinis. ${ }^{329}$

\section{[fol. 26r]}

\section{[64] [Martin Steenberch leistet als Greffier seinen Treueeid.]}

Apres s'est alé mettre a genoulx devant mondit seigneur le souverain maistre Martin Steenberch, doyen de Brouxelles, graffier de l'ordre, et a fait a mondit seigneur pareil serment en son nom comme graffier d'icellui ordre ainsi que l'avoit fait a son endroit ledit maistre Jehan Gros, tresorier en la mesme forme cy devant contenue. Lequel serment par lui fait, mondit seigneur le souverain lui a baillié la main benignement comme dessus.

\section{[65] [Gilles Gobet leistet als Toison d'or seinen Treueeid.]}

Semblablement et pour le darrenier s'est mis a genoulx devant mondit seigneur Gilles Gobet, dit Thoison d'or, roy d'armes dudit ordre, et mettant l'une de ses mains sur la sainte croix et l'autre sur ledit canon du missel a fait en son nom comme roy d'armes d'icellui ordre a mondit seigneur le souverain serment en pareille forme de mot a autre, que cy dessus est contenue ainsi comme lesdis tresorier et graffier d'icellui ordre illec l'avoient fait et juré devant lui. Et ledit serment fait, mondit seigneur l'a aussi touchié de la main en signe de benivolence.

[66] [Die Ordensmitglieder kleiden sich erneut um und nehmen danach in "privater « Kleidung an der großen Messe teil.]

Ces ceremonies ainsi faites et observees, tantost ont sonné les trompettes et menestriers, et lesdis instrumens cessans tantost ceulx de la chappelle de mondit seigneur ont entonné et commenchié la cantique Te deum laudamus a discant et alterne a tout les orgues solemnellement et devotement. ${ }^{330}$ Et mondit seigneur le souverain, messeigneurs les chevaliers freres et les quatre officiers de l'ordre se sont levez et mis a chemin, les officiers dudit ordre alans devant et messeigneurs les plus jeunes chevaliers freres apres et consequenment les plus vielz en l'ordre apres, deux a deux tenans leur ordre. Et mondit seigneur le souverain vint le darrenier tout seul, tenant et gardant l'onneur, lieu et estat du chief et souverain dudit ordre. Et ainsi passant parmy le grant chœur se sont retournez ${ }^{331}$ es lieux desdis retrais ordonnez dehors au lez dextre dudit chœur ou ilz s'estoient revestus des habis de l'ordre pour illec eulx devestir

329 Ms.: Diese Randbemerkung, die links und rechts mit einer senkrechten geschweiften Linie umrahmt ist, steht zu Beginn der Zeile, die mit a mondit seigneur le duc, chief et souverain beginnt.

330 Zur Bedeutung und Verbreitung dieses Hymnus vgl. u. a. HäUssling, Te Deum, 1997.

331 Ces ceremonies ainsi faites et observees [...] le grant chœur se sont retournez wird zitiert bei Merkley, Role, 1998, S. 356. 
desdis habis de l'ordre et vester d'autres habis honnestes chascun a sa plaisance. Et mondit seigneur revestu d'une riche robe de drap d'or et messeigneurs les chevaliers revestus chascun a son plaisir ont convoyé mondit seigneur le souverain jusques a son oratoire pour lui ordonné au lez dextre empres le grant autel en maniere accoustumee. Messeigneurs [fol. 26v] les chevaliers freres de l'ordre se mirent au mesme lez es haultes formes sans ordre et les officiers a leur plaisir et tantost la grant messe s'est commenchee par mondit seigneur l'evesque de Tournay, chancellier de l'ordre. Laquelle messe s'est continuee moult solemnellement et mondit seigneur est seul alé a l'offrande partant de sondit oratoire en la maniere cothidienne sans autre solemnité.

\section{[67] [Zum weiteren Verlauf der Messe und dem anschließenden Auszug aus der Kirche.]}

Apres ladite l'offrande [!] faite s'est presenté et mis a genoulx devant mondit seigneur le souverain messire Jehan de la Bouvrie, seigneur de Wiere, licencié en loix, president de son conseil, ${ }^{332}$ requerant treshumblement et reverenment l'ordre et estat de chevalerie. ${ }^{333}$ Et mondit seigneur appellé le conte de Nassouw, son marischal, ${ }^{334}$ tenant l'espee d'honneur, a prins de lui ladite espee et a tout icelle a cree et fait chevalier ledit seigneur de Wiere le premier apres que mesme il avoit receu ledit ordre de chevalerie. Et ce fait, mondit seigneur s'est retourné en sondit oratoire et la messe s'est parachevee et accomplié sans sermon, mais apres la fraction y ot benediction solemnelle. La messe dite et finie, mesdites dames sont descendues de loxal parties d'eglise et retournees vers la court a tout leur compaignie. Et mondit seigneur le souverain surattendit ung peu jusques que le prelat, assavoir monseigneur le chancellier de l'ordre, qui avoit dit ladite grant messe, fut revestu des habis de l'ordre. Et lui venu se departit de l'eglise et monta a cheval et pareillement messeigneurs les chevaliers freres ensembles les officiers dudit ordre alans ordonneement devant lui et ainsi retournerent devers la court, tenans et gardans leur ordre et maniere d'aler comme devant. ${ }^{335}$ Saulf tant que mondit seigneur le souverain ala le darrenier seul, tenant et gardant le lieu, honneur et estat du souverain dudit ordre.

\section{[68] [Sitzordnung beim Festmahl.]}

Mondit seigneur le souverain arrivé en sa court et descendu de son cheval, messeigneurs lesdis chevaliers freres ensemble lesdis officiers de l'ordre, aussi descendus, l'ont convoyé jusques a la sallette devant la chambre ordonnee pour le chappittre dudit ordre. Et a mondit seigneur retenu au disner mesdis seigneurs les chevalliers [!], ses freres de l'ordre, ensemble les quatre officiers d'icellui ordre. Et fut couverte la table de [fol. 27r] mondit seigneur et l'estat tenu en la petite salle de sondit hostel audit Bruges ${ }^{336}$ ou avoit trois tables drecees, assavoir la grande pour mondit seigneur

$332 \mathrm{Zu}$ Jan van der Bouverien, Herr von Wiere, vgl. die Angaben in § 47 mit Anm. 239.

333 Diesen Ritterschlag erwähnen auch Chroniques de Molinet, I, 1935, S. 253; Delepierre, Fête en 1478, 1842, S. 540. Weitere Ritterschläge erfolgten am 1. Mai im Laufe der der „Große Messe“; vgl. § 95. - Auch Karl der Kühne hat 1473 das Ordensfest zum Anlass genommen, Georges Chastellain und Thomas Malet zum Ritter zu schlagen; vgl. PB 3, S. 42 f. § 18 und S. 45 § 22.

$334 \mathrm{Zu}$ Adolf, Gf. von Nassau, vgl. die Angaben § 47 mit Anm. 238.

335 Vgl. § 45.

336 Zur Ausstattung des Festsaales vgl. auch die Angaben in $§ 39$ sowie in $§ 68$. 
le souverain, a laquelle s'assirens avec lui monseigneur l'evesque de Tournay, comme prelat qui avoit dit la grant messe, au dextre de lui, et a l'autre debout ou mesme bancq au senestre monseigneur de Ravestein $\{55\}$, qui l'avoit fait chevalier. A l'autre table estoient assis messeigneurs les chevaliers freres de l'ordre, monseigneur l'evesque de Mets $^{337}$, monseigneur le marquis de Bade $\{102\}^{338}$, monseigneur de Saintpol $\{83\}^{339}$ et monseigneur de Wierre ${ }^{340}$, president, et autres grans seigneurs tant d'Alemaigne que de la langue franchoise qui avoient honnoré et accompaigné mondit seigneur es actes dudit jour, et pour les autres trois officiers, assavoir les tresorier, graffier et roy d'armes dudit ordre, avoit une autre petite table a laquelle ilz s'assirent. Et fut ledit disner bel, honnerable et plantureux et le drecsoir y estoit bien garny de riches joyaulx et vaisselles d'or et d'argent et d'autres bonnes bagues. ${ }^{341}$

[69] [Nachdem bekannt geworden war, dass der französische König in den Hennegau eingefallen ist, wurde über den weiteren Verlauf des Ordensfestes diskutiert.]

Apres disner graces dites, mondit seigneur se devisa ung peu avec messeigneurs les chevalliers freres et chancellier de l'ordre et autres. Et finablement prinses vin et espices il se retrahit et messeigneurs lesdis chevaliers freres ensemble les officiers dudit ordre le convoierent jusques au lieu cappitulaire. Ouquel lieu eulx venus fut parlé des premieres vespres de la feste de l'ordre que selon les status dudit ordre ne se devoient dire jusques a lendemain apres disner, premier jour du mois de may, ${ }^{342}$ jour a ce statué et ordonné par lesdis status. ${ }^{343}$ Et fut mis en deliberacion par l'ordonnance de mondit seigneur le souverain, se lesdites vespres se pourroient anticiper d'un jour pour estre dites apres disner ensuivant, veu les nouvelles qu'il avoit journellement de l'approichement du roy de France et de son armee venant sur son pays de Haynnau. Et mesmement que le roy faisoit assieger la ville de Condet. ${ }^{344}$ Et la matiere bien debattue a esté la deliberacion de mondit seigneur le souverain et de tous messeigneurs les chevaliers freres de l'ordre illec presens, qu'il estoit besoing de anticiper le devin service accoustumé pour la feste et de haster et abbregier le chappittre de l'ordre, afin que mondit seigneur et ses capitaines se puissent mettre a champs, a tout son armee le plus tost que faire se pourroit pour aler secourir a ladite ville de Condet et resister aux entreprinses de ses adversaires a la preservacion et deffence de ses pays et subgiez.

$337 \mathrm{Zu}$ Georg von Baden, Ebf. von Metz vgl. die Angaben in $§ 5$ mit Anm. 17. - Zu den bei den Ordensfeierlichkeiten anwesenden Gäste vgl. auch § 41, Anm. 213.

$338 \mathrm{Zu}$ Christoph von Baden vgl. die Angaben in $\S 10$ mit Anm. 58.

$339 \mathrm{Zu}$ seiner Person vgl. die Angaben in § 47 mit Anm. 237.

$340 \mathrm{Zu}$ Jan van der Bouverien, Herr von Wiere, vgl. die Angaben in $\S 47$ mit Anm. 239.

341 Zum Schaugeschirr vgl. die Angaben in PB 3, S. 51 mit Anm. 126 sowie KümmeL, Fürsten im Wettstreit, 2009; SPIEss, Schatz, 2010, S. 274-276; CARoN, Banquet, 2007, S. $18 \mathrm{f}$.

342 1. Mai 1478.

343 Nach $\S 52$ (neu § 27) der Statuten (dazu S. 16, Anm. 14) sollen die Mitglieder am Abend vor dem eigentlichen Beginn des Ordensfestes gemeinsam eine Vigilienmesse besuchen.

344 Am 28. April überfiel Ludwig XI. die Stadt Condé. Vgl. dazu u. a. Mémoires de la Marche, 3, 1885, S. 251 f. mit Anm. 5; Barante/Gachard, Histoire, II, 1838, S. 602; Bock, Maximilian, 1970, S. 41 f.; Wiesflecker, Maximilian, 1, 1971, S. $142 \mathrm{f}$. 
Et veu que l'article des status de l'ordre parlant du premier jour de may pour dire lesdites premieres vespres de la feste n'est pas du nombre de ceulx qui sont exceptez et reservez comme non muables, [fol. 27v] mais se peut moderer et interpreter par et selon l'exigence et necessité des affaires du souverain et de l'ordre pour le temps, et que autre fois lesdites premieres vespres et la solemnité de la feste pour moindre cause avoient esté retardees par aucuns jours, a finablement conclut mondit seigneur par l'advis et deliberacion de messeigneurs ses freres dessusdis de anticiper pour ceste fois lesdites premieres vespres d'un jour et consequenment la feste de l'ordre pour la grant necessité des affaires dessusdites. ${ }^{345}$

345 Ms.: Der Rest der Seite und das folgende Blatt (fol. 28) sind unbeschrieben. 


\title{
Teil 2: Das Ordensfest 1478 in Brügge
}

\author{
[fol. 29r/1r] ${ }^{1}$ \\ [70] [Es folgen die Eintragungen zum 21. Ordensfest, abgehalten 1478 in Brügge.]
}

Cy apres s'ensuivent les actes du $\mathrm{xxj}^{\mathrm{e}}$ chappittre du noble ordre de la Thoison d'or, ${ }^{2}$ tenu et celebré par tresexcellent et trespuissant prince monseigneur le duc Maximilian, duc d'Austrice, de Bourgoingne, de Brabant etc., apres qu'il avoit relevé et receu ledit ordre comme chief et souverain d'icellui en sa ville de Bruges par la maniere contenué et declairee ou quayer icy precedent l'an M cccc lxxviij.

\section{April 1478}

[71] [Die versammlten Mitglieder warten auf das Erscheinen des neuen Souveräns.]

Ledit darrenier jour dudit mois d'avril l'an milquatrecens soixante dixhuit ${ }^{3}$ qui fut le jour de l'ascension Nostre Seigneur, apres disner devant vespres, se assamblerent oudit lieu cappitulaire messeigneurs les chevaliers freres et compaignons de l'ordre cy apres nommez. C'est assavoir messire Jehan, seigneur de Lannoy $\{50\}$, monseigneur Adolf de Cleves $\{55\}$, seigneur de Ravestein, messire Loys, seigneur de Gruythuse $\{61\}$, conte de Wincestre, messire Phelippe de Croy $\{74\}$, conte de Chimay, et messire Engelbert, conte de Nassow $\{77\}$, seigneur de Breda, ensemble les quatre officiers dudit ordre. Et en attendant la venue de monseigneur le duc, chief et souverain d'icellui ordre, fut par eulx ung peu loqueté des affaires du mesme ordre dont faisoit a advertir mondit seigneur, mais obstant qu'il estoit ja tard et qu'il leur faloit aler aux vespres premieres de la feste dudit ordre, anticipees pour cause et en la maniere dessus declarees, ${ }^{4}$ fut leur advis et conclusion pour ceste fois que de riens ilz ne parleroient a mondit seigneur le souverain devant vespres, mais seulement a lui se presenteroient et reverenment et humblement le remercieroient et feroient remercier encore de rechief du grant honneur que pour ce jour il leur avoit fait et demonstré et audit ordre en ce qu'il s'estoit fait chevalier et avoit receu et relevé ledit ordre comme chief et souverain d'icellui. Et entretant y est survenu mondit seigneur, mis et colloqué en son siege, illec pour lui ordonné et richement paré comme siege du souverain dudit ordre. ${ }^{5}$

1 Zur doppelten Foliierung siehe die Erklärung in der Einleitung S. 37 mit Anm. 133.

2 Zur Zählung der Ordensfeste vgl. § 1.

3 30. April 1478.

4 Vgl. dazu die Angaben in $§ 69$ mit Anm. 343.

5 Zur Ausstattung des Versammlungsraumes vgl. die Angaben in § 39. 
[72] [Der Kanzler dankt dem neuen Souverän im Namen der Mitglieder für dessen Übernahme des Ordens und weist ihn darauf hin, dass einige Ordensangelegenheiten zu klären sind.]

Item et mondit seigneur le duc ainsi estant assis oudit siege, mesdis seigneurs les chevaliers freres et compaignons de l'ordre treshumblement par la bouche dudit reverend pere monseigneur l'evesque de Tournay, chancellier dudit ordre, l'ont remercié par congratulacion deue de son joieux advenement, de l'onneur qu'il avoit fait et faisoit a l'ordre et a la noble compaignie d'icellui, moult joyeux de ce et consolez et mesmement rendant graces a Dieu tresdevotement de ce qu'il lui avoit pleu leur pourveoir d'un si tresnoble et tant verteux prince, pour estre leur chief et souverain oudit ordre. Et combien qu'il eust des affaires beaucop en l'ordre, toutevoie veans mesdis seigneurs qu'il estoit tard et <qu'il estoit> heure pour aler a vespres, ilz attendroient de plusavant lui $<$ en $>$ parler et de mettre chose aucune en termes jusques au retour desdis vespres.

[73] [Der Souverän bedankt sich und äußert seine Freude, dem Orden als Souverän angehören zu dürfen, und erkärt sich bereit, über die Ordensangelegenheiten zu sprechen.]

Oyes lesquelles remonstrances et remerciemens, mondit seigneur le souverain benignement recueillant mesdis seigneurs les chevaliers freres et compaignons de l'ordre et les officiers aussi, dit et respond liberalement qu'il l'avoit fait volentiers et lui estoit grant plaisir de estre en ceste compaignie et d'en estre le chief et qu'il semploieroit a son povoir ${ }^{6}$ pour entretenir ledit ordre et aussi s'il povoit le augmenter. Et en oultre que lesdiz seigneurs freres le advertissent de ce qu'il devoit faire et volentiers le feroit, qu'il estoit content de s'en aler a vespres, au retour desquelles il seroit tout prest avec eulx en tout ce qui seroit a faire.

[74] [fean Gros ist während der Vakanz zum Trésorier ernannt worden und bittet nun um seine offizielle Bestätigung seines Amtes.]

Du tresorier de l'ordre. ${ }^{7}$

Retenue de maistre Jehan Gros a l'office de tresorier de l'ordre ${ }^{8}$

$[a]^{9}$ Apres ceste response de mondit seigneur le souverain s'est mis a genoulx oudit chappittre devant mondit seigneur le souverain maistre Jehan Gros, remonstrant que pieça feu monseigneur le duc Charles \{34\}, que Dieu absoille, en son vivant chief et souverain du noble ordre de la Thoison d'or, pour consideracion de ses services et pour aultres causes a ce le monvans le avoit eu fort pour recomandé a l'office du tresorier de l'ordre quant premiers il vaqueroit par trespas, cession, $<$ ou $>$ resignacion ou autrement

6 Ms.: a son povoir steht über der Zeile und eine Marke zeigt auf die dafür vorgesehenen Stelle im Text.

7 Ms.: Diese Zeile steht am Rand zu Beginn des Absatzes. - Steenberch hatte wohl nachträglich und zur besseren Übersicht immer wieder Zwischenüberschriften eingefügt; je nach freiem Platz stehen sie zwischen den Absätzen oder am linken Rand und sind in einer größeren Schrift geschrieben.

8 Ms.: Diese Zeile wurde zwischen den Absätzen eingefügt und ist unterstrichen; vgl. dazu Anm. 7.

9 Ms.: Zur besseren Lesbarkeit dieses langen Paragraphen wurden Absätze und Unterpunkte eingefügt. 
[fol. 29v/ 1v] comment qu'il fust et qu'il lui donnoit de estre preferé devant tout aultre. Parquoy, vacant darrenierement ledit office de tresorier par le departement de cellui qui darrenierement l'avoit excercé,$^{10}$ il avoit adverti de ce que dit est mondit seigneur le duc et pluseurs de messeigneurs les freres de l'ordre dessusdit et en fait apparoir, parquoy avoit lors pleu a mondit seigneur par l'advis d'aucuns de messeigneurs lesdis chevaliers freres de l'ordre icy presens lors estans lez lui et du consentement d'aucuns autres absens, le ordonner et commettre a l'administracion et excercice dudit office de la tresorrie de l'ordre par maniere de provision jusques autrement en seroit pourveu et ordonné en l'assamblee lors prouchaine avenir de mesdis seigneurs les chevaliers freres dudit ordre, et ce a cause que icellui ordre n'avoit lors aucun chief et que mondit seigneur le duc n'avoit encore relevé ne receu ledit ordre. Et en vertu de sadite commission faite par maniere de provision il avoit fait le serment accoustumé dudit office de tresorier et receu en administracion et garde les joyaulx, manteaulx, escriptures et autres biens dudit ordre que encores il gardoit. ${ }^{11}$

[b] Consideré d'onques que mondit seigneur le duc avoit a ce jour relevé et receu ledit ordre de la Thoison d'or comme chief et souverain d'icellui et que lui et mesdis seigneurs estoient assamblez en leur chappittre, supplia ${ }^{12}$ treshumblement ledit maistre Jehan Gros a mondit seigneur le souverain et a tous mesdis seigneurs les chevaliers freres dudit ordre illec presens, que a mondit seigneur pleust de sa grace par l'advis de mesdis seigneurs les freres lui confermer, ottroier et donner plainement et de nouvel, se mestier estoit, ledit office de tresorier pour par lui le povoir, retenir, garder et excercer dorsenavant et en joyr ensemble des gaiges, robes ou pension, honneurs, prouffis, prerogatives, franchises, libertez et autres drois et emolumens accoustumez et qui y appartiennent selon les status et ordonnances dudit ordre.

[c] Oyé laquelle supplicacion dudit maistre Jehan Gros, il a esté fait retraire hors du chappittre pour par mesdis seigeneurs y avoir leur advis apres lequel lui seroit fait response.

[d] Et ledit maistre Jehan Gros parti du chappittre, monseigneur l'evesque de Tournay, chancellier de l'ordre, a par le commandement de mondit seigneur le souverain demandé les opinions sur ladite supplicacion d'icellui maistre Jehan Gros et pour savoir s'il avoit chose a redire en sa personne, parquoy il ne deust porter et excercer ledit office de tresorier de l'ordre.

[e] Et ouys les veux de tous mesdis seigneurs les chevaliers freres non saichant que tout bien en la personne dudit maistre Jehan Gros, et icellui rappellé, par leur advis

10 Jean Gros (1434-1484) war unter Hz. Karl seit 1453 als dessen Audienzier und dazu noch seit 1468 als Sekretär für Finanzangelegenheiten tätig; zur Person vgl. BARTIER, Légistes, 1955, S. 372- 377, hier S. 375 f. zu seiner Ernennung zum Trésorier; KolLER, Service, 1971, S. 65-67; Cockshaw, Prosopographie, 2006, S. 47 f., Nr. 37. Eine schriftliche Fixierung von Hz. Karls Versprechen konnte bisher nicht gefunden werden.

11 Die Aufgaben des Trésoriers wird in § 33-39 (neu § 7-11 der Amtsträger) der Statuten (dazu S. 16, Anm. 14) geregelt. Jean Gros erhielt das Amt des Ordenstrésorier, nachdem sein Vorgänger Guillaume de Clugny ins französisiche Lager gewechselt war und sein Ordensamt zurückgegeben hatte; vgl. dazu § 9, Anm. 40. Jeans provisorische Ernennung erfolgte am 29. Nov. 1477; so Koller, Service, 1971, S. 63 f. Im Protokollbuch feht unter dem genannten Datum ein Hinweis auf eine Sitzung.

12 Ms.: Am linken Seitenrand befindet sich vor der Zeile, die mit supplia beginnt ein Doppelstrich. 
et deliberacion mondit seigneur le souverain l'a confermé oudit office de tresoirer et le lui a donné de nouvel avec les gaiges, robes ou pensions, prerogatives, franchises, libertez et aultres drois, prouffis et emolumens accoustumez et qui y appartiennent, dont il a de rechief fait le serment oudit chappittre en la presence de mesdis seigneurs selon les articles et chappittres desdis ordonnances dudit ordre, touchans et regardans ledit office de tresorier d'icellui ordre, et m'a commandé mondit seigneur le souverain d'en faire audit maistre Jehan Gros ses lettres patentes en forme deue soubs le seel de l'ordre. ${ }^{13}$

[f] Dont ledit maistre Jehan a remercié treshumblement mondit seigneur $l \mathrm{e}<\mathrm{s}>$ souverain et tous mesdis seigneurs les chevaliers freres dudit ordre.

\section{[fol. 30r/2r]}

\section{[75] [Der gemeinsame Gang zum Vesper-Gottesdienst.]}

Ce fait mondit seigneur le souverain est allé a vespres. ${ }^{14}$ Et en y alant les chevaliers [et] escuiers de l'ostel alerent tous a piet, et apres suivrent les officiers d'armes, aussi a piet vestus de leurs cottes d'armes. Et apres lesdis officiers d'armes Thoison d'or, le roy d'armes, alant a cheval et apres lui le graffier et le tresorier apariez ensemble, puis monseigneur l'evesque de Tournay seul. Apres mondit seigneur de Tournay monseigneur le conte de Nassouwe $\{77\}$, chevalier frere, aussi seul pour ce que le nombre de messeigneurs les chevaliers freres estoit non per. Apres lui suivirent les autres mesdis seigneurs les chevaliers freres de l'ordre, deux a deux, les plus jeunes devant et consequenment les anchiens. Et mondit seigneur le duc seul le darrenier comme chief et souverain dudit ordre. Apres mondit seigneur suivrent pour l'accompaingner reverend pere en Dieu monseigneur l'evesque Sibinicensis, ${ }^{15}$ orateur de nostre Saint Pere cum potestae legati, monseigneur l'evesque de Mets ${ }^{16}$, monseigneur Jaques de Savoye $\{84\}$, conte de Romont, ${ }^{17}$ monseigneur Phelippe de Cleves, filz de monseigneur de Ravestein $\{55\},{ }^{18}$ messeigneurs les contes de Saintpol

13 Vgl. Reg. 48.

14 Nach § 49 (neu § 24) der Statuten (dazu S. 16, Anm. 14) waren die Mitglieder des Ordens verpflichtet, am Abend vor Beginn des eigentlichen Ordensfestes am VesperGottesdienst teilzunehmen.

$15 \mathrm{Zu}$ Lucas de Tolentis vgl. die Angaben in $\S 8$ mit Anm. 32. - Zu den bei den Ordensfeierlichkeiten anwesenden Gästen vgl. auch $\S 41$, Anm. 213. Einige der Gäste nahmen auch an der Mahlzeit des Ordens teil; vgl. § 97.

$16 \mathrm{Zu}$ Georg von Baden, Ebf. von Metz, vgl. die Angaben in $\S 5$ mit Anm. 17.

17 Jakob von Savoyen wird noch während des Festes in den Orden aufgenommen, vgl. dazu § 138; mehr Angaben zu seiner Person finden sich in § 261 mit Anm. 283.

18 Philipp von Kleve (1456-1528) wuchs am burgund. Hof auf und wurde im Frühjahr 1477 als einer der möglichen Heiratskandidaten für Hz.in Maria gehandelt. Er diente Hz. Maximilian als Rat, Kammerherr und Truppenführer und in Zeiten der Abwesenheit seines Vaters war er als dessen Stellvertreter als burgund. Statthalter im Hennegau tätig. Spätestens 1488 beteiligte er sich dann aber an der flämischen Opposition gegen Hz. Maximilian. Kg. Ferdinand von Neapel \{72\} nannte ihn 1478 in seiner Kandidatenliste; vgl. Reg. 37. Zu seiner Person vgl. u. a. Cools, Mannen, 2000, S. 338 f., Nr. 133; Debris, Felix Austria, 2005, S. 581; Philippe de Clèves, 2007; DünNebeIl, Erbtochter, 2008, S. 179. 
$\{83\}^{19}$ et de Porcien ${ }^{20}$ et pluseurs aultres princes et grans seigneurs et messeigneurs les presidens et autres notables du conseil de mondit seigneur, tous a cheval. ${ }^{21}$

\section{[76] [Einzug in die Kirche und Platzierung.]}

Mondit seigneur le duc arrivé a la porte de l'eglise Saint Saulveur, lui vint au devant tout le clergié processionellement et mondit seigneur de Tournay, chancellier de l'ordre, ja revestu de chappe ecclesiastique moult riche et belle ${ }^{22}$ cum infula et baculo pastorali, accompaignié d'autres pluseurs prelas, lui vint baillier l'eaue benite a l'entree de ladite eglise. Et le clergié ensemble ${ }^{23}$ lesdis prelas ont ainsi convoié et conduit processionellement et tout chantant mondit seigneur le souverain jusques ou grant chœur d'icellui eglise. La ou mondit seigneur arrivé s'est mis en son siege, richement paré de ciel dorssier, ${ }^{24}$ et devant de bien riche drap d'or fait, [au dessus] lequel siege estoit mis le tableau de ses armes et pardessus sondit tableau le blason des armes de feu mondit seigneur le duc Charles $\{34\}$, son beaupere et predecesseur, tout d'une mesme longuer et largeur qu'estoit ledit tableau desdis armes de mondit seigneur. ${ }^{25}$ Messeigneurs les chevaliers freres de l'ordre se mirent aux deux ren[g]s es haultes formes, chascun soubz le tableau de ses armes. ${ }^{26} \mathrm{Et}$ les trois officiers de l'ordre, assavoir le tresorier, le graffier et le roy d'armes, se mirent devant mondit seigneur sur le banc illec pour eulx ordonné. Et les autres officiers d'armes se mirent es basses formes des deux ren[g]s de tous vestus de leurs cottes d'armes, saulf ledit Thoison d'or qui avoit le grant collier, servant pour son office a tour du $\mathrm{col}^{27}$

$19 \mathrm{Zu}$ seiner Person vgl. die Angaben in § 47 mit Anm. 237.

20 Philippe de Croy, Gf. von Porcien ( $†$ 1511), Sohn Antoines de Croy $\{15\}$, befand sich in frühen 1470er Jahren in den Diensten Ludwigs XI., Kg. von Frankreich, wechselte dann aber wieder zu Hz. Karl, mit dem er zusammen aufgewachsen war. 1476 führte er aber burgund. Truppen nach Lothringen und wurde vor Nancy gefangen genommen. Auch unter Hz. Maximilian diente er als Truppenführer. Jean de Melun $\{28\}$ nominierte ihn 1478 als einen der Aufnahmekandidaten (Reg. 46). Zu seiner Person vgl. u. a. Wymans, Inventaire de Croy, 1977, S. 50, Nr. 37-40; BorN, Croy, 1981, S. 67 f.; Cools, Mannen, 2000, S. 283 f., Nr. 60.

21 Die Reihung entspricht der Prozession vom Vormittag anlässlich Maximilians Ernennung zum Ordenssouverän; vgl. § 45-67. Bei den früheren Ordensumzügen war die Reihung jedoch eine andere: als erstes der gesamte burgund. Hof, dann der Orden und zuletzt die Gesandten; vgl. z. B. die Beschreibung von 1473 in PB 3, S. 37 f., § 12. Dazu auch DüNNEBEIL, Innen und Außen, 2005, S. $252 \mathrm{f}$.

22 Der Orden selbst besitzt noch heute ein äußerst wertvolles, reichbesticktes Messornat aus dem 15. Jahrhundert, das in der Schatzkammer des Kunsthistorischen Museums in Wien zu sehen ist. Vgl. dazu u. a. Schmitz-von Ledebur, Messornat, 2008; dies., Textilien, 2009, S. 89-107; dies., Messornat, 2010; Hamilton, Art of Embroidery, 2013; http://bilddatenbank.khm.at/viewArtefact?id=86213 (11.11.2015) (alle mit zahlreichen Abb.).

23 Ms.: ensamble steht über einer Radierung.

24 Vgl. Beschreibung der Ausstattung der Kirche St. Salvator anlässlich des Ordensfestes in § 36-38.

25 Vgl. dazu die Angaben in $\S 30$ mit Anm. 183.

$26 \mathrm{Zu}$ den Wappentafeln vgl. oben § 31-34 mit Anm. 187.

27 Zur Kette des Toison d'or vgl. in § 42, Anm. 216. 


\section{[77] [Der Orden versammelt sich nach dem Gottesdienst zu einer Sitzung.]}

\section{L'assise du premier chappittre de ceste feste ${ }^{28}$}

Apres vespres mondit seigneur le souverain et messeigneurs les chevaliers freres de l'ordre ensemble les quatre officiers sont retournez devers l'ostel de mondit seigneur par les mesmes chemin et ordonnance que venus estoient. Et mondit seigneur retourné en sondit hostel, il s'est retrait ou chappittre et mesdis seigneurs les chevaliers freres ensemble les quatre officiers avec lui. Mondit seigneur s'est mis et assis en son siege et messeigneurs les chevaliers freres es bancs des deux rengs au dextre et au senestre. Et lesdis < quatre> officiers ou petit darrenier la table a l'opposite de mondit seigneur pour eulx ordonnez au debout du parquet consistorial.

[78] [Diskussion, wie mit den fünf in Frankreich befindlichen Mitgliedern während der Offrande verfahren werden soll.]

\section{Touchant les $\mathbf{v}$ chevaliers estans en France ${ }^{29}$}

En ce chappittre a esté premierement adverti mondit seigneur le souverain, pour ce qu'il estoit nouvel en l'ordre, des ceremonies qui seroient a tenir en l'eglise le lendemain a l'offrande de la [fol. 30v/2v] grant messe et l'autre jour apres a la messe des ames. Et lui a fait rapport monseigneur de Tournay, chancellier, par l'ordonnance de mesdis seigneurs les chevaliers freres de l'ordre de ce que desja avoit par eulx esté avisé saulve sa bonne correction, touchant les ceremonies de ladite offrande, pour lesdis deux messes solemnelles, mesmement au regart ${ }^{30}$ des $\mathrm{v}$ chevaliers estans ou parti contraire. Assavoir que pour eulx nulle offrande ne seroit et qu'ilz ne seroient appellez pour y aller, mais a leur tour qui seroit pour les appeller le roy d'armes Thoison d'or yroit devant les lieux des tableaux de leurs armes, faisant petite inclinacion de la teste devers leursdis tableaux et sans mot dire passeroit oultre et yroit appeller le plus prouchain apres eulx non noté, tant d'ung lez que d'aultre. ${ }^{31}$ Lequel advis a bien pleu a mondit seigneur. Et combien qu'il eust samblé a aucuns de mesdis seigneurs, que le cas de monseigneur le bastart \{54\} et de monseigneur Jaques de Luxembourg $\{67\}$, qui avoient esté prins en exploit de guerre ou service et en la querelle de feu mondit seigneur le duc Charles $\{34\}$, parquoy encore se povoient presumer estre prisonniers du roy, fust different et non pareil au cas des autres trois chevaliers, assavoir des sires de la Roiche de Nolay $\{60\}$, d'Escardes $\{69\}$ et de Clessy $\{65\}$, qui de leur volunté sans constrainte nulle s'estoient tournez au parti contraire; veu que ce que mondit seigneur le bastart et monseigneur Jaques en avoient fait ou faisoient estoit vraissemblablement contre leur cuer et volunté et par constrainte a qouy l'on deust avoir regart; toutevoye $<$ finablement $>$ la chose bien debattue, consideré mesmement et attendu que deux

28 Ms.: Dieses Zwischenüberschrift steht zu Beginn des Absatzes am linken Rand und ist links und rechts mit geschweiften Klammern versehen; vgl. dazu Anm. 7.

29 Ms.: Dieses Zeile steht am Beginn des Absatzes und ist mit geschweiften Klammern links und recht versehen; vgl. dazu Anm. 7. - Fortsetzung von § 28 f., dort mit Angaben zur Mitgliedschaft dieser Mitglieder im Michaelsorden umd zum Exklusitätsgebot des Ordens vom Goldenen Vlies.

30 Ms.: au regart steht über einer Radierung.

$31 \mathrm{Zu}$ ihrem Ausschluss vom öffentlichen Zeremoniell vgl. in der Einleitung S. 18f. sowie die Ausführung in § 88-91, 123 und 145. 
de mesdis seigneurs les chevaliers freres presens en ce chappittre affermoient avoir veu de leurs yeulx, que ledit monseigneur Jaques de Luxembourg avoit relenqui et delaissié le collier de l'ordre de la Thoison d'or et portoit au col le collier de l'ordre du roy de France; qu'il estoit aussi tout notoire selon le rapport et tesmoingnaige de pluseurs nobles hommes et d'autres gens de bien affermans avoir veu, que mondit seigneur le bastart de Bourgoingne, <avoit> delaissié le collier dudit ordre de la Thoison d'or, portoit publiquement le collier dudit ordre dudit roy de France, ce qu'ilz n'avoient peu ne d'eu faire selon les status et ordonnances d'icellui ordre de la Thoison d'or que chascun d'eulx solemnellement avoit jurez et promis: La conclusion dudit chappittre finablement a esté par l'accord et consentement commun d'eulx tous, qu'il seroit fait d'eulx deux comme des aultres trois dessusnommez en tant qu'il touchoit la mistere de ladite offrande. Mais s'ilz vouloient cy apres dire ou alleguer aucune chose pour leur excuse, ilz seroient oys et l'ordre y auroit lors tel regard qu'il appartendroit. ${ }^{32}$

[79] [Die Mitglieder werden aufgefordert, über mögliche Kandidaten für die Neuwahl nachzudenken.]

\section{Touchant les elections a faire (3) $^{33}$}

Apres a esté loqueté et parlé du fait des elections a faire pour remplir les lieux des chevaliers freres trespassez oudit ordre depuis le chappittre d'icelle darrenier present $^{34}$ et y ont esté nommez pluseurs tresexcellens princes et autres grans seigneurs et nobles hommes de divers royaumes, <et> provinces et pays, et mesmement pluseurs des pays et seignories de mondit seigneur le souverain et tant de son hostel comme aultres. Les noms et surnoms desquelz Thoison d'or, le roy d'armes, avoit mis par escript en une cedule que [!] [fol. 31r/3r] y fut levé pour par mesdis seigneurs y penser. ${ }^{35}$ Ont aussi mesdis seigneurs les chevaliers freres de l'ordre fait advertir mondit seigneur le souverain que, s'il avoit affection ou desir a aucuns particuliers pour les avoir accompaingnez a l'ordre, que son plaisir fust de le leur dire pour aussi y penser. Surquoy mondit seigneur le souverain a fait ouverture touchant aucuns de son hostel, mais pour ce qu'ilz n'estoient encores point chevaliers s'en passoit disant qu'il y penseroit. ${ }^{36}$

\section{[80] [Vor der Wahl sollen noch die corrections durchgeführt werden.]}

\section{Que premiers l'on besongneroit sur le fait des corrections ${ }^{37}$}

Ce fait pour ensuir les status et ordonnances de l'ordre en la maniere accoustumee par cy devant a esté deliberé et declaré par le chappittre dudit ordre que preallablement et premiers l'on y besoigneroit sur le fait des corrections des messeigneurs de l'ordre que

32 Fortsetzung in $§ 122$.

33 Ms.: Diese Zeile steht zwischen den Absätzen; vgl. dazu Anm. 7.

34 Gemeint ist hier das Ordensfest, das 1473 in Valenciennes gefeiert wurde; vgl. PB 3.

35 Vgl. Reg. 47. - In Anm. 132 der Verweis auf die die Neuwahl betreffenden Statutenartikel.

36 Fortsetzung in $§ 127$.

37 Ms.: Dieses Zeile steht am Beginn des Absatzes und ist mit geschweiften Klammern links und recht versehen; vgl. dazu Anm. 7. 
on fait desdites elections. ${ }^{38}$ Et pour ce qu'il estoit tard a la chose esté remise jusques au lendemain.

\section{Mai 1478}

[81] [Am Morgen des 1. Mai begegeben sich die Mitglieder in die Kirche, um an der Großen Messe teilzunehmen.]

Le lendemain, qui fut le premier jour du mois de may l'an xiiij ${ }^{\mathrm{C}}$ lxxviiij dessusdit ${ }^{39}$ mondit seigneur le souverain et messeigneurs de Lannoy $\{50\}$, de Ravestein $\{55\}$, de Gruythuse $\{61\}$, de Chimay $\{74\}$ et de Nassowe $\{77\}$, chevaliers freres et compaignons, ensemble les quatre officiers de l'ordre, cy dessus nommez, environ ix heures du matin, tous revestus et habillez des habis dudit ordre, chascun a son endroit, partirent de la court et alerent devers ladite eglise Saint Saulveur pour y oyr la grant messe, et tant y aller comme au retourner fut moult noblement et honnestement accompaigné mondit seigneur et y fut gardee l'ordonnance du soir precedent. ${ }^{40}$

\section{[82] [Zum Ablauf der Großen Messe.]}

Et mondit seigneur le souverain de l'ordre arrivé et descendu devant ladite eglise, lui et ceulx de l'ordre gardans leur ordonnance premiere, sont allez tout droit passans parmy la nef d'icelle jusques ou grant chœur, la ou mondit seigneur s'est mis en son siege, pour lui illec ordonné et paré, et messeigneurs les chevaliers freres se sont mis chascun soubz le tableau de ses armes es deux rengs des haultes formes. Et les trois officiers, assavoir les tresorier, graffier et roy d'armes dudit ordre, se sont tenus devant mondit seigneur ou banc, pour eulx illec ordonné. Et mondit seigneur l'evesque de Tournay, chancellier de l'ordre, s'est revestu pour dire la grant messe. Et mondit seigneur le souverain ainsi arrivé en sondit siege, monseigneur l'evesque de Tournay accompaigné d'autres deux prelas, revestus pour lui ministrer, l'ung comme diacre et l'autre comme soubzdiacre porta[n]s leurs bastons pastoraulx comme lui, est venu baillier l'eaue benoite a mondit seigneur. Et ce fait, tantost il est retourné vers l'autel et a commencié ladite grant messe. Laquelle s'est celebree moult solemnellement et devotement a orgues et a discant et jubilacion et continuee jusques a l'offertoire inclus. A la fin duquel offertoire monseigneur le souverain et messeigneurs les chevaliers freres se sont disposez et preparez pour aler a l'offrande ${ }^{41}$ pour laquelle faire y ont esté gardees et observees les ceremonies qui s'ensuivent. C'est assavoir: ${ }^{42}$

38 Fortsetzung in $\S 101$.

39 1. Mai 1478.

40 Zum Umzug vgl. § 75.

41 Laquelle s'est celebree moult solemnellement [...] pour aler a l'offrande wird zitiert bei MERKLeY, Role, 1998, S. 356.

42 Diese Zeremonie beschreibt Delepierre, Fête en 1478, 1842, S. 339 f.; in seiner Beschreibung erfolgte die offrande jedoch gleich im Anschluss nach Hz. Maximilians Ernennung zum Ordenssouverän. - Den Ablauf der "großen Messe“ und dem dazugehörigen Münzopfer ist in aller Kürze in $\S 51$ (neu § 26) der Statuten (dazu S. 16, Anm. 14) geregelt; erste ausführlicher Beschreibungen sind bei den Festen von 1468 und 1473 zu finden; vgl. PB 2, S. 81-83, § 47-52 sowie PB 3, S. 42-49, § 17-38, dazu auch DüNNEBEIL, Innen und Außen, 2005, S. $244 \mathrm{f}$. 


\section{[Der Souverän wird als erstes zur Offrande aufgerufen.]}

\section{S'ensuit la mystere de l'offrande solemnelle du jour de la feste ${ }^{43}$ Touchant les ceremonies - de l'offrande ${ }^{44}$}

Que le roy d'armes Thoison d'or s'est venu premierement presenter devant mondit seigneur le souverain et illec il a appellé a haulte voix icellui monseigneur le souverain pour venir a l'offrande, le nommant reverenment et honnerablement par son nom [fol. 31v/3v] et par ses tiltres et dignitez comme chief et souverain du noble ordre de la Thoison d'or. ${ }^{45}$ Lequel ouy, mondit seigneur tantost s'est descendu et parti de sondit siege et seul allé faire son offrande d'ung denier d'or au prelat devant ledit autel, ledit roy d'armes le convoiant et alant devant lui. Et son offrande faite, mondit seigneur est retourné vers sondit siege et au passer et repasser mesdis seigneurs les chevaliers freres ensemble les autres officiers lui ont faite reverence deue.

\section{[84] [Aufruf der Könige von Aragon und England.]}

Apres a ledit roy d'armes Thoison d'or appellé au lez dextre treshault et tresexcellent prince le roy d'Arragon $\{57\}$ et au lez senestre treshault et trespuissant prince le roy d'Angleterre $\{63\}$, les nommant chascun par leurs noms, tiltres et dignitez pour chascun d'eulx venir a l'offrande ou procureur pour eulx. Ouy lequel appel monseigneur Adolff de Cleves $\{55\}$, seigneur de Ravestein, est parti de son lieu du lez senestre et tiré ou lieu dudit roy d'Arragon qui estoit le premier audit lez dextre pour tenir son lieu. ${ }^{46}$ Et monseigneur de Gruythuse \{61\}, conte de Wyncestre, s'est parti de son lieu du costé dextre et allé mettre ou lieu premier du costé senestre soubz le tableau des armes dudit roy d'Angleterre pour le representer selon l'ordonnance sur ce faite ledit penultieme jour du mois d'avril precedent. ${ }^{47}$ Et lesdis representacions ainsi faites pour ces deux roys, mesdis seigneurs de Ravestein et de Wyncestre sont descendus et eulx venus joindre ensemble ou milieu dudit chœur devant mondit seigneur le souverain lui faire la reverence et d'illec sont allez vers l'autel conjoinctement faire offrande pour lesdis roys, Thoison d'or les convoiant et allant devant eulx. Apres laquelle offrande faite, sont ensemble retournez jusques au lieu de leurdis premiere assamblee $<\mathrm{la}>$ devant mondit seigneur lui faisant le reverence et d'illec sont retournez et allez chascun vers son lieu propre soubz les tableaux de leurs armes.

\section{[85] [Aufruf der Könige von Sizilien und Kastilien.]}

Et apres est alé ledit Thoison d'or devant le second lieu du lez dextre, ou il a appellé pour venir a l'offrande tresexcellent don Fernande $\{72\}$, roy de Jherusalem, de Secille et de Naples. Et de la est il alé devant le second lieu du lez senestre, ou il a appellé

43 Ms.: Dieses Zeile steht am Beginn des Absatzes und ist mit geschweiften Klammern links und recht versehen; vgl. dazu Anm. 7.

44 Ms.: Der Text steht in der Kopfzeile der Doppelseiten fol. 3v/4r und 4v/5r; der Bindestrich trennt die Worte von der linken und rechten Seite. Vgl. dazu auch Anm. 7.

45 Nach Delepierre, Fête en 1478, 1842, S. 339, rief Toison d'or den Souverän mit folgenden Worten auf: Très haut, très excellent et très puissant prince, chef $d u$ très noble ordre de la Toison d'or, venez à l'offrande. Dazu auch Chroniques de Molinet, I, 1935, S. $253 \mathrm{f}$.

46 Chroniques de Molinet, I, 1935, S. 254, berichtet, dass Jean de Lannoy hier die Rolle des Stellvertreters übernahm.

47 Zur Benennung der Stellvertreter am 29. April 1478 vgl. § $26 \mathrm{f}$. 
le tresexcellent infant don Fernande $\{71\}$, roy de Castille, de Leon, de Cecille etc., prince de Navarre, pour venir a l'offrande. Lequel appel ouy, tantost monseigneur le conte de Chymay $\{74\}$, procureur dudit roy de Naples, fondé de povoir et procuracion souffisante ${ }^{48}$ dont il est apparu, s'est parti de son lieu privé qui estoit ou mesme costé dextre et s'est ${ }^{49}$ alé mettre ou lieu dudit roy de Naples. Et monseigneur de Lannoy $\{50\}$ s'est parti de son lieu privé qui estoit au lez senestre et [s'est] alé mettre ou lieu dudit roy de Castille estant ou mesme costé pour le representer. Et ce fait, sont eulx d'eulx descendus <et vennus> des lieux desdis excellens roys et venus joindre ensemble [fol. 32r/4r] ou milieu dudit chœur devant mondit seigneur le souverain et la reverence a lui faite, ilz sont conjonctement allez a l'offrande, ledit Thoison d'or, roy d'armes, alant devant eulx et les convoiant. Et leurdite offrande faite, sont retournez ensemble jusques devant ledit siege de mondit seigneur, la ou la reverence faite, ilz sont deppartis et tirez chascun d'eulx en son sondit lieu privé.

\section{[86] [Aufruf von Jean de Melun, Herr von Anthoing.]}

Ce fait, Thoison d'or, le roy d'armes, passant les lieux de feu messire Anthoine, seigneur de Croy $\{15\}$, au costé dextre et de feu monseigneur le duc d'Alençon $\{39\}$ du costé senestre, trespassez, appella audit lez dextre messire Jehan de Melun $\{28\}$, seigneur d'Anthoing, absent, pour venir a l'offrande ou procureur pour lui. Au lez senestre ou lieu opposite dudit monseigneur d'Anthoing estoit le blason des armes de feu messire Balduin de Lannoy $\{19\}$, jadis seigneur de Molembais, trespassé, parquoy n'y appella nul. Mais tantost s'est parti de son propre lieu mondit seigneur de Chymay $\{74\}$ et alé mettre ou lieu ${ }^{50}$ dudit monseigneur d'Anthoing estant au mesme lez dextre comme son procureur pour tenir son lieu et le representer. Et ce fait, icellui monseigneur de Chymay est venu seul devant mondit seigneur le souverain lui faire la reverence et apres ledit Thoison d'or alant devant lui, il est allé offrir pour et ou lieu d'icellui monseigneur d'Anthoing. Apres laquelle offrande faite, il est retourné jusques devant mondit seigneur le souverain, lui faire la reverence deue et, ce fait, il est retourné en son privé lieu dont il estoit party.

\section{[87] [Aufruf von Jean de Neufchâtel.]}

Ce fait est ledit roy d'armes Thoison d'or venu appeller audit lieu dextre messire Jehan de Neufcastel $\{52\}$, seigneur de Montagu, absent, pour venir a l'offrande ou procureur pour lui. Au lez senestre ou lieu opposite estoit le blason des armes de feu messire Symon de Lalaing $\{26\}$, jadis seigneur de Montigny, trespassé, parquoy ledit roy d'armes n'y appella nul. Mais tantost messire Loys, seigneur de Gruythuse $\{61\}$, conte de Wyncestre, se partit de son propre lieu ou lez dextre et se alla mettre ou lieu dudit seigneur de Montagu, pour le representer et supplier son lieu. Et incontinent il est descendu et venu devant mondit seigneur le souverain, lui faire la reverence. Laquelle faite, ledit roy d'armes Thoison d'or alant devant lui et le convoiant il est allé offrir pour icellui seigneur de Montagu. Laquelle offrande faite, il est retourné jusques devant mondit seigneur le souverain, lui faire la reverence comme devant et ce fait s'est alé remettre en son lieu premier.

48 Vgl. Reg. 35.

49 Ms.: mesme costé dextre et s'est steht über einer Radierung.

50 Ms.: ou lieu steht über der Zeile und eine Marke zeigt auf die dafür vorgesehenen Stelle im Text. 


\section{[88] [Aufruf von Ludwig von Brügge, Herr von Gruuthuse.]}

Apres est venu ledit roy d'armes Thoison d'or au costé dextre devant le lieu des armes de messire Phelippe Pot $\{60\}$, seigneur de Roiche de Nolay, estant en France. Et faite petite inclinacion de la teste devers lesdis armes sans mot dire et sans appeller aussi le frere opposite du lez senestre, ${ }^{51}$ assavoir feu messire Jehan, ber et seigneur d'Auxy $\{45\}$, car il estoit trespassé, il est passé oultre et alé devant monseigneur de Gruythuse $\{61\}$, conte de Wyncestre, present en personne audit costé dextre, lequel il a appellé pour venir a l'offrande. Au lez senestre il n'a point appellé, car feu messire Henry de Borssele \{44\}, seigneur de la Vere, a lui opposite, estoit trespassé.

\section{[89] [Aufruf von Johann, Hz. von Kleve.]}

Ce fait, est venu ledit roy d'armes devant le lieu des armes messire Phelippe de Crevecuer $\{69\}$, seigneur d'Escardes, estant aussi en France. Vers lesquelles armes il a semblablement fait [fol. $\mathbf{3 2 v} / \mathbf{4 v}$ ] petite inclinacion de la teste et passé oultre sans mot dire. Au lez senestre a lui opposite estoit le blason des armes de feu messire Regnault, seigneur de Brederode \{43\}, trespassé, parquoy ledit roy d'armes ne l'a point appellé. Apres est icellui roy d'armes Thoison d'or alé au lez senestre devant le lieu des armes de hault et puissant prince monseigneur Jehan, duc de Cleves $\{47\}$, conte de la Marke, absent, et a illec appellé mondit seigneur le duc de Cleves pour venir a l'offrande ou procureur pour lui. Et de la est ledit roy d'armes retourné au lez dextre devant le lieu des armes de messire Jaques de Luczembourg \{67\}, seigneur de Richebourg, estant aussi en France. Devers lesquelles armes il a fait petite inclinacion la de teste comme il avoit ja fait devant celles desdis freres de la Roiche $\{60\}$ et d'Escardes. Et ce pendant est parti de son lieu propre monseigneur Adolph de Cleves $\{55\}$, seigneur de $<\mathrm{Ra}>$ Ravestein, qui estoit du mesme costé senestre et s'est alé mettre ou lieu de mondit seigneur de Cleves, son frere, pour le representer et pour lui aler faire l'offrande. Et ladite representacion faite, est mondit seigneur de Ravestein descendu devant le lieu de mondit seigneur le souverain, lui faire la reverence. Apres laquelle il est alé offrir pour icellui monseigneur le duc de Cleves, son frere, convoyé par ledit roy d'armes Thoison d'or. Et a son retour de ladite offrande en passant devant mondit seigneur, la reverence a lui faite, il s'est alé remettre en son lieu propre.

\section{[90] [Aufruf von fean de Lannoy.]}

Ce fait est le roy d'armes Thoison d'or alé au lez senestre devant monseigneur de Lannoy $\{50\}$, present en personne. Lequel il a appellé pour venir a l'offrande et de la est ledit roy d'armes retourné vers le lez dextre devant le lieu des armes de messire Jehan de Damas \{64\}, seigneur de Clessy, aussi estant en France. Devers lesquelles armes il a fait petite inclinacion de la teste sans mot dire, comme devant les autres trois dessus nommez. Et ce pendant est descendu de son lieu mondit seigneur de Lannoy et venu devant monseigneur le souverain lui faire la reverence et de la est alé devers l'autel faire son offrande, convoyez ledit roy d'armes alant devant lui, et a son retour passant devant mondit seigneur lui a fait reverence et s'est mis en son lieu premier.

51 Dazu auch Chroniques de Molinet, I, 1935, S. 254. - Vgl. dazu den Beschluss in § 78. 
[91] [In der nächsten Reihe gibt es keinen Aufruf, da Anton, Bastard von Burgund, sich in Frankreich befindet und Louis de Chalon verstorben ist.]

Apres est le roy d'armes Thoison d'or alé au lez sensestre devant les armes de monseigneur Anthoine, bastart de Bourgoingne \{54\}, estant en France. Devers lesquelles armes il a fait petite inclinacion de la teste, sans mot dire ainsi qu'il avoit fait des autres quatre dessus nommez. Et pour ce que le siege opposite, assavoir feu monseigneur Loys de Chalon \{64\}, seigneur de Chastaeuguion, estoit trespassé, Thoison d'or n’y a nul appellé.

[92] [Aufruf von Philipp von Savoyen und Adolf von Kleve.]

Consequenment est alé le roy d'armes Thoison d'or devant le lieu des armes de monseigneur Phelippe de Savoye $\{68\}$, conte de Baugey, absent, lequel il a appellé pour venir a l'offrande ou procureur pour lui. Et de la s'est tourné [fol. 33r/5r] devers le lez senestre devant monseigneur Adolph de Cleves $\{55\}$, seigneur de Ravestein, present en personne. Lequel il a aussi appellé5 ${ }^{2}$ pour venir a l'offrande. Et entretant est parti de son lieu du lez senestre messire Engelbert de Nassouwe $\{77\}$ et s'est alé mettre ou lieu de monseigneur de Baugey le representer pour aler faire pour lui offrande. Et ce fait, sont descendus mesdis seigneurs de Ravestein et de Nassouwe desdis lieux jusques devant mondit seigneur le souverain, la ou ilz se sont joins ensemble, et la reverence faite a mondit seigneur le souverain, sont alez a l'offrande, convoiez par ledit roy d'armes alant devant eulx et a leur retour, venus devant mondit seigneur et la reverence faite, se sont departis et alez mettre chascun en son propre lieu premier.

[93] [Aufruf von Philipp de Croy, Gf. von Chimay.]

Apres ce, delaissez par ledit roy d'armes Thoison d'or les lieux des blasons des armes de feu messire Jehan de Reubempre $\{73\}$, jadis seigneur de Bievre, au lez dextre et de feu monseigneur Adolf de Gheldres $\{58\}$ au lez senestre, trespassez, est il alé audit lez dextre devant le lieu de monseigneur le conte de Chymay $\{74\}$, present en personne, lequel il a appellé pour venir a l'offrande. A l'opposite du quel au lez senestre estoit le blason des armes de feu messire Guy, jadis seigneur de Humbercourt $\{76\}$, conte de Megen, trespassé. Parquoy mondit seigneur de Chymay seul est descendu de son lieu et, venu devant mondit seigneur, lui faite la reverence et de la passé oultre et alé faire son offrande, convoié par ledit roy d'armes Thoison d'or, alant devant lui et faite la reverence a mondit seigneur a son retour, il s'est remis en son premier lieu.

\section{[94] [Als letztes wird Engelbert von Nassau aufgerufen.]}

Ce fait est alé ledit roy d'armes Thoison d'or au lez senestre devant monseigneur Engelbert, conte de Nassouwe \{77\}, present en personne, lequel il a appellé pour venir a l'offrande. Et pour ce que a l'oppossite de lui au lez dextre estoit le blason des armes de feu messire Jehan de Luczembourg \{75\}, jadis conte de Marle, trespassé, est mondit seigneur de Nassouwe alé seul et le darrenier faire son offrande, convoyé par ledit roy d'armes, alant devant lui et a son retour d'icelle, la reverence faite a mondit seigneur en passant, il s'est alé remettre en son lieu premier. Et ainsi a esté parachevé et accompli le mistere de ladite offrande pour ce jour.

52 Ms.: appellé steht über der Zeile und eine Marke zeigt auf die dafür vorgesehenen Stelle im Text. 
[95] [Im weiteren Verlauf der Großen Messe werden noch verschiedene Adlige zum Ritter geschlagen.]

Apres laquelle offrande a eu sermon brief et moult notable fait par le prelat disant la messe, assavoir monseigneur l'evesque de Tournay, chancellier de l'ordre, a la declaracion du mistere de ladite Thoison d'or, exhortant et amonestant messeigneurs les chevaliers freres dudit ordre et autres a vie honneste, œuvres et meurs vertueuses. Et a la fin de la messe mondit seigneur le souverain a devant le grant autel fait et cree trois chevaliers, ${ }^{53}$ assavoir messire Bertremy de Lichtesteyn $\{85\}$, son grant maistre d'ostel d'Ostrice ${ }^{54}$ messire Bartremy de Starnberg ${ }^{55}$ et messire Michiel de Traon ${ }^{56}$, tous nobles Bavieres. Fist aussi chevalier mondit seigneur [...] d'Anteluys, ${ }^{57}$ maistre de d'ostel. ${ }^{58}$

[96] [Nach dem Ende des Gottesdienstes kehren alle in die hzl. Residenz zurück.] Ce fait et le prelat revestu des habis de l'ordre, mondit seigneur le souverain s'est retourné [fol. 33v/5v] vers son hostel et avec lui messeigneurs les chevaliers freres ensemble les officiers de l'ordre, et a esté accompaignié mondit seigneur par l'ordonnance et tenant le chemin premiers. ${ }^{59}$

\section{[97] [Das Festmahl.]}

Mondit seigneur retourné en son hostel et convoyé parmy la grant salle jusques a la chambre devant le chappittre, assez tost il est venu disner en ladite grant salle, riche-

53 Diese Ritterschläge erwähnen auch Chroniques de Molinet, I, 1935, S. 254; Kuyer, Veertiende kapittel, 1981, S. 76. - Schon am 30. April hatte Maximilian anlässlich des Gottesdienstes zu seiner Ernennung zum Ordenssouverän Jan van der Bouverien zum Ritter geschlagen; vgl. § 67 mit Anm. 333.

54 Bartholomäus von Liechtenstein wurde noch am selben Tag in den Orden aufgenommen (§ 133); zu seiner Person vgl. die Angaben in § 10, Anm. 61 oben.

55 Chroniques de Molinet, I, 1935, S. 254, nennt ihn Berthemieu de Traembourg, baron. Es handelt sich dabei um Bartholomäus von Starhemberg (1460-1531), der 1482 zum Rat Ks. Friedrichs III. \{94\} ernannt wurde, 1501 zu Maxilmilians Rat und und Regent in Niederösterreich. Am 26. März 1477 hatte er von Ks. Friedrich III. den Befehl erhalten, gut gerüstet und mit vier Knechten, Hz. Maximilian auf seiner Brautfahrt zu begleiten; vgl. Chmel, Regesta, 1838, Nr. 7104; Rausch, Heirat, 1880, S. 167. Zu seiner Person vgl. u. a. Schwerding, Starhemberg, 1830, S. 146-150 (datiert S. 146 den Ritterschlag irrtümlich 1486 anlässlich der Königskrönung Maximilian in Aachen); Siebmacher, Oberösterreich, 1984, S. 392; HeInIG, Friedrich III., 1997, I, S. 253.

56 Chroniques de Molinet, I, 1935, S. 254, nennt ihn Michiel de Train, baron, Deutscher. Es handelt sich dabei um Michael von Traun ( $\dagger$ ca. 1522), der ab den 1490er Jahren als Maximilians Verwalter der niederösterreichischen Hauptmannschaft belegt ist. $\mathrm{Zu}$ seiner Person vgl. u. a. Hoheneck, Oesterreich ob der Enns, 1732, S. $706 \mathrm{f}$.

57 Ms.: Steenberch ließ für den Vornamen eine Lücke. - Nicolas d'Aveluys († um 1484) versah seit Nov. 1477 das Amt des zweiten Hofmeisters Hz. Maximilians; vgl. zu seiner Person u. a. Cools, Mannen, 2000, S. 232, Nr. 001. Molinet, I, 1935, S. 254, bezeichnet ihn als messire Colart de Havelu, Walon.

58 Ms.: Der letzte Satz wurde nachträglich zwischen den Zeilen von Steenberch mit kleinerer Schrift eingefügt.

59 Vgl. § 75 . 
ment a ce paree. ${ }^{60}$ Et tantost il s'est mis a table et messeigneurs les chevaliers freres avec lui au dextre et au senestre selon leur ordre et les quatre officiers ensemble a l'autre table pour eulx illec ordonnee. A la main senestre le drechoir ou buffet de la credence estoit moult richement furny et garny de beaucop riches $<$ s $>$, joyaulx et de vaisselle d'or et d'argent de grant valeur. Et fut le disner moult bel, riche, honnorable et plantureux. ${ }^{61}$ Et les plas de mondit seigneur furent honnorez et accompaignez par messeigneurs le conte de Romont $\{84\}$, le marquis de Baden $\{102\}$, monseigneur Phelippe de Cleves, ${ }^{62}$ le conte de Saintpol $\{83\}$ et autres pluseurs haulx contes, barons et grans seigneurs, a tout jeux et jubilacion de trompettes, menestrers et foison d'officiers d'armes vestus de leurs cottes d'armes en grant nombre. ${ }^{63}$

\section{[98] [Vorbereitungen für den Besuch der Vigilien.]}

Apres disner, < disner> graces dites et eues aucunes devises, mondit seigneur a mandé querir vin et espices et collacion faite d'iceulx, il s'est retourné en la chambre dudit chappittre, convoyé par mesdis seigneurs les chevaliers freres ensemble les officiers de l'ordre a tout grant noblesse. Et prinse l'eure pour aler a vigilles, chascun s'est retrait et alé devestir des habis de l'ordre devant le lieu capittulaire et retrait jusques a l'eure ordonnee pour aler a vigilles, pour lesquelles chascun se revesteroit d'abis noirs a ce servans en signe et par mistere de deul. ${ }^{64}$

\section{[99] [Kleidung und Ausstattung der Kirche für die Totenvigil.] \\ De l'office des vigilles des mors ${ }^{65}$}

Ledit premier jour dudit mois de may, ${ }^{66}$ apres disner environ quatre heures, mondit seigneur le souverain moult noblement et honnestement accompaignié et messeigneurs les chevaliers, freres et compaingnons dessus nommez ensemble les quatre officiers dudit ordre de la Thoison d'or, toutes revestus en deul de robes, manteaulx et chapperons noirs, excepté le roy d'armes Thoison d'or, qui n'avoit point de manteau, mais sur sa robe avoit et portoit atour du col ledit grant collier d'icellui ordre ${ }^{67}$ et son chapperon noir sur l'espalle, allerent devers ladite eglise Saint Salveur de Bruges, pour y oyr lesdis vigilles des mors, que, tantost mondit seigneur venu, y furent dites moult

60 Die Einrichtung des Festsaales wurde auch schon in $\S 39$ beschrieben. Vgl. auch die Angaben zum Festmahl, das am Vortag nach Maximilians Erhebung zum Ordenssouverän veranstaltet wurde in $\S 68$.

61 Die Zusammensetzung der Speisen zählt Delepierre, Fête en 1478, 1842, S. 540 f. (ohne Quellenangabe) auf.

$62 \mathrm{Zu}$ seiner Person vgl. die Angaben in $\S 75$ mit Anm. 18.

$63 \mathrm{Zu}$ den namentlich genannten Ehrengästen vgl. die Angaben in § 75, wo die Teilnehmer des Vespergottesdienst am Vorabend genannt sind. In der Aufzählung hier fehlt Philippe de Croy, Gf. von Porcien, während Christoph, Markgraf von Baden, erst hier genannt ist; zu seiner Person vgl. die Angaben in $§ 10$ mit Anm. 58. Auffällig ist, dass bei dieser Festmahlzeit die geistlichen Würdenträger nicht teilnahmen. - Auch am nächsten Tag nahmen die Ordensglieder ein gemeinsames Festmahl ein, vgl. § 147.

64 Der Ablauf der Totenvigil ist in aller Kürze in $\S 52$ (neu § 27) der Statuten (dazu S. 16, Anm. 14) geregelt; zum schwarzen Ordensornat, der zu diesem Anlass getragen werden musste, vgl. die Angaben in $§ 40$ mit Anm. 210.

65 Ms.: Diese Zwischenüberschrift steht vor dem folgenden Absatz; vgl. dazu auch Anm. 7.

66 1. Mai 1478.

67 Zur Kette des Wappenkönigs vgl. die Angaben in § 42, Anm. 216. 
devotement et reverenment par mondit seigneur l'evesque de Tournay, [fol. 34r/6r] chancellier de l'ordre, accompaignié de beaucop d'abbez mitrez et aultres prelas et grans d'eglise notables. Et pour l'office desdis vigilles et le lendemain a la messe des mors estoient le grant autel et le siege de mondit seigneur le souverain parez richement de draps d'or noirs et les aornemens et habis des officiers de coleur semblable.

\section{[100] [Der Orden versammelt sich nach dem Gottesdienst zu einer Sitzung.]}

Apres lesdis vigilles des mors, mondit seigneur le souverain et messeigneurs les chevaliers freres et compaignons ensemble lesdis officiers de l'ordre retournez de ladite eglise, se sont incontinent devant le lieu capittulaire devestus des habis de deul et revestus habillez de leurs habis dudit ordre et ainsi retrais ou lieu capittulaire, et a par eulx esté commencié solemnellement le chappittre dudit ordre, mondit seigneur le souverain seant en son siege competant a la dignité et estat du chief et souverain et messeigneurs les chevaliers freres es bancs pour eulx ordonnez es deux rengs au dextre et au senestre, assavoir messeigneurs de Gruythuse $\{61\}$ et de Chimay $\{74\}$ au costé dextre et messeigneurs de Lannoy $\{50\}$, de Ravestein $\{55\}$ et de Nassouwe $\{77\}$ au costé senestre de mondit seigneur, et les officiers ou banc pour eulx ordonné a l'opposite de mondit seigneur le souverain, gardans leur ordre accoustumé.

[101] [Die Anwesenden verpflichten sich, nichts von dem, was während der Sitzung besprochen wird, nach Außen zu tragen.]

\section{Cy s'ensuit le mistere des corrections}

\section{Du serment icy fait ${ }^{68}$}

En ce chappittre, pour proceder et besoingner ou fait des corrections selon la conclusion du soir precedent ${ }^{69}$ et en ensuivant les statuts et ordonnances de l'ordre ${ }^{70}$ tous mesdis seigneurs les chevaliers freres de l'ordre la presens et pareillement lesdis quatre officiers dudit ordre ont par l'ordonnance de mondit seigneur le souverain promis et juré chascun particulierement et l'un apres autre, de tenir secret tout ce que es conseaulx dudit chappittre seroit dit, traitié et demené, et mesmement les corrections qui se feroient sur les chevaliers d'icellui ordre, sans riens en reveler a aucuns, fors les procureurs des absens qui pourroient advertir leurs maistres de ce qui leur toucheroit seulement, et semblablement et pour le darrenier l'a ainsi juré et promis mondit seigneur le souverain. ${ }^{71}$

\section{[102] [Der Kanzler ermahnt die Mitglieder zu einer vorbildlichen Lebensweise.]}

\section{L'exhortacion preambulé ${ }^{72}$}

Lesdis sermens ainsi fais, monseigneur l'evesque de Tournay, chancellier de l'ordre, a fait une brieve et sommiere exhortacion a mesdis seigneurs les chevaliers freres de l'ordre a la louenge et recommendacion de l'ordre de chevalerie et de noblesse, per-

68 Ms.: Die erste Zwischenüberschrift steht am linken Rand zu Beginn von § 101 und die zweite oberhalb; vgl. dazu auch Anm. 7.

69 Vgl. § 80.

70 Vgl. dazu die Angaben in Anm. 74.

$71 \S 55$ (neu § 30) der Statuten (dazu S. 16, Anm. 14) verlangt, dass nichts von dem, was während der Ordenssitzungen besprochen wird, in die Öffentlichkeit gelangen darf.

72 Ms.: Diese Zwischenüberschrift steht vor dem folgenden Absatz; vgl. dazu auch Anm. 7. 
suadant la correction des vices, l'amendement et meloracion des meurs et bonne <vie> vie et l'establissement de toutes vertus. ${ }^{73}$

[fol. 34v/6v]

\section{Touchant les corrections ${ }^{74}$}

[103] [Engelbert von Nassau wird aufgefordert, den Raum zu verlassen.]

Ceste exhortacion ainsi faite, mondit seigneur le chancellier de l'ordre, pour ensuir l'ordre et forme des statuts dudit ordre, a ordonné de par le chappittre et dit a monseigneur Engelbert, conte de Nassouw $\{77\}$, chevalier frere, qui estoit le plus jeune des autres freres illec presens et le darrenier du banc ou costé senestre, qu'il yssist du chappittre jusques il y seroit rappellé. A quoy reverenment et humblement mondit seigneur de Nassow obeit, soy partant dudit chappittre et se retrahit en une autre chambre honneste a ce servant.

\section{Messire Engelbert, conte de Nassouwe $\mathrm{e}^{75}$}

[104] [Im Wesentlichen gibt es nichts zu beanstanden, wenngleich er mehrfach in Gesellschaft junger Leute zweifelhaften Rufes gesehen wurde und es ihm an der ehelichen Treue mangle. Diese Verfehlungen werden jedoch seiner Jugend zugeschrieben. Deshalb soll er dafür nicht bestraft, sondern nur zur Besserung ermahnt werden.]

Ledit monseigneur Engelbert, conte de Nassow $\{77\}$, frere chevalier dudit ordre ainsi absenté et departi dudit chappittre, ledit monseigneur le chancellier ou nom de mondit seigneur le souverain et par son ordonnance a demandé par ordre a tous messeigneurs lesdis chevaliers freres d'icellui ordre illec presens et a chascun d'eulx particulierement sur le serment par eulx fait audit ordre et commenchant du siege d'embas et procedant continuellement jusques au hault et jusques a la personne de mondit seigneur le souverain inclusivement, s'ilz avoient ouy, savoient ou avoient ouy dire a personne digne

73 Nach Delepierre, Fête en 1478, 1842, S. 342 (ohne Quellenangabe), sagte der Ordenskanzler folgendes: Chevaliers et frères! Vous savez qu'entr'autres choses qui nous sont imposées, nous sommes tenus de faire une information des vies et mours, afin que les membres de notre ordre auguste soient plus pénétrés de leurs devoirs. Pour cet examen qui doit commencer, selon nos statuts, par le roi d'armes et autres officiers pour continuer par le dernier chevalier reçu, et remonter jusu'au souverain, je vous somme de déclarer ouvertement tout ce que vous savez ouï dire à personne digne de foi, sur ce que votre frère et compagnon a fait, dit ou commis qui soit contre l'honneur, la renommée, ou le devoir de chevalerie, notamment contre les statuts et ordonnances, et nous délibérons sur la correction que chascun d'eux aura respectivement méritée. Fe prescris donc à Toison d'or de sortir du conseil et d'attendre qu'on le rappelle.

74 Ms.: Diese Zwischenüberschrift steht in der Kopfzeile von fol. 6v sowie auf der Doppelseite fol.7v/8r; vgl. dazu auch Anm. 44. - Den Ablauf der corrections regeln die § 56-60 (neu § 31-35) der Statuten (dazu S. 16, Anm. 14); mit der damit verbundenen Sozialkontrolle beschäftigt sich ausführlich STERCHI, Umgang, 2005, S. 420-440 sowie Ders., Rendre compte de leur honneur, 2007, S. 148-154; dazu auch Melville, Rituelle Ostentation, 1997, S. 220 f.; DünnebeIL, Entwicklung, 2007, S. 31 f. Mit der Prozedur von 1478 beschäftigen sich u. a. DünNEBEIL, Zeichen, 2012, S. 120. - Siehe dazu auch in der Einleitung S. 17.

75 Ms.: Diese Zwischenüberschrift steht vor dem folgenden Absatz; vgl. dazu auch Anm. 7. 
de foy que monseigneur de Nassowe, leur frere et compaignon yssu du chappittre, eust fait, dit ou commis chose que fust contre honneur, renommee, estat et devoir de chevalerie, mesmement contre les status, poins et ordonnances de cest ordre et aimable compaignie et dont elle puist estre blamee ou diffamee aucunement. Et par les scrutine et enqueste sur lui faites a ledit messire Engelbert, conte de Nassouwe, esté loué et recommandé grandement de noblesse et bonnairité, qu'il est belle personne, aimable, doulx et leal envers ses subgiez et voisins et doué de beaucop d'autres vertus, qu'il est aussi haultement et noblement allyé par mariaige, car sa femme est bien prouchaine a l'empereur $\{94\}$ et aussi a mondit seigneur le souverain de l'ordre. ${ }^{76}$ Mais qu'il avoit en lui des legieres meurs, conversoit souvent de nuyt et de jour avec jeunes gens et legiers en lieux deshonnestes et publiques, querant ses voluptez, delices et plaisirs, qu'il se delitoit en telles choses et s'en vantoit. Et n'avoit pas grant temps que par nuyt il s'estoit trouvé a Brouxelles en certain lieu avec jeunes gens et legiers la ou l'ung de sa compaingnie avoit battu ung autre d'ung baston tellement que bien brief apres il en morut, dont il se trouva en dangier. Qu'il j[o]uoit volentiers a dez et mesmement que a madame sa femme tant noble il ne portoit pas tel honneur ne tel amour que faire devoit selon le sacrement de mariaige, mais se delitoit plus avec femmes dissolues. Que par fois aussi il avoit esté non chalant es choses dont il avoit charge. Et que encore le jour precedent, combien qu'il fust admonesté et adverti de l'assamblee de messeigneurs ses freres de l'ordre pour y [fol. 35r/7r] venir et entendre avec eulx es besoingnes et affaires dudit ordre, toutevoye ne y estoit il venu ne comparu ne aussi excusé pour aultre affaire, lesquelles choses ont samblé mal seantes en la personne d'ung si noble homme et mesmement en chevalier frere de cest ordre, et qu'il faisoit a blamer et a exhorter qu'il s'en vueille corriger et amender dorsenavant tellement que mondit seigneur et l'ordre ne oyent plus de lui telles choses, mais aient meilleur rapport de lui et de son amendement. Car, combien que pour regart de sa jeunesse ${ }^{77}$ ilz s'en passent en dissimulant avec lui pour ceste fois qui est la premier depuis qu'il a esté en l'ordre sur espoir de sondit amendement, toutevoie se plus il avenoit qu'ilz eussent de lui telz rappors, ilz n'y pourroient ne vouldroient plus dissimuler ne le passer sans en faire et ordonner sur lui pour l'onneur et descharger dudit ordre et de la compaingnie telle punicion et correction que au cas ils verroient appartenir et que ce seroit exemple aux aultres.

\section{[105] [Engelbert von Nassau wird vom Ergebnis seiner correction unterrichtet.]}

Apres ceste deliberacion a esté rappellé en chappittre ledit messire Engelbert, conte de Nassou \{77\}, lequel illec venu s'est mis a genoul devant mondit seigneur le souverain a l'entree du part consistorial. Et lui estant ainsi a genoul monseigneur le chancellier de l'ordre par le commandement et ordonnance de mondit seigneur le souverain et du chappittre premierement l'a loué et recomandé de sa noblesse, fidelité, de bonnairité et d'autres ses vertus, mais apres lui a remonstré et declaré bien au long les poins et

76 Am 19. Dezember 1468 hatte er Cimburga von Baden (1450-1501) geheiratet, Tochter von Karl I., Mgf. von Baden (1427-1475), und der Katharina von Österreich (1420-1493), einer Schwester Kaiser Friedrichs III.; vgl. WIn, Engelbert van Nassau-Dillenburg, 1992, S. 87; Chevaliers de la Toison d'or, ${ }^{2} 2000$, S. 180, Nr. 77.

77 Der 1451 geborene Engelbert war zu diesem Zeitpunkt 27 Jahre alt; vgl. Chevaliers de la Toison d'or, ${ }^{2} 2000$, Nr. 77. - Seine correction erwähnt Win, Engelbert van Nassau, 1992, S. 115. 
choses, dont il avoit esté noté et blamé, le exhortant et advertissant par la maniere cy dessus deliberee et touchee.

\section{[106] [Engelbert von Nassau bedankt sich und verspricht Besserung.]}

Surquoy mondit seigneur Engelbert, conte de Nassow $\{77\}$, a remercié treshumblement mondit seigneur le souverain et tous messeigneurs ses freres de l'ordre illec presens de leur benigne remonstrance, disant qu'il lui desplaisoit de avoir failly et que au plaisir Dieu il se condu[i]roit et gouverneroit doresenavant tellement que mondit seigneur et tout l'ordre auroient cause d'estre de lui bien contens. ${ }^{78}$

\section{Messire Phelippe de Croy, conte de Chimay ${ }^{79}$}

\section{[107] [Bei Philippe de Croy gibt es nichts zu beanstanden.]}

Apres s'est levé et parti du chappittre reverenment monseigneur le conte de Chimay $\{74\}$, sur lequel a aussi esté faite demande et enqueste. Mais par les veuz de tous, il a esté loué grandement recommandé et prisé de sa noblesse, saigesse et vaillance et n'a l'on trouvé sur lui chose que feist a blamer, ains [fol. 35v/7v] que l'ordre a honneur de l'avoir a frere et compaingnon, parquoy a esté la deliberacion du chappittre, que, lui rappellé, il faisoit a recommander et a exhorter que doresenavant y vueille continuer de bien en mieulx.

\section{[108] [Philippe de Croy wird vom Ergebniss seiner correction unterrichtet.]}

Mondit seigneur de Chimay $\{74\}$ rappellé en chappittre, s'est mis a genoul a l'entree du part. Et monseigneur le chancellier par l'ordonnance de monseigneur le souverain et du chappittre de l'ordre l'a loué et recommandé et aussi exhorté comme dessus.

\section{[109] [Philippe de Croy bedankt sich.]}

Surquoy mondit seigneur de Chimay a remercié treshumblement monseigneur le souverain et tous messeigneurs les freres de l'ordre la estans de ce, qu'il leur avoit pleu supporter ses ignorances, disant que au plaisir Dieu, par le bon exemple qu'il veoit et esperoit tousjours trouver en eulx, il se travailleroit et mettroit en paine de son povoir pour acquerir quelque partie des biens qu'il leur plaisoit estimer en lui estre. ${ }^{80}$

\section{Messire Loys, seigneur de Gruythuse $\{61\}$, conte de Wyncestre ${ }^{81}$}

\section{[110] [Bei Ludwig von Brügge gibt es nichts zu beanstanden.]}

Sur lui n'a esté trouvé vice ne reproiche, mais a esté grandement loué et recommandé de noblesse, saigesse, richesse et d'autres graces et vertus pluseurs et en tout bien et honneur, dont messeigneurs sont bien joyeux de l'avoir a frere et compaingnon en

78 Beim nächsten Ordensfest im Jahr 1481 fiel Engelberts Beurteilung durch den Orden ähnlich aus; vgl. PB 5, fol. 23v-24r.

79 Ms.: Diese Zwischenüberschrift steht vor dem folgenden Absatz; vgl. dazu auch Anm. 7.

80 Auch beim nächsten Fest im Jahr 1481 fiel seine Beurteilung durch den Orden sehr gut aus; vgl. PB 5, fol. 33r

81 Ms.: Diese Zwischenüberschrift steht vor dem folgenden Absatz. Sie scheint jedoch gleichzeitig entstanden zu sein, denn im folgenden Absatz wird der Name nicht wiederholt; vgl. dazu auch Anm. 7. 
l'ordre et ont ordonné a monseigneur le chancellier de le exhorter a y continuer et parseverer tousjours et de bien en mieul. ${ }^{82}$

\section{[111] [Er soll über den Stand seiner Ausseinandersetzung mit fosse de Lalaing befragt werden.]}

$<$ Mondit seigneur de Gruythuse rappellé en chappittre s'est mis a genoul comme les autres. $>^{83}$

Apres a ordonné mondit seigneur le souverain par l'advis de messeigneurs ses freres audit monseigneur le chancellier, qu'il touchast ung peu par forme d'exhortacion a mondit seigneur de Gruythuse $\{61\}$ du different estant entre lui et messire Josse de Lalaing $\{80\}$, seigneur de Montigny, ${ }^{84}$ pour et afin qu'il s'en voulsist appaiser en son ceuraige et laisser traiter et manier aimablement la chose par main d'amis, gens notables, qui s'emploiassent pour y trouver voye et moyen de bon appointement.

\section{[112] [Ludwig von Brügge wird vom Ergebnis seiner correction unterrichtet.]}

Monseigneur de Gruythuse $\{61\}$ rappellé en chappittre, s'est mis a genoul comme les autres. Et mondit seigneur le chancellier par l'ordonnance de mondit seigneur le souverain et du chappittre de l'ordre, l'a loué, recommandé et exhorté comme dessus.

\section{[fol. 36r/8r]}

\section{[113] [Ludwig von Brügge bedankt sich und bittet den Orden um Vermittlung in seiner Auseinandersetzung mit fosse de Lalaing.]}

Sur ce mondit seigneur de Gruythuse $\{61\}$ a remercié treshumblement monseigneur le souverain et tous messeigneurs ses freres de l'ordre de la benigne et bonne extimacion qu'ilz avoient de lui, esperant par l'aide de Dieu doresenavant tousjours tellement soy gouverner et conduire envers mondit seigneur le souverain et devers l'ordre, qu'ilz auront cause d'estre contens de lui. Touchant le different d'entre messire Josse $\{80\}$ et lui, dont il a fait brieve remonstrance pour sa justificacion, finablement il a esté content de le mettre en la main de mondit seigneur le souverain et de messeigneurs ses freres de l'ordre, veuz ses tiltres et lettres et ceulx de son filz ${ }^{85}$, mais que l'expedicion s'en face brief. Et mondit seigneur le souverain y a commis monseigneur de Lannoy $\{50\}$, frere, et monseigneur l'evesque de Tournay, chancellier dudit ordre de la Thoison d'or, pour par eulx oyr sommierement les parties et veoir les lettres et tiltres d'ung costé et d'autre, et apres aimablement les appointier de leursdis differens, se faire le pevent, ou

82 § 110-112 zitiert Sterchi, Umgang, 2005, S. 426, Anm. 156. - Schon beim Ordensfest 1473 war Ludwigs Lebensstil gelobt worden (PB 3, S. 76, § 95), aber 1481 wurde ihm aufgrund seines Fehlens beim Ordensfest ein Bußgeld aufgebürdet (PB 5, fol. 31r und passim).

83 Ms.: Der gestrichene Satz wird in $\S 112$ wiederholt.

84 Josse de Lalaing wird noch am selben Tag zum neuen Mitglied des Ordens gewählt (§ 134); mehr Angaben zu seiner Person sind in $§ 162$ mit Anm. 232 zu finden.

85 Ludwigs einziger Sohn war Johann V. van Brügge, Herr von Gruuthuse und Spiere (1458-1512), der im Nov. 1477 zu Maximilians Kammerherren zählte und anlässlich der Schlacht von Guinegatte (vgl. Anm. 286) zum Ritter geschlagen wurde. Spätestens 1484 wechselte er zu Ludwig XI. über und war einer der führenden Köpfe der anti-habsburgischen Partei Flanderns; vgl. PraEt, Recherches, 1831, S. 64-71; Cools, Mannen, 2000, S. 263 f., Nr. 39; Haemers, Common Good, 2009, S. $111 \mathrm{f}$. 
autrement faire de tout plain rapport a mondit seigneur, ensemble des difficultez qu'ilz y auront trouvees, pour au surplus par mondit seigneur les appointer aimablement ou par droit, selon qu'il le verra estre a faire pour le mieulx. ${ }^{86}$

\section{Monseigneur de Ravestein ${ }^{87}$}

\section{[114] [Bei Adolf von Kleve, Herr von Ravenstein, gibt es nichts zu beanstanden.]}

Monseigneur de Ravestein $\{55\}$, par l'enqueste faite sur lui ${ }^{88}$, a esté moult loué et recommandé en toutes vertus et en tout bien et honneur, et qu'il s'est demonstré leal tousjours et vaillant pour la noble maison de Bourgoingne et envers monseigneur et madame et qu'il fait grant honneur a l'ordre. Et finablement a esté exhorté d'y perseverer et continuer de plus en plus.

\section{[115] [Adolf von Kleve bedankt sich für den erhaltenen Lob.]}

Mondit seigneur de Ravestein $\{55\}$ rappellé et mis a genoul comme les autres, oye la louenge et exhortacion, a remercié treshumblement monseigneur le souverain et tous messeigneurs ses freres de l'ordre de l'amour et bonne extimacion que devers lui demonstroient, disant que au plaisir Dieu il mettrra peine et fera tout devoir envers mondit seigneur et devers madite dame et aussi devers mesdis seigneurs ses freres de l'ordre, qu'ilz cognoistront l'entier et parfait vouloir qu'il a de tousjours leaument soy porter et acquiter envers eulx et qu'ilz auront cause d'estre de lui contens.

\section{Monseigneur de Lannoy ${ }^{89}$}

\section{[116] [Bei fean de Lannoy gibt es nichts zu beanstanden.]}

Par l'enqueste faite sur monseigneur de Lannoy $\{50\}$, a esté ledit monseigneur de Lannoy loué et recommandé grandement de vertueuse saigesse, prudence et vaillance par tous messeigneurs et a esté exhorté d'y vouloir continuer et parseverer. ${ }^{90}$

\section{[117] [Jean de Lannoy bedankt sich für den erhaltenen Lob.]}

Mondit seigneur de Lannoy $\{50\}$ rappellé en chappittre et mis a genoul comme dessus, a remercié treshumblement monseigneur le souverain et l'ordre de l'onneur qu'ilz lui portent, disant que, s'il estoit en eaige et ou povoir de faire a mondit seigneur tel service qu'il desireroit et lui competeroit, il le feroit leaulment et de tout son cuer tresvolentiers et tousjous au plaisir Dieu fera a mondit seigneur le souverain et a l'ordre tout le devoir et service que possible lui sera.

86 Zur Funktion der Ordensschiedsgerichtsbarkeit vgl. in der Einleitung S. 23 mit Anm. 96; zur Fortsetzung dieser Angelegenheit § 162, wo man etwas mehr über die Auseinandersetzung erfährt.

87 Ms.: Diese Zwischenüberschrift steht vor dem folgenden Absatz; vgl. dazu auch Anm. 7.

88 Ms.: lui steht über der Zeile und eine Marke zeigt auf die dafür vorgesehenen Stelle im Text. -Auch bei den Festen von 1473 und 1481 gab es bei Adolf von Kleve nichts zu beanstanden; vgl. u.a PB 3, S. 80, § 105; PB 5, fol. 23v-24r.

89 Ms.: Diese Zwischenüberschrift steht vor dem folgenden Absatz; vgl. dazu auch Anm. 7.

90 Auch 1473 und 1481 wurde Jean de Lannoys Lebensstil gelobt; vgl. PB 3, S. 83 f., § 115 f.; PB 5, fol. 24r. 
[fol. 36v/8v]

\section{Touchant la correction des absens freres ${ }^{11}$}

[118] [Die correctiones der fehlenden Mitglieder wird aus Zeitgründen auf das nächste Fest verschoben, das im kommenden Jahr Anfang Mai stattfinden soll.]

Au sur plus quant a la correction de messeigneurs les chevaliers freres de l'ordre absens: Monseigneur le souverain par l'advis de messeigneurs les freres presens oudit chappittre pour cause des grans affaires qu'il a et mesmement a cause des nouvelles qui journellement lui viennent de l'approicement du roy de France et de son armee vers ses pays, n'y peut quant au present bonnement entendre, mais l'a remise $<$ s $>$ et remet au prouchain chappittre de l'ordre qu'il a intencion de tenir ou mois de may prouchain venant au plaisir Dieu et en tel lieu que cy apres il avisera et signifiera a ceulx de l'ordre par ses lettres en la maniere accoustumee. ${ }^{92}$

\section{Monseigneur Phelippe de Savoye ${ }^{93}$}

[119] [Philipp von Savoyen und Jean de Neufchâtel, Herr von Montaigu, fehlen ohne Entschuldigungsschreiben.]

Et en tant qu'il touche monseigneur Phelippe de Savoye $\{68\}$, seigneur de Bresse, et monseigneur de Montagu \{52\} qui estoient appellez pour venir a ce chappittre de l'ordre pour y respondre d'aucuns poins, dont es chappittres precedens ilz avoient esté notez. ${ }^{94}$ Et toutevoye n'y sont venus ne comparus, n'ont aussi point envoyé leurs procuracions ne excuse ne aussi leurs cedules pour l'election a faire, dont de prime face ilz seroient a blamer.

[120] [Der Herold Ferrette berichtet, dass bei seiner Gefangennahme in Mâcon die Antwortschreiben Philipps von Savoyen und die Einladungsschreiben an Jean de Neufchâtel und Jean de Damas verloren gegangen sind. Es wird beschlossen, dass Philipp von Savoyen und Jean de Neufchâtel zum nächsten Fest vorgeladen werden sollen.]

$[a]^{95}$ Ouy le rapport fait par Farrettes le herault, qui estoit ordonné et envoyé pour leur porter les lettres de l'intimacion et significacion de ceste feste et chappittre et pareillement celles du seigneur de Clessy $\{65\} .{ }^{96}$ Affermant comme officier d'armes qu'il avoit presenté a mondit seigneur de Bresse $\{68\}$ les lettres que tant monseigneur le duc comme messeigneurs de l'ordre lui escrivoient touchans ladite significacion.

91 Ms.: Diese Zwischenüberschrift steht in der Kopfzeile der Doppelseite fol. 8v/9r und in leichter Abwandlung (Touchans les corrections de messeigneurs les freres absens) auf der Doppelseite fol. 9v/10r. Vgl. dazu auch Anm. 44.

92 Zur weiteren Planung des neuen Ordensfestes vgl. die Fortsetzung in § 171.

93 Ms.: Diese Zwischenüberschrift steht am linken Rand des folgenden Absatzes; vgl. dazu auch Anm. 7.

94 Fortsetzung von § 26. - Angaben zu Philipps Kritikpunkten sind in Reg. 82, Anm. 87, und zu Jeans Kritikpunkten in Reg. 7, Anm. 5, genannt.

95 Ms.: Zur besseren Lesbarkeit dieses langen Paragraphen wurden Absätze und Unterpunkte eingefügt.

96 Vgl. Reg. 13, 8, 7 und 25-18. - Zwischen 1469 und 1477 ist Gilles Jaspart als Herold Ferrette belegt; vgl. DB Heraudica ID Person 7 und 190. 
Lesquelles mondit seigneur de Bresse avoit de lui benignement et aimablement receues et visitees, lui avoit fait bone chiere et benigne recueil, l'avoit deffrayé en l'ostellerie pour sa bouche et pour son cheval et avoit rescript a messeigneurs de l'ordre lettres aimables ${ }^{97}$ qu'il lui avoit baillees pour les apporter a mesdis seigneurs, mais de leur contenu ne scet autrement a parler, l'avoit tenu seur parmy son pays jusques aux portes de Mascon.

[b] Et pour ce que ledit Farrettes s'estoit a lui descouvert qu'il avoit autres lettres sembables adreçans a monseigneur de Clessy et autres a mondit seigneur de Monta$\mathrm{gu}\{52\}$, lesquelles il leur vouloit porter et que premiers il yroit devers ledit seigneur de Clessy, pour de la son retourner et passer devers mondit seigneur de Montagu, mondit seigneur de Bresse benignement l'avoit adverti du dangier qu'il pourroit avoir a Mascon, le advisant qu'il se feist bien asseurer devant qu'il entrast en la ville de Mascon, demonstrant par ce mondit seigneur de Bresse devers icellui Farrette benivolence et faveur pour honneur de mondit seigneur le duc et de messeigneurs de l'ordre.

[c] Et que neantmoins ledit Ferrette cuidant soy faire bien asseurer, afin qu'il peust presenter lesdites lettres qu'il avoit adreçans audit monseigneur de Clessy, s'estoit parti en ceste façon de mondit seigneur de Bresse et tiré devers Mascon, et [fol. 37r/9r] combien que lui arrivé a la porte de la ville de Mascon et vestu de sa cotte d'armes il eust demandé et requis aux gardes de ladite porte congié et seurté pour y entrer et par gentil homme, s'aucun y avoit, et que lesdis congié et seurté lui fussent ottroiez et donnez par lesdis gardes et mesmement par l'ung d'eulx soy disant gentil homme $<$ s'aucun y avoit, et que lesdis congié et seurté lui fussent ottroiez et donnez par lesdis gardes $>{ }^{98}$ qui l'asseuroit, toutevoye incontinent comme sur confidence de ladite seurté il y estoit entré, non obstant icelle, il avoit esté prins apprehendé rudement et injurieusement manié et traitié, que sadite cotte d'armes lui avoit esté sur lui deschieree toute en pieces, que ses lettres, toutes ses bagues et quant qu'il avoit tout lui avoit esté prins, tollu et desrobé et lui emmené et bouté en dure et vile prison et detenu par aucuns jours audit lieu de Mascon avec criminelz et malfaiteurs, dont le lendemain de sa prinse y avoit eu deux executez a mort. ${ }^{99}$

[d] Que apres il avoit esté amené prisonnier jusques devers le roy et apres lui longuement et en divers lieux longtains en tresgrant povreté, travail, peine et misere et en peril evident de sa vie. Certiffiant aussi ledit Ferrettes que la lettre responsive que mondit seigneur de Bresse lui avoit baillee, adreçant a mesdis seigneurs de l'ordre et pareillement celles qu'il portoit pour mondit seigneur de Montagu lui avoient esté tollues et prinses ensembles sesdis autre[s] bagues a son entree de ladite porte de Mascon et ne s'avoit a quoy elles estoient devenues. Mais savoit bien que mondit seigneur de Montagu n'avoit pas eu les siennes, car il avoit proposé et deliberé que a son retour dudit Mascon, la ou il aloit pour y cuider presenter et baillier a monseigneur de Clessy les lettres qui a lui s'adreçoient pour cas semblable, il passeroit pardevers mondit seigneur de Montagu, pour lui baillier aussi les siennes. Ce que lui fut empeschié par la maniere dite.

97 Vgl. Reg. 26.

98 Ms.: Der durchgestrichene Text ist eine Wiederholung schon geschriebener Worte und weist darauf hin, dass Steenberch von einer Vorlage abgeschrieben hat.

99 Nach Melville, Heroldwesen, 2002, S. 305, haben Herolde im Tappert normalerweise bei ihren Reisen (auch im Feindesland) Immunität genossen. 
[e] Ces choses considerees et mesmement ladite aimable rescription de mondit seigneur de Bresse, jasoit que ses lettres fussent ainsi perdues, a semblé a mondit seigneur le souverain et a messeigneurs les chevaliers freres de l'ordre estans oudit chappittre que du costé de mondit seigneur de Bresse plus faisoit a esperer et presumer le bien que le mal.

\section{Monseigneur de Montagu ${ }^{100}$}

[f] Et au regart de monseigneur de Montagu, veu qu'il n'avoit point eu ses lettres principales sur l'intimacion et significacion de ceste feste, leur a semblé que mondit seigneur de Montagu a eu coleur d'excusé, non obstant que par autres lettres ${ }^{101}$ depuis il ait peu assez estre adverti de cestedite feste de l'ordre, car ces lettres darrenieres n'estoient qui relatives desdis premiers que l'on presumoit par lui estre receues, ce que non, et n'estoient pas lesdites darrenieres lettres souffisantes pour en deffaulte de sa comparicion le contumacer. ${ }^{102}$

\section{Quelconque touchans les deux ${ }^{103}$}

[g] Parquoy, la matiere bien debattue par mesdis seigneurs oudit chappittre de l'ordre, a esté leur conclusion que, touchant les poins dont aultresfois mesdis seigneurs de Bresse et de Montagu chascun a son endroit ont esté notez, il leur soit rescript qu'ilz viennent ou futur chappittre pour y respondre en tel estat et ainsi que aultrefois il leur a esté signifié et mandé cum intimacion etc. ${ }^{104}$

\section{Touchant monseigneur le duc de Cleves ${ }^{105}$}

\section{[121] [Es wird beschlossen, dass Johann, Hz. von Kleve beim nächsten Ordensfest über die Gründe seines unentschuldigten Fehlens beim gegenwärtigen Fest zu befragen.]}

Quant a monseigneur le duc de Cleves $\{47\}$, attendu qu'il a eu les principales lettres de l'intimacion et significacion de la presente feste et du chappittre de l'ordre et [fol. 37v/9v] encores depuis autres lettres iteratives pour l'exhorter d'y venir en personne pour cause du petit nombre des chevaliers freres qui vraissemblablement se trouveroient a cestedite feste pour accompaigner monseigeur le duc et decorer l'ordre en si grant affaire, ${ }^{106}$ lesquelles lettres lui ont esté portees et presentees par Lembourg

100 Ms.: Diese Zwischenüberschrift steht am linken Rand in der Höhe, wo die Eintragungen über Jean de Neufchâtel beginnen.

101 Vgl. Reg. 28.

102 Vgl. dazu Reg. 43.

103 Ms.: Die Zwischenüberschrift steht am rechten Rand des folgenden Absatzes; vgl. dazu auch Anm. 7.

104 Vgl. Reg. $81 \mathrm{f}$. Zu dem in der Folgezeit entstandenen Briefwechsel zwischen Hz. Maximilian und Jean de Neufchâtel vgl. auch STERCHI, Überläufer, 2003, S. 82-84 und S. 97-103; STERCHI, Umgang, 2005, S. 458-460. - Fortsetzung in § 209 und 226.

105 Ms.: Diese Zwischenüberschrift steht vor dem folgenden Absatz und ist durch einen Strich von diesem getrennt. Zu Beginn der folgenden Seite (fol. 9v) steht auch noch Touchant mondit seigneur de Cleves am linken Rand. - Eine Kopie des folgenden Absatzes befindet sich in AOGV, Codex 45, fol. 61r. Dort befindet sich fol. 55r-62r ein Dossier mit Kopien der Korrespondenz zwischen dem Orden von Johann, Hz. von Kleve.

106 Vgl. Reg. 5, 19 und 39 sowie § 27. 
le herault, ${ }^{107}$ parquoy bonnement il ne povoit alleguer excuse d'ignorance, et posé qu'il puist avoir quelque coleur d'excusacion par la maladdie, ${ }^{108}$ toutevoie s'il eust volunté d'y venir et de soy acquiter en son devoir de l'ordre, il le povoit bien faire et venir seurement et a son bel aise. Mais il n'y est venu, ne a envoyé sa procuracion, ne cedule pour l'election ou fait faire quelque excuse de sa part par lettre ne de bouche. Dont tant monseigneur le souverain comme messeigneurs les chevaliers freres de l'ordre ont esté aucunement esmerveilliez et mis en suspeçon d'aucun contempt, ce qui seroit a blamer. Neantmoins mondit seigneur a remis et remet la chose ou chappittre prouchain de l'ordre. Et au regard de la maniere de le mander et faire venir audit futur chappittre pour sur ce respondre a son honneur selon les chappittres de l'ordre qu'il a jurez, mondit seigneur y advisera et sur tout conclura cy apres en temps et en lieu par l'advis et deliberacion de messeigneurs les chevaliers freres dudit ordre, qui se trouveront devers lui, quant il deliberera de faire intimer et signifier le temps et lieu ou et quant ladite feste et le chappittre prouchain avenir d'icellui ordre tenir se devront. ${ }^{109}$

\section{Touchant les v chevaliers estans en France ${ }^{110}$}

[122] [Die fünf in Frankreich befindlichen Mitglieder sollen vor das nächste Ordensfest vorgeladen werden, damit sie sich zu ihrer Abwendung vom Orden äußern können. $]^{111}$

Item et combien que mondit seigneur le souverain et messeigneurs les freres de l'ordre eussent assez matiere pour desmaintenant et en ce present chappittre proceder contre les cinq chevaliers estans ou parti contraire, assavoir contre les sires de la Roiche de Nolay $\{60\}$, d'Escordes $\{69\}$ et de Clessy $\{65\}$ qui de leur volunté se sont tournez audit parti, et semblablement aussi contre monseigneur Anthoine, bastart de Bourgoingne $\{54\}$, et messire Jaques de Luxembourg $\{67\}$, veu que leur cas est evident et tout notoire, et mesmement que tous ont delaissié le collier de l'ordre de la Thoison d'or et receu le collier de l'ordre du roy et ont fait serment au roy, ${ }^{112}$ ce que faire ne povoient selon les status dudit ordre de la Thoison d'or, par chascun d'eulx solemnellement jurez et promis. Toutevoye en ensuivant le contenu d'aucuns desdis status de l'ordre a ce servans et sur ce veuz bien meurement, mondit seigneur le souverain par l'advis et deliberaction du chappittre de l'ordre a revisé et remet ceste matiere oudit prouchain chappittre avenir d'icellui ordre. ${ }^{113}$ Et a ordonné que tous cinq et chascun d'eulx soient adjournez par lettres patentes seellees du seel dudit ordre en placcart, ${ }^{114}$ et aussi de bouche par Thoison d'or, le roy d'armes, [fol. 38r/10r] ou par autre officier

107 Zur Person des Herold Limburgs vgl. § 19, Anm. 99.

108 In $\S 9$ mit Anm. 49 wurde angemerkt, dass die Entschuldigung wegen Krankheit nur eine vorgeschobene Ausrede war.

109 Fortsetzung in § 171; vgl. dazu auch § 209 sowie Reg. 89 f.

110 Ms.: Diese Diese Zwischenüberschrift steht vor dem folgenden Absatz. Sie ist unterstrichen und davor steht ein $c$ / für capitulum.

111 Fortsetzung von § 78. Vgl. dazu auch in der Einleitung S. 18.

112 Zur Mitgliedschaft im frz. Michaelsorden vgl. die Angaben in § 28, Anm. 174.

113 Item, et combien que mondit seigneur [...] oudit prouchain chappittre avenir d'icellui ordre zitiert Sterchi, Umgang, 2005, S. 457 f., Anm. 302. Dazu auch Commies, Anton van Bourgondie, 1979, S. 70. - In § 14-16 der Statuten (dazu S. 16, Anm. 14) werden die Anlässe für den Ausschluss von Ordensrittern genannt, darunter auch Verrat.

114 Vgl. Reg. 75-79. 
d'armes aiant povoir et commission a ce especiales en forme patente soubz ledit seel de l'ordre ${ }^{115}$ pour venir et comparoir personnelliement chascun d'eulx oudit prouchain chappittre et y respondre aux choses que illec leur seront remonstrees et dites et dont ilz ont esté blamez et notez ou present chappittre, et au surplus y veoir proceder par mondit seigneur le souverain et par l'ordre comme il appartendra - o intimacion ${ }^{116}$ que viennent ou non, neantmoins l'on procedera en leur matiere ainsi qu'il sera trouvé se devoir faire par raison. ${ }^{117}$

\section{[123] [Diese fünf Mitglieder sollen am folgenden Tag vom Kerzenopfer ausge- schlossen werden.]}

\section{Touchant l'offrande au regart desdis $\mathbf{v}$ chevaliers ${ }^{118}$}

Apres a esté aussi parlé en ce chappittre des cierges mises en la harce ${ }^{119}$ a tous les escuçons des armes desdiz cinq chevaliers, estans ou parti contraire comme dit est, pour savoir se le lendemain quant ce vendra a l'offertoire de la grant messe ${ }^{120}$ que se dira pour les freres trespassez, Thoison d'or, le roy d'armes, porteroit a l'offrande lesdis cierges ou s'il les estandroit sur ladite harce ou autrement comment il en feroit. ${ }^{121} \mathrm{Et}$ la matiere mise en deliberacion, a esté debattu par aucuns que es vigilles ja chantees lesdis v chierges y avoient esté alumees, disans que iceulx chierges n'y deussent pas avoir esté allumees, mais demourer sans lumiere, veu que lesdis cinq chevaliers avoient habandonné et delaissié l'ordre. Toutevoie finablement a esté la conclusion de mondit seigneur le souverain et du chappittre, que iceulx cinq chevaliers ne seroient appellez, ne leurs chierges pour eulx portez a l'offrande, mais que ledit roy d'armes $<$ les $>$ laisseroit leursdis cierges ardans sur ladite harche sans les bougier jusques a la fin de la messe quant les autres. ${ }^{122}$

115 Vgl. Reg. 80.

116 Nur im Zusammenhang mit der Vorladung der nach Frankreich gewechselten Mitglieder wird die Formulierung cum intimacion oder o intimacion verwendet; damit gemeint ist, dass die Vorladung - im Falle der Unzustellbarkeit bei den Adressaten an öffentlichen Orten verkündet werden sollte; vgl. dazu die Worterklärung u.a. http://www.rzuser.uni-heidelberg.de/ cd2/drw/e/in/timi/eren/intimieren.htm (Juli 2015).

117 Fortsetzung in $\S 209$; eine kurze Erwähnung dazu findet sich auch in $§ 171$.

118 Ms.: Diese Zwischenüberschrift steht vor dem folgenden Absatz und ist durch einen Strich von diesem getrennt.

119 Zu großen Kerzenständer (harce) des Ordens, der während der Totenmesse seinen Einsatz fand, vgl. die Angaben in § 143 mit Anm. 186.

120 Ms.: messe steht über der Zeile und eine Marke zeigt die dafür vorgesehene Stelle im Text. - Schon beim Münzopfer wurden diese Fünf von der Zeremonie ausgeschlossen; vgl. § 78 und 88-91 sowie in der Einleitung S. $18 \mathrm{f}$.

121 Der Ablauf der Totenmesse mit dem damit verbundenen Kerzenopfer ist in aller Kürze in $§ 52$ (neu § 27) der Statuten (dazu S. 16, Anm. 14) geregelt. Vgl. dazu auch die entsprechenden Beschreibungen zu den Festen aus den Jahren 1468 und 1473; vgl. PB 2, S. 86-92, § 59-65 und PB 3, S. 53-59, § 47-60; dazu auch DünNEBEIL, Entwicklung, 2007, S. 30 f.

122 Zur Ausführung vgl. § 145. 


\section{[124] [Überlegungen zum Nachruf auf Hz. Karl nach dem Kerzenopfer.] \\ Commemoracion a l'onneur de feu monseigneur le duc Charles ${ }^{123}$}

Pareillement y a esté parlé de ce qui ledit jour du lendemain a ladite messe des trespassez se diroit par le graffier de l'ordre apres l'offrande parfaite a la louenge et recommendacion de feu mondit seigneur le duc Charles $\{34\}$, jadis chief et souverain de cest ordre, darrenier deffunct, a la commemoracion et recordacion de messeigneurs les chevaliers freres dudit ordre trespassez depuis l'institucion d'icellui. ${ }^{124}$ Et la matiere debattue, a esté la conclusion de mesdis seigneurs telle, c'est assavoir: Que ledit feu monseigneur le duc Charles a esté prince tressaige et tresvaillant, liberal et magnifique moult singulierement, aimant et favoirisant justice, prince treshonnorable aorné et decoré d'autres beaucop grandes vertus. Qu'il a aussi moult amé, decoré et exaulcé ce noble ordre et tresgrandement s'est employé pour l'accroissement et augmentacion de la tresnoble maison de Bourgoingne et pour la preservacion et deffense de ses pays et seignouries et en toute magnificence et vaillance a esté renommé singulierement entre les autres princes de son temps. ${ }^{125}$

[b] No(ta) a la louenge de feu monseigneur le duc Charles. ${ }^{126}$

[125] [Der Nachruf auf den Ordensgründer Hz. Philipps wird in Erinnerung gerufen.]

Aussi a en cestui chappittre par la deliberacion de mesdis seigneurs abbregié ce que es deux festes darrenieres avoit esté a la messe de requiem dit a la louenge et recommendacion de feu monseigneur le duc Phelippe, premier fondateur, chief et souvervain [fol. 38v/10v] de cest ordre, en ceste maniere, assavoir: ${ }^{127}$

\section{A la louenge de feu monseigneur le duc Phelippe, premier fondateur de cest ordre ${ }^{128}$}

[126] [Hz. Philipp war ein hervorragender christlicher Fürst, der von allen geliebt wurde und zurecht den Beiname «le bon » erhielt.]

Que ledit feu duc Phelippe $\{01\}$ qui trespassa l'an xiiij ${ }^{c}$ lxvij le $x^{e}$ jour du mois de jung ${ }^{129}$ a esté prince moult catholique, tresaffecté et portant grant zel[e] au bien et relievement de la foy et religion chrestienne, pour laquelle il se travailla grandement et fray a beaucop par les armees qu'il envoya au service et secours d'icelle a divers temps en Levant et ailleurs que de son vivant il fut amy et tresamé de tous en la pluspart de la chrestienté et souverainement en et par ses pays, seignories, nobles, vassaulx, serviteurs et subgiez et que par la bonté et doulceur qui estoit en lui il acquist et at-

123 Ms.: Diese Zwischenüberschrift steht vor dem folgenden Absatz. Sie ist unterstrichen und davor steht ein $c$ / für capitulum.

124 Vgl. dazu die Mitgliederliste im Anhang S. 229-232.

125 Zur Ausführung vgl. § 146.

126 Ms.: Die Randbemerkung steht links von der Zeile, die mit Que ledit feu monseigneur le duc Charles a esté prince beginnt.

127 Vgl. PB 2, S. 90 f. § 63.

128 Ms.: Diese Zwischenüberschrift steht am linken Rand des folgenden Absatzes und ist durch einen Strich von diesem getrennt.

129 15. Juni 1467. 
tribua a lui ce tiltre et ceste honnorable memoire entre ceulx qui l'ont cogneu, que en parlant de lui, ilz le nomment et dient communement le bon duc Phelippe Dieu face vray pardon et mercy a son ame.

\section{$\mathrm{N}$ (ota): Le proces touchant le fait des elections ${ }^{130}$}

[127] [Bevor mit der Neuwahl begonnen wird, müssen alle beeiden, dass sie sich bei der Auswahl neuer Mitglieder nicht von persönlichen Interessen leiten lassen.]

\section{Le serment a ce servant ${ }^{131}$}

Ces choses ainsi faites, ont deliberé et conclut mesdis seigneurs le souverain et chevaliers freres de l'ordre capittulans, de proceder ou fait des elections des nouveaulx chevaliers pour remplir les lieux vacans en l'ordre. Et en ensuivant les ordonnances et status dudit ordre ont preallablement mesdis seigneurs les chevaliers freres fait serment solemnellement et reverenment en la main de mondit seigneur le souverain l'un apres aultre, commençant du plus anchien d'eulx jusques au plus jeune, de proceder chascun endroit soy leaulment et justement a ladite election, selon le contenu du xlvj article desdis status a ce servant, ${ }^{132}$ lequel ensemble les autres status illec ensuivans et servans au propos leur ont esté leuz publiquement et entendiblement. Et pareil serment a fait mondit seigneur le souverain pour son endroit.

\section{[128] [Ermahnung des Kanzlers.]}

Lequel serment ainsi fait, par la deliberacion et ordonnance de messeigneurs lesdis chevaliers freres de l'ordre a reverend pere en Dieu monseigneur l'evesque de Tournay, chancellier dudit ordre, exhorté et adverti mondit seigneur le souverain, pour ce que le soir precedent, il avoit prins delay pour adviser touchant ses parens, amis ou serviteurs s'il vouldroit aucuns recommander pour la future election $<$ s $>$, pour ce mesmement qu'il avoit touchié d'ung chevalier auquel sembloit qu'il portast singuliere affection. Que son plaisir fust de nommer ledit chevalier et aultres ung ou deux desquelz il se pourroit ayder. ${ }^{133}$

\section{[129] [Hz. Maximilian schlägt seinen Vater, Kaiser Friedrich III., vor.]}

Ce oyant mondit seigneur le souverain, il se ouvrit parlant de la personne de l'empereur $\{94\}$, son pere, donnant espoir que, s'il estoit esleu, il accepteroit l'ordre.

130 Ms.: Diese Zwischenüberschrift steht vor dem folgenden Absatzes und touchant le fait des elections ist unterstrichen. - Fortsetzung von $\S 79$.

131 Ms.: Diese Zwischenüberschrift steht am linken Rand des folgenden Absatzes.

132 Nach § 71 (neu § 46) der Statuten (dazu S. 16, Anm. 14) soll bei der Auswahl neuer Mitglieder nicht persönliche Interessen des Einzelnen im Vordergrund stehen, sondern die Kandidaten sollen für den Souverän und dessen Herrschaften sowie für die Ehre und das Gedeihen des Ordens förderlich sein. Das weitere Verfahren zur Wahl neuer Mitglieder ist in § 70-74 (neu § 45-49) der Statuten geregelt. - Zu den Neuwahlen siehe auch in der Einleitung S. 20-22.

133 Nach Delepierre, Fête en 1478, 1842, S. 343, sprach der Kanzler folgende Worte: «Messeigneurs, pour faire justement et saintement l'élection des douze nouveaux frères et compagnons que nous devons élire, en remplacement d'autant de chevaliers décédés, vous devez jurer de ne choisir ni par amour, ni pour en tirer avantage; mais de nommer des gentilshommes de nom et d'armes, sans reproche.» 
[fol. 39r/11r]

\section{Touchant l'election ${ }^{134}$}

[130] [Die Mitglieder zeigen sich erfreut über eine Mitgliedschaft des Kaisers, weisen jedoch darauf hin, dass dennoch ein ordentliches Wahlverfahren notwendig sei.]

Laquelle ouverture entendue par mesdis seigneurs les chevaliers freres de l'ordre, qui moult en furent joyeux et consolez, disans que l'empereur \{94\}, son pere, feroit grant honneur a l'ordre, se son plaisir d'y estre accompaingnié, fut requis et ordonné par commun accord que l'on garderoit la maniere et forme des status dudit ordre es elections qui se feroient. ${ }^{135}$

\section{[131] [Kaiser Friedrich III. wird einstimmig zum neuen Ordensmitglied gewählt.]}

\section{La premiere election ${ }^{136}$}

En ensuivant laquelle forme mondit seigneur le souverain escrivit de sa main deux cedules, les mettant ou bacin et chascun de messeigneurs les chevaliers freres la presenz la sienne et si y furent aussi mises oudit bachin les cedules des absens toutes closes. ${ }^{137}$ Et lesdictes cedules des presens veues et visitees l'une apres autre et faite ouverture des cedules desdis absens, furent trouvez les veuz de tous mesdis seigneurs presens et absens, reservé ung desdis absens seulement, concordans uniformement en la personne dudit empereur \{94\}. Et ce fait, mondit l'evesque de Tournay, chancellier de l'ordre, en ensuivant les status et ordonnances dudit ordre, a demandé et interrogué a tous mesdis seigneurs les freres encommenchant du plus anchien jusques au plus jeune, pour savoir s'il y avoit quelcun d'eulx qui sceust ou eust ouy dire par gens dignes de foy chose aucune de la personne de l'empereur illec esleu, parquoy il ne puist estre en l'ordre. Et semblablement en a interrogué mondit seigneur le souverain. Et tous mesdis seigneurs ont respondu et dit chascun que non, mais que l'empereur feroit grant honneur a l'ordre de l'accepter. Parquoy mondit seigneur le souverain a pronnoncé l'empereur, son pere, esleu et appellé a frere et compaignon de l'ordre de la Thoison d'or. Dont tous mesdis seigneurs les freres ensemble les officiers dudit ordre firent grant joye et congratulacion, esperans tous que ce sera grant bien, honneur et exaulcement pour icellui ordre.

134 Ms.: Diese Zwischenüberschrift steht in der Kopfzeile von fol. 11r und 13r.

135 Vgl. die Angaben in Anm. 132.

136 Ms.: Diese Zwischenüberschrift steht am linken Rand des folgenden Absatzes und ist durch einen Strich von diesem getrennt.

137 Auch der abwesende Jean de Melun \{28\} hatte Ks. Friedrich III. vorgeschlagen; s. Reg. 46; andere erhaltene Wahlvorschläge sind in Reg. 31 und 37 verzeichnet. 


\title{
Ouverture et remonstrance faites par monseigneur le souverain touchant et a la faveur du roy de Honguerie et du duc Albert de Saxe ${ }^{138}$
}

\author{
[132] [Hz. Maximilian schlägt als nächstes Matthias Corvinus, Kg. von Ungarn, \\ und Albert, Hz. von Sachsen vor. In der darauffolgenden Diskussion zeigt \\ sich eine Unsicherheit, ob der Kaiser gleichzeitig mit Kg. Matthias einem \\ Ritterorden angehören möchte. Als Hz. Maximilian vorschlägt, dazu erst \\ einmal Ks. Friedrichs Meinung einzuholen, wird er darauf hingewiesen wird, \\ dass ein solche Vorgehensweise nicht den Statuten entspricht.]
}

$[a]^{139}$ Ladite election ainsi faite de la personne de l'empereur $\{94\}$, mondit seigneur le souverain a aussi parlé de deux autres princes, assavoir du roy de Honguerie $^{140}$ et du duc de $<$ Saxe $>$ Saxe $\{96\},{ }^{141}$ donnant assez a cognoistre qu'il avoit bonne affection a leurs personnes et qu'il desiroit qu'ilz fussent accompaingnez a l'ordre, se faire se

138 Ms.: Diese Zwischenüberschrift steht vor dem folgenden Absatz und ist durch einen Strich von diesem getrennt. Saxe ist wegen eines Flecks im Papier nur schwer lesbar.

139 Ms.: Zur besseren Lesbarkeit dieses langen Paragraphen wurden Absätze und Unterpunkte eingefügt.

1401458 wurde Matthias Corvinus (1443-1490) von den Magnaten zum König von Ungarn gewählt, während die gegnerische Partei Kaiser Friedrich III. \{94\} 1459 zum Gegenkönig bestimmte. Erst nach weitreichenden Zugeständnissen gab Friedrich III. seine Ansprüche auf die ungarische Krone auf, sodass am 29. März 1464 Matthias zum König gekrönt werden konnte. Aber auch in der Folgezeit gab es immer wieder Spannungen zwischen Matthias und Friedrich III., denn der ehrgeizige König strebte auch nach der böhmischen Königskrone und nach den im Osten liegenden Besitzungen Ks. Friedrichs III., die er ab 1482 nach und nach eroberte; vgl. dazu u. a. Nehring, Matthias I., 1993. Kg. Matthias unterhielt auch zu Hz. Karl \{34\}, der ähnlich ehrgeizige Pläne verfolgte wie er, gute Beziehungen und hatte auch im Jahr 1473 eine Gesandtschaft entsandt, die sich während eines der Gottesdienste des Ordens vorstellte; vgl. PB 3 S. 62 f., § 69. Nach dem Tode Karls bemühte sich Kg. Matthias jedoch in enger Zusammenarbeit mit Kg. Ludwig XI. von Frankreich darum, die habsburgisch-burgundische Heiratsverbindung zu hintertreiben, indem er versuchte, einige deutsche Fürsten gegen die Heirat aufzubringen und in Österreich Ks. Friedrich III. und dessen Sohn durch zahlreiche kriegerische Streifzüge abzulenken; vgl. dazu Rausch, Heirat, 1880, S. 172 f.; Bachmann, Reichsgeschichte, 2, 1894, S. 584 ff.; Wiesflecker, Maximilian, 1, 1971, S. 129, DüCKER, Konfrontation und Kooperation, 2011, sowie künftig Kunde, Antipoden der Macht. 1478 hoffte Hz. Maximilian wohl, mit der Aufnahme Kg. Matthias' in den Orden vom Goldenen Vlies die Ende November 1477 geschlossene Beilegung des Konflikts (vgl. Koller, Friedrich III., 2005, S. 200-203) zu festigen. Da er sich aber der Reaktion seines Vaters nicht sicher war, schlug er zwar Matthias vor, aber machte die endgültige Aufnahme von der Zustimmung seines Vaters abhängig. Maximilian betonte vor dem Orden aber, dass die Mitgliedschaft Matthias' seiner maison imperial und somit auch seiner Person und seinen Herrschaften nützen würde.

141 Albrecht, Hz. von Sachsen (1443-1500) war ein Neffe Ks. Friedrichs III. und stand in dessen Diensten. 1477 und später beteiligte er sich immer wieder an den ksl. Feldzügen gegen Ungarn, wenngleich dabei auch Eigeninteressen eine Rolle spielten. 1488 ernannte ihn Hz. Maximilian zu seinem Statthalter in den Niederlanden. $\mathrm{Zu}$ seiner Person vgl. u. a. Blockmans, Albrecht de Soutmoedige, 1992; HeInig, Friedrich III., 1997, S. 435-439; Cools, Mannen, 2000, S. 396 f., Nr. 227, Chevaliers de la Toison 
povoit, car ce seroit son bien et de ses affaires et aussi le bien de ses pays comme il esperoit et lui sembloit.

[b] Surquoy entre aultres pluseurs paroles messeigneurs lesdis freres de l'ordre lui firent humblement remonstrer par la bouche dudit evesque de Tournay, chancellier dudit ordre, que dez paravant l'election faite de la personne de l'empereur, son pere, il avoit ja quatre roys en l'ordre, assavoir le roy d'Arragon $\{57\}$, le roy d'Angleterre $\{68\}$, le roy de Naples $\{72\}$ et le roy de Castille $\{71\}$, et maintenant en estoit l'empereur le $v^{\mathrm{e}}$ qui est le plusgrant de tous. Ce qui povoit souffire a leur advis, saulve sa benigne correction, sans plus y accumuler si grans princes pour ceste fois, mesmement qui fussent d'estrainges et longtain [fol. 39v/11v] marches. ${ }^{142}$ Mais leur sambloit plus expedient pour mondit seigneur, veu l'estat de ses pays et ses grans affaires, de choisir et eslire des nobles hommes chevaliers de sesdis pays et seignouries, dont en y avoit pluseurs grans seigneurs et vaillans hommes desquelz il pourroit estre bien et honestement accompaingnié, servi et aydé et dont sa maison et l'ordre seroient honnorez et decorez.

[c] Laquelle remonstrance mondit seigneur receut et ouy benignement et aggreablement. Mais neantmoins dit au regart dudit roy de Honguerie que s'il estoit esleu a l'ordre et il plaisoit a l'empereur, son pere, qu'il y fust associé et accompaingnié comme lui et qu'il y fust propice et ydoine, il y prendroit grant plaisir. Bien estoit vray, qu'il ne sçavoit pas encores de certain comment l'empereur, son pere, et le roy de Hunguerie s'entendent ensemble, ne se l'empereur vouldroit estre en l'ordre avec lui, ne se ce seroit le bien dudit empereur et de lui et aussi le bien du mesme ordre que ensamble ilz y fussent accompaingnez, ains s'en vouldroit rapporter a l'ordonnance, advis et bon plaisir d'icellui empereur, son pere, mettant ces choses en termes par forme de devises et que l'election se pourroit faire du roy de Honguerie. Mais elle ne lui seroit point signifiee, ne aussi le collier envoyé ains que l'on l'envoiast a l'empereur, son pere, le advertissant de l'election que seroit faite de la personne du roy de Honguerie, pour sentir de lui s'il aggreeroit et seroit content que ledit collier fust porté oultre devers ledit roy de Honguerie et mesmement pour savoir son advis, se icellui roy de Honguerie seroit bon, propice et ydoine pour ledit ordre et aussi pour sa maison imperial et consequenment pour mondit seigneur le souverain et pour ses pays, seignories et subgiez, tant de pardela que de pardeça. ${ }^{143}$ Et se le porteur dudit collier trouvoit qu'il eust bon entendement entre eulx et l'empereur, ainsi le aggreoit et consentoit mesmement par son ordonnance et advis, ledit porteur du collier passeroit oultre et s'en yroit devers ledit roy de Honguerie lui annuncer l'election faite de lui a l'ordre, et s'il l'acceptoit, il recevroit de lui le serment en lui baillant ledit collier en la maniere qu'il appartient, pourroit aussi l'empereur pareillement y envoyer aucun de ses gens pour le mieulx exhorter et animer a ladite recepcion. Et se le roy de Honguerie reffusoit de accepter sadite election et le collier de l'ordre, ou mesmement se l'advis et conseil de

d'or, ${ }^{2} 2000$, Nr. 96; Cools, Quelques hommes, 2006, S. 167 f., sowie den Tagungsband Herzog Albrecht der Beherzte, 2002.

1421473 hatte Karl der Kühne während des Wahlverfahrens verkündet, dass mit vier Königen dem Orden genügend hochgestellte Mitglieder angehörten; vgl. PB 3, S. 117, $\S 177$; DünNeBEIL, Beherrschung, 2010, S. 178.

143 Unter den „pays de par-deça“ versteht man die burgundischen Niederlanden und unter den „pays de par-dela“ das Herzogtum und die Freigrafschaft Burgund; vgl. dazu u. a. PAviot, Recrutement, 1996. 
l'empereur estoit que ledit roy de Honguerie ne fust propice, pour lui, pour mondit seigneur ne pour l'ordre, que en ces cas ou de l'ung d'iceulx l'empereur envoiast ledit collier au duc de Saxe et que l'empereur eust le choix et l'option d'envoier le collier a cellui d'eulx deux, que mieulx lui plaroit.

[d] Sur ce mesdis seigneurs les chevaliers freres de l'ordre, eue deliberacion et advis ensamble, ont fait dire et remonstrer de rechief humblement et reverenment a mondit seigneur le souverain, qu'il ne se povoit bonnement ainsi faire ne conduire et que, saulve sa reverence, il n'estoit pas bien adverti des status et ordonnances ne des observances et coustumes de l'ordre, ausquelles ceste maniere de faire par lui proposee seroit repugnant et contraire. ${ }^{144}$ Car en ensuivant lesdis status et ordonnances dudit ordre la coustume de messeigneurs ses predecesseurs, chiefs et souverains, et [fol. 41r/13r ${ }^{145}$ aussi des chevaliers de cest ordre avoit et a tousjours esté de faire en leur chappittre fiancement ${ }^{146}$ et absolutement leurs elections sans si et sans condicion et sans ce que nul aultre, fors ceulx de l'ordre en sceussent a parler et ceulx qui estoient aptes, ordonnez et commis pour a ceulx, qui en chappittre avoient esté esleuz, aler annuncer et signifier leur election, et sentir et savoir desdis esleuz secretement s'ilz la vouldroient accepter ou non. Car ilz estoient frans pour l'accepter ou reffuser. ${ }^{147}$ Et en cas de leur acceptacion ledit commis leur bailloit le collier en prenant et recevant d'eulx le serment qui est incorporé es chappittres et status de l'ordre. ${ }^{148}$ Et se lesdis esleuz le refusoient, oudit cas le collier se rapportoit au souverain par ledit commis secretement et demouroit ce lieu vacant jusques a l'autre chappittre de l'ordre lors prouchain apres avenir. Sans ce que autre personne quelconque, fors ledit futur chappittre plus s'en meslast ou eust auctorité de transporter ledit collier a aultre personne ne aultrement eust cognoissance ou disposicion aucune touchant icellui collier.

[e] Et pour ce qu'il estoit tard, prierent mesdis seigneurs a mondit seigneur le souverain que son plaisir fust que l'on procedast oultre et besoingnast ou fait desdites elections jusques aux deux darreniers lieux, lesquelz, s'il lui plaisoit, l'on tendroit ouvers jusques aux aultres elections faites, pour ce pendant par mondit seigneur et eulx plus meurement penser sur ceste matiere touchant lesdis deux princes. ${ }^{149}$

144 Zum Wahlverfahren vgl. die Angaben in Anm. 132.

145 Ms.: Nachträglich wurde fol. 40 mit $§ 133$ eingelegt. Um zu zeigen, dass der laufende Text aber erst auf fol. 41r weitergeht, wurden am unteren Rand von fol. 39v nachträglich die ersten Worte von fol. 41r nachgetragen: aussi des chevaliers etc. sowie in der Zeile darunter noch c(ontinu)iez on second fueillet. - Vgl. dazu auch die Angaben in der Einleitung S. 27 sowie unten Anm. 150.

146 Lies: finalement.

$147 \mathrm{Zu}$ den Bemühungen, dass die Namen neuer Mitglieder erst nach ihrem Beitritt bekannt wurden, siehe in der Einleitung S. 22.

148 Vgl. dazu die Angaben in § 156, Anm. 222.

149 Fortsetzung in $§ 149$. 
$[\text { fol. 40r/12r }]^{150}$

\section{La seconde election ${ }^{151}$}

\section{[133] [Auf Hz. Maximilians Vorschlag hin, wird Bartholomäus von Liechtenstein zum neuen Mitglied gewählt.]}

Apres et en ce mesme chappittre a parlé mondit seigneur le souverain honnestement et bien favorablement de la personne de messire Bertremy de Lichtenstein $\{85\}$, chevalier, son grant maistre d'ostel d'Austrice, ${ }^{152}$ duquel il a dit du bien beaucop et entre aultres choses que ledit messire Bertremy l'avoit servi et eu les gouvernement et garde de sa personne < de sa personne $>$ depuis son enfance continuellement jusques a cy et tousjours s'estoit devers lui porté, gouverné et conduit honnorablement et leaument. Dont fort l'a loué et recommandé mondit seigneur, affermant que ledit messire Bertremy est noble homme et de noble extraction de deux costez et qu'il a pluseurs nobles parens ${ }^{153}$ en l'ostel de l'empereur $\{94\}$, son pere, et es pays et marches dont il est natif. Qu'il a aussi esté vaillant en armes de son temps. Et a demonstré mondit seigneur qu'il avoit bon amour et affection audit messire Bertremy et desir qu'il fust en l'ordre. Laquelle chose oyé et entendue par mesdis seigneurs les chevaliers freres apres petite deliberacion sur ce eue entre eulz, ilz ont fait dire et remonstrer humblement a mondit seigneur le souverain que de la personne dudit messire Bertremy ilz n'avoient cognoissance aucunes fors depuis sa venue pardeça, pendant lequel temps il l'avoient veu devers lui et en sa compaignie, servant en estat honnorable. Mais de sa noblesse et vaillance ne s'il seroit propice et ydoine pour l'ordre, ilz ne savoient car point n'en avoient enquis et n'en estoient ${ }^{154}$ informez aultrement que par le rapport que mondit seigneur leur en faisoit, qui estoit bel et honneste a leur advis et pour ce a lui s'en rapportoient et a sa conscience. Lesquelles remonstrances ainsi faites d'une part et d'autre, a esté procedé oultre ou fait des elections. Et mondit seigneur le souverain a baillié et mis ou bachin les deux cedules de son veu et consequenment mesdis seigneurs les chevaliers freres chascun la sienne en la maniere accoustumee. Et a esté trouvé que ledit messire Bertremy de Lichtestein avoit le plusgrant nombre

150 Ms.: fol. 40r wurde nachträglich von Steenberch eingefügt und umfasst § 133. Ein großes $A$ und eine Markierung am linken Rand zeigen an, dass dieser Absatz zwischen $\S 132$ und 134 gehört. Das untere Drittel des Blattes ist unbeschrieben und zwei geschlängelte, den freien Platz ausfüllende Linie und dazwischen das Wort nul sollen anzeigen, dass dieser Platz auch leer bleiben soll. Fol. 40r ist ebenfalls unbeschrieben und eine senkrechte, geschlängelte Linie, die von den Worten vacat nul unterbrochen ist, kennzeichnet ebenfalls, dass diese Seite leer bleiben soll. Vor Beginn von $\S 134$ befindet sich die gleiche Marke wie auf fol. 40r und zu Beginn des danach folgenden Absatzes steht am linken Rand ein großes B. Beides soll ebenfalls anzeigen, dass $§ 133$ hierher gehört. - Vgl. dazu auch die Angaben in Anm. 145.

151 Ms.: Diese Zwischenüberschrift steht in der Kopfzeile von fol. 40r.

152 Bartholomäus von Liechtenstein wurde am Morgen während der Großen Messe des Ordens von Hz. Maximilian zum Ritter geschlagen (§ 95). Zu seiner Person vgl. die Angaben in Anm. 61 oben zu $§ 10$.

153 Wilhelm von Liechtenstein-Karneid († 1432) und Martha von Wolkenstein-Trostburg; Pfeifer, Liechtensteiner, 1998, S. 85-88; Chevaliers de la Toison d'or, ${ }^{2} 2000$, S. 203.

154 Ms.: estoient steht über der Zeile und eine Marke zeigt die dafür vorgesehene Stelle im Text. 
des voix en ceste elelction. Parquoy apres scrutine fait sur sa personne pour savoir se aucun de mesdis seigneurs les chevaliers freres sceust en lui chose, parquoy il ne puist estre receu en l'ordre selon les status d'icellui, et que riens n'y fut trouvé, mais s'en estoient rapportez et raportoient a mondit seigneur, eulx confians de lui et de sa conscience comme dessus est dit, mondit seigneur le souverain a pronnoncé ledit messire Bertremy de Lichtestein estre esleu et appellé pour frere et compaignon dudit ordre de la Thoison d'or. ${ }^{155}$

\section{[fol. 41r/13r (Fortsetzung) $]^{156}$}

[134] [Es folgen die Wahl von Philippe von Burgund, Herr von Beveren, fosse de Lalaing, Pierre de Luxembourg und des in Frankreich gefangenen Herrn von Chalon.]

Apres ont mondit seigneur le souverain et messeigneurs les chevaliers freres et compaingnons de l'ordre de la Thoison d'or besoingnié en leurdit chappittre ou fait desdites elections. Et en ensuivant la forme des status et ordonnances dudit ordre ont procedé sur icelles par cedules comme devant. Et a la premiere fois a esté esleu par la pluralité des voix messire Phelippe, seigneur de Bevre $\{82\} .{ }^{157}$ Apres laquelle election a esté demandé par mondit seigneur de Tournay, chancellier de l'ordre, a mesdis seigneurs les chevaliers freres et consequenment a monseigneur le souverain dudit ordre pour savoir d'eulx, s'il y avoit personne d'eulx qui sceust ou eust ouy dire par gens dignes de foy chose aucune de la personne dudit messire Phelippe, seigneur de Bevre, illec eslu, parquoy il ne puist estre en l'ordre. Et tous lui ont donné louenge et recommendacion de sa vertu, vaillance, leaulté et noblesse sans savoir en lui chose quelconque, parquoy il ne puist et doive esté accompaingnié en l'ordre. Laquelle chose entendue par mondit seigneur le souverain, il a pronnoncié icellui messire Phelippe, seigneur de Bevre, esleu frere et compaignon dudit ordre de la Thoison d'or.

A la seconde election ensuivant a esté trouvé avoir le plusgrant nombre de voix messire Josse de Lalaing $\{80\}$, seigneur de Montigny. ${ }^{158}$

A la tierce election a eu concurrence par equalité de nombre des voix sur deux, parquoy elle fut cassee et l'election reiteree, par laquelle a esté trouvé que monseigneur Pierre de Luczembourg $\{83\}$, conte de Saintpol, avoit le plusgrant nombre de voix. ${ }^{159}$

A la iiije election a esté trouvé avoir le plusgrant nombre des voix monseigneur [Hugues] ${ }^{160}$ de Chalon, seigneur de Chasteauguion, prisonnier en France.

155 Fortsetzung in $§ 154$.

156 Zu Reihung der Absätze vgl. Anm. 150.

157 Philipp von Burgund, Herr von Beveren, wurde im März 1468 zum Statthalter in Namur ernannt und führte immer wieder burgund. Truppen an. Schon 1473 stand er auf der Kandidatenliste und bei diesem Fest wurde er u. a. von den abwesenden Mitglieder Ferdinand, Kg. von Kastilien $\{71\}$, und Jean de Melun $\{28\}$ vorgeschlagen (Reg. 31 und 46). Zu seiner Person vgl. u. a. Cools, Mannen, 2000, S. 250 f., Nr. 26; Chevaliers de la Toison d'or, ${ }^{2} 2000$, S. 198 f., Nr. 82; Haemers, Common Good, 2009, S. 121 f.; PB 3, S. 115, § 176 mit Anm. 432 sowie unten § 261.

158 Er stand schon 1473 auf der Kandidatenliste; vgl. PB 3, S. 115, § 176 mit Anm. 430; mehr Angaben zu seiner Person sind in $§ 162$ mit Anm. 232 zu finden.

$159 \mathrm{Zu}$ seiner Person vgl. die Angaben in $§ 47$ mit Anm. 237.

160 Ms.: Steenberch ließ eine größere Lücke, um den Vorname nachtragen zu können. Es handelt sich dabei um Hugues de Chalon-Arlay, Herr von Orbe und Châtel-Guyon 
[fol. 41v/13v] Sur lesquelz trois seigneurs, cy nommez et darrenierement esleuz, assavoir monseigneur de Montigny, monseigneur de Saintpol et monseigneur de Chasteauguion, et sur chascun d'eulx particulierement apres l'election faite de sa personne a esté fait scrutine et demande, s'il avoit personne qui sceust ou eust ouy dire du chevalier l'a nommé et esleu chose que feist a blamer, parquoy il ne peust estre accompaingnié en l'ordre. Et tous mesdis seigneurs les chevaliers freres et semblablement mondit seigneur le souverain ont parlé en tout bien et honneur desdis trois chevaliers et de chascun d'eulx et reputé iceulx dignes, ydoines et propices pour mondit seigneur le souverain et pour l'ordre, parquoy mondit seigneur le souverain les a chascun a part, et particulierement apres lesdites e<e>lection et scrutine d'eulx faites, pronnoncié esleuz freres et compaignons dudit ordre. ${ }^{161}$

\section{[135] [Die weiteren Wahlen werden auf den nächsten Tag vertagt.]}

Et ce fait, mondit seigneur le souverain et messeigneurs les chevaliers freres de l'ordre ont continué leur election, quant aux aultres six lieux encores vacans et a remplir, et leur chappittre jusques au lendemain, car il estoit bien tard et tous estoient travailliez. ${ }^{162}$

\section{Mai 1478}

\section{Sabmedi, le second jour dudit mois de may oudit an $\mathbf{l x x v i i j}{ }^{163}$}

\section{[136] [Um 9 Uhr versammelt sich der Orden erneut.]}

Ce jour a l'eure de ix heures devant la messe comparurent et se assamblerent oudit chappittre monseigneur le souverain, messeigneurs Jehan, seigneur de Lannoy $\{50\}$, Adolff de Cleves \{55\}, seigneur de Ravestein, Loys, seigneur de Gruythuse $\{61\}$, conte de Wincestre, Phelippe, conte de Chimay $\{74\}$, et Engelbert, conte de Nassouwe $\{77\}$, tous chevaliers, ensemble les quatre officiers de l'ordre de la Thoison d'or.

(† 1490), Sohn des 1463 verstorbenen Louis de Chalon, Prinz von Orange und hzl. Rat, Kammerherr und Truppenführer. 1473 wurde sein Name auf die Kandidatenliste bei der Neuwahl des Ordens vom Goldenen Vlies gesetzt, ohne jedoch gewählt zu werden. Nach Hz. Karls Tod \{34\} unterstützte Hugues Hz.in Maria und wurde im Frühjahr 1478 bei der Verteidigung der burgund. Besitzungen in der FrancheComté von dem Sénéschal von Toulouse gefangen genommen. Danach wurde er in Chalons-sur-Saône etwa 18 Monate gefangengehalten, denn Kg. Ludwig XI. verlangte 52.000 écus d'or für seine Freilassung. 30.000 wurden im Januar 1479 bezahlt, des Weiteren wurde eine Rente über 1.000 Francs aus der Saline von Salins übergeben. Ein Teil seiner Schuld wurde Hugues wohl nachgelassen, nachdem er im Mai 1479 sich Kg. Ludwig XI. angeschlossen und auf dessen Bemühungen hin im Oktober 1479 Louise von Savoyen (1462-1503) geheiratet hatte, dem Mündel Kg. Ludwigs XI. und Tochter von dessen im August 1478 verstorbenen Schwester Yolande, Regentin von Savoyen. Zu seiner Person vgl. u. a. Gingins-La SArra, Recherches, 1857, S. 244-300, hier S. 283-287 zu seiner frz. Gefangenschaft; VAughan, Charles the Bold, 1973, S. 232 f.; ES II/61; Recueil du Fay, 2003, S. 166, Anm. 1191; PB 3 § 176 mit Anm. 411. - Vgl. dazu auch in der Einleitung S. 21.

161 Fortsetzung in $\S 154$.

162 Fortsetzung in $\S 138$.

163 Ms.: Diese Zwischenüberschrift steht vor dem Absatz, wurde aber während des eigentlichen Schreibvorgangs eingetragen. 


\section{Acte de chappittre ${ }^{164}$}

[137] [Nach einer Diskussion wird beschlossen, dass bei der offrande der verstorbenen Hz. Karl auf gleiche Weise verabschiedet werden soll, wie es nach dem Tode Hz. Philipps dies 1468 geschehen war.]

\section{De l'onneur fait par monseigneur le souverain a feu monseigneur le duc Charles, son beaupere et predecesseur, a l'offrande etc. ${ }^{165}$}

En ce chappittre ont mesdis seigneurs les chevaliers freres de l'ordre fait advertir et informer mondit seigneur le souverain par monseigneur le chancellier de l'ordre des ceremonies a tenir et observer a la grant messe de ce jour, que se diroit pour les trespassez et mesmement a l'offrande du cierge et du blason des armes de feu mondit seigneur le duc Charles $\{34\}$, son beaupere et predecesseur. Et lui a declairé monseigneur l'evesque de Tournay, chancellier de l'ordre, ce que selon le contenu du registre des actes du chappittre dudit ordre, tenu par ledit feu duc Charles en ceste ville de Bruges l'an lxviij, lors avoit esté conclut et fait au regard du cierge et du blason des armes de feu monseigneur le duc Phelippe $\{01\}$, premier fondateur, chief et souverain d'icellui ordre, paravant trespassé, ${ }^{166}$ pour savoir le noble plaisir de mondit seigneur le souverain s'il vouldroit ensuivi l'ordonnance et les ceremonies lors gardees et tenues pour ledit feu duc [fol. 42r/14r] Phelippe. Assavoir que lui mesmes porteroit et yroit offrir le cierge dudit feu monseigneur le duc Charles et Thoison d'or, le roy d'armes, porteroit devant lui ledit blason de ses armes et tous messeigneurs les chevaliers freres ensemble les officiers dudit ordre l'accompaigneroient ainsi comme il avoit esté fait pour icellui feu duc Phelippe l'an lxviij dessusdit. Et combien que la matiere communiquee oudit chappittre, il eust esté debattu par aucuns, que la qualité ne fust pas pareille entre feu mondit seigneur le duc Charles et mondit seigneur le souverain quelle avoit esté entre icellui feu monseigneur le duc Charles et feu mondit seigneur le duc Phelippe, premier fondateur de cest ordre, sondit pere, duquel le mesme duc Charles estoit seul filz, heritier et successeur universel et pour le tout, parquoy selon toute raison ledit duc Charles bien le devoit honnorer apres son deces. Neantmoins mondit seigneur le souverain, considerant que a cause de madame la duchesse, sa compaingne, seule fille et heritiere universele et pour le tout dudit feu duc Charles, il lui a succedé aussi en ses pays et seignories, prerogatives et dignitez et mesmement en l'estat et dignité du chief et souverain de cest ordre, a accordé et conclut par l'advis et conseil desdiz seigneurs freres chevaliers dudit ordre de faire tout honneur a icellui feu duc Charles, son beaupere, et de porter a l'offrande sondit cierge et ledit roy d'armes Thoison d'or porteroit le blason de sesdis armes et messeigneurs les chevaliers freres ensemble lesdis officiers de l'ordre l'accompaigneroient en la maniere qu'il avoit esté fait du cierge et du blason des armes du devantdit feu duc Phelippe comme dessus est touchié. ${ }^{167}$

164 Ms.: Diese Zwischenüberschrift steht am linken Rand zu Beginn des folgenden Absatzes und ist durch einen Strich von diesem getrennt.

165 Ms.: Diese Zwischenüberschrift steht vor dem Absatz und ist durch einen Strich von diesem getrennt. Aufgrund des wenigen Platzes ist sie kleiner als die übrigen Zwischenüberschriften geschrieben.

166 Vgl. PB 2, S. 86 f., § 60 f. sowie die Angaben in § 126.

167 Zur Durchführung vgl. § $142 \mathrm{f}$. 
[138] [Es werden facques de Luxembourg, Wolfart van Borssele, Willem van Egmond und fakob von Savoyen gewählt und für den Fall, dass letzterer die Mitgliedschaft ablehnt, Claude de Toulongeon als Ersatzkandidaten ernannt.]

\section{Aultre election $^{168}$}

Ce fait, mondit seigneur le souverain et messeigneurs les chevaliers freres dudit ordre ainsi assamblez oudit chappittre ont deliberé de besoingner et proceder oultre ou fait desdites elections et successivement ont par ordre et selon les status esté esleuz messeigneurs, cy apres nommez. C'est assavoir:

Messire Jaques de Luxembourg $\{81\}$, seigneur de Fiennes, ${ }^{169}$

messire Wolffart de Borssele $\{79\}$, conte de Grantpré, seigneur de la Vere, ${ }^{170}$ et messire Guillaume, seigneur d'Egmonde $\{78\} .{ }^{171}$

Par commun accord et par les veuz de tous les presens semblablement a esté esleu les veuz ${ }^{172}$ de tous lesdis presens monseigneur Jaques de Savoye \{84\}, seigneur de Romont. ${ }^{173}$ Mais pour ce que mondit seigneur le souverain et mesdis seigneurs les chevaliers freres la presens par l'advertissement d'aucuns faisoient aucunement doubte dudit monseigneur de Romont, s'il accepteroit son election ou la refuseroit par excuse, fut en son lieu, ou cas seulement qu'il se excuseroit de accepter ladite election faite de sa personne et de recevoir le collier de l'ordre, nommé [fol. 42v/14v] et esleu desmaintenant par ladite condicion et par les veux d'eulx tous messire Claude de Thoulongeon $\{93\}$, seigneur de la Bastie, chevalier bien recommandé. ${ }^{174}$

168 Ms.: Diese Zwischenüberschrift steht vor dem folgenden Absatz. Sie ist unterstrichen und davor steht ein $c$ / für capitulum.

169 Er stand schon 1473 auf der Kandidatenliste; vgl. PB 3, S. 116, § 176 mit Anm. 435; zu seiner Person vgl. u. a. Cools, Mannen, 2000, S. 356-358, Nr. 160; Chevaliers de la Toison d'or, ${ }^{2} 2000$, Nr. 81.

170 Zu seiner Person vgl. u. a. Cools, Mannen, 2000, S. 242-244, Nr. 19; Chevaliers de la Toison d'or, ${ }^{2} 2000$, Nr. 79; Haemers, Common Good, 2009, S 47 f.; Sicking, Louis, Ten faveure, 2009, S. 42-44.

171 Zu seiner Person vgl. u.a. Cools, Mannen, 2000, S. 296 f., Nr. 72; Chevaliers de la Toison d'or, ${ }^{2} 2000$, Nr. 78.

172 Lies: voix.

173 Ms.: Vor und nach dem Namen monseigneur faques de Savoye, seigneur de Romont, befinden sich jeweils zwei senkrechte Striche. - Zu seiner Person vgl. die Angaben unten § 261 mit Anm. 283.

174 Claude de Toulongeon stand schon 1473 auf der Kandidatenliste; vgl. PB 3, S. 113, $\S 176$ mit Anm. 410. Nachdem Jakob von Savoyen aber seine Wahl angenommen hatte, wurde Claude de Toulongeon 1481 noch einmal gewählt; vgl. PB 5, fol. 40r (dort wird auch vermerkt, dass er schon bei der Neuwahl im Jahr 1468 etliche Stimmen erhalten hatte). Zu seiner Person vgl. u. a. Richard, Claude de Toulongeon, 1992; Cools, Mannen, 2000, S. 401 f., Nr. 240; Chevaliers de la Toison d'or, ${ }^{2} 2000$, Nr. 93. Zur Aufstellung von Ersatzkandidaten vgl. in der Einleitung S. 21, Anm. 80. 


\section{Touchant les elections ${ }^{175}$}

\section{[139] [Die Wahlbestätigung der Gewählten durch den Souverän.]}

Item et apres ladite nominacion et election de chascun desdis quatre chevaliers ainsi esleuz, a par monseigneur le chancellier de l'ordre esté enquis et demandé a tous mesdis seigneurs les chevaliers freres et aussi a mondit seigneur le souverain, s'il avoit aucun qui sceust ou eust ouy dire chose aucune de tel chevalier illec nommé et esleu, parquoy il ne peust estre accompaingnié a l'ordre. Et riens n'a esté trouvé sur eulx, mais ont tous lesdis chevaliers et chascun d'eulx particulierement esté grandement louez et recommandez comme bien dignes, propices et ydoines pour estre oudit ordre. Laquelle chose ouye et entendue par mondit seigneur le souverain, il les a tous par ordre et successivement chascun d'eulx apres la nomminacion et election faite de sa personne pronuncié, esleuz et appellez a freres et compaingnons dudit ordre de la Thoison d'or. Et semblables scrutine et enqueste ont esté faites sur la personne dudit seigneur de la Bastie $\{93\}$ et riens n'a esté trouvé sur lui, fors que tout bien, mais esté recommandé de vaillance et de grant leaulté qu'il avoit monstrees et gardees devers monseigneur le souverain et devers madame la duchesse, sa compaingne, et qu'il estoit bien digne et ydoine pour estre en l'ordre, parquoy en cas et par condicion seulement que mondit seigneur de Romont $\{84\}$ ne accepteroit sadite election et le collier de l'ordre, mondit seigneur le souverain par l'advis et consentement de mesdis seigneurs les freres de l'ordre l'a prononcié esleu desmaintenant pour ou cas dessus dit et non autrement estre frere et compaingnon dudit ordre ou mesme lieu auquel estoit esleu ledit monseigneur de Romont. ${ }^{176}$

\section{[140] [Die Ordensmitglieder bereiten sich für die Totenmesse vor.]}

Ces choses ainsi faites, mondit seigneur le souverain et par l'advis de mesdis seigneurs les chevaliers, ses freres de l'ordre, pour ce qu'il estoit ja tard et failloit aller a la grant messe, a continué le surplus de l'election qui restoit a faire et le chappittre jusques apres disner. ${ }^{177}$ Et est tantost allé vers l'eglise pour y ouyr ladite grant messe et messeigneurs les chevaliers freres ensemble les officiers de l'ordre l'ont accompaingné tous habillez eu deul de robes longues manteaulx et chapperons noirs et alans a cheval en la maniere et par l'ordre gardez le soir precedent. ${ }^{178}$

175 Ms.: Diese Zwischenüberschrift steht in der Kopfzeile von fol. 42v.

176 Zu Claude de Toulongeon vgl. die Angaben in Anm. 174. - Forsetzung des Wahlverfahren in § 149 und Fortsetzung zu den hier Gewählten in § 154.

177 Fortsetzung in $§ 149$.

178 Angaben zur Totenmesse mit dem dazugehörigen Kerzenopfer finden sich in $\S 123$, Anm. 121; zum schwarzen Ordensornat vgl. in § 40 mit Anm. 210 und zum prozessionsartigen Gang in die Kirche $§ 75$ mit Anm. 21. - Diesen Gottesdienst beschreibt auch Delepierre, Fête en 1478, 1842, S. 541. 


\section{[fol. 43r/15r]}

\section{Touchant les ceremonies de l'office et messe des trespassez ensamble de l'offrande faite a ladite messe ${ }^{179}$}

\section{[141] [Zum Beginn der Totenmesse.]}

Mondit seigneur le souverain arrivé en l'eglise Saint Salveur et mis en son siege qui estoit tout paré de drap de velou noir ou grant chœur de ladite eglise soubz le tableau de ses armes et mesdis seigneurs les chevaliers freres en leurs lieux chascun soubz son tableau de ses armes, ${ }^{180}$ reverend pere en Dieu messire Ferry, evesque de Tournay, chancellier de l'ordre, ja revestu pour dire la grant messe et affulé d'une moult riche chappe de drap d'or noir, ${ }^{181}$ a apporté l'eaue benoite a mondit seigneur, accompaingnié de deux abbez, a tout croches non mitrez et de deux ministres assavoir diacre et soubzdiacre, prelas aussi. Et deux autres abbez tenoient le chœur au chappittre qui entonnerent la messe ou parquet des chantres. ${ }^{182}$

\section{[142] [Der Ordenskanzler fordert die versammelten Ordensangehörigen auf, das Kerzenopfer für den verstorbenen $\mathrm{Hz}$. Karl durchzuführen.]}

Tantost apres a ladite messe esté encommençee et continuee mout solemnellement pour lesdis trespassez jusques a l'offertoire d'icelle. Apres lequel offertoire ledit monseigneur l'evesque de Tournay, prelat celebrant, tourné du visaige devers le chœur, a remonstré et dit a haulte voix a messeigneurs les chevaliers freres et compaingnons de l'ordre, comment mondit seigneur le souverain pour honnorer feu monseigneur le duc Charles $\{34\}$, son beaupere et predecesseur, jadis chief et souverain de ce noble ordre, darrain trespassé, porteroit a l'offrande le cierge ordonné pour ledit feu. Et Thoison d'or, le roy d'armes, porteroit le blason des armes d'icellui feu. Exhortant pour ce mesdis seigneurs les chevaliers freres qu'ilz voulsissent accompaingner mondit seigneur le souverain et faire honneur au tresnoble prince trespassé. ${ }^{183}$

[?] $\mathrm{No}(\mathrm{ta}){ }^{184}$

179 Ms.: Diese Zwischenüberschrift steht in der Kopfzeile von fol. 43r und ist durch einen Strich von diesem getrennt. Davor steht ein $c$ / für capitulum. Auch in der Kopfzeile von fol. 43v steht als Zwischenüberschrift Touchant les ceremonies de ladite messe de trespassez.

180 Vgl. zur Ausstattung der Kirche vgl. § 36-38 und zu den Wappentafeln § 31 mit Anm. 187.

181 Vgl. dazu auch die Angaben in § 76 mit Anm. 22.

182 Nur die Namen von drei beim Ordensfest anwesenden Äbte sind belegt: Kurz vor dem Ordensfest hatte Hz. Maximilian den Abt von Sint-Pieters in Gent aufgefordert, mit seinen kirchlichen Festgewändern am Ordensfest teilzunehmen (Reg. 44), und am 4. Mai assistierte der Abt von Saint-Bertin (§ 179) und 5. Mai der Abt von Clairmarais bei den Gottesdiensten des Ordens (§ 196).

183 Vgl. dazu die Planung in § 124 und 137. - Vgl. dazu auch die Beschreibung bei Verschelde, Feeste, 1873, S. 27 (nach Stadtbibl. Brügge, Historisch Fonds ms. 437 [Excellente Chronycke van Vlaanderen]).

184 Ms.: Die Randbemerkung steht am linken Rand, die mit visaige devers le choer a remonstré beginnt. Direkt neben dieser Zeile befindet sich auch noch ein Doppelstrich. 


\section{[143] [Das Kerzenopfer für den verstorbenen Hz. Karl.]}

Laquelle exhortacion ainsi faite, ledit Thoison d'or, le roy d'armes, est allé lever et prendre reverenment le blason des armes de feu mondit seigneur le duc Charles $\{34\}$ du lieu ou il estoit mis pardessus le tableau des armes de mondit seigneur le souverain et l'a apporté bas devant le siege de mondit seigneur le souverain et illec l'a baillié a Fusil le herault, ${ }^{185}$ pour reverenment le tenir pendant qu'il yroit <querir > comme il ala incontinent querir et lever de la harce ${ }^{186}$ le cierge y mis a tout ung petit escuçon ou blason desdis armes dudit feu monseigneur le duc Charles. Lequel cierge il a apporté a mondit seigneur le souverain qui le attendoit en sondit siege et en le baillant la baisé par grant reverence. Et si tost que mondit seigneur a receu de lui ledit cierge, est ledit Thoison d'or descendu ${ }^{187}$ et venu devers ledit Fusil, prenant de lui par grant reverence ledit blason des armes d'icellui feu monseigneur le duc Charles, et tantdis sont descendus de leurs lieux des deux costez mesdis seigneurs les chevaliers freres et venus rendre devant icellui monseigneur le souverain encores attendant en son siege et tenant ledit cierge en sa main et lui ont mesdis seigneurs [fol. 43v/15v] fait reverence deue. Et incontinent est descendu mondit seigneur le souverain de son siege, prenant chemin pour aler a l'offrande et les <trois > officiers, assavoir les tresorier et graffier, allans devant jusques aux premiers degrez et messeigneurs les chevaliers freres de l'ordre suivans deux et deux, par tel ordre que les plus anchiens estoient au plus pres de mondit seigneur, et devant mondit seigneur immediatement aloit ledit roy d'armes Thoison d'or, portant ledit blason et le darrenier estoit mondit seigneur passant parmy lesdis chevaliers freres, alant devers l'autel offrir ledit cierge qu'il portoit. Lequel chierge ainsi offert par mondit seigneur, ledit roy d'armes offrit aussi ledit blason, lequel il ala mettre sur le grant autel. Et tous messeigneurs les freres de l'ordre furent a genoulx comme mondit seigneur le souverain tandis qu'il faisoit ladite offrande et receut la benediction du prelat. Et tantost ledit cierge ainsi offert fut estaint par Fusil le herault, qui incontinent le ala remettre ainsi extaint sur ladite harce en son lieu premier. Et mondit seigneur le souverain apres ladite offrande par lui faite, se retourna devers son siege, passant entre mesdis seigneurs les chevaliers freres et officiers qui l'attendoient et reverenment se separerent par lui donner lieu et passaige parmy eulx, et lui precedent et les plus anchiens chevaliers freres au plus

185 Zwischen 1477 und 1481 wurde das Amt des Herolds Fusil von Jean Loncle versehen; vgl. DB Heraudica ID Person 107.

186 Der Orden besaß einen großen Kerzenständer (harce), der bei dieser Zeremonie benutzt wurde. Es handelte sich dabei um einen vielarmigen Ständer, bei dem in der Mitte die Kerze des Souveräns aufgesteckt werden konnte. Davon ausgehend fanden links und rechts jeweils 15 weitere Kerzen Platz, die durch ein kleines Wappenschild die Ordensmitglieder ihrem Rang entsprechend repräsentierten. Eine Beschreibung des Kerzenständers findet sich in PB 5, fol. 16r. Erhalten hat sich eine Abbildung des 1556 in Antwerpen benutzten Kerzenständers, der aber entsprechend der 1516 erhöhten Mitgliederzahl 50 Kerzen für die Mitglieder und zwei Kerzen für den Souverän halten konnte; vgl. AOGV, Codex 24, fol. 28v-29r, sowie in einem weiteren Exemplar in BM Valenciennes, Ms. 505, fol. 31v-32r. Dazu auch Lemaire, L'arbe d'or, 2001; Lemaire, Miradas, 2007, S. 75 (Abb.), 77 und 493; DünnebeIL, Gründung, 2013 mit Abb.

187 Ms.: Links vor der Zeile, die mit est ledit Thoison d'or descendu beginnt, befindet sich ein senkrechter Strich. 
pres de lui et consequenment les aultres selon leur ordre le suivans ensemble lesdis officiers le convoierent jusques a sondit siege. Et comme il y fut remonté, messeigneurs les chevaliers freres a reverence deue ont prins congié et se sont retrais chascun vers son propre lieu au dextre et au senestre soubz leurs tableaux de leurs armes et lesdis officiers se sont remis en leur banc devant mondit seigneur.

\section{[144] [Die offrande des Souveräns.]}

Ce fait, ledit roy d'armes Thoison d'or ala tantost querir et lever de ladite harce le cierge y estant a tout l'escuçon des armes de mondit seigneur le souverain a tout lequel il s'est venu < mettre > rendre devant le siege d'icellui monseigneur le souverain, appellant par la maniere du jour precedent a haulte voix mondit seigneur pour venir a l'offrande. ${ }^{188}$ Et ce fait, ledit Thoison d'or, roy d'armes, lui porta et bailla ledit cierge en le baisant reverenment et tantost descendit mondit seigneur de sondit siege et ledit roy d'armes seul alant devant lui et le convoiant est il est allé offrir icellui cierge. Lequel offert, mondit seigneur s'est retourné devers son siege et Fusil le herault, a recouvré ledit cierge tout ardant et ainsi l'est alé remettre en son lieu premier sur ladite harce.

\section{[145] [Zum Kerzenopfer der übrigen Ordensmitglieder.]}

Consequenment s'est continuee et faite l'offrande des aultres cierges par messeigneurs les chevaliers freres illec presens, tant pour eulx comme pour les absens, pour chascun appellé a son tour comme le jour precedent, ${ }^{189}$ excepté et reservé les cinq cierges estant en ladite harce a tout les escuçons [fol. 44r/16r] des armes des cinq chevaliers estans en France ou parti contraire. Lesquelz chevaliers n'ont point esté appellez pour aler a l'offrande, ne leursdis cierges bougez de ladite harce ou chandelabre, mais quant leur tour estoit pour les appeler, le roy d'armes Thoison d'or ala devant le lieu du tableau de leurs armes, faisant petite inclinacion et ainsi passa oultre sans mot dire et demourerent leursdis cierges ardans sur ladite harce jusques en fin de la messe. ${ }^{190}$

\section{[146] [Als nächstes gedenkt der Greffier der toten Mitglieder und danach leitet der Ordenskanzler den weiteren Verlauf der Messe.]}

\section{La commemoracion des souverain $<s>$ et chevaliers freres de l'ordre trespas- sé faite par le graffier de l'ordre. ${ }^{191}$}

Les ceremonies de ladite offrande ainsi observees et parfaites, tantost le graffier de l'ordre s'est mis ou mylieu du chœur et illec, la reverence par lui faite a Dieu premierement par treshumble et devote inclinacion < faite > devers le grant autel et consequenment a mondit seigneur le souverain par obeissance deue et apres a messeigneurs les chevaliers freres de l'ordre estans aux dextre et senestre costez, il a faite commemoration et recitacion a haulte voix de tous les feuz messeigneurs, tant du premier fondateur comme des aultres chiefs et souverains, comme de tous les roys, ducs et princes, comme aussi des aultres chevaliers, freres et compaingnons qui depuis l'institucion dudit ordre ont esté accompaignez et sont trespassez en icellui jusques a

188 Vgl. § 83.

189 Vgl. § 83-94.

190 Vgl. dazu $§ 123$.

191 Ms.: Diese Zwischenüberschrift steht vor dem folgenden Absatz. Sie ist unterstrichen und davor steht ein $c$ / für capitulum. - Vgl. dazu die Vorbereitungsbesprechung in $\S 124 \mathrm{f}$. 
present, en les nommant tous par noms et surnoms, tiltres et dignitez et touchant en brief de leurs haulx fais et gestes a leur louenge et recommandacion. ${ }^{192}$ Et mesmement et par especiales des haulx fais et gestes de feu monseigneur le duc Phelippe $\{01\}$, jadis duc de Bourgoingne et de Brabant etc., premier fondateur, chief et souverain, et de mondit seigneur le duc Charles \{34\}, son filz, seul heritier et successeur, aussi chief et souverain de cest ordre, darrenier deffunct, que Dieu absoille. Et finablement a ledit graffier exhorté mesdis seigneurs de l'ordre illec presens et tous aultres de prier Nostre Seigneur Dieu devotement pour lesdis trespassez et pour le sauvement de leurs ames, comme il estoit contenu en certain escript par lui leu en la maniere accoustumee. Et tantost finie ladite exhortacion, monseigneur l'evesque de Tournay disant la messe a commençié le pseaulme De profundis clamavi ad te Domine etc. ${ }^{193}$ et les chappellains tenans chœur l'ont continué le versoiant jusques a fin, et a ledit prelat amonesté tous a haulte voix pour dire le Pater noster. Lequel fini, il a dit les verset et collecte pour les trespassez. Et ce fait, il a procedé oultre et continué l'office de la messe jusques a fin d'icelle moult solemnellement et devotement.

\section{[147] [Nach dem Gottesdienst nehmen alle Ordensmitglieder eine Mahlzeit ein.]}

Apres ceste messe finié, monseigneur le souverain a surattendu ung peu ledit prelat, chancellier de l'ordre, tant qu'il fust deshabillié des aornemens d'eglise [fol. 44v/16v] et revestu en deul comme les autres dudit ordre. Et ledit chancellier venu mondit seigneur s'est parti de l'eglise et retourné devers son hostel et messeigneurs les chevaliers freres ensemble les quatre officiers de l'ordre l'ont convoyé tous alans a cheval par l'ordonnance premiere. ${ }^{194}$ Et eulx arrivez a la court mondit seigneur et tous ceulx dudit ordre se sont alez devestir de leurs manteaulx de deul et retournez disner en la petite salle. Et mondit seigneur le souverain estoit seul a sa table. Et au dextre de lui avoit une autre table a laquelle se assirent messeigneurs les chevaliers freres. Et au costé senestre avoit une autre petite table, a laquelle se asseirent monseigneur l'evesque de Tournay, chancellier, et les autres trois officiers de l'ordre, tous vestus en deul de robes noires. Et fut ce disner bien liberal et plantureux. ${ }^{195}$

\section{[148] [Nach dem Essen wird die Ordensversammlung weitergeführt.]}

Ce jour apres disner comparurent et se assamblerent en chappittre de l'ordre mondit seigneur le souverain et tous messeigneurs les chevaliers freres de l'ordre dessus nommez, assavoir monseigneur de Lannoy $\{50\}$, monseigneur de Ravestein $\{55\}$, monseigneur de Wyncestre $\{61\}$, monseigneur de Chimay $\{74\}$ et messire Engelbert, conte de Nassow $\{77\}$, ensemble les quatre officiers dudit ordre.

192 Toison d'or und der Greffier hatten die Aufgabe, die guten Taten und Verdienste der einzelnen Mitglieder aufzuzeichnen, damit die verstorbenen Mitglieder während der Totenmesse entsprecht gewürdigt werden konnten. Leider ist über den Verbleib dieser Listen nichts bekannt. Vgl. dazu § 31, 42 und 69 (neu: Mitglieder § 44 und Offiziere $\S 13$ und 17) der Statuten (dazu S. 16, Anm. 14) sowie die Angaben in PB 3, S. $61, \S 65$.

193 Psalm 130, 1-8. Vgl. dazu auch Merkley, Music and patronage, 1999, S. 230 f. (mit Hinweis auf MERKLEY, Role, 1998).

194 Vgl. § 75.

195 Vgl. dazu auch die Angaben zum Festmahl vom Vortag in $§ 97$. 


\section{Aultres actes du chappittre touchant l'election ${ }^{196}$}

[149] [Hz. Maximilian kündigt an, dass er am Abend Brügge verlassen werde, um gegen den frz. König ins Feld zu ziehen. Davor sollen aber die Neuwahlen abgeschlossen werden. Es wird erneut über die Wählbarkeit von Matthias Corvinus, Kg. von Ungarn, diskutiert.]

En ce chappittre pour abbregier la chose a cause que mondit seigneur le souverain avoit conclut de partir le soir et s'en aler vers Gand et soy mettre a champs pour les nouvelles qu'il avoit du siege mis devant la ville de Condet et de l'approichement du roy et de son armee devers et contre ses pays, ${ }^{197}$ a esté premierement besoingné sur le fait des elections qui restoient a faire, qui estoit des deux darreniers lieux seulement. Et eues petites devises et communicacion entre mondit seigneur le souverain et messeigneurs les chevaliers freres de l'ordre, touchant les deux personnaiges dont la nuyt passee mondit seigneur leur avoit parlé, assavoir le roy de Honguerie et monseigneur Albert, duc de Saxe $\{96\},{ }^{198}$ mesdis seigneurs recors et souvenans du demené de ladite nuyt passee au regart de ces deux princes et sentans l'affection de desir que mondit seigneur avoit a eulx pour les avoir en l'ordre, delibererent et conclurent de faire leur election en la maniere qu'il appartenoit selon les status de l'ordre. Par tel si que ladite election seroit franc[h]e et absolue aussi bien du roy de Honguerie, en cas qu'il seroit esleu comme des aultres. Saulf que, se cellui ou ceulx qui seroient ordonnez et commis de par mondit seigneur et de par l'ordre pour anuncer et signifier audit roy de Honguerie sadite election, en cas qu'il seroit esleu, et lui porter le collier, sentoient et trouvoient chose raisonnable au contraire, fust devers l'empereur $\{94\}$ apres qu'il auroit [fol. 45r/17r] accepté son election et le collier et seroit accompaignié audit ordre ou autrement, parquoy bonnement icellui roy de Honguerie ne peust ou deust estre accompaignié au mesme ordre et que ce ne seroit le bien de mondit seigneur ne dudit ordre qu'il en fust, que oudit cas lesdis commis ne passeroient oultre, mais s'en tairoient et rapporteroient ledit collier. Semblablement aussi, s'il avenoit que ledit roy de Honguerie s'excusast ou feist reffus de accepter sadite election, apres quelle lui seroit signiffiee, ledit collier se rapporteroit devers mondit seigneur et devers l'ordre et demourroit le lieu vacant jusques au chappittre prouchain avenir, sans ce que nul aultre s'en doye mesler ou avoir faculté ne auctorité d'en disposer autrement en maniere quelconque.

\section{[150] [Die Wahl von Matthias, Kg. von Ungarn.]}

\section{L'election du roy de Honguerie ${ }^{199}$}

Ceste deliberacion et declaracion ainsi faite et consentie par mondit seigneur le souverain, ont mesdis seigneurs procedé oultre en leur election. Et a la premiere foiz par leurs cedules mises ou bachin, icelles veues et publiees, s'est trouvé avoir la pluralité

196 Ms.: Diese Zwischenüberschrift steht vor dem folgenden Absatz. Sie ist unterstrichen und davor steht ein $c$ / für capitulum.

197 Vgl. dazu die Angaben in § 69 mit Anm. 344.

198 Fortsetzung von $§ 132$.

199 Ms.: Diese Zwischenüberschrift steht vor dem folgenden Absatz. Sie ist unterstrichen und davor steht ein $c$ / für capitulum. 
des voix treshault et tresexcellent prince le roy Mathias, roy de Honguerie. ${ }^{200}$ Et inquisicion faite et demandee a mesdis seigneurs et a monseigneur le souverain s'il y avoit aucun qui sceust ou eust ouy dire dudit roy de Honguerie chose, parquoy il ne peust estre receu en l'ordre, n'a esté trouvé sur lui riens qui l'en doyé empeschier dont mesdis seigneurs saichent a parler. Mais tous l'ont estimé et reputé pour propice et ydoine et que ce sera l'onneur de mondit seigneur et de l'ordre, s'il lui plaist de l'accepter et y estre accompaingnié. Parquoy mondit seigneur le souverain a pronnoncié ledit Mathiam, roy de Honguerie, estre esleu et appellé pour frere et compaingnon dudit ordre de la Thoison d'or. ${ }^{201}$

\section{[151] [Die Wahl von Albert, Hz. von Sachsen.]}

\section{Election du duc Albert de Saxe ${ }^{202}$}

Apres et pour la darreniere foiz ont mesdis seigeneurs les souverain et chevaliers freres de l'ordre fait aultre election par aultres et nouvelles leurs cedules mises en bacin. Lesquelles veues, publiees et enregistrees s'est trouvé avoir la pluralité des voix hault et puissant prince monseigneur Albert, duc de Saxe \{96\}. Et scrutine et inquisicion sur lui faite s'il avoit personne d'entre eulx qui sceust ou eust ouy dire dudit duc Albert de Saxe chose, parquoy il ne peust estre receu en l'ordre, ont mesdis seigneurs les freres dit et respondu que non, car de sa personne n'avoient cognoissance aucune. Mais s'en rapportoient a mondit seigneur le souverain, qui mieulx que eulx le povoit cognoistre et savoir a parler de son affaire et de ses meurs et condicions, parquoy mondit seigneur le souverain, qui grandement a loué et recommandé ledit duc Albert de haulte noblesse, vaillance, saigesse et prudence, a prononcié icellui duc Albert, duc de Saxe, esleu et appellé pour frere et compaingnon dudit ordre de la Thoison d'or. ${ }^{203}$

\section{Les noms et surnoms ou tiltres des chevaliers trespassez ensemble de ceulx qui ont esté esleuz en ce present chappittre de l'ordre ${ }^{204}$}

\section{[152] [Damit ist die Wahl der neuen Mitglieder abgeschlossen.]}

Et ainsi a esté parfaite et furnie ladite election par laquelle ont successivement esté esleuz autant de nobles chevaliers qu'il avoit de lieux vuys et vacans en l'ordre qui estoient en nombre de xij, car depuis la derreniere feste dudit ordre, tenue a Valenciennes [fol. 45v/17v] l'an lxxiij, ${ }^{205}$ douze chevaliers freres d'icellui ordre estoient trespassez, sans y comprende feu mondit seigneur le duc Charles $\{34\}$, jadis chief et souverain. C'est assavoir:206

200 Auch Ferdinand \{71\}, Kg. von Kastilien, und Ferdinand \{72\}, Kg. von Neapel, hatten in ihren Wahlvorschlägen Kg. Matthias genannt; vgl. Reg. 31 und 37.

201 Fortsetzung in $\S 154$.

202 Ms.: Diese Zwischenüberschrift steht vor dem folgenden Absatz und ist durch einen Strich von diesem getrennt.

203 Fortsetzung in $\S 154$.

204 Ms.: Diese Zwischenüberschrift steht in der Kopfzeile von fol. 17v.

$205 \mathrm{Zu}$ diesem Fest vgl. Anm. 80.

206 Vgl. dazu auch die Aufzählung der toten Mitglieder in § 26f. (dort mit Sterbedaten) und § 33 f. sowie Reiffenberg, Toison d'or, 1830, S. 95. 
[153] [Nennung der verstorbenen Mitglieder:]

Au lez dextre

Feuz messire Anthoine, seigneur de Croy $\{15\}$, conte de Porcien; messire Loys de Chalon $\{64\}$, seigneur de Chasteauguyon;

messire Jehan de Reubempré $\{73\}$, seigneur de Bievre, et

messire Jehan de Lucembourg $\{75\}$, conte de Marle. ${ }^{207}$

\section{[154] [Die neugewählten Mitglieder:]}

Au lez senestre

Feuz hault et puissant prince Jehan, duc d'Alençon \{39\}, conte du Perche; messire Bauduin de Lannoy $\{19\}$, dit le Besque, seigneur de Molembais;

messire Symon de Lalaing $\{26\}$, seigneur de Montigny;

messire Jehan, ber et seigneur d'Auxj \{45\}; messire Henry de Borssele \{44\}, seigneur de la Vere, conte de Grantpré;

messire Regnault, seigneur de Breederode et de Vyanen $\{43\}$;

hault et puissant prince monseigeur Adolph de Gheldres et de Zutphen \{58\};

messire Guy de Brimeu $\{76\}$, seigneur de Humbercourt, conte de Meghen.

Pour et ou lieu desquelz chevaliers trespassez ont es chappittres de ceste feste esté esleuz messeigneurs les chevaliers, cy apres nommez es jours et par la maniere cy dessus declarés. C'est assavoir:208

Treshault, tresexcellent, trespuissant et tresvirtorieux prince seigneur Frederic $\{94\}$, par la grace de Dieu empereur de Rome etc., duc d'Austrice etc., pere naturel de mondit seigneur le souverain de l'ordre; ${ }^{209}$

messire Bertremy de Lichtenstein $\{85\}$, chevalier; ${ }^{210}$

messire Phelippe de Bourgoingne $\{82\}$, seigneur de Bevre etc.; ${ }^{211}$

messire Josse de Lalaing $\{80\}$, seigneur de Montigny; ${ }^{212}$

messire Pierre de Luczembourg $\{83\}$, conte de Saintpol, de Conversan et de Bryenne etc.; messire [Hugues] de Chalon, seigneur de Chasteauguion, prisonier en France; ${ }^{213}$ messire Jaques de Luczembourg $\{81\}$, seigneur de Fyennes $;{ }^{214}$

207 Ms.: Ein Kreuz unterhalb dieses Namens zeigt an, dass auf dieser Seite kein weiterer Name mehr eingetragen werden sollte.

208 Zu den Wahlen vgl. § 129-134, 138 f. und 149f. - Diese Namen nennen auch ChrisTYN, Jurisprudentia heroica, 1, 1668, S. 486; REIFFEnBERG, Toison d'or, 1830, S. 94; Barante/Gachard, Histoire, II, 1838, S. 602 mit Anm. 6; Delepierre, Fête en 1478, 1842, S. 343; SMEDT, Orden vom Goldenen Vlies, 2003, S. 129 f.; DünNeBeIL, Burgund und Österreich, 2006, S. 22 und 27; Auer, Maximilian Ir, 2008, S. 59. Vgl. dazu auch die Angaben in der Einleitung S. 20-23, insbesondere S. 22.

209 Fortsetzung in $\S 188$.

210 Fortsetzung in $§ 155$ und 157.

$211 \mathrm{Zu}$ seiner Aufnahme vgl. die Angaben in Reg. 53.

$212 \mathrm{Zu}$ seiner Aufnahme sowie die von Jakob von Savoyen und Pierre de Luxembourg vgl. § $155 \mathrm{f}$. und 160 .

213 Fortsetzung in $\S 221$.

214 Er trat dem Orden am 16. Mai 1478 bei; vgl. Reg. 52 und 59. 
messire Wolffart de Borssele $\{79\}$, conte de Grantpré, seigneur de la Vere $;^{215}$ messire Guillaume, seigneur d'Egmonde etc. $\{78\} ;^{216}$

monseigneur Jaques de Savoye $\{84\}$, conte de Romont etc.; ${ }^{217}$

treshault et trespuissant prince seigneur Mathias, par la grace de Dieu roy de Honguerie etc.; ${ }^{218}$

hault et puissant prince monseigneur Albert $\{96\}$, duc de Saxe etc.

\section{[fol. 46r/18r]}

\section{L'ordre et forme de la recepcion de messeigneurs les chevaliers nouvelle- ment esleuz ${ }^{219}$}

[155] [Von den Neugewählten halten sich mehrere in Brügge auf. Jakob von Savoyen soll durch Ludwig von Brügge verdeckt befragt befragt werden, ob er seine Wahl annehmen wolle.]

Apres laquelle election ainsi parfaite et furnie, comme dit est, ont mondit seigneur le souverain et messeigneurs les chevaliers freres capittulans deliberé et conclut de faire appeller les chevaliers lors estans presens en la ville de Bruges qui avoient esté ainsi esleuz a l'ordre, assavoir messire Bertremy de Lichtensteyn $\{85\}$, messire Josse de Lalaing $\{80\}$, seigneur de Montigny, monseigneur Pierre de Luczembourg $\{83\}$, conte de Saintpol, et monseigneur Jaques de Savoye $\{84\}$, conte de Romont. Et pour ce que en faisant l'election de la personne de mondit seigneur de Romont aucune doubte estoit s'il l'a vouldroit accepter ou non ${ }^{220}$ monseigneur de Gruythuse $\{61\}$, conte de Wincestre, $\mathrm{a}^{221}$ qui par monseigneur le souverain et par le chappittre estoit ordonné et consenti d'en sentir de lui secretement et couvertement son intencion et volenté, fist son rapport et dit qu'il avoit parlé audit monseigneur de Romont et estoit venu en devises avec lui du collier de l'ordre qu'il portoit et entre aultres choses lui avoit demandé s'il avenoit que a ce il fust esleu, il vouldroit porter tel collier. Surquoy ledit monseigneur de Romont lui avoit respondu qu'il feroit ce que monseigneur lui ordonneroit ou en semblable substance, dont tous messeigneurs furent bien contens.

[156] [Die in Brügge befindlichen Neugewählten sollen befragt werden, ob sie die Wahl annehmen wollen.]

Et tantost furent envoiez querir les quatres chevaliers dessusnommez pour parler a eulx et savoir et sentir d'eulx $<$ s $>$ leur intencion, s'ilz accepteroient chascun l'election

215 In PB 5, fol. 64r, bestätigt Toison d'or dem Ordenssekretär, dass er Wolfart im Jahr 1478 in einer öffentlichen Zeremonie in dessen Kapelle in Veere in den Orden aufgenommen hat. Dies muss vor dem am 25. Sept. 1478 gewesen sein, denn von diesem Datum an wird er im PB 4 als Mitglied genannt; vgl. § 199 und 204 sowie Reg. 75.

216 Willem van Egmond wurde im Mai 1478 in Arnheim von Toison d'or in den Orden aufgenommen, er leistete dann auch noch während des Festes von 1481 seinen Aufnahmeeid in Gegenwart des versammelten Ordens; vgl. PB 5, fol. 21v und fol. 64r.

217 Fortsetzung in $\S 155$.

$218 \mathrm{Zu}$ den Aufnahmeverhandlungen der beiden letztgenannten siehe die Fortsetzung in $\S 188$.

219 Ms.: Diese Zwischenüberschrift steht in der Kopfzeile von fol. 46r.

220 Vgl. § 138.

221 Ms.: $a$ steht über der Zeile. 
faite de sa personne et s'ilz vouldroient chascun a son endroit faire le serment et les aultres devoirs accoustumez et qu'il appartient. ${ }^{222}$

\section{Messire Bertremy de Lichtestein ${ }^{223}$}

[157] [Ludwig von Brügge und Engelbert, Gf. von Nassau, sollen als erstes Bartholomäus von Liechtenstein unterrichten und Befragen.]

Et pour ce que ledit messire Bertremy de Lichtestein $\{85\}$ fut trouvé le premier par l'advertissement de monseigneur le souverain, considerant qu'il ne savoit point de françois et peu de latin, parquoy fauldroit que mondit seigneur fust son interprete, fut icellui messire Bertremy appellé et fait venir en la chambre devant le chappittre et fut ordonné et consenti qu'il seroit le premier expedié en attendant la venue des aultres trois. Et furent ordonnez et depputez par mondit seigneur le souverain et par le chappittre messire Loys, seigneur de Gruythuse $\{61\}$, conte de Wyncestre, et messire Engelbert, conte de Nassouw $\{77\}$, freres chevaliers capittulaires, pour aler parler audit messire Bertremy, le advertir de l'election que avoit esté faite de sa personne pour estre frere en l'ordre, pour les grans biens que messeigneurs avoient oys de lui et sentir et savoir de lui, s'il vouldroit accepter sadite election et faire les devoirs qu'il appartient a l'ordre.

\section{[158] [Bartholomäus von Liechtenstein nimmt die Wahl an.]}

En ensuivant ceste ordonnance mesdis seigneurs de Wyncestre $\{61\}$ et de Nassow $\{77\}$ sont partis du chappittre et alez devers ledit messire Bertremy $\{85\}$, lequel ilz ont adverti et interrogué selon leur charge. Surquoy icellui messire Bertremy liberalement et honnestement leur a respondu, rendant treshumbles graces a Dieu et consequenment a mondit seigneur le souverain et a tous messeigneurs de l'ordre de l'honneur qu'ilz lui faisoient, soy offrant prest et appareillié pour faire tout ce que mondit seigneur lui ordonneroit et qu'il appartendroit a son povoir. Ce ouy, mesdis seigneurs de Wincestre et de Nassow sont retournez oudit chappittre et ont fait rapport a mondit seigneur le souverain et a leurs confreres dudit chappittre de la response que leur avoit faite ledit messire Bartremy, de laquelle ilz ont tous esté joyeux et bien contens. Et ont ordonné qu'ilz retournassent devers [fol. 46v/18v] icellui messire Bertremy pour le faire vestir d'un mantaul de l'ordre et ainsi vestu l'amener ou chappittre, ce que ainsi a esté fait. Et ledit messire Bertremy venu en chappittre, s'est humblement mis a genoulx devant mondit seigneur le souverain, et pour ce que la devant il avoit entendu de messeigneurs les contes de Wyncestre et de Nassouwe qui la estoient venus devers lui, comment de la grace de mondit seigneur et de leur chappittre il avoit esté esleu pour estre frere et compaingnon du noble ordre de la Thoison d'or, treshumblement de ce les a remerciez, disant qu'il estoit prest pour faire de son costé ce qu'il appartendroit a l'ordre de son povoir.

222 Das Aufnahmeverfahren wird in § 75-85 (neu § 50-61) der Statuten (dazu S. 16, Anm. 14) geregelt; darin findet sich auch der Text des zu leistenden Eides.

223 Ms.: Diese Zwischenüberschrift steht am linken Rand zu Beginn des folgenden Absatzes. 


\section{Touchant la recepcion - de nouveaulx chevaliers esleuz ${ }^{224}$}

\section{[159] [Seine Aufnahme in den Orden erfolgt in lateinischer und deutscher Spra- che.]}

\section{Les sermens de messire Bertremy ${ }^{225}$}

Oyé ceste response, mondit seigneur le souverain lui a fait en brief recitacion de l'effect des status de l'ordre et des sermens qu'il auroit a faire, pour de tout le advertir en son langaige allemant. Et ledit messire Bertremy $\{85\}$ tout ouy et entendu, a respondu de rechief et dit qu'il en feroit tout devoir a son leal povoir. Et apres s'est approchié icellui messire Bertremy devers mondit seigneur, devant lequel avoit ja sur ung scabelle paré mise une croix d'or, garnié d'une piece de la vraie croix Nostre Seigneur et benoit Saulveur, y avoit aussi mis ung missel ouvert devers le canon de la messe. ${ }^{226}$ Et illec s'est engenoullié humblement et reverenment ledit messire Bertremy, mettant l'une de ses mains sur la sainte croix et l'autre sur ledit missel, et reverend pere en Dieu monseigneur l'evesque de Tournay, chancellier de l'ordre, tenant en sa main le livre des status et ordonnances dudit ordre translaté du françois en latin, ${ }^{227}$ a leu a haulte voix a mondit seigneur le souverain de point en point les sermens ordonnez et accoustumez a faire par les chevaliers nouvellement esleuz a leur entree et recepcion oudit ordre. Et mondit seigneur le souverain a exposé audit messire Bertremy de point en point en langaige allemant la forme dudit serment, laquelle icellui messire Bertremy a juree solemnellement tout selon contenu du livre desdis statuts. ${ }^{228}$ Lequel serment ainsi fait par ledit messire Bertremy, mondit seigneur le souverain lui a baillié et mis autour du col le collier dudit ordre, disant en alemant apres mondit seigneur de Tournay lisant du livre en latin les mots des ceremonies en tel cas pertinentes selon les statuts dessusdis. Et sur ce a respondu ledit messire Bertremy disant « Amen, Deus hanc michi det graciam. ${ }^{229}$ Et ce fait, monseigneur de Lannoy $\{50\}$, le plus anchien de messeigneurs les chevaliers freres dudit ordre presens oudit chappittre, s'est levé de son lieu et venu lever ledit messire Bertremy et l'a amené devers mondit seigneur le souverain pour le baisir, ce que mondit seigneur a fait benignement, et tantost s'est ledit seigneur de Lannoy alé remettre en son premier lieu, la ou ledit messire Bertremy l'est allé baiser et consequenment tous lesdis aultres chevaliers freres qui la estoient, l'ung apres aultre selon leur ordre et en leurs lieux.

224 Ms.: Diese Zwischenüberschrift steht in der Kopfzeile der Doppelseite fol. 18v/19r.

225 Ms.: Diese Zwischenüberschrift steht am linken Rand, etwas oberhalb der Mitte des folgenden Absatzes bei der Zeile, die mit mettant l'une de ses mains sur la sainte croix beginnt, und ist links und rechts mit einer Klammer versehen.

226 Zum Schwurkreuz und dem Meßbuch vgl. die Angaben in § 56 mit Anm. 315.

227 Vgl. dazu die Angaben in § 12 mit Anm. 71.

228 Vgl. die Angaben in Anm. 222.

229 Vgl. die entsprechende frz. Formel in § 84 (neu § 59) der Statuten (dazu S. 16, Anm. 14). Vgl. dazu auch die Eidesleistungen mit anschließendem Bruderkuss anlässlich Hz. Maximilians Aufnahme in den Orden in § 58-61. 


\section{Monseigneur de Romont, monseigneur de Saintpol et monseigneur de Montigny ${ }^{230}$}

[160] [Die anderen drei in Brügge weilenden Neugewählten sollen von ihrer Wahl unterrichtet werden.]

Item et pendant ce mistere sont venus l'ung apres aultre en ladite chambre, seant devant ledit lieu capittulaire, les aultres trois chevaliers, [fol. 47r/19r] assavoir monseigneur de Romont $\{84\}$, messire Pierre de Lucembourg \{83\}, conte de Saintpol, et messire Josse de Lalaing $\{80\}$, seigneur de Montigny. Pardevers lesquelz y furent tantost envoiez par mondit seigneur le souverain et par le chappittre monseigneur de Wincestre $\{61\}$ et monseigneur le conte de Chimay $\{74\}$, accompaigniez de roy d'armes Thoison d'or, pour les advertir particulierement chascun et a part de l'election que ou chappittre avoit esté faite de leurs personnes, pour estre freres et compaignons de l'ordre de la Thoison d'or et savoir et sentir d'eulx s'ilz accepteroient leurs elections.

[161] [Ludwig von Brügge, Philippe de Croy und Toison d'or unterrichten die drei, die erfreut ihrer Aufnahme zustimmen.]

Mesdis seigneurs de Wincestre $\{61\}$ et de Chimay $\{74\}$ ensemble ledit roy d'armes Thoison d'or y sont allez et les ont advertis particulierement et a part chascun de leurdite election pour en savoir leurdite intencion. Et tous et chascun a son endroit ont grandement remercyé mondit seigneur le souverain et tous messeigneurs de l'ordre de l'onneur qu'ilz leur avoient fait et faisoient et liberalement et volentiers ont accepté leursdites elections, offrans chascun a son endroit de faire tout le devoir qu'il appartiendroit a l'ordre. Ce que mesdis seigneurs de Wincestre et de Chimay ont ainsi rapporté en chappittre, de quoy tant mondit le souverain comme tous messeigneurs les chevaliers freres de l'ordre ont esté moult joyeux et bien contens. Et ont ordonné a leursdis commis de retourner devers eulx et les faire vestir des manteaulx de l'ordre et les amener oudit chappittre l'ung apres l'autre.

[162] [Ludwig von Brügge bittet den Orden, vor der Aufnahme von fosse de Lalaing bei den zwischen ihm und fosse bestehenden Differenzen zu vermitteln.]

\section{Du different d'entre monseigneur de Gruythuse et son filz d'une part et messire Josse de Lalaing, seigneur de Montigny d'autre ${ }^{231}$}

Laquelle ordonnance oyé et entendue par mondit seigneur de Gruythuse $\{61\}$, conte de Wincestre, il s'est mis a genoulx oudit chappittre devant mondit seigneur le souverain, remonstrant treshumblement a mondit seigneur et a messeigneurs les chevaliers, ses freres de l'ordre, comment es jours passez ou mesme lieu cappitulaire, eulx besoingnans sur le fait des corrections, il avoit pleu a mondit seigneur et a eulx, de lui parler du different d'entre ledit messire Josse, seigneur de Montigny $\{80\}$, et lui, tant

230 Ms.: Diese Zwischenüberschrift steht am linken Rand zu Beginn von fol. 19r und ist durch einen Strich von diesem getrennt.

231 Ms.: Diese Zwischenüberschrift steht am linken Rand zu Beginn des folgenden Absatzes und ist links und rechts mit einer Klammer versehen. - Diese Angelegenheit kam auch schon während Ludwigs correction zur Sprache (§ 111-113); vgl. dazu auch in der Einleitung S. 31f. mit Anm. 96. 
a cause de l'estat du chevalier d'honneur devers ma tresredoubtee dame madame la duchesse, comme pour l'office du grant veneur de Flandres, ${ }^{232}$ donné a son filz, ${ }^{233}$ et sur ce lui avoient fait faire certaines remonstrances afin qu'il s'en voulsist rapporter et submettre par voye aimable, fust a l'ordonnance de mondit seigneur et de l'ordre ou d'autres amis, tant qu'il s'en estoit submis en mondit seigneur et en l'ordre, pour en estre appointié se faire se povoit veuz ses drois et tiltres et pourveu qu'il en puist avoir brieve fin et conclusion. Toutevoie riens n'en avoit esté fait depuis, mais avoit esté esleu ledit messire Josse qui prestement vendroit en chappittre pour y estre receu a frere et compaignon en l'ordre, parquoy humblement les en advertissoit afin que apres que ledit messire Josse seroit receu, leur plaisir fust de semblablement lui faire parler de ceste matiere, pour de son costé aussi s'en submettre en mondit seigneur et en l'ordre, pour les appointier de leursdis differens et brief tellement, que, puis qu'ilz seroient d'ung mesme ordre et serment, ilz puissent avoir amour et charité fraternelle ensemble [fol. 47v/19v] telle et ainsi, que selon les status dudit ordre il appartenir et faire se devoit. Disant aussi que de son costé ne tendroit que ainsi ne fust, moyennant que ledit messire Josse lui laissast et a sondit filz ce que de droit leur appartient, comme il disoit. ${ }^{234}$ Surquoy fut respondu audit monseigneur de Wincestre, que de ceste matiere ilz feroient aussi parler audit messire Josse, et a esté ordonné de le amener et faire entrer le premier.

\section{[163] [fosse de Lalaing erscheint vor dem versammelten Orden.]}

Tantost apres sont revenus en chappittre mesdis seigneurs de Wincestre $\{61\}$ et de Chimay $\{74\}$ et ont amené avec eulx ledit messire Josse de Lalaing $\{80\}$, seigneur de Montigny, habillié et vestu de [!] manteau de l'ordre. Lequel seigneur de Montigny ainsi arrivé oudit chappittre, s'est mis a genoulx devant mondit seigneur le souverain et a remonstré et dit, qu'il avoit sceu et entendu par messeigneurs de Wincestre et de Chimay, comment de la grace de mondit seigneur le souverain et des treshonnorez freres et compaignons de l'honnorable ordre de la Thoison d'or, il avoit esté esleu audit ordre et a leur aimable compaignie. Dont il se tenoit grandement honnoré, l'avoit reverenment et aggreablement receu et accepté et humblement et de tout son ceur

232 Im März 1477 ernannte Hz.in Maria Josse de Lalaing zu ihrem chevalier de compaigne und im Juli 1477 wird er als ihr zweiter chevalier d'honneur bezeichnet werden; vgl. dazu Cools, Mannen, 2000, S. 343 f., Nr. 136. Schon unter Hz. Karl \{34\} war Josse de Lalaing als dessen Rat und Kammerherr tätig gewesen und seit 1468 war er auch Souverän-Bailli von Flandern. Lt. BorN, Lalaing, 1986, S. 184 (ohne Quellenangabe), hatte Josse de Lalaing nach dem Tode seines Vaters Simon \{26\} Anfang 1477 dessen Ämter des grand veneur von Flandern, des amiral de la mer und des capitaine von Sluis übernommen. Später [wohl nach dem Ordensfest 1478] wurde er von Hz. Maximilian in diesen Ämtern bestätigt. Zu seiner Person vgl. auch BoRN, Lalaing, 1986, S. 179-192; Chevaliers de la Toison d'or, ${ }^{2} 2000$, Nr. 80. - Ludwig von Brügge wurde seit März 1477 als Marias premier chevalier d'honneur und erster Kammerherr bezeichnet; vgl. dazu u. a. Ussel, Regeering van Maria, 1943, S. 8; Cools, Mannen, 2000, S. 264. Zu seiner Person vgl. auch Ussel, Regeering van Maria, 1943, S. 10 f.; Martens, Biografie, 1992; Cools, Mannen, 2000, S. 264-266, Nr. 40.

233 Zu Ludwigs Sohn Jan von Brügge, Herr von Spiere, vgl. die Angaben in § 113 mit Anm. 85.

234 Mais avoit esté esleu ledit messire fosse [...] leur appartient comme il disoit wird zitiert bei Sterchi, Umgang, 2005, S. 426, Anm. 157. 
les en remercioit. Si estoit il venu devers eulx soy presentant prest d'obeir et faire touchant icellui ordre tout ce qu'il devroit et seroit tenus de faire. Surquoy par ordonnance de mondit seigneur le souverain lui fut respondu par monseigneur de Tournay, chancellier de l'ordre: « Sire, monseigneur le souverain et messeigneurs les chevaliers compaingnons de cest ordre, qui de vous ont ouy moult de biens, esperans que y doiez parseverer et les augmenter a l'exaltacion et honneur de l'ordre de chevalerie et a vostre merite, <et> louenge et recommendacion vous ont esleu a estre perpetuellement, se Dieu plaist, frere et compaignon d'icellui ordre et aimable compaignie, parquoy aurez a faire les sermens qu'il appartient. Mais pour ce que les aultres deux chevaliers estans en l'autre chambre sont pareillement esleuz a l'ordre et doivent faire pareil serment comme vous, vous surattendrez ung peu, tant qu'ilz se soient presentez et par l'ordre receuz pour faire vostre serment avoit eulx pour cause de briefté. »

[164] [Auch er erklärt sich bereit, wegen der Differenzen mit Ludwig von Brügge
sich der Ordensgerichtsbarkeit zu unterwerfen.] Touchant le different d'entre messire Josse et monseigneur de Gruythuse ${ }^{235}$

Apres ce a fait, dire et remonstrer, mondit seigneur le souverain audit messire Josse de Lalaing $\{80\}$, seigneur de Montigny, par l'advis de messeigneurs les chevaliers freres de l'ordre et par la bouche dudit chancellier, comment mesdis seigneurs estoient advertis qu'il avoit certain different et question entre lui et le seigneur de Gruythuse $\{61\}$, conte de Wincestre, leur frere et compaignon de cest ordre, et le seigneur de le Pierre, son filz, ${ }^{236}$ a cause d'aucuns estas ou offices. Lesquelz differens leur desplaisoient et voudroient bien qu'ilz en fussent appointiez aimablement pour oster d'entre eulx toute rancune et malvueillance, et de [fol. 48r/20r] tant plus consideré que maintenant mondit seigneur de Gruythuse et lui seroient d'ung mesme ordre, a cause duquel, selon les status et ordonnances d'icellui, ilz devroient avoir et maintenir doresenavant entre eulx bon amour et charité fraternelle et vouloir le bien et honneur l'un de l'autre. ${ }^{237} \mathrm{Si}$ avoient mondit seigneur le souverain et messeigneurs les chevaliers freres de cest ordre parlé de ceste matiere, audit seigneur de Gruythuse et icellui tellement exhorté que de ladite matiere il s'estoit submis en mondit seigneur et en l'ordre par ainsi que pareillement il le voulsist faire de son costé ad ce le exhortant. Car desja mondit seigneur le souverain y avoit commis et depputé le seigneur de Lannoy $\{50\}$, chevalier frere, et ledit reverend pere l'evesque de Tournay, chancellier dudit ordre. ${ }^{238}$ Sur quoy ledit messire Josse, seigneur de Montigny, soy mettant a genoulx et faisant brieve et moult humble remonstrance du droit qu'il maintenoit avoir en ceste partie. A respondu et dit, que dez pieça voulentiers il s'en fust rapporté sur amis pour estre appointié aimablement avec mondit seigneur de Gruythuse et n'avoit tenu a lui ne encoire tendroit. Remerciant treshumblement mondit seigneur le souverain et tous messeigneurs

235 Ms.: Diese Zwischenüberschrift steht am linken Rand zu Beginn des folgenden Absatzes und ist links und rechts mit einer Klammer versehen.

$236 \mathrm{Zu}$ Jan von Brügge, Herr von Gruuthuse und Spiere, vgl. die Angaben in Anm. 85 zu $§ 113$.

237 lesquelz differens leur desplaisoientet [...] le bien et honneur l'un de l'autre wird zitiert bei Sterchi, Umgang, 2005, S. 426, Anm. 157. - § 4 der Statuten (dazu S. 16, Anm. 14) gebietet den Mitgliedern gegenseitige Freundschaft und Hilfeleistung. 
de l'ordre de ce qu'il leur avoit pleu d'en parler et que au regart de lui, il estoit et seroit prest de s'en rapporter et submettre pareillement de son costé en mondit seigneur et en par ou en ceulx qu'il leur plairot y deputer et commettre moyennant que son droit soit entendu et que ses tiltres et lettres qu'il en a soient veuz comme il appartient. De laquelle response dudit monseigneur de Montigny ont mondit seigneur le souverain et tous messeigneurs les freres de l'ordre esté bien contens. ${ }^{239}$

[165] [Auch Pierre de Luxembourg, Gf. von Saint-Pol, und Jakob von Savoyen, Gf. von Romont, nehmen die Wahl an und treten zusammen mit fosse de Lalaing zur Aufnahme vor den Orden.]

Ce fait, mondit seigneur de Gruythuse $\{61\}$ et monseigneur de Chimay $\{74\}$ sont alez querir monseigneur le conte de Saintpol $\{83\}$ premiers et apres monseigneur le conte de Romont $\{84\}$, lesquelz, successivement et ung apres autre arrivez et entrez oudit chappittre, ont fait les remonstrances, remerciements et offres en semblables substance et effect que fait les avoit ledit monseigneur de Montigny $\{80\}$ et leur y a esté respondu comme a lui en substance. Et quant lesdis trois chevaliers furent ainsi receuz, leur fist mondit seigneur le souverain pour abbregier la chose declarer et exposer par monseigneur de Tournay, chancellier de l'ordre, l'effect sommié du contenu des status dudit ordre de la Thoison d'or et les motifs justes et honnestes et raisonnables causes de l'institucion d'icellui, et leur eust fait lire tout au long le livre desdis status [fol. 48v/20v] en la maniere accoustumee, ${ }^{240}$ se n'eust esté pour la haste que mondit seigneur avoit de partir et que la nuyt fort approichoit, mais especialement les fist advertir des sermens qu'ilz auroient a faire chascun pour lui mesmes, dont ilz se tindrent pour assez advertis.

\section{[166] [Die drei leisten ihren Aufnahmeeid.]}

\section{Icy sont le[s] serment[s] messeigneurs de Romont, de Saintpol et de Montigny ${ }^{241}$}

Ceste informacion faite et donnee ausdiz trois chevaliers nouveaulx esleuz, tantost eulx trois ensemble ordonneement et reverenment se mirent a genoulx devant la sainte croix, reposant avec ledit missel sur ledit scabelle, paré et estant devant le siege de mondit seigneur le souverain comme dessus est dit, et mettans chascun d'eulx l'une de ses mains sur ladite croix et l'autre sur ledit saint canon du missel. ${ }^{242}$ Ilz firent tous trois par ensemble et chascun a par lui le serment accoustumé de point en point en la forme et maniere qu'il est escript et contenu ou livre desdis status de l'ordre, hors duquel mondit seigneur de Tournay, chancellier dudit ordre, leur lisoit ledit serment a haulte voix de mot a aultre. Concluant par chascun sondit serment sur sa foy et sur son honneur par attouchement de ladite sainte croix et des saintes Evangilles.

239 Über den weiteren Verlauf der Angelegenheit schweigen die Protokollbücher des Ordens.

240 Vgl. die Angaben zum Aufnahmeverfahren in Anm. 222.

241 Ms.: Diese Zwischenüberschrift steht am linken Rand etwas oberhalb der Mitte des folgenden Absatzes und ist links und rechts mit Klammern versehen.

242 Vgl. dazu die Angaben zur Eidesleistung von Bartholmäus von Liechtenstein $\{85\}$ in $\S 159$. 
[167] [Die neuen Mitglieder erhalten ihre Ketten, der Bruderkuss wird ausgetauscht und danach werden ihnen ihre (vorläufigen) Sitzplätze zugewiesen.]

Ledit serment ainsi fait par mesdis seigneurs de Montigny $\{80\}$, de Saintpol $\{83\}$ et de Romont $\{84\}$, mondit seigneur le souverain a baillié a chascun d'eulx et mis a tour du col ung collier dudit ordre en disant au bail de chascun desdis colliers les mots et gardant les ceremonies a ce servans et accoustumees selon lesdis status. Et tantost comme le premier d'eulx avoit receu de mondit seigneur ledit collier, mondit seigneur de Lannoy $\{50\}$ l'a fait lever et l'a mené baiser a la bouche mondit seigneur le souverain et pareillement l'a fait des aultres deux et monseigneur de Lannoy retrourné et remis en son lieu, tous trois l'un apres autre le sont alez baiser et consequenment ont ilz baisé tous les aultres chevaliers freres illec presens ordonneement en leurs lieux, l'ung apres l'autre. Et au surplus en tout et par tout y ont esté gardees et observees en fait et en parolles les ceremonies ${ }^{243}$ accoustumees en tel cas et qu'il appartenant selon les status de l'ordre dessusdis. Et de prime face sans prejudice furent donnez et assignez lieux oudit chappittre ausdis quatre nouveaulx chevaliers freres ja receuz, assavoir a monseigneur de Saintpol et a messire Bertremy de Lichtesteyn $\{85\}$ ou banc du lez dextre et a monseigneur de Romont et a messire Josse, seigneur de Montigny, ou banc du lez senestre jusques qu'il seroit advisé et ordonné des lieux qui a chascun d'eulx competeroient selon lesdis status de l'ordre. ${ }^{244}$

[168] [Das Ende des Ordensfestes wird beschlossen, davor sind aber noch einige Dinge zu regeln:]

Ceste recepcion ainsi faite, mondit seigneur le souverain desirant et volant tantost [fol. 49r/21r] partir et s'en aler vers Gand pour soy mettre aux champs a la cause dessus touchee ${ }^{245}$ par l'advis et consentement de mesdis seigneurs les chevaliers, ses freres et compaignons de l'ordre assamblez avec lui oudit lieu cappittulaire, a deliberé et conclut de $\mathrm{e}^{246}$ abbregier et conclure son chappittre de l'ordre pour ceste fois. Et devant ladite conclusion a ordonné et fait les choses qui s'ensuivent:

[169] [Die in Brügge verbleibenden Mitglieder und Amtsträger des Ordens sollen die noch ausstehenden Gottesdienste absolvieren.]

\section{Ordonne monseigneur le souverain que les chevaliers qui demouront facent continuer le devin service ${ }^{247}$}

Assavoir premierement: Que messeigneurs les chevaliers freres de l'ordre qui demouront a Bruges et ne s'en yront avec lui, continuent et facent continuer ensemble les officiers dudit ordre les solemnitez du divin service en l'eglise qui encores restent a faire. Assavoir la messe de Nostre Dame et la messe du Saint Esprit qui selon les ordonnances d'icellui ordre encore se doivent dire et celebrer en la mesme eglise

243 Ms.: ceremonies nach einem Schreibfehler gleichzeitig korrigiert.

244 Zu ihrer Plazierung vgl. die Angaben in der Einleitung S. 28.

245 Vgl. dazu die Angaben in $\S 149$.

246 Ms.: de steht über einer Radierung und füllt den dadurch entstandenen Raum nicht ganz aus.

247 Ms.: Diese Zwischenüberschrift steht vor dem folgenden Absatz und ist durch einen Strich von diesem getrennt. Diese Zwischenüberschrift steht vor dem folgenden Absatz und wird mit einem $c$ / für capitulum eingeleitet. 
et ou lieu ou la principale solemnité s'est a tenue. ${ }^{248}$ Voulant que ladite messe de Nostre Dame solemnellement soit celebree lundy prouchain, ${ }^{249}$ pour cause de la procession generale a tout le Saint Sang, qui sera demain en $\mathrm{ce}^{250}$ lieu de Bruges et tant pour reverence dudit Saint Sang, comme pour l'occupacion que toutes gens d'eglise et autres audit Bruges auroient pour ce jour par le fait de ladite procession et autrement. ${ }^{251}$ Et que la messe du Saint Esprit se die a mardi ensuivant, $v^{\mathrm{e}}$ jour $\mathrm{du}$ present mois de may. ${ }^{252}$ Ordonna aussi mondit seigneur que ausdites deux messes messeigneurs les chevaliers freres et aussi lesdis officiers de l'ordre fussant et soient habituez et habillez selon l'ordonnance et devise sur ce faites ou chappittre darrenier precedent, tenu a Valenciennes l'an lxxiij. ${ }^{253}$

[170] [Sie sollen auch für die Ausführung der während des Kapitels erfolgten Beschlüsse sorgen.]

A ordonné en oultre mondit seigneur le souverain que messeigneurs les chevaliers freres qui demouront avisent ensemble ce qui sera de faire au surplus pour l'execucion des choses qui ont esté deliberees en conclues ou present chappittre de l'ordre. ${ }^{254}$

[171] [Alle nicht erledigten Angelegenheiten des Ordens sollen auf dem nächsten Fest im kommenden fahr erledigt werden.]

\section{Icy se conclut de tenir la feste au second jour de may ensuivant que sera l'an lxxix ${ }^{255}$}

Et pour ce que mondit seigneur le souverain n'a peu pour le present, obstant sesdites affaires de la guerre, vaquer ne entendre es aultres besoingnes et affaires de l'ordre, tant touchant la correction au regart des freres absens, comme pluseurs aultres choses qui restent et demeurent a faire. ${ }^{256} \mathrm{~A}$ par l'advis, deliberacion et du consentement expres de mesdis seigneurs les chevaliers freres estans oudit chappittre conclut de tenir la feste de l'ordre a l'encommencement du mois de may prouchain venant, remettant tout le surplus desdites affaires dudit ordre jusques a lors. Et a declairé desmaintenant que les cinq chevaliers encores tenans lieu oudit ordre, estans en France ou parti contraire, soient adjournez par mandement patent, donné en placcart et par Thoison d'or, le

248 Vgl. dazu die Angaben in Anm. 280 in § 177 und Anm. 330 in § 196.

249 4. Mai 1478. - Fortsetzung in $§ 177$.

250 Ms.: en ce steht über einer Radierung.

251 Schon bei dem 1468 ebenfalls in Brügge gefeierten Ordensfest wurden die Termine des Ordens wegen des Hlg. Blut-Festes verschoben. Höhepunkt des Brügger Hlg. Blut-Festes, das eine überregionale Bedeutung bis in die heutige Zeit hinein hat, ist die große Prozession am 2. Mai, bei der alle großen Kirchen der Stadt besucht werden; vgl. dazu u. a. Toussaert, Sentiment religieux, 1963, S. 259-267; Scheler, Inszenierte Wirklichkeit, 1992, S. 124-127; PB 2, S. 13 mit An. 31; Brown, Civic Ceremony, 2011, S. 37-72.

252 5. Mai 1478. - Fortsetzung in § 196.

253 Zum 1473 neueingeführten Ordensornat und Kleiderordnung vgl. die Angaben in $\S 53$, Anm. 309.

254 Fortsetzung in $\S 181$.

255 Ms.: Diese Zwischenüberschrift steht am linken Rand etwas oberhalb der Mitte des folgenden Absatzes und ist links und rechts mit einer Klammer versehen.

256 Vgl. dazu § 118. 
roy d'armes, ou par aultre officiers d'armes, ayant povoir et commission especiale sur ce soubz le seel d'icellui ordre. ${ }^{257}$ Mais du temps quant la significacion s'en devra faire et de la maniere de appeller monseigneur de Cleves $\{47\}$ noté en ce chappittre, ${ }^{258}$ mondit seigneur le souverain en delibera en conclura cy apres avec messeigneurs les chevaliers, ses freres dudit ordre, qui lors se trouveront devers lui pour et afin de faire faire expedier et envoier les lettres de ladite signifcacion de ladite feste avenir a tous ceulx dudit ordre et les advertir du lieu ou tenir et faire se devra a temps convenable et competent et chascun a son endroit. ${ }^{259}$

[fol. 49v/21v]

[172] [Nach Anfrage bestätigt Hz. Maximilian die von Hz. Karl im fahr 1473 erteilten Vorrechte der Ordensmitglieder und Amtsträger.]

\section{La confirmacion, aggreacion et augmentacion des privileges et libertez de messeigneurs les chevaliers freres ensamble des quatre officiers de l'ordre ${ }^{260}$}

Apres ce oyé et entendue par mondit seigneur le souverain l'umble remonstrance, requeste et supplicacion que messeigneurs les chevaliers freres et compaignons et les quatre officiers de l'ordre de la Thoison d'or moult humblement et reverenment lui ont fait faire par la bouche dudit reverend pere l'evesque de Tournay, chancellier dudit ordre, touchant les honneurs ${ }^{261}$, amour et faveur que feu monseigneur le duc Phelippe $\{01\}$, jadis duc de Borgoingne, premier fondateur, et feu monseigneur le duc Charles $\{34\}$, son filz, darrenier deffunct, jadis chiefs et souverains de cest ordre, ses predecesseur que Dieu absoille, avoient en leur temps portez et demonstrez aux freres et compaignons dudit ordre, et ${ }^{262}$ mesmement et par especiales les honneurs, drois, prerogatives, libertez, franchises et exemption que icellui feu monseigneur le duc Charles, son beaupere et predecesseur immediat, ou chappittre darrenier precedent du devantdit ordre tenu a Valenchiennes l'an lxxiij leur avoit ottroiez et donnez et ausdis quatre officiers du mesme ordre, dont il apparissoit par acte incorporé et enregistré entre les actes dudit chappittre de Valenciennes. ${ }^{263}$ Lui suppliant treshumblement que son tresnoble plaisir fust de leur aggreer, ratifier et confermer lesdis drois, prerogatives, libertez et franchises, telles et ainsi que ledit feu duc Charles, son beaupere, les leur avoit ottroiees et concedees comme dit est. ${ }^{264}$

257 Vgl. dazu § 122 sowie die Vorladungsschreiben in Reg. 75-80. - Fortsetzung in § 209 und 225.

258 Vgl. dazu § 121 sowie Reg. 83 und 89f. - Fortsetzung in $§ 209$ und 221.

259 Fortsetzung in $§ 192$ und 208. Vgl. dazu auch in der Einleitung S. 32 f.

260 Ms.: Die Zwischenüberschrift, die mit einem $c$ / für capitulum eingeleitet wird, steht vor dem Absatz (oberhalb des eigentlichen Schriftraumes) und ist durch einen Strich von diesem getrennt.

261 Ms.: honneurs steht über einer Radierung.

262 Ms.: et wurde über ein le korrigiert.

263 Am 12. Mai 1473 hatte Hz. Karl den Ordensmitgliedern und -amtsträgern ein weitreichendes Privileg erteilt. Zum Inhalt von Karls Privileg siehe ausführlich die Angaben in Reg. 74, dazu auch in der Einleitung S. $24 \mathrm{f}$.

264 Ms.: Nach dit est befindet sich eine größere Lücke und ein Doppelstrich; in der Edition wurde dafür ein Zeilenumbruch gewählt. 
A de sa grace benignement et liberalement aggree, ratifié et confermé a mesdis seigneurs les chevaliers freres et compaingnons dudit ordre de la Thoison d'or et ausdis quatre officiers, assavoir aux chancellier, tresorier, graffier et au roy d'armes d'icellui ordre presens et avenir, et a chascun d'eulx a leur endroit et si comme il leur peut toucher les poins et articles desdis honneurs, drois, prerogatives, libertez, franchises et exemption telz et en la forme et maniere que icellui feu duc Charles, son beaupere, leur avoit ottroié et concedez. Et a prins et mis en sa sauvegarde especiale mesdis seigneurs les chevaliers freres et compaingnons ensemble lesdis quatre officiers dudit ordre et chascun d'iceulx. Et mesmement a declaré et consenti de plusample grace a la supplicacion et remonstrance que dessus, que en cas que aucuns qui qu'ilz fussent par forme de commotion tumulte ou autrement feissent envahissement, injure grief, oppression ou violence de fait et de force hors forme et ordre de droit aux personnes desdis chevaliers freres et compaingnons ou des quatre officiers dudit ordre de la Thoison d'or ou d'aucun d'iceulx, que point il ne pardonnera ne remettra ladite injure et violence aux coulpables qui qu'ilz soient, que ce ne soit par l'advis et consentement des chevaliers freres dudit ordre et en leur chappittre, et sur tout a ordonné et commandé mondit seigneur le souverain audit graffie[r] [fol. 50r/22r] d'en faire et expedier de par lui ses lettres patentes en forme deue soubz le seel d'icellui ordre que soient enterinees et publiees en tous lieux et a tous qu'il appartendra. ${ }^{265}$

[173] [Hz. Maximilian bestätigt Martin Steenberch, dessen von Hz. Karl verliehenen lebenslangen Einnahmen zu Brüssel.]

\section{Touchant le graffier ${ }^{266}$}

Avec ce a aggree et confermé mondit seigneur le souverain a maistre Martin Steenberch, son secretaire et graffier dudit ordre de la Thoison d'or, sa provision par an sa vie durant, telle et ainsi que feu mondit seigneur le duc Charles \{34\}, son beaupere, oudit chappittre de l'ordre tenu a Valenciennes et par ses lettres patentes ${ }^{267}$ la lui avoit ottroiee, <et> donnee et assignee sur les deniers de sa recepte du quartier de Brouxelles en Brabant, ${ }^{268}$ voulant et ordonnant que nouvelles lettres de ratificacion et confirmacion de par lui en fussent faites et baillees audit maistre Martin en la forme qu'il appartendroit pour sa seurté d'icelle provision. ${ }^{269}$

265 Die schriftliche Niederlegung dieser Betätigung erfolgte erst im Okt. 1478; vgl. Reg. 74. Die Regesten Friedrichs III., Suppl. 1, 2008, S. 58, Nr. 31, erschlossen aufgrund der Erwähnung im Inventar von Türck (Brüssel, AGR, Mss. div. 1050), fol. 131v-132r zusätzlich noch ein Depertitum mit der Datierung von 1478 [April 30 bis Anfang Mai].

266 Ms.: Diese Zwischenüberschrift steht vor dem folgenden Absatz und ist durch einen Strich von diesem getrennt.

267 In den Aufzeichnungen zum Ordensfest im Jahr 1473 (PB 3) ist nichts von diesen Vorrechten für Steenberch und Toison d'or zu lesen; sie werden auch nicht in der in § 9, Anm. 38 f. genannten Literatur erwähnt.

268 Ms.: en Brabant steht über der Zeile.

269 Vgl. Reg. 49. - Zu Steenberchs diversen Einkünften vgl. HoorebeEck, Steenberch, 2006, S. 316. 


\section{[174] [Desgleichen für eine Pension aus Saint-Omer zugunsten des Wappenkönigs} Toison d'or.]

\section{$\mathbf{N}\left(\right.$ ota): Touchant le roy d'armes de l'ordre ${ }^{270}$}

Semblablement a confermé mondit seigneur le souverain a Thoison d'or, roy d'armes dudit ordre, sa pension en la maniere que par icellui feu monseigneur le duc Charles \{34\} ladite pension lui avoit esté assignee sur la recepte de Saint Omer. ${ }^{271}$

[175] [Das Ende des Ordensfestes.]

\section{$\mathbf{N}\left(\right.$ ota): Conclusio capittuli $\mathrm{xxj}$ ordinis ${ }^{272}$}

Toutes lesquelles choses ${ }^{273}$ ainsi faites, mondit seigneur le souverain et messeigneurs les chevaliers freres et compaingnons de l'ordre de la Thoison d'or delibererent et conclurent par commun accord de cloire pour ceste foiz le chappittre dudit ordre. Et par l'ordonnance et expres commandement de mondit seigneur le souverain ledit reverend pere en Dieu messire Ferry, evesque de Tournay, chancellier d'icellui ordre, a illec pronunciee et faite ladite cloision dudit chappittre ou mesme lieu cappitulaire, en disant ces mots a haulte voix "Concludimus in nomine Patris et Filij et Spiritus Sancti. Amen ». Ce fut fait oudit lieu cappitulaire ledit second jour du mois de may environ viij heures du vespre l'an $\mathrm{M}$ cccc soixante dixhuit, presens a ce lesdis autres officiers du mesme ordre, assavoir maistre Jehan Gros, tresorier, Thoison d'or, le roy d'armes, et moy, Martin Steenberch, graffier dessusdit.

$$
M(\operatorname{artin}) \text { Steenberch }{ }^{274}
$$

\section{[176] [Alle verlassen den Versammlungsort und Hz. Maximilian bricht nach Gent auf.]}

Laquelle cloison et conclusion dudit chappittre de l'ordre ainsi faite et pronunciee, mondit seigneur le souverain incontinent s'est parti dudit chappittre et lieu cappitulaire et s'est allé armer et habillier pour partir et s'en aller vers sa ville de Gand ${ }^{275}$ et messeigneurs les chevaliers freres <aussi> ensemble lesdis quatre officiers s'en partirent aussi et alerent devestir des habits de l'ordre, eulx revestans d'autres leurs habis chascun a son plaisir.

270 Ms.: Diese Zwischenüberschrift steht vor dem folgenden Absatz und ist durch einen Strich von diesem getrennt.

271 Vgl. Reg. 50. Am 30. Nov. 1468 hatte Hz. Karl Gobet für sein Amt als Toison d'or eine jährliche Gage von 157 Livres und 10 sous zugesagt; vgl. PB 2, S. 27 und S. 197, Reg. 67. Schon im Laufe des Jahres 1477 erhielt dieser eine Bestätigung über die Einnahme von zwei Pensionen für seine Kleidung; überliefert in Lille ADN, B 2112; danach IADNB IV, 1881, Nr. 2112; Koller, Service, 1971, S. 140. - Auch bei dem Ordensfest von 1481 ließen sich die Amtsträger ihre Einnahmen von Hz. Maximilian bestätigen; vgl. PB 5, fol. 47v.

272 Ms.: Diese Diese Zwischenüberschrift steht vor dem folgenden Absatz. Sie ist unterstrichen und davor steht ein $c /$ für capitulum. Dazu ist auch noch von Steenberch am linken Rand zu Beginn des folgenden Absatzes Conclusion du chappittre notiert worden.

273 Ms.: choses steht über der Zeile und eine Marke zeigt auf die dafür vorgesehene Stelle im Text.

274 Steenberch benutzt hier seine „offizielle“ Unterschrift; vgl. dazu Angaben in PB 2, S. 11.

275 Hz. Maximilians Abreise erwähnen u. a. die Mémoires de la MARCHE, 3, 1885, S. 251. 
[fol. 50v/22v]

\section{Mai 1478}

[177] [Die in Brügge verbliebenen Mitglieder versammeln sich für den gemeinsamen Besuch der Marien-Messe.]

\section{Comment en ensuivant l'ordonnance de monseigneur le souverain faite en chappittre devant la conclusion d'icllui le devin service a esté continué ${ }^{276}$}

Le lundi, iiije jour dudit mois de may, ${ }^{277}$ environ ix heures du matin, se assemblerent en l'ostel de mondit seigneur le souverain audit lieu de Bruges en la mesme chambre, ou es jours passez le chappittre de l'ordre s'estoit tenu, messeigneurs Jehan, seigneur de Lannoy $\{50\}$, Adolff de Cleves $\{55\}$, seigneur de Ravestein, Loys, seigneur de Gruythuse $\{61\}$, conte de Wincestre, Pierre de Luczembourg $\{83\}$, conte de Saintpol, et Josse de Lalaing $\{80\}$, seigneur de Montigny, tous chevaliers freres et compaingnons dudit ordre de la Thoison d'or, ${ }^{278}$ et avec eulx reverend pere en Dieu messire Ferry, evesque de Tournay, chancellier, maistre Jehan Gros, tresorier, Martin Steenberch, doyen de Brouxelles, graffier, et Gilles Gobet, dit Thoison d'or, roy d'armes, tous officiers d'icellui ordre, vestus de robes de damas blances sans manteaul $\mathrm{x}^{279}<$ mais $>$ affullez de leurs chapperons de velou cramoisy brun, servans sur leurs manteaulx et habis de l'ordre, pour eulx en aller ainsi habillez devers l'eglise Saint Saulveur y oyr la grant messe, que selon les ordonnances et status du mesme ordre dire et celebrer se y devoit de Nostre Dame. ${ }^{280}$

276 Ms.: Diese Zwischenüberschrift steht vor dem folgenden Absatz.

277 4. Mai 1478.

278 Demnach haben folgende Mitglieder zusammen mit Hz. Maximilian Brügge verlassen: Philippe de Croy $\{74\}$, Engelbert von Nassau $\{77\}$, Jakob von Savoyen $\{84\}$ und Bartholomäus von Liechtenstein $\{85\}$.

279 Ms.: sans manteaulx steht über der Zeile und eine Marke zeigt auf die dafür vorgesehene Stelle im Text.

280 Von dieser Messe berichtet auch Verschelde, Feeste, 1873, S. 28 f. (nach Stadtbibl. Brügge, Historisch Fonds ms. 437 [Excellente Chronycke van Vlaanderen]); Delepierre, Fête en 1478, 1842, S. 345. Der Besuch der Marien-Messe ist in § 53 (neu § 28) der Statuten (dazu S. 16, Anm. 14) geregelt; zur Kleiderordnung für diesem Anlass vgl. § 53 mit Anm. 309. 
[178] [Zuvor ergeben sich noch zwei Fragen: Bei den früheren Festen waren die neuen Mitglieder erst nach Absolvierung aller Gottesdienste in den Orden aufgenommen worden. Da dies nun aber früher geschah, besteht gewisse Ratlosigkeit, wo die Neuen in der Kirche platziert werden sollen. Auch über den Rang des Ordenskanzlers besteht gewisse Unsicherheit, denn in Abwesenheit des Souveräns fungiert er als dessen Stellvertreter und gleichzeitig ist er während des Gottesdienstes auch der für Brügge zuständige Bischof.]

Du lieu pour messeigneurs les nouveaulx esleuz en l'eglise ${ }^{281}$

Mesdis seigneurs ainsi la estans assemblez, question et demande y a esté proposee et misé en termes <l'une que fut $>$ telle en effect, pour ce que paravant aux festes et solemnitez de l'ordre qui avoient successivement esté tenues, l'on avoit communement a chascun fois fait parachevé et accompli le divin service accoustumé en l'eglise premiers et devant que l'on besoingnast en chappittre, et n'avoit jamais esté veu en l'ordre, mesmement par messeigneurs dudit ordre qui la estoient, qu'il fust quelque election faite, ne chevaliers esleu et receu en icellui ordre devant ledit divin service parfait et furny en ladite eglise. Ce que a ceste foiz advenu ${ }^{282}$ et fait estoit <advenu>, car pour cause des guerres et grans affaires de mondit seigneur le souverain besoing $\mathrm{a}^{283}$ esté de haster, anticiper et abbregier tant la feste que le chappittre dudit ordre, tellement que desja l'election des nouveaulx chevaliers freres est faite et celebree, dont desja en a<voit> quatre desdiz chevaliers nouveaux receuz en l'ordre, assavoir monseigneur de Romont \{84\}, monseignur de Saintpol \{83\}, monseigneur de Montigny $\{80\}$ et messire Bertremy de Lichtestein $\{85\}$, devant que ladite messe de Nostre Dame $<$ fust ne $>$ soit celebree, laquelle reste encore et se celebrera a ce matin prestement, et celle du Saint Esprit, ordonnee pour celebrer demain matin. ${ }^{284}$ Ausquelles deux messes que [!] se diront solemnellement, tous messeigneurs les chevaliers et compaignons dudit ordre estans en ceste ville de Bruges, tant vielz que nouveaux, ${ }^{285}$ doivent estre personnellement ensemble les quatre officiers d'icellui ordre pareillement habituez et habillez selon certaines ordonnances $<$ cy dessus escripte $>$ sur ce faite ou darrenier chappittre de l'ordre, tenu a Valenchiennes, comme dessus est dit. ${ }^{286}$ Pour savoir quel lieu auront en l'eglise pendant que lesdites messes se celebreront mesdis seigneurs les chevaliers freres nouvellement esleuz et ainsi receuz en l'ordre, car le cas semblable n'a esté veu ne sceu advenir oudit ordre et n'ont encoires lesdis nouveaux [fol. 51r/23r] chevaliers point de lieu es rengs des tableaux des anchiens chevaliers freres survivans et qu'ilz se deussent mettre es estalz et lieux des trespassez seroit chose impertinente,

281 Ms.: Diese Zwischenüberschrift steht vor dem folgenden Absatz und ist durch einen Strich von diesem getrennt.

282 Ms.: advenu steht über einer Radierung.

283 Ms.: $a$ steht über der Zeile.

284 Vgl. dazu auch in der Einleitung S. 25.

285 Ms.: tant vielz que nouveaux steht über der Zeile und eine Marke zeigt auf die dafür vorgesehene Stelle im Text.

286 Vgl. die Angaben in Anm. 280. 
veu qu'ilz ne scevent et n'est encore ordonné ne determiné par l'ordre quel lieu par et selon les status dudit ordre leur ${ }^{287}$ competera et appartenir devra. ${ }^{288}$

\section{Du lieu de monseigneur l'evesque de Tournay, chancellier de l'ordre}

Avec ce y a esté mené et mise en termes une aultre question et demandé, touchant reverend pere en Dieu monseigneur l'evesque de Tournay, chancellier d'icellui ordre, pour savoir ou il se devra aussi tenir pendant le service desdites messes, attendue l'absence de mondit seigneur le souverain ${ }^{289}$ et que ledit $<$ monseigneur le $>$ chancellier est evesque et prelat diocesain audit lieu de Bruges et par toute ceste diocese de Tournay.

[179] [Die drei ältesten anwesenden Ordensmitgliedern regeln die Reihenfolge beim Gang zur Kirche und während des Gottesdienstes.]

\section{Advis sur ce ${ }^{290}$}

Sur lesquelles deux demandes et difficultez mesdis seigneurs de Lannoy $\{50\}$, de Ravestein $\{55\}$ et de Gruythuse $\{61\}$, anchiens ${ }^{291}<$ les $>$ freres de l'ordre, ont eu deliberacion et advis ensemble. Et leur conclusion a esté, quant a la premiere desdis demandes et difficultez par maniere d'avis et pour ceste foiz seulement: Que monseigneur le conte de Saintpol $\{83\}$ soit au lez dextre en lieu d'aucuns des aultres freres survivans et absens au dessoubz des freres anchiens illec present. Et ledit messire Josse de Lalaing $\{80\}$, seigneur de Montigny, au lez senestre ou lieu d'aucuns desdis aultres freres suivans et absens du mesme lez et au dessoubz des freres anchiens qui presens y seront, et tout sans prejudice et pour ceste foiz, comme dit est. $\mathrm{Au}$ regard de la seconde question et difficulté touchant mondit seigneur l'evesque de Tournay, chancellier de l'ordre, mesdis seigneurs les chevaliers freres, eu sur ce deliberacion et advis entre eulx, ont ordonné et dit que pour ceste foiz, veue ladite absence de mondit seigneur le souverain dudit ordre pour consideracion mesmement et regard de la qualité et dignité especiale dudit monseigneur de Tournay a laquelle ilz entendent et veulent deferer, ils s'en rapportent a lui de prendre tel lieu qu'il lui plaira devers le grant autel, soit emprins les sieges du celebrant estans au lez dextre dudit autel ou ailleurs la ou et ainsi que bon lui semblera. Pourveu toutevoye que les aultres trois officiers d'icellui ordre, assavoir le tresorier, le graffier et le roy d'armes Thoison d'or, se tiennent ensamble en leur lieu pour eulx ordonné devant le siege de mondit seigneur le souverain. Lesquelles deliberacion et advis ont par monseigneur de Lannoy de l'ordonnance et adveu de messeigneurs de Gruythuse et de Ravestein

287 Ms.: leur steht über der Zeile und eine Marke zeigt auf die dafür vorgesehene Stelle im Text.

288 Ms.: Nach appartenir devra befindet sich eine größere Lücke und ein Doppelstrich; in der Edition wurde dafür ein Zeilenumbruch gewählt. Die folgende Zwischenüberschrift steht am linken Rand auf fol. 51r bei der Zeile, die mit devra. Avec ce y a esté mené et mise beginnt, und ist links und rechts mit einer Klammer versehen.

289 Da Hz. Maximilian an den weiteren Ordenssitzungen nicht teilnehmen konnte, übernahm der Ordenskanzler in seiner Funktion als Stellvertreter des Souveräns den Vorsitz; vgl. dazu § 26 (neu Amtsträger § 6) der Statuten (dazu S. 16, Anm. 14).

290 Ms.: Diese Zwischenüberschrift, die mit einem $c$ /für capitulum eingeleitet wird, steht vor dem folgenden Absatz und ist unterstrichen.

291 Ms.: de Lannoy, de Ravestein et de Gruythuse, anchiens steht am linken Rand und eine Marke zeigt auf die dafür vorgesehene Stelle im Text. 
esté declarez a mesdis seigneurs de Saintpol et de Montigny, nouveaulx confreres, qui se y sont liberalement accordez pour leur endroit et aussi a mondit seigneur l'evesque de Tournay pour son endroit. Et ainsi a esté fait, car a aler devers l'eglise monseigneur le conte de Saintpol et monseigneur de Montigny alerent les premiers ensemble inmediatement apres mondit seigneur l'evesque de Tournay, chancellier de l'ordre, monseigneur de Gruythuse et monseigneur de Ravestein consequenment appariez et monseigneur de Lannoy ala le darrenier, tenant son reng au lez senestre car il n'avoit point de compaignon au lez dextre. ${ }^{292}$ Et mesdis seigneurs venus ou grant chœur de ladite eglise, monseigneur de Gruythuse, monseigneur de Ravestein et monseigneur de Lannoy se sont mis chascun en son lieu et estal soubz ses armes et monseigneur de Saintpol se mist ou lieu penultime du reng dextre soubz les armes de monseigneur le conte de [fol. 51v/23v] Chimay $\{74\}$ absent. Et ledit messire Josse, seigneur de Montigny, au les senestre ou lieu et soubz les armes de messire Engelbert, conte de Nassouwe $\{77\}$, aussi absent, qui est le darrenier du reng des tableaux de mesdis seigneurs de l'ordre audit lez senestre. Et monseigneur l'evesque de Tournay, chancellier dudit ordre, a eu son lieu pour lui preparé honnestement au dextre dudit grant autel devant les chayres du celebrant et ses ministres. Mais lesdis trois autres officiers d'icellui ordre se sont mis et tenus ou petit banc ${ }^{293}$ pour eulx ordonné devant ledit siege de mondit seigneur le souverain. Et tantost s'est encommencié et dite solemnellement la grant messe de Nostre Dame par reverend pere en Dieu monseigneur l'abbé de Saint Bertin, prelat mitre. ${ }^{294}$

\section{[180] [Nach dem Gottesdienst begeben sich die Mitglieder zum Abendessen.]}

Apres ladite messe messeigneurs les chevaliers freres ensemble les quatre officiers de l'ordre sont retournez ordonneement vers la court, tous a cheval ainsi que venus estoient, et descendus de cheval se sont retrais, deux a deux, en la chambre ou s'estoit tenu le chappittre dudit ordre es jours precedens et d'illec sont tantost allez disner en la petite sallette devant la chambre de mondit seigneur le souverain. Et tous mesdis seigneurs les chevaliers freres ensemble monseigneur l'evesque de Tournay, chancellier dudit ordre, se sont assis au disner a une table et fut le premier en chief mondit seigneur de Tournay et au plus pres de lui monseigneur de Lannoy $\{50\}$, monseigneur de Ravestein $\{55\}$, monseigneur de Gruythuse $\{61\}$, monseigneur le conte de Saintpol $\{83\}$ et monseigneur de Montigny $\{80\}$, chevaliers freres ${ }^{295}$. Et les autres trois officiers, assavoir le tresorier, le graffier et le roy d'armes, furent assis a une aultre petite table illec pour eulx ordonnee. Et fut ledit disner plantureux et liberal, haultement et grandement servi aux despens de mondit seigneur le souverain.

292 Zu der Reihung bei den Kirchgängen an den vorhergehenden Tagen vgl. vor allem $\S 45$.

293 Ms.: banc steht über der Zeile und eine Marke zeigt auf die dafür vorgesehene Stelle im Text.

294 Jean de Lannoy wurde im Okt. 1473 zum Abt von Saint-Bertin bei Saint-Omer ernannt und im Dez. 1480 zum Kanzler des Ordens vom Goldenen Vlies; dazu ausführlicher (auch zu seiner Person) unten in § 276.

295 Ms.: chevaliers freres steht über der Zeile und eine Marke zeigt auf die dafür vorgesehene Stelle im Text. 
[181] [Danach versammeln sich die Ordensmitglieder, um die offenen Angelegenheiten zu regeln.]

\section{Nota ce disner ${ }^{296}$}

Ce disner fait et graces dites, apres aucunes devises messeigneurs les chevaliers freres ensemble l'evesque de Tournay, chancellier de l'ordre, dessus nommez ${ }^{297}$ se sont tirez a part en ladite chambre, ont appellé devers eulx lesdis tresorier, graffier et roy d'armes dudit ordre et fait <tint> partir dehors icelle chambre tous les aultres qui n'estoient $<$ pas du serment $>$ d'icellui ordre, pour y tenir conseil et en ensuivant l'ordonnance de mondit le souverain, faite par la deliberacion du chappittre derrenierement devant la conclusion dudit chappittre, assavoir que ceulx de mesdis seigneurs les chevaliers freres qui ${ }^{298}$ ensemble les quatre officiers de l'ordre < qui> la demourroient apres son partement advisassent ensemble ce qui seroit de faire pour $<$ mettre a $>$ l'execucion des choses qui avoient esté deliberees et conclues oudit chappittre pour leur deliberacion et advis, sur ce lui signiffier le plus brief que faire se pourroit bonnement etc., illec communiquer, adviser et deliberer sur ce que dit est:

[182] [Nach Meinung der in Brügge verbliebenen Mitglieder sollten an die abwesenden Mitbrüder folgende Informationen gesandt werden: [1.] Hz. Maximilian ist ordnungsgemäß als Souverän des Ordens eingeführt worden. [2.] Wegen Zeitmangel sind die corrections der abwesenden Mitglieder auf das nächste, im kommenden Fahr geplante Fest verschoben. [3.] Die neugewählten Mitglieder, die sich nicht in Brügge aufgehalten haben, sollen von ihrer Wahl und die abwesenden Mitglieder über die Wahlergebnisse unterrichtet werden. Mit dieser Empfehlung wird Toison d'or zu Hz. Maximilian gesandt und mit einer entsprechenden Instruktion ausgestattet.]

\section{L'advis de messeigneurs les chevaliers freres ensamble du chancellier de l'ordre demo[u]rez a Bruges apres le departement de monseigneur le sou- verain touchant les affaires dudit ordre ${ }^{299}$}

Et tantost pour entrer en besoingne mondit seigneur l'evesque de Tournay, chancellier, [fol. 52r/24r] a par l'ordonnance de mesdis seigneurs les chevaliers freres illec assamblez mis en termes les matieres surquoy faisoit a deliberer <lors>, dependans des conclusions dudit darrain chappittre, lesquelles par maniere depilogacion il a divisees en trois parties: ${ }^{300}$

296 Ms.: Diese Zwischenüberschrift steht am linken Rand zu Beginn des folgenden Absatzes.

297 Vgl. § 177; zu ihrem Auftrag sich um die ausstehenden Ordensangelegenheiten zu kümmern vgl. 170.

298 Ms.: qui steht über der Zeile und eine Marke zeigt auf die dafür vorgesehene Stelle im Text.

299 Ms.: Diese Zwischenüberschrift, die mit einem $c$ / für capitulum eingeleitet wird, steht in der Kopfzeile von fol. 24r und ist durch einen Strich vom folgenden Absatz getrennt.

300 Ms.: Zur besseren Lesbarkeit dieses langen Paragraphen wurden Absätze eingefügt. Die folgende Nummerierung entspricht der von Steenberch am linken Rand vorgenommen Nummerierung, die nach der folgenden Zwischenüberschrift einsetzt. 


\section{No(ta) icy conseil sur iij poins $s^{301}$}

[1] Assavoir l'une touchant les misteres, solemnitez et ceremonies gardees et observees a creer et faire mondit seigneur le duc chevalier et mesmement a l'acceptacion, emprinse et relievement par lui faiz dudit ordre de la Thoison d'or comme chief et souverain d'icellui, pour aviser et deliberer par mesdis seigneurs les chevaliers freres, s'il seroit bon et expedient que mondit seigneur le souverain par ses lettres ou autrement le signifiast aux tresexcellentes roys et princes et aux aultres chevaliers freres dudit ordre absens et qui n'y avoient esté, ne procureur pour eulx..$^{302}$

[2] L'autre touchant le fait des corrections, mesmement au regart de messeigneurs les chevaliers freres absens dont parlé avoit esté oudit darrenier chappittre. Mais pour les grans affaires et empeschemens survenus a mondit seigneur a cause de la guerre, la matiere desdis corrections avoit par la conclusion dudit chappittre esté remise ou prouchain chappittre de l'ordre avenir, qui se tendroit a l'encommencement du mois de may prouchain venant etc. Pour deliberer et adviser s'il est expedient d'en faire desmaintenant la significacion ou de la differer jusques a autre temps convenant et competent selon les status dudit ordre, et aussi de la forme et maniere comment ladite significacion son devroit faire, mesmement a ceulx qui avoient esté notez en icellui darrenier chappittre pour divers cas et par divers moyens declairez assez au long es actes dudit chappittre. ${ }^{303}$

[3] Et la tierce partie estoit touchant le fait des elections faites ou mesme darrenier chappittre pour adviser et deliberer, s'il seroit bon et neccessaire de signiffier aux seigneurs chevaliers esleuz estans en marches longtaines l'election faite de leurs personnes $<$ et a chascun les siennes > pour estre chevaliers freres de l'ordre et a chascun la sienne, ${ }^{304}$ tant pour les en advertir comme pour savoir leurs intencions, s'ilz la vouldront accepter et estre accompaingnez audit ordre en faisant les devoirs qu'il appartient et chascun en son endroit ou non. ${ }^{305}$ Et de advertir aussi desdites elections faites les roys d'Angleterre $\{63\}$, d'Arragon $\{57\}$, de Castille $\{71\}$ et de Naples $\{72\}$ et pareillement les aultres chevaliers freres absens, mesmement au regard des personnes des nouveaulx esleuz qui desja ont accepté leur election, ont fait les devoirs et portent le collier dudit ordre. ${ }^{306}$

Sur lesquelles trois matieres ainsi mises en termes par mondit seigneur l'evesque de Tournay, chancellier de l'ordre, ont mesdis seigneurs les chevaliers freres deliberé meurement et donné leur opinion et advis. Lequel advis ilz ont par moy, graffier, fait rediger et mettre en escript par forme d'instruction et memoire pour le baillier audit Thoison d'or, le roy d'armes de l'ordre, auquel ilz ordonnerent de s'en aller devers mondit seigneur le souverain diligenment ou qu'il seroit pour selon ladite instruction par l'advis et adreçement de monseigneur le conte de Chimay \{74\}, qui seroit devers lui, et de monseigneur de Montigny $\{80\}$, qui avoit esté present a ceste deliberacion, et prestement s'en y aloit rapporter a mondit seigneur le souverain leurdit advis touchans

301 Ms.: Diese Zwischenüberschrift steht am linken Rand, die mit [relie]vement par lui faiz dudit ordre beginnt.

302 Vgl. Reg. 60-64.

303 Fortsetzung in $\S 186$.

304 Ms.: et a chascun la sienne steht über der Zeile und eine Marke zeigt auf die dafür vorgesehene Stelle im Text.

305 Vgl. Reg. 52-55 sowie 71. - Fortsetzung in § 188.

306 Vgl. Reg. 56-58, 66 und 68f. - In der nach dieser Verhandlung ausgestellten Instruktion für Toison d'or (Reg. 51) ist von diesem Punkt nicht mehr die Rede. 
ces matieres et plainement l'en advertir et informer de bouche et aussi par humble ostencion et exhibicion de sadite instruction, se mestier estoit, afin que mondit seigneur, plainement et bien sur tout informé et adverti, y puist penser et au surplus en ordonner et faire ainsi que son noble vouloir et plaisir seroit, par l'advis mesmement de messeigneurs dudit ordre qui lors se trouveroient devers lui.

Desquelz advis, instruction et memoire sur ce ainsi baillez audit roy d'armes Thoison d'or, la teneur s'ensuit et este telle: ${ }^{307}$

\section{[183] [Es folgen die für Toison d'or ausgestellten Instruktionen, in deren erstem Ab- satz die beteiligten Personen und der Auftrag Toison d'ors genannt werden:]}

\section{Instruction et memoire touchans les affaires deppendans du chappittre de la Thoison d'or ${ }^{308}$}

Memoire par forme de brieve instruction pour Thoison d'or, le roy d'armes du noble ordre de la Thoison d'or, des poins et choses que de la part de messeigneurs [fol. 52v/24v] Jehan, seigneur de Lannoy $\{50\}$, Adolph de Cleves $\{55\}$, seigneur de Ravestein, Loys, seigneur de Gruythuse $\{61\}$, conte de Wincestre, et Pierre, conte de Saintpol \{83\}, chevaliers freres et compaingnons, et reverend pere en Dieu monseigneur l'evesque de Tournay, chancellier dudit ordre de la Thoison d'or, demourez et estans en la ville de Bruges, ledit roy d'armes aura a dire, rapporter, exposer et remonstrer a nostre tresredoubté seigneur monseigneur le duc, chief et souverain d'icellui ordre, par l'advis de monseigneur le conte de Chimay $\{74\}$, premier chambellan de mondit seigneur, et de messire Josse de Lalaing $\{80\}$, seigneur de Montigny, chevaliers, aussi freres et compaingnons du mesme ordre.

\section{[184] [Als erstes soll Toison d'or Empfehlungen ausrichten.]}

Premierement ledit roy d'armes Thoison d'or recommandera treshumblement en reverence et obeissance deues mesdis seigneurs a la bonne grace de nostredit tresredoubté seigneur et aussi recommandera lesdis seigneurs a messeigneurs de Chimay $\{74\}$ et de Montigny $\{80\}$, ausquelz il exposera premiers sadite charge.

\section{[185] [Toison d'or soll im Beisein der bei Hz. Maximilian befindlichen Ordensritter Philippe de Croy und fosse de Lalaing über die Ergebnisse der Beratung der in Brügge verbliebenen Ordensritter unterrichten.]}

Item dira ledit Thoison d'or a nostredit tresredoubté seigneur monseigneur le duc et par l'adivs que dessus, comment depuis son departement de sa ville de Bruges messeigneurs de l'ordre dessus nommez, ensemble ledit seigneur de Montigny $\{80\}$, pour obeir a sa tresnoble ordonnance qu'il lui avoit pleu leur faire darrenierement en son chappittre dudit ordre devant la cloison dudit chappittre, assavoir de aviser et communiquer de et sur les choses qui restoient a faire selon les conclusions dudit

307 Vgl. Reg. 51.

308 Ms.: Diese Zwischenüberschrift steht vor dem folgenden Absatz und ist durch einen Strich von diesem getrennt. Dazu befindet sich in den Kopfzeilen der Doppelseiten fol. $24 \mathrm{v} / 25 \mathrm{r}$ und $25 \mathrm{v} / 26 \mathrm{r}$ auch noch jeweils der Vermerk Instruction pour le roy d'armes - Thoison d'or. 
chappittre, ont le iiije jour de ce present mois de may, ${ }^{309}$ eu deliberacion et advis ensemble < de et sur les choses qui restoient $>$ et finablement advisé les choses qui s'ensuivent soubz la benigne correction de mondit seigneur et saulf et reservé son tresnoble plaisir en tout et de mesdis seigneurs de Chimay $\{74\}$ et de Montigny.

\section{[186] [Empfehlung, dass Hz. Maximilian den beim Fest fehlenden Mitgliedern schreibt und sie von seiner ordnungsgemässen Übernahme des Ordens und über den Ablauf des Festes unterrichtet. $]^{310}$}

C'est assavoir que mondit seigneur a toute diligence doit escripre et signiffier au roy d'Angleterre $\{63\}$ et aux roys d'Arragon $\{57\}$, de Castille $\{71\}$ et de Naples $\{72\}$ et semblablement aux aultres messeigneurs les chevaliers freres et compaingons dudit ordre absens a lui bien vueillans et de son parti, comment mondit seigneur en ensuivant sa conclusion a eulx pieça par aultres ses lettres escripte et signiffiee, a receu [fol. 53r/25r] l'ordre et estat de chevallier le darrenier jour du mois d'avril passé en l'eglise Saint Salveur, eglise notable de ceste sadite ville de Bruges, et puis incontinent y a relevé solemnellement et emprins l'ordre et receu le collier de ladite Thoison d'or comme chief et souverain d'icellui ordre selon la forme des status dudit ordre, faisant le serment publiquement et gardees les ceremonies en tel cas requises, presens a ce pluseurs grans prelas, haulx princes, nobles hommes et aultres notables et a la veue du peuple sans nombre qui la estoienet assamblez. ${ }^{311}$ A aussi depuis sadite recepcion tenu la solemnité et feste et le chappittre dudit ordre de la Thoison d'or avec messeigneurs les chevaliers freres et compaingnons d'icellui ordre a ce convoquez et lors presens. Et a besoingnié sur le fait des corrections et des elections, pour remplir les lieux qui estoient vuys et vacans oudit ordre selon lesdis status et ordonnances d'icellui et y a vaqué par aucuns jours et encores eust plus contenué, se ne fussent les nouvelles qui lui survindrent de l'approichement du roy de France et de son armee en ses pays, parquoy mondit seigneur s'est abbregié de cloire sondit chappittre et remettre le surplus des affaires d'icellui ordre jusques a l'autre feste avenir. Et s'est incontinent mis a champs, pour a l'ayde de Dieu et des ses bons et leaulx parens, vassaulx, amis et subgiez obvier et resister de toute sa puissance aux entreprinses de sesdis adversaires, dont mondit advertist lesdis roys et aultres freres absens, chascun a son endroit, afin qu'ilz cognoissent et saichent, ce qui est fait et que de present il est chief et souverain dudit ordre et que a ce en tout est procedé selon lesdis status et ordonnances. Et comment son desir est non seulement entretenir et maintenir icellui ordre en bon estat, mais aussi de le honnorer, augmenter et decorer a son povoir, les exhortant par la conclusion desdites lettres qu'ilz le vueillent doresenavant tenir et cognoistre pour chief dudit ordre et, tant devers lui comme autrement au regart des devoirs et affaires d'icellui ordre, eulx acquiter et conduire par et selon lesdis statuts et ordonnances du mesme ordre, ainsi comme par serment et promesses solemnellement sur ce faites, ilz y sont astrains, obligiez et tenus, et mondit seigneur est et sera tousjours desirant de leur complaire a son povoir. ${ }^{312}$

309 4. Mai 1478.

310 Fortsetzung von $\S 182$.

311 Zu Maximilians Ritterschlag und Aufnahme in den Orden am 30. April 1478 vgl. § 45-67.

312 Vgl. Reg. 60-64. 
[187] [Dem Souverän wird empfohlen, in Briefen und mit Gesandtschaften sich von den königlichen Ordensmitgliedern den Fortbestand ihrer Allianz bestätigen zu lassen.]

Item dira aussi ledit Thoison d'or a mondit seigneur le duc, chief et souverain dudit ordre, que a mesdis seigneurs a samblé bon et expedient de haster l'expedicion desdites lettres, mesmement celles desdis roys d'Angleterre $\{63\}$, de Castille $\{71\}$ et de Naples $\{72\}$, tant pour le bien, honneur et devoir de mondit seigneur comme dudit ordre, especialement pour empescher et rompre les entendemens et alliances, que comme mondit seigneur est adverti se pourchasset [fol. 53v/25v] de la part dudit roy de France devers eulx, tendans de soubstraine a mondit seigneur l'amour, faveur et assistance d'iceulx roys, parquoy seroit bon les parvenir et advertir, dont comme espoir est lesdis roys moult se contenteront et en seront mieulx ediffiez a la faveur de mondit seigneur, et pour rebouter et reaetter les offres et pourchas de partie adverse que autrement ne seroient. Et feroit bien mondit seigneur d'envoier devers chascun desdis roys avec lettres personnes notables qui parlassent pour les informer et advertir de bouche de toutes choses mieulx et plus amplement qu'il ne seroit loisible de faire par lettres. ${ }^{313}$

[188] [Es sollen Gesandtschaften zu Kaiser Friedrich III. und evtl. auch zu Kg. Matthias Corvinus, Kg. von Ungarn, und Albrecht, Hz. von Sachsen, entsandt werden, um diese von ihrer Wahl zu unterrichten.]

\section{Touchant l'ambassade a envoier es Alemangnes ${ }^{314}$}

Item dira et remonstrera en oultre ledit Thoison d'or a mondit seigneur que par cy devant apres les elections faites en chappittre de l'ordre quant il y avoit esleuz aucuns grans < seigneurs> personnaiges comme roys ou ducs, ${ }^{315}$ la coustume de messeigneurs les predecesseurs, chiefs et souverains, et les chevaliers freres de cest ordre a esté d'envoier devers lesdis roys ou ducs ainsi esleuz aucun des chevaliers freres ensamble le roy d'armes dudit ordre Thoison d'or et ce le plus brief que faire se povoit pour leur signifier honnorablement ladite election et porter le collier d'icellui ordre, ${ }^{316}$

313 Vgl. dazu die Angaben in Reg. 60-63. - In der Aufzählung fehlt Johann, Kg. von Aragon $\{57\}$, möglicherweise ein Versehen Steenberchs - Von einer Gesandtschaft nach England ist Ende Sept. 1478 in $\S 201$ die Rede. Maximilians Bemühung um Unterstützung durch „Spanien“ in dieser Zeit erwähnt Wiesflecker, Maximilian, 1, 1971, S. 138.

314 Ms.: Diese Zwischenüberschrift steht am linken Rand, etwa in der Mitte des folgenden Absatzes und ist links und rechts mit einer Klammer versehen.

315 Gemeint sind damit Kaiser Friedrich III. \{94\}, Matthias Corvinus, Kg. von Ungarn, und Albrecht, Hz. von Sachsen \{96\}; zu ihrer Wahl vgl. § $131 \mathrm{f}$. und 149-151. Interessanterweise werden ihre Namen in dieser Instruktion nicht direkt genannt. Da dieses Dokument auch von Personen gelesen werden konnte, die nicht dem Orden angehörten, wollte man so wohl verhindern, dass ihre Namen frühzeitig bekannt wurden; vgl. dazu auch in der Einleitung S. $29 \mathrm{f}$.

316 Vgl. die Gesandtschaften anlässlich der Aufnahmen von Alfons V., Kg. von Aragon $\{41\}$, in PB 1, S. 98-104, § 21-38 und S. 151 f., § 13; von Johann, Kg. von Aragon $\{57\}$, ebd., S. 135, § 39 f. und S. 155 f., § 16; von Eduard IV., Kg. von England $\{63\}$ in PB 2, S. 150-161, § 192-203, sowie von Ferdinand, Kg. von Neapel \{72\}, und Ferdinand, Kg. von Sizilien \{71\} in PB 3, S. 139, § 220 f. und S. 163 f., § $254 \mathrm{f}$. 
en recevant desdis esleuz les sermens et gardant les ceremonies en tel cas requises selon les status du mesme ordre, parquoy, s'il plaisoit a mondit seigneur, semble a messeigneurs de l'ordre dessusnommez, veue ceste darrenier election faite de trois grans personnaiges, dont le premier est le plus grant qui puist estre, que mondit seigneur feroit bien de deputer et commettre ung ou deux de mesdis seigneurs les freres de l'ordre, accompaingnez d'aucun prelat ou clerc notable qui portast la parolle et avec ledit Thoison d'or, le roy d'armes, pour audit premier esleu signifier reverenment et honnestement sadite election et, s'il l'accepte, recevoir de lui le serment et icellui fait solemnellement et en la maniere qu'il appartient lui baillier le collier. Et apres ce en ensuivant la conclusion dudit darrain chappittre, prinse informacion par l'advis d'icellui premier esleu s'il n'y a chose raisonnable au contraire, l'ung desdis freres chevaliers passerant oultre et s'en yroit devers le penultime esleu qui est aussi grant et puissant prince, et l'autre s'en yroit devers le darrenier esleu leur signiffier a chascun en son endroit l'election faite de leurs personnes, recevoir leurs sermens et leur baillier le collier dudit ordre aux ceremonies que dessus.

\section{[189] [Mit ihrer Aufnahme sollten gleichzeitig auch Allianzen zum gegenseitigen Schutz geschlossen werden.]}

Item avec ce dira et remonstrera de par mesdis seigneurs a mondit seigneur le duc, souverain de l'ordre, ledit roy d'armes, qu'il leur samble expedient de haster et avancer l'expedicion de ceste ambassade pour advertir lesdis trois grans personnaiges de [fol. 54r/26r] leurdite election. Car il est vraissemblable que oultre l'amitié, alliance ou bienvueillance que puist estre entre eulx, encores par moyen de leur conscripcion oudit ordre en ensuivant les status et ordonnances d'icellui, accroisera et $\mathrm{se}^{317}$ confermera pour tousjours et perpetuellement, au moins leurs vies durant et celle de mondit seigneur. Et pourra ceste nouvelle alliance que se fera se Dieu plaist au moien dudit ordre par especiale d'entre les deux plus grans personnaiges, prouffiter grandement tant a la chose publique crestienne comme aux deux parties et singulierement a mondit seigneur et a sa seurté, tant au regart de ses pays et seignouries de pardela que de pardeça et lui sera grant honneur et louenge et consequenment pour ledit ordre par toutes les Allemaingnes. ${ }^{318}$

\section{[190] [Zur Vorgehensweise bei der Aufnahme der anderen Neugewählten.]}

$\mathrm{N}$ (ota): Item et quant aux aultres esleuz estans es marches de pardeça, ${ }^{319}$ mesdis seigneurs croient vraisemblablement que aucuns desdiz nouveaulx esleuz se pouroit trouver briefment devers mondit seigneur, lesquelz il pourra lors faire appeller pour savoir d'eulx secretement leur intencion et s'ilz acceptent leur election. Comme il fait a presumer mondit seigneur pourra recevoir d'eulx le serment et leur baillier le collier aux ceremonies qu'il appartient selon les status de l'ordre. Et a ceste fin

317 Ms.: se wurde nachträglich hinzugefügt.

318 Fortsetzung in $\S 197$.

319 Hiermit dürften Philipp von Burgund \{82\} und Jacques de Luxembourg \{81\} gemeint sein; vgl. dazu Reg. 52-53. 
portera avec lui ledit roy d'armes, Thoison d'or, deux colliers avec le livre desdis status et ordonnances dudit ordre en françois et en latin. ${ }^{320}$

\section{[191] [Zur Vorgehensweise bei zwei weiteren deutschsprachigen Neugewählten.]}

Item au regart des aultres deux esleuz de la langue thioise ${ }^{321}$ ledit Thoison d'or pourra, s'il plaist a mondit seigneur, aler devers eulx es marches de leur residence a tout lettres de credence de par mondit seigneur et portera avec lui deux aultres coliers et le livre desdis status et ordonnances de l'ordre pour leur signifier l'election fait de leurs personnes et savoir d'eulx leur intencion s'ilz l'accepteront ou non. Et en cas, que si comme il fait assez a presumer, il recevra d'eulx le serment et leur baillera le collier aux ceremonies qu'il appartient, moyennant toutevoie que chascun d'eulx deux baillera ses lettres patentes audit roy d'armes qui les rendra a mondit seigneur le souverain, et par icelles cognoisera et certifiera avoir aggreablement accepté l'election faite de sa personne, a lui signifiee par ledit roy d'armes, et avoit fait solemnellement le serment a l'ordre selon les chappittres et receu le colier d'icellui ordre, promettant de venir et comparoir ou prouchain chappittre se faire le peut bonnement ou devers mondit seigneur le souverain le plus tost qu'il pourra, ou tantost que mondit seigneur le lui fera savoir, pour y jurer de nouvel les poins dudit ordre et faire tout ce a quoy il sera tenu.

\section{[fol. 54v/26v]}

\section{[192] [Empfehlung, die Einladungsschreiben für das nächste Ordensfest erst fünf oder sechs Monate vor Festbeginn zu versenden.]}

Item et en tant qu'il touché la significacion du futur chappittre pour l'annee avenir a faire par lettres closes aux roys, princes et autres messeigneurs les chevaliers freres de l'ordre non estans notez etc., comme par plaquart a autres etc., ${ }^{322}$ il semble soubz la benigne correction de mondit seigneur que de cestedite significacion il pourra encore surseoir jusques a v ou vj mois avenir, car selon les status de l'ordre souffira que l'intimacion et signifacion dudit chappittre avenir leur soit faite quatre mois devant le jour. Et la peut conclure mondit seigneur et faire faire toutes et quantesfois a son plaisir par l'advis de six de mesdis seigneurs les chevaliers freres de l'ordre. ${ }^{323}$

$320 \mathrm{Zu}$ einer lateinischen Fassung der Statuten vgl. § $11 \mathrm{f}$. mit Anm. 71; eine niederländische Fassung beschreibt LiEFTINCK, Uniek handschrift, 1950.

321 Hiermit dürften Wolfart van Borssele $\{79\}$ und Willem van Egmond $\{78\}$ gemeint sein, über deren Aufnahmeverfahren jedoch nichts bekannt ist; vgl. dazu Reg. $54 \mathrm{f}$.

322 Fortsetzung von $§ 171$.

$323 \S 47$ (neu § 22) der Statuten (dazu S. 16, Anm. 14) regelt die Abfolge der Ordensfeste: Mit der Statutenrevision im Winter 1445/46 wurde der Versammlungsbegrinn auf den 2. Mai fixiert (vgl. dazu auch in der Einleitung S. 33) und die ursprünglich jährlichen Versammlungen wurden auf eine zeitliche Abfolge von drei Jahre ausgedehnt. Sollte es jedoch erforderlich sein, konnte auch schon früher, aber frühestens ein Jahr nach dem letzten Ordensfest eine Versammlung einberufen werden. Des Weiteren wird in diesem Statutenartikel geregelt, dass die Einladungen zum Ordensfest entsprechend der Entfernung der Ordensmitglieder zeitgerecht erfolgen sollen, ohne dass aber genaue Termine genannt werden. Für das Fest im Mai 1468 erfolgten die Einladungen z.B. im Februar und März dieses Jahres und für das Fest im Jahr 1473 schon im Dezember davor; vgl. PB 2, S. 180 f. und PB 3, S. 167 f. 
Et semble plus expedient de encore delaier ladite significacion dudit futur chappittre que de l'avenier pour les causes assez par mondit seigneur entendues. ${ }^{324}$

\section{[193] [Diese Vorschlägen sollen eine unterrichtete Entscheidung Hz. Maximilians ermöglichen.]}

De toutes lesquelles choses dessusdites mesdis seigneurs de l'ordre font advertir mondit seigneur le souverain en toute humilité, reverence et obeissance deues et aussi messeigneurs de Chimay $\{74\}$ et de Montigny $\{80\}$, leurs freres oudit ordre, pour et afin que a mondit seigneur de tout bien adverti plaise d'y avoir advis et d'en faire et ordonner ainsi que son tresnoble vouloir et plaisir sera.

\section{[194] [Er soll dem Souverän auch mitteilen, dass die in Brügge verbliebenen Mit- glieder wie verabredet, an zwei Messen teilgenommen haben.]}

Oultre plus dira et remonstrera a mondit seigneur le souverain ledit roy d'armes Thoison d'or, que mesdis seigneurs de l'ordre estans a Bruges en ensuivant son ordonnance ont lundi et mardi darrenier passez fait dire et celebrer solemnellement en l'eglise Saint Saulveur, ou la principale feste quant au divin service s'estoit, tenue les messes de Nostre Dame et de Saint Esprit et y sont alez ensemble les quatre officiers de l'ordre, ordonneement comme il appartenoit selon des ordonnances sur ce faites. ${ }^{325}$

\section{[195] [Ausgestellt von Martin Steenberch auf Befehl der Ordensmitglieder.]}

Avisees, ordonnees et conclues par messeigneurs les chevaliers freres du noble ordre de la Thoison d'or dessus nommez en la ville de Bruges, le viije jour de may l'an $\mathrm{lxxvij}^{326}$ et pour les rediger par escript commandees a moy M(artin) Steenberch ${ }^{327}$

\section{Mai 1478}

\section{[fol. 55r/27r]}

[196] [Die Ordensmitglieder besuchen die Hlg.-Geist-Messe.]

\section{De la messe du Saint Esprit ${ }^{328}$}

Le mardi ensuivant, $\mathrm{v}^{\mathrm{e}}$ jour dudit mois de may l'an lxxviij, ${ }^{329}$ environ ix heures du matin, se sont de rechief assamblez en l'ostel de mondit seigneur le souverain en la chambre de monseigneur de Chimay $\{74\}$, premier chambellan, la ou monseigneur Adolph de Cleves $\{55\}$, seigneur de Ravestein, pour lors estoit logié, monseigneur

324 Fortsetzung in § 208, vgl. auch Reg. 83-91.

325 Am 4. Mai besuchten sie die Marien-Messe und am darauf folgenden Tag die Hlg. Geist-Messe; vgl. § 177 und 196.

326 7. Mai 1478.

327 Zur Unterschrift Steenberchs vgl. Anm. 274. - Dieser Absatz ist eingerückt und ist links mit einem senkrechten und unten mit einem waagrechten Strich versehen, um zu zeigen, dass damit die Instruktion beendet ist.

328 Ms.: Diese Zwischenüberschrift steht in der Kopfzeile von fol. 27r.

329 5. Mai 1478. 
de Lannoy $\{50\}$, mondit seigneur de Ravestein, monseigneur Loys, conte de Wincestre et seigneur de Gruythuse $\{61\}$, et monseigneur Pierre, conte de Saintpol et de Bryenne $\{83\}$, chevaliers freres, ensemble les quatre officiers de l'ordre de la Thoison d'or. Et d'illec sont allez devers l'eglise Saint Saulveur ordonneement a cheval, tous vestus pareillement de leurs robes de velours cramoisy brun et affulez de leurs chapperons du mesmes, comme ilz avoient esté vestus au matin le jour de la principale feste dudit ordre, saulf des manteaulx que pour ceste fois point ne porterent, pour en ladite eglise oyr la messe solemnelle du Saint Esprit, selon l'ordonnance sur ce faite ou chappittre darrenier precedent d'icellui ordre tenu a Valenciennes l'an lxxiij. ${ }^{330}$ Et mesdis seigneurs les chevaliers freres arrivez en icelle eglise, monteront ou grant chœur es haulx sieges, chascun soubz le tableau de ses armes, reservé mondit seigneur le conte de Saintpol qui se mist et tint ou lieu et soubz le tableau de monseigneur de Chimay $\{74\}$, chevalier frere absent. Et monseigneur l'evesque de Tournay s'en alla mettre en son lieu pour lui comme prelat diocesain, paré devers le grant autel, la ou il s'estoit tenu le jour precedent, comme dessus est dit. ${ }^{331}$ Et les aultres trois officiers en leur lieu premier devant le siege de mondit seigneur le souverain. Et tantost s'est encommencee et dite ladite messe du Saint Esprit a preslat non mitré, assavoir par reverend pere en Dieu l'abbé de Clermares de l'ordre saint Bernard ${ }^{332}$, a discant et orgues moult solemnellement et devotement. Apres laquelle messe finie, messeigneurs les chevaliers freres ensemble les quatre officiers de l'ordre dessusdit sont ordonneement retournez devers la court et remontez en ladite chambre du logis de mondit seigneur de Ravestein, la ou ilz ont trouvé en la salle devant la table mise et le diner prest. Et mondit seigneur de Ravestein leur a donné le diner et les a receuz et festoiez grandement et liberalement. Et a ce disner avoit pluseurs autres chevaliers, grans seigneurs, officiers des hostelz de mondit seigneur le souverain et de madame la duchesse, sa compaingne, assis et meslez entremy ceulx de l'ordre.

\section{[fol. 55v/27v] [unbeschrieben.]}

330 Zur Einführung der Hlg.-Geist-Messe und der dazugehörigen Kleiderordnung während des 1473 gefeierten Ordensfestes vgl. die Angaben in PB 3, S. 21 (mit Hinweis auf die entsprechenden Stellen im Protokoll und in der Literatur).

331 Vgl. dazu § 178.

332 Engelram Grayben, gebürtig in Saint-Omer, war zwischen 1465 und 1484 Abt von Clairmarais, OCist.; vgl. zu ihm LAPLANE, Abbés de Clairmarais, 1868, S. 371-381. 



\section{Teil 3: Die Versammlungen zwischen 1478 und 1480}

\section{September 1478 in Brüssel}

[fol. 56r/28r]

[197] [Steenberch und Toison d'or legen Hz. Maximilian die Entwürfe der Gesandtschaftinstruktion für die Reise zu den neugewählten Mitgliedern im Reich vor. Dieser wünscht eine Übersetzung ins Deutsche, die aber aufgrund der Geheimhaltungspflicht im Orden problematisch ist.]

\section{Comment le graffier et Thoison d'or ont monstré a monseigneur le souve- rain les minutes conceues pour l'ambassade d'Alemaigne ${ }^{1}$}

Le ix ${ }^{\mathrm{e}}$ jour du mois de septembre l'an xiiij ${ }^{\mathrm{C}} \mathrm{lxxviij}^{2}$ mon tresredoubté seigneur monseigneur le duc Maximilian, duc d'Austrice, de Bourgoingne, de Brabant etc., chief et souverain du noble ordre de la Thoison d'or, estant en sa ville de Brouxelles, maistre Martin Steenberch, graffier dudit ordre, en la presence de messire Bertremy, seigneur de Lichenstein $\{85\}$, grant maistre d'ostel d'Austrice, chevalier, frere et compaingnon, et de Thoison d'or, le roy d'armes, montra et lut a mondit seigneur le souverain en son petit retrait les minues des instructions et povoirs avisez et conceuz pour les ambasseurs qui de par mondit seigneur et de par l'ordre s'envoieroient devers la souveraine maiesté imperial \{94\}, devers le tresexcellent roy de Honguerie et devers hault et puissant prince le duc Albert, duc de Saxe \{96\}, pour leur annuncer et signifier les elections, faites de leurs personnes pour estre freres, chevaliers et compaingons d'icellui ordre. ${ }^{3}$ Lesquelles minues oyes et entendues par mondit seigneur le souverain, il declara et dit ausdis graffier et Thoison d'or, que attendu que ledit messire Bartremy, seigneur de Lichestain, qui pourroit estre l'ung des ambassadeurs en cest[e] affaire, n'entendoit pas bien latin, et pour lui mesmes mieulx entendre ceste matiere, il desiroit que l'instruction servant pour l'empereur, son pere, s'eust translatee du latin en son aleman et que ledit graffier lui en laissast la minue, car il la feroit translater. Surquoy icellui graffier remonstra treshumblement a mondit seigneur pour soy acquiter, disant que ceste matiere estoit moult secrete et touchoit grandement l'onneur de l'ordre et a cause du serment dudit ordre bonnement elle ne le povoit communiquer ou reveler a nul qui ne fust du serment d'icellui ordre. ${ }^{4}$ A quoy mondit seigneur respondit et dit, qu'il avoit ung en sa chambre nommé Johannes ${ }^{5}$ qui longuement l'avoit servi et

1 Ms.: Diese Zwischenüberschrift steht in der Kopfzeile von fol. 56r. - Fortsetzung von $§ 189$.

2 9. Sept. 1478.

3 Vgl. Reg. 71.

4 Zum Gebot aller Angehörigen des Ordens, nichts von dem was auf den Ordensversammlungen besprochen wurde, an Dritte weiter zu geben, vgl. § 101 mit Anm. 71. Und gerade bei den Neuwahlen war es wichtig, dass die Namen der neuen Mitglieder erst bekannt wurden, wenn diese ihre Wahl auch akzeptiert hatten; vgl. dazu in der Einleitung S. 30.

5 In § 199 wird er als Johann Kelner, Maximilians valet de chambre und someliers de corps bezeichnet. Es handelt sich dabei um den in Nürnberg geborenen Juristen Johann Keller 
lui estoit feable et bien secret, par lequel il feroit faire ladite translation et il feroit le serment se besoing estoit de le tenir secret. Sur ce repliqua en toute humilité ledit graffier que saulve la reverence de mondit seigneur ce ne se devoit ne povoit ainsi faire sans le scea et consentement de messeigneurs les chevaliers, ses freres de l'ordre, au moins de ceulx qui estoient devers lui. Ce oyant mondit seigneur il ordonna et commanda ausdis graffier et Thoison d'or d'en parler a messeigneurs les chevaliers freres de l'ordre, lors estans audit Brouxelles, afin qu'ilz y voulsissent consentir.

[198] [Die in Brüssel anwesenden Ordensritter stimmen zu, dass ein vertrauenswürdiger Sekretär Maximilians die erforderlichen Übersetzungen ausfertigen kann, aber erst nachem er in Gegenwart des Souveräns und der Ordensritter ein Schweigegelübte abgelegt hat.]

Item et en ensuivant ladite ordonnance de mondit seigneur lesdis graffier et Thoison d'or firent ce rapport a messeigneurs de Gruythuse $\{61\}$, de Nassouw $\{77\}$, de Saintpol $\{83\}$ et de Bevre $\{82\}$, chevaliers, confreres de l'ordre, lors estans et trouvez audit Brouxelles qui pour ceste cause se assemblerent en la chambre de mondit seigneur de Gruythuse le lendemain. ${ }^{6}$ Lesquelz oy ledit rapport et eu advis et deliberacion ensemble sur ceste matiere pour complaire a mondit seigneur le souverain et pour le bien et avancement d'icelle accorderent et consentirent que moyenant que cellui par cui mondit seigneur feroit faire ladite translacion feist preallablement le serment solemnel en sa main en leur presence et d'autres freres de l'ordre qui lors se y trouveroient, de tenir secret le contenu desdites instructions et ce qu'il sauroit des affaires secrets dudit ordre, sans le relever a nul, il en pourroit apres faire ladite translacion. Ce que le graffier a depuis rapporté a mondit seigneur le souverain qui en a esté bien content.

\section{September 1478 in Brüssel}

[199] [Johann Keller schwört, über alles, was im Zusammenhang mit dem Orden steht, gegenüber Nichtordensangehörigen zu schweigen.]

Comment a la requeste de mondit seigneur le souverain fut ottroyé que mondit seigneur feist translater en alemant lesdis instructions par Johannem Kelner, son varlet de chambre, soubz serment etc. ${ }^{7}$

Le $x{ }^{e}$ jour dudit mois de september oudit an lxxviij, ${ }^{8}$ estans devers mondit seigneur le souverain assamblez audit Brouxelles en sa grant chambre pres du palle ${ }^{9}$ messeig-

(ca. 1435-1489), der bei Ks. Friedrich III. als dessen Rat und Fiskalprokurator diente und auch als ksl. Gesandter an den burgundisch-habsburgischen Heiratsverhandlungen beteiligt war. An 15. April 1478 stellte Ks. Friedrich III. eine Kredenz für Johann Keller für dessen Reise zu Hz. Maxinilian aus (CHMEL, Aktenstücke, 1, 1854, S. 395 f., Nr. 87). Dort diente er ihm als Rat, der durch seine starke antifranzösiche Haltung großen Einfluß hatte. Ab 1483 hielt er sich wieder vermehrt am ksl. Hof auf, wo er sich für die burgund. Belange einsetzte. Zu seiner Person vgl. u. a. MAdER, Johann Keller, 1991; Heinig, Friedrich III., 1997, S. 123-134; Eнm, Burgund, 2002, S. 144.

6 10. Sept. 1478.

7 Ms.: Vor dieser Überschrift steht ein $c /$ für capitulum.

8 25. Sept. 1478.

9 Zur hzl. Residenz Palais Coudenberg vgl. in § 13 mit Anm. 75. 
neurs Loys, seigneur de Gruithuse $\{61\}$, Engelbert, conte de Nassouwe $\{77\}$, Pierre, conte de Saintpol $\{83\}$, Wolffart, seigneur de la Vere $\{79\}$, monseigneur Jaques de Savoye $\{84\}$, conte de Romont, et Phelippe de Bourgoingne, seigneur de Bevre $\{82\}$, tous chevaliers freres et compaingnons [fol. 56v/28v] du noble ordre de la Thoison d'or, fut illec appellé et fait venir du commandement de mondit seigneur en leur presence Johannes Kelner, varlet de chambre et ung des sommeliers de corps d'icellui seigneur. Et lui venu remonstra et dit mondit seigneur que par ledit Johannes il feroit volentiers translater lesdites instructions, ordonnees pour l'ambassade que s'envoieroit devers l'empereur $\{94\}$, son pere, comme par le graffier de l'ordre le leur avoit fait dire et l'avoit mandé, afin qu'il feist le serment, comme il fist solemnellement en la main de mondit seigneur devant eulx tous de tenir secret le contenu desdites instructions que le graffier lui bailleroit ensemble tout ce qu'il sauroit du secret de l'ordre de la Thoison d'or, sans le reveler ou dire a personne vivant qui ne fust du serment dudit ordre, ainsi le jura il sur la foy et leaulté et sur sa part du paradix en la main de mondit seigneur comme dessus.

\section{[200] [Steenberch übergibt ihm die zu übersetzenden Instruktionen.]}

Apres lequel serment ainsi fait par ledit Johannem Kelner le graffier de l'ordre a baillié a mondit seigneur le souverain lesdites instructions en sa main closes $<\mathrm{d}>$ et seelees de son signet. ${ }^{10}$

[201] [Der burgundische Gesandte Guillaume de la Baume, Herr von Irlain, soll bei seiner geplanten Gesandtschaft nach England, nach den Gründen forschen, weshalb Kg. Eduard nicht mehr die Kette des Ordens trägt.]

\section{Touchant le roy d'Angleterre ${ }^{11}$}

En ce conseil a esté parlé et devisé du fait de la Garretiere, ordre du roy d'Angleterre ${ }^{12}$, a cause que le roy d'Angleterre $\{63\}$, comme l'on disoit, avoit delaissié puis aucun temps de porter le collier de l'ordre de la Thoison d'or et que monseigneur d'Yrlain $\{90\}^{13}$ estoit ordonné pour aler devers lui en Angleterre faire certaine ambaxade. ${ }^{14} \mathrm{Et}$ apres

10 Vgl. Reg. 71. - Fortsetzung in $§ 203$.

11 Ms.: Diese Zwischenüberschrift steht am linken Rand zu Beginn des folgenden Absatzes und ist links und rechts mit Klammern versehen.

12 Zur Geschichte des engl. Hosenbandordens vgl. u. a. Boulton, Knights of the crown, 1987, S. 96-166; Jones, Hosenbandorden, 1991; Order of the Garter, 1999.

13 Guillaume de la Baume, Herr von Irlain († 1497/98) war seit 1472 erster Kammerherr bei Margarete von York, Hz.in von Burgund, und 1477 war er für die Leitung ihres Haushaltes und ihre Sicherheit zuständig. Im Frühjahr 1477 setzte er sich für die Heirat zwischen Hz. Maximilian und Hz.in Maria ein und war einer der burgund. Räte, die den Ehevertrag der beiden mit unterschrieben. In den folgenden Jahren diente Guillaume bei dem Herzogspaar als deren Rat und Kammerherr und wurde immer wieder für diplomatische Gesandtschaften beauftragt. 1481 wurde er in den Orden vom Goldenen Vlies aufgenommen. Zu seiner Person vgl. u. a. Chevaliers de la Toison d'or, 1986, S. 213-216, Nr. 90; Cools, Mannen, 2000, S. 236 f., Nr. 007; RApp Buri/StuckySCHÜRRER, Tapisserien, 2001, S. 71-74.

14 Im Oktober 1478 wurde Guillaume de la Baume von Hz. Maximilian und Hz.in Maria in geheimer Mission nach England gesandt. Dafür wurden beim Brügger Händler Philippe Sellier fünf Tapisserien erworben, die er den Kämmerer Kg. Eduards schenken sollte; vgl. RAPp BURI/STUCKY-SchürRER, Tapisserien, 2001, S. 73. Vermutlich sollte für 
pluseurs devises eues sur ceste matiere, fut deliberé par mesdis seigneurs qu'il seroit ordonné audit monseigneur d'Yrlain que quant il se trouveroit en Angleterre devers le roy et verroit que le roy ne porteroit ledit collier, ${ }^{15}$ ile ${ }^{16}$ de soy mesmes par maniere de devises pouroit dire «Ha Sire, je voy maintenant et apparroy que ce que pardela devers madame, vostre seur et ailleurs, ${ }^{17}$ l'on dit soit vray.» Et le roy ce oyant vraissemblablement lui demanderoit quoy, sur ce pourroit lors respondre et dire ledit seigneur d'Yrlain «Sire, que vous ne portez point le collier de l'ordre de la Thoison d'or, comme vous aviez accoustumé.» Et par telle maniere de devises il pourroit entrer et sentir et savoir l'intencion du roy d'Angleterre et parvenir a la cause qui le ${ }^{18}$ mouveroit a non le porter. ${ }^{19}$ Et se ledit seigneur d'Irlain sentoit du roy qu'il le laissast a cause que mondit seigneur le souverain n'est point de son ordre de la Garretiere, comme estoit feu monseigneur le duc Charles $\{34\}$ en son vivant, et appartenoit que le roy d'Angleterre eust affection et desir que mondit seigneur fust pareillement de son ordre de ladite Garretiere, ${ }^{20}$ ou s'il y a aultres causes parquoy il ne porté ledit collier

eine Bestätigung der burgundisch-englischen Allianz zu geworben werden; vgl. dazu die dementsprechende Empfehlung der Ordensritter in § 187. Schon am 12. Juli 1478 hatten Hz. Maximilian und Hz.in Maria einem burgundisch-englischen Handelsvertrag zugestimmt, der am 8. September auch von Kg. Eduard ratifiziert wurde; vgl. dazu Regesten Friedrichs III., Suppl. 1, 2008, S. 61f., Nr. 39. In der Folgezeit bemühte sich Hz. Maximilian weiter um Kg. Eduard als Bündnispartner und konnte im Juli 1479 ein Heiratsbündnis ihrer Kinder und im Juli 1480 ein gegenseitiges Bündnis zur Waffenhilfe erreichen; vgl. dazu Wiesflecker, Maximilian, 1, 1971, S. 138f.; Trenkler, Maximilian und England, 1973, S. 18-32.

$15 \S 3$ der Statuten (dazu S. 16, Anm. 14) regelt neben dem Aussehen der Ordenskette auch die Pflicht der Mitglieder, die Kette ständig gut sichtbar zu tragen, widrigenfalls mussten 8 sous bezahlt werden, jeweils vier zur Lesung einer Messe und vier für Almosen. Von der Tragepflicht waren die Mitglieder nur während einer nötigen Reparatur der Kette befreit. Bei Krankheit, bei einem Waffengang, auf weiten Reisen und bei Situationen, die den Träger in Gefahr bringen könnten, waren es ihnen erlaubt, statt der Goldkette nur das Ordenzeichen zu tragen. 1473 bemühten sich die Mitglieder vergeblich, eine Lockerung der Tragepflicht zu erwirken; vgl. dazu PB 3, S. 19 (mit Verweis auf die entsprechenden Stellen in der Edition). Zur Tragepflicht vgl. auch Docouier, Collier, 2008, S. 128-131; dieser Beitrag bietet zudem einen guten Überblick über die schriftlichen und bildlichen Quellen zur Ordenskette aus der burgundischen Zeit des Ordens.

16 Lies: $\mathrm{Il}$.

17 Zur Person Margaretes von York, der Schwester Kg. Eduards IV. und Witwe Hz. Karls \{34\}, vgl. die Angaben in $\S 5$, Anm. 16.

18 Ms.: le steht über der Zeile und ein Marke zeigt auf die dafür vorgesehene Stelle im Text.

$19 \mathrm{Zu} \mathrm{Kg}$. Eduards mangelnder Bereitschaft die Vlies-Ordenskette zu tragen vgl. auch § 268 und sowie Armstrong, Échange culturel, ${ }^{2} 1983$, S. 414; DünNeBeIl, Burgund und Österreich, 2006, S. 22; Docouier, Collier, 2008, S. 129, Anm. 16; DünnebeiL, Zeichen, 2012, S. 120 f.

20 Ende des Jahres 1469 akzeptierte Kg. Eduard IV. seine Aufnahme in den Orden vom Goldenen Vlies und kurz darauf trat Hz. Karl dem englischen Hosenbandorden bei; vgl. dazu Paravicini, Magnificences, 2001, S. 364-366; PB 2, S. 25 f. (mit Verweis auf die entsprechenden Stellen in der Edition). Maximilian wurde 1490 in den Hosenbandorden gewählt, seine tatsächliche Aufnahme erfolgte aber erst 1502; vgl. dazu u. a. Order of the Garter, 1999, S. 232, Nr. 3 sowie die Abb. auf S. 203 und 233; Wiesflecker, Maximilian, 1, 1971, S. 325; Regesten Maximilian, Nr. 14.828, 17.200, 19.821, 19.927, 20.083, 20.265a, 20.266a und 20.270a. 
de la Thoison d'or ledit seigneur d'Irlain feroit de tout rapport a mondit seigneur et a ceulx de l'ordre qui devers lui seroient a son retour, pour apres lui ouy avoir sur tout plus ample advis et deliberacion.

[202] [Hz. Maximilian bittet Steenberch um eine lateinische Übersetzung der in Französisch abgefassten Statuten des englischen Hosenbandordens.]

Et afin que mondit seigneur le souverain ce pendant se peust informer du fait des status et ordonnances dudit ordre de la Garretiere, fut ordonné deslors audit graffier de translater du francois en latin lesdis status de l'ordre de ladite Garretiere. Et d'en baillier la translacion a mondit seigneur pour les estudier et incorperer a son bon loisir. Ce que ledit graffier a ainsi fait bien brief apres. ${ }^{21}$

[203] [Die Diskussion über die nach Deutschland zu entsendende Gesandtschaft wird aufgrund der Abwesenheit des Ordenskanzlers verschoben.]

Des ambassades pour aler en Alemaingne ${ }^{22}$

Item oudit conseil a aussi esté parlé du fait des ambassades a envoier es Allemaingnes devers les princes nouvellement esleus a l'ordre ${ }^{23}$ et [fol. 57r/29r] qu'il sembloit bon a messeigneurs que lesdis ambassades fussent expediees et envoiees le plus brief que faire se pourroit bonn(ement). Toutevoie la chose demoura encores suspendue et mise en delay pour celle fois, tant pour l'absence de monseigneur l'evesque de Tournay, chancellier de l'ordre, lors estant occupez en l'ambassade de mondit seigneur avec aultres a Cambray pour le fait de France, car aussi pour autres occupacions de mondit seigneur pour l'eure. ${ }^{24}$

\section{[204] [Das neue Mitglied Wolfart van Borsele bedankt sich für seine Wahl.] Touchant monseigneur de la Vere ${ }^{25}$}

Ces choses ainsi faites, s'est illec mis a genoulx devant mondit seigneur le souverain moult humblement et reverenment messire Wolffard de Borsele $\{79\}$, seigneur de la Vere, conte de Grantpré, ung des freres de l'ordre dessusnommez, et a remercié treshumblement mondit seigneur le souverain et tous messeigneurs les chevaliers freres et compaingnons dudit ordre, <qui la estoient> du grant honneur qu'ilz lui avoient fait et demonstré, quant en leur darrenier chappittre, tenu a Bruges ${ }^{26} \mathrm{ilz}$ l'avoient esleu pour frere et accompaingnié avec eulx audit ordre. Dont il se repputoit moult honnoré et grandement obligié et tenu a eulx et a icellui ordre ce qu'il ne attribuoit pas a ses merites, mais a leur vertu et a la benigne estimacion qu'ilz avoient faite et eue de lui. Disant que au plaisir Nostre Seigneur tellement il se porteroit et conduiroit doresenavant envers mondit seigneur et eulx et oudit ordre que eulx et tous autres d'icellui ordre auroient cause d'en estre de lui contens. Surquoy mondit seigneur, apres petite deliberacion sur ce eue avec mesdis seigneurs ses freres, fist

21 Fortsetzung in $\S 233$.

22 Ms.: Diese Zwischenüberschrift steht am linken Rand zu Beginn des folgenden Absatzes und ist links und rechts mit Klammern versehen.

23 Gemeint sind damit Kaiser Friedrich III. \{94\}, Matthias Corvinus, Kg. von Ungarn, und Albert, Hz. von Sachsen \{96\}. - Fortsetzung von § 200.

24 Fortsetzung in $\S 207$.

25 Ms.: Diese Zwischenüberschrift steht vor dem folgenden Absatz.

$26 \mathrm{Zu}$ seiner Wahl und Aufnahme vgl. § 138 und 154. 
tantost dire et respondre audit seigneur de la Vere, que ce qu'ilz en avoient fait estoit pour les grans biens qu'ilz avoient entenduz et aussi cogneuz en lui <eulx confians> et l'avoient fait tresvolentiers, eulx confians et sur vray espoir de ses vertus et qu'il y parseveroit profitant de bien en mieulx a son bien et honneur et dudit ordre.

\section{[205] [Wolfart van Borsele bittet den Orden, in seiner Auseinandersetzung mit fan van Wassenaar um Unterstützung.]}

Apres ce a remonstré ledit seigneur de la Vere $\{79\}$ a mondit seigneur le souverain et a messeigneurs ses confreres de l'ordre, comment il avoit entendu et sceu que aucuns ses hayneux et non bien vueillans avoient sevie et rapporté en darriere lui pluseurs langaiges a sa charge contre verité et sans sa deffene, saulf l'onneur de mondit seigneur et d'eulx. Surquoy nagaires paravant mondit seigneur estant lors en sa ville de Gand, ${ }^{27}$ il avoit devant lui respondu a son honneur et pour son excuse par telle maniere que mondit seigneur s'estoit lors de lui contenté. Et que neantmoins il estoit adverti que le seigneur de Wassenar ${ }^{28}$ et aultres ses hayneulx encores ne cessoient de le chargier en darriere lui ce que moult il regrettoit. Suppliant pour ce a mondit seigneur le souverain treshumblement qu'il ne voulsisit adjouster foy a telz sinistre rapports, ${ }^{29}$ mais, attendu et consideré qu'il estoit frere et compaingnon de son noble ordre, son plaisir fust de le garder et maintenir en son bon droit et honneur. ${ }^{30}$ Soy submettant ledit seigneur de la Vere en mondit seigneur le souverain et en l'ordre pour y respondre a son honneur et descharge alencontre de tous qui charger le vouldroient. Et s'il estoit trouvé coulpable desdites charges, ce que au plaisir Dieu par verité jamais ne seroit, que en ce cas mondit seigneur et l'ordre feissent de lui comme d'un malfacteur, car il n'en demanderoit ja grace ne pardon. Pria aussi et requist ledit seigneur de la Vere a mesdis seigneurs les chevaliers, ses freres de l'ordre illec presens, qu'ilz le voulsissent ayder a conseiller et lui assister pour la deffense et conservacion de son honneur comme leur frere oudit ordre. Surquoy mondit seigneur le souverain fist respondre audit seigneur le da Vere, qu'il estoit bien souvenant des remonstrances et requestes, que en ceste partie aultrefois il lui avoit faites a Gand ensemble de la response que illec il lui avoit faite. Laquelle ensuivant il lui feroit bonne justice, et pour le bien et conservacion de son honneur mondit seigneur

27 Lt. VAnder Linden, Itinéraires, 1934, S. 40 f., hielt Hz. Maximilian sich zwischen dem 26. Aug. und 3. Sept. 1478 hauptsächlich in Gent auf.

28 Jan I. van Wassenaar, Burggf. von Leiden (1427-1496) diente unter Hz. Karl, Hz.in Maria und Hz. Maximilian als Rat und Kammerherr; vgl. Cools, Mannen, 2000, S. 411 f., Nr. 259. 1481 wurde er als einer der möglichen Kandidaten für den Orden vom Goldenen Vlies genannt; vgl. PB 5, fol. 39v.

29 Im Frühjahr 1477 übernahm Wolfart van Borsele von seinem Schwager Ludwig von Brügge $\{61\}$ das Amt des Gouverneurs von Holland und Seeland. Während seine Ernennung bei der holländischen Adelspartei der Hoeken Zustimmung fand, wurde er von der Gegenpartei den Kabeljauwen abgelehnt. Deren prominentester Verbündeter, Jan van Wassenaar, startete darauf eine langwierige Hetzkampagne gegen Wolfart und unterstellte diesem heimliche Verhandlungen mit dem frz. König Ludwig XI.; vgl. dazu u. a. Gent, Saken, 1994, S. 207-211; Cools, Mannen, 2000, S. 243; BraAke, Parties, 2009, S. 103 f. Nach Cools, Mannen, 2000, S. 412 stritten sich Wolfart van Borsele und Jan van Wassenaar zu dieser Zeit auch um die Eigentumsrechte an den südholländischen Dünen.

30 Zum Gebot der gegenseitigen Freundschaft und Hilfe vgl. die Angaben in § 164 mit Anm. 237; zur Ordensschiedsgerichtsbarkeit in der Einleitung S. $31 \mathrm{f}$. 
et lesdis chevaliers, ses freres de l'ordre, lui feroient voulentiers toute l'assistence que bonnement et par raison faire pourroient ainsi que par et selon les status dudit ordre il appartendroit. De [fol. 57v/29v] laquelle response tant benigne ledit seigneur de la Vere moult se contenta et en rendit treshumbles graces a mondit seigneur le souverain et a messeigneurs lesdis freres chevaliers de l'ordre qui la presens estoient. ${ }^{31}$

\section{Oktober 1478 in Brüssel}

[206] [In Brüssel versammeln sich zahlreiche Ordensmitglieder, um einige Ordensangelegenheiten zu besprechen.]

Le ix ${ }^{\mathrm{e}}$ jour du mois d'octobre oudit an $\mathrm{lxxviij}^{32}$ mondit tresredoubté seigneur monseigneur le duc Maximilian, chief et souverain du noble ordre de la Thoison d'or, estant encore en sadite ville de Brouxelles, furent illec assamblez et appellez devers lui en la petite chambre de monseigneur le conte de Chimay $\{74\}$, son premier chambellan, messeigneurs Adolph de Cleves $\{55\}$, seigneur de Ravestein, Loys, seigneur de Gruythuse $\{61\}$, Phelippe <seigneur > de Croy, conte de Chimay, Engelbert, conte de Nassouwe $\{77\}$, Wolffart, seigneur de la Vere $\{79\}$, Phelippe de Bourgoingne $\{82\}$, seigneur de Bevre, et Bartremy, seigneur de Lichtestain $\{85\}$, tous chevaliers freres et compaingnons dudit ordre; monseigneur Jaques de Savoye $\{84\}$, conte de Romont, aussi chevalier confrere, excusé pour certains autres affaires que pour lors il avoit en ladite ville. Et avec eulx y estoient maistre Jehan Gros, tresorier, maistre Martin [Steenberch], graffier, et Thoison d'or, le roy d'armes. Reverend pere en Dieu monseigneur l'evesque de Tournay, chancellier d'icellui ordre, pour lors encore occupé et empeschié en ladite ambassade de mondit seigneur avec autres ses collegues audit Cambray. ${ }^{33}$ Et tint illec mondit seigneur le souverain conseil privé et secret avec mesdis seigneurs ses freres sur certains affaires du mesme ordre, cy apres touchiez et declarez:

[207] [Der Souverän wird darauf hingewiesen, dass angesichts des für den kommenden Mai geplanten Festes es an der Zeit ist, die in Deutschland lebenden Neugwählten von ihrer Wahl zu unterrichten. Hz. Maxmilian weist darauf hin, dass Friedrich III. zwar Interesse am Orden habe, die Eidesleistung aber für einen Kaiser rechtlich problematisch sei. Es wird beschlossen, dass Bartholomäus von Liechtenstein zum Kaiser reisen soll, um diesen offiziell von der Wahl zu unterrichten.]

\section{Des ambassades pour Alemaingne ${ }^{34}$}

$[a]^{35}$ Et premierement fut en ce conseil parlé des ambassades a envoier devers les princes d'Allemaingne nouvellement esleuz a l'ordre ${ }^{36}$ pour leur signiffier leur election et a

31 Über den weiteren Verlauf der Angelegenheit schweigt das Protokollbuch.

32 9. Okt. 1478.

33 Vgl. dazu § 203.

34 Ms.: Diese Zwischenüberschrift steht am linken Rand zu Beginn des folgenden Absatzes und ist links und rechts mit einer Klammer versehen.

35 Ms.: Zur besseren Lesbarkeit dieses langen Paragraphen wurden Absätze und Unterpunkte eingefügt.

36 Gemeint sind damit Kaiser Friedrich III. \{94\}, Matthias Corvinus, Kg. von Ungarn, und Albert, Hz. von Sachsen \{96\}. - Fortsetzung von § 203. 
ceste fin adviser et concluire des personnaiges que mondit seigneur y vouldroit envoier ensemble de leurs instructions et povoirs dont les minues ${ }^{37}$ estoient ja pourjectees, faites et veues et ne restoit, fors que les concluire et apres faire grossoier et expedier, mais que mondit seigneur et eulx se fussent determinez des personnaiges et d'aucunes minues circumstances servans au fait de ladite expedicion. Et combien que en loquetant de ces matieres de prime face il samblast a mesdis seigneurs les chevaliers freres expedient et besoing de haster et avancer ladite expedicion, mesmement pour l'onneur de mondit seigneur et de l'ordre, veu qu'il avoit ja long temps passé depuis leurdite election faite et que desja bruyt en avoit esté et estoit, attendu mesmement que mondit seigneur avoit conclut dez son darrenier chappittre dudit ordre, par lui tenu a Bruges ou mois de may passé, de tenir et celebrer la feste et le chappittre d'icellui ordre ou mois de may prouchain ensuivant, ${ }^{38}$ parquoy seroit besoing que lesdis princes esleuz fussent advertis de leurdite election, afin que en cas de leur acceptacion ilz eussent leurs colliers et feissent les sermens et devoirs accoustumez devant ladite feste avenir. ${ }^{39}$ Et que eulx aussi advertis de ladite prouchaine feste a terme et temps competens y peussent envoier leurs procuracions <et cedules> pour suppleer et tenir leurs lieux tant en l'eglise comme en chappittre, avec leurs cedules pour la future election, et que les tableaux de leurs armes peussent aussi estre fais et preses a temps deu pour les mettre en l'eglise quant et avec les aultres en l'eglise la ou le divin service accoustumé se devroit faire ainsi que selon les status et ceremonies dudit ordre il est accoustumé en tel cas et faire se doit. Ou en cas de leur reffus ou d'aucun d'eulx, mondit seigneur et les chevaliers freres de l'ordre estre oudit prouchain chappittre de l'ordre advertis dudit reffus quant [fol. 58r/30r] ilz vouldront proceder a leur election nouvelle, pour et afin de remplir lors les lieux qui leur estoient destinez oudit ordre,$^{40}$ et $<$ les $>$ oudit cas y choisir et eslire autres ydoines, comme il appartient selon lesdis status d'icellui ordre. Autrement les lieux desdis esleuz demourroient encore vuys et vacans et ladite prouchaine feste, car l'on n'y pourroit pourveoir bonnement par ladite nouvelle election que mondit seigneur le souverain et l'ordre preallablement ne fussent acertenez dudit reffus.

[b] Ces choses oyes et entendues par mondit seigneur le souverain il interrogua et demanda, se l'expedicion et envoy desdis ambassades se pourroit encore delayer pour aucun brief temps, et la cause qui le mouvoit a ce demander, comme il disoit, estoit par ce qu'il estoit adverti que l'empereur $\{94\}$, son pere, estoit pour lors en marches bien longtaines et de difficile acces, mais esperoit que briefment il descenderoit devers les marches de l'Empire plus prouchaines de pardeça, ${ }^{41}$ la ou il esperoit povoir encore assez temps $<$ povoir > envoier de ses gens devers lui pour ceste matiere et pour aultres ses affaires, et mesmement dit qu'il y envoieront ledit messire Bertremy, seigneur de Lichtestain $\{85\}$.

[c] Oultre plus dit mondit seigneur le souverain qu'il estoit adverti que l'empereur, sondit pere, portoit bonne affection et faveur a l'ordre et se continteroit assez de le recevoir. Mais sa difficulté principale seroit sur la maniere de jurer les sermens d'icellui ordre, pour ce que selon les statuts du mesme ordre le jurement se faisoit et fait

37 Vgl. Reg. 71.

38 Vgl. § 171.

39 Vgl. die Angaben zum Aufnahmeverfahren in Anm. 222.

$40 \S 86$ (neu § 60) der Statuten (dazu S. 16, Anm. 14) regelt die Vorgehensweise bei Ablehnung einer Mitgliedschaft.

41 Nach HeInIg, Friedrich III., 1997, S. 1381f., hielt sich Ks. Friedrich III. sowohl 1478 als auch 1479 hauptsächlich in Graz auf. 
manuellement par attouchement de la sainte croix ou d'aultres chose sainte. ${ }^{42}$ Ce que l'empereur comme mondit seigneur entendoit bonnement ne pourroit faire, <comme il disoit> a cause de sa souveraine couronne imperial, pour honneur et reverence de laquelle il n'avoit jamais depuis fait quelque serment manuel et ne lui seroit pas bonnement loisible de le faire manuellement. Mais par ses lettres il feroit pour la seurté dudit ordre tous sermens et promesses honnestes et raisonnes, demandant pour ce mondit seigneur se pour la personne dudit empereur moderacion s'en pourroit faire.

[d] Sur ces remonstrances et demandes de mondit seigneur le souverain ont mesdis seigneurs les chevaliers freres de l'ordre opiné et deliberé en la presence et par l'ordonnance de mondit seigneur. Et apres vision et lecture d'aucuns articles du livres des status et ordonnances dudit ordre, touchant la forme dudit serment et la maniere de le faire ${ }^{43}$ avec certains autres servans a ce propos leur advis a esté:

[e] Premierement quant au fait dudit delay qu'ilz s'en rapportoient a mondit seigneur et a son bon plaisir, combien qu'il leur semblast chose bien honneste que l'empereur et les aultres esleuz fussent advertis de leurdite election le plus brief que faire se pourroit. Car mesdis seigneurs les freres n'avoient veu ne sceu que tant longuement eust delayé en cas semblabe de faire faire aux princes ou aultres esleuz a l'ordre la significacion de leur election. Mais tousjours on l'avoit avancee pour en savoir l'intencion des esleuz fust de l'accepter ou reffuser.

[f] Et touchant ladite moderation: Attendu le contenu desdis articles des status et ordonnances de l'ordre que illec ilz avoient ouy lire, lesquelz ne sont point muables selon la conclusion dudit livre leur a samblé ceste matiere bien difficile et que bonnement moderacion aucune ne s'en pourroit faire. Et quant a eulx, consideré leurs sermens et que ladite matiere touche tous les freres de l'ordre, tant absens comme presens, qu'ilz n'y vouldroient faire changement moderacion ou mutacion aucune sans les <ser> absens et que preallablement ilz n'en fussent advertis pour en avoir leur advis et consentement, aussi ne se devroit faire ladite moderacion hors du chappittre de l'ordre.

[g] Mais se le plaisir de mondit seigneur estoit de faire advertir secretement l'empereur, son pere, de son election par ledit messire Bertremy, seigneur de Lichtestein, confrere de [fol. 58v/30v] l'ordre, faire le pourroit par bonne maniere pour ${ }^{44}$ et sentir en savoir son intencion et bon plaisir, dont icellui de Lichtestain hastivement pourroit faire advertir mondit seigneur et ceulx de l'ordre par les lettres qu'il escriroit de sa main et dilegenment renvoieroit par feable et seur messaige. Et en cas que l'empereur accepteroit son election et consentiroit de faire a l'ordre les sermens accoustumez manuellement selon la forme desdis status dudit ordre, oudit cas mondit seigneur, de ce adverti, envoieroit tantost aucuns aultres dudit ordre apres ledit messire Bertremy pour eulx joindre avec lui recevoir dudit empereur ledit serment et lui baillier le collier d'icellui ordre aux ceremonies et en la maniere qu'il appartient selon lesdis status. Ou se ledit messire Bertremy trouvoit aucunes difficultez devers l'empereur touchans aucuns poins ou articles desdis status et ordonnances de l'ordre, dont l'empereur demandast avoir moderacion, oudit cas icellui messire Bertremy le signiffieroit aussi secretement et diligenment a mondit seigneur et a ceulx de l'ordre, pour en parler ou prouchain chappittre dudit ordre. Et se l'empereur s'excusoit d'en faire ladite acceptacion pareillement le signiffieroit secretement ledit

42 Zum Schwurverbot für Könige und Kaiser vgl. in der Einleitung S. 29f. mit Anm. 86.

43 Vgl. die Angaben zum Aufnahmeverfahren und -eid in Anm. 222.

44 Ms.: maniere pour steht über der Zeile und eine Marke zeigt auf die dafür vorgesehene Stelle im Text. 
seigneur de Lichtestain a mondit seigneur et a ceulx de l'ordre, ensemble ${ }^{45}$ les raisons et motifs que l'empereur lui auroit alleguez ou declairez pour son excuse, pour mondit seigneur et eulx en estre advertis plainement oudit futur prouchain chappittre.

[h] Mais ledit messire Bertremy, seigneur de Lichtestein, ne reveleroit ou descouvreroit riens a l'empereur de l'election des aultres princes, assavoir du roy de Honguerie et du duc Albert de Saxe $\{96\}$ jusques a tant qu'il auroit ${ }^{46}$ fait le serment audit ordre. Et sur ces choses seroit bailliee audit messire Bertremy une petite instruction par forme de memoire, ${ }^{47}$ selon laquelle il se pourroit gouverner et conduire en ceste matiere. ${ }^{48}$ De laquelle deliberacion de mesdis seigneurs les chevaliers freres mondit seigneur le souverain a esté content, l'a eu pour aggreable et a conclut selon icelle. ${ }^{49}$

[s] Nota touchant le serment de l'empereur. ${ }^{50}$

\section{[208] [Das nächste Fest soll im kommenden Mai in Brüssel stattfinden.] \\ Conclusion de tenir et signifier la feste de l'ordre au second jour de may l'an lxxix ${ }^{51}$}

Apres a esté mis en deliberacion oudit conseil par l'ordonnance et commandement de mondit seigneur le souverain s'il tendroit la feste et le chappittre de son ordre ou mois de may lors pourchain avenir selon la conclusion du chappittre darrenier precedent, ensemble du lieu ouquel tenir les devroit. ${ }^{52}$ Et sur ce demandees et ouyes les opinions de mesdis seigneurs les chevaliers freres mondit seigneur a conclut avec la pluralité des voix qui estoit qu'il devoit tenir lesdites feste et chappittre ou mois de may prouchain avenir. Et quant au lieu il s'est determiné pour la ville de Brouxelles pour certaines consideracions a ce le mouvans et par lui alleguees.

\section{[209] [Steenberch wird mit der Ausstellung zahlreicher Schriftstücke beauftragt.] \\ Touchant l'expedicion des lettres de ladite significacion Pour les v chevaliers estans en France ${ }^{53}$}

\section{Touchant monseigneur de Cleves $^{54}$}

Cestedite conclusion ainsi prinse, mondit seigneur le souverain a ordonné et commandé audit graffier en la presence et du consentement de mesdis seigneurs ses freres de l'ordre de faire et expedier les lettres de la signifficacion et indiction desdites feste et

45 Ms.: ensamble steht über einer Radierung und füllt den dadurch geschaffen Raum nicht ganz aus.

46 Ms.: Das ursprüngliche aura wurde in auroit verbessert.

47 Vgl. Reg. 92.

48 Diese Reise von Bartholomäus erwähnt (ohne Details) PfeIfer, Liechtensteiner, 1998, S. 88.

49 Fortsetzung in $\S 234$.

50 Ms.: Diese Randbemerkung steht am linken Rand bei der Zeile, die beginnt mit <il disoit $>$ a cause de sa souveraine couronne imperial.

51 Ms.: Diese Zwischenüberschrift steht am linken Rand zu Beginn des folgenden Absatzes und ist links und rechts mit einer Klammer versehen.

52 Vgl. § 171 und 192.

53 Fortsetzung von $\S 122$.

54 Ms.: Diese drei unterstrichenen Zwischenüberschriften stehen untereinander am linken Rand zu Beginn des folgenden Absatzes. 
chappittre pour ledit prouchain mois de may en la forme qu'il appartient; ${ }^{.5}$ et mesmement les placquars pour les chinq chevaliers estans en France. ${ }^{56}$ Et pour monseigneur le duc de Cleves $\{47\}$ lettres closes, declarant comment mondit seigneur le souverain et les freres chevaliers de l'ordre ont esté de lui moult esmerveillez, a cause qu'il n'est venu ne a envoyé procuracion, cedule ne excuse ou chappittre de l'ordre darrain passé tenu a Bruges, ${ }^{57}$ et qu'il en a esté noté oudit chappittre pour et afin que personnellement il vienne et compare oudit prouchain chappittre, mesmement pour y respondre [fol. 59r/31r] sur ce dont oudit darrain chappittre il a esté noté o intimacion etc. ${ }^{58}$ Esté aussi advisé et conclut que mesdis seigneurs les chevaliers freres de l'ordre a part lui en escriproient soubz le seel dudit ordre, ainsi comme aultrefois par la deliberacion et conclusion du penultime chappittre d'icellui ordre, tenu a Valenchiennes, il avoit esté escript a monseigneur Phelippe de Savoye $\{68\}$, conte de Baugey, seigneur de Bresse. ${ }^{59}$ Et que Thoison d'or, le roy d'armes, porteroit ces lettres a mondit seigneur de Cleves sans avoir aultre charge de bouche.

[210] [Philippe von Croy berichtet, dass Philippe, Herr von Croy und Gf. von Porcien, fälschlich darüber unterrichtet worden ist, in den Orden gewählt zu sein. Dieser soll dazu befragt werden, wer ihm das mitgeteilt hat.]

\section{Touchant monseigneur de Chimay et monseigneur de Croy ${ }^{60}$}

Et finablement s'est levé de son siege et mis a genoulx reverenment devant mondit seigneur le souverain messire Phelippe de Croy $\{74\}$, conte de Chimay dessusnommé, et humblement a remonstré a mondit seigneur le souverain et a messeigneurs les chevaliers, ses confreres de l'ordre illec presens, qu'il avoit entendu et estoit adverti de vray que monseigneur de $\mathrm{Croy}^{61}$ avoit dit par pluseurs fois et devant gens notables dignes de foy par maniere de doleance et regret que a cause ou par le fait de lui, remonstrant il n'avoit esté esleu a l'ordre ou darrenier chappittre dudit ordre, tenu a Bruges, ${ }^{62}$ et qu'il l'avoit sceu par chevalier de l'ordre qui le lui avoit dit. De laquelle chose mondit seigneur de Chimay moult esmerveillié advertissoit mondit seigneur le souverain et messeigneurs les chevaliers, ses confreres de l'ordre, pour ce, comme il disoit, que la chose a son advis leur touchoit grandement et a l'onneur dudit ordre et trop plus que a lui ne faisoit, veu mesmement que mondit seigneur de Croy se vantoit par ses paroles que chevalier de l'ordre le lui avoit dit, ce qui ne faisoit a croire ne n'estoit vraissemblable, car oudit darrenier chappittre aux elections faire n'avoit eu

55 Vgl. Reg. 83-91. - Fortsetzung in § 223.

56 Der Beschluss, dass die in Frankreich weilenden Mitglieder Philippe Pot \{60\}, Philippe de Crèvecour $\{69\}$, Jacques de Luxembourg $\{67\}$, Jean de Damas $\{65\}$ und Anton, Bastard von Burgund \{54\}, separate Vorladungen erhalten sollen, wurde schon in $\S 122$ gefasst. - Vgl. dazu auch Reg. 75-78 sowie die Fortsetzung in $§ 225$.

57 Fortsetzung von $\S 171$. - Den in diesem Absatz Johann von Kleve betreffenden Teil ist in freier Wiedergabe auch in AOGV, Codex 45, fol. 63v zu lesen.

58 Vgl. Reg. 83 und 89 f. sowie die Fortsetzung in § 221.

59 Vgl. dazu Reg. 82 sowie die Fortsetzung in § 226.

60 Ms.: Diese Zwischenüberschrift steht vor dem folgenden Absatz. Sie ist unterstrichen und davor steht ein $c$ für capitulum.

61 Zur Person Philipps von Croy vgl. § 75 mit Anm. 20.

62 Die neugewählten Mitglieder sind in $§ 154$ genannt. 
que eulx cinq chevaliers, ${ }^{63}$ saulf mondit seigneur le souverain, comme il estoit chose notoire; requerant que pour l'onneur de l'ordre et de ceulx qui avoient esté oudit darrenier chappittre le plaisir de mondit seigneur fust de faire interroguer mondit seigneur de Croy sur ces paroles et du chevalier ou aultre qui telle chose lui auroit dite. ${ }^{64}$ Car quant a lui, remonstrant, saulve la reverence de chascun il n'avoit besoing d'en faire excuse, mais s'en rapportoit de la verité toute contraire a ce que mondit seigneur et tous ceulx de l'ordre qui avoient esté presens oudit darrenier chappittre en avoient de lui veu et ouy et ne povoit croire que aultre en sceust a parler. Oyes lesquelles remonstrances de mondit seigneur de Chimay, monseigneur le souverain par l'advis et deliberacion de messeigneurs les aultres chevaliers, confreres de l'ordre dessusnommez illec presens, comme dit est, a ordonné que par deux officiers dudit ordre ledit seigneur de Croy soit et sera interrogué desdites paroles pour savoir de lui, s'il les aura ainsi dites, ensemble du chevalier de l'ordre ou aultre qui lui aura dit et donné entendre telle chose, pour par lesdis officiers rapporter a mondit seigneur sa response et ce que de lui ouy et entendu auront en ceste partie. Et furent deslors depputez a ce par mondit seigneur le graffier et le roy d'armes de l'ordre, pour en faire leur devoir quant mondit seigneur de Croy seroit retourné audit Brouxelles, dont pour l'heure il estoit absent. ${ }^{65}$

[s] Il que appartenant nouveau q(ue) seullem(ent) aucun chevalier avec le chief et souverain avoit fait elections. ${ }^{66}$

\title{
30. November 1478 in Brüssel
}

\author{
[fol. 59v/31v]
}

[211] [Hz. Maximilian besucht in Brüssel mit großem Gefolge die Messe zu Ehren des Apostels St. Andreas.]

\section{Ceremonies du jour saint Andrieu l'an lxxviij ${ }^{67}$}

Le lundi, darrenier jour du mois de novembre l'an mil quatrecens soixante dix huit, ${ }^{68}$ jour solemnel et feste de monseigneur saint Andrieu l'apostre, mon tresredoubté seigneur monseigneur le duc Maximilian, duc d'Austrice, de Bourgoingne et de Brabant etc., chief et souverain du noble ordre de la Thoison d'or, estant en sa ville de Brouxelles, partit a l'eure de dix heures ou environ devant midi de son hostel audit Brouxelles $^{69}$ et alla oyr la grant messe en l'eglise collegial de Sainte Goudele, principale eglise $<$ collegiale $>$ du lieu, ${ }^{70}$ et l'accompaingnerent a cheval messeigneurs les princes,

63 Ms.: n'avoit eu que eulx cinq chevaliers ist unterstrichen.

64 Zum Schweigegebot der Ordensmitglieder vgl. die Angaben in Anm. 4.

65 Vgl. dazu auch in der Einleitung S. 30 sowie die Fortsetzung in $\S 221$.

66 Ms.: Diese Randbemerkung steht am linken Rand und fängt bei der Zeile an, die mit avoit dit, ce qui ne faisoit a croire beginnt.

67 Ms.: Diese Zwischenüberschrift steht in der Kopfzeile von fol. 31v. - Zu diesem Treffen anlässlich des St. Andreas-Tages (30. Nov.) 1478 vgl. in der Einleitung S. 33 f.

68 30. Nov. 1478.

69 Zur hzl. Residenz Palais Coudenberg vgl. in § 13 mit Anm. 75.

70 Zu dieser Kirche u. a. Gruben, Chapitres, 1997, S. 193; vgl. dazu auch die Angaben in $\S 224$. 
ses parens, et autres grans seigneurs, barons, chevaliers et escuiers de son hostel. Et droit devant mondit seigneur ala a cheval l'ambaxadeur du tresexcellent roy de Naples $\{72\}$. Et apres lui furent sans moyen monseigneur le marquis de Bade $\{102\}^{71}$, reverend pere en Dieu messire Ferry de Clugny, evesque de Tournay, chancellier de l'ordre, et monseigneur le conte de Saintpol $\{83\}$, messire Phelippe de Croy $\{74\}$, conte de Chimay, premier chambellan, messire Josse de Lalaing $\{80\}$, seigneur de Montigny, messire Phelippe de Bourgoingne $\{82\}$, seigneur de Bevre, et Jaques de Luxembourg $\{81\}$, seigneur de Fyennes, chevaliers freres et compaingnons, tous portans le grant ${ }^{72}$ collier dudit ordre, accompaingnez honnestement au dextre et au senestre et par darriere de pluseurs notables personnes, tant prelas et aultres gens d'eglise comme de gens nobles et de conseil et d'aultres notables pluseurs qui les su[i]voient.

\section{[212] [Sitzordnung in der Kirche.]}

Et mondit seigneur le souverain ainsi arrivé en ladite eglise de Sainte Goudele, il se ala rendre ou grant chœur d'icelle eglise en son oratoire, illec tendu et preparé au dextre et pres du grant autel ou lieu accustumé. Et messeigneurs les chevaliers freres et compaingnons de l'ordre qui estoient en nombre de chinq, se mirent es haultes formes audit lieu dextre dudit chœur ordonneement, assavoir monseigneur de Chimay $\{74\}$ en la premiere forme, monseigneur de Montigny $\{80\}$ en la seconde, monseigneur le conte de Saintpol $\{83\}$ en la $<$ sec $>$ tierce, monseigneur de Bevre $\{82\}$ en la quarte et monseigneur de Fyennes $\{81\}$ dessusnommez en la cinq ${ }^{\mathrm{e}}$ formes descendant vers west. Et par bas devant mesdis seigneurs les chevaliers confreres se mist Thoison d'or, le roy d'armes dudit ordre, en une basse forme. L'ambassadeur du roy de Naples $\{72\}$ et monseigneur l'evesque de Tournay, chancellier d'icellui ordre, se mirent es haultes formes du lez senestre droit a l'opposite de mesdis seigneurs les chevaliers et le graffier la empres en la tierce forme soubz mondit seigneur le chancellier.

\section{[213] [Hz.in Maria von Burgund nimmt ebenfalls am Gottesdienst teil.]}

Item mesdis seigneurs de l'ordre ainsi colloquez comme dessus, tantost y suivirent ma tresredoubtee dame madame la duchesse grandement et noblement accompaingnee, laquelle se alla rendre oudit oratoire de mondit seigneur <et>.

\section{[fol. 60r/32r]}

\section{[214] [Der Bischof von Dagnum liest die Messe.]}

Item et tantost apres la venue de madite dame la duchesse reverend pere en Dieu l'evesque Dagnensis, ${ }^{73}$ suffragan de monseigneur l'evesque de Cambray, prelat, revestu pour celebrer la grant messe, a porté l'eaue benoite a mesdis seigneurs et dame et incontinent apres s'est encommençee la grant messe a l'onneur de monseigneur saint Andrieu et s'est continué l'office de ladite messe jusques a l'offertoire.

$71 \mathrm{Zu}$ ihm vgl. die Angaben in $§ 10$ mit Anm. 58.

72 Ms.: grant steht über der Zeile und eine Marke zeigt auf die dafür vorgesehene Stelle im Text.

73 Ms.: Dagnensis ist unterstrichen. - Godefroy Greveray hatte seit 1456 das Amt des (Titular-)Bf.s von Dagnum, Suffragan des Bistums Cambrai, inne; zwischen 1460 und 1466 wird er auch mehrfach in den täglichen Gagenabrechnungen des burgund. Hofes genannt; zu seiner Person vgl. Hierarchia catholica, 2, 1900, S. 142 und 274; DB Prosopographia Curiae Burgundicae, ID n 2199. 


\section{[215] [Nach Aufforderung von Toison d'or begibt sich Hz. Maximilian zur offrande zum großen Altar.]}

Item ledit offertoire commençié, Thoison d'or, le roy d'armes, s'est allé presenter reverenment devant mondit seigneur le souverain a l'entree de son oratoire pour le mener devers l'autel y faire son offrande. Et mondit seigneur partant de sondit oratoire, est alé seul apres ledit roy d'armes faire son offrande au prelat devant ledit autel. Et icelle faite, s'est retourné et alé remettre en son oratoire dessusdit jusques a l'entree duquel le roy d'armes l'a mené et convoié. ${ }^{74}$

\section{[216] [Ihm folgt Philippe de Croy, Gf. von Chimay.]}

Item mondit seigneur ainsi retourné en son oratoire, Thoison d'or, le roy d'armes, lui a faite la reverence deue et est alé descendre devers les haultes formes du lez dextre, ou se tenoient medis seigneurs les chevaliers freres de l'ordre et s'est adreçié devant monseigneur le conte de Chimay $\{74\}$, estant ou premier siege, pour le querir et mener faire son offrande. Et tantost est parti de son lieu mondit seigneur de Chimay et alé apres ledit Thoison d'or seul sans compaignon devers ledit prelat, faire sadite offrande. Laquelle faite, il s'est retourné et alé remettre en son premier lieu, mené et conduit par icellui roy d'armes.

\section{[217] [Es folgenden nacheinander die übrigen anwesenden Mitglieder.]}

Item monseigneur le conte de Chimay ainsi retourné, ledit roy d'armes Thoison d'or s'est alé presenter devant messire Josse de Lalaing $\{80\}$, seigneur de Montigny. Lequel s'est aussi parti de son lieu et siege et alé apres ledit roy d'armes devers l'autel, faire son offrande seul sans compaingnon audit prelat. Et icelle faite, il est retourné en son lieu premier, mené et conduit par le roy d'armes devantdit. Et pareillement sont allez offrir et retournez en leurs lieux ordonneement et successivement lesdis aultres trois chevaliers freres convoiez par le roy d'armes, chascun a son tour et seul sans compaingon, comme dessus. Et au passer et repasser devant mondit seigneur le souverain lui ont chascun a son endroit et pareillement ledit roy d'armes fait la reverence deue.

\section{[218] [Danach wird der Gottesdienst fortgesetzt.]}

Item l'offrande ainsi faite, moult reverenment a procedé oultre ledit prelat et continué et parachevé le sacrifice et office de ladite grant messe jusques a fin. Et ladite messe finié, mondit seigneur le souverain est alé faire son oroison et offrande au saint sacrament de l'autel miraculeux, reposant en ladite eglise lequel lui fut porté et monstré devant ledit grant autel.

[fol. 60v/32v]

[219] [Anschließend nehmen die Ordensmitglieder an verschiedenen Orten eine Mahlzeit ein.]

Item et tantost apres retournerent mesdis seigneur et dame devers la court accompaingnez grandement, noblement et honnorablement. Et messeigneurs les chevaliers

74 Im Gegensatz zur Andreas-Messe während des Ordensfestes werden hier nur die anwesenden Mitglieder und nicht die fehlenden Mitglieder aufgerufen und von Toison d'or jeweils einzeln und nicht zu zweit zum Altar geführt; zum Ablauf der Andreas-Messe im Mai vgl. die Angaben in $§ 82$ ff. mit Anm. 42. 
confreres de l'ordre disnerent ce jour ensamble en la chambre de monseigneur de Chimay $\{74\}$, premier chambellan. Mais l'evesque de Tournay, chancellier, ne convoya point mondit seigneur le souverain, mais au partir de l'eglise s'en ala disner en son logis et le graffier avec lui. ${ }^{75}$

\section{[220] [Der Orden versammelt sich nach dem Essen.]}

\section{Acte du conseil de l'ordre tenu ledit jour saint Andrieu ${ }^{76}$}

Ledit jour saint Andrieu, apres disner devant vespres, messeigneurs les cinq chevaliers $^{77}$, freres et compaingnons de l'ordre cy devant nommez, assavoir messire de Chimay $\{74\}$, de Montigny $\{80\}$, de Saintpol $\{83\}$, de Bevre $\{82\}$ et de Fyennes $\{81\}$, ensemble les trois officiers, assavoir reverend pere en Dieu messire Ferry, evesque de Tournay, chancellier, le graffier et Thoison d'or, le roy d'armes de l'ordre, se assamblerent devers mondit seigneur le souverain a la court en la chambre de son petit retrait. Et illec mondit seigneur l'evesque de Tournay, chancellier, par l'ordonnance de mesdis seigneurs les chevaliers freres d'icellui ordre remercia humblement et reverenment de par eulx mondit seigneur le souverain de l'onneur que le mesme jour devant disner il avoit fait et porté a l'ordre en l'eglise et autrement du grant devoir et bon acquis que lui mesmes y avoit fait ensemble des louables et honnestes ceremonies qui avoient esté gardees et tenues a l'offrande de la grant messe et autrement.

[221] [Dabei wurden drei Punkte besprochen: Erstens: Bei dem neugewählten Hugues de Château-Guion sind die Umstände seiner Freilassung aus der französischen Gefangenschaft unklar, deshalb soll er bis zu deren Klärung noch nicht von seiner Wahl in den Orden unterrichtet werden. Zweitens: Die Unstimmigkeiten mit fohann, $\mathrm{Hz}$. von Kleve, will Hz. Maximilian in einem persönlichen Treffen regeln. Drittens: Der Herr von Croy wurde fälschlicherweise davon unterrichtet, dass er in den Orden gewählt worden sei. Er soll dazu befragt werden, wenn er nach Brüssel kommt. Und auf dem kommenden Fest soll geprüft werden, wer aus dem Kreis des Ordens diese Indiskretion begangen hat; der Schuldige soll dafür bestraft werden.]

\section{No(ta) de ces trois poins ${ }^{78}$}

[a] Apres exposa et remonstra mondit seigneur le chancellier qu'il estoit coustume en l'ordre de assambler et convenir chascun an quant faire se pouvoit bonnement au jour monseigneur saint Andrieu, patron dudit ordre, devers monseigneur le souverain d'icellui ordre estant pour le temps messeigneurs les chevaliers freres et compaingnons ensamble les officiers du mesme ordre estans au lieu, pour ledit jour et de parler et

75 Ms.: le graffier avec lui ist unterstrichen.

76 Ms.: Diese Zwischenüberschrift steht vor dem folgenden Absatz und ist durch einen Strich von diesem getrennt.

77 Ms.: Zwischen cinq chevaliers steht ein einzelnes $s$.

78 Ms.: Die Zwischenüberschrift steht am linken Rand bei der Zeile, die mit seigneur le souverain et messeigneurs les chevaliers confreres illec presens, trois poins beginnt. Zur besseren Lesbarkeit dieses langen Paragraphen wurden Absätze und Unterpunkte eingefügt; mit gelegentlichen Doppelstrichen zeigte schon Steenberch an, dass nun etwas neues folgt. 
communiquer ensamble par forme d'un petit chappittre des affaires dudit ordre s'aucuns lors survenoient. Et a ceste cause pour entretenir ladite coustume ledit monseigneur le chancellier a proposé et mis en termes devant mondit seigneur le souverain et messeigneurs les chevaliers confreres illec presens, trois poins et matieres touchans d'icellui ordre pour en deliberer s'il leur plaisoit:

\section{Premier touchant monseigneur de Chasteauguion ${ }^{79}$}

[b] Assavoir le premier point, touchant monseigneur de Chasteauguion ${ }^{80}$ pour ce que nouvelles estoient pardeça de son retour au lieu de Bleterens ou conté de Bourgoingne, venant de France parti contraire ou ja longuement il avoit esté detenu prisonnier par les François adversaire, [fol. 61r/33r] et disoit l'on que mondit seigneur de Chasteauguion avoit payé la moitié de sa rançon et baillié plesges pour l'autre moitié ou hostaiges, mais ne ${ }^{81}$ sçavoit on lequel, parquoy espoir estoit de sa deliverance. Ouquel cas veu que ou darrain chappittre de l'ordre ledit seigneur de Chasteauguion avoit esté esleu pour estre frere et compaingnon dudit ordre, faisoit a adviser et deliberer par mesdis seigneurs, se mondit seigneur le souverain envoieroit devers lui Thoison d'or, le roy d'armes, ou autre, atout ung collier de l'ordre pour lui signifier sadite election et savoir son intencion sur icelle et en [!] cas qu'il l'accepteroit, recevoir de lui le serment et lui baillier ledit collier aux solemnitez et ceremonies en tel cas pertinentes selon les status dudit ordre. Ou se la chose se devroit encoire delaier jusques a aultres temps.

\section{Le second touchant monseigneur le duc de Cleves $^{82}$}

[c] Le second point touchant monseigneur le duc de Cleves $\{47\}$, a cause des lettres closes que monseigneur le souverain et aussi messeigneurs les chevaliers confreres lui escrivoient, en lui signifiant la feste et le chappittre avenir de l'ordre, ${ }^{83}$ veu que lesdites lettres sonnoient ung peu aigrement, dont il se pourroit aucunement troubler ou malcontenter et qu'il estoit espoir que brief ledit monseigneur de Cleves se trouveroit devers mondit seigneur le souverain en la ville de Bosleduc ou la entour et se povoit bien aider de lui mondit seigneur en ses affaires du pays de Gheldres et autrement. ${ }^{84}$ Bien faisoit a deliberer

79 Ms.: Diese Zwischenüberschrift steht am linken Rand zu Beginn der folgenden Zeilen und ist von diesem rechts durch einen Strich getrennt. - Fortsetzung von 1154 .

$80 \mathrm{Zu}$ seiner Person und zu seiner Gefangenschaft vgl. § 134 mit Anm. 160.

81 Ms.: ne steht über der Zeile und eine Marke zeigt die dafür vorgesehene Stelle im Text.

82 Ms.: Diese Zwischenüberschrift steht am linken Rand zu Beginn der folgenden Zeilen und ist von diesem rechts durch einen Strich getrennt. - Den den Hz. von Kleve betreffenden Teil dieses Absatzes wird fast wörtlich in AOGV, Codex 45, fol. 61v-62r wiederholt. - Fortsetzung von § 209.

83 Vgl. Reg. 83 und $89 f$.

84 In Geldern wurden die burgund. Ansprüche auf das Herzogtum nicht anerkannt. Mit dem Tod Hz. Karls \{34\} wurde der eigentliche, in burgund. Gefangenschaft befindliche Herzog Adolf $\{58\}$ freigelassen und dieser bemühte sich darum, seine Ansprüche auf das Herzogtum wieder geltend zu machen (vgl. dazu oben $\S 27$, Anm. 166). Nach seinem Tod im Juni 1477 versuchte seine Schwester Katharina im Namen von Adolfs Sohn Karl die Ansprüche aufrecht zu erhalten und proklamierte sich als Regentin; sie fand dabei den Rückhalt der Bevölkerung und die finanzielle Unterstützung durch den frz. König. Die geldrischen Truppen zogen gegen 's-Hertogenbosch, wo sie durch Johann, $\mathrm{Hz}$. von Kleve, aufgehalten wurden. Im weiteren Verlauf war es aber vor allem das entschlossene Vorgehen des von Hz. Maximilian beauftragten Adolfs, Gf. von Nassau, zu 
s'il seroit plus expedient de differer et delaier encore l'envoy desdites lettres et la presentacion d'icelles jusques a ce que mondit seigneur de Cleves auroit esté et besoingnié avec mondit seigneur le souverain des besoingnes et affaires, dont ilz auront a communiquer et besoingner ensamble et qu'il seroit retrourné en son pays de Cleves. Ou de lui envoier prestement par Thoison d'or, le roy d'armes de l'ordre, lesdites lettres, ainsi que paravant nagaires il avoit esté deliberé et conclut par mondit seigneur le souverain.

\section{Le tiers touchant monseigneur de $\mathrm{Croy}^{85}$}

[d] Le tiers point estoit touchant monseigneur de Croy a l'occasion de certaines paroles qu'il deust avoir dites de monseigneur le conte de Chimay $\{74\}$, assavoir que a cause de mondit seigneur de Chimay il n'avoit pas esté esleu en l'ordre et qu'il avoit sceu ${ }^{86}$ par chevalier de l'ordre qui le lui avoit dit etc. Desquelles paroles nagaires adverti mondit seigneur le souverain en son conseil de l'ordre par lui tenu avec messeigneurs les chevaliers, ses freres dudit ordre, lors devers lui assamblez en plusgrant nombre et pour pluseurs autres matieres et affaires d'icellui ordre. Ouquel conseil aucuns de mesdis seigneurs estans en ceste assamblee avoient esté presens avoit par l'advis et deliberacion de mesdis seigneurs conclut et ordonné que, quant ledit seigneur de Croy vendroit en ladite ville de Brouxelles, il fust par deux officiers, assavoir par les graffier et roy d'armes de l'ordre, interrogué sur ledites paroles pour savoir de lui, s'il les a dites ou non. Et en cas que si qu'il fust interrogué especialement du chevalier de l'ordre par qui il l'a sceu et qui le lui a dit, pour sa response sur tout rapporter par lesdis officiers a mondit seigneur le [fol. 61v/33v] souverain et aux chevaliers freres de l'ordre. Orres estoit nouvellement arrivé en ladite ville de Brouxelles, mondit seigneur de Croy et estoient prestes lesdis officiers pour faire leur devoir en ce qui leur estoit ordonné.

Mais pour aucuns regars la touchiez povoit sembler a aucuns que l'execucion de ceste chose vaudroit autant ung peu delayee, que fort hastee, s'il plaisoit a mondit seigneur le souverain et a messeigneurs les chevaliers freres de l'ordre. Parquoy du bon plaisir et par l'ordonnance de mondit seigneur le souverain ont esté mises en deliberacion ces trois matieres et sur icelles demandees les opinions de mesdis seigneurs. Lesquelles opinions oyes et entendues par mondit seigneur le souverain, a esté sa conclusion quant ausdites matieres, conforme a la deliberacion de mesdis seigneurs les chevaliers freres et telle que s'ensuit de point en point:

\section{La Conclusion}

\section{Super primo $^{87}$}

[e] C'est assavoir premierement sur le premier point touchant monseigneur de Chasteauguion: Que veu et consideré que ledit seigneur de Chasteauguion a esté detenu

verdanken, dass der Aufstand bis zum Sommer 1481 niedergeschlagen werden konnte. Vgl. dazu u. a. Barante/Gachard, Histoire, II, 1838, S. 636 f.; Wiesflecker, Maximilian, 1, 1971, S. 145; Bock, Maximilian, 1970, S. 56 f.; Webern, Grafen von Nassau, 1978, S. 48-51; Böck, Herzöge, 2013, S. 555-585. - Vgl. Reg. 66.

85 Ms.: Diese Zwischenüberschrift steht am linken Rand zu Beginn der folgenden Zeilen und ist von diesem rechts durch einen Strich getrennt. - Fortsetzung von $§ 210$.

86 Ms.: sceu steht über der Zeile und eine Marke zeigt auf die dafür vorgesehene Stelle im Text.

87 Ms.: Diese beiden Zwischenüberschriften stehen am linken Rand zu Beginn der folgenden Zeilen. 
longuement prisonnier en France ou parti contraire, combien qu'il soit retourné ou pays comme l'on dit, toutevoie ne scevent mondit seigneur le souverain ne messeigneurs les chevaliers confreres de l'ordre en quel estat ne par quel moyen il est revenu, mesmement s'il est de tous poins delivré de sa prison et restabli en sa premiere franchise, s'il a parpayé sa rançon ou non, bien dient aucuns qu'il en a payé la moitié et par l'autre moitié a baillié plesges ou hostaiges. Mais mondit seigneur le souverain n'en scet riens de vray, car il n'en a point eu de lettre. Pour lesquelz regars et mesmement attendu que la significacion de sadite election a l'ordre, s'elle se faisoit devant que ledit seigneur de Chasteauguion fust et soit au delivré de tous poins et il estoit relevé ou venist a la cognoissance du roy ou de ceulx qui l'ont detenu prisonnier et le povoient revoquer pour faulte du parpayement de sa rançon ou aultrement, son fait et sa condicion s'en pourroient aggraver et empirer et ce lui pourroit tourner a prejudice et dommaige bien grans, ce que moult desplairoit a mondit seigneur le souverain et a la compaingnie de l'ordre. A conclut et ordonné mondit seigneur que ladite significacion a faire a mondit seigneur de Chasteauguion de son election a l'ordre dessusdite soit et sera mise en delay et surseance jusques a tant que par lettres d'icellui seigneur ou autrement deuement monseigneur le souverain sera informé et bien acertené de sa delivrance pleniere de sadite prison et des aultres choses dessusdites. Mais desmaintenant est accordé et conclut par mesdis seigneurs les chevaliers freres de l'ordre et de leur expres consentement, que mondit seigneur [fol. 62r/34r] le souverain pourra faire faire oudit seigneur de Chasteauguion ladite significacion, lui certiffié par la maniere dite, toutes les fois qu'il lui plaira sans ce que besoing soit ne sera de faire pour ce aultre convocacion ne d'en demander aultre deliberacion ou consentement de mesdis seigneurs les chevaliers freres de l'ordre. ${ }^{88}$

\section{Super secundo: Cleves $^{89}$}

[f] Sur le second point touchant monseigneur le duc de Cleves a conclut et ordonné mondit seigneur le souverain que, en ensuivant la conclusion aultresfois sur ce prinse, lesdites lettres closes lui soient envoiees diligenment premiers et devant que ledit monseigneur de Cleves se tienne devers lui, car se apres lesdites lettres veues il veult aucune chose dire ou remonstrer pour son excuse, lui venu devers mondit seigneur le souverain, icellui seigneur et mesdis seigneur les chevaliers freres qui lors se y trouveront, le pourront ouyr et remettre la chose ou prouchain chappittre de l'ordre. Autrement se lesdites lettres ne se bailloient jusques apres que mondit seigneur de Cleves auroit besoingnié avec mondit seigneur le souverain et en seroit departi, il s'en pourroit beaucop pis contenter et le prendre a plusgrant regret. ${ }^{90}$

\section{Super tercio: Croy $^{91}$}

[g] Et sur le tiers point touchant mondit seigneur de Croy, combien que par cydevant il fust ordonné que ledit seigneur de Croy seroit interrogué au plus tost qu'il vendroit a Brouxelles et que l'opinion d'aucuns encore fust telle: Toutevoie, attendu et consideré que les paroles qu'il auroit dites ne touchent pas monseigneur de Chimay, fors de tant qu'il y est nommé, mais touchent generalement tous les chevaliers freres

88 Fortsetzung in $\S 235$.

89 Ms.: Diese Zwischenüberschrift steht am linken Rand zu Beginn der folgenden Zeilen.

90 Fortsetzung in $\S 228$.

91 Ms.: Diese Zwischenüberschrift steht am linken Rand zu Beginn der folgenden Zeilen. 
de l'ordre qui furent ou darrain chappittre tenu a Bruges quant les elections y furent faites, parce que ledit seigneur de Croy allegue et dit que chevalier de l'ordre le lui a dit ce qui n'est vraissemblable. Toutevoie s'il estoit ainsi le chevalier qui auroit dit telle chose auroit grandement failly et mesprins contre verite et contre le secret de l'ordre. Laquelle chose se doit purgir en chappittre dudit ordre, parquoy, veu aussi que pluseurs desdis chevaliers freres qui furent presens au faire lesdis darrenieres elections et ausquelz la chose touche pour leure sont absens, de l'interrogacion que maintenant se feroit dudit monseigneur de Croy, ne vendroient fors que parolles sans fin ou conclusion. A conclut mondit seigneur le souverain avec la pluralité des voix y deliberans et ordonné, que la chose soit encore delayee et mise en surseance jusques au futur prouchain chappittre de l'ordre, ouquel vraissemblablement lesdis chevaliers freres et aultres, tant presentement absens comme presens, lors convendront et s'assembleront et se pourra illec lors purger et vuider ceste matiere comme il appartendra.

\section{März 1479 in Antwerpen}

\section{[222] [Am 12. März versammelt sich der Orden zu einer außerordentlichen Sit- zung.]}

\section{Acte du conseil de l'ordre tenu en la ville d'Anvers ${ }^{92}$}

Le xije jour du mois de mars oudit an soixantedixhuit ${ }^{93}$ mon tresredoubté seigneur monseigneur le duc Maximilien, chief et souverain du noble ordre de la Thoison d'or, [fol. 62v/34v] estant en sa ville d'Anvers et devers lui illec assamblez en son logis messeigneurs Loys, seigneur de Gruythuse $\{61\}$, conte de Wincestre, Phelippe de Croy $\{74\}$, conte de Chimay, premier chambellan, Guillame, seigneur d'Egmonde $\{78\}$, Pierre de Luczembourg $\{83\}$, conte de Saintpol, Jaques, monseigneur de Savoye $\{84\}$, conte de Romont, et Jaques de Luczembourg $\{81\}$, seigneur de Fyennes, tous chevaliers freres et compaingnons, ensemble reverend pere en Dieu messire Ferry, evesque de Tournay, chancellier, et le graffier dudit ordre; monseigneur Adolph de Cleves $\{55\}$ seigneur de Ravestein, empeschié pour lors en ladite ville par maladdie de goutes et excusé, ${ }^{94}$ tint illec mondit seigneur le souverain conseil secret avec mesdis seigneurs, ses confreres, sur les affaires et poins dudit ordre, cy apres desclarez:

\section{[223] [Nach kurzer Diskussion wird Brüssel als Austragungsort für das Ordensfest bestätigt.] \\ Conclusion iterative pour tenir la feste de l'ordre a Brouxelles en may l'an lxxix ${ }^{95}$}

Et premierement, combien que mondit seigneur le souverain pieça paravant eust deliberé et conclut par l'advis et consentement de messeigneurs les chevaliers freres de l'ordre qui pour lors devers lui estoient de tenir, faire et celebrer la feste solemnelle dudit ordre ensamble le general chappittre au second jour du mois de may prouchain et autres jours

92 Ms.: Diese Zwischenüberschrift steht vor dem folgenden Absatz und ist durch einen Strich von diesem getrennt.

93 12. März 1479 (n.St.).

94 Das Zusammentreffen erfolgte auf Einladung Hz. Maximilians vgl. Reg. 103.

95 Ms.: Diese Zwischenüberschrift steht am linken Rand zu Beginn von fol. 35r und ist von diesem rechts durch einen Strich getrennt. - Fortsetzung von $§ 209$. 
ensuit en sa ville de Brouxelles et que ainsi l'eust signifié et escript par ses lettres closes aux tresexcellens roys et a pluseurs aultres de messeigneurs les chevaliers, ses confreres du mesme ordre estans en divers royaumes et pays longtains, et a aucuns aultres par ses lettres patentes seellees du seel de l'ordre en placcart, ${ }^{96}$ toutevoie considerez les grans affaires survenus a mondit seigneur et mesmement la disposicion evidente moult dangereuse de la guerre que lui continuoit et faisoit le roy de France, ${ }^{97}$ sambloit a aucuns de mesdis seigneurs que chose plus honneste seroit pour mondit seigneur le souverain et plus expedient pour le bien de sesdites affaires qu'il tenist sadite prouchaine feste de l'ordre en sa ville de Lille que audit Brouxelles, tant pour monstrer visaige a ses ennemis comme pour donner cueraige a ses bonnes villes, gens et subgiez seans es frontieres de ses pays resistans a sesdis ennemis. Parquoy mondit seigneur le souverain a fait remettre en deliberacion ceste matiere et mesmement et par especial se le lieu pour tenir ladite feste prouchaine de l'ordre ja signifié et designé se pourroit oires changer et muer bonnement. Et la matiere bien debattue en ont esté demandees les opinions de mesdis seigneurs. Et la pluspart d'entre eulx s'est arrestee au lieu que mondit seigneur par ses lettres avoit ja intimé et signifié comme dit est, assavoir de la ville de Brouxelles, veu mesmement que le temps estoit si prouchain et trop brief pour faire a ceulx de l'ordre nouvelle indiction et significacion d'autre lieu. Aussi la mutacion qui se feroit sembleroit proceder d'une legierte ou inconstance a la charge dudit ordre. Mais mondit seigneur le conte de Saintpol $\{83\}$ et monseigneur de Fyennes $\{81\}$ opinerent pour la ville [fol. 63r/35r] de Lille pour les raisons devant touchees. Et finablement mondit seigneur le souverain s'est resolu et conclut avec la pluralité des voix pour la ville de Brouxelles dessusdite, tant pour consideracion de ladite assignacion et significacion ja faite par sesdites lettres et mesmement par ses lettres patentes en placcart aux chevaliers notez, ausquelz le lieu de Brouxelles avoit expressement esté assigné pour personellement y comparoir au jour, comme aussi a cause que mondit seigneur proposoit de s'en aller faire ung touc jusques en son pays de Hollande ou encore il n'avoit esté et dont plus aiseement et plus brief il pourroit retourner audit lieu de Brouxelles qu'il ne feroit a Lille pour y faire et tenir ladite feste de l'ordre. Aussi lui sambloit ladite ville de Brouxelles, lieu assez moyen entre ses pays de pardeça, la ou il pourra avoir tost nouvelles de toutes pars et selon la neccessite des affaires qui survenir pourroient pendant la feste pourveoir promptement la et ainsi que besoing et mestier seroit.

[224] [Olivier de la Marche und Philippe du Chesne sollen nach Brüssel reisen, um dort das Ordensfest vorzubereiten.]

\section{Monseigneur commet messire Olivier de la Marche et messire Pierre [!] du Chesne pour aler faire faire les apprestes pour la future feste de l'ordre a tenir a Brouxelles ${ }^{98}$}

Ceste conclusion ainsi prinse, a ordonné mondit seigneur le souverain et commis messire Olivier de la Marche, chevalier, son maistre d'ostel, ${ }^{99}$ et messire Phelippe du

96 Vgl. Reg. 75-91.

97 In § 239 werden die verschiedenen Krisenherde ausführlicher benannt und kommentiert.

98 Ms.: Diese Zwischenüberschrift, die mit einem $c$ / für capitulum eingeleitet wird, steht vor dem folgenden Absatz und ist durch einen Strich von diesem getrennt.

99 Zur Person Oliviers de la Marche vgl. die Angaben in § 20, Anm. 105. 
Chesne, aussi chevalier, maistre d'ostel de madame la duchesse, ${ }^{100}$ pour aler atout lettres de credence ${ }^{101}$ de par lui devers ceulx de la loy et de la policie de la ville de Brouxelles et par leur moyen faire reparer la porte de la court de mondit seigneur, ruyneuse par feu de meschief et en ladite court faire apprester et appointier la grant salle, les chambres et aultres lieux et offices y ruyneuses et neccessaires ${ }^{102}$ et aussi pour visiter l'eglise de Sainte Goudele et faire appointer icelle ou grant chœur, tant devers l'autel comme devers les haultes formes pour en oster les tableaux vielz des trespassez, feuz souverain et chevaliers freres de noble memoire que Dieu absoille et y remettre les nouveaulx des survivans et les blasons des trespassez en l'ordre depuis la feste darrenier precedent ${ }^{103}$ et au surplus faire apprester et appareiller les aultres choses audit Brouxelles neccessaires pour ladite prouchaine feste dudit ordre.

\section{[Fusil hat über seine Reise zu den in Frankreich verweilenden Mitgliedern} einen Bericht verfaßt.]

\section{Du rapport de Fusil le herault, retourné de France ${ }^{104}$ Des v chevaliers estans en France ${ }^{105}$}

Apres a esté parlé en ce conseil du rapport, fait par Fusil le herault, darrenier retourné puis nagaires de devers le roy de France. Lequel Fusil estoit envoyé atout povoir et commission especiale < pour aler $>$ devers les cinq chevaliers de l'ordre estans en Fance et tenans parti contraire, leur presenter les lettres patentes de mondit seigneur le souverain, faites en placcart soubz le seel de l'ordre, touchant l'indiction et significacion de ladite future prouchaine feste dudit ordre, a chascun la sienne particulierement et pour les adjourner a comparoir chascun d'eulx personnellement ou prouchain chappittre de l'ordre qui se tendroit au lieu de Brouxelles et ouyr ce que illec contre eulx seroit lors proposé et mis avant et y respondre etc. ${ }^{106}$ c'est assavoir monseigneur Anthoine, bastart de Bourgoingne $\{54\}$, messire Jaques de Luxembourg $\{67\}$, seigneur

100 Philippe du Chesne, Herr von Loupoigne und Hz. Maximilians Rat, war am Hof Hz. Karls \{34\} und Hz. Maximilian u. a. als huissier de salle tätig und am Hof Hz.in Marias als maistre d'ostel tätig. Im Dez. 1478 wurde ihm die hohe Gerichtsbarkeit in seiner Herrschaft Loupoigne verliehen. Zu seiner Person vgl. u. a. § 255; GACHARD, Ordonnance 1477, 1857, S. 123; Regesten Friedrichs III., Suppl. 1, 2008, S. 73 f., Reg. 56; DB Prosopographia Curiae Burgundicae, ID n 2353.

101 Vgl. Reg. 105.

102 Zur hzl. Residenz Palais Coudenberg vgl. in § 13 mit Anm. 75.

103 In dieser Kirche hatte der Orden während des Ordensfestes im Jahr 1435 seine Gottesdienste absolviert; vgl. dazu u. a. PB 1, S. 62-75; zur Kirche vgl. die Angaben in $\S 211$, Anm. 70. Die Wappentafeln dieses Festes sind leider nicht mehr erhalten. Später bemühte sich der Orden auf Betreiben des Greffiers Laurent du Blioul (1499), dass die Gottesdienste der Ordensfeste immer in verschiedenen Kirchen abgehalten wurden, damit die Wappentafeln früherer Feste nicht entfernt werden mussten; vgl. dazu u. a. STERCHI, Umgang, 2005, S. $400 \mathrm{f}$.

104 Ms.: Diese Zwischenüberschrift, die mit einem $c$ / für capitulum eingeleitet wird, steht vor dem folgenden Absatz. - Fortsetzung von § 209; vgl. dazu auch in der Einleitung S. 27.

105 Ms.: Diese Zwischenüberschrift steht am linken Rand zu Beginn des folgenden Absatzes und ist von diesem rechts durch einen Strich getrennt.

106 Vgl. Reg. 75-79. Zu dem an Fusil gegangenen Auftrag, diese Briefe zu überbringen, vgl. Reg. 80 . 
de Richebourg, messire Phelippe Pot $\{60\}$, seigneur de la Roiche de Nolay, messire Phelippe de Crevecuer $\{69\}$, seigneur [fol. 63v/35v] d'Escardes, et messire Jehan de Damas $\{65\}$, seigneur de Clessy. Et a ledit Fuzil le herault, faite et baillier par escript sa relacion du bon devoir et acquit qu'il avoit fais pour executer sa charge et commission a lui baillee en ceste partie, ensemble de l'empeschement qu'il y avoit trouvé, comme par sadite relacion que se gardé devers le graffe de l'ordre, signee de sa main, il puet apparoir plus a plain. ${ }^{107}$

[226] [Auch der Herold Rupelmonde hat einen Bericht über seine Reise zu Philipp von Savoyen und Jean de Neufchâtel abgegeben.]

\section{Du rapport de Ripelmonde le herault, retourné de devers messeigneurs de Bresse et de Montagu ${ }^{108}$}

Item a aussi esté parlé oudit conseil du rapport fait par Ripremonde le herault d'armes, ${ }^{109}$ qui estoit envoyé a tout lettres closes de mondit seigneur le souverain touchant l'indiction et significacion de ladite prouchaine feste de l'ordre devers monseigneur Phelippe de Savoye $\{68\}$, conte de Baugey, ${ }^{110}$ et messire Jehan de Neufchatel $\{52\}$, seigneur de Montagu, ${ }^{111}$ freres de l'ordre. Devers lesquelz seigneurs ledit Ripremenode avoit esté et nagaire en estoit retournez et avoit aussi bailliee sa relacion par escript, signee de sa main, gardee devers ledit graffier de l'ordre. ${ }^{112}$

[227] [Nach Anhörung der beiden Berichte der Herolde und nach Diskussion wird beschlossen, dass die Angelegenheit um die fünf in Frankreich befindlichen Mitglieder und die um Philipp von Savoyen beim kommenden Ordensfest zur Entscheidung kommen soll.]

\section{Touchant les v chevaliers estans en France ${ }^{113}$}

\section{Touchant monseigneur de Bresse ${ }^{114}$}

Item et apres certaines devises eues sur ces matieres, ont par l'ordonnance de mondit seigneur le souverain esté leues illec tout au long lesdis deux relacions de Fuzil et de Ripremonde, ${ }^{115}$ roix d'armes, ensemble certaines lettres closes que mondit seigneur Jaques de Luczembourg $\{67\}$ avoit rescriptes et par ledit Fusil envoiees a mondit seig-

107 Vgl. Reg. 100. - Fortsetzung in § 227.

108 Ms.: Diese Zwischenüberschrift, die mit einem $c$ / für capitulum eingeleitet wird, steht vor dem folgenden Absatz und ist durch einen Strich von diesem getrennt.Fortsetzung von $\S 120$ und 209.

109 Zwischen 1478 und 1481 wurde das Heroldsamt Ruplemonde von Gilles de Rebecque versehen; vgl. DB Heraudica, ID Person 83 und 29 sowie die Angaben in Reg. 81.

110 Vgl. Reg. 82.

111 Vgl. Reg. 81 sowie dessen Antwort in Reg. 98.

112 Vgl. Reg. 102. - Zur Fortsetzung in der Angelegenheit um Philipp von Savoyen vgl. den folgenden Absatz und um Jean de Neufchâtel § 240.

113 Ms.: Diese Zwischenüberschrift steht linken Rand zu Beginn des folgenden Absatzes und ist links und rechts mit einer Klammer versehen.

114 Ms.: Diese Zwischenüberschrift steht linken Rand bei der Zeile, die mit d'ignorance. Et apres la lecture faite d'aucuns status beginnt, und ist links und rechts mit einer Klammer versehen.

115 Vgl. Reg. 100 und 102. 
neur le souverain. ${ }^{116}$ Et tout ouy et entendu bien au long, a esté mis en deliberacion s'il y cheoit autre response ou significacion a faire, mesmement au regart des quatre chevaliers, assavoir monseigneur le bastart de Bourgoingne $\{54\}$, le seigneur de la Roiche de Nolay $\{60\}$, le seigneur d'Escardes $\{69\}$ et le seigneur de Clessy $\{65\}$, devers lesquelz le devantdit Fuzil le herault, empeschié de par le roy, n'avoit peu avoir acces pour leur presenter leurs placcars ${ }^{117}$ et les adjourner selon sa charge. Et s'il seroit expedient ou mestier de les plus faire appeller ou adjourner, fust per edictum ou autrement, afin qu'ilz ne peussent alleguer coleur ou excuse d'ignorance. Et apres la lecture faite d'aucuns status dudit ordre servans a la matiere, les opinions demandees et ouyes bien meurement, mondit seigneur le souverain par l'advis et deliberacion de mesdis seigneurs les chevaliers freres avec lui estans oudit conseil, a conclud finablement de surseoir le tout et mettre en delay et d'attendre jusques audit prouchain chappittre de l'ordre ${ }^{118}$ esperant entre cy et lors avoir la response de mondit seigneur de Bresse $\{68\}^{119}$ que selon le rapport dudit Ripremonde envoier lui devoit, pour oudit futur et prouchain chappittre avoir bon et meur advis sur tout avec messeigneurs les chevaliers, ses confreres de l'ordre qui lors y seront en plusgrant nombre, comme espoir est, et en tout faire et proceder au surplus comme il appartendra et faire se devra selon les ordonnances et status d'icellui ordre. ${ }^{120}$

\section{Touchant monseigneur de Cleves ${ }^{121}$}

\section{[228] [Der Orden befaßt sich mit Johann, Hz. von Kleve, und dessen Brief.]}

En ce mesme conseil a esté parlé de certaines lettres closes nagaires paravant escriptes [fol. 64r/36r] par monseigneur le duc de Cleves $\{47\}$ a messeigneurs les chevaliers freres de l'ordre et a Thoison d'or, le roy d'armes, cy apres transcriptes et contenues, dont la teneur s'ensuit, et premierement de la lettre adreçant a mesdis seigneurs ${ }^{122}$ de l'ordre, qui est telle: ${ }^{123}$

[229] [Er bestätigt den Mitgliedern des Ordens den Empfang des Einladungsschreibens für das kommende Fest.]

La superscripcion ${ }^{124}$

A nos treschiers et treschiers [!] et tresamez les chevaliers freres et compaingnons de l'ordre de la Thoison d'or

Treschiers et tresamez freres et compaingnons de la Thoison d'or. Nous vous signiffions par ces presentes avoir receu par ce porteur voz lettres a nous escriptes,

116 Vgl. Reg. 99.

117 Vgl. Reg. 75-79.

118 Zum Ausschlussverfahren vgl. S. 26 mit Anm. 67.

119 Vgl. Reg. 101.

120 Fortsetzung in $\S 240$.

121 Ms.: Diese Zwischenüberschrift steht linken Rand zu Beginn von fol. 36r und ist links und rechts mit einer Klammer versehen. Der Abstand zwischen § 227 und 228 ist kleiner als sonst üblich. - Fortsetzung von § 221.

122 Ms.: Das gekürzte seigneur wurde nachträglich eingetragen.

123 Vgl. Reg. $96 \mathrm{f}$.

124 Ms.: La superscripcion ist unterstrichen und befindet sich beim Original auf der Rückseite. 
faisans mencion de la feste et solemnité dudit ordre qui se doit tenir le second jour de may prouchain venant en la ville de Brouxelles. ${ }^{125}$ Treschiers et tresamez freres et compaingnons, Nostre Seigneur soit garde vous. Escript en nostre ville de Cleves, le xvije jour de decembre l'an etc. lxxviij. ${ }^{126}$

\section{Subscription ${ }^{127}$}

Jehan, duc de Cleves $\{47\}$, conte de la Marque

[230] [Er bestätigt Toison d'or den Empfang von drei Briefen.]

S'ensuit la copie de lettre adrechant audit roy d'armes Thoison d'or:

La superscripcion ${ }^{128}$

A nostre treschier et especial amy Thoison d'or

[Subscription:] Jehan, duc de Cleves $\{47\}$, conte de la Marque

Treschier et especial amy. Nous avons receu par ce porteur les trois lettres que par icellui nous avez envoyees, faisans mencion de la feste et solemnité de la Thoison d'or, qui se doit tenir le second jour de may prouchain venant en la ville de Bruxelles etc. ${ }^{129} \mathrm{Ce}$ que vous signifions par cestes. Treschier et especial amy, Nostre Seigneur soit garde de vous. Escript a Cleves, le xvije jour de decembre l'an etc. lxxviij. ${ }^{130}$

[231] [Der Orden beauftragt Adolf von Kleve, seinem Bruder Hz. Fohann zu schreiben, um diesem die Dringlichkeit seiner Teilnahme am kommenden Ordensfest $z$ u verdeutlichen.]

Lesquelles deux lettres originales, cy dessus inscriptes et gardees devers le graffe de l'ordre, ont esté veues et leues oudit conseil. Et du contenu d'icelles tant sobre ont esté esmerveillez mondit seigneur le souverain et tous messeigneurs les freres de l'ordre et non contens et leur a semblé que mondit seigneur de Cleves $\{47\}$ a peu [fol. 64v/36v] prisé ou estimé leursdites lettres et l'ordre ou non pas tant et ainsi qu'il deust avoir fait, consideree l'obligacion et astriction qu'il a audit ordre. Parquoy apres deliberacion et advis eues sur ceste matiere, mondit seigneur a ordonné que monseigneur Adolff de Cleves $\{55\}$, seigneur de Ravestein, confrere de l'ordre, escriproit a mondit seigneur de Cleves, son frere, priveement et a part, pour le exhorter et induire que oudit futur et prouchain chappittre il se mette en tel devoir et tellement s'acquite que l'onneur de l'ordre et le sien propre y soit garde. En ensuivant laquelle ordonnance mondit seigneur de Ravestein a sur ce escript a monseigneur le duc de Cleves, son frere, en la forme qui s'ensuit: ${ }^{131}$

125 Gemeint sind damit wohl die Schreiben aus Reg. 83 und $89 \mathrm{f}$.

126 17. Dez. 1478.

127 Ms.: Subscription ist unterstrichen.

128 Ms.: La superscripcion ist unterstrichen und befindet sich beim Original auf der Rückseite.

129 Vgl. dazu die Angaben in Anm. 125.

130 17. Dez. 1478.

131 Vgl. Reg. 107. 
[232] [Ermahnungsschreiben Adolfs von Kleve an seinen Bruder fohann, betr. dessen Haltung gegenüber dem Orden vom Goldenen Vlies.]

\title{
Copie de la lettre que monseigneur de Ravestain escripvit a monseigneur le duc de Cleves, son frere ${ }^{132}$
}

\author{
Superscripcion ${ }^{133}$ \\ A hault et puissant prince, mon treshonnoré seigneur et frere monseig- \\ neur le duc de Cleves $\{47\}$, conte de la Marque.
}

Hault et puissant prince, mon treshonnoré seigneur et frere. Je me recommande a vous tant comme je puis affectueusement et de cuer. Et vous plaise savoir, hault et puissant prince mon treshonnoré seigneur et frere, que j'ay sceu comment nagaires ou conseil de l'ordre de la Thoison d'or, monseigneur le duc, chief et souverain, et messeigneurs les chevaliers freres et compaingnons par son ordonnance assamblez devers lui en ceste ville sur aucunes affaires dudit ordre, ${ }^{134}$ a quoy j'estoie appellé, mais par l'empeschement de ma maladie je me excusay et n'y peuz estre, furent leues et veues certaines voz lettres closes, que darrenierement apres la recepcion des lettres de mondit seigneur et de celles desdis chevaliers freres dudit ordre a vous escriptes paravant et envoyees par Thoison d'or le roy d'armes, touchant la significacion de la conclusion de mondit seigneur, pour tenir au second jour du mois de may prouchain et es jours ensuivans la feste et solemnité ensemble le chappittre dudit ordre en sa ville de Brouxelles etc. ${ }^{135}$ Vous leurs aviez rescriptes, contenans en effect que aviez receu leursdites lettres, ce que leur signiffiez sans plus dire. Lesquelles voz lettres ont samblé a tous comme j'entens moult sobres et non souffisantes pour les contenter eu regard a la qualité de la matiere, dont ilz vous escrivoient. Pourquoy, hault et puissant prince, mon treshonnoré seigneur et frere, et que je sçay la conclusion de mondit seigneur estre telle, que dessus pour l'onneur et amour fraternelles que je vous porte ainsi que faire doy j'ecsrips devers vous et vous advertis de ces choses secretement et de moy mesmes vous exhortant et priant, tant que faire puis, que, en obtemperant a ce que tant mondit seigneur le souverain comme messeigneurs les chevaliers freres dudit ordre vous ont escript par leursdites lettres, vous vueillez tellement acquiter en ceste matiere et de vostre part vous mettre en tel devoir que monseigneur le souverain et messeigneurs lesdis chevaliers freres dudit ordre de la Thoison d'or raisonnablement s'en puissent et doyent contenter, et que l'onneur [fol. 65r/37r] du mesme ordre et de la noble compaingnie d'icellui ensemble le vostre y soient gardez comme il appartient. Enquoy me samble soubz correction que ferez bien, veu les status et estrois sermens de l'ordre dessusdis qui sont telz que les cognoissez et savez. Et sur ce vous plaist moy rescripre de vostre bonne intencion par le porteur de cestes, lequel j'envoie devers vous pour ceste cause, avec le bon estat et la bonne disposicion de vostre personne, lesquelles Nostre Seigneur Dieu vous doint par sa grace tousjours estre telz que pour moy mesmes souhaider les pourroie. Car singuliere et parfait joye je prens toutes et quantes foiz que j'en puis ouyr bonne nouvelles, ensamble aussi s'il est chose que pour vous je puisse faire

132 Ms.: Diese Zwischenüberschrift steht linken Rand zu Beginn des folgenden Absatzes ist links und rechts mit einer Klammer versehen. Ms.: La superscripcion ist unterstrichen.

134 Vgl. Reg. 103.

135 Reg. 83 und 89f. sowie Johanns Antwort in Reg. $96 \mathrm{f}$. 
pardeça, enquoy je m'emploieray de tresbon cuer. Priant au benoit filz de Dieu, hault et puissant prince, mon treshonnoré seigneur et frere, qu'il vous ait en sa sainte garde et vous doint bonne vostre vie et longue. Escript en la ville d'Anvers, le xxje jour du mois de mars l'an lxxviij, selon la coustume de pardeça. ${ }^{136}$

\section{Subscription ${ }^{137}$}

Vostre humble frere Adolph de Cleves et de la Marke $\{55\}$, seigneur de Ravesteyn. ${ }^{138}$

\section{[233] [Bericht des Herolds Ravenstein über seine Reise nach England, um Kg. Edu-} ard zum kommenden Ordensfest einzuladen.]

\section{Du rapport de Ravestein retourné devers le roy d'Angleterre ${ }^{139}$}

Encores a esté parlé oudit conseil du rapport fait par Ravestein le herault, ${ }^{140}$ retourné d'Angleterre, ${ }^{141}$ qui avoit porté et presenté au tresexcellent roy d'Angleterre $\{63\}$ les lettres closes de mondit seigneur le souverain qu'il lui avoit escriptes, sur et touchant l'indiction et significacion de ladite prouchaine feste de l'ordre. ${ }^{142}$ Lequel rapport est tel en effect, assavoir qu'il afferma avoir presenté audit roy d'Angleterre lesdites lettres de mondit seigneur le souverain. Apres lesquelles veues et visitees, le roy lui dit que par Garretiere, son roy d'armes, ${ }^{143}$ il lui feroit savoir son plaisir. Et quant sur cest espoir longuement il avoit attendu et sejourné veant qu'il n'avoit nouvelles du roy par ledit Garretiere ne par aultres. Finablement s'en estoit alé devers le roy pour savoir sa response, lors que le roy lui avoit dit de bouche ces paroles en effect: « Vous vous en yrez devers mon cousin, monseigneur d'Autrice, et lui direz que touchant les lettres que m'avez apportees je ne lui rescrips riens, mais par mon ambaxade que j'envoié devers lui, je lui feray response. » Et ainsi avoit ledit Ravestein prins congié et s'estoit parti du roy d'Angleterre et retourné devers monseigneur le souverain pardeça selon sadite affermacion. Veu lequel rapport et que jusques a cest heure mondit seigneur le souverain n'avoit eu aultre nouvelle ne response dudit roy d'Angleterre touchant

136 März 1479 (n.St.).

137 Ms.: Subscription ist unterstrichen.

138 Hz. Johann nahm beim nächsten Ordensfest in Hertogenbosch auch nicht persönlich teil, sondern ernannte seinen Bruder Adolf zu seinem Stellvertreter. In seiner correction wurde u. a. sein unentschuldigtes Fehlen von 1478 und seine doch eher unfreundlichen Briefe erwähnt. Die anwesenden Ordensritter beschränkten sich dann aber darauf, dass sie Adolf beauftragten, Hz. Johann die Anklagepunkte mitzuteilen und ihn aufzufordern sich beim folgenden Ordensfest persönlich zu äußern; vgl. vor allem PB 5, fol. 30v-31r.

139 Ms.: Diese Zwischenüberschrift steht linken Rand zu Beginn des folgenden Absatzes. - Fortsetzung von § 202.

1401470 erhielt Watelet de Haynnau das Amt dieses Herolds; vgl. die Angaben in PB 3, S. 33 Anm. 38; DB Heraudica ID Person 29 und 55.

141 Vgl. Reg. 104.

142 Vgl. Reg. 91.

143 Zwischen 1478 und 1504 versah John Wrythe das Amt des Wappenkönigs Garter; vgl. Order of the Garter, 1999, S. 335. Vergleichbar wie Toison d'or hatte der Wappenkönig Garter, auch Jarretiere genannt, am englischen Hof eine führende Position unter den Herolden und Wappenkönigen inne; vgl. dazu u. a. Collins, Garter, 2000, S. $31 \mathrm{f}$. 
ladite matiere, a ordonné mondit seigneur par l'advis de messeigneurs les chevaliers freres dessusnommez que messire Loys, seigneur de Gruythuse $\{61\}$, et Phelippe, conte de Chimay $\{74\}$, chevaliers freres, ensemble monseigneur l'evesque [fol. 65v/37v] de Tournay, chancellier de l'ordre, parlent de ceste matiere aux ambassadeurs dudit roy d'Angleterre, nouvellement arrivez en ladite ville d'Anvers, ${ }^{144}$ pour sentir et savoir d'eulx s'ilz ont quelque ordonnance ou charge de par icellui roy touchant ceste matiere. Et ce sceu par mondit seigneur, au surplus y adviser deliberer et concluire avec mesdis seigneurs de l'ordre comme il appartient. ${ }^{145}$

[234] [Die Ordensmitglieder befragen Hz. Maximilian und erfahren, dass der Kaiser prinzipell dem Orden zugeneigt sei, es aber Probleme wegen der Eidesleistung gäbe.]

\section{De l'ambassade pour Alemaingne ${ }^{146}$}

Apres ce a aussi esté parlé en ce conseil de l'ambassade a mettre sus et envoier es Alemaingnes devers les princes d'Alemaingne darrenier esleuz a l'ordre, ${ }^{147}$ pour leur signiffier les elections faites de leurs personnes audites laquelle significacion encore ne leur estoit faite. Et a esté humblement et reverenment interrogué mondit seigneur le souverain de la part de mesdis seigneurs les chevaliers freres s'il avoit eu quelzques nouvelles de messire Bertremy de Lichtestein $\{85\}$, chevalier frere de l'ordre, par lui envoyé devers l'empereur \{94\}, son pere, touchant le fait dudit ordre, afin qu'il lui pleust le leur communiquer. ${ }^{148}$ Surquoy mondit seigneur le souverain a respondu et dit, qu'il a sceu et se tient pour assez adverti que l'empereur, son pere, seroit bien enclin audit ordre pour le recevoir, mais sa principale difficulté estoit ou fait du serment a faire manuellement, surquoy il s'arreste le plus et sur ce fauldroit adviser et comuniquer avec lui. ${ }^{149}$

144 Nach Reg. 106 war eines der engl. Gesandtschaftsmitglieder Thomas de Montgomery; zu seiner Person vgl. die Angaben in $§ 268$ mit Anm. 309; zum regen Gesandtschaftsaustausch zwischen Burgund und England vgl. die Angaben in § 201, Anm. 14.

145 Die Befragung der engl. Gesandten hat wohl keine befriedigende Antwort gebracht, deshalb schrieb Hz. Maximilian an Kg. Eduard einen Brief, in dem er sein Missfallen über seine passive Haltung gegenüber dem Orden vom Goldenen Vlies zum Ausdruck brachte; vgl. Reg. 106. - Fortsetzung in § 268.

146 Ms.: Diese Zwischenüberschrift steht am linken Rand zu Beginn des folgenden Absatzes.

147 Gemeint sind damit Kaiser Friedrich III. \{94\}, Matthias Corvinus, Kg. von Ungarn, und Albert, Hz. von Sachsen \{96\}. - Fortsetzung von $§ 207$.

148 Zur Reise Bartholomäus von Liechtenstein zu Ks. Friedrich III. vgl. die Angaben in $\S 207$, Anm. 48.

149 Diese Angelegenheit endet hiermit in PB 4. Während des Ordensfestes von 1481 wurde die Wahl Ks. Friedrichs III. und Hz. Albrechts von Sachsen noch einmal bestätigt; vgl. PB 5, fol. 38v-41v und passim. 
[235] [Nach einer Diskussion, wie mit der Aufnahme des Hugues de Chalon, Herrn von Château-Guion, verfahren werden soll, wird beschlossen, mehrere Personen über die Umstände von dessen Freilassung zu befragen.]

\section{Touchant monseigneur de Chasteauguion ${ }^{150}$}

Oultre ce y a esté parlé de monseigneur de Chasteauguion, aussi darrenier esleu a l'ordre, auquel encore n'estoit signifiee son election, obstant que au temps d'icelle il estoit prisonnier en France et a esté longuement depuis, ${ }^{151}$ et combien que puis certain brief temps il soit retourné au pays. Toutevoie n'avoit jusques a orres peu savoir au vray monseigneur le souverain la maniere de sa deliverance, assavoir s'elle soit oultree et pleinere et s'il a parpayé sa rançon ou non. Et a esté l'advis ${ }^{152}$ d'aucuns de messeigneurs les chevaliers freres, que mondit seigneur mandast querir ledit seigneur de Chasteauguion pour s'en venir devers lui pardeça se faire le povoit bonnement, afin que lui venu on lui puist signifier et declarer sadite election a l'ordre et savoir de lui sa response de son acceptacion ou reffus. Aultres de mesdis seigneurs ont opiné que mondit seigneur pourroit envoier devers lui Thoison d'or, le roy d'armes, pour lui en faire ladite significacion et, s'il acceptoit sadite election, lui baillier le collier oudit cas et recevoir de lui le serment deu a l'ordre aux solemnitez et en la maniere accoustumees et pertinentes en tel cas, en le advertissant oudit cas par ledit Thoison d'or des futures prouchaines feste et chappittre de l'ordre qui au plaisir Dieu se tendroit, afin qu'il y vienne en personne, se faire le peut bonnement ou en cas de leal exoine y envoie sa procuracion seelee du seel de [fol. 66r/38r] ses armes, ordonnant ses procureurs aucuns des chevaliers confreres pour [1] esdites prouchaines feste et chappittre comparoir < pour lui> tenir son lieu et faire pour lui les devoirs ${ }^{153}$ qu'il appartient, et y envoie sa cedule pour l'election etc. Mais mondit seigneur le souverain, ouyes lesdis opinions, a volu et ordonné que preallablement et premiers que conclusion s'assee $^{154}$ sur ceste maniere, il soit enquis par bons moiens et secretement de monseigneur le prince d'Orenges ${ }^{155}$ et du maistre d'ostel dudit seigneur de Chasteauguion, ${ }^{156}$ nouvellement arrivez audit lieu d'Anvers, comment il en est touchant la deliverance d'icellui seigneur de Chasteauguion et se bonnement aussi il se pourroit absenter du

150 Ms.: Diese Zwischenüberschrift steht linken Rand zu Beginn des folgenden Absatzes. - Fortsetzung von $\S 221$.

151 Vgl. dazu § 134 mit Anm. 160.

152 Ms.: esté l'advis steht über einer Radierung.

153 Ms.: devoirs ist durch ein Tintenklecks nur schwer lesbar.

154 Lies: s'assoie.

155 Johann von Chalon-Arlay (1443-1502), Fürst von Orange, wurde 1478 zu Hz. Maximilians Statthalter in Burgund ernannt und bemühte sich letzlich vergeblich um den Erhalt der Freigrafschaft von Burgund. Im Januar 1480 war er einer der Taufpaten von Maximilians Tochter Margarete; zu seiner Person u. a. Bock, Maximilian, 1970, S. 49; Cools, Mannen, 2000, S. 272-274, Nr. 046. Anlässlich des Ordensfestes von 1478 hatten Ferdinand, Kg. von Kastilien $\{71\}$, und Jean de Melun $\{28\}$ ihn als mögliches neues Mitglied vorgeschlagen (vgl. Reg. 31 und 46) und auch beim Ordensfest von 1481 wurde er als einer der möglichen Kandidaten gehandelt (vgl. PB 5, fol. 38r und 40r).

156 Anfang 1477 versah Pierre de Jougne das Amt des Hofmeister von Hugues de Chalon; vgl. Gingins-La SARra, Recherches, 1857, S. 283. 
pays pour venir pardeça pour, apres ces choses sceues, y pren[d]re conclusion telle que avisee sera pour le mieulx. ${ }^{157}$

\section{[236] [Es folgt eine Vereinbarung zwischen Pierre de Luxembourg und Philippe de Croy.]}

Et finablement apres toutes ces choses ainsi proposees, deliberees et conclutes s'est illec levé de son lieu et mis a genoulx humblement et reverenment devant mondit seigneur le souverain presens messeigneurs les autres chavaliers freres dudit ordre dessus nommez, ledit messire Phelippe de Croy $\{74\}$, conte de Chimay, confrere d'icellui ordre, et a fait certaines remonstrances touchant le conte de Saintpol $\{83\}$, illec present. Et mondit seigneur de Saintpol lui a respondu et sur tout a esté ordonné et appointié comme il est declairé et contenu en certain actes sur ce fait du commandement de mondit seigneur pour la seurté des ${ }^{158}$ deux parties cy apres incorporé et escript, dont la teneur s'ensuit et est telle: ${ }^{159}$

[237] [Niederschrift über die Vermittlung des Ordens zwischen Pierre de Luxembourg und Philippe de Croy: Philippe de Croy beschuldigt Pierre de Luxembourg Negatives über seine Person zu verbreiten und dies auch noch nach einer durch Hz. Maximilian herbeigeführten Vermittlung in Brüssel. Nach längerer Diskussion erklärte sich Philippe bereit, in Maximilians Hand seine Unschuld zu beschwören, und Pierre akzeptierte dies als Ende der Auseinandersetzung.]

Acte de l'appointement et accord fait entre monseigneur Pierre de Luczembourg $\{83\}$, conte de Saintpol, d'une part, et messire Phelippe de Croy $\{74\}$, conte de Chimay, d'autre ${ }^{160}$

$[a]^{161}$ Le douzieme jour du mois de mars l'an mil quatrecens soixante dixhuit, ${ }^{162}$ mon tresredoubté seigneur monseigneur Maximilian, duc d'Autrice, de Bourgoingne et de Brabant etc., chief et souverain du noble ordre de la Thoison d'or, estant en sa ville d'Anvers, et devers lui pour l'eure assamblez en son hostel illec pour aultres besoingnes et affaires dudit ordre haulx, nobles et puissans seigneurs messeigneurs Loys, seigneur de Gruythuse $\{61\}$, conte de Wincestre, Phelippe de Croy $\{74\}$, conte de

157 Diese Angelegenheit endet hiermit in PB 4 und PB 5 wird seine Wahl in den Orden nicht mehr erwähnt. Vgl. dazu aber in der Einleitung S. 29.

158 Ms.: pour la seurté des steht über einer Radierung ist nur schwer lesbar.

159 Zur Ordensschiedsgerichtsbarkeit vgl. die Angaben in der Einleitung S. $31 \mathrm{f}$.

160 Ms.: Diese Zwischenüberschrift, die mit einem c/ für capitulum eingeleitet wird, steht vor Beginn des folgenden Absatzes. - Eine Abschrift des 17. Jh. dieser Vermittlungungsniederschrift befindet sich in BM Lille, ms. 626 (Recueil), fol. 273r-279v; danach Cat. gén. mss. bibl. publ. France, 26, 1897, S. 481-489, Nr. 626, hier S. 483 f. („Acte secret touchant l'appoinctement et appaisement faict en conseil du noble ordre de la Toison d'or, contre monseigneur le comte de Saint-Pol, d'une part, et monseigneur le comte de Chimay, d'autre, 1478 März 12“). Diese Angelegenheit erwähnt ohne Details STERCHI, Umgang, 2005, S. 412.

161 Ms.: Zur besseren Lesbarkeit dieses langen Paragraphen wurden Absätze und Unterpunkte eingefügt.

162 12. März 1479 (n. St.). 
Chimay, Guillaume, seigneur d'Egmonde et de Bair $\{78\}$, Pierre de Luczembourg $\{83\}$, conte de Saintpol et de Bryenne, Jaques de Savoye $\{84\}$, seigneur de Romont, et Jaques de Luczembourg $\{81\}$, seigneur de Fyennes, tous chevaliers freres et compaingnons, et reverend pere en Dieu messire Ferry de Clugny, evesque de Tournay, chancellier d'icellui ordre; monseigneur Adolph de Cleves \{55\}, seigneur de Ravesteyn, aussi chevalier frere et compaingnon dudit mesme ordre, lors estant audit lieu d'Anvers appellé mais excusé par maladdie. ${ }^{163}$

[b] Apres ce que mondit seigneur le [fol. 66v/38v] souverain et messeigneurs les chevaliers freres dudit ordre dessusnommez ensamble ledit chancellier, ainsi assemblez comme dit est, longuement illec avoient conferé et communiqué, besoingné et conclut entre eulx sur lesdis aultres besoingnes et affaires de l'ordre illec proposez et mis et termes ainsi que departir se vouloient, s'est illec levé de son lieu et siege et mis a genoulx humblement et reverenment devant mondit seigneur le souverain en la presence d'eulx tous ledit messire Phelippe de Croy, conte de Chimay, et a remonstré et dit:

[c] Qu'il estoit adverti de vray et par gens dignes de foy, que a monseigneur le conte de Saintpol, frere de ce noble ordre la present, se faisoient journellement pluseurs et divers rappors de lui sinistrement et contre verité a sa charge. ${ }^{164}$ Comme qu'il eust attempté, mis sus et pourchassé traitiez pour monseigneur le souverain et autrement devers le roy et ailleurs, ${ }^{165}$ desquelz mondit seigneur de Saintpol et les siens seroient forcloz, et querroit pour destruire et desfaire d'honneur, d'estat et chevance icellui monseigneur de Saintpol, non obstant et depuis l'appaisement fait entre eulx darrenierement a Brouxelles ${ }^{166}$ par moyen et en la presence de mondit seigneur le souverain et de mes tresredoubtees dames, par lui juré lors qu'ilz avoient esté appaisez et appoincties ensemble de toutes choses advenues ou temps passé jusques a lors et avoient promis amour et benivolence l'ung a l'autre comme serviteurs de mondit seigneur et freres d'ung mesme ordre. A cause desquelz rappors, comme bien il apprenoit, mondit seigneur de Saintpol y adjoustant foy lui vouloit mal et portoit mal talent a son grant tort sans sa desserte et sans cause, disant que onques depuis ledit temps, il n'avoit fait ne pourchassé par fait ne par parole en petit ne en grant chose prejudiciable ou derogant a mondit seigneur de Saintpol ne eu volunté de faire, ou contre les siens. Car aultrement il auroit tresmal fait tant a cause du service de mondit

163 Zur Einladung vgl. Reg. 103.

164 Worum es in dieser Auseinandersetzung ging, wird im folgendem nur z. T. erwähnt. Ein Grund, weshalb Pierre de Luxembourg grundsätzlich schlecht auf Philippe de Croy zu sprechen gewesen sein könnte, war, dass Philippe im Auftrag Hz. Karls von Burgund \{34\}, Pierres Vater Ludwig, den Konnetabel von Frankreich, gefangen genommen hatte, der dann 1475 an Frankreich ausgeliefert, im Auftrag Kg. Ludwigs XI. wegen Hochverrat zum Tode verurteilt und hingerichtet worden war; vgl. Cools, Mannen, 2000, S. 282; zu dem Prozess Paravicini, Peur, partiques, intelligences, ${ }^{2} 2002$; Blanchard, Commynes, 2008.

165 Philippe de Croy verlor als burgund. Truppenführer nach den Angriffen Kg. Ludwigs XI. im Mai 1478 mehrere Städte und war dann aber maßgeblich am Zustandekommen des einjährigen frz.-burgund. Waffenstillstandes beteiligt, der im Juli 1478 von Hz. Maximilian ratifiziert worden ist; vgl. dazu u. a. Born, Croy, 1981, S. 65; Cools, Mannen, 2000, S. 282; zum Waffenstillstand vgl. die Angaben unten in Anm. 180.

166 Lt. VAnder Linden, Itinéraires, 1934, S. 42-46, befanden sich Hz. Maximilian und Hz.in Maria zwischen dem 24. Sept. und dem 13. Dez. 1478 mit kurzen Unterbrechnungen seitens Hz: Maximilians in Brüssel. 
seigneur, ouquel il est, comme a cause dudit ordre dont ilz sont freres, et seroit digne de tresgrieve punicion s'il en estoit trouvé coulpable, ce que jamais ne se trouveroit par verité. Et se autrement se trouveroit cy apres ce que Dieu ne vueille, il n'en demanderoit point de grace, mais vouldroit estre autant puny du petit point comme du grant, s'il l'avoit commis.

[d] Desquelles choses ledit monseigneur de Chimay advertissoit mondit seigneur le souverain et messeigneurs lesdis freres de l'ordre pour sa descharge et excuse et pour entrement de l'amitié entre mondit seigneur de Saintpol et lui, soy submettant [fol. 67r/39r] entierement quant a ce a la correction et punicion de mondit seigneur et de l'ordre, s'il estoit trouvé coulpable du contraire.

[e] Ce oyant mondit seigneur de Saintpol il s'est aussi levé de son siege et mis a genoul $[\mathrm{x}]$ devant mondit seigneur le souverain humblement et reverenment respondant et disant en effect: Que verité estoit qu'il avoit puis certain temps ença en pluseurs et divers rappors touchans monseigneur de Chimay. Assavoir qu'il queroit et pourchassoit certains traitiez pour mondit seigneur le souverain devers le roy et aultrepart, desquelz lui et les siens seroient forcloz sans y estre comprins, et que autrement il contendoit et labouroit pour deffaire et destruire lui et les siens de tous poins, et encores depuis $\mathrm{v}$ ou vj jours ença il en avoit eu de jour a autre rappors et nouvelles de divers lieux. Ausquelz, s'il eust adjousté foy, il y eust autrement pourveu. Toutevoye il mettroit peine d'en savoir mieulx la verité et de s'en garder a son pouvoir. Et quant a ce que darrenierement avoit esté fait a Brouxelles, vray estoit que de l'ordonnance et commandement de mondit seigneur le souverain en la presence de mesdites dames, il s'estoit contenté des choses passees jusques a lors, mais ce qu'il disoit estoit advenu depuis et se practiquoit encore journellement contre lui et a son prejudice, comme il entendoit, dont, se ainsi estoit, il avoit bien cause de non soy contenter, car ce seroit contre les sermens et promesses darrenierement faictes, parquoy besoing lui estoit d'y obvier.

[f] Sur ce repliqua monseigneur de Chimay adreçant ses paroles a mondit seigneur de Saintpol <en> disant en substance: « Vous dites que je quiers et contens vous desfaire et destruire et ne dites en quoy ne comment ne nommez ceulx qui vous donnent entendre telles choses contre verité. Je vous dis que je n'en ay coulpe en fait ne en parole ne en volenté de le faire et que ne trouverez jamais le contraire, et toutevoie vous ne m'en voulez croire ne recevoir mon excuse, pour chose que je puisse faire ou dire. Mais voulez croire tous senistres rappors que mes hayneux querans mon mal vos pevent faire de moy et me menacez sans cause. Je n'en sauroie plus faire et suy reconforté d'attendre ce qui m'en peut avenir. »

[g] Ces remonstrances ainsi faites d'une part et d'autre et icelles oyes et entendues bien au long, par mondit seigneur le souverain et par $<$ mes $>$ aultres messeigneurs ${ }^{167}$ les chevaliers freres de l'ordre la presens, lesdites deux parties se sont retrait. Et mondit seigneur le souverain, eue deliberacion meure sur ceste matiere avec mesdis seigneurs les chevaliers freres et le chancellier de l'ordre, parties rappellees devant lui, a fait dire par mondit seigneur l'evesque de Tournay, chancellier dudit ordre, declaré et appointié:

[h] [fol. 67v/39v] Que monseigneur de Chimay feroit serment solemnel en la main de mondit seigneur sur sa foy et leaulté comme noble homme et sur le serment qu'il

167 Ms.: mes wurde nachträglich am linken Zeilenrand an seigneurs angehängt. 
a fait a l'ordre, que depuis l'appointement fait a Brouxelles comme dessus, il n'ait sollicité, procuré ne pourchassé par fait, par parolles ne autrement aucun traictié ne autre chose directement ou indirectement devers le roy ne ailleurs, pour en forclorre monseigneur de Saintpol, ne que lui puist deroguer, prejudicier ou porter mal ne dommaige en maniere quelconque ne aux siens, ne faire vouldroit ou pourchasser, et promett[e]roit vouloir le bien de mondit seigneur de Saintpol et eschiver son mal et dommaige a son povoir, ainsi comme ja aultrefois l'avoit juré et promis et comme en vertu des status dudit ordre les freres d'icellui sont tenus et doivent faire l'ung a l'autre. Et que moyenant ledit serment icellui monseigneur de Saintpol fust content, sans plus donner foy a quelzques senistres rappors que l'on lui pourroit faire de choses controuvees plus par fiction et malice que par verité pour troubler mondit seigneur le souverain et mettre ses parens et leaulx serviteurs de son hostel en division les ungs contre les aultres, ce que ne lui est point mestier, veue l'indisposicion du temps et ses grans affaires, mais lui pourroit torner a tresgrant inconvenient, prejudice et dommaige et consequenment a ses pays et subgiez.

[i] Surquoy a respondu et dit monseigneur de Saintpol qu'il enquerroit de la verité pour la savoir et selon qu'il trouveroit il se pourverroit et y obvieroit.

[j] Et monseigneur de Chimay a repliqué et dit non pas pour excuse de jurer, car il jureroit verité et Dieu, qui tout scet, scet qu'il est vray ce qu'il avoit dit. Mais puis que monseigneur de Saintpol comme il entendoit encore ne se vouloit contenter du serment qu'il feroit que chose vaine lui seroit de jurer, car il ne lui proufiteroit de riens. Neantmoins a l'ordonnance de monseigneur le souverain il vouldroit obeir. Et touchant les traictiez ou choses qu'il auroit poursu[iv]ys ou pourchassez devers mondit seigneur le souverain contre mondit seigneur de Saintpol, comme lui estoit donné entendre, dit qu'il n'en [fol. 68r/40r] demandoit autre tesmoing que mondit seigneur mesmes, qui mieulx le povoit savoir que autre homme du monde, parquoy lui supplia que son plaisir fust de dire la verité de ce qu'il en estoit. Et s'il se trouvoit autrement, il estoit encore content que monseigneur de Saintpol en fust son juge, pour en estre puny selon sa desserte. Mais jamais il ne se trouveroit par verité.

[k] Apres ces choses ainsi dites d'une part et d'autre, mondit seigneur le souverain a fait retraire de rechief lesdites parties. Et eue deliberacion sur tout avec mesdis seigneurs les chevaliers freres et chancellier de l'ordre, finablement icelles parties rappellees devant lui, a par la bouche dudit monseigneur de Tournay, chancellier, fait dire de rechief et ordonné a monseigneur de Chimay qu'il feist ledit serment pour sa descharge. A aussi fait dire et declarer a monseigneur de Saintpol qu'il n'avoit sceu ne apparceu en verité que le seigneur de Chimay eust sollicité, pourchassé ne poursu[iv] y devers lui, ne de par lui ou autrement quelzques traitiez ou choses contre lui ne qui lui fussent ou soient prejudiciables en fait ne en parole, et que se autrement le savoit il le lui diroit et le lui dira s'il en tienne le contraire. Et se monseigneur de Saintpol le trouvoit par verité qu'il le lui die. Car en ce cas mondit seigneur le souverain vouldroit estre aussi grant adversaire contre ledit seigneur de Chimay que monseigneur de Saintpol mesmes lui estre pourroit, et en feroit punicion telle que au cas appartendroit. Et requist mondit seigneur le souverain audit monseigneur de Saintpol que, veues ces choses et moyenant ledit serment, il se voulsist contenter dudit seigneur de Chimay. Et de par mondit seigneur le souverain traitié de paix ne se feroit, ouquel icellui monseigneur de Saintpol et les siens qui ont tenu son parti, fussent aucunement forcloz ne leurs biens, ains y seroient comprins eulx et leursdis biens. 
[l] En ensuivant laquelle ordonnance monseigneur de Chimay s'est mis a genoul, mettant sa main dextre en celle de mondit seigneur le souverain et a juré solemnellement sur sa foy, sur son honneur comme noble homme et sur les sermens qu'il avoit faiz a mondit seigneur et a l'ordre qu'il porte, que depuis ledit appaisement de Brouxelles il n'avoit par fait, par parolle, par escripture ne par autre moyen requis, pourchassé, sollicité ne poursu[iv]y directement, ne indirectement devers le roy ne aultre part aucuns traitiez ne aultres choses quelzconques qui puissent tourner au prejudice ou dommaige de mondit seigneur de Saintpol, [fol. 68v/40v] de son bien et honneur ou des siens, ne en voulenté de faire ne ne ${ }^{168}$ feroit doresenavant, mais vouldroit son bien et eschiver son mal et dommaige de son povoir, ainsi que leaulx freres dudit ordre doivent et sont tenus de faire l'ung a l'autre.

$[m]$ Lequel serment ainsi fait par ledit monseigneur de Chimay, il a dit et remonstré que de toute raison aussi monseigneur de Saintpol lui devroit promettre et jurer le semblable mesmement a cause dudit ordre. Sur ce mondit seigneur le souverain a requis mondit seigneur de Saintpol et lui a ordonné qu'il en fust content et le voulsist ainsi faire. Et monseigneur de Saintpol a dit et respondu a mondit seigneur le souverain que, puis que ainsi le ordonnoit il estoit content. Affermant par sa parolle qu'il ne vouloit mal a monseigneur de Chimay, ainsi vouldroit son bien et eschiver son mal.

[n] Ces choses faites, messeigneurs de Saintpol et de Chimay se ont approuchiez et ont embrassé et accueilly l'ung l'autre aimablement en lieu de touchier de la main et en signe de bon accord, paix et amitié d'entre eulx, car mondit seigneur de Saintpol portoit sa main en cerpe empeschee pour maladdie de gouttes. Et mondit seigneur le souverain m'a ordonné et commandé d'en faire registre.

$$
\mathrm{M}(\operatorname{artin}) \text { Steenberch }{ }^{169}
$$

\section{[fol. 69r]}

[238] [Es folgt die Kopie des Konzepts der Verschiebung des geplanten Ordensfestes auf das fahr 1480 sowie für die Absageschreiben.]

Copie de la minue de l'acte de la continuacion de la feste du noble ordre de la Thoison d'or, signifiee pour tenir a Brouxelles au second jour de may l'an xiiij ${ }^{\mathrm{C}}$ lxxix jusque a l'annee ensuivant, qui sera l'an xiiij ${ }^{\mathrm{C}}$ quatrevins. ${ }^{170}$

Ensemble des lettres closes du contremandement de ladite feste jusques a l'an revolu.

vacat. ${ }^{171}$

\section{[fol. 69v] vacat}

168 Ms.: Das erste ne steht am Zeilenende, das zweite am Anfang der zweiten Zeile; vermutlich handelt es sich hier um einen Schreibfehler Steenberchs.

169 Zur (offiziellen) Unterschrift Steenberchs vgl. Anm. 274. - Ms.: Der Rest der Seite ist unbeschrieben.

170 2. Mai 1479 bis 2. Maii 1480.

171 Ms.: Der Rest der Seite wie auch fol. 69v sind unbeschrieben bis jeweils ein vacat in der Mitte der Seite. 


\section{April 1479 in Gent}

\section{[fol. 70r/41r]}

L'acte de la continuacion de la feste de l'ordre signifiee pour tenir $\mathrm{a}^{172}$ Brouxelles en may l'an lxxxix jusques au may iiij ${ }^{\mathrm{xx} 173}$

[239] [Bei einer Ordensversammlung wird darüber diskutiert, ob das geplante Ordensfest Anfang Mai abgesagt werden soll, wofür folgende Gründe sprechen: Aufgrund der französischen Angriffe auf die verschiedenen burgundischen Herrschaftsgebiete, steht die Landesverteidigung im Vordergrund und unter den Truppenführer befinden sich zahlreiche Ordensritter, die deshalb unabkömmlich sind. Es ist zu befürchten, dass die schon bestehenden Unruhen in Flandern sich durch die Abhaltung des Ordensfestes verstärken werden. Auch Hz. Karl hatte schon aufgrund der unsicheren Lage ein Ordensfest verschoben, deshalb sei es durchaus legitim, aufgrund der vielfältigen Krisensituation das Fest $z$ u verschieben.]

$[a]^{174}$ Le xxije jour du mois d'avril l'an M cccc soixante dixneuf apres Pasques ${ }^{175}$ mon tresredoubté seigneur monseigneur l'archeduc Maximilian, duc d'Austrice, de Bourgoingne, de Brabant etc., chief et souverain du noble ordre de la Thoison d'or, estant en sa ville de Gand en son hostel de le Walle, ${ }^{176}$ illec et devers lui assamblez haulz nobles et puissans messeigneurs Jehan de Melun $\{28\}$, seigneur de Anthoing, Loys, seigneur de Gruythuse $\{61\}$, conte de Wyncestre, Josse de Lalaing $\{80\}$, seigneur de Montigny, et Piere, conte de Saintpol et de Brienne $\{83\}$, tous chevaliers freres et compaignons, ensemble les graffier et roy d'armes dudit ordre. Le chancellier pour les affaires de monseigneur en sa ville de Louvain lors occupé et le tresorier de l'ordre absens.

[b] Apres et que par l'ordonnance et expres commandement de mondit seigneur le souverain ${ }^{177}$ avoit esté mise en termes devant mesdis seigneurs les chevaliers, ses freres du mesme ordre, sa pe[r]plexité grande qu'il avoit touchans la feste et le chappittre dudit ordre pieça de par lui signiffiez et intimez pour les tenir en sa ville de Brouxelles

172 Ms.: Nach $a$ steht noch ein $B$ (rouxelles) und danach folgt die Folioangabe $x l j$; vermutlich hat der Schreiber festgestellt, dass Brouxelles nicht mehr in der Zeile Platz hat und nach dem $B$ aufgehört und mit Brouxelles eine neue Zeile angefangen.

173 Ms.: Die Zwischenüberschrift steht in der Kopfzeile der Seite. - In AOGV, Akten, Karton 5, Fasz. 14 A befindet sich ein Papierheft mit sechs Doppelblättern, in dem Steenberch (mit dem gleichen Schriftbild wie in PB 4; Wasserzeichen Einhorn [vgl. oben S. 38]) eine Abschrift der Diskussion vom 22. April 1479 um die Verschiebung des Ordensfestes (§ 239-250) erstellt hatte. Zwischen den letzten Seiten des Heftes sind lose die Briefe verschiedener Mitglieder eingelegt, die sich schriftlich zur Diskussion geäußert hatten; vgl. Reg. 112f. Eine Abschrift dieses Heftes (18. Jh.) befindet sich dazu noch in Brüssel, BR, ms. 20.851 (F. J. de Bors d'Overen, Histoire chronologique de l'ordre de la Toison d'or, Bd. 1), fol. 215r-222v; dazu Cat. mss. de BR, 12, 1936, S. 59, Nr. 7481/31.

174 Ms.: Zur besseren Lesbarkeit dieses langen Paragraphen wurden Absätze und Unterpunkte eingefügt.

175 22. April 1479.

176 Zur Genter Residenz vgl. die Angaben in § 8, Anm. 31.

177 Vgl. Reg. 114. 
au second jour du mois de may prouchain venant ${ }^{178}$ qui fort approichant, dont veuz ses grans affaires a lui nouvellement survenus, il se trouvoit en difficulté et faisoit grant doubte de non povoir tenir a ceste fois, qu'il ne lui tournast au grant dangier, detriment et retardement de sesdites affaires et du bien de ses pays et seignories tant de Bourgoingne et autres de pardela que de ceulx de pardeça, pour certaines raisons illec touchees qui en effect s'ensuivent:

[c] Assavoir la premiere: pour cause de certaines nouvelles que nagaires devant son departement de sa ville d'Anvers ${ }^{179}$ il avoit eues des estas de Bourgoingne et d'aucuns grans seignories du pays, mesmement que le roy de France avoit rompu ouvertement les treves oudit pays et y fait entrer ses gens de guerre en deux grandes puissances et de deux costez < que> qui avoient ja prins trois fortresses oudit pays. Et avec ce y faisoit tirer l'arri[e]re ban de son royaume pour gaster et destruire ledit pays et autres de pardela obeissans a mondit seigneur, qui sont de l'anchien patrimonie, de ma tresredoubté dame madame la duchesse, sa compaigne. ${ }^{180}$

[d] La seconde raison: pour ce que la pluspart de ses cappitaines, entre lesquelz a pluseurs qui sont freres et compaignons dudit ordre, comme messeigneurs le conte de Romont $\{84\}$, le conte de Saintpol, le conte de Nassouwe $\{77\}$ et messeigneurs de Bevre $\{82\}$ et Fiennes $\{81\}$, devroient oudit temps estre espars et necessairement occupez es frontires de ses pays et seignories de pardeça, pour la garde et deffense d'iceulx contre le[s] gens du roy et leurs aydans et complices venans [fol. 70v/41v] sur lesdites frontires pour entrer esdis pays de mondit seigneur et les gaster, piller et destruire s'ilz pevent. ${ }^{181}$ Et monseigneur le conte de Chymay $\{74\}$ se met sus a tout grant nombre de gens de guerre, dont il a charge, pour hastivement aler ou pays de Luczembourg a la garde dudit pays. ${ }^{182}$ Et monseigneur d'Egmonde $\{78\}$, aussi frere du

178 Vgl. Reg. 75-91.

179 Lt. VANDER Linden, Itinéraires, 1934, S. 50-52, hielt sich Hz. Maximilian zwischen dem 4. März und dem 19. April 1479 in Antwerpen auf.

180 Am 11. Juli 1478 hatten Maximilian und Kg. Ludwig XI. von Frankreich einen einjährigen Waffenstillstand geschlossen (vgl. dazu u.a. Mémoires de Commynes, III, 1747, S. 539-546, Nr. CCXCV f. [Druck]; MüNCH, Maria und Margarethe, II, 1832, S. 574-585; Regesten Friedrichs III., Suppl. 1, 2008, S. 61, Nr. 38; HaEmers, Common Good, 2009, S. 23). Kg. Ludwig XI. versuchte aber währenddessen an verschiedensten Fronten, die Burgunder zu schwächen. Auch in den burgund. Kernlanden, von denen er große Teile schon kurz nach Bekanntwerden von Hz. Karls \{34\} Tod annektiert hatte, ging er gegen die burgund. Verteidigungsbemühungen, die von Johann von Chalon-Arlay (vgl. § 235, Anm. 155) angeführt wurden, vor und zerstörte dabei u. a. Dole, Vesoul und das Amt Amont, auch Rochefort und Auxonne wurden erobert; vgl. dazu u. a. BARAnte/GACHARD, Histoire, II, 1838, S. 554-584 und 624-626; Roye, Chronique scandaleuse 2, 1896, S. $86 \mathrm{f}$.

181 Jakob von Savoyen war zu diesem Zeitpunkt der Oberkommandierende der flämischen Truppen (vgl. § 261, Anm. 283), aber auch die anderen Genannten waren an der burgund.-frz. Grenze tätig; vgl. u. a. Cools, Mannen, 2001, S. 373, Nr. 187, S. 251, Nr. 26; S. 356, Nr. 160.

182 Philippe de Croy bemühte sich zu dieser Zeit als lieutenant général, die Lage in Luxemburg zu beruhigen, das unter ständigen Angriffen frz. Truppen zu leiden hatte; vgl. Chevaliers de la Toison d'or, ${ }^{2} 2000$, S. 75 f., Nr. 74 und zur Lage in Luxemburg u. a. Bock, Maximilian, 1970, S. 49 f.; Recueil du Fay, 2003, S. 31-34. 
mesme ordre, doit estre en Gheldres, tant pour les affaires de mondit seigneur comme pour les siennes propres qui sont exoines tresnecessaires. ${ }^{183}$

[e] La tierce raison: Car le temps ouquel se feroit ladite feste et se tendroit ledit chappittre de l'ordre selon ladite significacion d'iceulx est la droite saison de apprester mondit seigneur et eulx et leurs gens de guerre et pour les mettre aux champs, tant pour donner secours aux pays de Bourgoingne comme pour pardela et pardeça resister et obvier ausdites entreprinses du roy et des siens, et aussi pour aler exploitier sa guerre a l'encontre de sesdis adversaires de toute puissance. Parquoy en cas que lesdites feste et chappittre de l'ordre se tendroient aux jour et lieu designez, ce seroit grant empeschement et destourbement pour mondit seigneur et pour lesdis chevaliers freres de l'ordre et autrement es affaires et choses dessusdites, dont mondit seigneur pourroit souffrir et prendre perte et dommaige irreparabiles [!] pour lui et pour sesdis pays et subgiez.

[f] La iiije raison: Car mondit seigneur le souverain est adverti que son peuple de ce pays de Flandres murmure ja fort a cause de ladite feste de l'ordre, quelle se deust tenir en ceste saison et occuper longuement mondit seigneur le souverain et messeigneurs les chevaliers freres dudit ordre et autres ses cappitaines et que trop mieulx vauldroit de la continuer jusques a l'annee avenir et de vaquer et entendre vigoreusement au fait de ladite garde et deffense des pays ${ }^{184}$ veue la grant necessité qui en est, mesmement a cause de ladite infraction desdites treves avenue du costé du roy, ainsi que feu monseigneur le duc Charles \{34\}, beaupere et predecesseur de mondit seigneur, autre fois l'avoit fait de ladite feste qu'il avoit conclue et signiffiee pour tenir en sa ville de Tret sur Meuse, ${ }^{185}$ laquelle depuis il continua pour cas sembl[abl]e et de trop moindre necessité que la presente.

[g] La v ${ }^{\mathrm{e}}$ raison: Car se inconvenient ou perte aucune avenist a mondit seigneur ou a ses pays de pardeça ou de pardela pendant l'occupacion et ou temps de ladite feste de l'ordre, ce que Dieu ne vueille, ladite perte vraisemblablement se imputeroit a l'ordre et diroit le peuple que mondit seigneur et l'ordre eussent mieulx fait de avoir prevenu les adversaires et acquis avantaige sur eulx par diligence faite en saison deue. Que le contraire en avenist par negligence ou a l'occasion d'icelle feste, consideré le grant devoir et acquit, ouquel s'est ja mis et met le peuple de pardeça, tant par avoir anticipé de quinze jours le payement pour les gens de guerre, comme d'eulx habillier et mettre [fol. 71r/42r] sus par tout pour secourier a mondit seigneur et a son armee de toute puissance, se besoing estoit et le cas le requeroit. ${ }^{186}$ Et mesmement attendu

183 Zur Lage in Geldern vgl. die Angaben in § 221, Anm. 84.

184 Bestärkt durch die von Hz.in Maria erteilten Privilegien, bemühten sich die Stände von Flandern um mehr Unabhängigkeit gegenüber dem burgund. Herzoghaus und stellten sich deshalb wiederholt gegen Hz. Maximilans Beschlüsse und Wünsche. Aber auch sonst führte die Unzufriedenheit über die politische und wirtschaftliche Situation in den burgund. Niederlanden vielerorts zu kleineren oder größeren Aufständen; vgl. dazu u. a. ausführlich Haemers, Common Good, 2009.

185 Am 11. Dez. 1475 hatte Hz. Karl zu einem Ordensfest in Maastricht eingeladen. Es wurde dann aber aufgrund der für Karl katastrophalen Ereignisse in der Schweiz im Frühjahr 1476 abgesagt; vgl. dazu PB 3, S. 22 und S. 183f., Reg. 68-72.

186 Zu den Verhandlungen über Steuern vgl. Haemers, Common Good, 2009, S. 39-44; dort (S. 26-61) auch allgemein zur finanziellen Situation Maximilians in seiner frühen burgund. Regierungszeit. 
que mondit seigneur est ou droit chemin pour tirer sur ses ennemis en la frontire de sesdis pays de pardeça, dont s'il retournoit vers Brouxelles pour y faire sadite feste, sembleroit ${ }^{187}$ ainçois reculement que avancement, dont le peuple pourroit murmurer de plus en plus et larguer et deputer ou a negligence, pusillanimité ou non chalance, et consequenment soy descourraiger et refroidir du grant vouloir qu'il a, et dorsemais soy rendre difficile ou contre disant aux payemens, aydes et secours qu'il a ja consentis et encommençié de faire a mondit seigneur d'argent bien liberalement, et aussi de leurs propres corps et biens plus amplement, se mestier estoit comme dessus est dit.

[240] [Dagegen stehen folgende Gründe für die Durchführung des Festes: Es wurde nun schon mehrfach über die Verschiebung des Festes diskutiert und jedes Mal hatten man sich für die Durchführung entschieden. Auch sind die verschiedenen Einladungs- und Vorladungsschreiben schon ausgesandt und Absageschreiben würden weitentfernt lebende Mitglieder nicht mehr rechtzeitig erreichen. Eine kurzfristige Absage des Festes würde auch den Anschein einer unsicheren Verhaltens seitens Hz. Maximilian und des Ordens erregen. Auch sollte es kein Problem sein, dass die Stellvertreter der Truppenführer, die am Ordensfest teilnehmen, deren Aufgaben erledigen können.]

\section{Au contraires et afin d'entretenir ladite feste prouchaine aux jour et lieu ja signifiez et designez ont esté alleguees les raisons qui s'ensuivent en effect: ${ }^{188}$}

[a] Assavoir la premiere: qui est la conclusion du chappittre de l'ordre darrenier precedent tenu a Bruges l'an xiiij ' lxxviij portant par expres que mondit seigneur le souverain tendroit la feste dudit ordre a l'encommencement du mois de may lors avenir, qui estoit et est le mois de may prouchain venant, remettant tout le surplus des affaires d'icellui ordre jusques a lors. ${ }^{189}$

[b] La seconde raison est: La deliberacion et conclusion confirmatoire sur ce depuis ensuye [!] et faite a Brouxelles par mondit seigneur, accompaignié de huit de messeigneurs les chevaliers freres denommez ou registre de cest acte, qui est du ix ${ }^{e}$ octobre darrenier passé. ${ }^{190} \mathrm{La}$ ou mondit seigneur le souverain par l'advis et deliberacion de mesdis seigneurs les chevaliers freres illec presens determina par expres, de tenir et faire ladite feste de l'ordre ou mois de may lors avenir et prouchain venant en sadite ville de Brouxelles et commanda faire et expedier les lettres closes et patentes necessaires pour ladite significacion et aussi la commission et les placcars pour adjourner ceulx qui estoient en France, tout selon l'exigence et qualité de messeigneurs ausquelz elles s'adreceroient. ${ }^{191}$

[c] La tierce raison: A cause d'une autre conclusion sur ce, renforcee depuis en ung conseil de l'ordre, tenu par mondit seigneur en sa ville d'Anvers le xije jour du mois de

187 Ms.: Die gleichzeitige Kopie (vgl. Anm. 173) schreibt an dieser Stelle ce sembleroit.

188 Ms.: Die Zwischenüberschrift steht vor dem folgenden Absatz. Bei diesem wurden zur besseren Lesbarkeit Absätze und Unterpunkte eingefügt.

189 Vgl. § 171.

190 Vgl. dazu die Eintragungen zur Versammlung am 9. Okt. 1478 in § 206-210.

191 Vgl. Reg. 75-91. 
mars darrenier passé, ouquel avoit vj de messeigneurs les chevaliers freres denommez en l'acte ensemble monseigneur l'evesque de Tournay, chancellier de l'ordre. ${ }^{192} \mathrm{La}$ ou fut mise en termes certaine difficulté a cause du lieu designé pour tenir ladite feste de l'ordre qu'estoit la ville de Brouxelles, veue l'apparente disposicion de la guerre etc. ${ }^{193}$ Et combien qu'il y eust eu deux de messeigneurs opinans [fol. 71v/42v] pour cause de ladite disposicion et des affaires de mondit seigneur, que plus honneste chose seroit de tenir ladite future feste de l'ordre en sa ville de Lille que audit Brouxelles, tant pour monstrer visaige aux ennemis, comme pour donner ceuraige a ses gens de guerre, bonnes villes et autres subgiez, mesmement seans en la frontire des ennemis et a tout son peuple. Toutevoie veue la significacion ja faite et les adjournemens de pluseurs notez en l'ordre pour comparoir personnellement au jour designé pour ladite feste audit lieu de Brouxelles, la conclusion de mondit seigneur le souverain avoit esté par la pluralité des voix d'ensuir et entretenir ladite significacion ja faite dudit lieu de Brouxelles pour lesdites raisons et certaines autres par lui y adjoustees.

[d] La iiije raison estoit: que consideré ladite significacion de la feste avenir de l'ordre ainsi faite et qu'il estoit trop tard pour la contremander ou changier le lieu d'icellui, il est vraissemblable que les roys et princes longtains et autres messeigneurs freres de l'ordre, qui pour l'exoine de leurs personnes venir ne pourront a ladite feste, envoieront leurs procureurs audit Brouxelles. Et quant a ceulx qui sont en France y adjournez par lettres patentes et par officiers d'armes ad ce auctorisé ${ }^{194}$ et les autres comme monseigneur de Cleves $\{47\}$, monseigneur de Bresse $\{68\}$ et monseigneur de Montagu $\{52\}$ y appellez aussi personnellement par lettres closes, ${ }^{195} \mathrm{ilz}$ s'adreceront a Brouxelles comme au lieu a eulx intimé et designé, cuidans y trouver mondit seigneur et le chappittre de l'ordre pour y faire leur devoir. Parquoy en cas que la feste ne s'entretiennue aux mesmes jour et lieu, lesdis adjournez et appellez pourront alleguer et pretendre juste excuse et faire protestacion de l'acquit et devoir y fais de leur costé, non obstant la continuacion ou autre mutacion, que depuis seroit faite a eulx non signifiee deuement par temps competent, et a ceste cause presumer d'avoir satisfait quant a leur honneur, et que l'ordre facillement apres ne pourra ou devra proceder a l'encontre d'eulx ne de leurdit honneur.

[e] La $v^{e}$ raison: Que de ladite continuacion ou autre mutacion que si feroit pourroit ensuir grant bruyt, oblocucion ou detraction contre l'onneur de mondit seigneur et de l'ordre par note de legierté et inconstance, ou ${ }^{196}$ mesmement du costé du roy et des siens grande derision et vantise qu'ilz auroient destourbé et empeschié mondit seigneur de tenir sa feste de l'ordre pour ceste annee, et l'an passé le parfait d'icelle.

[f] La vje raison: Que mondit seigneur le souverain en tenant ladite feste de son ordre ne laisseroit point a besoingner tant ou fait de sadite armee que en ses autres affaires, ne ses cappitaines aussi, veu que le temps d'icelle feste est si prouchain et que l'armee de mondit seigneur ne pourra estre preste si tost pour la mettre aux champs. Mais par les [fol. 72r/43r] lieutenans de sesdis cappitaines se pourroient garder les-

192 Zu den Eintragungen zur Versammlung am 12. März vgl. § 222-237; dort § 223 zur Festlegung des Austragungsortes für das Ordensfest.

193 Vgl. dazu die Eintragungen zur Versammlung am 12. März 1479 (n.St.) in § 222-237.

194 Vgl. Reg. 75-80.

195 Vgl. Reg. $81 \mathrm{f}$. und $89 \mathrm{f}$.

196 Ms.: Anstelle von ou schreibt die gleichzeitige Kopie (vgl. Anm. 173) et. 
dis frontires a tout les gens de guerre qui ja y sont ordonnez et toujours se pourroit preparer le surplus de l'armee ce pendant.

[241] [Eine weitere Möglichkeit wäre, dass der Souverän nur drei Tage persönlich am Fest teilnimmt. Die bis dahin nicht erledigten Agenden des Ordens könnten von verbleibenden Mitgliedern erledigt oder bis zum nächsten Fest verschoben werden.]

Ou s'il plaisoit ainsi a mondit seigneur le souverain et se besoing estoit, ladite feste encommencee par trois jours seulement, il la pourroit faire abbregier et s'en departir et aler entendre a ses autres affaires en laissant jusques a vj ont ${ }^{197}$ vij de messeigneurs sesdis freres pour continuer la divin service et expedier les plus hastifs affaires d'icelle, reservé son bon plaisir en remettant les autres affaires a l'autre chappittre avenir. ${ }^{198}$

[242] [Hz. Maximilian hatte sich mit vier Ordensmitgliedern und dem Kanzler zu einer außerordentlichen Sitzung versammelt, bei der sich die Mehrheit für eine Verschiebung des Ordensfestes aussprach. Es sollen aber auch noch die schriftliche Meinung anderer sich in der Nähe befindlicher Mitglieder eingeholt werden.]

Pour laquelle perplexité dessus touchee, mondit seigneur le souverain devant sondit darrenier departement d'Anvers avoit tenu conseil avec messeigneurs de Ravestein $\{55\}$, de Nassouwe $\{77\}$, d'Egmonde $\{78\}$ et de la Vere $\{79\}$, confreres, ensemble monseigneur l'evesque de Tournay, chancellier de l'ordre, lors y estans devers lui. La ou ceste matiere avoit esté mise en deliberacion. ${ }^{199}$ Et toutes ces raisons servans d'une part et d'autre y avoient esté touchees et debattues bien meurement et les opinions de mesdis seigneurs les chevaliers freres de par lui demandees et leur advis et conseil, s'il tendroit ladite feste de son ordre aux jour et lieu designez ou la continueroit. Et finablement l'advis et oppinion de mesdis seigneurs de Ravestein, d'Egmonde et de Nassouwe avoit esté de continuer ladite feste de l'ordre jusques a ung an et ou mesme lieu de Brouxelles, ou mise estoit, pour regart des grans frais que lesdis de Brouxelles avoient fais, a cause et sur l'espoir d'icelle, ce qui ne seroit pas roupture, ains continuacion de ladite feste et qu'il valait mieulx ainsi le faire pour les premieres raisons que autrement. Toutevoye n'avoient pas entendu mesdis seigneurs d'en faire conclusion jusques a ce qu'on eust les opinions d'aucuns autres chevaliers de l'ordre et mesmement de messeigneurs d'Anthoing $\{28\}$, de Gruythuse $\{61\}$, de Montigny $\{80\}$, de Saintpol $\{83\}$ et de Romont $\{84\}$, qui estoient en lieu prouchain, assavoir a Gand et a Bruges. Au regart de monseigneur de la Vere, il avoit fait difficulté de ladite continuacion pour les secondes raisons, cy devant touchees, et que selon povoit tenir ladite feste prouchaine et pourveoir aux dangiers des pays ce seroit ${ }^{200}$ le mieulx, sans

197 Lies: ou.

198 In dieser Variante war schon das Ordensfest im Jahr 1478 durchgeführt worden; Maximilian reiste auch wegen der Nachricht vom frz. Einfall schon kurz nach Beginn des Ordensfestes mit einem Teil der Mitglieder ab und ein anderer Teil blieb noch in Brügge, um die wichtigsten Ordensangelegenheiten weiter zu regeln; vgl. § 175.

199 Lt. VAnder Linden, Itinéraires, 1934, S. 50-52, hielt sich Hz. Maximilian zwischen dem 4. März und dem 19. April 1479 in Antwerpen auf.

200 Ms.: Die gleichzeitige Kopie (vgl. Anm. 173) schreibt an dieser Stelle dangiers ce seroit. 
toutevoye soy resouldre en son opinion jusques il auroit oye l'oppinion des autres messeigneurs dessusdis, car il estoit nouveau en l'ordre et ne savoit bonnement ce qu'il y convenoit faire. Parquoy desiroit d'en oyr les oppinions des autres comme il disoit. Et quant [fol. 72v/43v] a mondit seigneur le souverain, il avoit esté de l'advis et opinion de mesdis seigneurs de Ravestein, de Nassouwe et d'Egmonde, fondee sur les premieres raisons, pour cause mesmement des grandes occupacions, affaires et charges que lui survenoient tant de Bourgoingne comme autrement, ausquelz bonnement il ne pouroit pourveoir a souffisance en tenant ladite feste prouchaine. Toutevoye n'avoit pas entendu d'y faire conclusion pour celle fois, mais avoit envoyé Thoison d'or, son roy d'armes dudit ordre, devers lesdis seigneurs freres de l'ordre estans a Gand et a Bruges, a tout instruction servant au cas pour leur declarer les choses dessusdites et en avoir aussi leur opinion et advis par escript, signé de leurs mains, afin que la chose se conclusist en nombre de six de mesdis seigneurs les chevaliers freres ou plusgrant ou de tenir ladite feste prouchaine ou de la continuer. ${ }^{201}$

\section{[243] [Die in Gent weilenden Mitglieder Jean de Melun, Josse de Lalaing, Pierre de Luxembourg, Jakob von Savoyen und Jacques de Luxembourg stimmen für eine Verschiebung des Festes. $]^{202}$}

Et combien que mondit seigneur le souverain eust ainsi envoyé ledit Thoison d'or, roy d'armes, devers pluseurs de mesdis seigneurs chevaliers freres de l'ordre et mesmement devers ceulx qui la estoient et qu'il lui eust rapporté certaines cedules, signees de leurs mains, contenans leurs opinions et advis touchans ceste matiere, assavoir cellui de messeigneurs d'Anthoing $\{28\}$, de Montigny $\{80\}$, de Saintpol $\{83\}$ et de Romont $\{84\}$, daté du xviije jour de ce mois d'avril, qui estoit en effect: ${ }^{203}$ Que consideré que l'on avoit fait savoir aux rois et princes portans ledit ordre ladite feste a tenir prouchainement et que encore de rechief puis nagaire mondit seigneur eu avoit escript au roy d'Angleterre $\{63\},{ }^{204}$ veu aussi que les chevaliers estans en France ou parti contraire et autres estoient adjournez pour comparoir en personne a ladite feste et ou chappittre prouchains, ${ }^{205}$ que mondit seigneur le souverain pourroit bien tenir sadite feste aux jour et lieu designez et ordonner messeigneurs de Romont, de Fiennes $\{81\}$ et de Bevre $\{82\}$ pour avec autres ses cappitaines aians charge de gens d'armes obvier aux entreprinses du roy que le temps pendant il pourroit faire. ${ }^{206}$ Et pour faire et accomplir ce que les depputtez des membres le xvije jour de ce mois en accordant le payement des gens d'armes avoient requis a mondit seigneur de Saintpol et a messeigneurs du conseil ordonnez en Flandres, assavoir que la guerre se feist incontinent ${ }^{207}$ apres ledit payement fait, veu que le roy avoit rompu lesdis treves ouvertement ou conté de Bourgoinge. Et neantmoins pourroit encores mondit seigneur tenir sadite feste de l'ordre et que assez de chevaliers lui demouroient sans les trois dessus nommez, qui durant icelle feste pourroient a l'aide de Dieu par l'advis et ordonnance de mondit

201 Vgl. Reg. 111.

202 Ms.: Bei den Eintragungen zwischen fol. 72v (§ 243) und fol. 75v (§ 249) sind die Abstände zwischen den Absätzen kleiner als sonst üblich.

18. April 1479. - Vgl. Reg. 112.

204 Vgl. Reg. 106.

205 Vgl. Reg. 75-91.

206 Vgl. dazu die Angaben in Anm. 181.

207 Vgl. dazu die Angaben in Anm. 186. 
seigneur faire quelque bon exploit de [fol. 73r/44r] guerre, a l'onneur et au bien de lui et de ses pays et subgiez, qui pourroit aussi estre cause de faire rompre au roy son emprinse de Bourgoingne et donner au peuple de pardeça grant appaisement, et par ainsi n'auroit le roy coleur ne cause de dire que par crainte de lui mondit seigneur auroit laissié a tenir sadite feste. Toutefois s'il sambloit a mondit seigneur le souverain et aux autres messeigneurs dudit ordre que besoing fust, que mondit seigneur tirast incontinent en sa personne sur lesdites frontires de pardeça, ou qu'il ne fust bonnement possible de faire les explois de guerre presentement necessaires, y tenir sadite feste: en ce cas ilz seroient plus d'opinion de la continuacion d'icelle que autrement. Auquel advis mondit seigneur de Fiennes, depuis arrivé a Gand, devers lesdis autres s'estait conformé le $\mathrm{xx}^{\mathrm{e}}$ jour dudit present mois ${ }^{208}$ par son opinion, escripte et signee de sa main au dos ladite cedule.

\section{[244] [Ludwig von Brügge stimmt für eine Verschiebung des Festes.]}

Et mondit seigneur de Gruythuse $\{61\}$ par sa cedule ${ }^{209}$ a part signee aussi de sa main eust donné son opinion: Que se le murmure du pays estoit tel, que l'on disoit a aucun dommaige avenist en tenant ladite feste, consideré que les depputez des membres de Flandres et autres estas des pays de pardeça estoient pour l'eure devers mondit seigneur le souverain ou en chemin pour y aler, que ce seroit pour le mieulx, ou cas que l'on voulsist rompre ladite feste, que ladite rompture fust par bon moyen practiquee et faite a la requeste desdis membres et estas ou autrement. Et d'autrepart attendu le jour qui estoit si prouchain de tenir ladite feste et qu'il estoit pardeça, voix ${ }^{210}$ que mondit seigneur se deliberoit de venir a Gand et de tirer dudit Gand en Hollande, qui pourroit sambler a pluseurs alongement des ennemis et long du chemin que de leur monstrer visaige et d'entendre la provision du pays et reboutement desdis ennemis, que oudit cas icellui monseigneur de Gruythuse ne seroit point d'avis que l'en rompist ladite feste, se mondit seigneur n'estoit bien certain de faire quelque grant exploit sur ses ennemis par non tenir icelle feste, le tout a la noble correction de mondit seigneur le souverain et d'autres messeigneurs les chevaliers dudit ordre.

[245] [Angesichts der unentschlossenen Stellungsnahmen die Absage des Festes betreffend ruft Hz. Maximilian den Orden zusammen.]

Lesquelles cedules desdis advis ledit roy d'armes Thoison d'or eust diligenment rapportees a mondit seigneur. ${ }^{211}$ Toutevoye mondit seigneur les a trouvé aucun(es) doubteux et sans conclusion arrestee et ferme du tenir ou continuer sadite feste de l'ordre. Parquoy il avoit fait assembler devers lui a ceste heure messeigneurs qui l'a estoient, requerant et demandant de savoir ouvertement et clerement d'eux leur opinion et advis du faire ou continuer icelle feste.

[246] [Steenberch wird beauftragt, die verschiedenen Meinungen aufzuschreiben.]

Ce oyans, mesdis seigneurs de l'ordre pour rafrecier leur mémoire, tant de l'instruction $^{212}$ baillee audit Thoison d'or comme de leursdis advis, ilz ont requis a mondit

208 20. April 1479.

209 Vgl. Reg. 113.

210 Lies: voire.

211 Vgl. Reg. 112 und 113.

212 Vgl. Reg. 111. 
seigneur qu'ilz peussent avoir vision et lecture de ladite instruction ensemble de [fol. 73v/44v] leursdis advis. Laquelle lecture par ordonnance de mondit seigneur le graffier de l'ordre leur a faite, et entendue icelle leur a fait demander de rechief mondit seigneur leurdis advis.

[247] [Die anwesenden Mitglieder bitten den Souverän um Auskunft, ob es noch unbekannte Gründe gibt, die eine Verschiebung des Festes notwenig machen.]

Surquoy mesdis seigneurs, devant ${ }^{213}$ qu'ilz ont opiné plusavant, ont requis de savoir a mondit seigneur s'il avoit quelque secret affaire, raison ou emprinse sur mare pour cause desquelz vaulsist mieulx de continuer ladite feste que de la tenir pour ceste fois.

[248] [Hz. Maximilian erklärt, dass für ihn die Verteidigung seiner Herrschaften äußerst wichtig sei. Deshalb will er auch am kommenden Dienstag in Brügge mit den Vertretern Flanderns wegen deren Unterstützung verhandeln und hat Bedenken, dass er deshalb nicht rechtzeitig nach Brüssel zum Ordensfest anreisen kann. Auch warten der Prinz von Orange und andere auf seine Unterstützung in Burgund und einige geheime Aktionen an den verschiedenen Fronten sind angelaufen, die möglicherweise seine persönliche Anwesenheit erforderlich machen werden. Er zeigt sich skeptisch, ob es sinnvoll ist, selbst nur wenige Tage persönlich am Ordensfest teilzunehmen. Wie mehrere Ordensritter befürchtet er auch in Flandern verstärkte Unruhen. Im Anschluss von Hz. Maximilians Ausführung stimmen mehrere anwesende Mitglieder nach kurzer Diskussion für die Verschiebung des Festes.]

$[a]^{214}$ A quoy mondit seigneur le souverain a respondu et dit, que souverainement il avoit a ceur le fait de son pays de Bourgoingne qui estoit en dangier de perdicion ou de totale destruction, se hastivement il n'estoit aydé et secouru. Ce qu'il desiroit et vouloit faire par tous moyens a lui bonnement possibles et ne si vouloit espargnier. Et pour practiquer la chose qui est treshastive et ne peut souffir dissimulacion ou delay, il avoit ja prins jour pour estre en sa ville de Bruges, mardi prouchain ${ }^{215}$ au plus tard, tant pour y faire finance a ceste fin, comme pour besoingner touchans ceste et autres matieres necessaires pour le bien et seurté de ses pays de pardeça avec les depputez des membres de son pays de Flandres, ausquelz desja en avoit parlé et fait parler et y doivent lors estre au devant de lui.

[b] Mais consideré la feste de Bruges et autres empeschemens et affaires qu'ilz pourront avoir audit Bruges, doubtoit bien que, combien qu'il puist faire sa requeste et la meilleure diligence au surplus que possible lui sera, toutevoye vraisemblablement il ne pourroit avoir desdis membres ne d'autres avec lesquelz il auroit a besoingner

213 Ms.: Statt devant steht in der gleichzeitigen Kopie (vgl. Anm. 173) premiers.

214 Ms.: Zur besseren Lesbarkeit dieses langen Paragraphen wurden Absätze und Unterpunkte eingefügt.

215 27. April 1479. Lt. Vander Linden, Itinéraires, 1934, S. 53, reisten Hz. Maximilian und seine Frau Maria schon am 24. April von Gent nach Brügge. 
quant a ce $^{216}$ leur response absolue que le jour et temps ausquelz sa feste est intimee, qui sont si prouchains ne se passent, parquoy s'il la devroit tenir et pour icelle partir de Bruges et retourner a Brouxelles, il delaisseroit la chose imparfaite et sans conclusion, ce que moult lui desplairoit, tant pour le dangier et peril qui pevent advenir par le retardement dudit secours, comme a l'occasion de monseigneur le prince d'Orenges, son cousin, et autres de sondit pays de Bourgoingne solicitans leur expedicion et delivrance ${ }^{217}$ lesquelz sentans leur escargement a cause de ladite feste de l'ordre, s'en pourroient fort troubler, descouraigier et aussi en pourroit refroidir l'affection de ceulx desdis membres et d'autres qui aider et secourier y devroient.

[c] Et d'autrepart que ses cappitaines par lui envoiez es frontieres de ses pays de pardeça avoient de son sceu et par son ordonnance sur main certaine entreprinse secrete sur ses ennemis, dont messeigneurs povoient estres assez advertis. Laquelle feroit a executer entre cy et ledit temps intimé pour ladite feste. Laquelle emprinse, s'il plaisoit a Nostre Seigneur quelle s'exploitast bien, seroit honneste et bien prouffitable pour lui et pour ses pays et subgiez [fol. 74 r/45r] de pardeça, dont singulierement il convoitoit et desiroit avoir bonnes nouvelles et a cause d'icelle aussi s'avanceroit pour tirer audit Bruges, a fin d'estre plus pres desdites frontieres et pour plustost avoir nouvelles de sesdis capitaines, touchans ladite emprinse, et aussi du convive des adversaires qui pourroient estre telles que, toutes autres choses delaissees, il fauldroit que en sa personne et a toute la puissance de gens qu'il pourroit finer se meist a champs pour les aler secourir et son emploier au parfait de la chose selon l'exigence du cas.

[d] Tiercement qu'il estoit vray aussi que le temps pour mettre son armee a champs pour exploitier sa guerre a l'encontre de < sesdites $>$ sesdis ennemis fort approuchoit, pour laquelle haster et conduire lui convenoit encore faire tant en sa personne que par ses gens pluseurs grandes diligences, et lui faloit aler tant en Brabant comme en Haynnau, Hollande et Zeelande pour requerir et obtenir desdis pays ayde d'argent et service de ses vassaulx et subgiez d'iceulx. Pendant lequel temps s'appresteroit aussi le charroy pour son artillerie et les autres provisions se feroient en tel cas necessaires, afin que le plus tost qu'il lui sera possible il se puist mettre a champs a tout sadite armee et aler exploiter sa guerre a bon proufit par l'aide et grace Nostre Seigneur. En tous lesquelz ses affaires l'occupacion de sadite feste de l'ordre lui feroit et donneroit grant empeschement et retardement, ce que lui pourroit tourner a tresgrant prejudice et domaige et a sesdis pays et subgiez.

[e] Car pour entendre le fait de l'entretenement de sadite feste de l'ordre il lui fauldroit faire icelle par l'une des troys voyes. C'est assavoir: la premiere par la tenir oultrement et besoingner tout au long es besoingnes et affaires dudit ordre, qui sont grans et pluseurs jusques a l'expedicion d'iceulx. Laquelle chose, quant orres il n'auroit aultre affaire necessaire qui l'empeschast, il ne pourroit furnir dedans xv jours ou trois sepmaines apres icelle commencee. La seconde par aler commencer au jour icelle audit Brouxelles pour trois ou quatre jours et apres s'en partir et aler besoingner en ses autres affaires, en laissant aucuns des chevaliers freres pour continuer le divin service et remettant les affaires dudit ordre jusques aux autres feste et chappittre avenir. ${ }^{218}$ Et la tierce voye qu'il commest aucun de messeigneurs les chevaliers dudit ordre son

216 Vgl. dazu die Angaben in § 239 mit Anm. 186.

217 Vgl. dazu die Angaben in § 239 mit Anm. 180

218 Ms.: Die gleichzeitige Kopie (vgl. Anm. 173) schreibt an dieser Stelle chappittre apres avenir. 
lieutenant qui aille tenir en son nom ladite feste de l'ordre avec certain nombre des freres chevaliers d'icellui ensemble les officiers.

[f] Quant a la premiere voye, elle lui est impossible pour cause de ses grans affaires dessus touchiez, lesquelz et la saison du [fol. 74v/45v] temps ne pevent souffrir si grant retardement ou delay. Et quant a la seconde voie, elle ne lui seroit aussi bonnement possible sans grant retardement, reculement et empeschement de sesdites affaires attendu mesmement ladite emprinse secrete, de laquelle il attendoit nouvelles qui pourroient estre telles et si soudaines qu'il n'auroit pas espace ou respit de ij ou iij jours pour faire sadite feste, mais fauldroit que incontinent delaissez les habis ${ }^{219}$ et feste dudit ordre, il s'en partist et allast mettre a champs comme dit est. Mais au regart de la tierce voye qu'estoit de commettre ung lieutenant pour tenir et garder son lieu tant en l'eglise comme en chappittre durant ladite feste, elle lui seroit la plus faisable, car par ce moyen il pourroit vaquer et besoingner pendant icelle en ses autres affaires, par ainsi toutevoie qu'ilz le lui conseillent et leur semble, que par et selon les status de l'ordre bonnement il se puist faire, dont aussi demanda et requist avoir d'eulx leur advis et conseil.

[g] Lesquelles remonstrances de mondit seigneur le souverain oyes et entendues bien au long par mesdis seigneurs les chevaliers freres de l'ordre, de prime face ilz ont debattu ladite tierce et darreniere voye comme non expedient quant a present, veu que mondit seigneur au regart de sa personne n'a empeschement de maladdie ne autre accident, l'a Dieu grace, parquoy lui fust besoing de commettre lieutenant pour tenir la feste en son absence, aussi n'avoit jamais esté veu le cas semb[lab]le fait en l'ordre et aussi consideré, que pluseurs des freres et des principaulx convenoit a cause desdites affaires estre absens, que le chappittre seroit bien demi[nu]é du chief et d'iceulx principaulx freres.

[h] Mais entant qu'il touché les aultres deux voyes, veue la necessité de ses affaires et l'impossiblité de povoir par mondit seigneur en sa personne vaquer et entendre au fait de la feste, du chappittre et des affaires de son ordre, pour les raisons cy dessus par lui alleguees, combien que la continuacion de ceste feste leur eust semblé bien difficile de prime face pour les secondes raisons dessus touchees, neantmoins, les premieres raisons bien pesees, qui sont fort pregnantes et necessairement urgentes, avec la declaracion a eulx icy faite par mondit seigneur le souverain de son tresnoble et grant vouloir pour practiquer et donner ayde et secours a son pays de Bourgoingne et le delivrer du dangier ouquel il est et de soy emploier aussi en sa personne es frontieres et ailleurs pour la garde et deffence de des pays et seignories de pardeça et mesmement selon les nouvelles qu'il attend de sadite emprinse secrete, et aussi de apprester et haster sa grant armee pour la mener aux champs et aler mesmes par l'aide de Dieu exploitier [fol. 75r/46r] sa guerre a bon prouffit et vigoreusement contre sesdis ennemis et adversaires de toute puissance, tant pour preserver ses pays et subgiez a lui obeissans comme pour recouvrer ceulx que le roy et autres ses ennemis lui ont soubstrais et occupent, qui sont œuvres, exoines et excuses honnestes et legittimes et plus pregnans que l'observacion et entretenue de ladite feste pour ceste fois et aussi consideré l'advis et opinion des autres freres dessus nommez, assavoir de messires de Ravestein $\{55\}$, de Nassouwe $\{77\}$ et d'Egmonde $\{78\}$ declairez audit lieu d'Anvers, se sont cedit jour conclus et resolus de leurs opinions et advis en ceste maniere:

219 Ms.: habis ist dünn unterstrichen. 
[i] Assavoir monseigneur de Gruythuse $\{61\}$ et monseigneur de Saintpol $\{83\}$, attendu que depuis la venue de mondit seigneur le souverain en cestedite ville de Gand, ilz avoient plus amplement esté advertis du murmure du peuple de pardeça sourdant a cause de ladite feste de l'ordre a tenir a Brouxelles, qu'ilz dient estre l'alongement de lui et de ses capitaines, chevaliers dudit ordre, des frontieres de ses pays pardeça et de ses ennemis, et mesmement que par ceulx des membres de Flandres estans icy ilz estoient fort requis d'eulx emploier a ce que ladite feste soit continuee pour cause du grant inconvenient, trouble et murmure qui autrement sans doubte s'en ensuivroit et aussi empeschement pour mondit seigneur en ses aydes et affaires, se sont corrigiez de leur opinion premiere et joint avec l'oppinion de mondit seigneur le souverain et des messires de Ravestein, de Nassouw et d'Egmonde, qu'estoit de continuer ladite feste prouchain de l'ordre jusques a l'annee avenir par la maniere dite.

[249] [Auch Josse de Lalaing, Herr von Montigny, und Jean de Melun, Herr von Anthoing, sind für eine Verschiebung.]

Monseigneur de Montigny $\{80\}$ a dit pour son opinion premiere que se monseigneur le souverain vouloit aler prestement sur les frontieres de ses pays a consolacion de son peuple illec et pourveoir au fait de la garde d'iceulx et monstrer visaige a ses ennemis ou mesmement se pour cause de ladite emprinse secrete besoing estoit qu'il se meist aux champs ou s'il povoit faire quelque bon exploit sur sesdis ennemis, son opinion seroit pour ladite continuacion. Mais autrement il en faisoit difficulté, car au regart du fait de Bourgoingne, lui sembloit que combien que mondit seigneur pour ceste matiere soy voise a Bruges, toutevoie n'est pas vraisemblable que tantost apres sa proposicion et requeste faite ceulx des membres et autres lui facent si tost response, mais requerront et prendront delay, pour eulx retraire et deliberer de leurdite response. Ouquel cas mondit seigneur, ce ouy, s'il lui plaisoit les pourroit faire advertir, que entretant il yroit hastivement jusques a Brouxelles pour y estre au jour et faire et tenir sa feste pour trois ou quatre jours seulement et il laisseroit audit Bruges [fol. 75v/46v] monseigneur le prince d'Orenges, qui sollicite ${ }^{220}$ ledit secours de Bourgoingne, et autres de son conseil pour solliciter lesdis membres, afin de abbregier leurdite response pour l'avoir incontinent lui retourné de sadite feste de l'ordre audit Bruges et esperoit mondit seigneur de Montigny que, ceste chose ainsi faite et bien remonstree, appaiser et contenter tant ceulx desdis membres de Flandres comme mondit seigneur le prince d'Orenges et les autres de Bourgoingne demandans leur expedicion, <ilz faire contenteroient $>$ car leur expedicion n'en seroit pas retardee et ne perdroit point de temps mondit seigneur, mais feroit honneur et le devoir de son ordre. Lequel expedient ainsi ouvert par mondit seigneur de Montigny n'a point semblé convenable ne faisable a mondit seigneur pour les raisons cy devant alleguees de son costé, mesmement pour la briefté du temps que le pressoit. Parquoy ce oyant mondit seigneur de Montigny il s'est condescendu a ladite continuation avec les autres freres et chevaliers de l'ordre dessusdis. Et au regard de monseigneur d'Anthoing \{28\}, il a dit qu'il avoit ja donné son opinion par escript avec lesdis autres es jours passez. ${ }^{221}$ Et quant a la continuacion de ceste feste de l'ordre, la matiere lui sembloit difficile et parplexe. Neantmoins monseigneur le souverain savoit mieulx l'estat, disposion et la necessité de ses affaires qu'il

220 Ms.: Die gleichzeitige Kopie (vgl. Anm. 173) schreibt an dieser Stelle sollicter.

221 Vgl. Reg. 112. 
ne povoit faire, parquoy il s'en rapportoit a lui et aux autres messeigneurs, ses freres, qui la estoient pour en faire ce qu'ilz < de > aviseroient pour le mieulx.

[250] [Die Verschiebung des Festes um ein Jahr wird beschlossen. Alle Mitglieder und Amtsträger sollen demensprechend unterrichtet werden. Für den Fall, dass trotzdem einige Mitglieder nach Brüssel reisen oder Gesandte dahin schicken sollten, wird Toison d'or aufgefordert, nach Brüssel zu reisen und sie dort in Empfang zu nehmen. Steenberch wird beauftragt, einen entsprechenden Vermerk in das Protokollbuch einzutragen.]

\section{Conclusion sur ladite continuacion}

Parquoy finablement mondit seigneur le souverain, oyes et entendues lesdites opinions de mesdis seigneurs les chevaliers deliberees audit Gand et avec icelles jointes celles de mesdis seigneurs de Ravestein $\{55\}$, de Nassouwe $\{77\}$ et d'Egmonde $\{78\}$ qui audit lieu d'Anvers eu avoient opiné et donné advis par la maniere dessus touchee et lesquelles opinions ensemble joinctes avec celle de mondit seigneur le souverain, que sembleroit estre en nombre souffisant pour conclure sur la matiere dessusdite, mesmement consideré ladite necessité et pesé le xxije article des status dudit ordre faisant mencion du temps pour tenir et signiffier la feste de l'ordre. ${ }^{222}$ Lequel article monseigneur peut interpreter par l'advis et deliberacion de messeigneurs les chevaliers ses freres au bien de l'ordre et selon l'exigence et necessité de ses affaires, veu qu'il n'a passé que ung an que la feste et le chappittre dudit ordre furent tenues. A conclut pour ladite continuacion et a continué ladite feste ensemble le chappittre de sondit ordre du second jour du mois de may prouchain venant, ${ }^{223}$ ausquelz il les avoit intimez, jusques au second jour du may prouchain apres ensuivant l'an revolu, ${ }^{224}$ pour lors les tenir ou mesme lieu que intimez estoient, assavoir en sadite ville de Brouxelles et non ailleurs, pour consideracion [fol. $\mathbf{7 6} \mathbf{r} / \mathbf{4 7 r}$ ] mesmement et regart des grans frais et missions que a sa contemplacion et requeste lesdis de Brouxelles avoient ja fais et faisoient des apparaulx et aprestes et sur l'espoir d'icelle feste. Et pour tant que ce n'est que continuacion et pour autres bonnes causes et consideracions, a aussi ordonné mondit seigneur le souverain par ledit advis de le signifier aux autres seigneurs les chevaliers freres et aux chancellier et tresorier dudit ordre, ainsi qu'il appartendra. ${ }^{225}$ Et en oultre a continué jusques a lors mondit seigneur ${ }^{226}$ le souverain par l'advis dessusdites tous adjournemens pour comparoir en personne et autres significacions et explois qui fais estoient pour servir au second jour dudit mois de may prouchain, et iceulx et tous autres actes a faire a ladite prouchaine feste a remises et assignees, remet et assigne audit second jour de may l'an revolu et ou lieu de Brouxelles dessusdis. Et a mondit seigneur le souverain par l'advis de mesdis seigneurs ordonné et commis ledit Thoison d'or, le roy d'armes, pour aler et estre en ladite ville de Brouxelles sabmedi le premier

222 Zur Regelung der zeitlichen Abfolge der Ordensfeste vgl. die Angaben zu § 47 (neu $\S 22)$ der Statuten in Anm. 323. Vgl. dazu auch § 264.

223 2. Mai 1479.

224 2. Mai 1480.

225 Vgl. Reg. 115-125.

226 Ms.: Bei der Zeile, die mit a lors mondit seigneur beginnt, fängt am linken Rand eine über sieben Zeilen reichende senkrechte Linie an, vor der noch hic nota steht. 
jour de may prouchain ${ }^{227}$ a l'eure de midi et d'y sejourner et demourer par ce jour et les trois jours ${ }^{228}$ ensuivans entrement, afin d'y attendre de par et ou nom de mondit seigneur et pour l'ordre messeigneurs les chevaliers freres dudit ordre illec adjournez pour comparoir en personne esdites prouchain[es] feste et chappittre, que lors se y tenir devoient selon la forme des significacions et adjournemens a eulx faites et aussi aux aultres et leur declarer ou a leurs commis s'aucuns y envoient ${ }^{229}$ ladite continuacion faite de ladicte feste jusques a l'annee avenir, et prendre et recevoir d'eulx par ledit Thoison d'or toutes lettres et procuracions s'aucuns vueillent exhiber pour les apporter a mondit seigneur le souverain. En cas toutevoie que eulx ou leursdis commis ne vueillent aler jusques devers mondit seigneur a Bruges ou la ou il sera lors, ce que ledit Thoison d'or leur requerra de faire et ad ce les induira s'il peut et avec ce pour dire et faire par icellui Thoison d'or tout ce que appartient a l'effect de ladite continuacion et ce que s'en doit ensuir. De toutes lesquelles choses dessus contenues mondit seigneur m'a ordonné faire acte pour le mettre ou registre de l'ordre et en avoir memoire et souvenance d'icelle ou temps avenir.

\section{[fol. 76v/47v]}

\section{[251] [Es folgen die Kopien der Absageschreiben.]}

Cy ensuivent les copies des lettres closes qui par mondit seigneur le souverain en ensuivant la conclusion cy devant contenue, touchant la continuacion de sadite feste de l'ordre jusques a l'annee avenir, ont esté escriptes a messeigneurs de l'ordre absens.

\section{[252] [Absagebriefe an Adolf von Kleve und Jakob von Savoyen.]}

Et premierement a messeigneurs de Ravestein $\{55\}$ et de Romont $\{84\}$ en ceste forme: ${ }^{230}$

Treschier et tresamé cousin. Combien que, comme assez savez, pieça je eusse deliberé et conclut de tenir les feste et chappittre de mon ordre de la Thoison d'or en ma ville de Brouxelles au second jour du mois de may prouchain venant et que ainsi l'eusse signiffié a ceulx dudit ordre, comme il appartenoit. ${ }^{231}$ Toutevoie veu mon present tresgrant affaire a moy survenu nouvellement, tant du costé de France et des mes pays de Bourgoingne comme des frontieres de mes pays de pardeça, ne m'est bonnement possible d'entendre au fait desdites feste et chappittre d'icellui ordre pour ceste fois. Car que je suys informé que le roy de France en enfraingnant les treves darrenierement prinses et jurees entre lui et moy, a par ses gens et par exploit de guerre fait prendre trois fortresses en ma conté de Bourgoingne et qu'il y envoyé la pluspart de son armee ensemble l'arriere ban de son royaume, pour conquerir sur moy et a lui subjuguer madite conté de Bourgoingne et autres mes pays et seignouries de pardela estans de mon obeissance. ${ }^{232}$ Ains m'est besoing d'y pourveoir et obvier hastivement, toutes autres choses delaissees et mesmement veue ladite infraction desdis treves

227 1. Mai 1479.

228 Ms.: jours steht über der Zeile und eine Marke zeigt auf die dafür vorgesehene Stelle im Text.

229 Vgl. dazu Reg. 126 sowie Toison d'ors Bericht zu dieser Reise in § 256 und Reg. 127.

230 Ms.: Links vor diesem Eintrag befindet sich ein Doppelstrich. - Vgl. Reg. $115 \mathrm{f}$.

231 2. Mai 1479. Vgl. dazu die Einladungsschreiben an die Mitglieder in Reg. 83-88.

$232 \mathrm{Zu}$ den verschiedenen Krisenherden vgl. vor allem die Angaben in § 239. 
advenue du costé du roy conviendra que en ma personne et de toute puissance je m'emploie a la tuicion, garde et deffense de mes pays, seignories et subgiez de pardeça, a l'encontre de lui et d'autres mes ennemis et adversaires les voulans nuyre ou grever. Et a ceste cause par l'advis et deliberacion de mes treschiers freres, les chevaliers et compaignons dudit ordre estans lez moy, ay continué et remis lesdites feste et chappittre d'icellui ordre jusques a l'annee avenir, assavoir jusques au second jour du mois de may l'an xiiij ${ }^{\mathrm{C}}$ quatre vins, ${ }^{233}$ pour lors au plaisir Nostre Seigneur les tenir avec nosdis freres d'icellui nostre ordre au mesmes lieu de Brouxelles, tout ainsi que signifié les avoie pour l'annee presente. Laquelle chose je vous escrips et signifie, treschier et tresamé cousin, et vous en advertis par cestes, pour et afin que ne vous travaillez de aler audit lieu de Brouxelles pour ladite cause a ceste fois. Car pour les consideracions dessusdites et autres raisons que cy apres plus amplement vous entendiez et cognoistiez ay faite ladite continuacion et je vous en descharge et deporte par cesdites presentes jusques audit second jour de may l'an revolu. Treschier et tresamé cousin, Nostre Seigneur vous ait en sa benoite garde. Escript en nostre ville de Gand, le xxije jour du mois d'avril l'an lxxix. ${ }^{234}$

Maximilian, duc d'Austrice, de Bourgoingne etc.

[Superscription:] A mon treschier et tresamé cousin messire Adolf de Cleves, seigneur de Ravestein.

alia[s]

A mon treschier et tresamé cousin messire Jaques de Savoye, conte de Romont.

\section{[fol. 77r/48r]}

\section{[253] [Absagebrief an die übrigen Mitglieder.]}

En ceste forme a escript mondit seigneur a tous les autres messeigneurs les chevaliers freres de l'ordre qui ne furent a ladite conclusion de ladite continuacion faite a Gand. ${ }^{235}$

Treschier et feal cousin. ${ }^{236}$ Combien que, comme assez savez, pieça eussions deliberé et conclut de tenir les feste et chappittre de nostre ordre de la Thoison d'or en nostre ville de Brouxelles au second jour du mois de may prouchain venant et que ainsi l'eussions signiffié a ceulx dudit ordre, comme il appartenoit. Toutevoye veus noz presens tresgrans affaires a nous survenus nouvellement, tant du costé de France et de noz pays de Bourgoingne comme des frontires de noz pais de pardeça, ne nous est bonnement possible d'entendre au fait desdites feste et chappittre ne aux affaires

233 2. Mai 1480.

234 22. April 1479.

235 Ms.: Diese Zwischenüberschrift steht in der Kopfzeile oberhalb der zeitgenössischen Folienzählung und oberhalb des folgenden Absatzes. - Vgl. Reg. 117-122.

236 Die nun folgende Briefvorlage ist inhaltlich nahezu identisch mit dem Brief aus $§ 252$, deshalb vgl. dort den Nachweis zu verschiedenen genannten Details. Auffälliger Unterschied ist, dass Hz. Maximilian an Adolf von Kleve $\{55\}$ und Jakob von Savoyen $\{84\}$ in Ich-Form schrieb, an die anderen Mitglieder in pluralis majestatis. Nur wenige Mitglieder werden in den Absageschreiben mit tresamé cousin angeredet, die meisten mit feal cousin. Hier zeigt sich nun deutlich, dass trotz aller nach Außen hin getragen Gleichheit der Ordensmitglieder sehr wohl Standesunterschiede bestanden haben. 
d'icellui pour ceste fois. Car nous sommes informé que le roy de France en enfraingnant les treves darrenierement prinses et jurees entre lui et nous, a par ses gens et par exploit de guerre fait prendre trois fortresses en nostre conté de Bourgoingne et qu'il y envoyé la pluspart de son armee ensemble l'arriere ban de son < de son $>$ royaume, pour conquerir sur nous et a lui subjuguer nostredicte conté de Bourgoingne et autres noz pays et seignouries de pardela estans de nostre obeissance. Parquoy nous est besoing d'y pourveoir et obvier hastivement, toutes autres choses delaissees et mesmement veue ladite infraction desdis treves advenue du costé du roy conviendra que en nostre personne et de toute puissance nous emploions a la tuicion, garde et deffense de noz pays, $<$ s $>$ seignories et subgiez de pardeça a l'encontre de lui et d'autres noz ennemis et adversaires. Et a ceste cause par l'advis et deliberacion de noz treschiers freres, les chevaliers et compaignons dudit ordre estans lez nous, avons continué et remis lesdites feste et chappittre d'icellui nostre ordre jusques a l'annee avenir, assavoir jusques au second jour du mois de may l'an xiiij ${ }^{\mathrm{C}}$ quatre vins, pour lors au plaisir Nostre Seigneur les tenir avec nosdis freres d'icellui ordre au mesme lieu de Brouxelles, tout ainsi que signiffié les avions pour l'annee presente. Laquelle chose vous escrivons et signiffions, treschier et feal cousin, et vous en advertissons par cestes, pour et afin que ne vous travaillez de aler audit Brouxelles pour ladite cause a ceste fois. Car pour les consideracions dessusdites et autres raisons que cy apres plus amplement vous entendiez et cognoistiez avons faite ladite continuacion et vous en deschargeons et depportons par cesdites presentes jusques audit ${ }^{237}$ second jour de may l'an revolu. Treschier et feal cousin, Nostre Seigneur vous ait en sa benoite garde. Escript en nostre ville de Gand, le xxije jour du mois d'avril l'an ut supra.

[Superscription:] A nostre treschier et feal cousin et premier chambellan messire Phelippe de Croy $\{74\}$, conte de Chimay.

A nostre treschier et amé238 cousin messire Guillaume d'Egmonde $\{78\}$ et de Bair

A nostre treschier ${ }^{239}$ et feal cousin $<$ messire Phelippe de Bourgoingne> et cappitaine generale de Piccardie messire Phelippe de Bourgoingne $\{82\}$, seigneur de Bevre.

A nostre treschier et feal cousin et seneschal de Brabant messire Engelbert, conte de Nassow $\{77\}$ et seigneur de Breda
A nostre treschier et feal cousin ${ }^{240}$ messire Wolffart de Borssele $\{79\}$, conte de Grantpré, seigneur de Vere

A nostre treschier ${ }^{241}$ et feal cousin messire Jaques de Luxembourg $\{81\}$, seigneur de Fiennes

237 Ms.: audit steht über einer Radierung.

238 Ms.: amé ist dünn unterstrichen.

239 Ms.: treschier ist dünn unterstrichen.

240 Ms.: cousin ist dünn unterstrichen.

241 Ms.: treschier ist dünn unterstrichen. 


\title{
[fol. $77 \mathrm{v} / 48 v$ ]
}

\section{[254] [Kopie eines entsprechenden Briefes an den Ordenskanzler Ferry de Clugny.]}

\author{
Autre lettre a monseigneur l'evesque de Tournay ${ }^{242}$
}

Maximilian duc d'Ostrice, de Bourgoingne, de Brabant etc. Reverend pere en Dieu, treschier et feal. Depuis que sommes arrivez en ceste ville avons icy fais et remettre en deliberacion devant noz treschiers et feaulx les chevaliers, freres et compaingnons de nostre ordre icy trouvez la matiere de nostre perplexité et difficulté touchans le fait de la feste et du chappittre de nostredit ordre, que avions conclut et signiffié se devoir tenir en nostre ville de Brouxelles au second jour du mois de may prouchain venant. Et finablement pour cause de noz grans affaires qui pour le present nous occupent, destourbent et empeschent avons par leur advis et deliberacion en ensuivant l'oppinion de ceulx qui en oppinerent en nostre ville d'Anvers darrenierement, vous present, continué et remis lesdites feste et chappittre de nostredit ordre jusques a l'annee avenir. Ce que vous escrivons et signiffions et de ce vous advertissons, pour et afin que ne vous travaillez de aler audit Brouxelles pour ladite cause a ceste fois. Car par cestes nous vous en deportons jusques a l'annee avenir, veu ce que dit est. Reverend pere en Dieu, treschier et feal, Nostre Seigneur soit garde de vous. Escript en nostre ville de Gand, le xxije jour du mois d'avril l'an lxxix. ${ }^{243}$

[Superscription:] A tres reverend pere en Dieu nostre treschier et feal conseiller et chancellier de nostre ordre de la Thoison d'or, l'evesque de Tournay

\section{[255] [Die Stadtobrigkeit von Brüssel wird von Verschiebung des Ordensfestes un- terrichtet.]}

Autre lettre pour la ville de Brouxelles ${ }^{244}$

De par le duc d'Austrice, de Bourgoingne, de Brabant, de Lembourg etc., conte de Flandres, de Tyroll, d'Artois, de Bourgoingne etc.

Treschiers et bien amez. Combien que pieça par l'advis et deliberacion de noz treschiers et feaulx les chevaliers, noz freres et compaignons de nostre ordre de la Thoison d'or lors estans lez nous, eussions deliberé et conclut de faire la feste et solemnité et tenir le chappittre de nostre ordre de la Thoison d'or en nostre ville de Brouxelles au second jour du mois de may prouchain venant et que ainsi l'eussions signifié a ceulx dudit ordre comme il appartenoit et fust nostre parfait desir et vouloir de ainsi le faire. Toutevoye obstans noz presens tresgrans affaires a nous depuis et nouvellement survenues, tant du costé de France et de noz pays de Bourgoingne et autres de pardela comme des frontieres de noz pays de pardeça, ne nous est bonnement possible d'entendre au fait desdites feste et chappittre ne aux affaires dudit ordre pour ceste fois. Car veritablement sommes informé que le roy de France, obliant les treves darrenierement prinses et solemnellement jurees entre lui et nous pour duree jusques ou mois de juillet prouchain avenir et enfraingnant notoirement icelles, a par ses gens et par exploit de guerre fait prendre trois fortresses en nostre

242 Vgl. Reg. 123.

243 22. April 1479.

244 Ms.: Diese Zwischenüberschrift steht am linken Rand zu Beginn des folgenden Absatzes und ist mit geschweiften Klammern links und recht versehen. - Vgl. Reg. 124. 
conté de Bourgoingne et qu'il y envoyé la [fol. 78r/49r] pluspart de son armee et mesmement l'arriere ban de son royaume, pour conquerir sur nous et a lui subjuguer nostredis conté de Bourgoingne et autres noz pays et seignories de pardela, qui sont $\mathrm{du}$ tresancien patrimoine de nostre treschier et tresamee compaigne la duchesse et de nostre obeissance. Parquoy nous est besoing d'y pourveoir et obvier hastivement a toute diligence possible et toutes autres choses delaissees. Et mesmement, venue ladite infraction desdis treves advenue de costé du roy, comme dit est, conviendra que en nostre personne, de toute puissance nous emploions a la tuicion, garde et preservacion de noz pays et seignories de pardeça dessusdis, a l'encontre de lui et des siens et d'autres noz ennemis et adversaires par tout ou mestier sera. Et a ceste cause par l'advis et deliberacion de noz treschiers les chevaliers freres et compaignons de nostredit ordre estans lez nous, avons de certaine science par vraie necessité et pour eschivier plusgrant inconvenient continué, remis et delay lesdites feste et chappittre de nostre avan[t]dit ordre dudit second jour du mois de may prouchain jusques a l'annee revolu a jour semb[lab]le dudit mois de may apres ensuivant en vraye intencion et vouloir de tenir lors lesdites feste et chappittre de nostredis ordre devers vous en nostredite ville de Brouxelles, au plaisir Nostre Seigneur, tout ainsi comme signifié les avions pour l'annee presente. Laquelle chose vous escrivons et signifions, treschiers et bien amez, pour vous en advertir, trescontens de vous et du bon et grant devoir et acquit que avez fais et fait faire pardela, tant en l'eglise comme en nostre hostel et par tout ou mestier estoit des apparaulx et apprestes necessaires pour nostredite feste de l'ordre. Lesquelles, combien que ne puissent servir pour l'annee presente, toutevoye serviront et vendront bien apoint pour la feste de l'annee avenir, se Dieu plaist, enquoy nous avez fait grant et singulier plaisir et ne le oblierons point, mais recognoistrons devers vous en nostredite ville cy apres, quant chose sera que pour vous et $<a b>$ au bien d'icelle faire puissons bonnement, comme avons ordonné a nostre amé et feal chevalier et conseiller messire Phelippe de Chesne, seigneur de Loppoing, maistre d'ostel de madite compaigne la duchesse ${ }^{245}$, lequel envoyons devers vous presentement, ces choses et autres de nostre intencion vous dire et remonstrer de bouche de nostre part plus au long, auquel vueillez quant a ce pour ceste fois donner plaine foy et creance. Treschiers et bien amez, Nostre Seigneur soit garde de vous. Escript en nostre ville de Gand, le xxij jour du mois d'avril < Ainsi sign $>$ l'an lxxix. ${ }^{246}$

Ainsi signé: Maximilian

$\mathrm{M}(\operatorname{artin})$ Steenberch

[Superscription:] A noz treschiers et bien amez les bourgermaistres, echevins, conseil et maistres de la police de nostre ville de Brouxelles.

$245 \mathrm{Zu}$ seiner Person vgl. die Angaben in § 224 mit Anm. 100.

246 April 1479. 
[fol. 78v/49v] [unbeschrieben.]

[fol. 79r] $]^{247}$

[256] [Bericht des Toison d'or über seinen Aufenthalt zwischen dem 30. April und 4. Mai in Brüssel, um auf mögliche Besucher des abgesagten Ordensfestes zu warten.]

S'ensuit la relacion de Thoison d'or, le roy d'armes, du devoir par lui fait en la ville de Brouxelles au second jour de may l'an lxxix ${ }^{248}$ pour y attendre et recevoir les chevaliers estans en France adjournez pour en leurs personnes comparoir ou chappittre de l'ordre signifié pour tenir audit Brouxelles ledit second jour de may et es jours ensuivans oudit an lxxix. ${ }^{249}$

$[a]^{250} \mathrm{~A}$ vous ${ }^{251}$, treshault, tresexcellent et trespuissant prince, mon tresredoubté seigneur monseigneur Maximilian, par la grace de Dieu, archeduc, duc d'Austrice, de Bourgoingne, de Lothrijc, de Brabant, de Lembourg, de Luczembourg etc., conte de Flandres, de Tyroll, d'Arthois, de Bourgoingne, de Haynnau, de Hollande, de Zeelande etc., chief et souverain du tresnoble ordre de la Thoison d'or, et a vous, haulx nobles et puissans mes tresredoubtez seigneurs, messeigneurs les chevaliers freres et compaingnons dudit ordre, Gilles Gobert, dit Thoison d'or, roy d'armes d'icellui ordre, vostre treshumble et tresobiessant subget et serviteur, tout honneur et subiection, reverence et obiessance deues.

[b] Plaisir vous soit de savoir, mon tresredoubté seigneur et mes tresredoubtez seigneurs, que comme le xxije jour du mois d'avril darrain passé a vous, mondit tresredoubté seigneur monseigneur le souverain, lors estant en vostre ville de Gand, apres la conclusion illec prinse par l'advis et deliberacion de pluseurs d'entre vous, mesdis seigneurs les chevaliers freres et compaignons dudit ordre, illec devers vous, mesdis seigneurs, lors assamblez, sur et touchant la continuacion de la feste dudit ordre depuis le second jour du present mois de may lors prouchain et presentement passé, ${ }^{252}$ auquel elle estoit signiffié et intimé jusques au second jour du mois de may prouchain apres ensievant qui sera l'an revolu et au mesme lieu de Brouxelles auquel tenir se devoit, eust pleu en la presence et par l'advis de mesdis seigneurs lors estant vers vous, moy ordonner et commander, que je me tirasse audit lieu de Brouxelles pour y estre le premier jour de ce present mois de may a l'eure de midy ou mesmement a l'eure de

247 Ms.: Der folgende Bericht hat keine zeitgenössischen Folienzählung und befindet sich als Doppelblatt (fol. 79r-80v) im Anschluss an die Lage fol. alt 40b-40v.

248 2. Mai 1479.

249 Steenberch scheint sich hier bei seiner Abschrift genau an die Vorlage des Originals gehalten zu haben, denn es fallen einige orthographisch für ihn unübliche Schreibweisen auf; zur Überlieferung vgl. Reg. 127.

250 Ms.: Zur besseren Lesbarkeit dieses langen Paragraphen wurden Absätze und Unterpunkte eingefügt.

251 Ms.: Ein kleines Loch im Papier macht vous schwer lesbar. Zur besseren Lesbarkeit dieses langen Paragraphen wurden Absätze eingefügt.

252 Zum Ablauf der Sitzung am 22. April 1479, die zur Absage des einberufenen Ordensfestes führte, und zu den in diesem Zusammenhang ausgestellten Schriftstücken vgl. $\S 239-255$. 
vespres au plus tard et illec sejourner, demourrer et attendre par les trois jours appres continuellement ensievans ledit premier jour de cedit mois. ${ }^{253}$

[c] Afin de y recevoir par vostredite ordonnance et ou nom de l'ordre dessusdis messeigneurs les chevaliers freres d'icellui ordre, qui par mandemens patens, donnees en forme de placcars, et par bouche d'officiers d'armes a ce auctorisez par commission especiale, seelé du seel de mesme ordre, ou par lettres closes y estoient adjournez ou appellez pour comparoir personnellement ou aultrement aux jours et lieu que dessus esdites feste et chappittre de l'ordre qui tenir se devoient, ou leurs procureurs et commis qui pour eulx illec comparoient, et leur signiffier et denonchier ladite continuacion de ladite feste ainsi faite pour causes raisonn(able)s et moult necessaires ensemble la continuacion des adjournemens et signifficacions a eulx faites, et leur declairer comment tout estoit continué et remis ou meisme estat au second jour dudit mois de may prouchain [fol. 79v] l'an mil quatrecens et quatre vings et au mesme lieu dudit Brouxelles. ${ }^{254}$ Et lesdis comparicions et aussi les procuracions et toutes autres lettres et choses que exhiber vaudroient chascun a son endroit prendre et recevoir, en cas toutesvoies et par ainsi que par mon exhortacion et indinction que leur feroie ilz ne voulsissent venir devers vous, mondit seigneur le souverain, en vostre ville de Bruges ou ailleurs la ou vous serrez. Et par moy oudit cas le tout vous rapporter feablement, afin de au surplus en ordonner comme il appartendroit.

[d] Je en obeissant a vostredictes ordonnance et commandement me suys transporté en vostredite ville de Bruges des vendrey, darrain jour dudit mois d'avril passé, devant midy, et illec ay sejourné et attendu par tout le jour et oultre les premier, second, tiers et quatreisme jours dudit present mois de may continuellement, et entierement y suys demouré sans m'en departir. ${ }^{255}$

[e] Et mesmement ledit premier jour de cedit mois de may environ deulx heures apres midy et devant l'eure de vespres me suys transporté en l'ostel de vous, mondit tresredoubté seigneur le souverain, et illec suys demourez sans m'en bougier jusques apres six heures du vespre sonnees.

[f] Et lendemain, qui fut le second jour dudit mois de may, y suys retourné a l'eure de sept heures du matin et demouré jusques a neuf heures, lors que avec reverend pere en Dieu monseigneur Ferry de Clugny, evesque de Tournay, chancellier du mesme ordre, la estant suys allé oyr la grant messe en l'eglise collegial de Sainte Goudele audit Brouxelles, qui estoit l'eglise ordonnee pour y faire ledit jour le divin service accoustumé pour la feste dudit ordre en cas qu'elle si fust tenue. ${ }^{256}$ Et en ladite eglise sommes esté a ladite grant messe des l'encommencement jusques a la fin d'icelle, mondit seigneur l'evesque de Tournay, chancellier, maistre Martin Steenberch, doyen de ladite eglise, graffier, et moy, roy d'armes dudit ordre, et de la sommes venus disner ensemble avec mondit seigneur de Tournay, chancellier. Et l'apres disner suys de rechief allé en ladite court en la grant salle et ailleurs en vostredite hostel, moy pourmenant ${ }^{257}$ tant dedans comme de hors devant icell[u]y jusques apres trois heures apres midy, lors que nous, trois officiers dessus nommez, pour aultres affaires dudit ordre sommes alles en la maison de la ville audit Brouxelles.

254 Vgl. dazu die zahlreichen Einladungs- und Vorladungsschreiben in Reg. 80-91.

255 30. April bis 4. Mai 1479.

256 Vgl. dazu § 224.

257 Lies: promenant. 
[g] Et le tiers jour dudit mois de may apres ce que longuement me estoie pourmené [!] tant en ladite court et devant icelle que es autres lieux dudit hostel ay accompaignié mondit seigneur l'evesque de Tournay et suys allé avec lui, oyr le grant messe en l'eglise de Saint Jaques de Coudenberghe, seant empres ledit court.

[h] Et le mesme jour apres disner [fol. 80r] et lendemain, qui fut le iiij jour dudit present mois de may, ${ }^{258}$ me suys de rechief et souventesfois allé pourmener [!] tant en ladite court comme devant icelle et allé audit hostel, tousjours gardant, accoutant et attendant, se personne de mesdis seigneurs de l'ordre y adjournez, appellez ou intimes y verroient et comparoient ou aultres pour eulx ou aucun d'iceulx.

[i] Mais personne quelconque n'y est venue, presentee ne comparue durant lesdis quatre jours et n'ay peu sçavoir, entendre ne apparcevoir que aucun y ait esté soy renommant pour aucun de mesdis seigneurs de l'ordre quel qu'il fust pendant ne durant les jours et temps dessus declairez.

[j] Laquelle chose je afferme et certiffie a vous, mondit tresdoubté seigneur monseigneur le souverain, et a vous, mes aultres seigneurs les chevaliers freres et compaignons de l'ordre dessusdis, ensemble a tous autres cui ce regardera, comme chose veritable par ceste ma relacion pour valloir audit ordre et autrement ainsi qu'il appartendra. Laquelle ma presente relacion en tesmoignaige de verité, j’ay signé de ma main et seelé de mon seel audit lieu de Brouxelles, le $\mathrm{v}^{\text {me }}$ jour dudit mois de may l'an milquatrecens soixante et dix neuf. ${ }^{259}$

\section{Dezember 1479 in Gent}

\section{[fol. 81r/50r] ${ }^{260}$}

\section{[257] [Auf einer Sitzung Ende Dezember 1479 wird beschlossen, dass auch 1480} kein Ordensfest veranstaltet werden soll.]

Touchant la continuacion de la feste de l'ordre du second jour du mois de may l'an xiiij ${ }^{\mathrm{C}}$ lxxix jusques a autre temps convenable, comme apparra par les actes ensuivans. ${ }^{261}$

Le $x_{x i x}{ }^{e}$ jour du mois de decembre l'an mil cccc soixante dixneuf ${ }^{262}$ mon tresredoubté seigneur monseigneur l'archeduc Maximilian, par la grace [de] Dieu duc d'Austrice, de Bourgoingne, de Brabant etc., chief et souverain du noble ordre de la Thoison d'or, estant en sa ville de Gand, et par son ordonnance ${ }^{263}$ illec devers lui lors appellez et assamblez haulx nobles et puissans messeigneurs Jehan, seigneur d'Anthoing \{28\}, Jehan, seigneur de Lannoy $\{50\}$, Josse, seigneur le Montigny $\{80\}$, Pierre de Luczembourg $\{83\}$, conte de Saintpol, Jaques de Luxembourg $\{81\}$, seigneur de Fyennes, et monseigneur Jaques de Savoie $\{84\}$, conte de Romont, tous chevaliers freres [et] compaignons, ensamble reverend pere en Dieu messire Ferry de Clugny, evesque de Tournay, chancel-

258 4. Mai. 1479.

259 5. Mai 1479. - Ms.: Der Rest der Seite und fol. 80v ist unbeschrieben.

260 Ms.: Fol. 81r-82v befindet als (einzelnes) Doppelblatt in die Lage eingefunden, ist aber im Gegensatz zum vorgehenden Doppelblatt (fol. 79r-80v) zeitgenössisch foliiert.

261 Diese Versammlung erwähnt auch BAUchau, Jacques de Savoie, 1992, S. 142 (datiert 24. Dez.).

262 29. Dezember 1479.

263 Vgl. Reg. 128. 
lier dudit ordre, pour communiquer et aviser sur aucunes affaires d'icellui ordre. Fut illec par l'ordonnance de mondit seigneur le souverain mis en termes par mondit seigneur le chancellier le fait des futures feste et chappittre general du mesme ordre pour aviser et deliberer, se lesdites feste et chappittre se pourroient tenir et celeber au mois de may prouchain venant selon la continuacion qui en avoit esté faite ou mois de may darrenier passé. ${ }^{264} \mathrm{Ou}$ se encores differer et delayer se devroient jusques a l'autre annee prouchaine apres ensuivant qui seroit l'an quatrevins et ung, pour cause des guerres et d'autres grans affaires qui vraissemblablement occuperoient et empescheroient tant mondit seigneur le souverain comme la pluspart de messeigneurs les chevaliers freres du mesme ordre a ladite saison prouchaine. Et apres pluseurs raisons et motifs sur ce ouvres par forme de loqueture persuadans et tendans a l'une fin et a l'autre, assavoir les unes pour tenir ladite feste en may prouchain et les aultres pour la differer et delaier jusques a l'annee apres ensuivant. Et la matiere bien debattue et aussi deliberee par opinions, a esté l'advis que plus expedient estoit pour le bien de mondit seigneur le souverain et de ses affaires et pour la conservacion de ses pays et subgiez ${ }^{265}$ tout consideré de differer et delayer encore ladite feste et le chappittre general du devantdit ordre jusques a autre temps que mondit seigneur le souverain et messeigneurs les chevaliers, sesdis freres, par la grace Dieu mieulx et plus convenablement et a meilleur loisir et commodit puissent et pourront faire et tenir icelle leur feste et chappittre et vaquer et entendre plus longuement et meurement aux grandes besoingnes et affaires d'icellui ordre que vraissemblablement faire ne pourroient a ladite saison prouchaine, pour pluseurs raisons qui sur ce furent alleguees et remonstrees. Parquoy mondit seigneur le souverain, soy conformant a l'advis et deliberacion que dessus, a accordé de delaier et differer encore pour ladite saison prouchaine avenir lesdites feste et chappittre de son ordre jusques a aultre temps plus convenable. Neantmoins vouloit bien qu'il eu fust encore parlé et communiqué cy apres avec aultres messeigneurs chevaliers freres de l'ordre quant il s'en trouveroit en quelque lieu mieulx accompaingnié.

\section{[258] [Die weitentfernt lebenden Mitglieder sollen über die Verschiebung des Festes unterrichtet werden.]}

Apres fut lors parlé oudit conseil par ordonnance de mondit seigneur et demandé l'advis de mesdis seigneurs les chevaliers freres de l'ordre, s'il sembleroit bon de advertir les roys et princes longtains, chevaliers freres de cest ordre, des continuacions qui ainsi s'estoient faites et faisoient desdites futures feste et chappittre dudit ordre ensemble des causes et motifs d'icelles. Et les opinions sur ce demandees, portoit l'advis et deliberacion de messeigneurs, que bon seroit d'en escripre aux absens, mesmement estans en loingtaines marche. Mais de la forme et maniere comment, l'on pouroit deliberer plus amplement et conclure a ladite prouchaine assamblee de mesdis seigneurs et jusques a lors l'on sur servoit de ladite escripture, car ce pendant pourroient survenir

264 Vgl. die Beschlussfassung in § 250 .

265 Trotz Maximilians Sieg gegen die Franzosen bei Guinegatte (vgl. Anm. 286) im Sommer 1479 gab es auch weiterhin in seinen Herrschaftsgebieten unzählige Krisenherde; vgl. dazu u. a. Bock, Maximilian, 1970, S. 44 ff.; Wiesflecker, Maximilian, 1, 1971, S. 150-154; Haemers, Common Good, 2009, S. $21 \mathrm{ff}$. 
choses et matieres, raisonables et honnestes selon la disposicion du temps pour colorer et funder lesdis continuacions ja faites tant pour l'annee passee comme la presente. ${ }^{266}$

[fol. 81v/50v]

[259] [Steenberch erhält vom Ordenskanzler den Auftrag, die Beschlüsse zu notieren.]

Lesquelz deux poins j'ay icy mis et enregistrez par l'ordonnance et rapport de mondit seigneur l'evesque de Tournay, chancellier de l'ordre, car je n'avoie point esté a Gand a la deliberacion d'iceulx, mais estoie lors absent et m'en fist mondit seigneur le chancellier ledit rapport a Brouxelles, le $x^{\mathrm{e}}$ jour du mois de janvier l'an lxxix dessusdit. ${ }^{267}$

\section{Januar 1480 in Brüssel}

[260] [In einem größeren Kreis diskutieren die versammelten Ordensangehörigen erneut über die Verschiebung des Ordensfestes. Dabei wird beschlossen, dass das nächste Ordensfest im Mai 1481 abgehalten werden soll, sofern die politische Situation dies zulässt.]

Acte de la continuacion de la feste de l'ordre depuis may l'an xiiij ${ }^{\mathrm{C}}$ iiij $^{\mathrm{xx}}$ jusques au may iiij ${ }^{\mathrm{xx}}$ et ung ou aultre temps convenable.

$[a]^{268}$ Le lundi, xvije jour dudit mois de janvier oudit an xiiij $^{\mathrm{C}}$ soixante dixneuf ${ }^{269}$ mondit tresredoubté seigneur monseigneur le duc, chief et souverain du noble ordre de la Thoison d'or, estant en sa ville de Brouxelles ${ }^{270}$ et devers lui estans lors appellez et assamblez en son hostel en la chambre de son retrait illec environ $\mathrm{x}$ heures devant disner haulx, nobles et puissans mes redoubtez seigneurs, assavoir monseigneur Adolf $\{55\}$, frere $\mathrm{au}^{271}$ duc de Cleves $\{47\}$, seigneur de Ravestein, messire Loys de Bruges $\{61\}$, seigneur de Gruythuse, conte de Wyncestre, messire Phelippe de Croy $\{74\}$, conte de Chimay, premier chambellan, messire Engelbert, conte de Nassouwe $\{77\}$, seigneur de Breda, monseigneur Pierre de Luczembourg $\{83\}$, conte de Saintpol et de Bryenne, messire Phelippe de Bourgoingne \{82\}, seigneur de Bevre, messire Jaques de Luczembourg $\{81\}$, seingeur de Fyennes, et monseigneur Jaques de Savoye $\{84\}$, conte de Romont, tous chevaliers freres et compaingnons, ensemble reverend pere en Dieu messire Ferry, evesque de Tournay, chancellier dudit ordre de la Thoison d'or.

[b] Fut illec de l'ordonnance et commandement de mondit seigneur le souverain remis en termes par mondit seigneur le chancellier la matiere de la future feste d'icel-

266 Am 17. Jan. 1480 wurde erneut über diesen Beschluss diskutiert und man kam überein, dass nur die dem Orden angehörige Könige über die Verschiebung des Festes informiert werden sollten; vgl. § 260 und Reg. $130 \mathrm{f}$.

267 15. Januar 1480 (n.St.).

268 Ms.: Zur besseren Lesbarkeit dieses langen Paragraphen wurden Absätze und Unterpunkte eingefügt.

269 17. Januar 1480 (n.St.). - Dieses Versammlung erwähnt auch BAUchaU, Jacques de Savoie, 1992, S. 142.

270 Lt. VAnder Linden, Itinéraires, 1934, S. 69, hielt sich Hz. Maximlian zwischen dem 9. und 22. Januar 1480 in Mecheln auf.

271 Lies: $d u$. 
lui ordre pour deliberer, se bonnement elle se pourroit tenir et aussi le chappittre general du mesme ordre ou mois de may prouchain ensuivant selon la continuacion que paravant en avoit esté faite jusques audit temps ou non et s'elle se continueroit et delaieroit encore jusques a aultre temps plus convenable.

[c] Et reduisit [!] a memoire ledit chancellier la communicacion que nagaire sur ce avoit eue mondit seigneur le souverain en sa ville de Gand avec six de messeigneurs les chevaliers freres de l'ordre, la plus part desquelz icy estoit presente, qui tous apres pluseurs raisons et motifs a ce alleguez audit lieu de Gand par forme et loqueture avoient opiné et esté d'avis, que plus expedient leur sambloit, veu l'estat et disposicion des guerres et aultres grans affaires de mondit seigneur le souverain et pour le bien du mesme ordre, de differer et delayer encore lesdites feste et chappittre de l'ordre dessusdit jusques a aultre temps plus convenable, ${ }^{272}$ auquel mondit seigneur le souverain et messeigneurs les chevaliers freres par la grace Dieu mieulx et plus a loisir pourroient vaquer entendre et besoingner [fol. 82r/51r] es affaires d'icllui ordre que vraisemblablement faire ne pourroient a la saison prouchaine. Auquel advis mondit seigneur le souverain s'estoit audit lieu de Gand confermé et accordé avec eulx, sans toutevoie sur ce faire conclusion arrester. Mais avoit volu que encore il eu fust parlé aux aultres chevaliers, ses freres et compaingnons de l'ordre, quant premiers devers lui seroient assamblez a Malines ou ailleurs.

[d] Parquoy icellui monseigneur le souverain, considerant que a ceste foiz il se trouvoit accompaingnié de mesdis seigneurs en plus grant nombre qu'il n'avoit eu a Gand, a ordonné que de rechief ceste matiere fust la devant eulx remise en termes pour mieulx y deliberer et en avoir les opinions et mesmement de ceulx qui n'avoient esté a ladite communicacion de Gand.

[e] $\mathrm{Et}^{273}$ finablement lesdites opinions demandees, tous mesdis chevaliers les chevaliers freres ont deliberé que bonnement mondit seigneur, veu l'empeschement de la guerre et ses grans affaires et aussi la qualité, multitude et grandeur des affaires dudit ordre, ne pourroit a la saison, assavoir ou mois de may prouchain, faire ne tenir la feste ne le chappittre d'icellui ordre, mais qu'il valoit mieulx et estoit plus expedient de les delaier encores et continuer jusques a aultre temps. C'est assavoir du premier jour du mois de may prouchain jusques a temps plus convenable ou mesmement jusques au mois de may apres ensuivant, qui sera en l'an M cccc quatre vins et ung, ${ }^{274}$ sur l'espoir que au plaisir Nostre Seigneur entre cy et lors les guerres et aultres affaires de mondit seigneur le souverain se modereront et radoulcheront par telle façon, que lors lui et messeigneurs les chevaliers, ses freres dudit ordre, pourront francement et a bon loisir vaquer entendre et besoingner par bon et meur advis es besoingnes [et] affaires d'icellui ordre et les conduire et mener a fin deue selon les status et ordonnances et au bien, honneur et conservacion du mesme ordre et de la noble compaingnie d'icellui.

[f] Et en oultre, pour ce que audit lieu de Gand la communicacion, dont dessus est faite mencion, avoit aussi par maniere de loqueture esté dit, que mondit seigneur le souverain devroit escripre et signiffier lesdis deux continuacions et delations ainsi

272 Zur außerordentlichen Sitzung des Ordens am 29. Dezember 1479 in Gent vgl. $\S 257-259$.

273 Ms.: Links vor der Zeile, die mit et finablement beginnt, beginnt eine über 19 Zeilen gehende geschweifte, senkrechter Linie, in deren Mitte sich die unten genannte Randbemerkung befindet; vgl. dazu auch Anm. 280. 
conclutes de ladite feste de l'ordre pour les temps dessus declaré a messeigneurs de l'ordre et mesmement aulx roys et aultres absens non estans notez devers ledit ordre, mais de ce et de la forme et maniere d'escripre ce que dit est, seroit encore parlé a ladite prouchaine assamblee des mesdis seigneurs, ${ }^{275}$ a ordonné ${ }^{276}$ mondit seigneur le souverain que de rechief ce point fust mis en deliberacion, ce que a esté fait. Et finablement la matiere bien debattue a esté l'opinion de mesdis seigneurs par ung mesme accord, que monseigneur le souverain doit escripre aux trois roys, freres de l'ordre, seulement, assavoir au roy d'Angleterre $\{63\}$, au roy de Castille et d'Aragon $\{71\}^{277}$ et au roy de Naples $\{72\}$, et non aulx aultres freres dudit ordre absens par ceste fois et leur signifier en termes generaulx comment pour certaines grandes et raisonnables causes et affaires [fol. 82v/51v] a declarer plus au long ou prouchain chappittre de l'ordre, il a par l'advis et deliberacion des chevaliers, ses freres et compaingnons dudit ordre estans devers lui, continué, differé et delayé la feste ensemble le chappittre d'icellui par deux fois, assavoir du mois de may darreniere passé, auquel signiffié estoit se devoir tenir, jusques au may avenir et encore presentement et de rechief pour les mesmes causes et raisons que dessus et pour aultres bien neccessaires depuis survenues jusques a aultre temps plus convenable, lequel cy apres il leur signifiera et escripra a temps deu et competent selon les status du mesme ordre, ${ }^{278}$ et par leurs procureurs, qu'ilz ordonneront oudit futur chappittre, ilz seront apres icellui plus amplement advertis des causes et raisons desdis continuacions et delays, qu'il n'est expedient ne loisible de leur escripre quant au present, dont espoire mondit seigneur que bien se contenteront, en leur priant que leur bon vouloir et affection qu'ilz ont eu et porté a mondit seigneur et a l'ordre, ilz vueillent continuer et demonstrer tousjours, et a la garde et observacion des status et ordonnances dudit ordre eulx emploier et aquiter chascun pour son endroit, ainsi comme mondit seigneur et ses freres d'icellui en ont d'eulx ferme esperance et pleniere confidence.

[g] Oyes lesquelles opinions de mesdis seigneurs les chevaliers freres, mondit seigneur le souverain a eu aggreable leur deliberacion et advis en ceste partie. Et a conclut avec eulx le delay et la suspension et continuacion de ladite future feste de son ordre et de la signifier et escripre aux rois dessusnommez, pour iceulx en advertir et les exhorter par la maniere dite. ${ }^{279}$ Et quant aulx aultres chevaliers freres de l'ordre absens, cy apres quant mondit seigneur sera determiné du temps et lieu ou et quant il devra tenir sadite prouchaine feste de l'ordre, il aura advis sur la maniere d'en faire lors la significacion a chascun selon son endroit comme il appartendra.

$[\mathrm{x}]$ Conclusion de la seconde continuacion ${ }^{280}$

275 Vgl. § 258.

276 Ms.: Links vor der Zeile, die mit A ordonné beginnt, befindet sich ein senkrechter Doppelstrich.

277 Kg. Ferdinand übernahm mit dem Ableben seines Vaters Johann \{57\} (19. Januar 1479) die Königswürde von Aragon.

278 Die zeitliche Abfolge der Ordensfeste und die damit verbundenen Einladungsschreiben sind in $\S 47$ (neu § 22) der Statuten geregelt, dazu ausführlicher in $§ 192$, Anm. 323.

279 Vgl. Reg. $130 \mathrm{f}$.

280 Ms.: Die Randbemerkung steht auf fol. 82r links vor der Zeile, die mit les guerres et aultres affaires de mondit seigneur beginnt; vgl. dazu auch die Angaben in Anm. 273. 


\section{[261] [Schlichtung der Differenzen zwischen Fakob von Savoyen und Philipp von Burgund.]}

\section{L'appointement et accord fait entre monseigneur de Romont $\{84\}$ et monseigneur de Bevre $\{82\}^{281}$}

D'aultre part pour ce que oudit conseil mondit seigneur le souverain et messeigneurs lesdis chevaliers freres de l'ordre illec presens estoient advertis d'aucuns differens et debats survenus nagaires entre monseigneur le conte de Romont d'une part [fol. 83r/52r] et monseigneur de Bevre d'aultre, illec aussi presens. Mondit seigneur le souverain ensemble messeigneurs, sesdis aultres freres de l'ordre, desplaisans dudit debat, ont par la bouche de mondit seigneur l'evesque de Tournay, chancellier de l'ordre, fait requerir et prier bien instamment et acertes monseigneur de Romont premiers et mondit seigneur de Bevre apres et chascun a part, ${ }^{282}$ que consideré et attendu que tous deux estoient et sont du sang de mondit seigneur et de son hostel ${ }^{283}$ et mesmement sont freres de l'ordre, a cause et selon les status duquel ilz devroient et doivent avoir amour et charité ensamble [et] aymer le bien et honneur et eschiver le mal et deshonneur de l'ung l'autre, qu'ilz se voulsissent appaiser ensamble et effacer de leur cueraiges toute hayne, rancune et malvueillance qu'ilz povoient pretendre ou avoir l'ung contre l'autre, et dorsenavant estre comme freres et bons amis ensamble ainsi que a cause desdis status de l'ordre, a l'observacion desquelz ilz estoient et sont astrains par serment faire devoient, et que en son service se voulsissent acquiter chascun a son endroit comme jusques a orres fait l'avoient grandement et lealement, dont mondit seigneur se reputoit et disoit d'eulx trescontent. ${ }^{284}$ Surquoy respondit mondit seigneur de Romont que pour ce ilz ne laisseroient a le servir et qu'il en feroit bien. Monseigneur de Bevre, oyes lesdis remonstrances et requeste, respondit qu'il feroit ce que mondit seigneur lui ordonneroit. Et apres sur ce interrogué, mondit seigneur de Romont repliqua et dit, qu'il feroit ce que mondit seigneur lui commanderoit. Apres lesquelles response et replique mondit seigneur le souverain approichant lesdis parties les a tous deux prins par leurs mains dextres et fait touchier ensamble et apres ce ilz ont tantost

281 Ms.: Diese Zwischenüberschrift steht vor dem folgenden Absatz und wird mit einem einem $c$ / für capitulum eingeleitet.

282 Zur Ordensschiedsgerichtsbarkeit vgl. die Angaben in der Einleitung S. 31f. - Diese Angelegenheit erwähnt auch BAUCHAU, Jacques de Savoie, 1992, S. 142.

283 Jakob von Savoyen war durch seine Großmutter Maria ( $† 1422)$, einer Tochter Hz. Philipps des Kühnen ( $†$ 1404), mit dem Haus Burgund verbunden; vgl. Deмотz, Amadeus VIII., 1980. Unter Hz. Karl diente er seit 1468 als Heerführer und wurde 1475 zum Gouverneur von Burgund ernannt. Nach Karls Tod kämpfte er im Dienste Maximilians für die burgund. Interessen und wurde am 5. Juni 1479 von diesem zum Oberkommandierenden (capitaine général) der flämischen Truppen ernannt. Später stellte er sich jedoch auf die Seite der niederländischen Städte, die gegen Maximilian rebellierten, und musste den Dienst des Herzogs verlassen. Zu seiner Person vgl. u. a. Colot, Jacques de Savoie, 1980; Bauchau, Jacques de Savoie, 1992; Cools, Mannen, 2000, S. 398 f., Nr. 233; Chevaliers de la Toison d'or, ${ }^{2} 2000$, Nr. 84; Kat. Karl der Kühne, 2008, S. 242, Nr. 60 (mit Abb. seines Porträts). - Philipp von Burgund, Herr von Beveren, hat als Sohn des Anton, Bastard von Burgund \{54\}, den gleichen Großvater wie Hz.in Maria, nämlich Philipp, Hz. von Burgund \{01\}. Bei Hz. Maximilian war er als Rat und Kammerherr tätig; vgl. dazu auch die Angaben in § 134, Anm. 157.

284 Zum Gebot der gegenseitigen Freundschaft und Hilfe vgl. die Angaben in § 164 mit Anm. 237. 
embrachié l'ung l'autre, tout pardonné et se sont accordez et appaisé ensamble liberalement, promettant oster et effacer de leurs cueraiges toute rancune, hayne et malvueillance. Dont mondit seigneur le souverain et tous mesdis seigneurs les chevaliers confreres et les officiers dudit ordre a ce presens ont esté bien joyeulx.

\section{[262] [Die Ordensketten, die mehrere Mitglieder in der Schlacht von Guinegatte verloren hatten, werden auf ihre Bitte hin erstetzt.]}

Touchant les coliers de l'ordre perdus a la journé de la Vieville lez Therouenne ${ }^{285}$

En ce mesme conseil ces choses faites, ont remonstré a mondit seigneur le souverain messeigneurs Engelbert, conte de Nassouwe $\{77\}$, Phelippe, seigneur de Bevre $\{82\}$ et Jaques, seigneur de Fyennes $\{81\}$, chevaliers freres de l'ordre, comment a la journee de la Vieville empres Therouenne ${ }^{286}$ ilz et messire Josse de Lalaing $\{80\}$, seigneur de Montigny, aussi frere de l'ordre, avoient en la compaingnie de cellui seigneur et en son service perdu leurs grans colliers de l'ordre, parquoy selon certain statut dudit ordre il leur devoit donner nouveaulx colliers, ${ }^{287}$ prians et supplians pour ce a mondit seigneur que son plaisir fust de ainsi le faire. Parquoy mondit seigneur le souverain en ensuivant ledit statut accorda incontinent ladite requeste et ordonna expressement et commanda a [fol. 83v/52v] Nicolas de Gondeval, son conseiller et tresorier sur le fait de ses domaine et finances, ${ }^{288}$ et a Woutre de Housdam, garde de ses joyaulx, ${ }^{289}$

285 Ms.: Diese Zwischenüberschrift steht vor dem folgenden Absatz und ist durch einen Strich von ihm getrennt.

286 Im Sommer 1479 belagerte Hz. Maximilian mit seinen Truppen die Stadt Thérouanne, die eine frz. Enklave im burgund. Artois darstellte. Kg. Ludwig XI. entsandte darauf ein Entsatzherr, sodass es am 7. August 1479 zwischen Thérounne und Guinegatte zu einer Schlacht mit den zahlenmässig unterlegenen Burgundern kam. Anfangs schlugen die Franzosen die burgund. Reiter in die Flucht und erbeuteten einiges, wie z. B. die hier erwähnten Ordensketten. Dann konnte das burgund. Fußvolk, in dessen vorderster Reihe auch Hz. Maximilian mitkämpfte (dafür wurde er 1481 gerügt, vgl. PB 5 fol. 24v-25r), in einem erfolgreichen Gegenstoß die frz. Truppen bis nach Hesdin zurückdrängen. In den Protokollbüchern des Ordens vom Goldenen Vlies (auch PB 5) wird in diesem Zusammenhang von der Schlacht bei Vieville-lez-Therouenne gesprochen, heute ist dieses Ereignis jedoch bekannter als Schlacht von Guinegatte. Zum Verlauf vgl. u. a. Despars, Chronycke van Vlaenderen, 4, 1840, S. 190-192; Richert, Guinegate 1907; Fichtenau, Maximilian, 1959, S. 37 f.; Wiesflecker, Maximilian, 1, 1971, S. 146-152 mit ausführlichen Literaturangaben in Anm. 24 auf S. 459; Wiesflecker, Guinegat(t)e, 1989; Verbruggen, Guingate, 1993; Hollegger, Maximilian I., 2005, S. 45 f.; Haemers, Common Good, 2009, S. 23 f.

287 Nach § 65 (neu § 40) der Statuten (dazu S. 16, Anm. 14) muss der Souverän einem Mitglied eine neue Ordenskette zur Verfügung stellen, wenn dieser sie im Krieg, während einer ritterlichen Tat oder im Laufe eines Ehrenhandels verliert.

288 Nicolas de Gondeval ( $†$ 1485) war seit 1471 bei Hz. Karl als Rat und Argentier tätig und diente Hz. Maximilian auch als dessen maistre d'hostel. Im April 1484 übernahm er von Jean Gros das Amt des Trésoriers des Ordens vom Goldenen Vlies; zu seiner Person vgl. Koller, Service, 1971, S. 68f.; Albrecht, Monatsrolle Gondeval, 1995.

289 In Hz. Maximilians Hofordnung aus dem Sept. 1477 wurden Woutre de Housdam in seiner Funkton als garde de ses joyaulx eine tägliche Zuwendung von 18 solz zugesprochen; vgl. GaCHARD, Ordonnance 1477, 1857, S. 122. 
de leur faire faire a chascun d'eulx et delivrer ung collier nouveau a la façon et du poix des aultres. ${ }^{290}$

\section{Dezember 1480 in Brügge}

[fol. 84r $]^{291}$

[263] [Im Dezember findet eine Zusammenkunft statt, bei der es um die Planung eine neuen Festes gehen soll.]

Le samedi, $x v j$ jour de decembre l'an milquatrecens et quatrevins, ${ }^{292}$ monseigneur le duc Maximilian, souverain de l'ordre de la Thoison d'or, estant en sa ville de Bruges, par son ordonnance et plaisir se assamblerent a part en son absence en la chambre de monseigneur de Chimay $\{74\}$, premier chambellan, logié a la court, messeigneurs de Lannoy $\{50\}$, de Gruythuse $\{61\}$, ledit de Chimay, Engelbert, conte de Nassouw $\{77\}$, Wolffart, seigneur de la Vere $\{79\}$ et messire Piere, conte de $<$ Neuf $>$ Saintpol $\{83\}$, et eurent communicacion et devises ensemble sur aucunes affaires de l'ordre pour les apprester par forme de loqueture ${ }^{293}$ sans parler par opinion ou deliberacion, mais pour estre plus advertis et plus prompts d'en opiner et deliberer devant mondit seigneur le souverain, quant son plaisir seroit de les mander devers lui ensamble les autres freres pareillement mandez et que encore n'estoient arrivez audit Bruges. ${ }^{294}$ Et premierement ont eu devises mesdis seigneurs sur le fait des futures feste et chappittre de l'ordre, s'il seroit expedient de conseiller a mondit seigneur de les tenir a l'encomencement du mois de may prouchain venant, veues les deux continuacions, qui ja en sont faites depuis le darrenier chappittre dudit ordre tenu en ladite ville de Bruges l'an lxxviij, ou se encore se pourroient continuer jusques a autre temps plus convenable. Et a ceste matiere bien debattue pour et $<\mathrm{e}>$ contre par grandes et vives raisons sur ce alleguees d'une part et d'aultre.

[264] [Aufgrund der gegenwärtigen Kriegssituation ist man sich unsicher, ob die Veranstaltung eines großen Fest überhaupt angebracht ist. Andererseits sind nun schon mehrere Jahre ohne Ordensfest vergangen und sowohl die Bestimmungen der Statuten als auch diverse Angelegenheiten fordern eine Zusammenkunft des gesamten Ordens.]

Assavoir premierement pour ladite continuacion a esté alleguee l'incertaineté, qui est encore de paix ou de treves du costé de France. Mais fait a doubter la guerre plus forte et plus dangereuse pour la saison prouchaine que par cy devant n'a esté, parquoy pourroit avenir tel affaire que, quant orres ladite feste seroit signiffier et commencee, qu'il l'a faudroit laisser et habandonner, vestir le harnais et aler au devant des en-

290 Vgl. Reg. 129. Diese Angelegenheit erwähnen auch Serrure, Engelbert de Nassau, 1862, S. 16; Docouier, D'or et d'émail, 2008, S. 41; Docouier, Collier, 2008, S. 138. Am 31. Dez. 1480 quittierte der Ordenstrésorier Jean Gros, dass er neue Ketten Engelbert von Nassau und Philipp von Burgund übergeben hat; vgl. Reg. 139. - Ms.: Der Rest der Seite ist unbeschrieben.

291 Vgl. dazu die Angaben in der Einleitung S. 37.

292 16. Dezember 1480.

293 Ms.: loqueture ist unterstrichen.

294 Vgl. Reg. $133 \mathrm{f}$. 
nemis pour resister a leurs dampnables entreprinses. ${ }^{295}$ Item les estrainges langaiges malcontentent [!] et murmure du peuple de pardeça, qui s'en pourroit ensuir, mesmement en ce pays de Flandres, ${ }^{296}$ se ladite feste se fa[i]soit en temps de telz trouble et parplexité desdites guerres, et vouldroient dire, qu'il ne seroit pas la saison pour faire tellement feste ne despens mais que mieulx vaudroit d'exploitier ladite guerre vigoreusement contre lesdis ennemis et adversaires de mondit seigneur pour la garde et deffense de ses pays et subgiez. Et se d'aventure pendant l'occupacion desdites feste et chappittre quelque inconvenient advenist par la non resistence desdis adversaires le peuple le vouldroit imputer a la compainge, dont grant dangier et peril avenir pourroit, ce que Dieu ne vueille. A aussi esté touchié comment mondit seigneur le souverain n'est point furny de joyaulx tant pour sa chappelle comme pour sa credence et aultrement que messeigneurs ses predecesseurs et lui par cy devant ont esté, ce que pour honnesteté pourroit aucun retarder ladite feste jusques a aultre temps avenir, quant mondit seigneur n'aurroit pas tel empeschement de ladite guerre et qu'il seroit mieulx furny et pourveu [fol. 84v] de joyaulx et d'autres bagues et choses honnestes et convenables pour la solemnité et decoracion de ladite feste. ${ }^{297}$ Et pour demonstrer qu'il soit expedient et chose necessaire de avancier et tenir lesdites futures feste et chappittre de l'ordre a ladite saison prouchaine, ont esté au contraire alleguees et induites autres pluseurs raisons et bien urgentes, assavoir premierement la conclusion sur ce faite oudit darrain chappittre tenu a Bruges oudit an lxxviij, les deulx continuacions qui depuis sont ensuyes [!] et faites avec le contenu du xxij ${ }^{\mathrm{e}}$ article des status de l'ordre, disposant que lesdites feste et chappittre de l'ordre se doivent tenir de trois ans, bien se pevent anticiper par distance d'ung an $<\mathrm{s}>$ entre les deux festes ${ }^{298}$ mais que plus longuement que trois ans ladite feste se puist continuer ou delayer il ne se treuve point par lesdis status, qua re etc.

\section{[265] [Zahlreiche Mitgliederplätze sind unbesetzt.]}

D'aultre part qu'il a en l'ordre pluseurs lieux vacans ou aumoins non furnis comme estre doivent selon iceulx status, car cinq chevaliers qui en estoient freres sont en France pieça et ont delaissié de porter le colier de cest ordre, portans ordre d'aultre roy ou prince. ${ }^{299}$ Et depuis ung an ença ou environ s'est aussi retrait en France messire Jehan

295 Unter dem Eindruck eines am 1. Aug. 1480 geschlossenen burgundisch-englischen Freundschafts- und Hilfsvertrages zeigte Ludwig XI., Kg. von Frankreich, sich am 21. Aug. 1480 bereit, einem neuen halbjährigen Waffenstillstand zu Notre-Dame-lezDouai zu zustimmen. Die darauf folgenden Verhandlungen um einen dauerhaften Frieden scheiterten und Kg. Ludwig XI. nahm seinen verdeckten Krieg gegen Burgund wieder auf; vgl. dazu u. a. Bock, Maximilian, 1970, S. 50 und 52; Wiesflecker, Maximilian, 1, 1971, S. 157.

296 Zur Situation in Flandern vgl. die Angaben in § 239 mit Anm. 184.

297 Bald nach seiner Ankunft in den Niederlanden hatten Maximilian und Maria eine große Zahl der burgund. Kleinodien für 140.000 Gulden versetzt; vgl. dazu Maximilians Brief an Sigmund Prüschenk vom 18. Okt. 1477; gedruckt bei Kraus, Briefwechsel, 1875, S. 26 f.; dazu auch Wiesflecker, Maximilian, 1, 1971, S. 137 und 141. Zur finanziellen Situtation vgl. HaEmers, Common Good, 2009, S. 26-62.

298 Zur Regelung der zeitlichen Abfolge der Ordensfeste vgl. die Angaben zu § 47 (neu $\S 22)$ der Statuten in Anm. 323. Vgl. dazu auch § 250.

299 Vgl. zum Ausschlussverfahren § 122 mit Anm. 113 sowie § 28, Anm. 175 zum Exklusivitätsgebot der Mitgliedschaft. 
de Neufcastel $\{52\}$, seigneur de Montagu, ung des plus anchiens freres chevaliers dudit ordre, tenant deput parti contraire de mondit seigneur et ne scet on [s']il porte l'ordre du roy ou non. ${ }^{300}$ Et oudit darrain chappittre furent esleuz quatre chevaliers pour estre freres de ceste compaigne, ausquelz ne sont encore signiffiies leurs elections. Et le roy d'Aragon \{57\} qui estoit de cest ordre est trespassé depuis ladite darreniere feste $^{301}$ et par ainsi appert evidentement qu'il a en l'ordre dix lieux de chevaliers freres, sans mondit seigneur de Montagu non furnis, comme estre doivent qui est le droit tiers de la compaingnie saulf monseigneur le souverain..$^{302}$

\section{[266] [Ein weiterer Gründe für ein baldiges Fest ist, dass der Souverän den Orden kaum kennt und auch nicht alle Mitglieder.]}

Oultre ce qu'il faisoit a considerer que oudit darrenier chappittre tenu a Bruges n'avoit eu fors que cinq chevaliers freres ${ }^{303}$ car plus n'en avoit ou peu recouvrer pour l'eure, et monseigneur le souverain est assez nouvel oudit ordre, car il n'a tenu que une fois lesdites feste et chappittre d'icellui, avec ce pluseurs des chevaliers plus experimentez en l'ordre sont ja viez, valitudinaires ${ }^{304}$ et anchiens, parquoy fait a doubter que, se plus longuement se delaioient lesdites feste et chappittre dudit ordre, la plus part d'eulx n'y pouroit venir a aultre temps, ouquel les freres nouveaulx en n'aurroient l'experience du temps passé ne telle adrece es affaires et au bien de l'ordre comme espoir est qu'ilz trouveront par l'informacion desdis anchiens en cas que a ladite saison prouchaine la feste se tienne. Avec ce sont bien a poser les affaires presens, qui sont aussi grans et plus que jamais se sont trouvez oudit ordre, et est grant besoing d'y entendre et les affiner par bon et meur conseil et le plus tost sera le meilleur, autres pourroit en brief tomber l'ordre ou venir a telle dechoite qu'elle seroit irreparable.

[267] [Es sind mehrere Städte als mögliche Veranstaltungsorte für das nächste Fest im Gespräch.]

Toutes lesquelles raisons pesees d'une part et d'autre, a semblé a tous messeigneurs, saulf toutevoye et reserve le bon plaisir de mondit seigneur le souverain, qu'il doit [fol. 85r] tenir la feste et chappittre de l'ordre en may prouchain et qu'il est expedient,

300 Bisher war nur die Rede davon, dass er beim Fest im Jahr 1478 unentschuldigt gefehlt und er sich bisher noch nicht zu den 1473 gegen ihn erhobenen Vorwürfe geäußert hatte (siehe dazu die Angaben in Reg. 7 mit Anm. 5). Hier wird nun zum ersten Mal der Vorwurf ausgesprochen, dass er möglicherweise auch den Michaelsorden von Kg. Ludwig XI. von Frankreich angenommen habe; in den Mitgliederliste bei Colleville/Saint-Christo, Ordres, [1925], S. 68 f. feht jedoch sein Name. Sein Aufenthalt am frz. Hof ist seit Juni 1479 sicher belegt; vgl. Cools, Quelques considérations, 2002, S. 176. Der Vorwurf der frz. Parteinahme fehlt jedoch in dem während der folgenden Tage erlassenen Vorladungsschreiben; vgl. PB 5, Reg. sub dato 1480 Dez. 22. - Während des Festes im Jahr 1481 wurde er aus dem Orden ausgeschlossen; vgl. PB 5, fol. 27r-v.

301 Er verstarb am 19. Jan. 1479; vgl. u. a. Chevaliers de la Toison d'or, ${ }^{2} 2000$, S. 137, Nr. 57.

302 In den in den folgenden Tagen ausgestellten Einladungsschreiben für das Fest im kommenden Jahr werden die Mitglieder aufgefordert, im Falle der Nichtteilnahme 12 Ritter zur Neuwahl vorzuschlagen; vgl. dazu die Angaben in Reg. 136.

303 Vgl. u. a. § 22 und 71.

304 Ms.: valitudinaires ist unterstrichen. 
voire necessaire qu'il le face $<$ comme $>$, et la deust il tenir en cas du renforcement de la guerre en tentes ou pavillons sur les champs, ouquel cas il n'y auroit besoing de grans paremens. Et quant au lieu pour tenir la feste, a semblé a pluseurs de mesdis seigneurs qu'il auroit des autres lieux a ce plus propice selon l'estat et dispense des affaires et du temps presens que n'est la ville de Brouxelles, ${ }^{305}$ assavoir la ville de Saint Omer, la ville de Lille ou de Douay ou autre ville, seant sur la frontiere des ennemis, afin que monseigneur le souverain et messeigneurs les chevaliers freres fussent prests pour aussi exploiter la guerre se mestier estoit, combien que ladite feste ne les occuperoit de gaires et au plus que pour quatre ou cinq jours quant autre grant besoing ou affaire survendroit. Lesquelles choses seroient a remonstrer a mondit seigneur, pour en deliberer apres en sa presence et y conclure a son noble ${ }^{306}$ plaisir.

[268] [Weitere Besprechungspunkte betreffen den Ordenskanzler und Kg. Eduard IV., der die Ordenskette nicht mehr trägt.]

Item y a esté touchié du chancellier nouveau etc. ${ }^{307}$ et du roy d'Angleterre $\{63\}$, qui ne porte point le colier de l'ordre ${ }^{308}$ et a semblé bon que monseigneur en sa presence et de ceulx de l'ordre en feist parler en doulx termes a messire Thomas de Mont Gommery, chevalier de l'ordre de la Garretiere ${ }^{309}$ et ambaxeur dudit roy d'Angleterre, pour en parler au roy et soy employer a ce qu'il porte le collier de cest ordre ainsi qu'il doit. ${ }^{310}$

\section{Dezember 1480 in Brügge}

[269] [Während eines Treffens des Ordens mit Hz. Maximilian wird als erstes diskutiert, ob im kommenden Mai ein Ordensfest stattfinden solle.]

Le $^{311}$ jour saint Thomas l'appostre, $\mathrm{xx}^{\mathrm{e}}$ jour du mois de decembre l'an mil quatrecens $\operatorname{lxxx}^{312}$ a l'eure de trois heures ou environ apres disner, monseigneur le souverain estant en sa ville de Bruges et devers lui convoquez et assamblez en son hostel en la chambre de son retrait messeigneurs de son noble ordre cy apres nommez. C'est assavoir messeigneurs de Lannoy $\{50\}$, de Ravestein $\{55\}$, de Gruythuse $\{61\}$, de Chimay $\{74\}$, de Nassouwe $\{77\}$, de la Vere $\{79\}$ et de Romont $\{84\}$, tous chevaliers freres

305 Im April 1479 war beschlossen worden, dass das nächste Fest in Brüssel stattfinden solle, denn die Stadt hatte schon umfangreiche Vorbereitungen für das nun kurzfristig abgesagte Fest getroffen; vgl. § 250.

306 Ms.: son wurde aus sa verbessert. - Fortsetzung in $\S 270$.

307 Dazu ausführlicher in § 276.

308 Schon am 25. September 1478 war davon die Rede gewesen, vgl. § 201 mit Anm. 19.

309 Thomas Montgomery († 1495) war 1476 in den Hosenbandorden gewählt worden; vgl. Order of the Garter, 1999, S. 313, Nr. 217. - Schon im März 1479 gehörte er einer engl. Gesandtschaft an, die Hz. Maximilian in Antwerpen aufsuchte; vgl. dazu § 233 und Reg. 106. - Ende 1480 befand er sich ebenfalls am burgund. Hof, um im Auftrag Kg. Eduards ein Treffen seines Herrn mit mit Hz. Maximilian zu arrangieren; vgl. dazu u. a. Trenkler, Maximilian und England, 1973, S. $28 \mathrm{f}$.

310 Diese Angelegenheit kam wohl während dieser Sitzung nicht mehr zur Sprache, es wurde darüber aber beim Ordensfest im Jahr 1481 diskutiert; vgl. PB 5, fol. 30v.

311 Ms.: Vor der ersten Zeile dieses Absatzes findet sich am linken Rand ein senkrechter Doppelstrich.

312 20. Dezember 1480. 
et compaignons; monseigneur le conte de Saintpol $\{83\}$, aussi chevalier frere, excusé par l'accident de maladdie. Et avec eulx tres reverend pere en Dieu messire Ferry de Clugny, cardinal et evesque de Tournay, gardant encore le seel et faisant l'office de chancellier dudit ordre, ${ }^{313}$ ensamble maistre Jehan Gros, tresorier, Thoison d'or, le roy d'armes, et moy, Martin Steenberch, graffier, mondit ${ }^{314}$ seigneur le souverain a illec tenu conseil sur les affaires dudit ordre. Et premierement en ceste assamblee par l'ordonnance de mondit seigneur le souverain a mondit seigneur le cardinal mis en termes deux poins: Assavoir le premier point: S'il est expedient et besoing que mondit seigneur tiegne sa feste de son ordre a la saison prouchaine, assavoir au second jour du mois de may prouchain et es jours ensuivans. Ou se ladite feste bonnement se pourroit encore delayer jusques a l'annee avenir ou aultre temps plus convenable, consideree un[e] dispense du temps et l'estat de ses affaires. Et par l'ouverture de ceste matiere [fol. 85v] ont esté touchees et alleguees pluseurs raisons pour et contre, assavoir: Pour avancier ladite feste a esté reduit a memoire le xxij ${ }^{\mathrm{e}}$ article du livre des status et ordonnances dudit ordre, ${ }^{315}$ lequel y a esté leu tout au long, a esté parlé des grans affaires dudit ordre et de l'estat d'icellui, car il y a dix lieux de chevaliers freres empeschiez et comme vacans. ${ }^{316}$ Pour le contraire a esté alleguee l'incertaineté qui est de paix ou de treve, a cause des estrainges termes que les François ont tenues a la journee darreniere tenue a Lille, ${ }^{317}$ mais a plus d'apparence d'avoir la guerre ouverte et plus forte que devant a la saison nouvelle, et mesmement environ ledit temps auquel lesdites festes et chappittres tenir se devroient, parquoy mondit seigneur le souverain et messeigneurs les chevaliers de l'ordre pourroient estre tellement occupez et empeschiez que bonnement ilz ne pourroient vaquer ou entrer au fait de ladite feste ne ausdites affaires de l'ordre, mais leur faudroit tout habandonner et delaisser et eulx armer et aler emploier a la deffence du pays et exploitir la guerre.

[270] [Als nächstes wird über den Austragungsort diskutiert und in Frage gestellt, ob Brüssel der geeignete Ort sei.]

Le second point pour, en cas que la deliberacion de messeigneurs porteroit de tenir ladite feste de l'ordre a ladite saison prouchaine, pour aviser et deliberer du lieu ou bonnement ladite feste tenir se pourroit. ${ }^{318}$ Car quant au lieu de Brouxelles, combien que mondit seigneur leur ait promis d'y faire sa prouchaine feste et que sur espoir d'icelle ilz aient dez l'autre fois, que signiffiee estoit, fait et supporté des grans frais et despens ou fait des preparatoires y necessaires et ja faites tant en l'eglise Sainte Goudule comme en l'ostel de mondit seigneur. ${ }^{319}$ Toutevoye ${ }^{320}$ ne se pouvoit venu mondit

313 Vgl. dazu unten § 276 mit Anm. 341.

314 Ms.: Vor der Zeile, die mit mondit seigneur beginnt, befindet sich am linken Rand ein senkrechter Strich.

315 Zur Regelung der zeitlichen Abfolge der Ordensfeste vgl. die Angaben zu § 47 (neu $\S 22)$ der Statuten in Anm. 323.

316 Vgl. dazu die Angaben in § 265.

317 Nach Abschluss des Waffenstillstandes am 21. Aug. 1480 begannen am 15. Okt. in Lille die Friedensverhandlungen; vgl. dazu die Angaben in § 264 mit Anm. 295.

318 Fortsetzung von $\S 267$.

319 Vgl. dazu § 250 sowie $\S 267$ mit Anm. 305.

320 Ms.: Vor der Zeile, die mit toutevoye beginnt, befindet sich am linken Rand ein senkrechter Strich. 
seigneur encore determiner de quelque lieu certain, obstant que en cas de la guerre il faudroit qu'il alast sur la frontiere au devant de ses ennemis et seroit dangier de publier le lieu, car quant les ennemis le sauroient ilz se $<$ s $>$ forceroient pour l'empester, et fait a doubter qu'ilz s'en yroient faire leurs emprinses tout a l'opposite ou ameneroient toute leur puissance vers le lieu de ladite signifficacion pour troubler icelle feste.

\section{[271] [Die anwesenden Mitglieder befürworten Lille als geeigneten Austragungs- ort für das Ordensfest.]}

Sur ces deux poins ont esté demandeez les opinions de messeigneurs les chevaliers freres qui pour la plus part le sabmedi paravant <avoit communiquer > par le congié et plaisir de mondit seigneur le souverain avoient communiqué et loqueté ensamble sur ceste matiere et avoit esté leur advis, saulf le bon plaisir de mondit seigneur et sans y conclure, ${ }^{321}$ que la feste se devoit tenir et que bonnement elle ne se povoit plus delayer ou ralonguer, consideré le contenu dudit $\mathrm{xxij}^{\mathrm{e}}$ article desdis status ${ }^{322}<\mathrm{en-}$ semble> l'estat de disposition ens(uivant) les grans affaires dudit ordre. Mais quant au lieu, veue l'apparence des guerres et les autres grans affaires de mondit seigneur, a aucuns d'eulx a samblé que la ville de Lille seroit mieulx propice pour la tenir qu['a] Brouxelles, car < ladite> elle est pres de la frontiere des ennemis.

\section{[fol. 86r]}

\section{[272] [Aber auch Saint-Omer, Ypern und Brüssel kommen als mögliche Festorte in Frage.]}

Autres ont parlé de la ville de Saint Omer sur espoir que se le roy d'Angleterre $\{63\}$ a la prouchaine saison passoit la mer $^{323}$ et les affaires de lui et de mondit seigneur se povoient a ce disposer. Le roy pourroit mesmes venir a la feste. Et aucuns ont aussi parlé de la ville d'Ippre qui est bonne ville et situee pres de la frontiere desdis ennemis. Neantmoins la pluspart de messeigneurs a bien eu regard a la promesse faite a ladite ville Brouxelles et aux grans frais et despens qu'elle a fais et supportez sur l'esperan[ce] d'y avoir la prouchaine feste. ${ }^{324}$ Parquoy se a cause de la guerre il faulsist choisir aultre lieu, il les en faudroit contenter par bonne remonstrance le mieulx que faire se pourroit.

\section{[273] [Wegen der zahlreichen Krisengebiete wäre es aber möglicherweise sinnvol- ler, den Veranstaltungsort erst kurz vor dem Termin zu bestimmen.]}

$\mathrm{Oyes}^{325}$ ces opinions, mondit seigneur le souverain n'a encore volu conclure sur ceste matiere, mais premiers et avant qu'il en voulsist dire opinion ou y pren[d]re conclusion a fait remonstrer et declarer par mondit seigneur le cardinal, sa principale difficulté estre touchant le lieu qui se signifieroit pour tenir la feste, car bonnement il ne se

321 Ms.: Am linken Rand befindet sich vor der Zeile, die mit et sans y conclure beginnt, ein kleiner senkrechter Strich.

322 Zur Regelung der zeitlichen Abfolge der Ordensfeste vgl. die Angaben zu § 47 (neu $\S 22)$ der Statuten in Anm. 323.

$323 \mathrm{Zu}$ dem in dieser Zeit in Planung befindlichen Treffen zwischen Kg. Eduard IV. und Hz. Maximilian vgl. die Angaben in § 268, Anm. 309.

324 Vgl. die Angaben in $\S 267$ mit Anm. 305.

325 Ms.: Vor der ersten Zeile dieses Absatzes findet sich am linken Rand ein senkrechter Doppelstrich. 
povoit encore determiner de quelque ville ou lieu de pardeça, veu qu'il ne scet ou ne en quelle marche le plusgrant fait de la guerre aviendra ne ou les ennemis voudront faire leurs entreprinses, et $^{326}$ est vraisemblable que quant ilz s'auroient quelque lieu determiné, ilz se pourroient tirer et aler faire leurs entreprinses en l'autre debout de ses pays, comme ou pays de Luczembourg ou en Haynnau ou la entour, dont il a plus d'apparence que sur Flandres, ou quel cas mondit seigneur seroit au besoing bien longs pour leur secourir et resister ausdites entreprinses, mesmement est la doubte plusgrande dudit pays de Luczembourg que de Flandres etc., a cause du sire de Rodemach et du conte de Vernembourg et leurs aidans et complices, ${ }^{327}$ les treves desquelz faudront environ la chandeleur prouchaine. ${ }^{328} \mathrm{Si}^{329}$ a fait demander mondit seigneur se la signifficacion de la feste se pourroit faire sans nommer aucunes villes, mais nommant aucuns pays et quelque lieu convenable ou lors il se trouverent pour le bien et selon la disposision de ses affaires. Et veuz sur ce les xxije et xxiij ${ }^{\mathrm{e}}$ articles desdis status de l'ordre ${ }^{330}$ ensemble les minues des lettres de signifficacion d'autres festes par cy devant faites et tenues, tant par feu monseigneur le duc Phelippe $\{01\}$, premier fondateur, comme par feu monseigneur le duc Charles $\{34\}$, son filz, en leur vivant souverains de cest ordre, predecesseurs de mondit seigneur, trouvees devers le graffier et la maniere par lesdis feuz observee en leur temps, ${ }^{331}$ a esté demandee l'oppinion de mesdis seigneurs, pour savoir lequel leur sembleroit me[i]lleur, ou de signiffier pluseurs villes en divers pays pour tenir ladite feste ou d'en faire la signifficacion pour la tenir en aucun de ses pays de pardeça la mer. Et les opinions sur ce ont esté diverses: Aucuns de la moindre partie de messeigneurs les chevaliers freres ont opiné de nommer les villes Brouxelles, Lille et de Saint Omer, aucunes ont aussi parlé de la ville d'Yppre et [fol. 86v] de la ville de Valenchienes, autres et la pluralité des voix a esté de la tenir en l'ung de ses pays de Brabant, Luczembourg, Flandres, d'Arthois ou Haynau qui sont assez voisins et pardeça la mer.

326 Ms.: Am linken Rand befindet sich vor der Zeile, die mit et est vraisemble beginnt, ein kleiner senkrechter Strich.

327 Georg, Gf. von Virneburg, und sein Onkel Gerhard, Herr von Rodenmacher (14391492), gehörten zu den Anführer des antiburgundischen Widerstandes in Luxemburg. 1478 hatte Claude de Neufchâtel $\{100\}$ als burgund. Statthalter Luxemburgs etliche Siege erzielt, die Lage hatte sich aber damit nicht entspannt; vgl. dazu u.a. Recueil du Fay, 2003, S. 33 f. und passim.

328 Zum frz.-burgund. Waffenstillstand, der demnach nur bis zum 2. Febr. 1481 dauern sollte, vgl. die Angaben in § 264 mit Anm. 295.

329 Am linken Rand befindet sich vor der Zeile, die mit si a fait beginnt, ein kleiner senkrechter Strich.

$330 \S 47$ (neu § 22) der Statuten regelt die zeitliche Abfolge der Ordensfeste (vgl. dazu Anm. 323) und § 48 (neu § 23) regelt die Verpflichtung der Mitglieder, an den Ordensfesten teilzunehmen oder bei Verhinderung einen Stellvertreter zu benennen.

331 Sowohl bei Hz. Philipp als auch bei Hz. Karl wurde des Öfteren der Austragungsort der Ordensfeste in ihren Einladungsschreiben offengelassen; vgl. u. a. PB 1, S. 171, Reg. 49 f. (1439); S. 173, Nr. 58-70 (1441); S. 181-185, Reg. 112-116 (1441), Reg. 112 116 (1451), Reg. 122 f. (1456) und Reg. 129-135 (1461); PB 2, S. 204 f., Nr. $93-97$ (1472) sowie PB 3, S. 167 f., Nr. 1-10 (1473). 
[274] [Hz. Maximilian vertagt seine Entscheidung der Ortswahl auf den kommenden Tag. Der Greffier soll aber schon einmal die entsprechenden Einladungsund Vorladungsschreiben aufsetzen.]

Apres ces opinions oyes, mondit seigneur qui quant a tenir la feste, veu que tous ainsi deliberoient, n'y vouloit seul resister, mais bien vouloit que encore y voulsissent penser, <et il> a differé d'en dire sa deliberacion et d'en faire conclusion jusques a lendemain devant disner, pour lors prendre une heure, estre ensemble et y conclure et aussi parler des autres affaires de l'ordre, qui se pourroient presentement deliberer et preparer pour le futur chappittre. Et combien que a aucuns de messeigneurs semblast qu'il ne cheoit delay quant au conclure de tenir la feste ou may prouchaine, toutevoye pour le plaisir de mondit seigneur s'en raportoient a lui d'en faire desmaintenant la conclusion ou de la susprendre jusques a demain, mais que ce pendant le graffier feroit les minues des lettres a l'aventure, pour demain les veoir et sur ce pren[d]re conclusion finable. ${ }^{332} \mathrm{~A}$ aussi esté ordonnés ${ }^{333}$ de faire la signifficacion aux chevaliers estans en France par adjourement en leurs personnes, s'ilz pevent estre trouvez et apparhendez $^{334}$ et les officiers d'armes ${ }^{335}$ pevent avoir passaige et sur acces jusques a eulx, qui se pourroit tempter et essayer par divers chemins et passaiges. Et en cas que non, que la signifficacion s'en face par edictum etc., present Thoison d'or, le roy d'armes, es villes des frontieres de France oudit parti, se faire se puet. Si non a Chambray, a Tournay, a Lille, a Saint Omer, a Calais et en aultres villes marchandes seant en frontiere afin que l'adjournement puisse venir a leur cognoissance et qu'ilz ${ }^{336}$ ne puissent pretendre excuse d'ignorance. Et que cest ajournement par edictum soit auctorisé etc. comme s'il fust fait a leurs personnes, cum intimacion etc. ${ }^{337}$

[275] [Der Austragungsort soll 10 oder 15 Tage vor Beginn des Festes in Lille zu erfahren sein.]

Item que leur adjournement porte, que dix ou xv jours devant la feste de l'ordre les adjournez comparent en la ville de Lille, lieu certain, la ou ilz trouveront gens notables a ce commis de par mondit seigneur le souverain et l'ordre pour les acertener du lieu, duquel mondit seigneur sera lors determiné pour tenir sadite feste et le chappittre de l'ordre, et pour d'illec les amener et conduire devers mondit seigneur audit lieu seurement. ${ }^{338}$

332 Vgl. dazu die Angaben in Reg. 136 und die ausführlichen Regesten in PB 5, Reg. sub dato 1480 Dez. $20-24$.

333 Ms.: esté steht über der Zeile und eine Marke zeigt auf die dafür vorgesehene Stelle im Text. Ordonné steht über einer Radierung.

334 Ms.: et apparhendez ist unterstrichen. - Vgl. dazu die Angaben in Anm. 332 sowie in der Einleitung S. 27.

335 Ms.: d'armes steht über der Zeile und eine Marke zeigt auf die dafür vorgesehene Stelle im Text.

336 Ms.: qu'ilz steht über der Zeile und eine Marke zeigt auf die dafür vorgesehene Stelle im Text.

337 Vgl. die Angaben in Anm. 332.

338 Vgl. dazu PB 5, Reg. sub dato 1481 Jan. 9. 


\section{[fol. 87r]}

[276] [Der Ordenskanzler Ferry de Clugny wurde zum Kardinal ernannt, womit er neue Aufgaben übernimmt und viel unterwegs sein wird. Deshalb kann er die Interessen des Ordens nur noch unzureichend vertreten und tritt aus diesem Grund von diesem Amt zurück. Die anwesenden Mitglieder des Ordens wählen daraufhin Jean de Lannoy, Abt von Saint Bertin, zum neuen Ordenskanzler.]

\section{Remonstrance [de] monseigneur de Ferry, chancellier de l'ordre, comme il feust promeu cardinal. ${ }^{339}$}

$[a]^{340}$ Apres ces matieres ainsi deliberees et conclutes oudit conseil de l'ordre, tresreverend pere en Dieu mondit seigneur le cardinal de Saintvital s'est levé dudit lieu, sur lequel il seoit au costé de mondit seigneur le souverain. Et moult reverenment il a exposé et remonstré a mesdis seigneurs la parplexité, en quoy il se trouvoit a cause de l'office du chancellier de cest noble ordre, consideré sa promocion a l'estat et dignité de cardinal de Sainte Eglise de Rome. ${ }^{341}$ Et apres moult belles regraciacions des graces, biens, honneurs et promocions qu'il avoit receues par cy devant de messeigneurs les predecesseurs prinses [!] et en la maison de Bourgoingne et par leur moyen, ${ }^{342}$ et mesmement aussi de mesdis seigneurs depuis et pendant qu'il avoit servi l'ordre et a cause d'icellui jusques a present, dont il se sentoit moult obligié a eulx et a les servir et leur complaire et qu'il desiroit et entendoit faire, tant qu'il vivroit, a se soy offrant prest et appareillié de tout son pouvoir comme il disoit. Requerant de mesdis seigneurs sur ce leur benigne et bon advis et conseil pour savoir mesmement, comment doresenavant il se devroit et pourroit conduire envers eulx et ledit ordre au regard dudit office du chancellier d'icellui ordre.

339 Ms.: Am linken Rand des folgenden Absatzes finden sich drei Bemerkungen von Hand s. In der Edition wurden die Randbemerkungen als Zwischenüberschriften zu dem jeweils passenden Text eingefügt. Die erste Bemerkung steht im oberen Drittel von fol. $87 \mathrm{r}$ bei der Zeile, die mit en quoy il se trouvoit a cause de l'office du chancellier beginnt. - Der Rücktritt des Kardinals ist auch in einem mehrseitigen Text mit vielen Streichungen und Korrekturen thematisiert, es scheint sich aber nicht um den Entwurf für den im folgenden niedergeschriebenen Text zu halten; vgl. OGV, Akten, Karton 5, Fasz. 14 I, fol. 12r-13v, Dok. 10.

340 Ms.: Zur besseren Lesbarkeit dieses langen Paragraphen wurden Absätze und Unterpunkte eingefügt.

341 Am 15. Mai 1480 hatte ihn Papst Sixtus IV. zum Kardinal von St. Vitale ernannt; vgl. Hierarchia catholica, 2, 1900, S. 19.

342 Ferry de Clugny war einer der Räte Hz. Philipps \{01\} und Hz. Karls \{34\}, letzterer ernannte ihn auch zum Kanzler des Ordens (Sept. 1473) und zum Vorsitzenden des Parlaments von Mecheln. Sicherlich verdankte Clugny diesen beiden Herzögen seine Ernennung zum Bischof von Tournai und zu anderen kirchlichen Würden sowie verschiedene Einnahmen im burgund. Einflußgebiet. Angaben zu seiner Person und zu seiner Laufbahn finden sich u. a. bei Koller, Service, 1971, S. 12 f.; Dykmans, Guillaume de Clugny, 1983; PB 3, S. 21 f., S. 164-166 mit Anm. 640 sowie die ausführliche Biographie (mit zahlreichen Literatur- und Quellenangaben) bei PARAVICINI, Kardinäle, 2012, S. 275-280. 


\section{Declaraction de monseigneur, chief et souverain et de messeigneurs de l'ordre. ${ }^{343}$}

[b] Lesquelles remonstrances et offres oyes et entendues bien aulong par mondit seigneur le souverain et mesdis seigneurs les chevaliers freres dudit ordre, apres grande congratulacion de ladite promocion de mondit seigneur le cardinal, qui leur estoit tresplaisant et dont moult ilz estoient resjoys, l'ont fort loué et recommandé et aussi remercié des notables, grans, leaulx et bons services qu'il avoit fais a mondit seigneur le souverain et a l'ordre ensemble des honnorables offres qu'il leur faisoit, recevant et acceptant moult aggreablement sesdis offres.

[c] Mais entant qu'il touchoit ledit office du chancellier dudit ordre, finablement lui ont fait dire et declairer par la bouche de monseigneur de Chimay $\{74\}$, qu'ilz entendoient icellui office avoir vaqué et vaquer par sadite promocion a ladite dignité de cardinal, car par icelle il estoit obligié a nostre Saint Pere et au Saint Collegie des cardinaulx, pour estre prest de s'en aller devers eulx ou ailleurs a leur mandement et plaisir et n'estoit pas aisie oie ${ }^{344}$ en sa franchise pour doresmais [!] povoir exercer et conduire l'office dudit chancellier de l'ordre et vaquer et entendre aux affaires d'icellui ordre, quant et ainsi que besoing et mestier seroit.

[d] En ensievant laquelle declaracion, mondit seigneur le souverain et messeigneurs lesdis chevaliers freres de l'ordre ont advisé et deliberé de proceder a l'election d'un notable prelat pour leur futur chancellier dudit ordre, prians mondit seigneur le cardinal de les y vouloir conseillier et adrecier a personne, qui a ce fust ydoine et propice pour le bien de l'ordre. Et ont esté nommez et mis par escript pluseurs notables prelas et aultres seigneurs tant d'eglise comme seculiers jusques [fol. 87v] au nombre de dix, tous prelas en grans clers et personnes dignes et notables, pour en choisir et eslire l'ung d'icelux ou aultre tel que Dieu leur inspireroit, qui fust propice pour ledit ordre et ydoine pour exercer et faire icellui office. ${ }^{345}$

\section{Election de Jehan de Lannoy, abbé de Saint Bertin, a l'estat du chancellier de l'ordre. ${ }^{346}$}

[e] Et finablement mondit seigneur le souverain et mesdis seigneurs les chevaliers, ses confreres et compaignons dudit ordre, ont eu leur election, choisy et esleu la personne de reverend pere en Dieu messire Jehan de Lannoy, abbé du monastere Saint Bertin a Saint Omer. ${ }^{347}$ Laquelle election ainsi faite, mondit seigneur le cardinal a treshumbles graces a rendu et remis en la main de monseigneur le souverain le

343 Ms.: Diese Bemerkung steht am linken Rand bei der Zeile, die mit sesdis offres. Mais entant qu'il touchoit ledit office beginnt; vgl. dazu auch die Angaben in Anm. 339.

344 Lies: aisement.

345 Zur Wahl des Ordenskanzlers und deren Voraussetzung vgl. § 24 (neu Amtsträger § 1) der Statuten (dazu S. 16, Anm. 14); zum Aufnahmeeid § 91 (neu Amtsträger § 20) und zu seinem Besitz des Ordenssiegels $\S 25$ und 92 (neu Amtsträger $\S 2$ und 21).

346 Ms.: Diese Bemerkung steht am linken Rand bei der Zeile, die mit pour exercer et faire icellui office beginnt; vgl. dazu auch die Angaben in Anm. 339.

347 Jean de Lannoy $(† 1492)$ folgte dem im Aug. 1473 verstorbenen Ordenskanzler Guillaume Fillastre in dessen Amt als Abt von Saint-Bertin. Unter Hz. Maximilian, dem er als Rat und Vertrauter diente, unternahm er zahlreiche wichtige Gesandtschaftreisen. 1490 wurde er zum Vorsitzenden des Großen Rats in Mecheln ernannt. Zu seiner Person vgl. u. a. Koller, Service, 1971, S. 14-16; LAPlane, Abbés de Saint- 
seel de l'ordre. Et ce fait, mondit seigneur le souverain et messeigneurs l'ont aussi grandement remercié, disans et declairans que encore ilz le reputoient et tenoient du conseil de l'ordre, mesmement tandis qu'il seroit pardeça. Mais qu'il s'avoit bien comment par lesdis status de l'ordre, il n'avoit ordonnee fors de quatre officiers oudit ordre, assavoir du chancellier et de la suyte des aultres trois, lui priant pour ce que es affaires de l'ordre, fuist en chappittre ou aultrement, il les voulsist aider a conseiller et adreçer quant mestier seroit et par eulx en seroit requis et qu'il voulsist aussi adreçer et informer le nouveau chancellier, par eulx illec esleu, en ce qu'il auroit a faire et comment il se devroit conduire es besoingnes et affaires de l'ordre.

[f] A quoy mondit seigneur le cardinal se offrit prest et appareillé liberalement, pour toutes et quantesfois qu'il plairoit a mondit seigneur et ausdis messeigneurs les freres de l'ordre de l'y appeler, ce que mesdis seigneurs accepterent et prinrent de lui tresaggreablement.

[g] Et ce fait, mondit seigneur le souverain bailla en garde ledit seel de l'ordre audit tresorier et ordonna a Thoison d'or, qu'il feist venir devers lui lendemain matin ledit abbé de Saint Bertin, pour lui signiffier son election et savoir de lui son intencion, s'il l'acceptera en la presence de mondit seigneur le souverain et de messeigneurs les chevaliers freres qui estre y pourront.

[h] Et mondit seigneur le cardinal a requis et demandé acte de la delivrance et rendue par lui faite dudit seel de l'ordre ensemble de ladite belle et honnorable response a lui faite par monseigneur et par l'ordre, ce que mondit seigneur par l'advis de messeigneurs les chevaliers illec presens lui a accordé et consenti et comandé au greffier d'en faire registre et acte, pour la descharge dudit monseigneur le cardinal, fait l'an et jour et ou lieu que dessus.

\section{Dezember 1480 in Brügge}

\section{[277] [fean de Lannoy, Abt von Saint-Bertin, nimmt seine Wahl zum Ordenskanz- ler an und bedankt sich.]}

$[a]^{348}$ Le xxiije jour dudit mois de decembre ${ }^{349}$ comparurent et s'assamblerent devers monseigneur le souverain en sa chambrette a Bruges messeigneurs de Lannoy $\{50\}$, de Ravestein $\{55\}$, de Gruyt-huse $\{61\}$, de Chimay $\{74\}$, de Nassouw $\{77\}$ et de la Vere $\{79\}$, chevaliers freres et compaignons, ensemble les tresorier, graffier et roy d'armes de l'ordre et ens(uivant) l'election faite en soir precedent ${ }^{350}$ de la [fol. 88r] personne de reverend pere en Dieu messire Jehan de Lannoy, abbé du monastere Saint Bertin, a l'estat et office du chancellier dudit ordre, vacant par la promocion de tresreverend pere en Dieu monseigneur Ferry de Clugny, evesque de Tournay, nagaire chancellier dudit ordre, a l'estat et dignité de cardinal de Saint[e] Eglise de Rome au tiltre monseigneur Saintvital.

Bertin, 2, 1855, S. 31-52; Cools, Mannen, 2000, S. 349 f., Nr. 145; Prietzel, Imitation, 2004, S. 102.

348 Ms.: Zur besseren Lesbarkeit dieses langen Paragraphen wurden Absätze und Unterpunkte eingefügt.

349 Dez. 1480.

350 Damit wäre der Abend vom 22. April gemeint, die Eintragungen über die Wahl sind aber unter dem 20. Dezember verzeichnet, vgl. § 276. 
[b] Et tantost, eu ce conseil de l'ordre, fut envoyé Thoison d'or, le roy d'armes, devers ledit reverend pere en Dieu l'abbé de Saint Bertin, estant en une aultre chambrette la pres, pour le advertir secretement de l'election que le soir precedent avoit esté faite de sa personne a l'estat et office du chancellier de l'ordre et en cas, qu'il se accorderoit de accepter sadite election, le amener devers mondit seigneur, ce que ainsi a esté fait.

[c] Et tantost ledit reverend pere en Dieu monseigneur l'abbé de Saint Bertin arrivé en ladite chambre, mondit seigneur le souverain par l'advis de messeigneurs les chevaliers freres lui a fait dire et remonstrer par le graffier de l'ordre, comment pour le notable et louable rapport, que mondit seigneur et messeigneurs les chevaliers freres de l'ordre avoient ouy de sa personne et de sa science et bonne prudence et d'aultres ses grans vertus et merites, et mesmement, aussi de la noble extraction, eulx confians de ses vertus, loyaulté, preudomie et bonne diligence l'avoient le soir precedent en leur conseil de l'ordre esleu a chancellier dudit ordre ou lieu de mondit seigneur le cardinal, par la promocion duquel estoit devolu et vaquant a leur disposicion l'estat et office dudit chancellier d'icellui ordre, lequel longuement et moult notablement il avoit exercé jusques a lors. Parquoy mondit seigneur le souverain et messeigneurs les chevaliers, ses freres dudit ordre, desiroient savoir l'intencion dudit monseigneur de Saint Bertin, s'il accepteroit ceste election et entreprendroit la charge dudit estat et office, qui estoit bel et honnorable, comme assez le povoit concevoir et entendre.

[d] Et ledit reverend pere monseigneur l'abbé de Saint Bertin ce oyant, rendit et dit treshumbles graces a mondit seigneur <l'abbé de Saint Bertin ce oya $>^{351}$ le souverain et a tous messeigneurs de l'ordre du grant honneur qu'ilz lui faisoient et sans presumer qu'il fust ydoine ou souffisant a si grant honnorable et digne office, mais fort craingnant sa jeunesse et qu'il n'avoit pas grant experience en choses mondaines, mesmement es affaires de ceste noble court ne dudit ordre, considerant aussi les grans meritez, dignitez et qualitez des notables prelas qui jusques a lors avoient esté oudit estat, ausquelz ilz ne vouloit comparer aucunement, veu neantmoins la bonne et benigne estime que mesdis seigneurs avoient de sa personne et le grant honneur qu'ilz lui faisoient. Attendu aussi qu'il estoit subgiet naturel de mondit seigneur le souverain, natif de ses pays et mesmement que est cest ordre il avoit eu feu monseigneur son pere $\{12\}$ et deux ses oncles chevaliers freres, que Dieu absoille, ${ }^{352}$ et que encore il estoit de present monseigneur de Lannoy $\{50\}$, chief de ses armes, parquoy tousjours [fol. 88v] il avoit eue tressingulier[e] affection audit ordre. Respondit en conclusion et dit qu'il feroit ce qu'il plairoit a mondit seigneur le souverain et a messeigneurs de l'ordre lui ordonner et commander, soubz confiance de leur grace et benigne supportacion et qu'ilz le aideroient a adreçer et conduire et suppleroient ses imparfections et deffaultes, combien que a son povoir se voudroit garder de failler.

[278] [Der neue Kanzler leistet seinen Amtseid. Danach wird ihm das Ordenssiegel übergeben.]

Oyé laquelle response et humble acceptacion dudit monseigneur de Saint Bertin, mondit seigneur le souverain commanda audit graffier de lui dire, que de sadite response

351 Ms.: Diese Streichung wiederholt schon geschriebene Wort und zeigt so deutlich, dass es sich um einen Abschreibfehler handelt.

352 Sein Vater war Guilbert de Lannoy $\{12\}(† 1462)$, der zusammen mit seinen Brüdern Hue $\{7\}(† 1456)$ und Baudouin $\{19\}(† 1474)$ zu der ersten Generation der Ordensritter gehörte. 
lui et messeigneurs, ses freres de l'ordre estoient bien contens et que, sur l'espoir et confidence qu'ilz avoient de lui et de sa bonne continuacion en ses vertus et qu'il seroit propice et ydoine pour ledit ordre, ilz l'avoient esleu et le commettoit $<\mathrm{t}>$ mondit seigneur audit office de chancellier d'icellui ordre, moyenant qu'il feroit le serment a ce [a]partement selon les ordonnances dudit ordre. ${ }^{353}$ Et ce fait, fust tantost illec apporté tout prest devant mondit seigneur le souverain et mis sur le lit, sur lequel il seroit ung missel, et mettant illec ledit abbé de Saint Bertin l'une de ses mains sur la figure de la sainte croix et l'autre sur le saint canon dudit missel, ${ }^{354}$ feist icellui abbé le serment, tel qu'il est contenu esdis ordonnances, a la prononcacion verbale dudit greffier. Et ledit serment fait, icellui monseigneur de Saint Bertin se remist a genoux, remerciant de rechief mondit seigneur le souverain et messeigneurs les chevaliers freres de l'ordre, disant que au plaisir de Dieu il en feroit tout devoir possible. Et tantost mondit seigneur le souverain print de la main dudit tresorier le seel de l'ordre, lequel il bailla audit chancellier illec sermenté et receu comme dit est et commanda audit graffier de lui faire ses lettres de sa retenue et commission en forme accoustumee. ${ }^{355}$

\section{[279] [Der neue Kanzler erhält die Ordenstatuten.]}

Apres ce a supplié a mondit seigneur ledit abbé, chancellier de l'ordre, que les status et ordonnances de l'ordre lui fussent communiquez et les autres choses competans a sondit office. Ce que mondit seigneur lui accorda liberalement.

[280] [Der neue Kanzler bittet die Ritterbrüder um Rat; diese weisen darauf hin, dass der alte Kanzler beauftragt ist, ihm Rat zu erteilen.]

Item a prié messeigneurs les chevaliers freres, qu'ilz le voulsissent aider a adreçer et informer en ce qu'il auroit a faire touchans les affaires de l'ordre, ce qu'ilz lui accorderent, le advertissant en oultre par la bouche de monseigneur le conte de Chimay $\{74\}$, comment le soir precedent ilz en avoient parlé a monseigneur le cardinal, qui avoit esté present a l'election faire de sa personne et lequel encore ilz tenoient et reputeroient du conseil de l'ordre et lui avoient prié de le vouloir eu sangnier et adreçer es affaires de l'ordre. Ce qu'il leur avoit accordé de faire liberalement.

\section{[fol. 89r]}

[281] [Der neue Kanzler wird darüber unterrichtet, dass die Einladungsschreiben für das kommende Ordensfest schon ausgestellt und von den anwesenden Mitglieder auf ihre Richtigkeit hin überprüft sind.]

Avec ce fut dit et declairé audit monseigneur l'abbé de Saint Bertin par la bouche de mondit seigneur de Chimay $\{74\}$, que bien il pourroit seeler les lettres touchant l'onneur des chevaliers de l'ordre, qui auroient esté commandees par monseigneur le souverain en la presence de six chevaliers freres de l'ordre. ${ }^{356}$ Lesquelz seroient par le

353 Vgl. dazu die Angaben in Anm. 345.

354 Zum Gebrauch von Meßbuch und Schwurkreuz bei Eidesleistungen innerhalb des Ordens vgl. § 56 .

355 Vgl. Reg. 140.

356 Schon am 20. Dez. hatte Hz. Maximilian Steenberch aufgefordert, die Einladungsschreiben vorzubereiten und den sechs anwesesenden Mitgliedern, die u. a. in § 277 genannt sind, zur Durchsicht zu geben. Vgl. dazu die Angaben in Anm. 302. 
graffier denommez et escrips en la signature du commandement qu'il en auroit receu jasoit que au seeler il n'y eust pas six en nombre presens, mais qu'il feroit bien d'y avoir tousjours ceulx, qu'il trouver(ent) au lieu qui bonnement y pourroient vaquer.

\section{[282] [Es soll diese Schreiben nun nur noch mit dem Ordenssiegel versehen.]}

Lui declaira aussi de bouche de mondit seigneur le souverain, presens mesdis seigneurs les freres de l'ordre, qu'il avoit ja ordonné et commandé faire les lettres de la signifficacion de la future feste de l'ordre et que les minues avoient ja par eulx esté veues pour la pluspart, afin que mondit seigneur l'abbé, chancellier, fust certain dudit commandement lequel mondit seigneur le souverain lui declaira avoir fait, presens messeigneurs les chevaliers qui la estoient <estoient>, pour son appaisement a cause qu'il n'avoit esté present a la deliberacion ne au commander les choses et qu'il n'y feist difficulté de seeler du seel de l'ordre les lettres pour ce ordonnees et requises.

[fol. 89v-100v] unbeschrieben. 


\section{Regesten}

\section{[14]77 Dez. 26, Brüssel}

Hz. Maximilian teilt den Mitgliedern des Ordens vom Goldenen Vlies seine Bereitschaft mit, aufgrund seiner Heirat mit Hz.in Maria von Burgund die Souveränität über den Orden zu übernehmen. Dafür lädt er sie nach Mons im Hennegau oder einen anderen noch zu bestimmenden Ort zur Ordensübergabe am kommenden 1. Mai ein. Im Anschluss daran wird das ordentliche Ordensfest stattfinden. Im Falle einer Nichtteilnahme sollen entsprechend den Bestimmungen der Statuten ein Stellvertreter ernannt und Vorschläge für 12 vakante Mitgliederplätze eingereicht werden. - eigenh. Unterschrift Hz. Maximilians. - Sekretär: Steenberch.

Bem.: Der Inhalt, die Besiegelung, die Kanzleivermerke sowie die Überbringung der Briefe (lettres de l'intimacion et significacion) wurde am 17. Dez. 1477 und 3. Jan. 1478 ausführlich von den am burgund. Hof weilenden Ordensmitgliedern diskutiert; vgl. PB 4 § 13-19. Diese sandten dazu noch eigene Briefe an ihre abwesenden Mitbrüder mit, um die Richtigkeit von Maximilians Einladungsschreiben zu bestätigen; vgl. Reg. 14-20. Mehreren Mitgliedern, die sich verschiedener Vergehen schuldig gemacht hatten, wurden ebenfalls Einladungsschreiben zugesandt, sie variieren aber im zweiten Teil des Textes; vgl. dazu Reg. 7-13. Zu den Einladungen vgl. auch in der Einleitung S. 19.

Kop. zeitgen. (Steenberch): AOGV, Codex 45, fol. 33v-35v. ${ }^{1}$

Reg.: Cat. mss. de BR, 12, 1936, S. 59, Nr. 7481/21 (nach Kop. in BR Brüssel); Regesten Friedrichs III., Suppl. 1, 2008, S. 57, Nr. 29.

Erw.: PB 4 § 13-19; Chroniques de Molinet, I, 1935, S. 249; Damme, Adolf van Kleef, 1967, S. 134.

Folgende Exemplare sind bekannt:

An Eduard IV., Kg. von England \{63\}. - frz.

Bem.: Dieses Schreiben wurde zusammen mit dem in Reg. 20 genannten Schreiben durch den Wappenkönig Toison d'or überbracht.

Kop. zeitgen. (Steenberch): AOGV, Codex 45, fol. 35v-37v.

Erw.: PB 4 § 19 sowie im Schreiben aus Reg. 29.

An Ferdinand, Kg. von Neapel $\{72\}$. - lat.

Bem.: Dieses Schreiben wurde zusammen mit dem in Reg. 15 genannten Schreiben durch den Wappenkönig Flandern² überbracht.

1 Diese Abschrift des Einladungsschreibens beginnt mit treschier et feal cousin und am linken Rand steht, dass diese Version aux communs chevaliers freres de l'ordre gesandt wurde. Es handelt sich demnach um einen Musterbrief für die untergebenen Mitglieder, die keine Königswürde besaßen und auch nicht direkt mit Hz. Maximilian oder dem Haus Burgund verwandt waren; letztere wurden mit treschier et tresamé cousin angeredet; vgl. dazu auch die Angaben in § 253, Anm. 236 sowie zu den Einladungsschreiben vom 9. Okt. 1479 in Reg. 83-88.

2 Zum Wappenkönig Flandern vgl. die Angaben in § 19, Anm. 97. 
Kop. zeitgen. (Steenberch): AOGV, Codex 45, fol. 28r-29v.

Erw.: $\quad$ PB 4 § 19 sowie in Reg. 34-36.

An Johann, Kg. von Aragon \{57\}. - lat.

Bem.: Dieses Schreiben wurde zusammen mit dem in Reg. 14 genannten Schreiben durch den Wappenkönig Hennegau ${ }^{3}$ überbracht.

Kop. zeitgen. (Steenberch): AOGV, Codex 45, fol. 29v-30v.

Erw.: $\quad$ PB 4 § 19 und 26.

An Ferdinand \{71\}, Kg. von Kastilien.- [lat.].

Bem.: Dieses Schreiben wurde zusammen mit dem in Reg. 16 genannten Schreiben durch den Wappenkönig Hennegau überbracht.

Erw.: $\quad$ PB 4 § 19 und 27 sowie in den Schreiben aus Reg. 30 und 63.

An Johann, Hz. von Kleve \{47\}. - frz.

Bem.: Dieses Schreiben wurde zusammen mit dem in Reg. 19 genannten Schreiben durch den Herold Limburg ${ }^{4}$ überbracht, der später auch noch mit der Wiederholung der Einladung (Reg. 39) zu Hz. Johann reiste.

Kop. zeitgen. (Steenberch): AOGV, Codex 45, fol. 30v-32r und 55r-58r (datiert 28. Dez.).

Erw.: $\quad$ PB 4 § 19, 27 und 121 sowie in den Schreiben aus Reg. 64 und 89.

An Adolf von Kleve $\{55\}$, Herr von Ravenstein. - frz.

Kop. zeitgen. (Steenberch): AOGV, Codex 45, fol. 38r-39r.

[14]77 Dez. 26, Brüssel

Hz. Maximilian lädt Jean de Neufchâtel $\{52\}$, Herr von Montaigu, desgleichen ein (wie Reg. 1-6). Er fordert ihn aber auf, persönlich zu erscheinen, um zu den 1473 zusammengetragenen und ihm durch Philippe Pot $\{60\}$ mitgeteilten Verfehlungen ${ }^{5}$ Stellung zu nehmen. Des Weiteren bittet er ihn, dem Überbringer dieses Schreiben schriftlich seine Absichten kundzutun. - frz.

Bem.: Dieser Brief sowie das Schreiben der Ordensmitglieder (Reg. 17) sollte der Herold Ferrette überbringen, der aber bei seiner Gefangennahme in Mâcon alle mitgeführten Briefe verlor; vgl. dazu die Angaben in Reg. 13. Nachdem der Verlust der Einladungsschreiben bekannt wurde, wiederholten die Ordensmitglieder die Einladung (vgl. Reg. 28). - Zum Einladungsschreiben allgemein vgl. die Angaben in Reg. 1.

3 Zur Person des Wappenkönigs Hennegau vgl. die Angaben in § 19, Anm. 98.

4 Zur Person des Herold Limburgs vgl. § 19, Anm. 99.

5 Bei der correction im Jahr 1473 wurden folgende Kritikpunkte zusammengetragen: Bis dahin hatte Jean de Neufchâtel sich noch nicht zu seiner Rolle bei diversen Familienangelegenheiten, die beim Ordensfest von 1468 beanstandet wurden, geäußert. Dazu kam noch, dass die Ordensmitglieder ihn des Ungehorsams gegenüber Hz. Karl $\{34\}$ und einer entscheidenden Anteilnahme am Verlust der Festung Buxy im Jahr 1471 bezichtigten. Da Jean bei diesem Ordensfest gefehlt hatte, wurde sein Stellvertreter Philippe Pot beauftragt, ihm die Vorwürfe schriftlich mitzuteilen. Dieser Brief ist am 14. Mai 1473 ausgestellt worden; vgl. dazu PB 3, S. 84-86, § 117-122, S. 158-161, § 252 und S. 176, Reg. 42. 
Kop. zeitgen. (Steenberch) des Zusatzes: AOGV, Codex 45, fol. 35v.

Erw.: $\quad$ PB 4 § 13, 26 und 120.

[14]77 Dez. 26, Brüssel

Hz. Maximilian lädt Philipp von Savoyen $\{68\}$, Gf. von Bugey, desgleichen ein (wie Reg. 1-6). Er fordert ihn auf, persönlich zu erscheinen, um zu den 1473 zusammengetragenen und ihm mitgeteilten Verfehlungen ${ }^{6}$ Stellung zu nehmen. Des Weiteren bittet er ihn, dem Überbringer dieses Schreiben schriftlich seine Absichten kundzutun. - frz.

Bem.: Überbracht durch den Herold Ferrette, dem Philipp auch sein Antwortschreiben (Reg. 26) mitgab. Zur unglücklichen Reise Ferrettes vgl. die Angaben in Reg. 13 und zum Einladungsschreiben allgemein die Angaben in Reg. 1.

Kop. zeitgen. (Steenberch) des Zusatzes: AOGV, Codex 45, fol. 32r-33v.

Erw.: $\quad$ PB 4 § 26, 120 und Reg. 26.

\section{Dez. 26, Brüssel}

Hz. Maximilian lädt desgleichen (wie Reg. 1-6) verschiedenen Mitgliedern, die sich der französischen Seite angeschlossen haben, zu seiner Ordensübernahme und zu dem darananschließenden Ordensfest ein. Aufgrund verschiedener Verfehlungen fordert er sie auf, persönlich beim Ordensfest zu erscheinen, um ihre Handlungsweise zu verteidigen. - frz.

Bem.: Die Ausstellung dieser Schriftstücke, die entweder als lettres patentes en plaacart oder als Briefe (lettres closes) ausgeführt und durch Wappenkönige überbracht werden sollten, wurde am 17. Dezember 1478 von den am burgund. Hof weilenden Ordensmitgliedern diskutiert; vgl. dazu die Angaben in Reg. 1. Diese sandten ihrerseits ein Beglaubigungsschreiben; vgl. Reg. 21-25.

Erw.: $\quad$ PB § 15; AOGV, Codex 45, fol. 39v; sowie oben in der Einleitung S. 25.

Folgende Exemplare sind bekannt:

An Philippe de Crèvecœur, Herr von Esquerdes $\{69\}$.

Bem.: Der Herold Namur wurde damit beauftragt, die am frz. Hof weilenden Ordensmitglieder Philippe de Crèvecœur, Anton, Bastard von Burgund \{54\}, Philippe Pot $\{60\}$ und Jacques de Luxembourg $\{67\}$ die Vorladungsschreiben zusammen mit den Bestätigungsschreiben der versammelten Ordensmitglieder (Reg. 21-25) zu

6 Bei der correction Philipps von Savoyen im Jahr 1473 wurde kritisiert, dass er in den vergangenen Jahren von Hz. Karl \{34\} zahlreiche Ämter und Pensionen erhalten und ein gegenseitiges Hilfsbündnis unterschrieben hatte. Seine daraus erwachsenen Verpflichtungen kam er aber nicht nach, auch trug er nicht die Ordenskollane sondern nur das Vlies an einem Seidenband und beim Ordensfest fehlte er unentschuldigt. Am 14. Mai teilte ihm der Orden die Kritikpunkte schriftlich mit; vgl. PB 3, S. 76-80, $\S 96-103$, S. 155-158, § 251 und S. 176, Reg. 41. Philippe de Savoyen erhielt diesen Brief nach eigenen Aussagen am 27. Jan. 1476 (n.St.) und antwortete darauf in einem Brief an den Orden d.d. o.J. [1476] Jan. 28, in dem er beteuert, dass es an seinem Lebensstil nichts zu beanstanden gebe; Or. Pap. mit eigenh. Unterschrift in AOGV, Akten, Karton 5, Fasz. 14 D, Dok. 7. 
überbringen. Aber nur dem letztgenannten konnte er den Brief tatsächlich übergeben; vgl. dazu PB 4 § 28.

Or. Pap.: AOGV, Akten, Karton 5, Fasz. 14 B, Dok. 2 (aufgedr. Verschlußsiegel unter Papier). Kop. zeitgen. (Steenberch): AOGV, Codex 45, fol. 39v-40v.

Kop. (18. Jh.): Brüssel, BR, ms. 20.851 (F.J. de Bors d'Overen, Histoire chronologique de l'ordre de la Toison d'or, Bd. 1), fol. 179r-180r.

Erw.: $\quad$ PB 4 § 19 und 28.

An Anton, Bastard von Burgund \{54\}. - frz.

Bem.: Der beauftragte Herold Namur konnte jedoch diesen Brief wie auch den aus Reg. 22 nicht zustellen; vgl. dazu Reg. 9.

Or. Pap.: AOGV, Akten, Karton 5, Fasz. 14 B, Dok. 1 (aufgedr. Verschlußsiegel unter Papier). Erw.: $\quad$ PB 4 § 19 und 28.

An Jacques de Luxembourg $\{67\}$.

Bem.: Dieses Schreiben wurde zusammen mit dem aus Reg. 21 durch den Herold Namur überbracht; vgl. dazu Reg. 9.

Erw.: $\quad$ PB 4 § 19 und 28.

An Philippe Pot, Herr von la Roche-Nolay $\{60\}$.

Bem.: Der beauftragte Herold Namur konnte jedoch diesen Brief wie auch den aus Reg. 23 nicht zustellen; vgl. dazu Reg. 9.

Or. Pap.: AOGV, Akten, Karton 5, Fasz. 14 B, Dok. 9 (aufgedr. Verschlußsiegel unter Papier). Erw.: $\quad$ PB 4 § 19 und 28.

An Jean de Damas, Herr von Clessy $\{65\}$.

Bem.: Dieser Brief wie auch andere Einladungsschreiben (Reg. 7, 8, 17, 18 und 25) sollten durch den Herold Ferrette ${ }^{7}$ überbracht werden. Er vermutete Jean de Damas in Mâcon und reiste deshalb, nachdem er die Einladung bei Philipp von Savoyen $\{68\}$ abgeliefert hatte (vgl. Reg. 8), dort hin. Beim Betreten der Stadt wurde er gefangen genommen und er verlor dabei seine mitgeführten Briefe. Deshalb konnte er die Briefe an Jean de Damas (Reg. 13 und 25) und Jean de Neufchâtel \{52\} (Reg. 7 und 17) nicht zustellen; zu Ferrettes unglückliche Reise vgl. die Angaben in PB 4 § 26 und vor allem $\S 120$.

Erw.: $\quad$ PB 4 § 26, 28 und 120.

\section{[14]77 Dez. 26, Brüssel}

Die in Brüssel anwesenden Mitglieder des Ordens vom Golden Vlies, Adolf von Kleve $\{55\}$, Ludwig von Brügge $\{61\}$ und Philippe de Croy $\{74\}$, bestätigen ihren Mitbrüdern den Inhalt von Maximilians Einladungsschreiben (Reg. 1-13) und fordern sie auf, an dem geplanten Ordensfest teilzunehmen oder die erforderlichen Absageschreiben auszustellen. - Sekretär: Steenberch.

Bem.: Der Beschluss für die Verfassung dieser Briefe, die mit dem Ordenssiegel versehen werden sollten, faßten die versammelten Mitglieder am 17. Dez. 1477; vgl. dazu auch die Angaben in Reg. 1.

7 Zu Ferrette vgl. die Angaben in $§ 120$, Anm. 96. 
Kop. zeitgen. (Steenberch): AOGV, Codex 45, 43v-44v (ohne Anrede).

Erw.: $\quad$ PB 4 § 14-19.

Folgende Exemplare sind bekannt:

An Johann, Kg. von Aragon \{57\}. - lat.

Bem.: Dieses Schreiben wurde zusammen mit dem aus Reg. 3 durch den Wappenkönig Hennegau überbracht.

Kop. zeitgen. (Steenberch): AOGV, Codex 45, fol. 41r-v.

Erw.: $\quad$ PB 4 § 19 und 26.

An Ferdinand, Kg. von Neapel $\{72\}$. - lat.

Bem.: Dieses Schreiben wurde zusammen mit dem aus Reg. 2 durch den Wappenkönig Flandern überbracht.

Kop. zeitgen. (Steenberch): AOGV, Codex 45, fol. 41r-v.

Erw.: $\quad$ PB 4 § 19 sowie in den Schreiben aus Reg. 34-36.

An Ferdinand $\{71\}$, Kg. von Kastilien. - lat.

Bem.: Dieses Schreiben wurde zusammen mit dem aus Reg. 4 durch den Wappenkönig Hennegau überbracht.

Kop. zeitgen. (Steenberch): AOGV, Codex 45, fol. 41r-v.

Erw.: $\quad$ PB 4 § 19 und 27 sowie in dem Schreiben aus Reg. 30.

An Philipp von Savoyen, Gf. von Bugey $\{68\}$. - frz.

Bem.: Dieses Schreiben wurde zusammen mit dem aus Reg. 8 durch den Herold Ferrette überbracht; zu dessen Reise vgl. die Angaben in Reg. 13.

Kop. zeitgen. (Steenberch): AOGV, Codex 45, fol. 42v-43r.

Erw.: PB 4 § 26 und 120 .

An Jean de Neufchâtel, Herr von Montaigu \{52\}. - frz.

Bem.: Dieses Schreiben ging bei der Festnahme des Herolds Ferrette verloren; vgl. dazu die Angaben in Reg. 7 und 13.

Kop. zeitgen. (Steenberch): AOGV, Codex 45, fol. 43r-v.

Erw.: $\quad$ PB 4 § 26 und 120.

An Johann, Hz. von Kleve \{47\}. - frz.

Bem.: Dieses Schreiben wurde zusammen mit dem aus Reg. 5 durch den Herold Limburg überbracht.

Kop. zeitgen. (Steenberch): AOGV, Codex 45, fol. 44v-45r und 56v.

Erw.: $\quad$ PB 4 § 19, 27 und 121 sowie in den Schreiben aus Reg. 64 und 89.

An Eduard IV., Kg. von England \{63\}. - [frz.].

Bem.: Dieses Schreiben wurde zusammen mit dem aus Reg. 1 durch den Wappenkönig Toison d'or überbracht.

Erw.: $\quad$ PB 4 § 19; in Reg. 29.

\section{[14]77 Dez. 26, Brüssel}

Die in Brüssel anwesenden Mitglieder des Ordens vom Golden Vlies, Adolf von Kleve $\{55\}$, Ludwig von Brügge $\{61\}$ und Philippe de Croy $\{74\}$, bestätigen ihren Mitbrü- 
dern, die sich in Frankreich befinden, den Inhalt von Maximilians Vorladungsschreiben (Reg. 9-13) und fordern sie auf, an dem geplanten Ordensfest persönlich teilzunehmen, um gegen die erhobenen Vorwürfe Stellung zunehmen. - Sekretär: Steenberch.

Bem.: Vgl. dazu auch die Angaben in Reg. 1.

Folgende Exemplare sind bekannt:

An Jacques de Luxembourg \{67\}. - frz.

Bem.: Dieses Schreiben wurde zusammen mit dem aus Reg. 11 durch den Herold Namur überbracht; vgl. dazu Reg. 9.

Kop. zeitgen. (Steenberch): AOGV, Codex 45, fol. 42r.

Erw.: $\quad$ PB 4 § 19 und 28.

An Anton, Bastard von Burgund \{54\}. - frz.

Bem.: Der beauftragte Herold Namur konnte jedoch diesen Brief wie auch den aus Reg. 10 nicht zustellen; vgl. dazu Reg. 9.

Or. Pap.: AOGV, Akten, Karton 5, Fasz. 14 B, Dok. 7 (aufgedr. Ordenssiegel ab und verloren).

Erw.: PB 4 § 19 und 28; AOGV, Codex 45, fol. 42r.

An Philippe Pot, Herr von la Roche-Nolay $\{60\}$ - frz.

Bem.: Der beauftragte Herold Namur konnte jedoch diesen Brief wie auch den aus Reg. 12 nicht zustellen; vgl. dazu Reg. 9.

Or. Pap.: AOGV, Akten, Karton 5, Fasz. 14 B, Dok. 8 (aufgedr. Ordenssiegel ab und verloren). Erw.: $\quad$ PB 4 § 19 und 28; AOGV, Codex 45, fol. 42r.

An Philippe de Crèvecœur, Herr von Esquerdes \{69\}. - frz.

Bem.: Der beauftragte Herold Namur konnte jedoch diesen Brief wie auch den aus Reg. 9 nicht zustellen, vgl. dazu die Angaben dort.

Or. Pap.: AOGV, Akten, Karton 5, Fasz. 14 B, Dok. 5 (aufgedr. Ordenssiegel ab und verloren).

Brüssel, BR, ms. 20.851 (F. J. de Bors d'Overen, Histoire chronologique de l'ordre de la Toison d'or, Bd. 1), fol. 181r.

Erw.: $\quad$ PB 4 § 19 und 28.

An Jean de Damas, Herr von Clessy $\{65\}$. - frz.

Bem.: Dieser Brief sollte zusammen mit dem Schreiben aus Reg. 13 durch den Herold Ferrette überbracht werden, der aber bei seiner Gefangennahme in Mâcon alle mitgeführten Briefe verlor; vgl. dazu die Angaben dort.

Erw.: $\quad$ PB 4 § 26, 28 und 120; AOGV, Codex 45, fol. 42r.

[Nach 1477 Dez. 26, - ]

Philipp von Savoyen $\{68\}$, Gf. von Bugey, antwortet auf das Einladungsschreiben (Reg. 8).

Bem.: Philipp von Savoyen gab dieses Schreiben dem burgund. Herold Ferrette mit, der aber kurz danach in Mâcon gefangen genommen wurde und dabei seine mitgeführten Briefe verlor; zu dessen Reise vgl. die Angaben in Reg. 13.

Or.: verloren.

Erw. $\quad$ PB 4 § 26 und 120 . 
Konzept eines Formulars, mit dem die dem Orden zugehörigen Könige bei Nichtteilnahme an einem Ordensfest, ihre Stellvertreter bevollmächtigen können. - lat. [Sekretär: Steenberch].

Bem.: Bei dem Schriftstück handelt es sich um die Abschrift eines früheren Formulars für das von Hz. Karl dem Kühnen \{34\} geplante, aber nicht durchgeführte Ordensfest in Maastricht im Mai 1476. Darin eingefügt wurden Korrekturen, um dieses Schreiben an die Begebenheit für das von Hz. Maximilians geplante Ordensfest im Mai 1478 anzupassen. Aufgrund des lateinischen Wortlauts ist anzunehmen, dass dieses Formular für Könige Ferdinand von Kastilien $\{71\}$, Ferdinand von Neapel $\{72\}$ und Johann von Aragon $\{57\}$ gedacht war, mit denen der Orden in lat. Sprache korrespondierte. Vermutlich wurde eine Kopie dieses Formulars den Einladungsschreiben, d.d. 1477 Dez. 26, an die jeweiligen Könige (Reg. 2-4) beigelegt.

Konz. Pap.: AOGV, Urkunden, Nr. 49 (Türck'sche Systematik: 2. Partie § 2, 13 A).

Reg.: Ruwet, Vienne, 1956, S. 773, Nr. 49 (datiert [1478]).

[14]78 März 9 (n.St.), Gent ${ }^{9}$

Der Orden vom Goldenen Vlies und Hz. Maximilian schreiben an Jean de Neufchâtel $\{52\}$, Herr von Montaigu, und wiederholen die Einladung zum Ordensfest, nachdem die ersten Einladungsschreiben (Reg. 7 und 18) verloren gegangen waren.

Bem.: Vgl. dazu das Antwortschreiben von Jean de Neufchâtel in Reg. 43.

Erw.: $\quad$ PB § 26 und 120 sowie in Reg. 43.

\section{o.J. [1478] März 14, Greenwich}

Eduard IV. \{63\}, Kg. von England, sagt in einem Brief aufgrund der ihm zugesandten Einladungsschreiben (Reg. 1 und 20) seine Teilnahme am Ordensfest ab. Er erklärt, dass er keinen Stellvertreter oder Wahlvorschläge sendet, da die Einladung von keinem autorisierten Souverän erfolgte. - frz. - eigenh. Unterschrift und Unterschrift des Sekretärs.

Bem.: Der Orden bestellte Ludwig von Brügge $\{61\}$ als seinen Stellvertreter; vgl. PB 4 § 27.

Or. Pap.: AOGV, Urkunden, Nr. 50 (aufgedr. Verschlußsiegel mit einer gold-weißer Seidenschnur umfasst) (Türck'sche Systematik: 2. Partie § 2, 13 A).

Reg.: $\quad$ Ruwet, Vienne, 1956, S. 773, Nr. 50.

Erw.: $\quad$ PB $4 \S 27$ sowie in den Schreiben aus Reg. 60 und 91; DünnebeIL, Burgund und Österreich, 2006, S. 22; DüNnEBEIL, Zeichen, 2012, S. 121, Anm. 32.

1478 März 24, Madrid

Ferdinand $\{71\}$, Kg. von Kastilien, bestätigt Hz. Maximilian den Empfang der Einladungsschreiben (Reg. 4 und 16) und sagt seine Teilnahme am Ordensfest ab. Er benennt den Grafen von Sunaya [Philippe de Croy $\{74\}$, Gf. von Chimay], Adolf von

8 Vgl. dazu die Angaben in der Bemerkung.

9 Datum und Ausstellungsort nach den Angaben aus dem Schreiben von Reg. 43. 
Kleve $\{55\}$, Herr von Ravenstein, und Ludwig von Brügge $\{61\}$, Herr von Gruuthuse, als seine Stellvertreter und sendet gesondert seine Wahlvorschläge (Reg. 31). - lat. eigenh. Unterschrift - Sekretär: Arinyo.

Bem.: Vgl. die in diesem Zusammenhang stehenden Schreiben Kg. Ferdinands (Reg. 31-33). $\mathrm{Zu}$ Beginn des Ordensfestes, am 29. April 1478, waren seine Schreiben jedoch noch nicht in Brügge angekommen; deshalb hatten die Mitglieder Jean de Lannoy $\{50\}$ als seinen Stellvertreter bestimmt; vgl. PB 4 § 27 sowie den Eingangsvermerk Steenberchs auf der Rückseite dieses Or.

Or. Perg.: AOGV, Urkunden, Nr. 51 (beschädigtes anh. Siegel an purpur-grün-goldener Seidenschnur) (Türck'sche Systematik: 2. Partie § 2, 13 A).

Kop. Perg. zeitgen. (Steenberch): ebd. (nach Or.).

Reg.: Ruwet, Vienne, 1956, S. 773, Nr. 51 (nach Or.).

Erw.: in Reg. 65; DünNeBEIL, Burgund und Österreich, 2006, S. 22.

[1478 März 24, Madrid]

Ferdinand $\{71\}$, Kg. von Kastilien, nennt seine Wahlvorschläge für die vakanten Mitgliederplätze: Matthias, Kg. von Ungarn ${ }^{10}$ - Alfons von Aragon, Hz. von Kalabri$\mathrm{en}^{11}$ - [Johann II. von Chalon] Prinz von Orange ${ }^{12}$ - Incluytus Hieronimus, Vizegf. von Riario, ${ }^{13}$ Neffe des Papstes - Alfons Enriquez, Admiral von Kastilien ${ }^{14}$ - Diego Hurtado de Mendoza, Hz. von Infantado, Marques von Santillana ${ }^{15}$ - García Álvarez de Toledo, Hz. von Alba de Tormes, Marques von Coria ${ }^{16}$ - Pedro de Velasco, Gf. von Haro, Konstabler von Kastilien ${ }^{17}$ - Juan [Ramon Folch], Gf. von Cardona und Prades, Admiral

10 Matthias, Kg. von Ungarn, wurde während des Ordensfestes zum neuen Ordensmitglied gewählt, vgl. dazu u. a. § 132 und 150.

11 Alfons von Aragon (1448-1495), Hz. von Kalabrien, wurde nach dem Tod seines Vaters, Ferdinand \{72\}, 1494 König von Neapel und Jerusalem; zu seiner Person vgl. Moscati, Alfonso II d'Aragona, 1960, S. 330 f.; Del Treppo, Alfons II., 1980. Schon 1473 war sein Name auf der Kandidatenliste für neue Mitglieder zu lesen; vgl. PB 3, S. 113, § 176 und 117, § 177.

12 Zu seiner Person vgl. § 235, Anm. 155.

13 Girolamo Riario della Rovere (1443-1488) stammt aus der italienische Adelsfamilie Riario aus Savona war, war militärischer Befehlshaber und ein Neffe (Nepot) von Papst Sixtus IV., der ihn zum Herrn von Imola und Forlì ernannte; zu seiner Person vgl. u.a. LeE, Sixtus IV, 1978, S. 83f.; Menniti Ippolito, Riario, 1994.

14 Alfons Enriquez (1435-1485) entstammt einer alten Adelsfamilie in Kastilien, war ein Onkel Kg. Ferdinands und seit 1464 der Admiral von Kastilien; vgl. dazu u. a. VonEs, Enriquez, 1986; Ortega Gato, Esteban, Los Enriquez, 1999.

15 Diego Hurtado de Mendoza (1417-1479) wurde 1475 zum Hz. von Infantado ernannt; vgl. u. a. Vones, Infantado, 1991; Vones-Liebenstein, Mendoza, 1993.

16 García Âlvarez de Toledo († 1488) erhielt 1472 den erblichen Herzogstitel, der die Grafschaft Alba de Tormes in ein Herzogtum umwandelte. Darüber hinaus trug er u. a. auch noch den Titel des Marqués de Coria. Vgl. dazu u. a. MolénAt, Toledo, 1997.

17 Pedro de Valesco (1425-1492) stammt aus einer Adelsfamilie Kastiliens und versah seit 1473 das Amt des Konstablers von Kastilien; vgl. dazu u. a. Vones, Velasco, 1997. 
von Aragon ${ }^{18}$ - Rodrigo Pimentel, Gf. von Benavente ${ }^{19}$ - Pedro Manrique, Gf. von Trevino $^{20}$ - [Philipp von Burgund \{82\},] Herr von Beveren ${ }^{21}$. - lat. - Sekretär: Arinyo.

Bem.: Zu den anderen in diesem Zusammenhang stehenden Schreiben Kg. Ferdinands vgl. die Angaben in Reg. 30.

Or. Pap.: AOGV, Urkunden, Nr. 51 (geöffnetes aufgedr. Verschlußsiegel) (Türck’sche Systematik: 2. Partie § 2, $13 \mathrm{~A})$.

Kop. (18. Jh.): Brüssel, BR, ms. 20.851 (F.J. de Bors d'Overen, Histoire chronologique de l'ordre de la Toison d'or, Bd. 1), fol. 189r.

Reg.: Cat. mss. de BR, 12, 1936, S. 59, Nr. 7481/23 (nach Kop. in BR Brüssel).

Erw.: in Reg. 30 und 65; Ruwet, Vienne, 1956, S. 773, Nr. 51.

\section{März 24, Madrid}

Ferdinand \{71\}, Kg. von Kastilien, sagt in einem Brief an Hz. Maximilian seine Teilnahme am Ordensfest ab und sendet ihm seine Grüße. - lat. - eigenh. Unterschrift - Sekretär: Arinyo.

Bem.: Zu den anderen in diesem Zusammenhang stehenden Schreiben Kg. Ferdinands vgl. die Angaben in Reg. 30.

Or. Perg.: AOGV, Urkunden, Nr. 51 (geöffnetes aufgedr. Verschlußsiegel unter Papieroblate) (Türck'sche Systematik: 2. Partie § 2, 13 A).

Kop. Pap. zeitgen. (Steenberch): ebd. (nach dem Or.).

1478 März 24, Madrid

Ferdinand $\{71\}$, Kg. von Kastilien, bevollmächtigt in einem Brief den Grafen von Sumaya [Philippe de Croy $\{74\}$, Gf. von Chimay], Adolf von Kleve \{55\}, Herr von Ravenstein, und Ludwig von Brügge $\{61\}$, Herr von Gruuthuse, ihn auf dem Ordensfest zu vertreten. - lat. - eigenh. Unterschrift - Sekretär: Arinyo.

Bem.: Zu den anderen in diesem Zusammenhang stehenden Schreiben Kg. Ferdinands vgl. die Angaben in Reg. 30.

Or. Perg.: AOGV, Urkunden, Nr. 51 (geöffnetes aufgedr. Verschlußsiegel unter Papieroblate) (Türck'sche Systematik: 2. Partie § 2, 13 A).

Kop. Pap. zeitgen. (Steenberch): ebd. (nach dem Or.).

\section{März 27, Neapel}

Ferdinand $\{72\}$, Kg. von Neapel, bevollmächtigt aufgrund der erhaltenen Einladungsschreiben (Reg. 2 und 15) die Ordensritter Philippe de Croy \{74\}, Antoine de Melun $\{28\}$ und Ludwig von Brügge $\{61\}$, ihn auf dem Ordensfest zu vertreten. - lat. - eigenh. Unterschrift und Kanzleivermerk.

18 Juan Ramon Folch (um 1390-1486) wurde schon 1468 von Johann, Kg. von Aragon \{57\}, als möglicher Kandidat genannt; vgl. PB 3, S. 185, Reg. 74. Zu seiner Person vgl. u. a. Udina, Cardona, 1983.

19 Rodrigo Alfonso Pimentel ( $\uparrow 1499)$ gehörte dem Adel Kastiliens an, war 4. Gf. von Pimentel und wurde 1473 zum ersten Hz. von Benavente ernannt; vgl. dazu u. a. Montero TejadA, Pimentel, 1993.

20 Pedro Fernandez Manrique († 1515); wurde 1482 zum Hz. von Najera ernannt; vgl. dazu u. a. Montero TejadA, Manrique, 1993.

21 Er wird 1478 tatsächlich gewählt; vgl. § 105 mit Angaben zu seiner Person. 
Bem.: Kg. Ferdinands verschiedene Schreiben, die er wegen seiner Nichtteilnahme an den Orden sandte (Reg. 34-37), kamen rechtzeitig in Brügge an. Sie wurden durch den Wappenkönig Flandern überbracht, der mit den Einladungsschreiben (Reg. 2 und 15) zu Kg. Ferdinand gereist war. Wunschgemäß wurde Philipp von Croy $\{74\}$ mit der Vertretung beauftragt; vgl. PB 4 § 26.

Or. Perg.: AOGV, Urkunden, Nr. 52 (anh. beschädigtes Siegel an rot-goldener Seidenschnur) (Türck'sche Systematik: 2. Partie § 2,13 A).

Kop. Perg. zeitgen. (Steenberch): AOGV, Urkunden, Nr. 53 (nach Or.).

Reg.: $\quad$ Ruwet, Vienne, 1956, S. 773 f., Nr. 52.

Erw.: $\quad$ PB 4 § 24-26 und 85; DünNEBEIL, Burgund und Österreich, 2006, S. 22.

\section{März 28, Neapel}

Ferdinand $\{72\}$, Kg. von Neapel, schreibt an Hz. Maximilian und bestätigt den Erhalt der Einladungsschreiben (Reg. 2 und 15), entschuldigt sich, dass er nicht am Ordensfest teilnehmen kann, benennt Philippe de Croy $\{74\}$, Antoine de Melun $\{28\}$ und Ludwig von Brügge $\{61\}$ als seine Stellvertreter und sendet seinen Stimmzettel für die Wahl neuer Ordensritter (Reg. 37). - lat. - eigenh. Unterschrift - Sekretär: F.A.

Bem.: Zu den anderen in diesem Zusammenhang stehenden Schreiben Kg. Ferdinands vgl. die Angaben in Reg. 34.

Or. Perg.: AOGV, Urkunden, Nr. 53 (aufgedr. Verschlußsiegel unter Papieroblate) (Türck'sche Systematik: 2. Partie $\S 2,13$ A).

Kop. Pap. zeitgen. (Steenberch): ebd. (nach Or.).

Reg.: Ruwet, Vienne, 1956, S. 774, Nr. 53.

Erw.: $\quad$ PB 4 § 24-26 und 85; im Schreiben von Reg. 61.

1478 März 28, Neapel

Ferdinand $\{72\}$, Kg. von Neapel, schreibt desgleichen an den Orden vom Goldenen Vlies. - lat. - eigenh. Unterschrift - Sekretär: F.A.

Bem.: $\mathrm{Zu}$ den anderen in diesem Zusammenhang stehenden Schreiben Kg. Ferdinands vgl. die Angaben in Reg. 34.

Or. Perg.: AOGV, Urkunden, Nr. 53 (aufgedr. Verschlußsiegel unter Papieroblate) (Türck'sche Systematik: 2. Partie $\S 2,13$ A).

Kop. Pap. zeitgen. (Steenberch): ebd. (nach dem Or.).

[1478 März 28, Neapel]

Ferdinand $\{72\}$, Kg. von Neapel, nennt seine Wahlvorschläge für die vakanten Mitgliederplätze: ${ }^{22}$ Matthias, Kg. von Ungarn ${ }^{23}$ - Ernst, Hz. von Sachsen ${ }^{24}$ - Al-

22 Mehrere der hier genannten Kandidaten (Ferdiands Söhne Alfons und Friedrich, Diomede Carafa, Francesco del Balzo und Ferrante Guevara) sind Mitglieder von Kg. Ferdiands Hermelinordens; vgl. Boulton, Knights of the crown, 2000, S. 414 f. Sie konnten aufgrund des Exklusivitätsgebots (vgl. dazu § 28, Anm. 175) gar nicht in den Orden vom Goldenen Vlies gewählt werden.

23 Vgl. dazu die Angaben in Reg. 31 mit Anm. 10.

24 Kurfürst und Hz. Ernst von Sachsen (1441-1486) ist ein Bruder des 1478 gewählten Albrecht, Hz. von Sachsen \{96\}, und Begründer der Ernestinischen Linie der Wettiner; zu seiner Person vgl. u. a. BlaschKe, Ernst von Sachsen, 1959. 
fons, Hz. von Kalabrien ${ }^{25}$ - Albrecht, Mgf. von Brandenburg ${ }^{26}$ - Fredericus comes Palatinus $^{27}$ - [Christoph], Mgf. von Baden $\{102\}^{28}-$ Johann, Junghz. von Kleve $^{29}-$ Philipp von Kleve, Sohn Adolfs $\{55\}$, Herrn von Ravenstein ${ }^{30}$ - Sigmund, Hz. von Österreich ${ }^{31}$ - Philibert, Hz. von Savoyen ${ }^{32}$ - Don Friedrich von Aragon ${ }^{33}$ - Diomede Carafa, Gf. von Maddaloni ${ }^{34}$ - Francesco del Balzo, Hz. von Andria ${ }^{35}$ - Don Ferrante Guevara, Gf. von Belcastro. ${ }^{36}$ - lat.

Bem.: Zu den anderen in diesem Zusammenhang stehenden Schreiben Kg. Ferdinands vgl. die Angaben in Reg. 34.

Or. Pap.: AOGV, Urkunden, Nr. 53 (Türck’sche Systematik: 2. Partie § 2, 13 A).

Kop. Pap. zeitgen. (Steenberch): AOGV, Urkunden, Nr. 51 (unter der Abschrift von Reg. 32 und somit Kg. Ferdinands $\{71\}$ zugeordnet).

Kop. (18. Jh.): Brüssel, BR, ms. 20.851 (F.J. de Bors d'Overen, Histoire chronologique de l'ordre de la Toison d'or, Bd. 1), fol. 188r.

Erw.: $\quad$ in Reg. 35.

$25 \mathrm{Kg}$. Ferdinand hat hier seinen Sohn auf die Kandidatenliste gesetzt; zu seiner Person vgl. die Angaben in Reg. 31 mit Anm. 11.

26 Zur Person Albrecht (Achilles), Kurfürst und Markgf. der Brandenburg (1414-1486), vgl. u. a. BöHm, Albrecht von Brandenburg, 1875; HeInRIch, Albrecht Achilles, 1980.

27 Im März 1478 gab es keinen amtierenden Pfalzgrafen namens Friedrich; Pfalzgraf war zu dieser Zeit Philipp († 1508). Er folgte seinem Onkel und Vormund Friedrich, der am 12. Dezember 1476 verstorben war. Es ist anzunehmen, dass Kg. Ferdinand aber genau diesen (verstorbenen) Friedrich meinte, der zu Lebzeiten im Spannungsfeld zwischen Ks. Friedrich III. \{94\}, dem Reich und Hz. Karl \{34\} eine wichtige Rollge gespielt hatte. 1473 stand sein Name auf der Kandidatenliste für mögliche neue Vliesritter. Zu seiner Person vgl. u. a. PB 3, S. 113, § 176 mit Anm. 405; KrIEger, Friedrich, 1989; Holtz, Friedrich I., 1995; EHM, Burgund, 2002, S. $101 \mathrm{ff}$.; PARAvicini, Adelskultur, 2002, S. $461 \mathrm{ff}$.

$28 \mathrm{Zu}$ ihm vgl. die Angaben in $\S 10$ mit Anm. 58.

29 Johann II., Hz. von Kleve (1458-1521), ist der Sohn des Vliesritters Johann I., Hz. von Kleve $\{47\}$, der es gerne gesehen hätte, wenn sein am burgund. Hof aufgewachsener Sohn Hz.in Maria geheiratet hätte; vgl. dazu § 9, Anm. 49 und zur Person u.a. Harless, Johann II., 1881; PARAvicini, Kleve, Geldern und Burgund, ${ }^{22002}$, S. 626 mit Anm. 41; PB 3, S. 44 mit Anm. 92.

$30 \mathrm{Zu}$ seiner Person vgl. die Angaben in $§ 75$ mit Anm. 18.

$31 \mathrm{Zu}$ Sigmund, Hz. von Österreich (1427-1496), einem Onkel Hz. Maximilians, vgl. u. a. BAum, Sigmund der Münzreiche, 1987.

32 Zur Person Philiberts, Hz. von Savoyen (1465-1482), vgl. u.a Demotz, Philibert, 1993.

33 Hier nominierte Ferdinand seinen zweiten Sohn Friedrich (1452-1504), der 1496 König von Neapel wurde. Friedrich war 1474 an den burgund. Hof gereist, wohl auch in der Hoffnung, mit Hz.in Maria vermählt zu werden; vgl. dazu u. a. PB 3, S. 180 f. und zur Person u. a. Vultaggio, Friedrich I. von Aragon, 1989.

34 Diomede Carafa $(\dagger$ 1487), der aus einer Adelsfamilie aus Neapel stammte, war Erzieher und später Berater Kg. Ferdinands und wurde von diesem zum 1. Grafen von Maddaloni ernannt; zu seiner Person vgl. u. a. Reumont, Carafa, 1851, S. 195-211; PaszTor, Diomedo Carafara, 1983.

35 Francesco del Balzo (Bautro, Les Baux) († 1482), Hz. von Andria, war ein Cousin Kg. Ferdinands; vgl. dazu u. a. ES III/4 (1989) Tafel 745 f.

36 Er stammt aus einem Adelsgeschlecht Kastiliens und war Mitglied in Kg. Ferdinands Hermelinorden; vgl. VonEs, Guevara, 1989. 
1478 März 30, Barcelona

Johann, Kg. von Aragon \{57\}, entschuldigt in einem Brief an den Orden vom Goldenen Vlies sein Fernbleiben beim kommenden Ordensfest. - lat. - eigenh. Unterschrift Sekretär: [Johannes de] Colonia. ${ }^{37}$

Bem.: Zu Beginn des Ordensfestes lag sein Entschuldigungsschreiben noch nicht vor, deshalb wurde Adolf von Kleve $\{55\}$ als sein Stellvertreter bestimmt; vgl. PB 4 § 26.

Or. Pap.: AOGV, Urkunden, Nr. 54 (aufgedr. Verschlußsiegel) (Türck'sche Systematik: 2. Partie § 2, $13 \mathrm{~A})$.

Reg.: $\quad$ Ruwet, Vienne, 1956, S. 774, Nr. 54.

\section{[1478 Ende März, - ] ${ }^{38}$}

Hz. Maximilian und die bei ihm anwesenden Mitglieder des Ordens vom Goldenen Vlies fordern die anderen Ordensmitglieder aufgrund der zu erwartenden geringen Teilnehmerzahl dringlich auf, am kommenden Ordensfest teilzunehmen.

Folgende Exemplare sind bekannt:

An Johann, Hz. von Kleve $\{47\}$.

Bem.: Diese Schreiben, wie auch die ersten Einladungsschreiben (Reg. 5 und 19), überbrachte der Herold Limburg.

Erw.: $\quad$ PB 4 § 27 und 121 sowie in den Schreiben aus Reg. 64 und 89.

An Jean de Melun $\{28\}$.

Erw.: in dem Schreiben aus Reg. 45.

\section{April 7, Den Haag}

Hz. Maximilian teilt dem Ordenskanzler, Ferry de Clugny, Bf. von Tournai, in einem Brief mit, dass das Ordensfest im kommenden Mai in Brügge und in der Kirche St. Salvator stattfinden soll. Er bittet ihn, zusammen mit Olivier de la Marche die dazu nötigen Vorkehrungen zu treffen.

Erw.: PB 4 § 20; Reiffenberg, Toison d'or, 1830, S. 90; Barante/Gachard, Histoire, II, 1838, S. 601, Anm. 4; Delepierre, Fête en 1478, 1842, S. 334; VAnder Linden, Itinéraires, 1934, S. 31; DAmme, Adolf van Kleef, 1967, S. 134.

1478 April 7, Den Haag

Hz. Maximilian beauftragt Olivier de la Marche, in Brügge das Fest des Ordens vorzubereiten.

Erw.: $\quad$ PB 4 § 20; Fugger, Spiegel der Ehren, 1668, S. 880 f.; Воск, Maximilian, 1970, S. 40 mit Anm. 5.

37 Der kgl. Sekretär Johannes de Colonia hatte auch schon die Absageschreibe Kg. Ferdinands für das Ordensfest von 1468 ausgestellt; vgl. PB 2, S. 186, Reg. 25 und PB 3, S. 185, Nr. 74.

38 So die Angaben in Reg. 89. 
Jean de Neufchâtel $\{52\}$, Herr von Montaigu, bestätigt Hz. Maximilian den Erhalt seines Einladungsschreiben zum Ordensfest vom 9. März (Reg. 28) und erkärt, dass er davor keine Einladungsschreiben erhalten habe. ${ }^{39}$ Aufgrund des späten Eintreffens der Einladung könne er nicht rechtzeitig zum Ordensfest erscheinen, auch erlauben ihm seine Gesundheit und die Kriegsgefahr keine weiten Reisen. Demenstprechend hat er sich auch an Philippe de Croy $\{74\}$, Gf. von Chimay, gewendet. Er beglaubigt hiermit seinen Kaplan als Überbringer dieses Briefes und entschuldigt sein Fehlen am Ordensfest. - frz. - eigenh. Unterschrift.

Bem.: Diese Entschuldiungsschreiben kam nicht mehr rechtzeitig zum Ordensfest in Brügge an; vgl. dazu auch PB 4 § 26 und 120. Die Ordensmitglieder bestellten deshalb Ludwig von Brügge $\{61\}$ als Jeans Stellvertreter (§ 26). - Vgl. dazu auch die Angaben in Reg. 81, Anm. 84.

Or. Pap.: AOGV, Akten, Karton 5, Fasz. 14 D, Dok. 12 (mit Resten des Verschlußsiegels).

Druck: STERCHI, Überläufer, 2003, S. 97 f., Nr. 1; Sterchi, Umgang, 2005, S. 458 mit Anm. 305 (Teildruck).

Erw.: STERCHI, Überläufer, 2003, S. 82.

\section{[14]78 April 22, Gent}

Hz. Maximilian teilt [Philippe Conrault], Abt von Sankt-Peters in Gent, ${ }^{40}$ mit, dass er sich entschlossen habe, von seinem verstorbenen Schwiegervater, Hz. Karl von Burgund \{34\}, den Orden vom Goldenen Vlies zu übernehmen. Deshalb hat der die Ordensmitglieder zu einem Ordensfest eingeladen und und ersucht ihn, sich am 1. Mai mit Chormantel, Mitra und Stab in Brügge einzufinden, um an den Gottesdiensten des Ordens teilnehmen zu können. - frz. - eigenh. Unterschrift. - Sekretär: Steenberch.

Reg. (19. Jh.): Brüssel, AGR, Mss. div. 1939, fol. 1r.

Druck: Lettres ... Saint-Pierre à Gand, 1845, S. 9f., Nr. 4.

Reg.: Lichnowsky, Geschichte, 8, 1844, S. DXXXVIII, Nr. 40; Regesten Friedrichs III., Suppl. 1, 2008, S. 57 f., Reg. 30 (nach AGR Brüssel).

Erw.: Barante/Gachard, Histoire, II, 1838, S. 601, Anm. 4.

1478 April 28, o. O.

Jean de Melun $\{28\}$, Rat und Kammerherr Hz. Maximilians, schreibt aufgrund eines Einladungsschreibens Hz. Maximilians, mit der Aufforderung am 2. Mai persönlich in Brügge zu erscheinen (Reg. 40), an den Orden vom Goldenen Vlies. Damit sagt er seine Teilnahme am Ordensfest ab und bevollmächtigt Philippe von Croy $\{74\}$, Ludwig von Brügge $\{61\}$ und Jean de Lannoy $\{50\}$, ihn zu vertreten. - frz.

Bem.: Tatsächlich vertrat ihn Philipp von Croy beim Ordensfest; vgl. PB 4 § 26.

Or. Perg.: AOGV, Urkunden, Nr. 55 (anh. Siegel) (Türck’sche Systematik: 2. Partie § 2, 13 A).

39 Die ersten Einladungsschreiben (Reg. 7 und 18) gingen bei der Gefangennahme des Herolds Ferrette verloren; vgl. dazu die Angaben in Reg. 13.

40 Seit 1471 Abt des Klosters war er Hz. Maximilians Beichtvater und Rat; zu seiner Person vgl. Regg. Friedrichs III., Suppl. 1, 2008, S. 58 (mit Hinweis auf Berings/Simaey, S. Pierre de Gand, S. 96 ff.). 
Reg.: $\quad$ Ruwet, Vienne, 1956, S. 774, Nr. 55.

Erw.: $\quad$ PB 4 § 24-26.

\section{o. D. [1478 April 28, - ]}

Jean de Melun $\{28\}$ nennt seine Wahlvorschläge für die vakanten Mitgliederplätze: $:^{41}$ Ks. Friedrich III. \{94\} - [Pierre de Luxembourg \{83\}] Gf. von Saint-Pol - [Christoph], Mgf. von Baden $\{102\}^{42}$ - [Philippe de Croy] Herr von Porcien ${ }^{43}-$ [Wilhelm IV.] Hz. von Jülich ${ }^{44}$ - [Jacques de Luxembourg \{81\}] Herr von Fiennes - [Albrecht Achilles, Kurfürst und] Mgf. von Brandenburg ${ }^{45}$ - [Jean \{87\}] Herr von Ligne $^{46}$ - [Jakob von Savoyen \{84\}] Herr von Romont - Josse, Herr von Lalaing \{80\} - [Philipp von Burgund $\{82\}$ ] Herr von Beveren - [Johann II. von Chalon] Prinz von Orange ${ }^{47}-$ Herr von Becan. ${ }^{48}$ - frz.

Or. Pap.: AOGV, Urkunden, Nr. 55 (Türck’sche Systematik: 2. Partie § 2, 13 A).

Erw.: Ruwet, Vienne, 1956, S. 774, Nr. 55.

[Vor 1478 April 30, - ] ${ }^{49}$

Cedule des Wappenkönig Toison d'or mit den Namen der seit dem letzten Fest verstorbenen Mitglieder: [Karl, Herzog von Burgund $\{34\}$ - Antoine de Croy $\{15\}$ - Louis de Chalon $\{64\}$ - Jean de Rubempré $\{73\}$ - Jean de Luxembourg $\{75\}$ - Johann, Herzog von Alençon $\{39\}$ - Baudouin de Lannoy $\{19\}$ - Simon de Lalaing $\{26\}$ - Jean d'Auxy $\{45\}$ Hendrik van Borssele $\{44\}$ - Reinald van Brederode $\{43\}$ - Adolf von Geldern $\{58\}$ - Guy de Brimeu $\{76\}] .^{50}$

Erw.: $\quad$ PB 4 § 79 .

41 Sechs der hier von Jean de Melun vorgeschlagenen Kandidaten (diejenigen ohne eigene Fußnote) wurden 1478 tatsächlich in den Orden gewählt; vgl. § 154.

$42 \mathrm{Zu}$ ihm vgl. die Angaben in $\S 10$ mit Anm. 58.

$43 \mathrm{Zu}$ seiner Person vgl. die Angaben in § 75, Anm. 20.

44 Wilhelm IV. (1455-1511) übernahm 1475 die Regentschaft über das Hzt. Jülich-Berg. Seine Politik war proburgundisch ausgerichtet. Er unterhielt enge Beziehungen zu Hz. Karl \{34\} und später auch zu Hz. Maximilian; zu seiner Person vgl. u. a. RedLIch, Wilhelm IV., 1989.

$45 \mathrm{Zu}$ seiner Person vgl. die Angaben in Reg. 37, Anm. 26.

46 Jean de Ligne (1435-1491) wurde erst 1481 in den Orden vom Goldenen Vlies gewählt; vgl. Chevaliers de la Toison d'or, ${ }^{2} 2000$, Nr. 87.

$47 \mathrm{Zu}$ seiner Person vgl. die Angaben in § 235 mit Anm. 155.

48 Möglicherweise handelt es sich dabei um Wolfart van Borssele \{79\}, der bei diesem Fest tatsächlich gewählt wurde. Wolfart hatte mit seiner Heirat von Maria Stuart, der Tochter Jakobs I., Kg. von Schottland, den Titel des Grafen von Buchan verliehen bekommen. Allderdings verlor er diesen Titel mit dem Tod Marias im Jahr 1465. Zu seiner Person vgl. die Angaben in § 138, Anm. 170.

49 Diese cedule wurde am 30. April dem Orden vorgelegt.

50 Vgl. dazu die Auflistung der verstorbenen Mitglieder in PB 4, § 153, aber auch § $26 \mathrm{f}$. und 32-34. 
Jean Gros wird zum Trésorier des Ordens vom Goldenen Vlies ernannt. - Martin Steenberch.

Or: $\quad$ Verbleib unbekannt (mit Ordenssiegel).

Erw.: $\quad$ PB $4 \S 74$.

\section{[1478 Mai 2, Brügge]}

Hz. Maximilian bestätigt dem Ordensgreffier Martin Steenberch seine von Hz. Karl \{34\} während des Ordensfestes im Jahr 1473 verliehenen lebenslangen Einnahmen aus Brüssel.

Bem.: Während des Ordensfestes bestätigte Hz. Maximilian dies am 2. Mai 1478 mündlich und beauftragte Steenberch mit der Ausstellung einer entsprechenden Urkunde; vgl. PB 4 § 173 .

Erw.: $\quad$ PB 4 § 173; AOGV, Codex 34/1, S. 129; Reiffenberg, Toison d'or, 1830, S. 96.

[1478 Mai 2, Brügge]

Hz. Maximilian bestätigt dem Wappenkönig Toison d'or [Gilles Gobet] seine von Hz. Karl $\{34\}$ verliehene Pension aus Saint-Omer.

Bem.: Während des Ordensfestes bestätigte Hz. Maximilian dies am 2. Mai 1478 mündlich und beauftragte Steenberch mit der Ausstellung einer entsprechenden Urkunde; vgl. PB 4 § 174 .

Erw.: $\quad$ PB 4 § 174; AOGV, Codex 34/1, S. 129 f.; Reiffenberg, Toison d'or, 1830, S. 96.

1478 Mai 7, Brügge

Instruktionen für den Wappenkönig Toison d'or, der Hz. Maximilian über die Beschlüsse der in Brügge zurückgebliebenen Ordensmitglieder unterrichten und dazu auch die bei Hz. Maximilian weilenden Ordensmitglieder Philippe de Croy $\{74\}$ und Josse de Lalaing $\{80\}$ bitten soll. Er soll folgende Empfehlungen aussprechen: [1.] Die Mitglieder, die nicht am vergangenen Ordensfest teilgenommen haben, sollen über die rechtmässige Einsetzung Hz. Maximilians zum Ordenssouverän und über den Verlauf des darauf folgenden Ordensfestes unterrichtet werden. [2.] Bei Eduard IV. $\{63\}$, Kg. von England, Ferdinand \{72\}, Kg. von Neapel, und Ferdinand \{71\}, König von Kastilien sollen Gesandtschaften für die Bestätigung des politischen Bündnisses werben. [3.] Die neugewählten Mitglieder, die sich zum Zeitpunkt ihrer Wahl nicht in Brügge aufgehalten haben, sollen je nach ihrer Herkunft und ihrem Rang verschieden über ihre Wahl in den Orden unterrichtet und die Aufnahmeverfahren durchgeführt werden. [4.] Die Einladungsschreiben für das für das kommende Jahr geplante Fest sollen vier Monate vor Beginn ausgesandt werden. - frz. - Sekretär: Martin Steenberch.

51 Tag und Ort, wo die Ausstellung der Urkunde vom versammelten Orden vom Golden Vlies beschlossen wurde. Möglicherweise wurde sie auch auf den Tag seiner provisorischen Ernennung, die nach Koller, Service, 1971, S. 63f., am 29. Nov. 1477 erfolgte, rückdatiert; so geschehen bei der Ernennung Ferry de Clugny zum Ordenskanzler im Jahr 1473; vgl. PB 3, S. 178, Reg. 51. 
Bem.: Mit der Ausstellung dieses Schreibens wurde am 4. Mai 1478 Martin Steenberch beauftragt; vgl. § PB 4 § 182; dort finden sich auch Angaben, in wieweit die verschiedenen Empfehlungen umgesetzt wurden.

Kop. zeitgen.: PB 4 § 183-195.

Erw.: $\quad$ PB 4 § 182; AOGV, Codex 34/1, S. 131 f.; Reiffenberg, Toison d'or, 1830, S. 97.

[Nach 1478 Mai 7, - ]

Hz. Maximilian fordert Jacques de Luxembourg $\{81\}$, Herr von Fiennes, auf, sich bei ihm einzufinden.

Bem.: In einem Schreiben verschiedener Ordensmitglieder an Hz. Maximilian, empfehlen diese, die beiden in den burgundischen Niederlanden befindlichen neugewählten Mitglieder Jacques de Luxembourg und Philipp von Burgund \{82\}, ohne Angabe von Gründen zu sich einzuladen und ihnen nach ihrer Ankunft ihre Wahl zum Ordensmitglied secretement mitzuteilen; vgl. PB 4 § [190 sowie Reg. 51. Ob diese Aufforderung schriftlich oder mündlich erfolgte, ist nicht bekannt. Jacques wurde am 16. Mai 1478 in den Orden aufgenommen; vgl. Reg. 59.

Erw.: $\quad$ PB 4, § 190.

[Nach 1478 Mai 7, - ]

Hz. Maximilian beglaubigt seinen Wappenkönig Toison d'or bei Philipp von Burgund $\{82\}$, Herrn von Beveren.

Bem.: PB 4, § 190 und Reg. 51 zufolge, wäre zu erwarten gewesen, dass Hz. Maximilian Philipp nur aufforderte, sich bei ihm einzufinden. In PB 5, fol. 64r, bestätigt Toison d'or aber, dass er bei Philipp die Aufnahmeprozedur im Juni 1478 durchgeführt habe. Es ist deshalb eher anzunehmen, dass Hz. Maximilian ähnlich wie in Reg. 54 und 55, mit diesem Brief Toison d'or beglaubigte.

Erw.: $\quad$ PB 4, § 190 .

[Nach 1478 Mai 7, - ]

Hz. Maximilian beglaubigt seinen Wappenkönig Toison d'or bei Wolfart van Borssele $\{79\}$ in einem Kredenzschreiben.

Bem.: In Folge einer Versammlung am 4. Mai empfahlen verschiedene Ordensmitglieder Hz. Maximilian in einem Schreiben vom 7. Mai 1478, Toison d'or zu den deux esleuz de la langue thioise [Wolfart van Borssele $\{79\}$ und Willem van Egmond \{78\}] zu senden, um diese über ihre Wahl in den Orden zu unterrichten und gegebenenfalls das Aufnahmeverfahren durchzuführen; vgl. PB 4 § 182 und 191 sowie Reg. 51. Dafür sollte Toison d'or mit Kredenzbriefen ausgestattet werden. Über die tatsächliche Aufnahme dieser beiden Kandidaten ist jedoch nichts bekannt; Wolfart wird Ende 1478 als Mitglied bezeichnet und Willem im Mai 1479; vgl. dazu die Angaben in $\S 154$.

Erw.: $\quad$ PB 4, § 191 und in dem Schreiben aus Reg. 51. 
[Nach 1478 Mai 7, - ]

Hz. Maximilian beglaubigt desgleichen seinen Wappenkönig Toison d'or bei Willem van Egmond $\{78\}$.

Bem.: Vgl. die Angaben in Reg. 54.

Erw.: $\quad$ PB 4, § 191 und im Schreiben aus Reg. 51.

\section{[Nach 1478 Mai 7, - ]}

Den Mitgliedern, die bei dem diesjährigen Ordensfest gefehlt haben, werden die Namen der neuen und schon beigetretenen Mitglieder mitgeteilt.

Bem.: Dies wurde am 4. Mai 1478 von den in Brügge anwesenden Mitgliedern beschlossen und am 7. Mai als Empfehlung an Hz. Maximilian geschrieben; vgl. PB 4 § 182, Reg. 51 sowie die einleitende Bemerkung zu Reg. 60-64. Die einzelnen Schreiben wurden wohl an unterschiedlichen Tagen ausgestellt, denn die entsprechende Schreiben an Johann, Hz. von Kleve \{47\}, und ein königliches Mitglied in lateinischer Spreche datieren vom 4. Juli 1478 (Reg. 66 und 67) und das an Ferdinand, Kg. von Neapel \{72\}, von 13. bzw. 23. Juli 1478 (Reg. 68 und 69).

Erw.: $\quad$ PB 4 § 182.

Folgende Exemplare sind bekannt:

An Eduard IV., Kg. von England \{63\}. - [frz.].

Erw.: $\quad$ PB 4 § 182 und in Reg. 91.

An Johann, Kg. von Aragon \{57\}. - [lat.].

Bem.: Möglicherweise identisch mit Reg. 67.

Erw.: $\quad$ PB 4 § 182.

An Ferdinand, Kg. von Neapel \{72\}. - [lat.].

Bem.: Möglicherweise identisch mit einem der in Reg. 67-69 genannten Schreiben.

Erw.: $\quad$ PB 4 § 182.

\section{[14]78 Mai 16, o. O. [Mons]}

Jacques de Luxembourg $\{81\}$, Herr von Fiennes und Rat und Kammerherr Hz. Maximilians, bestätigt, dass er am heutigen Tag in Mons vor Hz. Maximilian und in Gegenwart von Philippe de Croy \{74\}, Josse de Lalaing \{80\} und Bartholomäus von Liechtenstein $\{85\}$ den Aufnahmeeid des Ordens abgelegt und die Ordensinsignien erhalten hat. ${ }^{52}$ - frz. - eigenh. Unterschrift.

Bem.: Vgl. dazu auch Reg. 52. - In PB 5, fol. 64r, bestätigt Toison d'or dem Ordenssekretär, dass Jacques' Beitritt in Mons im Jahr 1478 erfolgte, an Stelle von Bartholomäus von Liechtenstein erwähnt er jedoch Jakob von Savoyen $\{84\}$ und sich selbst als Zeugen.

Or. Perg.: AOGV, Urkunden, Nr. 56 (abh. Siegel) (Türck'sche Systematik: 2. Partie § 2, 13 B). Reg.: $\quad$ Ruwet, Vienne, 1956, S. 774, Nr. 56.

52 Zu seiner Wahl vgl. § 138 und 154. 


\section{[14]78 Mai 28, Mons}

Den Mitgliedern, die bei dem diesjährigen Ordensfest gefehlt und keinen Stellvertreter ernannt haben, wird mitgeteilt, dass Hz. Maximilian bei einer öffentlichen Zeremonie in Brügge zum Ritter geschlagen wurde und die Souveränität über den Orden übernommen hat. Danach fand ein ordentliches Mitgliedertreffen statt, mit Durchführung der corrections der anwesenden Mitglieder und Neuwahlen. Aufgrund des französischen Einfalls wurde das Fest aber abgebrochen, ohne alle offenen Fragen und Punkte zu klären, weshalb im kommenden Jahr ein weiteres Ordensfest veranstaltet werden soll. - frz.

Bem.: Während der Sitzung am 4. Mai 1478 beschlossen die in Brügge anwesenden Mitglieder, dass dieses Schreiben an die tresexcellentes roys et princes et aux aultres chevaliers freres dudit ordre absens et qui n'y avoient esté ne procureur pour eulx gesandt werden solle; vgl. PB 4 § 182. Das impliziert, dass die anderen fehlenden Mitgliedern (statutengemäß) von ihren Stellvertretern, die sie sich selbst ausgesucht hatten, über den Verlauf des Ordensfestes unterrichtet werden sollten; dies betrifft aber nur Jean de Melun $\{28\}$. Neben den unten genannten Empfängern müsste dieses Schreiben dann auch an Jean de Neufchâtel $\{52\}$ und Philipp von Savoyen $\{68\}$ gegangen sein. Ob die am frz. Hof weilenden Mitglieder (Anton, Bastard von Burgund \{54\}, Philippe Pot $\{60\}$, Philippe de Crèvecœur $\{69\}$, Jacques de Luxembourg $\{67\}$ und Jean de Damas $\{65\}$ ) ebenfalls detailliert unterrichtet wurden, ist eher unwahrscheinlich. - Die Namen der neugewählten und schon aufgenommenen Mitglieder wurden in seperaten Schreiben mitgeteilt, vgl. dazu Reg. 56-58, 66 und 67.

Erw.: $\quad$ PB 4 § 182 und 186 sowie in Reg. 51; ReIffenberg, Toison d'or, 1830, S. 97.

Folgende Exemplare sind bekannt:

An Eduard IV., Kg. von England \{63\}. - frz.

Bem.: Überbracht durch Toison d'or; vgl. Reg. 70. - Die Ordensmitglieder empfahlen Hz. Maximilian in einem Schreiben vom 7. Mai, dass zusammen mit diesem Schreiben ein weiteres Schreiben oder eine Gesandtschaft an den Adressanten gesandt werden sollte, um den Fortbestand der politischen Allianz bestätigen zu lassen; vgl. PB 4 § 187 mit Anm. 658 sowie Reg. 51.

Kop. zeitgen. (Steenberch): AOGV, Codex 45, fol. 45v-47r.

Erw.: $\quad$ PB 4 § 182 und 186 sowie in Reg. 51, 70 und 91.

An Ferdinand, Kg. von Neapel $\{72\}$. - lat.

Bem.: Überbracht durch den Herold Flandern; vgl. Reg. 72. - Gleichzeitig sollte der Adressat zu einer Bestätigung des Fortbestands der politischen Allianz bewogen werden; vgl. dazu die Angaben in Reg. 60.

Kop. zeitgen. (Steenberch): AOGV, Codex 45, fol. 49r-51r.

Erw.: $\quad$ PB 4 § 182 und 186 sowie in Reg. 51.

An Johann, Kg. von Aragon \{57\}.

Erw.: $\quad$ PB 4 § 182 und 186 sowie in Reg. 51 und 93. 
An Ferdinand $\{71\}$, Kg. von Kastilien. - lat.

Bem.: Überbracht durch den Herold Lothier ${ }^{53}$; vgl. Reg. 73. - Gleichzeitig sollte der Adressat zu einer Bestätigung des Fortbestands der politischen Allianz bewogen werden; vgl. dazu die Angaben in Reg. 60.

Kop. zeitgen. (Steenberch): AOGV, Codex 45, fol. 47v-49r.

Erw.: $\quad$ PB 4 § 182 und 186 sowie in Reg. 51 und 73.

An Johann, Hz. von Kleve $\{47\}$. - frz.

Kop. zeitgen. (Steenberch): AOGV, Codex 45, fol. 52r-53r und 57r-v.

\section{[14]78 Juni 4, Mons ${ }^{54}$}

Hz. Maximilian bestätigt Ferdinand $\{71\}$, Kg. von Kastilien, den Empfang von Reg. 30 und 31 und kündigt ein Ordensfest im kommenden Jahr an. - lat.

Kop. zeitgen. (Steenberch): AOGV, Codex 45, fol. 51r-52r.

\section{[14]78 Juli 4, Mons ${ }^{55}$}

Hz. Maximilian teilt in einem seperaten Schreiben die Namen der während des letzten Ordensfest aufgenommenen neuen Mitglieder mit: Willem van Egmond \{78\}, Josse de Lalaing $\{80\}$, Jacques de Luxembourg \{81\}, Philipp von Burgund $\{82\}$, Pierre de Luxembourg $\{83\}$, Jakob von Savoyen $\{84\}$ und Bartholomäus von Liechtenstein $\{85\} .{ }^{56}$

Bem.: Vgl. dazu auch Reg. 56-58.

Folgende Exemplare sind bekannt:

Johann, Hz. von Kleve \{47\}. - frz.

Bem.: Dieses cedule wurde als Beilage zu einem anderen Schreiben Maximilians an Hz. Johann gesandt, in dem er diesen um Waffenhilfe bat; vgl. dazu auch PB 4 § 221.

Kop. zeitgen. (Steenberch): AOGV, Codex 45, fol. 58r.

An ein nicht namentlich genanntes kgl. Mitglied. - lat.

Bem.: Da dieses Schreiben in lateinischer Sprache verfaßt ist, kommen Ferdinand, Kg. von Neapel $\{72\}$, Ferdinand, Kg. von Kastilien $\{71\}$, und Johann, Kg. von Aragon $\{57\}$, als Adressaten in Frage. Es ist anzunehmen, dass dieses Schreiben an alle drei genannten versandt wurde. Eduard, Kg. von England \{63\}, wurde dagegen normalerweise in frz. Sprache angeschrieben und wird hier wohl nicht gemeint sein. - Vermutlich identisch mit den Schreiben aus Reg. 57, 58, 68 und 69.

Kop. zeitgen. (Steenberch): AOGV, Codex 45, fol. 53r-v.

53 Zwischen 1468 und 1475 ist Jean de Sainte-Aldegonde als Herold Lothier belegt; vgl. DB Prosopographia Curiae Burgundicae, ID n 2706; DB Heraudica, ID Person n 16 und $n^{\circ} 57$.

54 Lt. VAnder Linden, Itinéraires, 1934, S. 36, befand sich Hz. Maximilian in Valenciennes.

55 Lt. VANDER Linden, Itinéraires, 1934, S. 37, befand sich Hz. Maximilian in Pont-àVendin.

56 Vgl. dazu in der Einleitung S. 30 mit Anm. 91. 
Hz. Maximilian schreibt an Ferdinand, Kg. von Neapel $\{72\}$, zwei Briefe, worin er in einem die neugewählten Mitglieder des Ordens nennt.

Bem.: Möglichweise identisch mit den in Reg. 57, 61 und 67 genannten Schreiben. Überbringer war der Herold Flandern; vgl. Reg. 72.

Erw.: in Reg. 72 .

\section{o.J. [1478] Aug. 17, Windsor}

Eduard IV., Kg. von England \{63\}, beglückwünscht aufgrund eines durch Toison d'or überbrachten Mitteilungsschreiben (Reg. 60) Hz. Maximilian zur Übernahme der Ordenssouveränität. Über die Ergebnisse seines Gesprächs mit Toison d'or soll dieser persönlich berichten. - frz. - eigenh. Unterschrift - Sekretär: O[liver] King. ${ }^{58}$

Bem.: Diese Schreiben wurde von Toison d'or überbracht; so der Eingangsvermerk von Steenberch auf der Rückseite des Or.

Or. Pap.: AOGV, Urkunden, Nr. 57 (beschädigtes aufgedr. Verschlußsiegel) (Türck'sche Systematik: 2. Partie § 2, 13 C).

Kop. (18. Jh.): Brüssel, BR, ms. 20.851 (F. J. de Bors d'Overen, Histoire chronologique de l'ordre de la Toison d'or, Bd. 1), fol. 195v.

Reg.: Cat. mss. de BR, 12, 1936, S. 59, Nr. 7481/24 (nach Kop. in BR Brüssel); Ruwet, Vienne, 1956, S. 774, Nr. 57 (nach Or.).

Erw.: $\quad$ in Reg. 106; DüNNEBEIL, Burgund und Österreich, 2006, S. 22; Auer, Maximilian I ${ }^{\text {er }}$, 2008, S. 58.

\section{[Vor 1478 Sept. 9, Brüssel]}

Konzept der Instruktionen für die Gesandten des Ordens vom Goldenen Vlies, die eine Reise zu Kaiser Friedrich III. \{94\}, Matthias Corvinus, Kg. von Ungarn, und Albrecht, Hz. von Sachsen $\{96\}$, unternehmen sollten, um diese von ihrer Wahl in den Orden zu unterrichten. - lat.

Bem.: Schon am 7. Mai empfahlen die Ordensmitglieder Hz. Maximilian aufgrund ihre Beschlüsse vom 4. Mai 1478 die Entsendung dieser Gesandtschaft; vgl. PB 4 § 182, 188 und 189 und Reg. 51. Am 9. Sept. 1478 legten Martin Steenberch und Toison d'or dieses Konzept in lateinischer Sprache Hz. Maximilian in Brüssel vor. Doch dieser bestand auf einer deutschen Übersetzung. Diese sollte sein Rat Johann Keller anfertigen, der dafür am 25. Sept. 1478 vor den versammelten Ordsmitgliedern beeiden musste, seine internen Kenntnisse über den Orden nicht an Dritte weiterzugeben; vgl. § 197 und 199.

Erw.: $\quad$ PB 4 § 197-200; ReIfFEnBerg, Toison d'or, 1830, S. 97.

57 Lt. Vander Linden, Itinéraires, 1934, S. 387, befand sich Hz. Maximilian am 13. Juli in Pont-à-Vendin und am 23. Juli in Lille.

58 Oliver King war zwischen 1476 und 1480 als Sekretär für frz. Sprache in der Kanzlei Kg. Eduards IV. tätig, danach wurde er zu dessen persönlichen Sekretär ernannt; zu seiner Person vgl. Otway-Ruthven, King's Secretary, 1939, S. 102-103, 129, 156. 
Ferdinand, Kg. von Neapel $\{72\}$, bestätigt in einem Brief den Erhalt von Briefen vom 28. Mai, 13. und 23. Juli 1478 (Reg. 61, 68 und 69) durch den Herold Flandern ${ }^{59}$ und beglückwünscht Hz. Maximilian zur Übernahme der Ordenssouveränität. - lat. - eigenh. Unterschrift - Sekretär: F.A.

Bem.: Dieses Schreiben wurde von dem Herold Flandern überbracht; so der Eingangsvermerk von Steenberch auf der Rückseite des Or.

Or. Perg.: AOGV, Urkunden, Nr. 58 (geöffnetes aufgedr. Verschlußsiegel unter Papier) (Türck'sche Systematik: 2. Partie § 2, 13 C).

Kop. (18. Jh.): Brüssel, BR, ms. 20.851 (F.J. de Bors d'Overen, Histoire chronologique de l'ordre de la Toison d'or, Bd. 1), fol. 192r-193r.

Reg.: Cat. mss. de BR, 12, 1936, S. 59, Nr. 7481/24 (nach Kop. in BR Brüssel); Ruwet, Vienne, 1956, S. 774, Nr. 58 (nach Or.).

Erw.: DünnebeIl, Burgund und Österreich, 2006, S. 22; Auer, Maximilian I ${ }^{\text {er }}$, 2008, S. 58.

1478 Sept. 27, Sevillia

Ferdinand, Kg. von Sizilien $\{71\}$, bestätigt in einem Brief, dass er vom Herold Lothier ${ }^{60}$ Briefe in Ordensangelegenheiten ${ }^{61}$ erhalten hat, und beglückwünscht Hz. Maximilian zur Übernahme der Ordenssouveränität. - lat. - eigenh. Unterschrift - Sekretär: Arinyo.

Or. Pap.: AOGV, Urkunden, Nr. 59 (aufgedr. Verschlußsiegelrest) (Türck'sche Systematik:

2. Partie $\S 2,13 \mathrm{C})$.

Kop. (18. Jh.): Brüssel, BR, ms. 20.851 (F.J. de Bors d'Overen, Histoire chronologique de l'ordre de la Toison d'or, Bd. 1), fol. 194v-195r.

Reg.: Cat. mss. de BR, 12, 1936, S. 59, Nr. 7481/24 (nach Kop. in BR Brüssel); Ruwet, Vienne, 1956, S. 774, Nr. 59 (nach Or.).

Erw.: DünNEBEIL, Burgund und Österreich, 2006, S. 22; Auer, Maximilian I ${ }^{\text {er }}$, 2008, S. 58.

1478 Okt. o. T., Brüssel ${ }^{62}$

Hz. Maximilian verleiht den Angehörigen des Ordens vom Goldenen Vlies (Ritter und Amtsträger) eine Reihe von Privilegien und Vorrechten: Nachdem er aufgrund seiner Heirat mit Hz. Maria von Burgund, der einzigen Erbtochter Hz. Karls \{34\}, statutengemäß zum Souverän des Ordens vom Golden Vlies ernannt worden war, haben die versammelten Mitglieder und Amtsträger um die Bestätigung der von seinen Vorgängern Hz. Philipp $\{01\}$ und Hz. Karl erteilten Vorrechte gebeten. Es handelt sich dabei vor allem um das von Hz. Karl erteilte Privileg, das er im Mai 1473 in Valenciennes erlassen hatte, das inhaltsgetreu wiedergeben wird: ${ }^{63}$ Karl hatte damit den Mitgliedern das Recht erteilt, bei öffentlichen Auftritten seines Hofes aus den ihrem

59 Zum Wappenkönig Flandern vgl. die Angaben in § 19, Anm. 97.

$60 \mathrm{Zu}$ seiner Person vgl. die Angaben in Reg. 63, Anm. 53.

61 Vermutlich sind hier die Schreiben aus Reg 63, 65 und 67 gemeint.

62 Lt. VAnder Linden, Itinéraires, 1934, S. 42-44, befand sich Hz. Maximilian den gesamten Oktober hindurch in Brüssel.

63 Zu Hz. Karls Privileg vgl. PB 3, S. 143-146, § 229 f., dazu auch ebenda S. 21 f. und S. 175, Reg. 39 (mit Angaben zur weiteren Überlieferung); DünnEBEIL, Entwicklung, 2007, 
sozialen Rang entsprechenden Plätzen hervorzutreten und sich als geschlossene Gruppe der Vliesritter nach der herzoglichen Familie und vor den anderen Mitgliedern des Hofes einzugliedern. ${ }^{64}$ Bei den hzl. Audienzen und den Ratsversammlungen durften die Ordensritter ebenfalls eine hervorgehobene Position einnehmen. Die Vliesritter sollten bei der Quartierverteilung und bei der Ausgabe von Lebensmitteln nach der hzl. Familie und vor den übrigen Mitgliedern des Hofes berücksichtigt werden. Darüber hinaus wurden den Vliesrittern und Amtsträgern und deren Familien noch zusätzliche Nahrungsmittelrationen sowie weitreichende Steuer- und Abgabenfreiheiten gewährt. Maximilian bestätigt nun für sich und seine Nachfolger als Hzz. von Burgund diese Vorrechte, Freiheiten und Privilegien und erweitert sie, indem er den Ordensangehörigen und deren Familien eine allgemeine Zoll-, Maut- und Abgabenfreiheit und freie Passage in allen burgundischen Herrschaften gewährt. Er stellt sie auch unter seinen speziellen Schutz und verspricht ihnen, dass Personen, die diese Privilegien mißachten, von ihm keine Gnade erwarten können, es sei denn, der versammelte Orden entscheide sich dagegen. Er befiehlt, dass sämtliche Amtsträger Kenntnis von diesem Privileg erhalten sollen, damit die Ordensangehörigen ihre Vorrechte ungehindert genießen können und sich niemand auf Unwissenheit berufen kann. Dafür sollen zahlreiche besiegelte Vidimus erstellt werden, die den gleichen rechtlichen Stellenwert wie das Original besitzen sollen. Er verpflichtet im Gegenzug aber die Ordensangehörigen dazu, dass sich für ihn und seine Herrschaftsrechte jeder Zeit einzusetzen. Des Weiteren bestimmt er, das vorliegende Privileg Vorrecht vor anderen (älteren) Verfügungen hat, dass es aber durch (spätere) Verfügungen von Königen, Herzögen oder andere Fürsten, die dem Orden angehören, eingeschränkt werden kann. - frz. - Par monseigneur le duc, monseigneur l'evesque de Metz ${ }^{65}$, monseigneur le marquis de Bade $\{102\}^{66}$, le conte de Werdemberch ${ }^{67}$, le seigneur de Wierre, chief du grant conseil $^{68}$, le seigneur de Champvans, president de Bourgoingne ${ }^{69}$, l'abbé de Saint Pierre lez Gand ${ }^{70}$ et pluseurs autres presens: $N\left(\right.$ icolas de) Ruter. ${ }^{71}$

Bem.: Schon während des Ordensfestes hatte Hz. Maximilian am 2. Mai 1478 die Vorrechte mündlich bestätigt und und den Greffier mit der Ausstellung entsprechender lettres patentes beauftragt; vgl. § 172. Der Kanzleivermerk zeigt aber, dass bei der

S. 22-24 und S. 34f. (Druck von Hz. Karls Privileg); DünnebeIL, Beherrschung, 2010, S. 180. Vgl. dazu die Angaben in § 172, Anm. 265.

64 Hier fehlt der Passus von 1473, dass die Ordensritter Adolf von Kleve $\{55\}$ und Anton, Bastard von Burgund \{54\}, wählen konnten, ob sie sich in die Reihe der Blutsverwandten oder in die Reihe der Vliesritter einordnen wollten.

$65 \mathrm{Zu}$ Georg von Baden, Ebf. von Metz, vgl. die Angaben in $\S 5$ mit Anm. 17.

$66 \mathrm{Zu}$ Christoph von Baden vgl. die Angaben in $\S 10$ mit Anm. 58.

67 Vermutlich handelt es sich hier um Gf. Haug von Werdenberg ( $†$ 1508), der unter Ks. Friedrich III. \{94\} und Maximilian zahlreiche wichtige politische Funktionen einnahm, und beiden zwischen 1477 und 1487 diente; HeINIG, Friedrich III., 1997, S. 353.

$68 \mathrm{Zu}$ Jan van der Bouverien, Herr von Wiere, vgl. die Angaben in $§ 47$ mit Anm. 239.

$69 \mathrm{Zu}$ Jean Carondelet, Herr von Champvans, vgl. die Angaben in $\S 47$ mit Anm. 241.

70 Zu Abt Philippe Conrault vgl. die Angaben in Reg. 44 mit Anm. 40.

711477 wird Nicolas de Ruter († 1509) als der erste Sekretär von Hz.in Maria und Hz. Maximilian bezeichnet, er war aber auch schon unter ihrem Vater Hz. Karl tätig; zu seiner Person vgl. Gachard, Ordonnance 1477, 1857, S. 122; Cockshaw, Prosopographie, 2006, S. 82 f., Nr. 84. 
tatsächlichen Ausstellung der Urkunde kein Angehöriger des Ordens anwesend war. - Diverse Eintragungen auf der Plica und der Rückseite des Originals bezeugen die Verbreitung der Urkunde ${ }^{72}$ : Am 27. Nov. 1479 wurde sie bei der CC Lille von G[uillaume] de Cottignies registriert. Am selben Tag legte sie Fastré Hollet, controlleur de la despenses, ${ }^{73}$ im Auftrag der beiden maitres d'hostel, Olivier de la Marche $^{74}$ und Nicolas d'Aveluys ${ }^{75}$, verschiedenen Beamten am burgundischen Hof vor, um diese mit der Weitergabe des Inhalts zu beauftragen. Desgleichen unternahm am 8. Dez. $1478 \mathrm{~N}$ (icolaus de) Gondeval ${ }^{76}$ bei verschiedenen Finanzbeamten. ${ }^{77}$ Während des Ordensfestes im Jahr 1481 wurde beschlossen, dass Hz. Maximilian für die weitere Verbreitung des Privilegs an seine Amtsträger schreiben solle; vgl. PB 5, fol. 47r mit dem dazugehörigen Regest sub dato 1481 Mai 23.

Or. Perg.: AOGV, Urkunden 60 (beiliegender Rest von Maximilians Siegel an rot-grüner Seidenschnur) (Türck'sche Systematik: 1. Partie § 1,3).

Kop.: $\quad$ AOGV, Akten, Karton 4 (10 Kop. Pap. aus 15-17. Jh.; Türck'sche Systematik: 1. Partie $\S 1$, 3); Brüssel, BR, Ms. 12.648-50, fol. 1-9 (erstellt von Steenberch; 15. Jh.); Lille, ADN, B 1285, Nr. 16.304, Dok. 1 (Pap., zeitgen. erstellt von Steenberch); Brüssel, AGR, Mss. div. 273b, fol. 63v-68v (16. Jh.) und Mss. div. 264, fol. 171r-181r (17. Jh.); Paris, BNF, ms. fr. 5046, fol. 61r-67r, Nr. 24 (16. Jh.); inseriert in einem nicht näher bezeichneten Registereintrag wohl des Jahres 1481 in Lille, ADN, B 1285, Nr. 16.304, Dok. 2 (zeitgen. Kop.) (8) $^{7}$ inseriert in der Bestätigung des 6. Ordenssouveräns Philipps II., d.d. Gent, 1556 Okt. o.T. ${ }^{79}$

Druck: Privileges l'ordre de la Toison d'or; gedruckt Brüssel 1632 und eingebunden in Brüssel, BR, ms. II 5799, Nr. 10; Toison d'or, 1689, S. 56-81; Delepierre, Fête en 1478, 1842, S. 544 f. (Auszug).

Reg.: Brüssel, AGR, Mss. div. 1051 (Inv. Türck, 2), fol. 1; Lille, ADN, B 204; GaIllard, Inv. Grand Conseil 1, 1900. S. 4, Nr. 13 (nach [Brüssel, AGR], Registre Mémoriaux du Grand Conseil de Malines, Bd. 1, fol. 51v); Bibl. nat. Cat. des mss. fr., Ancien fonds, 4, 1905, S. 496, Nr. 24 (nach Kop. in Paris); Inv. AD Nord B, I/2, 1906, S. 286 (nach Kop. in Lille); VAERNEwyck, Bibliographie, 1907, S. 222 f., Nr. 73 (datiert fälschlich auf 1478 Dez. 8; mit Hinweis auf ein von Steenberch erstelltes Statutenbuch in Brüssel, BR, ms. 12.648-50); Cat. mss. de BR, 12, 1936, S. 39, Nr. 7468 (nach Kop. in Brüssel, ms. 12.648-50) sowie S. 40-42, Nr. 7470, hier S. 41 (nach Druck in ebd.,

72 In den Kopien finden sich diese Angaben im Anschluss an den Urkundentext.

73 In Hz. Maximilians Hofordnung von Sept. 1477 wurden Fastré Hollet in seiner Funkton als Rechnungsprüfer und garde de ses joyaulx jeweils ein halbes Jahr lang eine tägliche Zuwendung von 12 solz zugesprochen; vgl. GACHARD, Ordonnance 1477, 1857, S. 123.

74 Zur Person Oliviers de la Marche vgl. die Angaben in § 20, Anm. 105.

$75 \mathrm{Zu}$ seiner Person vgl. die Angaben in $§ 95$ mit Anm. 57.

76 Zu seiner Person vgl. die Angaben in § 262 mit Anm. 288.

77 Die entsprechenden Vermerke druckt Regesten Friedrichs III., Suppl. 1, 2008, S. 67 f.

78 Der Eintrag wurde in Folge des 1481 während des Ordensfestes gefaßten Beschlusses zur weiteren Verbreitung des Privilegs verfasst; dazu mehr oben in der Bemerkung.

79 Kop. Pap.: Lille, ADN, B 204, Anhang, fol. 1r-6r (zeitgen.; erstellt nach dem Or. vom Greffier des Ordens Nicolas Nicolai [† 1571]); AOGV, Akten, Karton 4 (16. Jh.; Türck'sche Systematik: 1. Partie § 1, 4); AOGV, Akten, Karton 23, 1720, Nr. 2. Reg.: Inv. AD Nord B, Rép. num., 1921, S. 86 (nach Kop. in Lille); Inv. AD Nord B, I/1, 1899, S. 195 (nach Kop. in Lille). Erw.: Reiffenberg, Toison d'or, 1830, S. 82, Anm. 3 und S. 456 f. 
ms. II 5799); Ruwet, Vienne, 1956, S. 774, Nr. 60 (nach Or.); Regesten Friedrichs III., Suppl. 1, 2008, S. 66-69, Nr. 53 (nach der Überlieferung in AGR Brüssel).

Erw.: $\quad$ Pb 4, § 172; AOGV, Codex 34/1, S. 129; AOGV, Codex 34/3, S. 2 f.; Mémoires de la Marche, 3, 1885, S. 249, Anm. 3 (nach Paris, ms. fr. 5046); Reiffenberg, Toison d'or, 1830, S. 96; LEMAIre, Considérations codicologiques, 1996, S. 37 (datiert fälschlich auf 1478 Dez. 8; mit Hinweis auf die Statutenbücher in Brüssel, BR, ms. 12.648-650; Den Haag, Rijksmuseum, Meermanno-Westreenianum, ms. 10 C 11; Den Haag, KB, ms. 76 E 12) ${ }^{80}$; DünNEBEIL, Burgund und Österreich, 2006, S. 25 mit Anm. 54; DünnebeIl, Entwicklung, 2007, S. 24 mit Anm. 71; Auer, Maximilian I ${ }^{\text {er }}$, 2008, S. 59; DüNnEBEIL, Beherrschung, 2010, S. 180 sowie in der Einleitung S. $24 \mathrm{f}$.

\section{Okt. 9, Brüssel}

Der Orden vom Goldenen Vlies schreibt an die fünf in Frankreich weilenden Mitglieder, dass sie mit ihrer Hinwendung zum französischen König gegen die Statuten verstoßen haben, und fordert sie auf, beim nächsten Ordensfest persönlich zu erscheinen, um dazu Stellung zu nehmen. - frz. - Par monseigneur le duc, chief et souverain, messeigneurs Adolph de Cleves et de la Marke \{55\}, seigneur de Ravestein, Loys, seigneur de Gruythuse \{61\}, conte de Wyncestre, Phelippe de Croy \{74\}, conte de Chimay, Engelbert, conte de Nassow \{77\}, seigneur de Breda, Wolffart de Borssele \{79\}, conte de Grantpré, seigneur de la Vere, Phelippe de Bourgoigne $\{82\}$, seigneur de Bevre, ${ }^{81}$ et Pierre de Lucxembourg \{83\}, conte de Saintpol, tous chevaliers freres et compaingnons dudit ordre de la Thoison d'or, presens: Steenberch (nach Reg. 77).

Bem.: Schon während des Ordensfestes wurde am 1. Mai 1478 die Ausstellung dieser Urkunden beschlossen. Sie sollten mit dem aufgedrückten Ordenssiegel versehen und durch Toison d'or oder einem anderen Wappenkönig, der dazu schriftlich aufgefordert werden sollte, zugestellt werden; vgl. PB 4 § 122. Als Überbringer wurde dann der Herold Fusil beauftragt; vgl. Reg. 80 .

Erw.: $\quad$ PB 4 § 122, 171, 210, 223, 225, 227, 239 und 240; in den Schreiben aus Reg. 80, 95, 100 sowie in den Vorladungsschreiben zu dem Fest von 1481 vom 22. Dez. 1480 AOGV, Codex 34/1, S. 128 f.; ReIfFenberg, Toison d'or, 1830, S. 96; Docouier, D'or et d'émail, 2008, S. 41, Anm. 11, sowie oben in der Einleitung S. $26 \mathrm{f}$.

Folgende Exemplare sind bekannt:

An Anton, Bastard von Burgund $\{54\}$.

Bem.: Fusil konnte den Brief nicht zustellen; vgl. dazu PB 4 § 227.

Or. Perg.: AOGV, Urkunden 62 (aufgedr. Ordenssiegel, teilw. beschädigt) (Türck'sche Systematik: 1 . Partie $§ 1,14 \mathrm{~B})$.

Kop. zeitgen. (Steenberch nach dem Or.): AOGV, Codex 45, fol. 65r und 78r.

Reg.: $\quad$ Ruwet, Vienne, 1956, S. 775, Nr. 62 (nach Or.).

$80 \mathrm{Zu}$ diesen drei Statutenbüchern vgl. die Angaben in PB 1, S. 191.

81 Sein Name fehlt im Kanzleivermerk des Schreibens an Anton, Bastard von Burgund (Reg. 75).

82 Diese Vorladungsschreiben werden ausführlich in PB 5, Reg. sub dato dokumentiert; vgl. dazu auch die Angaben in Reg. 136. 
An Jacques de Luxembourg $\{67\}$.

Bem.: Seine Antwort verzeichnet Reg. 99, die er Fusil mitgab.

Kop. zeitgen. (Steenberch): AOGV, Codex 45, fol. 66r und 79r.

An Philippe Pot, Herr von la Roche-Nolay $\{60\}$.

Bem.: Fusil konnte den Brief nicht zustellen; vgl. PB 4 § 227.

Or. Perg.: AOGV, Urkunden 63 (aufgedr. Ordenssiegel, teilw. beschädigt) (Türck'sche Systematik: 1. Partie § 1, 14 B).

Kop. zeitgen. (Steenberch): AOGV, Codex 45, fol. 65v und 78v.

Kop. (18. Jh.): Brüssel, BR, ms. 20.851 (F.J. de Bors d'Overen, Histoire chronologique de l'ordre de la Toison d'or, Bd. 1), fol. 206r.

Reg.: Cat. mss. de BR, 12, 1936, S. 59, Nr. 7481/28 (nach Kop. in BR Brüssel); Ruwet, Vienne, 1956, S. 775, Nr. 63 (nach Or.).

An Philippe de Crèvecœur, Herr von Esquerdes $\{69\}$.

Bem.: Nach PB 4, § 227 konnte Fusil diesen Brief nicht zustellen und so ist es erstaunlich, dass sich das Original heute in der BR Brüssel und nicht wie die Schreiben aus Reg. 75 und 77 im Ordensarchiv befindet.

Or.: Brüssel, BR., Ms. I/20.863, Nr. 119 (aufgedr. Ordenssiegel).

Kop. zeitgen. (Steenberch): AOGV, Codex 45, fol. 66v und 79v.

Abb.: Laurent, Sceaux, I/2, 1993, Abb. 364 (nach dem Or.). ${ }^{83}$

Erw.: Laurent, Sceaux, I/1, 1993, S. 619, Nr. 58, Anm. 204.

An Jean de Damas, Herr von Clessy $\{65\}$.

Bem.: Fusil konnte den Brief nicht zustellen; vgl. PB 4 § 227.

Kop. zeitgen. (Steenberch): AOGV, Codex 45, fol. 67r und 80r.

1478 Okt. 9, Brüssel

Hz. Maximilian beauftragt Toison d'or oder bei seiner Abwesenheit den Herold Fusil, die in Frankreich befindlichen Ritter Anton von Burgund \{54\}, Philippe Pot $\{60\}$, Philippe de Crèvecœur $\{69\}$, Jacques de Luxembourg $\{67\}$ und Jean de Damas $\{65\}$ die Vorladungsschreiben (Reg. 75-79) für das am 2. Mai 1479 in Brüssel geplanten Ordensfest zu überbringen und auch persönlich mit ihnen über die Dringlichkeit zu reden. Zu Beginn des Festes soll Toison d'or einen Bericht über diese Reise geben. - frz. - Par monseigneur le duc, chief et souverain, messeigneurs Adolph de Cleves et de la Marke \{55\}, seigneur de Ravestain, Loys, seigneur de Gruythuse $\{61\}$, conte de Wyncestre, Phelippe de Croy \{74\}, conte de Chimay, Engelbert, conte de Nassuw \{77\}, seigneur de Breda, Wolffart de Borssele \{79\}, conte de Grantpré, seigneur de la Vere, Phelippe de Bourgoingne \{82\}, seigneur de Bevre, et Pierre, conte de Saintpol et de Brienne \{83\}, tous chevaliers, freres et compaingnons dudit ordre de la Thoison d'or, presens: M(artin) Steenberch.

Bem.: Am Ende der Abschrift in Codex 45 (fol. 68r) vermerkte Steenberch, dass er von diesem Schreiben fünf Abschriften erstellt hatte, die der Wappenkönig zusammen mit dem Vorladungsschreiben jedem der genannten Mitglieder überreichen sollte. Der obige Auftrag wurde von Fusil ausgeführt; vgl. dazu sein Bericht von 19. Jan. 1480 in Reg. 100.

83 Für den Hinweis danke ich Prof. Werner Paravicini (Kiel). 
Or. Perg.: AOGV, Urkunden 61 (anh. Ordenssiegel, teilw. beschädigt) (Türck’sche Systematik: 1. Partie § 2, 14 B).

Kop. zeitgen. (Steenberch): AOGV, Codex 45, fol. 67v-68r und 80v-81r.

Kop. (18. Jh.): Brüssel, BR, ms. 20.851 (F.J. de Bors d'Overen, Histoire chronologique de l'ordre de la Toison d'or, Bd. 1), fol. 207r-209v.

Reg.: Ruwet, Vienne, 1956, S. 775, Nr. 61 (nach Or.).

Erw.: $\quad$ PB 4 § 122 und 240; Reg. 100; AueR, Maximilian I ${ }^{\text {er }}$, 2008, S. 59; sowie oben in der Einleitung S. $26 \mathrm{f}$.

Hz. Maximilian fordert Jean de Neufchâtel \{52\}, Herrn von Montaigu, auf, persönlich am 30. April in Brüssel zu erscheinen. Während des am 2. Mai beginnenden Ordensfestes soll er zu seinem unentschuldigtem Fehlen bei dem im Mai 1478 abgehaltenen Fest $^{84}$ sowie zu den 1473 zusammengetragenen Verfehlungen, die ihm durch Philippe Pot $\{60\}$ mitgeteilt worden waren, ${ }^{85}$ Stellung nehmen. Falls er nicht persönlich teilnimmt, soll gegen ihn verfahren werden, wie es die Statuten vorsehen. Des Weiteren bittet er ihn, dem Überbringer dieses Schreibens schriftlich den Erhalt zu bestätigen und seine Absichten kundzutun. - frz.

Bem.: Die Ausstellung dieses Briefes wurde schon am 1. Mai beschlossen; vgl. PB 4 $\S 120$. Überbracht wurde der Brief dann durch den Persevant Rupelmonde, der auch das geforderte Schreiben mitbrachte; vgl. Reg. 98 und 102. Gilles de Rebecque, dit Ruplemonde, poursuivant d'armes de mondit seigneur, erhielt für diese Reise, avoir porté ses lettres closes en Bourgoingne adressans a monseigneur de Montaigu et d'illec aultres ses lettres closes a messires Philippe de Savoye \{68\}, seigneur de Bresse estant lors en sondit pays de Bresse, touchant certaines matieres et affaires de l'ordre de la Thoison d'or, de mondit seigneur dont il n'eult veult aultre ni plusieurs declaracion icy estre faicte, wofür er zwischen dem 9. Dez. 1478 bis 27. Jan. 1479 unterwegs war, von der hzl. Rechnungskammer $6 £$ ausbezahlt; vgl. DB Heraudica ID Source 12753 (mit Zitat aus Lille, ADN, B 2118, fol. 232v).

Kop. zeitgen. (Steenberch): AOGV, Codex 45, fol. 62v und 74r.

Erw.: PB 4 § 120, 223, 226 und 240; in Reg. 98, 108 und 109 sowie im Vorladungsschreiben für das Ordensfest von 1481 vom 22. Dez. 1480 (dazu ausführlicher in PB 5, Reg. sub dato).

[14]78 Okt. 9, Brüssel

Hz. Maximilian fordert Philipp von Savoyen $\{68\}$ auf, beim nächsten Ordensfest persönlich zu erscheinen, um zu seinem unentschuldigtem Fehlen bei dem im Mai 1478 abgehaltenen Fest ${ }^{86}$ sowie zu den 1473 zusammengetragenen und ihm mitgeteilten

84 Tatsächlich hatte Jean seine Teilnahme am Ordensfest abgesagt (Reg. 43). Das Schreiben kam jedoch nicht rechtzeitig zum Ordensfest an und ist wohl danach auch ignoriert worden.

85 Vgl. dazu die Angaben in Reg. 7 mit Anm. 5.

86 Tatsächlich hatte Philipp von Savoyen auf die Einladung geantwortet, das Schreiben ging aber bei der Gefangennahme des Boten, dem Herold Ferrette, verloren; vgl. Reg. 26. 
Verfehlungen ${ }^{87}$ Stellung zu nehmen. Des Weiteren bittet er ihn, dem Überbringer dieses Schreibens schriftlich den Erhalt zu bestätigen und seine Absichten kundzutun. - frz.

Bem.: Die Ausstellung dieses Briefes wurde am 1. Mai beschlossen und noch einmal am 9. Okt. bekräftigt; vgl. PB 4 § 120 und 209. Überbracht wurde der Brief dann durch den Herold Rupelmonde (vgl. Reg. 81 und 102), der seinerseits Philipps Antwort zu Hz. Maximilian brachte (Reg. 101).

Konz. Pap. (Steenberch): AOGV, Akten, Karton 5, Fasz. 14 G, Dok. 5.

Kop. zeitgen. (Steenberch): AOGV, Codex 45, fol. 73v; AOGV, Akten, Karton 5, Fasz. 14 I, fol. 11r, Dok. 9 sowie Fasz. 14 K, fol. 11.

Erw.: $\quad$ PB $4 \S 120,209,223,226$ und 240 sowie in den Vorladungsschreiben zu dem Fest von 1481 vom 22. Dez. 1480 (dazu ausführlicher in PB 5, Reg. sub dato).

\section{[14]78 Okt. 9, Brüssel}

Hz. Maximilian lädt die Mitglieder des Ordens vom Goldenen Vlies brieflich zum nächsten Ordensfest ein, das am kommenden 2. Mai in Brüssel beginnen soll. Im Falle einer Nichtteilnahme sollen die den Statuten entsprechenden Absageschreiben zugesandt werden. Des Weiteren bittet er die Empfänger, dem Überbringer dieses Schreibens schriftlich den Erhalt zu bestätigen und ihre Absichten kundzutun.

Bem: Die Einladung beruht auf einem Beschluss des Ordens vom 2. Mai 1478. Dort wurde auch festgelegt, dass die Einladungsschreiben als mandement patent, donné en placcart ausgeführt und von Toison d'or oder anderen Herolden überbracht werden sollten, die dafür mit einer commission especiale sur ce soubz le seel d'icellui ordre auszustatten sind; vgl. PB 4 § 171. In einem Schreiben vom 7. Mai 1478 (Reg. 51) empfehlen einige Ordensmitglieder Hz. Maximilian, die Einladungsschreiben fünf bis sechs Monate vor Festbeginn auszusenden; vgl. PB 4 § 192. Am 9. Okt. erhielt Steenberch den Befehl, die Schreiben auszustellen; vgl. § 209.

Kop. zeitgen. (Steenberch): AOGV, Codex 45, fol. 70v-71r (Formular für die ihm untergebenen Mitglieder, die mit treschier et feal cousin angeredet werden) und fol. 76v-77r (Formular für Mitglieder, die mit treschier et bien amé angeredet werden). ${ }^{88}$

Erw.: $\quad$ PB 4 § 209, 223, 239, 240, 252 und 253 sowie in den Schreiben von Reg. 115-122.

Folgende Exemplare sind bekannt:

An Johann, Hz. von Kleve $\{47\}$

Bem.: Dieses Schreiben wurde zusammen mit zwei weiteren (Reg. 89 und 90) durch einen namentlich nicht genannten porteur überbracht, dem Johann seine Antwortschreiben (Reg. 96 und 97) mitgab.

Erw.: $\quad$ in Reg. 96, 97 und 107; PB 4 221, 229, 230 und 232.

An Ferdinand $\{72\}$, Kg. von Neapel. - lat.

Kop. zeitgen. (Steenberch): AOGV, Codex 45, fol. 70r-v.

87 Vgl. dazu die Angaben in Reg. 8 mit Anm. 3.

88 Vgl. dazu auch die Angaben bei Reg. 1 mit Anm. 1. 
An Adolf von Kleve $\{55\}$, Herr von Ravenstein (mon treschier et tresamé cousin). frz.

Kop. zeitgen. (Steenberch): AOGV, Codex 45, fol. 71r-v.

An Pierre de Luxembourg \{83\}, Gf. von Saint-Pol (mon treschier et tresamé cousin). frz.

Kop. zeitgen. (Steenberch): AOGV, Codex 45, fol. 73r-v und 77r-v.

An Ferdinand $\{71\}$, Kg. von Kastilien. - lat.

Kop. zeitgen. (Steenberch): AOGV, Codex 45, fol. 72r-v.

An Bartholomäus von Liechtenstein $\{85\}$. - lat.

Bem.: Er wird zusätzlich noch aufgefordert, schriftlich acht oder neun Wahlvorschläge zu schicken.

Kop. zeitgen. (Steenberch): AOGV, Codex 45, fol. 72v-73r.

[14]78 Okt. 9, Brüssel

Der Orden vom Goldenen Vlies fordert Johann, Hz. von Kleve \{47\}, nach Erwähnung diverser an ihn gerichtete Schreiben (Reg. 5, 19, 39, 64) auf, beim nächsten Ordensfest persönlich zu erscheinen, um sein unentschuldigtes Fehlen bei dem im Mai 1478 abgehaltenen Fest zu begründen. - frz.

Bem.: Seine Vorladung wurde am 1. Mai 1478 beschlossen und noch einmal am 2. Mai und 9. Okt. in Erinnerung gerufen; vgl. PB 4 § 121 und 171 und 209. Den Brief sollte Toison d'or überbringen, der sich dazu nicht mündlich äußern durfte (§ 209). Tatsächlich wurden der Brief zusammen mit den Einladungsschreiben aber von einem namentlich nicht genannten porteur überbracht; vgl. dazu Reg. 83.

Or.: Verbleib nicht bekannt (mit Ordenssiegel).

Kop. zeitgen. (Steenberch): AOGV, Codex 45, fol. 59r-v.

Erw.: $\quad$ PB 4 § 121, 171, 209, 221, 223, 229, 230, 232 und 240; in Reg. 95-97 und 107; im Schreiben Adolfs von Kleve an Hz. Johann, d.d. 1481 Mai 21, in dem über den Verlauf des Festes von 1481 berichtet (zeitgen. Kop. in PB 5, fol. 58v-59r); REIFFENBERG, Toison d'or, 1830, S. 100.

[14]78 Okt. 9, Brüssel

Hz. Maximilian schreibt in derselben Angelegenheit an Johann, Hz. von Kleve \{47\}. frz.

Bem.: Vgl. dazu auch die Angaben in Reg. 89.

Kop. zeitgen. (Steenberch): AOGV, Codex 45, fol. 60r-v.

Erw.: $\quad$ PB 4 §221, 230, 232 und 240; in Reg. 95, 97 und 107.

[14]78 Okt. 9, Brüssel

Hz. Maximilian lädt Eduard IV., Kg. von England \{63\}, zum nächsten Ordensfest ein, das am kommenden 2. Mai in Brüssel beginnen soll. Mit Hinweis auf den von Eduard IV. anläßlich des letzten Ordensfest gesandten Briefes (Reg. 29) und mehrerer eigener Schreiben (Reg. 56 und 60) ermahnt Maximilian ihn, sich enstprechend des geleisteten Aufnahmeeides wie ein Ordensmitglied zu verhalten und bei Nichtteilnahme Stellver- 
treter mit lettres patentes zu benennen. Des Weiteren bittet er ihn, dem Überbringer dieses Schreibens schriftlich den Erhalt zu bestätigen und seine Absichten kund zu tun. - frz.

Bem.: Überbracht durch den Herold Ravenstein; vgl. Reg. 104 und 106.

Konz. Pap. (Steenberch): AOGV, Akten, Karton 5, Fasz. 14 F, Dok. 4.

Kop. zeitgen. (Steenberch): AOGV, Codex 45, fol. 76r-v.

Kop. (18. Jh.): Brüssel, BR, ms. 20.851 (F.J. de Bors d'Overen, Histoire chronologique de l'ordre de la Toison d'or, Bd. 1), fol. 210r-v.

Reg.: Cat. mss. de BR, 12, 1936, S. 59, Nr. 7481/26 (nach Kop. in BR Brüssel; datiert 9. März 1478).

Erw.: $\quad$ PB 4 § 233; in Reg. 106; Scofield, Edward IV., 2, 1923/1967, S. 239 (nennt einen Herold „Ostriche“ als Überbringer).

[Nach 1478 Okt. 9, Brüssel]

Der Orden vom Goldenen Vlies instruiert Bartholomäus von Liechtenstein $\{85\}$, wie er sich bei Kaiser Friedrich III. $\{94\}$ verhalten soll, nachdem er diesem von dessen Wahl in den Orden unterrichtet hat. Bei Friedrichs Zustimmung soll er ihm den Aufnahmeeid abnehmen und ihm die Ordenskette übergeben. Sollte der Kaiser Bedenken zu seiner Aufnahme äußern, Modifikationen an den Statuten wünschen oder gar seine Wahl ablehnen, so soll Liechtenstein dies Hz. Maximilian und dem Orden in einem „geheimen“ Schreiben mitteilen.

Bem.: Bei der Ordenssitzung am 9. Oktober in Brüssel wurde Liechtensteins Vorgehensweise mündlich besprochen und festgelegt, dass dieser dazu auch noch une petite instruction par forme de memoire erhalten solle.

Erw.: $\quad$ PB 4 § 207.

\section{Okt. 31, Barcelona}

Johann, Kg. von Aragon \{57\}, bestätigt Hz. Maximilian den Erhalt von Briefen mit Ordensangelegenheiten (Reg. 62) durch den Wappenkönig Hennegau ${ }^{89}$ sowie den Brief mit der Nachricht über Maximilians Waffenstillstand mit Ludwig XI., Kg. von Frankreich, dem er beigetreten ist. ${ }^{90}$ Des Weiteren gratuliert er Hz. Maximilian zur Übernahme der Ordenssouveränität. - lat. - eigenh. Unterschrift.

Bem.: Vgl. dazu auch Reg. 94.

Or. Pap.: AOGV, Urkunden, Nr. 65 (aufgedr. Verschlußsiegel) (Türck'sche Systematik: 2. Partie $\S 2,13 \mathrm{C})$.

Kop. (18. Jh.): Brüssel, BR, ms. 20.851 (F.J. de Bors d'Overen, Histoire chronologique de l'ordre de la Toison d'or, Bd. 1), fol. 193v-194v.

Reg.: Cat. mss. de BR, 12, 1936, S. 59, Nr. 7481/24 (nach Kop. in BR Brüssel); Ruwet, Vienne, 1956, S. 775, Nr. 65 (nach Or.).

Erw.: DünneBeIl, Burgund und Österreich, 2006, S. 22; Auer, Maximilian I ${ }^{\text {er }}$, 2008, S. 58.

89 Zur Person des Wappenkönigs Hennegau vgl. die Angaben in § 19, Anm. 98.

90 Im Ordensarchiv befindet sich dazu noch eine Notariatserklärung, dass Kg. Johann dem Waffenstillstand am 28. Oktober beigetreten ist. Or. Pap.: AOGV, Urkunden, Nr. 64 (Türck’sche Systematik: 2. Partie § 2, 13 A); Reg.: Ruwet, Vienne, 1956, S. 775, Nr. 64. 
Notiz des Philippe de Croy $\{74\}$ für den Ordenssekretär Martin Steenberch, mit der er diesem das Schreiben Kg. Johanns von Aragon \{57\} (Reg. 93) mit dem Auftrag sendet, dieses bis zum nächsten Ordensfest aufzubewahren. - frz. - eigenh. Unterschrift.

Bem.: Steenberch vermerkte auf der Rückseite den Erhalt dieses Schreiben am 27. März 1479 (n. St.).

Or. Pap.: AOGV, Urkunden, Nr. 65.

\section{[14]78 Nov. o. T., Brüssel}

Die in Brüssel versammelten Ordensmitglieder Adolf von Kleve \{55\}, Ludwig von Brügge $\{61\}$, Philippe de Croy $\{74\}$, Engelbert von Nassau $\{77\}$, Pierre de Luxembourg \{83\}, Wolfart van Borssele $\{79\}$ und Philipp von Burgund $\{82\}$ schreiben dem Ordenskanzler Ferry de Clugny, der bei ihrer Versammlung gefehlt hatte. Sie bitten ihn, die von Steenberch in ihrem Auftrag geschriebenen und von ihnen geprüften Schriftstücke mit dem Ordenssiegel zu versehen. Es handelt sich dabei um die Vorladungsschreiben an die fünf in Frankreich befindlichen Ritter in Form von lettres patentes (Reg 75-79) und einen Brief an Johann, Hz. von Kleve $\{47\}^{92}$ - frz.

Kop. zeitgen. (Steenberch): AOGV, Codex 45, fol. 68v und 81r-v.

1478 Dez. 17, Kleve

Johann, Hz. von Kleve \{47\}, bestätigt den Mitgliedern des Ordens den Empfang von mehreren Schreiben (Reg. 83, 89 und 90), die das für den 2. Mai in Brüssel geplante Ordensfest anzeigen. - frz.

Bem.: Vgl. dazu auch Reg. 97 sowie die Angaben zum Überbringer in Reg. 83.

Or. Pap.: AOGV, Urkunden, Nr. 66 (aufgedr. Verschlußsiegel unter Papier) (Türck'sche Systematik: 2. Partie § 2, 13 A).

Kop. zeitgen.: PB 4 § 229.

Reg.: Ruwet, Vienne, 1956, S. 775, Nr. 66 (nach Or.).

Erw.: $\quad$ PB 4 § 228, 231 und 232; AOGV, Codex 34/1, S. 140; ReIffenberg, Toison d'or, 1830, S. 102.

1478 Dez. 17, Kleve

Johann, Hz. von Kleve $\{47\}$, bestätigt Toison d'or den Empfang von drei Briefen (Reg. 83, 89 und 90). - frz.

Bem.: Vgl. dazu die Angaben in Reg. 96.

91 Zeitlich liegt dieses Schreiben zwischen Reg. 93 und der Übergabe an Steenberch am 27. März 1479.

92 Im Brief steht une autre close pour monseigneur de Cleves. Im Zusammenhang mit den Einladungsschreiben wurden jedoch drei verschiedene Schreiben an Hz. Johann verfasst (Reg. 83 und 89 f.), aber nur bei dem aus Reg. 89 ist bekannt, dass dieses das Ordenssiegel trug. 
Or. Pap.: AOGV, Urkunden, Nr. 66 (aufgedr. Verschlußsiegel unter Papier) (Türck’sche Systematik: 2. Partie $\S 2,13$ A).

Kop. zeitgen.: PB 4 § 230 und 232.

Reg.: $\quad$ Ruwet, Vienne, 1956, S. 775, Nr. 66.

Erw.: PB 4 § 228 und 231; AOGV, Codex 34/1, S. 140; ReIfFenberg, Toison d'or, 1830, S. 102 .

Jean de Neufchâtel \{52\}, Herr von Montaigu, schreibt an Hz. Maximilian und bestätigt den Erhalt seines Einladungsschreiben zum Ordensfest (Reg. 81), das ihm der Persevant Rupelmonde überbracht hat. ${ }^{93}$ Er kündigt seine Teilnahme am Ordensfest an. - frz.

Or. Pap.: AOGV, Akten, Karton 5, Fasz. 14 D, Dok. 11 (mit Resten des Verschlußsiegels).

Druck: Sterchi, Überläufer, 2003, S. 98, Nr. 2; Sterchi, Umgang, 2005, S. 458, Anm. 306 (Teildruck).

Erw.: $\quad$ in Reg. 109; STERCHI, Überläufer, 2003, S. 83; STERCHI, Umgang, 2005, S. 458.

\section{o.J. $[1478]^{94}$ Dez. 29, Tours}

Jacques de Luxembourg $\{67\}$ antwortet Hz. Maximilian in einem Brief auf die Vorladung zum kommenden Ordensfest (Reg. 76), die ihm der Herold Fusil überbracht hat. Er erklärt, dass er im Dienst Hz. Karls \{34\} gefangen genommen wurde, er trotzdem diesem weiterhin treu ergeben geblieben ist. Nach Karls Tod ist nun Kg. Ludwig XI. von Frankreich, bei dem er in Gefangenschaft war, sein souverain seigneur, da dieser der sucesseur heredital des Herzogtums Burgund ist. Damit ist Kg. Ludwig auch Souverän des Ordens vom Goldenen Vlies und kein anderer. Kg. Ludwig hat ihn in der Zwischenzeit auch freigelassen, in seinen Dienst und in seinen Orden von St. Michael aufgenommen. ${ }^{95}$ Zuletzt betont er die Wahrung seiner Ehre und dass die gefahrvollen Zeiten ihn bewogen haben, sich dem frz. König anzuschließen. - frz. - eigenhändige Unterschrift.

Bem.: Vgl. dazu auch Reg. 100.

Or. Pap.: AOGV, Akten, Karton 5, Fasz. 14 D, Dok. 16 (mit Resten des Verschlußsiegels). ${ }^{96}$ Erw.: $\quad$ PB 4 § 227; Reg. 100; ReIfFenberg, Toison d'or, 1830, S. 10 sowie oben in der Einleitung S. 16f., Anm. 17.

93 Vgl. dazu auch Rupelmondes Bericht über diese Reise in Reg. 102.

94 Die Jahreszahl ergibt sich durch die Erwähnung in Reg. 100.

95 Jacques de Luxembourg zählte zur engeren Umgebung Hz. Karls und wurde häufig als burgund. Truppenführer und Gesandter eingesetzt; vgl. u. a. PAviot, Jacques de Luxembourg, 2000; zu seinem Wechsel zu Kg. Ludwig XI. vgl. die Angaben in § 29 mit Anm. 178.

96 Bei diesem Stück ist gut das Wasserzeichen mit einem Einhorn, welches auch bei PB4 verwendet wurde [vgl. oben S. 38], zu sehen. 
Der Herold Fusil berichtet Hz. Maximilian und den Mitgliedern des Ordens vom Goldenen Vlies ausführlich über seine Reise nach Frankreich: Entsprechend seinem Auftrag (Reg. 80) reiste er nach Poitiers, wo er nach einigen Tage Wartezeit während der Weihnachtstage bei Ludwig XI., Kg. von Frankreich, in Gegenwart von zahlreichen Ratsmitgliedern sowie des Jacques de Luxembourg \{67\} vorsprechen durfte. Dort bat er um Erlaubnis, die Vorladungsschreiben für das kommende Fest des Ordens vom Goldenen Vlies an die an seinem Hof weilenden Vliesritter übergeben zu dürfen (Reg. 75-79). Darauf erwiderte Kg. Ludwig, dass er nach dem Tod Hz. Karls \{34\} der eigentliche Souverän des Ordens sei ${ }^{97}$ und sein Anliegen damit gegenstandslos. Ihm wurde dann aber doch noch erlaubt, in Gegenwart des kgl. Rates Jacques de Luxembourg das Vorladungsschreiben auszuhändigen. Dieser antwortete ihm, dass er von Kg. Ludwig aus seiner Gefangenschaft befreit worden sei und von diesem u. a. auch den Michaelsorden erhalten habe. Auch sehe er nach dem Tode Hz. Karls Kg. Ludwig als den rechtmässigen Souverän des Ordens vom Goldenen Vlies an. Vor seiner Abreise habe ihm Jacques de Luxembourg aber noch einen Brief an die Ordensmitglieder mitgegeben (Reg. 99). - frz. - eigenh. Unterschrift.

Bem.: Fusil hat diesen Bericht dem Greffier des Ordens übergeben.

Or. Pap.: AOGV, Akten, Karton 5, Fasz. 14 C, Dok. 1.

Kop. (18. Jh.): Brüssel, BR, ms. 20.851 (F.J. de Bors d'Overen, Histoire chronologique de l'ordre de la Toison d'or, Bd. 1), fol. 198r-200v.

Reg.: Cat. mss. de BR, 12, 1936, S. 59, Nr. 7481/25 (nach Kop. in BR Brüssel).

Erw.: $\quad$ PB 4 § 225 und 227; AOGV, Codex 34/1, S. 139 f.; Reiffenberg, Toison d'or, 1830, S. 101; DünnebeIL, Zeichen, 2012, S. 116 sowie oben in der Einleitung S. 13, Anm. 17.

[Vor 1479 Jan. 27, - ] ${ }^{98}$

Philipp von Savoyen $\{68\}$ antwortet in einem Brief auf seine Vorladung (Reg. 82).

Bem.: Überbracht durch den Poursivanten Rupelmonde.

Erw.: $\quad$ PB 4 § 227.

o. D. [Zwischen 1479 Jan. 27 und März 12, - ] ${ }^{99}$

Bericht des Poursivanten Rupelmonde über seine Reise zu Philipp von Savoyen $\{68\}$ (Reg. 82) und Jean de Neufchâtel \{52\} (Reg. 81), um diese zum kommenden Fest vorzuladen. Am 31. Dezember 1478 traf er am Hof Philipps von Savoyen ein. Dort übergab

97 Il est verité dire, lors me dit que lui [Kg. Ludwig XI.] mesmes estoit chief et souverain de l'ordre de la Thoison d'or. Et qu'il apartenoit alui et quant ainsi seroit que le duc Charles seroit mort sur son lit et non pas en bataille, si doit revenir ledit ordre a la couronne et non pas par confiscacion mais par empenaige.

98 Ruplemonde kehrte von seiner Reise am 27. Jan. 1479 zurück; vgl. dazu die Angaben in Reg. 81.

99 Am 27. Jan. 1479 kehrte Rupelmonde von seiner Reise zurück (vgl. dazu die Angaben in Reg. 81) und am 12. März wurde bei dem außerordentlichen Treffen des Ordens über diesen Bericht gesprochen. 
er seinen Brief Philipps Sekretär, Jehan Saynage, da es ihm nicht möglich war, persönlich mit Philipp zu reden. Kurz vor seiner Abreise am 31. Januar 1481 wurde ihm mitgeteilt, dass Philipps sich den Brief angeschaut habe, aber keine Antwort geben wolle. - frz. - eigenh. Unterschrift.

Bem.: Rupelmonde hat diesen Bericht dem Greffier des Ordens übergeben. - Rupplemondes Reise wird auch im Antwortschreiben des Jean de Neufchâtel (Reg. 98) erwähnt.

Or. Pap.: AOGV, Akten, Karton 5, Fasz. 14 C, Dok. 6.

Erw.: $\quad$ PB 4 § 226 und 227; Reiffenberg, Toison d'or, 1830, S. 101.

[Vor 1479 März 12, - ]

Hz. Maximilian fordert die Mitglieder und Amtsträger des Ordens vom Goldenen Vlies mit einer ordonnance auf, am 12. März 1479 zu einer außerordentlichen Ordenssitzung in Antwerpen zu erscheinen.

Bem.: Zu der Versammlung am 12. März 1479 vgl. PB 4 § 231-238.

Erw.: $\quad$ PB 4 § 232 und 237.

[Vor 1479 März 12, - ] ${ }^{100}$

104

Bericht des Herolds Ravenstein ${ }^{101}$ über seine Reise zu Eduard IV. \{63\}, Kg. von England, um diesen die Einladungsschreiben für das kommenden Ordensfest (Reg. 91) zu überbringen. - frz. - eigenh. Unterschrift.

Erw.: $\quad$ PB 4 § 233; Reg. 106; AOGV, Codex 34/1, S. 140 f.; ReIffenberg, Toison d'or, 1830, S. 102.

[1479 März 12, Antwerpen] ${ }^{102}$

Hz. Maximilian beglaubigt in einem Kredenzbrief bei der Stadtobrigkeit von Brüssel Olivier de la Marche und Pierre de Chesne, die in seinem Auftrag das für den Mai geplante Ordensfest in Brüssel vorbereiten sollen.

Erw.: $\quad$ PB 4 § 224.

[14]79 März 19 (n.St.), Antwerpen

Hz. Maximilian weist in einem Brief an Eduard IV., Kg. von England \{63\}, diesen darauf hin, dass er bisher noch keine Antwort auf sein durch den Herold Ravenstein überbrachte Einladungsschreiben zum Ordensfest (Reg. 91) erhalten hat. Weder von Ravenstein noch von Eduards Gesandtschaft, zu der auch Thomas de Montgomery gehört, hat er etwas den Orden betreffendes erfahren. ${ }^{103}$ Dankt aber für das Gratulationsschreiben (Reg. 70) zur Ordensübernahme und fordert ihn auf, sich als Ordens-

100 Am 12. März wurde bei dem außerordentlichen Treffen des Ordens über diesen Bericht gesprochen.

101 Zur Person Ravensteins vgl. die Angaben in § 233, Anm. 140.

102 Bei der außerordentlichen Sitzung des Ordens in Antwerpen wurde dies am 12. März 1479 beschlossen.

103 Vgl. dazu auch die Angaben in § 233. 
bruder zu betätigen und am kommende Ordensfeste teilzunehmen oder mit lettres patentes Stellvertreter zu benennen. - frz. - eigenh. Unterschrift. - Sekretär: M[artin] Steenberch.

Bem.: Überbringer dieses Briefes war Armand de Quiquelberghes, dit Orscamp, aussi poursuivant d'armes de mondit seigneur, ${ }^{104}$ der an diesem Tag von der hzl. Rechnungskammer $20 £$ ausbezahlt bekam, um aler hastement de par mondit seigneur et porter ses lettres closes devers le tres excellent roy d'Engleterre ou qu'il fust touchant aucunes matieres secretes concernans le noble ordre de la Thoison d'or, dont icellui seigneur ne veult aultre declaracion icy estre faicte; vgl. DB Heraudica ID Source 12754 (mit Zitat aus Lille, ADN, B 2118, fol. 233r).

Kop. Pap. zeitgen.: AOGV, Akten, Karton 5, Fasz. 14 F, Dok. 2.

Kop. (18. Jh.): Brüssel, BR, ms. 20.851 (F. J. de Bors d'Overen, Histoire chronologique de l'ordre de la Toison d'or, Bd. 1), fol. 202r-203r.

Erw.: $\quad$ PB 4 § 242 .

[14]79 März 21, Antwerpen

Adolf von Kleve $\{55\}$ schreibt im Auftrag des Ordens an seinen Bruder, Johann, Hz. von Kleve \{47\}, um ihn dazu bewegen, sein Stillschweigen gegenüber dem Orden zu beenden. - frz.

Kop. zeitgen.: PB 4 § 232.

Erw.: $\quad$ PB 4 § 231; AOGV, Codex 34/1, S. 140; ReIfFenberG, Toison d'or, 1830, S. 102.

1479 April 12, o. O. [Amance $]^{105}$

Jean de Neufchâtel $\{52\}$ bevollmächtigt nach Erhalt seines Einladungsschreiben (Reg. 81) Jakob von Savoyen \{84\}, Pierre de Luxemburg \{83\}, Philippe de Croy $\{74\}$, Jacques de Luxembourg $\{81\}$, Philipp von Burgund \{82\}, Ludwig von Brügge $\{61\}$, Josse de Lalaing $\{80\}$ oder Jean de Lannoy $\{50\}$ als seine Stellvertreter und entschuldigt sein persönliches Fernbleiben. - frz. - eigenh. Unterschrift.

Bem.: Vgl. dazu auch die anderen Briefe von Jean de Neufchâtel vom selben Tag (Reg. 109 und 110).

Or. Perg.: AOGV, Urkunden, Nr. 67 (abh. Siegelrest) (Türck'sche Systematik: 2. Partie § 2, $14 \mathrm{~B})$.

Reg.: $\quad$ Ruwet, Vienne, 1956, S. 775, Nr. 67.

[14]79 April 12, Amance

109

Jean de Neufchâtel $\{52\}$ schreibt an Hz. Maximilian und sagt seine Teilnahme am Ordensfest ab. Obwohl er nach Erhalt des Einladungsschreibens vom 9. Okt. 1478 (Reg. 81) seine Teilnahme angekündigt hatte (Reg. 98), erlaube ihm nun sein hohes Alter nicht, zum Ordensfest zu reisen. Ein weiterer Hindernisgrund sind seine Bemühungen, seine burgundischen Besitzungen zu verteidigen, wofür Maximilian ihn

104 Armand de Quiquelberghe ist zwischen 1477 und 1479 in diesem Amt belegt; vgl. DB Heraudica ID person 118 und 223.

105 Entsprechend des genannten Ausstellungsort bei den anderen Schreiben von Jean de Neufchâtel vom selben Tag. 
zu wenig finanziell unterstütze. Er sieht auch keine Notwendigkeit der correction, da er stets ein guter und loyaler Ritter ohne Tadel gewesen sei, der sich immer für das Haus Burgund eingesetzt habe. - frz.

Bem.: Vgl. dazu auch die anderen Briefe von Jean de Neufchâtel vom selben Tag (Reg. 108 und 110).

Or. Pap.: AOGV, Akten, Karton 5, Fasz. 14 D, Dok. 9 (mit Resten des Verschlußsiegels).

Druck: Sterchi, Überläufer, 2003, S. 98 f., Nr. 3; ders., Umgang, 2005, S. 458, Anm. 307 (Teildruck).

Erw.: Sterchi, Überläufer, 2003, S. 82 f.; STERChI, Umgang, 2005, S. 458.

[14]79 April 12, Amance

Jean de Neufchâtel $\{52\}$ teilt Ludwig von Brügge $\{61\}$ mit, dass er am Ordensfest nicht teilnehmen werden, die Gründe dafür werde ihm der Überbringer dieses Briefes mitteilen. Er bittet Ludwig, als seinen Stellvertreter beim Ordensfest zu fungieren. - frz.

Bem.: Vgl. dazu auch die anderen Briefe von Jean de Neufchâtel vom selben Tag (Reg. 108 und 109).

Or. Pap.: AOGV, Akten, Karton 5, Fasz. 14 D, Dok. 10.

Druck: STERCHI, Überläufer, 2003, S. 99, Nr. 4.

[14]79 April 13, Antwerpen

Instruktionen Hz. Maxmilians für Toison d'or, der die in Gent und Brügge weilenden Mitglieder aufsuchen soll, um diesen die Argumente für und wider einer Absage des geplanten Ordensfest darzulegen ${ }^{106}$. Zuletzt soll er von ihnen eine Abstimmung in schriftlicher Form verlangen. - frz. - eigenh. Unterschrift. - Sekretär: M[artin] Steenberch.

Bem.: Bei einer außerordentlichen Sitzung in Antwerpen beschlossen Hz. Maximilian, vier anwesende Mitglieder und der Ordenskanzler, dass Toison d'or beauftragt werden sollte, die Meinung der in der Nähe befindlichen Mitglieder bezüglich der Verschiebung des Ordensfestes einzuholen; vgl. PB 4 § 242. Zur Antwort vgl. Reg. 112 und 113.

Kop. zeitgen.: AOGV, Akten, Karton 5, Fasz. 14 D, Dok. 6.

Kop. (18. Jh.): Brüssel, BR, ms. 20.851 (F.J. de Bors d'Overen, Histoire chronologique de l'ordre de la Toison d'or, Bd. 1), fol. 212r-213v und 223r-224v.

Reg.: Cat. mss. de BR, 12, 1936, S. 59, Nr. 7481/30 (nach Kop. in BR Brüssel).

Erw.: $\quad$ PB 4 § 242, 243 und 246.

1479 April 18, o. O. [Gent]

Jean de Melun $\{28\}$, Herr von Anthoing, Josse de Lalaing $\{80\}$, Herr von Montigny, Pierre de Luxembourg \{83\}, Gf. von Saint-Pol, und Jakob von Savoyen \{84\}, Gf. von Romont, stimmen für eine Verschiebung des Ordensfestes. - frz. - eigenh. Unterschriften.

106 Die mitgeteilten Argumente entsprechen inhaltlich dem, was in § 239-242 notiert wurde. 
Bem.: Ein paar Tage zuvor hatte Hz. Maximilian Toison d'or zu ihnen nach Gent gesandt, um sie nach ihrer Meingung zu fragen; vgl. Reg. 111. - Am 20. April wurde die hier verzeichnete cedule auch noch von Jacques de Luxembourg \{81\}, Herrn von Fiennes, auf der Rückseite eigenhändig unterzeichnet.

Or. Pap.: AOGV, Akten, Karton 5, Fasz. 14 A, fol. 12 (unbesiegelt). ${ }^{107}$

Erw.: $\quad$ PB 4 § 243, 245, 248 und 249.

\section{o. D. [Vor 1479 April 22, Brügge] ${ }^{108}$}

Ludwig von Brügge $\{61\}$, Herr von Gruuthuse, nennt in einer cedule seine Argumente für eine Absage des Ordensfestes. - eigenh. Unterschrift.

Bem.: Ein paar Tage zuvor hatte Hz. Maximilian Toison d'or zu ihm nach Brügge gesandt, um nach seiner Meinung zu fragen; vgl. Reg. 111.

Or. Pap.: AOGV, Akten, Karton 5, Fasz. 14 A, fol. 11 (unbesiegelt). ${ }^{109}$

Kop. (18. Jh.): Brüssel, BR, ms. 20.851 (F. J. de Bors d'Overen, Histoire chronologique de l'ordre de la Toison d'or, Bd. 1), fol. 229r.

Erw.: $\quad$ PB 4 § 244 und 245.

[Vor 1479 April 22, - ]

Hz. Maximilian fordert die Mitglieder und Amtsträger des Ordens vom Goldenen Vlies auf, zu einer außerordentlichen Ordenssitzung am 22. April 1479 in Gent zu erscheinen.

Erw.: $\quad$ PB 4 § 239.

\section{[14]79 April 22, Gent}

Hz. Maximilian unterrichtet mit Briefen die Mitglieder des Ordens, dass aufgrund der Kriegsbedrohung durch Ludwig XI., Kg. von Frankreich das für den kommende 2. Mai in Brüssel geplante Ordensfest um ein Jahr verschoben wird.

Bem.: In PB 4 § 251 wurde notiert, dass die Absage an alle Mitglieder gehen sollte, die sich nicht zu der am 22. April gehaltenen Sondersitzung eingefunden hatten (messeigneurs de l'ordre absens). Anwesend waren dabei Jean de Melun \{28\}, Ludwig von Brügge $\{61\}$, Josse de Lalaing $\{80\}$ und Pierre de Luxembourg $\{83\}$ (§ 239). Im Folgenden werden die Briefe an acht Mitglieder genannt, aber es fehlen Hinweise, ob auch die übrigen 14 Ordensritter unterrichtet wurden. Bei denjenigen mit langer Anreise (wie z. B. auch Bartholomäus von Liechtentein \{85\}) wird man wohl davon ausgegangen sein, dass sie das Absageschreiben nicht mehr rechtzeitig erhalten werden, weshalb Toison d'or nach Brüssel gesandt wurde, um diese dort zu empfangen (vgl. Reg. 126). Auch sollte dieser dort diejenigen Mitglieder empfangen, deren persönliche Anwesenheit beim Ordensfest von Hz. Maximilian eingefordert worden war, möglicherweise erhielten auch sie keine Absageschreiben. ${ }^{110}$ Die per-

$107 \mathrm{Zu}$ diesem Bestand vgl. die Angaben in § 239, Anm. 173.

108 Am 22. Mai wurde über diese cedule gesprochen.

$109 \mathrm{Zu}$ diesem Bestand vgl. die Angaben in § 239, Anm. 173.

110 Zum Kreis dieser Mitglieder zählen die in Frankreich befindlichen Philippe Pot $\{60\}$, Philippe de Crèvecœur $\{69\}$, Jacques de Luxembourg $\{67\}$, Jean de Damas $\{65\}$ und 
sönliche Teilnahme der Könige Johann von Aragon \{57\}, Ferdinand von Neapel \{72\}, Eduard von England $\{63\}$ und Ferdinand von Sizilien $\{71\}$, wurde von seiten des Ordens wohl nicht erwartet, vielleicht wurde ihnen deshalb die Absage des Festes auch nicht mitgeteilt. Auffällig ist, dass Jean de Lannoy $\{50\}$ nicht als Empfänger eines Absageschreibens genannt wird, aber auch nicht in dem Prozeß der Entscheidungsfindung miteinbezogen war.

Erw.: $\quad$ PB 4 § 250; Reiffenberg, Toison d'or, 1830, S. 103.

Folgende Exemplare sind bekannt:

An Adolf von Kleve $\{55\}$, Herr von Ravenstein. - frz. 115

Bem.: Überbracht wurde dieser Brief von Colinet Rose, dit Lembourg, herault d'armes de mondit seigneur, der am 24. April 1479 für den Auftrag, porter hastivement et a toute dilligence lettres closes de mondit seigneur a messeigneurs de Ravestain, de la Veere \{79\} et d'Egmond \{78\}, quelque part qu'ilz fussent, touchant affaires secrez dudit ordre de la Thoison d'or, dont mondit seigneur ne veult aultre mencion icy estre faicte, $7 £ 4$ sous ausbezahlt; vgl. DB Heraudica ID Source 12749 (mit Zitat aus Lille, ADN, B 2118, fol. 138v).

Kop. zeitgen.: PB 4 § 252.

An Jakob von Savoyen \{84\}, Gf. von Romont. - frz. 116

Kop. zeitgen.: PB 4 § 252.

An Philippe de Croy $\{74\}$, Gf. von Chimay. - frz.

Kop. zeitgen.: PB 4 § 253.

An Wilhelm von Egmond $\{78\}$. - frz.

Bem: Überbracht durch Herold Limburg; vgl. dazu Reg. 115.

Kop. zeitgen.: PB 4 § 253.

An Philippe von Burgund \{82\}, Herr von Bevern. - frz.

Kop. zeitgen.: PB 4 § 253.

An Engelbert, Gf. von Nassau \{77\}. - frz.

Kop. zeitgen.: PB 4 § 253.

An Wolfart van Borssele \{79\}, Gf. von Grantpré. - frz.

Bem: Überbracht durch Herold Limburg; vgl. dazu Reg. 115.

Kop. zeitgen.: PB 4 § 253.

An Jacques de Luxembourg \{81\}, Herr von Fiennes. - frz.

Kop. zeitgen.: PB 4 § 253.

Anton, Bastard von Burgund \{54\}, aber auch Jean de Neufchâtel \{52\}, Philipp von Savoyen $\{68\}$ und Johann, Hz. von Kleve \{47\}; vgl. Reg. 75-82 und 89-91. 
Hz. Maximilian unterrichtet den Ordenskanzler Ferry de Clugny mit einem Brief über Verschiebung des Ordensfestes um ein Jahr. - frz.

Kop. zeitgen.: PB 4 § 254.

Erw.: $\quad$ PB 4 § 250.

[14]79 April 22, Gent

Hz. Maximilian unterrichtet die Stadtobrigkeit von Brüssel in einem Brief davon, dass das geplante Ordensfest wegen kriegerischer Handlungen des französischen Königs nicht stattfinden kann. Er sagt ihnen aber zu, dass das Fest ein Jahr später wie geplant in ihrer Stadt nachgeholt werden soll. Gleichzeitig beglaubigt er Philippe du Chesne, seinen Rat und Hofmeister seiner Frau Maria, der ihnen seine Entscheidung noch einmal persönlich erklären wird. - frz. - eigenh. Unterschrift - Sekretär: M[artin] Steenberch.

Kop. zeitgen.: PB 4 § 255 .

[14]79 April 22, Gent

Hz. Maximilian unterrichtet den Ordenstrésorier Jean Gros mit einem Brief über Verschiebung des Ordensfestes um ein Jahr. - frz.

Erw.: $\quad$ PB $4 \S 250$.

[1479 April 22, Gent]

Der Orden vom Goldenen Vlies beauftragt seinen Wappenkönig Toison d'or, Gilles Gobet, nach Brüssel zu reisen, um dort von der Mittagszeit des 1. Mai an drei Tage lang eintreffende Ordensmitglieder oder deren Gesandte zu empfangen. Er soll ihnen dann die Absage des Festes mitteilen, eingehende Schriftstücke entgegen nehmen und Gesandte, so fern sie es wünschen, zu Hz. Maximilian bringen.

Bem.: Dies wurde bei der außerordentlichen Ordenssitzung am 22. April beschlossen; vgl. PB 4 § 250. Siehe dazu auch den Bericht von Toison d'or über diesen Auftrag in Reg. 127.

Or.: Verbleib nicht bekannt (mit Ordenssiegel).

Erw.: $\quad$ PB 4 § 250 und 256 sowie in Reg. 127.

\section{Mai 5, Brüssel}

Der Wappenkönig Toison d'or, Gilles Gobet, berichtet Hz. Maximilian und den Mitgliedern des Ordens vom Goldenen Vlies in einem Brief ausführlich, dass er gemäß seines Auftrages (Reg. 126) nach Brüssel gereist ist und dort zwischen dem 30. April und 4. Mai vergeblich auf anreisende Mitglieder, deren Gesandte oder Schriftstücke gewartet hat. ${ }^{111}$ - frz. - eigenh. Unterschrift.

111 Jean de Neufchâtel \{52\} hatte aber Absageschreiben entsandt (vgl. Reg. 108-110), sie scheinen Anfang Mai noch nicht in Brüssel angekommen zu sein. 
Or. Perg.: AOGV, Urkunden, Nr. 68 (abh. Siegel ab und verloren) (Türck'sche Systematik: 2. Partie $\S 2,14 \mathrm{~A})$.

Kop. zeitgen.: PB 4 § 256.

Kop. (18. Jh.): Brüssel, BR, ms. 20.851 (F. J. de Bors d'Overen, Histoire chronologique de l'ordre de la Toison d'or, Bd. 1), fol. 225r-226r.

Reg.: Ruwet, Vienne, 1956, S. 775, Nr. 68 (nach Or.).

Erw.: Reiffenberg, Toison d'or, 1830, S. 103 f.; Koller, Service, 1971, S. 140 mit Anm. 6; Auer, Maximilian I ${ }^{\text {er }}$, 2008, S. 59.

[1479 vor Dez. $29,-$ ]

Hz. Maximilian fordert mit einer ordonnance die Mitglieder und den Kanzler des Ordens vom Goldenen Vlies auf, sich am 29. Dezember bei ihm in Gent zu einer außerordentlichen Sitzung einzufinden.

Erw.: $\quad$ PB 4 § 257.

[1480 Januar 17 (n.St.), Brüssel] ${ }^{112}$

Hz. Maximilian beauftragt Nikolaus de Gondeval, seinen Rat und Trésorier, und Woutre de Housdam, den garde de ses joyaulx, ${ }^{113}$ für vier verlorene Ordensketten gleichwertigen Ersatz herstellen zu lassen.

Bem.: Vgl. dazu auch Reg. 139.

Erw.: $\quad$ PB 4 § 262; Reiffenberg, Toison d'or, 1830; S. 105.

\section{[14]80 Jan. 17, Brüssel}

Hz. Maximilian verkündet den Mitgliedern mit Königswürde freudig die Geburt seiner Tochter Margarete, die am 10. Januar zur Welt gekommen ist, und dass sie nach seiner Schwiegermutter benannt wurde. ${ }^{114}$ Des Weiteren teilt er mit, dass er nach Beratung mit einigen Mitgliedern des Ordens vom Goldenen Vlies beschlossen hat, aufgrund der politisch unsicheren Lage das für den kommenden Mai geplante Ordensfest ${ }^{115}$ um ein weiteres Jahr zu verschieben. Die dazu erforderlichen Einladungsschreiben werde er zeitgemäß versenden.

Erw.: $\quad$ PB 4 § 258 und 260; Reiffenberg, Toison d'or, 1830, S. 104.

Folgende Exemplare sind bekannt:

An Eduard IV. \{63\}, Kg. von England. - frz.

Kop. zeitgen. (Steenberch): AOGV, Codex 45, fol. 82v-83v.

An Ferdinand $\{72\}$, Kg. von Neapel. - lat.

Kop. zeitgen. (Steenberch): AOGV, Codex 45, fol. 82r-v.

112 Bei der außerordentlichen Sitzung des Ordens am 17. Jan. 1480 wurde dies beschlossen.

113 Zur Identifizierung der beiden Adressaten vgl. die Angaben in § 262.

114 Zu ihrer Person vgl. u. a. Blockmans, Margarete von Burgund, 1993; EIchBerger, Women of Distinction, 2005.

115 Vgl. die Einladungsschreiben in Reg. 115-122. 
An Ferdinand $\{71\}$, Kg. von Kastilien.

Bem.: Vermutlich handelt es sich um diesen Brief, den Guillaume le Peletier als Herold Namur ${ }^{116}$ überbringen sollte, als die hzl. Rechnungskammer ihm am 12. Febr. 148066 $£$ auszahlte, pour avoir porté lettres closes d'icellui seigneur au roy de Castille touchant le fait de l'ordre de la Thoison d'Or, dont il ne veult autre declaracion icy estre faicte.

Erw.: DB Heraudica ID Source 13292 (mit Zitat aus Lille, ADN, B 2121, fol. 314r).

\section{Dez. 1, Gent}

Hz. Maximilian teil verschiedenen Ordensmitgliedern mit, dass er sich anläßlich des St. Andreas-Tages (30. Nov.) mit verschiedenen Mitgliedern getroffen hat. Dabei wurde festgestellt, dass diverse Ordensangelegenheiten zu regeln seien; aufgrund der geringen Anzahl sei die Versammlung abernicht beschlussfähig gewesen. Deshalb fordert er die Adressaten auf, am 9. Dezember in Brügge zu erscheinen. - frz. - eigenh. Unterschrift.

Erw.: $\quad$ PB 4 § 263 und in der Einleitung S. 33.

Folgende Exemplare sind bekannt:

An Josse de Lalaing $\{80\}$.

Or. Pap.: OGV, Akten, Karton 5, Fasz. 14 I, fol. 4, Dok. 3.

An Adolf von Kleve $\{55\}$, Herr von Ravenstein. - frz.

Erw.: in Reg. 135.

\section{[14]80 Dez. 12, Brügge}

Hz. Maximilian wendet sich mit einem Brief an Adolf von Kleve \{55\}, Herrn von Ravenstein: Nachdem dieser seiner Aufforderung, am 9. Dez. nach Brügge zu kommen (Reg. 134), nicht nachgekommen ist, fordert er ihn nun auf, persönlich bei ihm zu erscheinen oder eine Erklärung abzugeben. - frz.

Konz. Pap. (Steenberch): OGV, Akten, Karton 5, Fasz. 14 I, fol. 18r-v, Dok. 13.

1480 Dez. [20-24] ${ }^{117}$, Brügge

Für das im kommenden Mai geplante Ordensfest stellt der Orden vom Goldenen Vlies zahlreiche Einladungs- und Vorladungsschreiben aus.

Bem: Die Einladungen beruhen auf einem Beschluss einiger Mitglieder, die sich im Dezember 1480 bei Hz. Maximilian versammelt hatten. Während der Sitzung am 20. Dez. 1480 wurde Steenberch beauftragt, die verschiedenen Einladungs- und Vorladungsschreiben aufzusetzen, und am 23. Dez. wurde der neugewählte Ordenskanzler Jean de Lannoy aufgefordert, die Schreiben mit dem Ordenssiegel zu versehen; vgl. dazu PB 4, § 263-275 und 281-282 sowie in der Einleitung S. 34. Über die Einladungs- und Vorladungsschreiben wurde erneut bei einer Sitzung im Jan. 1481 diskutiert, die im PB 5 beschrieben werden wird. Auch sonst finden sich

116 Zu ihm vgl. die Angaben in § 19, Anm. 100.

117 Die einzelnen Schreiben wurden zwischen dem 20. und 24. Dez. 1481 datiert. 
in diesem Protokollbuch, das das Ordensfest von 1481 zum Thema hat, zahlreiche Verweise und auch kopiale Überlieferungen der Ein- und Vorladungsschreiben, deshalb wurde beschlossen, diese Schreiben ausführlich in PB 5 zu verzeichenen. Vgl. dazu PB 5, Reg. sub dato.

[Vor 1480 Dez. 23]

Engelbert von Nassau \{77\} quittiert Martin Steenberch den Erhalt einer neuen Ordenskette als Ersatz für die, die er während der Schlacht von Thérouanne verloren hatte.

Erw.: in Reg. 139.

[Vor 1480 Dez. 23]

Desgleichen quittiert Philipp von Burgund $\{82\}$.

Erw.: $\quad$ in Reg. 139.

1480 Dez. 23, o. O. [Brügge] ${ }^{118}$

Martin Steenberch, Sekretär des Ordens vom Goldenen Vlies, quittiert dem Trésorier Jean Gros, dass er die neuen Ordensketten, die als gleichwertiger Ersatz für die während der Schlacht von Thérouanne verlorenen Ordensketten angeschafft wurden, den rechtmässigen Besitzern Engelbert von Nassau $\{77\}$ und Philipp von Burgund \{82\} übergeben hat, und dafür von jedem eine schriftliche Empfangsbestätigung (Reg. 137 und 138) erhalten hat. - frz.

Bem.: Vgl. dazu PB 4 § 262.

Kop. zeitgen. (Steenberch): AOGV, Codex 45, fol. 97v.

1480 Dez. 23, Brügge

Hz. Maximilian bestätigt die Ernennung von Jean de Lannoy, Abt von Saint-Bertin bei Saint-Omer, zum Kanzler des Ordens vom Goldenen Vlies. Nach der Ernennung des alten Ordenskanzlers Ferry de Clugny zum Kardinal von San Vitale und seinem damit verbundenen Rücktritt als Ordenskanzlers wurde Lannoy bei seiner Versammlung mit einigen Ordensrittern und den übrigen Ordensamtsträgern zum neuen Ordenskanzler gewählt. Er hatte sogleich den Amtseid geleistet und das Ordenssiegel zur Verwahrung und Gebrauch erhalten. Des Weiteren bestätigt er Lannoy für dieses Amt eine jährliche Pension in Höhe von 200 Francs. - frz. - Par monseigneur le duc, chief et souverain, en son conseil de l'ordre de la Thoison d'or: M(artin) Steenberch.

Or.: Verbleib nicht bekannt (mit Ordenssiegel).

Kop. zeitgen. (Steenberch): AOGV, Codex 45, fol. 95r-96r.

Erw.: $\quad$ PB 4 § 278; AOGV, Codex 34/1, S. 147.

118 Vgl. den Ausstellungsort von Reg. 140. 



\section{Verzeichnisse}

\section{Verzeichnis der Feste und Mitglieder des Ordens vom Goldenen Vlies (1430-1478)}

Im folgenden Verzeichnis werden die Mitglieder in der Reihenfolge ihrer Wahl in den Orden vom Goldenen Vlies sowie die offizielle Liste der Ordensfeste aufgeführt. ${ }^{1}$

\section{Gründung des Ordens in Brügge 1430}

[01] ${ }^{2}$ Philipp, Hz. von Burgund, Gründer des Ordens und 1. Souverän (1430-1467)

1 Guillaume de Vienne, Herr von Saint-George und Sainte-Croix (1430-1434)

2 Renier Pot, Herr von La Prugne und La Roche-Nolay (1430-1432)

3 Jean, Herr von Roubaix und Herzeele (1430-1449)

4 Roland d'Uutkerke, Herr von Heemsrode und Heestert (1430-1442)

$5 \quad$ Antoine de Vergy, Gf. von Dammartin (1430-1439)

6 David de Brimeu, Herr von Ligny-sur-Canche (1430-1448)

$7 \quad$ Hue de Lannoy, Herr von Santes (1430-1456)

8 Jean de la Clite, Herr von Comines (1430-1443)

9 Antoine de Toulongeon, Herr von Traves und La Bastie-sur-Serdon (14301432)

10 Pierre de Luxembourg, Gf. von Saint-Pol (1430-1433)

11 Jean de la Trémoïlle, Herr von Jonvelle (1430-1449)

12 Guilbert de Lannoy, Herr von Willerval (1430-1462)

13 Jean de Luxembourg, Gf. von Ligny-en-Barrois (1430-1441)

14 Jean de Villiers, Herr von L'Isle-Adam (1430-1437)

15 Antoine de Croy, Gf. von Porcien, Herr von Croy (1430-1475)

16 Colart de Brimeu, dit Florimont, Herr von Maizicourt (1430-1442)

17 Robert, Herr von Masmines (1430)

18 Jacques de Brimeu, Herr von Grigny (1430-1447)

19 Baudouin de Lannoy, genannt le Bègue, Herr von Molembaix (1430-1474)

20 Pierre de Bauffremont, Gf. von Charny (1430-1472)

21 Philippe, Herr von Ternant (1430-1456)

22 Jean de Croy, Gf. von Chimay (1430-1473)

23 Jean, Herr von Créquy und Canaples (1430-1472)

24 Jean de Neufchâtel, Herr von Montaigu (1430-1431 [Ausschluss])

[o. N.] Louis de Chalon, Prinz von Orange (1430-1431 [Ausschluss]) ${ }^{3}$

1 Zum Aufbau der folgenden Mitgliederliste vgl. die Angaben in PB 1, S. 233-235.

2 Hz. Philipp hat in den offiziellen Ordensmatrikeln keine eigene Nummer erhalten; vgl. z. B. Liste nominale de la Toison d'or, 2007, S. 161.

3 Louis de Chalon wurde vom Orden ausgeschlossen, bevor er seinen Aufnahmeeid geleistet hatte, deshalb hat auch er keine eigene Matrikelnummer erhalten; vgl. PB 1 $\S \mathrm{I} / 8$. 


\section{Ordensfest 1431 in Lille}

25 Friedrich, Gf. von Moers (1431-1448)

26 Simon de Lalaing, Herr von Montignies (1431-1477)

\section{Ordensfest 1432 in Brügge}

27 André de Toulongeon, Herr von Mornay (1432)

28 Jean de Melun, Herr von Antoing (1432-1484)

\section{Ordensfest 1433 in Dijon}

29 Jacques de Crèvecœur, Herr von Thoix (1433-1439)

30 Jean de Vergy, Herr von Fouvent (1433-1460)

31 Guy de Pontailler, Herr von Talmay (1433-1437)

32 Baudot de Noyelle, Herr von Catheux (1433-1461)

33 Jean de Luxembourg, Bastard von Saint-Pol, Herr von Haubourdin (1433-1466)

34 Karl, Gf. von Charolais, dann Hz. von Burgund (1433-1477; 2. Ordenssouverän)

35 Ruprecht, Gf. von Virneburg (1433-1444)

36 Thiébaut, Herr von Neufchâtel (1433-1459)

4. Ordensfest 1434 in Dijon - keine Aufnahmen

5. (4.) Ordensfest 1435 in Brüssel- keine Aufnahmen

6. Ordensfest 1436 in Lille- keine Aufnahmen

7. Ordensfest 1437 ist ausgefallen

8. Ordensfest 1438 ist ausgefallen

9. Ordensfest 1439 ist ausgefallen

10. (6.) Ordensfest 1440 in Saint-Omer

37 Karl, Hz. von Orléans (1440-1465)

38 Johann, Hz. der Bretagne (1440-1442)

39 Johann, Hz. von Alençon (1440-1476)

40 Mathieu de Foix, Gf. von Comminges (1440-1453)

\section{Ordensfest 1441 ist ausgefallen}

12. Ordensfest 1442 ist ausgefallen

13. Ordensfest 1443 ist ausgefallen

14. Ordensfest 1444 ist ausgefallen 


\section{5. (7.) Ordensfest 1445 in Gent ${ }^{4}$}

41 Alfons, Kg. von Aragon (1445-1458)

42 Frank van Borssele, Gf. von Ostrevant (1445-1470)

43 Reinald, Herr von Brederode und Vianen (1445-1473)

44 Hendrik van Borssele, Gf. von Grandpré (1445-1474)

45 Jean, Herr von Auxy (1445-1474)

46 Dreux, Herr von Humières (1445-1458)

\section{6. (8.) Ordensfest 1451 in Mons}

47 Johann, Hz. von Kleve, Gf. von der Mark (1451-1481)

48 Iñigo de Guevara, Gf. von Ariano (1451-1462)

49 Pedro de Cardona, Gf. von Collesano (1451)

50 Jean, Herr von Lannoy (1451-1493)

51 Jacques de Lalaing, Herr von Bugnicourt (1451-1453)

52 Jean de Neufchâtel, Herr von Montaigu (1451-1481 [Ausschluss])

\section{7. (9.) Ordensfest 1456 in Den Haag}

53 Johann von Burgund, Gf. von Nevers, Étampes und Rethel (1456-1468 [Ausschluss])

54 Anton, Bastard von Burgund, Gf. von La Roche-en-Ardenne (1456-1504)

55 Adolf von Kleve, Herr von Ravenstein (1456-1492)

56 Johann, Hz. von Coïmbra (1456-1457)

\section{8. (10.) Ordensfest 1461 in Saint-Omer}

57 Johann, Kg. von Aragon und Navarra (1461-1479)

58 Adolf, Hz. von Geldern, Gf. von Zutphen (1461-1477)

59 Thiébaut, Herr von Neufchâtel und Châtel-sur-Moselle (1461-1469)

60 Philippe Pot, Herr von la Roche-Nolay (1461-1481 [Ausschluss])

61 Ludwig von Brügge, Herr von Gruuthuse, Gf. von Winchester (1461-1492)

62 Guy, Herr von Roye (1461-1463)

\section{9. (11.) Ordensfest 1468 in Brügge}

63 Eduard IV., Kg. von England (1468-1483)

64 Louis de Chalon, Herr von Châtel-Guyon (1468-1476)

65 Jean de Damas, Herr von Clessy (1468-1481)

66 Jacques de Bourbon (1468)

67 Jacques de Luxembourg, Herr von Richebourg (1468-1481 [Ausschluss])

68 Philipp von Savoyen, Gf. von Bugey, Herr von Bresse (1468-1497)

69 Philippe de Crèvecœur, Herr von Esquerdes (1468-1481 [Ausschluss])

70 Claude de Montaigu, Herr von Couches (1468-1471)

4 Das Fest in Gent wurde unter der Überschrift „La unión de principes - Gante 1445“ in der 2007 in Valencia gezeigten Ausstellung „A la búsqueda del Toisón de oro“ thematisiert; vgl. dazu Kat. Búsqueda del Toisón de oro, 2007, S. 173-201, hier S. 188-199 die Wappentafeln dieses Festes in guten Abbildungen; sowie der dazugehörige engl. Text auf S. 478-480; Delva, $7^{\circ}$ capítulo, 2007; Blasco Valés/Reche Ontillera, Documentos, 2007. 


\section{0. (12.) Ordensfest 1473 in Valenciennes}

71 Ferdinand, Kg. von Kastilien und Sizilien (1473-1516)

72 Ferdinand, Kg. von Neapel (1473-1494)

73 Jean de Rubempré, Herr von Bever (1473-1477)

74 Philippe de Croy, Gf. von Chimay (1473-1482)

75 Jean de Luxembourg, Gf. von Marle (1473-1476)

76 Guy de Brimeu, Herr von Humbercourt, Gf. von Megen (1473-1477)

77 Engelbert von Nassau, Gf. von Vianden (1473-1504)

\section{1. (13.) Ordensfest 1478 in Brügge}

$77^{\text {bis }}$ Maximilian I. von Habsburg, Hz. von Burgund (1478-1519, 3. Ordenssouverän) ${ }^{5}$

78 Willem van Egmond (1478-1483)

79 Wolfart van Borssele (1478-1486)

80 Josse de Lalaing, Herr von Montigny (1478-1483)

81 Jacques de Luxembourg, Herr von Fiennes (1478-1488)

82 Philipp von Burgund, Herr von Beveren (1478-1498)

83 Pierre de Luxembourg, Gf. von Saint-Pol (1478-1482)

84 Jakob von Savoyen, Gf. von Romont (1478-1486)

85 Bartholomäus von Liechtentein (1478-1493)

5 In der Liste nominale erhielt Maximilian selbst keine Mitgliedernummer, da er nie ein „normales“ Mitglied war. Bei Chevaliers de la Toison d'or, ${ }^{2} 2000$, S. 185-190, erhielt er deshalb eine Zwischennummer. 


\section{Abkürzungen}

A

Abb.

ADB

ADN

AGR

Anm.

AOGV

Aug.

AUR

B

Bd.

Bem.

Bf.

BM

BNF

BR

Cat.

Coll.

D

DB

Dép.

ders.

Dez.

d.d.

DHIP

dies.

Diss. masch

E

Erw.

ES

F

f.

Febr.

fol.

frz.

Gf.

HHStA

hg.

Hs.

$\mathrm{Hz}$.

Hz.in

hzl.

Hzt.

IADNB

ibid.

I
Österreich bzw. anwesend (in Tabelle 1 und Tabelle 2).

Abbildung

Allgemeine Deutsche Biographie

Archives départementales du Nord (in Lille)

Archives générales du royaume (in Brüssel)

Anmerkung

Archiv des Ordens vom Goldenen Vlies im HHStA Wien

August

Allgemeine Urkunden Reihe (im HHStA Wien)

Belgien

Band

Bemerkung

Bischof

Bibliothèque municipale

Bibliothèque nationale de France (Paris)

Bibliothèque royale Albert $\mathrm{I}^{\text {er }}$ (in Brüssel)

Catalogue

Collection

Deutschland

Datenbank (s. Wichtige Internetseiten)

Département

derselbe

Dezember

de dato

Deutsches Historisches Institut Paris

dieselbe

maschinengeschriebene (unveröffentlichte) Dissertation

Spanien

Erwähnung

Europäische Stammtafeln (s. Literaturverzeichnis)

Frankreich

folgend

Februar

Folio

französisch

Graf

Haus-, Hof- und Staatsarchiv (Wien)

herausgegeben

Handschrift

Herzog

Herzogin

herzoglich

Herzogtum

s. Literaturverzeichnis unter Inventaire sommaire

ibidem

Italien 


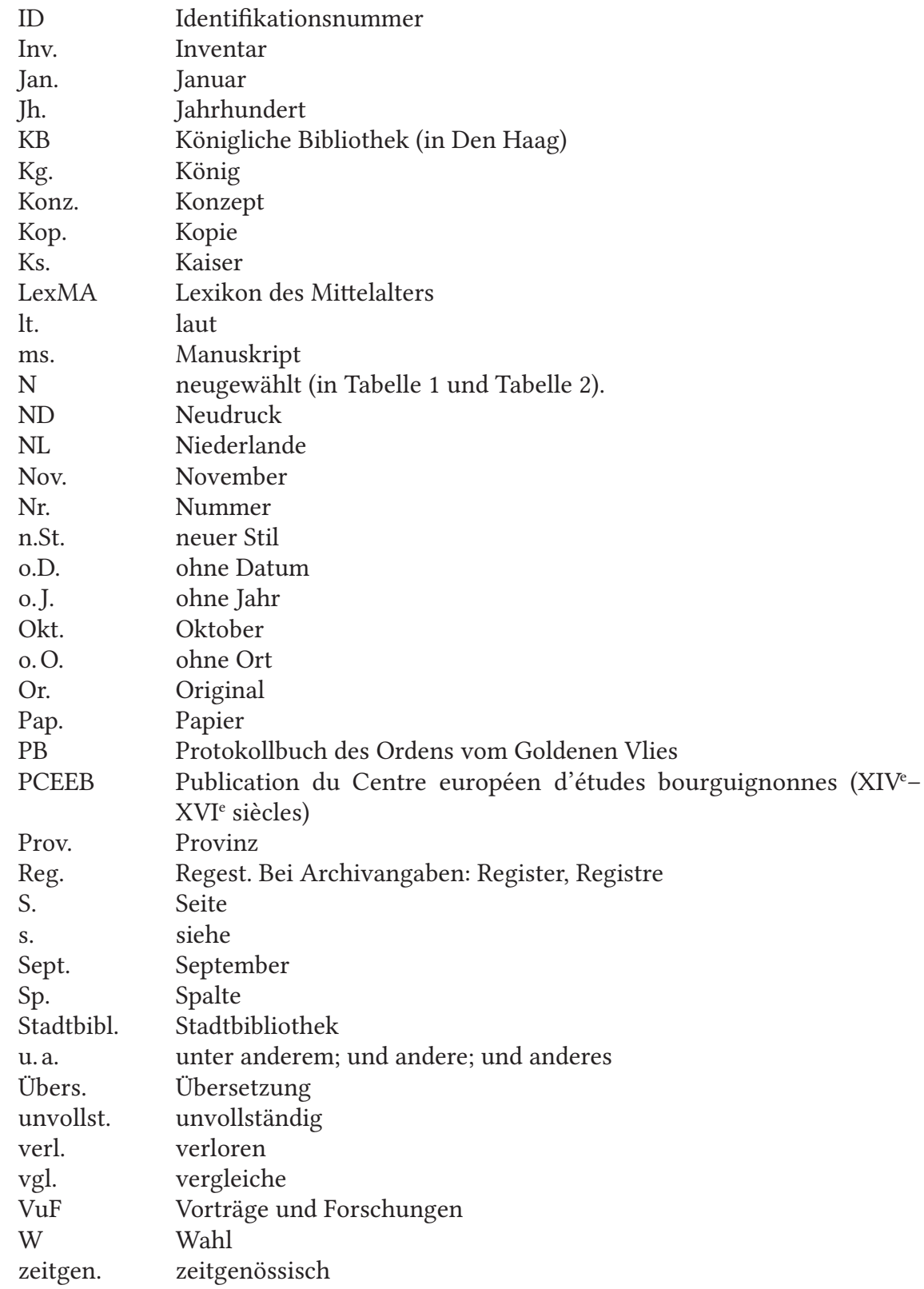




\section{Literatur}

Albrecht, Christian, Die Monatsrolle des burgundischen Argentiers Nicolas de Gondeval für den Oktober 1475, Teil 1: Einführung und Edition, in: Francia 22/1 (1995) S. 79-127.

Herzog Albrecht der Beherzte (1443-1500). Ein sächsischer Fürst im Reich und in Europa, hg. von André Thieme, (Quellen und Materialien zur Geschichte der Wettiner, 2) Köln/Weimar/Wien 2002.

Arbaumont, Jules d' s. Mémoires de la Marche.

Armstrong, Charles A.J., La politique matrimoniale des ducs de Bourgogne de la Maison de Valois, in: Annales de Bourgogne 40 (1968) S. 5-58 und S. 89-139.

- L'Échange culturel entre les cours d'Angleterre et de Bourgogne à l'époque de Charles le Téméraire, in: Ders., Collectes Studies, 1983, S. 403-417.

- The language question in the Low Countries. The Use of French and Dutch by the Dukes of Burgundy and their Administration, in: Europe in the Late Middle Ages, hg. von J.R. Hale, J.R.L. Highfield und B. Smalley, London 1965, S. 386-409. Erneut in: Ders., Collectes Studies, 1983, S. 189-212.

- England, France and Burgundy in the fifteenth century. Collected Studies, hg. von A.G. Dickens, (History series, 16), London 1983.

Auer, Leopold s. Das Haus Österreich und der Orden vom Goldenen Vlies, 2007.

- Maximilian I ${ }^{\text {er }}$ et la Toison d'or, in: Fondation et rayonnement de l'Ordre de la Toison d'or, 2008, S. 57-64.

Außenpolitisches Handeln im späten Mittelalter: Akteure und Ziele, hg. von Sonja DünnebeIL und Christine OtTneR, (Forschungen zur Kaiser- und Papstgeschichte des Mittelalters Beihefte zu J.F. Böhmer, Regesta Imprerii, 27) Wien/Köln 2008.

Bachmann, Adolf, Deutsche Reichsgeschichte im Zeitalter Friedrich III. und Max I. mit besonderer Berücksichtigung der österreichischen Staatengeschichte, 2 Bde., Unveränd. Neudruck nach Leipzig 1884-1894, Hildesheim 1970.

- Urkundliche Nachträge zur österreichischen Geschichte im Zeitalter Kaiser Friedrichs III. (Fontes Rerum Austriacarum II/46), Wien 1892.

Barante, Amable G.B. de, Histoire des ducs de Bourgogne de la Maison de Valois, 1364-1477. Nouvelle édition enrichie d'un grand nombre de notes par LouisProsper GACHARD, 2 Bde., Brüssel 1838.

- Histoire des ducs de Bourgogne de la Maison de Valois, 1364-1477. Bd. 9 und 10, Brüssel 1839; ND hg. und mit einem Vorwort von Yves CAZAux, (Les grands monuments de l'histoire, 8) Paris 1969.

BARTIER, John, Légistes et gens de finances au XVe siècle: les conseillers des ducs de Bourgogne Philippe le Bon et Charles le Téméraire, Brüssel 1955.

BAUchau, Blanche, Jacques de Savoie: histoire d'un portrait et portrait d'histoire, in: De orde van het Gulden Vlies te Mechelen in 1491, 1992, S. 117-148.

BAum, Wilhelm, Sigmund der Münzreiche. Zur Geschichte Tirols und der habsburgischen Länder im Spätmittelalter, (Schriftenreihe des Südtiroler Kulturinstitutes 14) Bozen 1987.

BAUtier, Robert-Henri s. Sources de l'histoire. 
Beaune, Henri s. Mémoires de la Marche.

Begent, Peter J. s. Order of the Garter, 1999.

Bergen-Pantens, Christiane van den, Chapitres de la Toison d'or au XVe siècle. Quelques ensembles héraldiques conservés en Belgique, in: Genealogica et Heraldica 14 (1980) S. 287-298.

- s. Ordre de la Toison d'or, 2013.

Berings, Geert/Simaey, Charles van, Abbaye de Saint-Pierre au Mont-Blandin à Gand, in: Monasticon belge, VII/1, Lüttich 1988, S. 69-154.

Berlin, Andrea, Aberglaube und Magie am Hof der Herzöge von Burgund, Diss. masch., Bochum 2012.

- Family Politics and Magic at the Court of Burgundy, in: Staging the Court of Burgundy, 2013, S. 67-72.

- La main protectrice du duc de Bourgogne. Les réactions de Philippe le Bon et de Charles le Téméraire face au cas de sorcellerie de Jean d'Etampes, in: PCEEB 53 (2013) S. 101-110.

Bibliothèque nationale - Département des manuscrits. Catalogue des manuscrits français, ancien fonds, Bd. 4: Nr. 4587-5525, Paris 1905.

Bittner, Ludwig s. Gesamtinventar HHStA Wien.

Birken, Sigmund von s. Fugger, Spiegel der Ehren, 1668.

Blaschke, Karlheinz, Ernst, Kurfürst von Sachsen, in: Neue Deutsche Biographie 4 (1959) S. 620.

Blasco Valés, Almudena/Reche Ontillera, Ablerto, Documentos referentes a la Orden del Toisón de Oro, contenidos en la cancillería de los reyes de Aragón, in: Búsqueda del Toisón de oro, 2007, Aufsatzband, S. 239-243, S. 435-460 (Dokumente) und engl. Übers. (Documents connected with the order of the Golden Fleece in the chancery of the monarchs of Aragon) S. 583-604.

Blockmans, Wim, Orden vom Goldenen Vlies (Toison d'or), in: LexMA 4 (1989) Sp. $1545 \mathrm{f}$.

- Albrecht de Soutmoedige, hertog van Saksen, stadhouder-generaal der Nederlanden (1443-1500), in: De orde van het Gulden Vlies te Mechelen in 1491, 1992, S. 189-200.

- Margarete von Österreich, in: LexMA 6 (1993) Sp. 238.

- Margarete von York, in: LexMA 6 (1993) Sp. 239.

- Maria von Burgund, in: LexMA 6 (1993) Sp. 279.

- Maximilian und die burgundischen Niederlande, in: Kaiser Maximilian I. Bewahrer und Reformer, hg. von Georg Schmidt-Von Rhein, Ramstein 2002, S. 51-67.

- Margret of York. The subtle Influence of a Duchess, in: Women of Distinction. Margaret of York / Margaret of Austria, hg. von Dagmar EICHBERgER, Turnhout 2005, S. 43-47.

- s. Staging the Court of Burgundy, 2013.

Bock, Dieter, Maximilian als Herzog der Niederlande (1477-1493), Diss. masch., Graz 1970. 
Böck, Matthias, Herzöge und Konflikt. Das spätmittelalterliche Herzogtum Geldern im Spannungsfeld von Dynastie, ständischen Kräften und territorialer Konkurrenz (1339-1543), (Veröffentlichungen des Historischen Vereins für Geldern und Umgebung, 110) Geldern 2013.

Böнм, Willy, Albrecht, Kurfürst von Brandenburg, in: ADB 1 (1875) S. 243-252.

Boone, Marc/Hemptinne, Thérèse de, Espace urbain et ambitions princières: les présences matérielles de l'autorité princière dans le Gand médiéval (12e siècle - 1540), in: Zeremoniell und Raum, hg. von Werner Paravicini (Residenzenforschung, 6) Sigmaringen 1997, S. 279-304.

Borchert, Till-Holger s. Karl der Kühne - Kunst, Krieg und Hofkultur, 2008.

- s. Staging the Court of Burgundy, 2013.

Born, Robert, Les Croy, Brüssel 1981.

- Les Lalaing. Une grande «mesnie» hennuyère, de l'aventure d'Outrée au siècle des Gueux (1096-1600), Brüssel 1986.

Boulton, D'Arcy J.D., The knights of the crown. The monarchical orders of knighthood in later medieval Europe (1325-1520), 2. verbesserte Aufl., Woodbrigde 2000.

- The order of the Golden Fleece and the Creation of Burgundian National Identity, in: The Ideology of Burgundy, 2006, S. 21-98.

- s. Ideology of Burgundy, 2006.

BraAke, Serge ter, Parties and Factions in the late Middle Ages: the Case of the Hoeken and Kabeljauwen in The Hague (1483-1515), in: Journal of Medieval History 35 (2009) S. 97-111.

Brachmann, Christoph, Tod und Bestattung Karls des Kühnen, in: Karl der Kühne Kunst, Krieg und Hofkultur, 2008, S. 340-343.

- «A la fois qui tout veult, tout pert.»Karls Nachleben in der Propaganda des lothringischen Hofes, in: Karl der Kühne von Burgund, 2010, S. 303-326.

Briquet, Charles M., Les Filigranes. Dictionaire historique des marques de papier dès leur apparition vers 1282 jusqu'en 1600, 4 Bde., Paris 1907.

Brown, Andrew s. Court and Civic Society, 2007.

- Civic Ceremony and Religion in Medieval Bruges c. 1300-1520, Cambridge 2011.

BRUCHET, Max s. Inventaire sommaire, 1921.

Bruges à Beaune - Marie, l'héritage de Bourgogne, [à l'occasion de l'Exposition Bruges à Beaune - Marie, l'Héritage de Bourgogne; présentée à Beaune à la porte Marie de Bourgogne et à l'Hôtel-Dieu du 18 novembre 2000 au 28 février 2001], hg. von Florence Jakubowicz, Paris 2000.

Burgund, Niederlande und Österreich (14.-16. Jahrhundert): Interkulturelle Kontakte und Konflikte - Pays bourguignons et autrichiens $\left(\mathrm{XIV}^{\mathrm{e}}-\mathrm{XVI}^{\mathrm{e}}\right.$ siècles): une confrontation institutionelle et culturelle, hg. von Jean-M. CAUCHIES und Heinz Noflatscher, (PCEEB 46) Neuchâtel 2006.

Buren-Hagopian, Anne van, Images monumentales de la Toison d'or: aux murs du château de Hesdin et en tapisserie, in: Ordre de la Toison d'or, 1996, S. 226-233. 
A la búsqueda del Toisón de oro. La Europe de los Principes. La Europa de las cuidades, hg. von Eduardo Mira und An Delva, 2 Bde. (Ausstellungskatalog und Aufsatzband), Valencia 2007.

CARon, Marie-Thérèse, La noblesse dans le duché de Bourgogne (1315-1477), Lille 1987.

- Le banquet dans la mémoire collective: la vision des chroniqueurs, in: PCEEB 47 (2007) S. 9-22.

CARton, C., Het boeck van al't gene datter gheschiedt is binnen Brugghe sichtent jaer 1477, 14 Februarii, tot 1491, (Maetschappy der Vlaemsche Bibliophilen, 3/2) Gent 1859.

Catalogue général des manuscrits des bibliothèques publiques de France, Bd. 26, Paris 187 (=Cat. gén. mss. bibl. publ. France).

Cauchies, Jean-Marie s. Mémoires conflictuelles et mythes, 2012.

- s. Burgund, Niederlande und Österreich, 2006.

CÉLÉrIER, Max, Regards sur la symbolique de la Toison d'or, Dijon 1990.

Charavay, Etienne s. Lettres Louis XI, 1883-1909.

Châtellier, Louis, Georg von Baden, in: Die Bischöfe des Heiligen Römischen Reichs (1448-1648). Ein biographisches Lexikon, hg. von Erwin GATz, Berlin 1996, S. 219 f.

Chauney-Bouillot, Martine s. Fondation et rayonnement de l'Ordre de la Toison d'or, 2008.

Checa Cremades, Fernando s. La Orden del Toisón de Oro, 2011.

Chesshyre, Hubert s. Order of the Garter, 1999.

Les chevaliers de l'ordre de la Toison d'or au XVe siècle: notices bio-bibliographiques, hg. von Raphaël DE SMEdT (Kieler Werkstücke, D 3), 2., verbesserte Auflage, Frankfurt 2000.

Cheyns-Condé, Myriam, La tapisserie à la cour de Bourgogne. Contribution d'un art mineur à la grandeur d'une dynastie, in: PCEEB 25 (1985) S. 73-89.

Chmel, Joseph, Regesta chronologico-diplomatica Friderici IV. Romanorum Regis, Wien 1838.

- Aktenstücke und Briefe zur Geschichte des Hauses Habsburg im Zeitalter Maximilian's I. aus Archiven und Bibliotheken, 3 Bde., (Monumenta Habsburgica, 1. Abtheilung), unveränd. ND nach Wien 1854-1858, Hildesheim 1968.

Christyn, Johannes B., Jurisprudentia heroica sive De jure Belgarum circa nobilitatem et insignia demonstrato in commentario ad edictum ... Alberti et Isabellae emulgatum 14. Decembris 1616, Brüssel 1668.

Chroniques de Jean Molinet, hg. von Georges Doutrepont und Omer Jodogne, 3 Bde., Brüssel 1935-1937.

Chronique des Faits et Gestes admirables de Maximilien I durant son mariage avec Marie de Bourgogne. Translatee du Flamand en français par Octave DelepierRe, Brüssel 1839.

Clément, José, Antoine de Bourgogne, dit le Grand bâtard, in: PCEEB 30 (1990) S. $165-182$. 
[Clèves] Entre la ville, la noblesse et l'État: Philippe de Clèves (1456-1528), homme politique et bibliophile, hg. von Jelle HaEmers, Hanno Wijsman und Céline van Hoorebeeck (Burgundica 13), Tournhout 2007.

Cockshaw, Pierre, Prosopographie des secrétaires de la cour Bourgogne (1384-1477), (Instrumenta, 16) Ostfildern 2006.

- s. Ordre de la Toison d'or, 2013.

Collins, Hugh E.L., The Order of the Garter 1348-1461. Chivalry and politics in late medieval England, Oxford 2000.

Colleville, Ludovic de/Saint-Christo, François de, Les ordres du roi. Répertoire général contenant les noms et qualités de tous les chevaliers des Ordres royaux, militaires et chevaleresques ayant existé en France de 1099 à 1830. Avec une histoire des Ordres du Saint-Esprit, de Saint-Michel, de Saint Louis etc., Paris o. J. [1925].

Colberg, Katharina, Der Eid des Königs. Kaiser Siegmund und das „Schwurverbot“, in: Staat und Gesellschaft in Mittelalter und Früher Neuzeit. Gedenkschrift für Joachim Leuschner, hg. von Katharina Colberg, Hans-Heinrich Nolte, Herbert Obenaus, Göttingen 1983, S. 92-118.

Colot, Louis, Jacques de Savoie, comte de Romont, homme ligne de la maison de Bourgogne, in: PCEEB 20 (1980) S. 89-102.

Commies, Aly, Nul ne s'y frote. Een biographische schets van Anton, Bastaard van Bourgondie, in: Excursiones mediaevales. Opstellen angeboden aan Prof. Dr. A. G. Jongkees door zijn leerlingen, Groningen 1979, S. 59-76.

Commynes, Philippe s. Mémoires de Comines, 1747.

Contamine, Philippe, L'ordre de Saint-Michel au temps de Louis XI et Charles VIII, in: Bulletin de la Société nationale des antiquaires de France, 1976 (Paris 1978) S. 212-238.

- Michaelsorden, in: LexMa 6 (1993) Sp. 607.

Cools, Hans, Mannen met macht. Edellieden en de Moderne Staat in de BourgondischHabsburgse landen, ca. 1475-1530, Zutphen 2001 [Diss. phil., Amsterdam 2001].

- Quelques considérations sur l'attitude des nobles comtois entre 1477 et 1500, in: PCEEB 42 (2002) S. 164-184.

- Quelques hommes de cour originaires des pays germaniques aux Pays-Bas à l'époque de Maximilian ${ }^{\mathrm{er}}$, in: Burgund, Niederlande und Österreich, 2006, S. 161-170.

- Edellieden en verschuivende grenzen. Enkele overwegingen over de Franche-Comté tussen 1477 en 1500, in: Staatsvorming onder Bourgondiërs en Habsburgers. Theorie en praktijk, hg. von J. GeurTs und H. de SchePper, Maastricht 2006, S. 113-125.

Het Coudenberpaleis te Brussel. Van middeleeuws kasteel tot archeologische site, hg. v. Vincent Heymans u. a., Brüssel 2014.

Court and Civic Society in the Burgundian Low Countries c. 1420-1530. Selected sources translated and annotated with an introduction, hg. von Andrew Brown and Graeme SMALL, Manchester 2007.

DAmme, Jozef van, Adolf van Kleef en van Mark, Heer van Ravenstein, in dienst van de Bourgondische politiek, 3 Bde. (masch)., Löwen 1967. 
Dauphant, Léonard, Les 700 pensionnaires de Louis XI. Étude et édition d'un rôle de 1481, in: Annuaire-Bulletin de la Société de l’Histoire de France 2011 [2015], S. $20-77$.

Debris, Cyrille, Tu, felix Austria, nube. La dynastie de Habsbourg et sa politique matrimoniale à la fin du Moyen Âge (XIII ${ }^{\mathrm{e}}-\mathrm{XVI}^{\mathrm{e}}$ siècles) (Histoire de famille. La parenté du Moyen Âge, 2) Turnhout 2005.

DÉBRY, Jacques, Claude de Neufchâtel. Dans la tourmente bourguignonne une fidélité sans faille, in: De orde van het Gulden Vlies te Mechelen in 1491, 1992, S. 201-257.

Delepierre, Octave s. Chronique de Maximilien I, 1839.

- Fête de la Toison d'or, célébrée à Bruges en 1478, in: Annales de la société d'émulation pour l'histoire et les antiquités de la Flandre occidentale 4 (1842) S. 333-346.

Dehaisne, Chrétien s. IADNB, 1881.

Delmaire, Bernhard, Thérouanne, in: LexMA 8 (1997) Sp. $679 \mathrm{f}$.

Delva, An s. Búsqueda del Toisón de oro, 2007.

- El $7^{\circ}$ capítulo de la Orden del Toisón de Oro, Gante 1445, in: Búsqueda del Toisón de oro, 2007, Aufsatzband, S. 227-237 und engl. Übers. (The $7^{\text {th }}$ chapter of the Order of the Golden Fleece, Ghent 1445) S. 577-582.

Demotz, Bernard, Amadeus VIII., in: LexMA 1 (1980) Sp. $502 \mathrm{f}$.

- Philibert I., Hz. von Savoyen, in: LexMA 6 (1993) Sp. 2055.

Despars, Nicolas, Chronycke van den landen ende graefscepe van Vlaenderen (4051492), 2. Ausgabe, hg. von Johann de Jonghe, Bd. 4 (1467-1492), Rotterdam 1840.

Devillers, Léopold, Les séjours des ducs de Bourgogne en Hainaut. 1427-1482, in: Bulletin de la Commission royale d'histoire 4, 6 (1879) S. 323-468.

Devliegher, Luc, De Sint-Salvatorskatedraal te Brugge. Inventaris (Kunstpatrimonium van West-Vlaanderen, 8) Tielt/Amsterdam 1979.

DíEz, Carlos Estepa, Política matrimonial en el siglo XV. El Ducado de Borgoña, los reinos ibéricos y el Imperio, in: „Das kommt mir spanisch vor.“ Eigenes und Fremdes in den deutsch-spanischen Beziehungen des späten Mittelalters, hg. von Klaus Herbers und Nikolas JASPERT, Münster 2004, S. 65-85.

Docouier, Gilles, D'or et d'émail. Les colliers des chevaliers de la Toison d'or durant la période burgondo-habsbourgeoise, in: Fondation et rayonnement de l'Ordre de la Toison d'or, 2008, S. 27-50.

- Le collier de l'ordre de la Toison d'or et ses représentations dans la peinture des Primitifs flamands ( $\mathrm{XV}^{\mathrm{e}}$ et première moitié du $\mathrm{XVI}^{\mathrm{e}}$ siècle), in: Annales de Bourgogne 80 (2008) S. 125-162.

- «L'heure du légitime tribut sonne pour Bruges » revendications brugeoises autour de l'ordre de la Toison d'or, in: Mémoires conflictuelles, 2012, S. 251-267.

Doutrepont, Georges s. Chroniques de Molinet, 1935-1937.

Dubois, Henri, Charles le Téméraire, Paris 2004.

Dücker, Jutta, Von Konfrontation und Kooperation - Matthias Corvinus und die Reichstage der Jahre 1479 bis 1481, in: Matthias Corvinus und seine Zeit. Europa am Übergang vom Mittelalter zur Neuzeit zwischen Wien und Konstantinopel, 
hg. von Christian Gastgeber, Ekaterini Mitsiou, Ioan Pop u. a. (Veröffentlichungen zur Byzanzforschung, 27) Wien 2011, S. 23-32.

Dünnebeil, Sonja, s. Stein, Catalogue des Actes, 1999.

- Soziale Dynamik in spätmittelalterlichen Gruppen, in: Menschenbilder Menschenbildner. Individuum und Gruppe im Blick des Historikers, hg. von Ulf C. Ewert und Stephan Selzer (Hallische Beiträge zur Geschichte des Mittelalters und der Frühen Neuzeit, 2), Berlin 2002, S. 153-175.

- Öffentliche Selbstdarstellung sozialer Gruppen in der Stadt, in: Memoria, Communitas, Civitas, hg. von Hanno Brand, Pierre Monnet und Martial Staub (Beihefte der Francia, 55), Ostfildern 2003, S. 71-84.

- Umzug und Tanz als Formen der >bewegten< Repräsentation, in: Geschlechtergesellschaften, Zunft-Trinkstuben und Bruderschaften in spätmittelalterlichen und frühneuzeitlichen Städten, hg. von Gerhard FouQuet, Matthias SteInbrink und Gabriel Zeilinger (Stadt in der Geschichte, 30), Stuttgart 2003, S. 129-145.

- Innen und Außen bei den Festen des Ordens vom Goldenen Vlies unter den Herzögen von Burgund, in: Virtuelle Räume. Raumwahrnehmung und Raumvorstellung im Mittelalter, hg. von Elisabeth VAVRA, Berlin 2005, S. 239-257.

- Der Orden vom Goldenen Vlies zwischen Burgund und dem Hause Österreich, in: Burgund, Niederlande und Österreich, 2006, S. 13-30.

- s. Protokollbücher, 2003 ff.

- Die Entwicklung des Ordens unter den Burgunderherzögen (1430-1477), in: Das Haus Österreich und der Orden vom Goldenen Vlies, 2007, S. 13-36.

- s. Das Haus Österreich und der Orden vom Goldenen Vlies, 2007.

- Schatz, Repräsentation und Propaganda am Beispiel Burgunds, in: Vom Umgang mit Schätzen, hg. von Elisabeth VAVRA (Veröffentlichungen des Instituts für Realienkunde des Mittelalters und der Frühen Neuzeit, 20), Wien 2007, S. 301-318.

- s. Außenpolitisches Handeln, 2008.

- Handelsobjekt Erbtochter - Die Verhandlungen um die Verehelichung Marias von Burgund, in: Außenpolitisches Handeln, 2008, S. 159-184.

- Der Orden vom Goldenen Vlies und die Beherrschung des Adels - Karl als Herr oder Ordensbruder? in: Karl der Kühne von Burgund, 2010, S. 171-183.

- Die Rolle Burgunds: Karl der Kühne - Friedrich III., in: Der Trierer Reichstag von 1512 in seinem historischen Kontext. Ergebnisse der Trierer Tagung vom 19.-21.10.2012, hg. von Michael Емвасн und Elisabeth DüHR, Trier 2012, S. 69-87.

- Der Orden vom Goldenen Vlies als Zeichen der burgundischen Einheit. Ideal oder Wirklichkeit unter Maximilian I.? in: PCEEB 52 (2012) S. 111-127.

- The Order of the Golden Fleece in the year 1478 - continuity or recommencement? in: Staging the Court of Burgundy, 2013, S. 59-65.

- Die Gründung des Ordens vom Goldenen Vlies 1430, Sammlung ÖsterreichEdition 4, Braunschweig 2013.

- Die Aufnahme Philipps des Schönen in den Orden vom Goldenen Vlies, in: PCEEB 54 (2014) S. 77-91. 
- Mary, the "diplomatic Weapon of Universal Value" of Charles the Bold, in: Mary of Burgundy: The Reign, the 'Persona' and the Legacy of a European Princess, Brussels and Bruges, hg. von Michael Depreter, Jonathan Dumont, Elizabeth L'Estange, Samuel MAREEL (in Vorbereitung)

- Auf der Suche nach dem Goldenen Vlies, dem Adler und Drachen. Kaiser Friedrich III. und die Ritterorden seiner Zeit, in: Der Kaiser und sein Grabmal. Interdisziplinäre Forschungen zum Hochgrab Kaiser Friedrichs III. im Wiener Stephansdom, hg. von Renate KoHn und Sonja DünNebeIL (in Vorbereitung).

Dumolyn, Jan, Justice, Equity and Common Good: The State Ideology of the Councilors of the Burgundian Dukes, in: The Ideology of Burgundy, 2006, S. 1-20.

Dumont, Georges-H., Marie de Bourgogne, Brüssel ${ }^{3} 1943$.

Dumont, Jean de, Corps universel diplomatique du droit des gens contenant un recueil des traitez d'alliance, de paix, de trêve, de neutralité, de commerce, d'échange, de protection \& garantie, de toutes les Conventions, Transactions, Pactes, Concordats \& autres Contrats qui ont été faits en Europe, depuis le règne de l'Empereur Charlemagne jusques à présent, 8 Bde., Amsterdam/'s-Gravenhage 1726-1731.

Eнм-Schnоскs, Petra, Burgund und das Reich. Spätmittelalterliche Außenpolitik am Beispiel der Regierung Karls des Kühnen (1465-1477) (Pariser Historische Studien, 61), München 2002.

- „... und begeret ein kunig zu werden“. Beobachtungen zu einem Herrschertreffen. Friedrich III. und Karl der Kühne in Trier 1473, in: Auswärtige Politik und internationale Beziehungen im Mittelalter (13.-16. Jahrhundert), hg. von Dieter Berg, Martin Kintzinger und Pierre Monnet, (Europa in der Geschichte, 6) Bochum 2002, S. 233-258.

- s. Recueil du Fay, 2003.

- Der Tag von Trier 1473 und die Grenze des Reiches: Karl der Kühne, Friedrich III. und die Kurfürsten, in: Außenpolitisches Handeln, 2008, S. 143-158.

EIchberger, Dagmar, Tapestry production in the Burgundian Netherlands, art for export and pleasure, in: Australian Journal of Art 10 (1992) S. 23-43.

- Margreta of Austria. A Princess with Ambition and Political Insight, in: Women of Distinction. Margaret of York - Margaret of Austria, hg. von derselben, Turnhout 2005, S. 49-55.

Eichmann, Eduard, Die Kaiserkrönung im Abendland. Ein Beitrag zur Geistesgeschichte des Mittelalters, mit besonderer Berücksichtigung des kirchlichen Rechts, der Liturgie und der Kirchenpolitik, 2 Bde., Würzburg 1942.

Eubel, Konrad s. Hierarchia catholica.

Europäische Stammtafeln. Stammtafeln zur Geschichte der europäischen Staaten, hg. von Detlef Schwennicke, Neue Folge, 25 Bde., Marburg 1980-2007 (= ES).

Fichtenau, Heinrich, Der junge Maximilian (1459-1482), (Österreich Archiv, Schriftenreihe des Arbeitskreises für österreichische Geschichte) Wien 1959.

Fillastre, Guillaume, Ausgewählte Werke. Mit einer Edition der Kreuzzugsbulle Pius' II. »Ezechielis prophete «, hg. von Malte Prietzel (Instrumenta, 11), Ostfildern 2003.

FILlitz, Hermann, Der Schatz vom Orden vom Goldenen Vlies, Salzburg, Wien 1988. 
- Der Schatz vom Orden vom Goldenen Vlies, in: Schätze der burgundischen Hofkunst, 2009, S. 39-54.

Finot, Jules s. IADNB, 1881.

Fondation et rayonnement de l'Ordre de la Toison d'or. Colloque organisé à l'occasion du Chapitre de la Toison d'or, Dijon, 30 novembre $-1^{\text {er }}$ décembre 2007, par l'Académie des sciences, arts et belles-lettres de Dijon, hg. von Martine CHAunEYBouillot (Mémoires l'Académie des sciences, arts et belles-lettres de Dijon, 142bis), Dijon 2008.

Franke, Birgit, Feste, Turniere und städtische Einzüge, in: Kunst der burgundischen Niederlande, 1997, S 65-84.

- Tapisserie - »portable grandeur « und Medium der Erzählkunst, in: Ibid. S. 121-140.

- s. Kunst der burgundischen Niederlande, 1997.

FugGer, Johann Jakob, Spiegel der Ehren des Hoechstloeblichsten Kayser- und Koeniglichen Erzhauses Oesterreich, bearb. von Sigmund von BIRKEN, Nürnberg 1668.

GABriËLS, Nele s. Staging the Court of Burgundy. 2013

Gachard, Louis Prosper s. BARAnte/Gachard, Histoire, 1838

- Ordonnance et état de la maison de Maximilien, duc d'Autriche et de Bourgogne (septembre 1477), in: Ders., Analectes historiques 5, in: Compte rendu des séances de la Commission royale d'Histoire, 2. Ser., 9 (1857) S. 103-256, hier S. 117-127, Nr. 163.

Gaillard, Artus, Inventaire des mémoriaux du Grand Conseil de Malines, Bd. 1, Brüssel 1900.

Gellinck de VAernewyck, Bibliographie de l'ordre de la Toison d'or, in: Bulletin de l'Académie royale d'archéologie de Belgique 1 (1907) S. 212-276.

- L'ordre de la Toison d'or et l'exposition de Bruges, in: Ibid. S. 183-211.

Gent, Michel J. van, Pertijelike saken. Hoeken en kabeljauwen in het BougondischOostenrijkse tijdperk (Hollandse Historische Reeks, 22), Leiden 1994.

Gesamtinventar des Wiener Haus-, Hof- und Staatsarchivs, hg. von Ludwig BitTNER, Bd. 4 (Inventare österreichischer staatlicher Archive, Reihe 5: Inventare des Wiener Haus-, Hof- und Staatsarchivs, 7), Wien 1938.

Gingins-La SARra, F. de, Recherches historiques sur les acquisitions des Sires de Montfaucon et de la Maison de Chalon dans le Pays-de-Vaud, Lausanne 1857.

Glaser, Birgit Charlotte s. Das Haus Österreich und der Orden vom Goldenen Vlies.

Glezerman, Abraham/Harsgor, Michael, Cleve - ein unerfülltes Schicksal. Aufstieg, Rückzug und Verfall eines Territorialstaates, (Historische Forschungen, 26) Berlin 1985.

Godefroy, Denis s. Mémoires de Comines, 1747.

Goossenaerts, Jonas, Charles the Bold's Ten Days of Marriage Celebration. Material Culture as a Means of Political Communication between Duke and City Council, in: Staging the Court of Burgundy, 2013, S. 97-104.

Gruben, Françoise de, Les chapitres de la Toison d'or vus par les chroniqueurs à l'époque bourguignonne, in: PCEEB 31 (1991) S. 127-137. 
- Les chapitres de la Toison d'or à l'époque bourguignonne (1430-1477) (Mediaevalia Lovaniensia, 1, 23), Löwen 1997.

Giustiniani, Vito R., Francesco Filelfo, in: LexMA 4 (1989) Sp. $444 \mathrm{f}$.

HAAG, Sabine s. Schätze der burgundischen Hofkunst, 2009.

НавLот, Laurent, Revêtir le prince. Le héraut en tabard, ung image idéale du prince. Pour une tentative d'interprétation du partage emblématique entre prince et héraut à la fin du Moyen Âge à travers le cas bourguignon, in: Le héraut, figure européenene (XIV $-\mathrm{XVI}^{\mathrm{e}}$ siècle), hg. von Bertrand Schnerb, Revue du Nord 88 (2006) S. 755-803.

Haemers, Jelle s. Philippe de Clèves, 2007.

- For the common Good: State Power and Urban Revolts in the Reign of Mary of Burgundy (1477-1482), (Studies in European urban history, 17) Turnhout 2009.

- s. Lievois / Haemers, Maria, 2014.

Hamilton, Andrew, The Art of Embroidery in the Burgundian Paraments of the Order of Golden Fleece, in: Staging the Court of Burgundy, 2013, S. 149-157.

HARLESS, Woldemar: Johann II. (Herzog von Kleve-Mark), in: ADB 14 (1881) S. 210-213.

Harsgor, Michael s. Glezerman/Harsgor, Cleve, 1985.

Häussling, Angelus, Te Deum, in: LexMA 8 (1997) Sp. 516.

Das Haus Österreich und der Orden vom Goldenen Vlies. Beiträge zum wissenschaftlichen Symposium am 30. November und 1. Dezember 2006 in Stift Heiligenkreuz, hg. von der Ordenskanzlei, redigiert von Leopold AuER, Sonja Dünnebeil, Birgit Charlotte Glaser und Alexander Pachta-Reyhofen, Graz 2007.

Heinig, Paul J., Kaiser Friedrich III. (1440-1493): Hof, Regierung und Politik, 3 Bde., (Forschungen zur Kaiser- und Papstgeschichte des Mittelalters, Beihefte zu J. F. Böhmer, Regesta Imperii, 17) Köln/Weimar/Wien 1997.

- Friedrich III., in: Höfe und Residenzen im spätmittelalterlichen Reich: ein dynastischtopographisches Handbuch. Teilbd. 1. Dynastien und Höfe, hg. von Werner Paravicini, Jan Hirschbiegel und Jörg Wettlaufer, (Residenzenforschung 15/1) Ostfildern 2003, S. 341-350.

- Kaiser, Reich und Burgund. Habsburgs „neue Weltpolitik“ im 15. Jahrhundert, in: Zeitschrift des Aachener Geschichtsvereins 106 (2004) S. 55-76.

- Akteure und Mediatoren burgundisch-österreichischer Beziehungen im 15. Jahrhundert, in: Burgund, Niederlande und Österreich, 2006, S. 115-144.

Heinrich, Gerd, Albrecht Achilles, in: LexMa 1 (1980) Sp. $317 \mathrm{f}$.

Hemptinne, Thérèse de s. Boone/Hemptinne, Espace, 1997.

Heuterus, Pontus, Opera historica omnia; Burgundica, Austriaca, Belgica ... Insertus est ejusdem de vetustate et nobilitate familiae Habspurgicae et Austriacae liber singularis, Löwen 1643.

Heymans, Vincent s. Coudenberpaleis, 2014.

Hezenmans, J.C.A., De St. Jans-Kerk te 's-Hertogenbosch en hare geschiedenis, 's-Hertogenbosch 1866.

Hierarchia catholica, hg. von Konrad EubeL, Bd. 2, Münster 1914. 
Hillewaert, Bieke, The Bruges Prinsenhof: Absence of Splendour, in: Staging the Court of Burgundy, 2013, S. 25-31.

Het princelijk Hof ten Walle in Gent, hg. von Marie Christine Laleman, Gent 2000.

Hoheneck, Johann G.A. von, Die löblichen Herren Herren Stände, des ErzHertzogthumb Oesterreich ob der Enns als Pälaten, Herren, Ritter und Städte oder Genealog und historische Beschreibung von deroselben Ankunft, Stifft, Erbau- und Fortpflanzung, Wapen, Schild und Helmen, ihren Clöstern, Herrschaften, Schlösser und Städten etc., Teil 2, Passau 1732.

Hollegger, Manfred, Maximilian I. (1459-1519). Herrscher und Mensch einer Zeitwende, Stuttgart 2005.

- Burgundische Regierungs-, Verwaltungs- und Finanztechniken in Österreich? Zum Institutionentransfer um 1500, in: Burgund, Niederlande und Österreich, 2006, S. 91-104.

- Persönlichkeit und Herrschaft. Zur Biografie Kaiser Maximilians, in: Kaiser Maximilian I. und die Kunst der Dürerzeit, hg. von Eva Michel und Marie Luise SternAth, München/London/New York 2012, S. 23-35.

Hollweg, Walter, Dr. Georg Heßler. Ein kaiserlicher Diplomat und römischer Kardinal des 15. Jahrhunderts. Versuch einer Biographie, Leipzig 1907.

Holtz, Eberhard, Friedrich I., Kurfürst von der Pfalz (1449-1476), in: Deutsche Fürsten des Mittelalters. Fünfundzwanzig Lebensbilderm hg. von dems. und Wolfgang Huschner, Leipzig 1995, S. 370-382.

Holzner-Tobisch, Kornelia s. Regesten Kaiser Friedrich III.

Holzschum-Hofer, Renate, Feuereisen im Dienst politischer Propaganda von Burgund bis Habsburg. Zur Entwicklung der Symbolik des Ordens vom Goldenen Vlies von Herzog Philipp dem Guten bis Kaiser Ferdinand I., in: RIHA Journal 6 (2010). [http://www.riha-journal.org/articles/2010/holzschuh-hofer-feuereisen-imdienst-politischer-propaganda]

Hommel, Luc, Marie de Bourgogne ou Le grand héritage, Brüssel ${ }^{2} 1945$.

Hoorebeeck, Céline van, A l'ombre de la librairie de Bourgogne: les livres de Martin Steenberch, secrétaire ducal $(† 1491)$, in: Revue belge de philologie et d'histoire. Belgisch tijdschrift voor philologie en geschiedenis 84 (2006) S. 307-363.

- s. Philippe de Clèves, 2007.

Hugenholtz, Frederik W.N., The 1477 crisis in the Burgundian duke's dominions, in: Britain and the Netherlands, hg. von John S. Bromley und Ernst H. Kossmann, Bd. 2, Groningen 1964, S. 33-46.

The Ideology of Burgundy. The Promotion of National Consciousness, 1364-1565, hg. von Jonathan Boulton und Jan Veenstra, (Brill's Studies in Intellectual History, 145) Leiden 2006.

Instructions pour la publication des textes historiques, hg. von der Commission royale d'histoire, Brüssel 1985.

Inventaire sommaire des Archives départementales antérieures à 1790. Nord. Archives civiles. Série B. Chambre des Comptes de Lille, Bd. 1, hg. von Chrétien Dehaisne und Jules Finot, Lille 1906; Bd. 4, hg. von Chrétien DeHAisne, Lille 1881 (= IADNB). 
Inventaire sommaire des Archives départementales antérieures à 1790. Nord. Archives civiles. Répertoire numérique, Série B (Chambre des Comptes de Lille), hg. von Max BRUChet, Lille 1921.

Jakubowicz, Florence s. Marie, l'héritage de Bourgogne, 2000.

Jefferson, Lisa S. Payne/Jefferson, Edward IV, 1996.

Jodogne, Omer s. Chroniques de Jean Molinet, 1935-1937.

Jones, Girard G., The order of the Golden Fleece: form, function and evolution (14301555), Diss. masch., Arlington 1988.

Jones, Michael, Hosenbandorden, in: LexMA 5 (1991) Sp. $131 \mathrm{f}$.

Jonge, Krista de, Het Paleis op de Coudenberg te Brussel in de vijftiende eeuw. De verdwenen hertogelijke residencies in de Zuidelijke Nederlanden in een nieuw licht geplaatst, in: Revue belge d'archéologie et d'histoire de l'art 60 (1991) S. 5-38.

Jonghe, Johann de s. Despars, Chronycke van Vlaenderen.

Just, Thomas, Burgund und das Haus Österreich im 15. Jahrhundert, in: Schätze der burgundischen Hofkunst, 2009, S. 15-38.

KAISER, Reinhold, Die Burgunder, (Kohlhammer Urban-Taschenbücher, 586) Stuttgart 2004.

KALFF, Johannes F., Funktion und Bedeutung des Ordens vom Goldenen Vlies in Spanien vom 16. bis zum 20. Jahrhundert. Ein Beitrag zur allgemeinen Ordensgeschichte, Diss phil. masch., Bonn 1963.

Karl der Kühne (1433-1477) - Kunst, Krieg und Hofkultur, hg. von Susan MarTI, Till-Holger Borchert und Gabriele Keск, Ausstellungskatalog des Historischen Museums Bern und des Bruggemuseum \& Groeningemuseum Brügge, Bern/ Brüssel/Brügge 2008.

Karl der Kühne von Burgund. Fürst zwischen europäischem Adel und der Eidgenossenschaft, hg. von Klaus Oschema und Rainer C. Schwinges, Zürich 2010.

Keск, Gabriele s. Karl der Kühne - Kunst, Krieg und Hofkultur, 2008.

Kerckhoffs-De Hey, Alida J.M., De Grote Raad en zijn funtionarissen 1477-1531, Teil 1: Darstellung; Teil 2: Biografieën van raadsheren, Amsterdam 1980.

Kervyn de Lettenhove, Joseph B.C., Histoire de Flandre, Bd. 5: Ducs de Bourgogne (1453-1500), Brüssel 1850.

- La Toison d'or: notes sur l'institution et l'histoire de l'ordre, Brüssel 1907.

Kintzinger, Martin, Der weiße Reiter, Formen der internationalen Politik im Spätmittelalter, in: Frühmittelalterliche Studien 37 (2003) S. 315-353.

- Caesar, der Staat und die Nation. Die Außenpolitik Karls des Kühnen, in: Karl der Kühne von Burgund, 2010, S. 124-152.

Kirchweger, Franz s. Schätze der burgundischen Hofkunst, 2009.

- Die Schatzkunst am Hof der burgundischen Herzöge und das Haus Habsburg, in: Schätze der burgundischen Hofkunst, 2009, S. 55-80.

KoHLER, Alfred, Expansion und Hegemonie. Internationale Beziehungen 1450-1559, (Handbuch zur Geschichte der Internationalen Beziehungen, 1) Paderborn/München/Wien/Zürich 2008. 
Koller, Fortuné, Au service de la Toison d'or (les officiers), Dison 1971.

Koller, Heinrich, Kaiser Friedrich III. (Gestalten des Mittelalters und der Renaissance) Darmstadt 2005.

Kondo, Hisara, Les statuts de l'ordre de la Toison d'or d'après le manuscrit KB 76 E 14 de La Haye, in: Bulletin of Takaoka College of Law 12 (2001) S. 84-124.

Korteweg, Anne S., Un présent offert au chapitre de 1473: le livre des statuts avec armorial, La Haye, KB, Hs. 76 E 10, in: Ordre de la Toison d'or, 1996, S. 50-55.

- La location des sièges des chevaliers dans les stalles des églises de 1431 à 1491, in: Ibid. S. 209-220.

KrAFFT, Jean-Laurent, L'Histoire générale de l'auguste maison d'Autriche, Bd. 1, Brüssel 1744.

Kraus, Victor von (Hg.), Maximilians I. vertraulicher Briefwechsel mit Sigmund Prüschenk Freiherrn zu Stettenberg nebst einer Anzahl zeitgenössischer das Leben am Hofe beleuchtender Briefe, Innsbruck 1875.

KrIEger, Karl-Friedrich, Friedrich I. der Siegreiche, in: LexMA 4 (1989) Sp. 955.

Kunde, Anne K., Antipoden der Macht. Anspruch und Legitimität im Verhältnis von König Matthias von Ungarn und Kaiser Friedrich III., in: Tagungsband zur Tagung „Legitimiert durch Repräsentation?“ Kulturelle Integrationsstrategien von Außenseitern und Aufsteigern in Mitteleuropa vom 14. bis 18. Jahrhundert. Am Geisteswissenschaftliches Zentrum Geschichte und Kultur Ostmitteleuropas an der Universität Leipzig, Leipzig, 7./8. Dezember 2007 (im Druck).

- s. Regesten Kaiser Friedrich III.

Kunst der burgundischen Niederlande: eine Einführung, hg. von Birgit Franke und Barbara Welzel, Berlin 1997.

Kuyer, P.Th.J., Het veertiende kapittel van de Orde van het Gulden Vlies te 's-Hertogenbosch in mei 1481, in: Het Gulden Vlies. 's-Hertogenbosch ten tijde van het $14^{\mathrm{e}}$ Kapittel van het Gulden Vlis, 1481, hg. von Peter-Jan van Der Heijden, Jozef Hoekx und Jan KLEyne (Hertog Hendrik Reeks, 1) 's-Hertogenbosch 1981, S. 67-86.

LAENEN, Joeseph, Les archives de l'État à Vienne au point de vue de l'histoire de Belgique, Brüssel 1924.

Laleman, Marie Christine s. Hof ten Walle, 2000.

Langenn, Friedrich A. von, Herzog Albrecht der Beherzte, Stammvater des königl. Hauses Sachsen. Eine Darstellung aus der sächsischen Regenten-, Staats- und Cultur-Geschichte des XV. Jhs. Leipzig 1838.

Laplane, Henri, Les abbés de Saint-Bertin d'après les anciens monuments de ce monastère, Bd. 2, Saint-Omer 1855.

- L'abbaye de Clairmarais d'après ses archives, Bd. 2: Les abbés de Clairmarais, SaintOmer 1868.

LAUREnt, René, Les sceaux des princes territoriaux belges du $\mathrm{X}^{\mathrm{e}}$ siècle à $1482, \mathrm{Bd}$. I, 2 Teile (Katalog) und Bd. 2 (Abb.), (Archives générales du royaume) Brüssel 1993.

- Inventaire des archives de l'ordre de la Toison d'or par E.J. de Turck, in: Ordre de la Toison d'or, 1996, S. 23.

- Les sceaux de l'ordre, in: Ordre de la Toison d'or, 1996, S. 24-30. 
LEE, Egmont, Sixtus IV and Men of Letters, Rom 1978.

LeIDL, August, Heßler, Georg, in: Die Bischöfe des Heiligen Römischen Reichs (14481648). Ein biographisches Lexikon, hg. von Erwin Gatz, Berlin 1996, S. 289-291.

Lemaire, Claudine, "L'arbe d'or" du 22 chapitre de la Toison d'or en janvier 1556 à Anvers, in: Liber Amicorum Raphael de Smedt, Bd. 3: Historia, hg. von Jacques Paviot, (Miscellanea Neerlandica 25) Leuven/Paris 2001, S. 247-258.

- Miradas cruzadas sobre la Orden del Toisón de Oro. La fundación de la Orden del Toisón de Oro. Influencia de la Orden la Jarretera. Los Estatutos, in: Búsqueda del Toisón de oro, 2007, Aufsatzband, S. 65-81 und engl. Übers. (Raw studies of the Order of the Golden Fleece. The Fondation of the Golden Fleece. Influence of the Order of the Garter. The statutes) S. 486-495.

Lenglet-Dufresnoy, Nicolas s. Mémoires de Comines.

Lettres de Louis XI roi de France, hg. von Joseph VAesen und Etienne Charavay, 12 Bde., Paris 1883-1909.

Lettres adressées de Maximilien I (Empereur germanique; 1459-1519) à l'abbé de SaintPierre à Gand (1477-1487), hg. von Jules de SAint-Genois Des Mottes, Gent 1845.

LichNowsky, Eduard M. von, Geschichte des Hauses Habsburg, Bd. 7 und 8, unveränd. ND nach Wien 1843-1844, Osnabrück 1973.

LiEfTINCK, G. I., Een uniek handschrift met een middelnederlandse versie van de statuten van het Gulden Vlies, in: Tijdschrift voor Nederlandse Taal- en Letterkunde 67 (1950) S. 209-214.

LiEz, Jean-Luc s. Toison d'or, 1998.

Lievois, Daniel/Haemers, Jelle, Maria van Bourgondië in Hof ten Walle. Over een jonge prinses en haar Gentse residentie (1465-1475), in: Handelingen van de Maatschappij voor Geschiedenis en Oudheidkunde te Gent 68 (2014), S. 141-163.

Ligne, Charles DE, Mémoires sur l'ordre de la Toison d'or (Mélanges militaires et litteraires, 30), Breda 1808.

Liste nominale des chevaliers de l'ordre de la Toison d'or, depuis son institution jusqu'à nos jours, in: Das Haus Österreich und der Orden vom Goldenen Vlies, 2007, S. 161-198.

MADER, Bernhard, Johann Keller (ca. 1435-1489): Reichsfiskalat und Herrschaftspraxis unter Kaiser Friedrich III., Diss. phil. masch., Mannheim 1991.

MANDrot, Bernard de s. Roye, Chronique scandaleuse.

MARche, Olivier de la s. Mémoires de la MARChe.

MArtens, Maximilian, De Biografie van Lodewijk van Gruuthuse, in: Lodewijk van Gruuthuse. Mecenas en europees diplomaat (ca. 1427-1492), hg. von dems., Brügge 1992, S. 13-45.

Marti, Susan s. Karl der Kühne - Kunst, Krieg und Hofkultur, 2008.

- Maria von Burgund (1457-1482), in: Karl der Kühne - Kunst, Krieg und Hofkultur, 2008, S. $32 \mathrm{f}$.

- Treffen in Trier 1473, in: Karl der Kühne - Kunst, Krieg und Hofkultur, 2008, S. 264-291.

Martínez-Correcher Y Gil s. La Orden del Toisón de Oro, 2011. 
Mazal, Otto, Zur Praxis des Handschriftenbearbeiters (Elemente des Buch- und Bibliothekwesens, 11), Wiesbaden 1987.

MELVILLE, Gert, Rituelle Ostentation und pragmatische Inquisition. Zur Institutionalität des Ordens vom Goldenen Vlies, in: Im Spannungsfeld von Recht und Ritual. Soziale Kommunikation in Mittelalter und Früher Neuzeit, hg. von Heinz DuchHARdT und Gert Melville (Norm und Struktur, 7), Köln 1997, S. 215-271.

- „Un bel office“. Zum Heroldwesen in der spätmittelalterlichen Welt des Adels, der Höfe und der Fürsten, in: Deutscher Königshof, Hoftag und Reichstag im späteren Mittelalter, hg. von Peter Moraw (VuF, 48) Stuttgart 2002, S. 291-321.

- Le „mystère“ de l'ordre de la Toison d'or. Symbole de l'élite aristocratique et instrument du pouvoir du prince au bas Moyen Âge, in: La cour de Bourgogne et l'Europe. Le rayonnement et les limites d'un modèle culturel. Actes du colloque international tenu à Paris les 9, 10 et 11 octobre 2007, hg. von Werner PARAvicini, unter Mitarbeit von Torsten Hiltmann und Frank Viltart, (Beihefte der Francia, 73) Ostfildern 2013, S. 217-228.

Mémoires de messire Philippe Comines, seigneur d'Argenton, où l'on trouve l'histoire des rois de France, Louis XI et Charles VIII, nouvelle édition, hg. von Denis Godefroy und Nicolas Lenglet-Dufresnoy, Bd. 1-4, Paris 1747.

Mémoires d'Olivier de la Marche, maître d'hôtel et capitaine des gardes de Charles de Téméraire, hg. von Henri Beaune und Jules d'Arbaumont, 4 Bde., Paris 1883-1888.

Mémoires conflictuelles et mythes concurrents dans les pays bourguignons (ca 13801580), hg. von Jean-Marie Cauchies und Pit Peporté, (Publications du Centre européen d'études bourguignonnes 52) Neuchâtel 2012.

Menniti Ippolito, Antonio, Riario, in: LexMa 7 (1994) Sp. 802.

Merkley, Paul A., The role of liturgical elements in fifteenth-century ceremonial, in: Chant and its periphery, hg. von Bryan Gillingham und Paul A. Merkley, Ottawa 1998, S. 339-358.

- und Lora L.M. Merkley, Music and patronage in the Sforza court, Turnhout 1999.

MirA, Eduardo, En busca del paradigma peridio, in: Búsqueda del Toisón de oro (2007) Aufsatzband, S. 21-59 und engl. Übers. (The question for the lost paradigm) S. $465-486$.

- s. Búsqueda del Toisón de oro, 2007.

MolÉnAt, Jean-Pierre, Toledo, Alvarez de, in: LexMa 8 (1997) Sp. $848 \mathrm{f}$.

Molinet, Jean s. Chroniques, 1935-1937.

Montero Tejada, Rosa, Manrique, in: LexMa 6 (1993) Sp. 199.

- Pimentel, in: LexMa 6 (1993) Sp. 2161.

Moscati, R., Alfonso II d'Aragona, in: Dizionario Biografico degli Italiani 1 (1960) S. $330 \mathrm{f}$.

Müller, Heribert, Um 1473: Warum nicht einmal die Herzöge von Burgund das Königtum erlangen wollten und konnten, in: Die Macht des Königs. Herrschaft vom Frühmittelalter bis in die Neuzeit, hg. von Bernhard Jussen, München 2005, S. 255-274.

- Der Griff nach der Krone, in: Karl der Kühne von Burgund, 2010, S. 124-152. 
Müller, Mathias F., Der Orden vom Goldenen Vlies und das Haus Habsburg im Heiligen Römischen Reich - Ein (Kultur-)geschichtlicher Rückblick, in: Mitteilungen der Gesellschaft für vergleichende Kunstforschung in Wien, 61. Jg., Heft 3, 2009.

MüNCH, Ernst H. J. von, Maria von Burgund nebst dem Leben ihrer Stiefmutter Margarethe von York, Gemahlin Karls des Kühnen, und allerlei Beiträgen zur Geschichte des öffentlichen Rechts und des Volkslebens in den Niederlanden zu Ende des 15. Jahrhunderts, 2 Bde., Leipzig 1832.

Nehring, Karl, Matthias I. Corvinus, Kg. von Ungarn (1458-1490), in: LexMA 6 (1993) Sp. $402 \mathrm{f}$.

Noflatscher, Heinz, Räte und Herrscher. Politische Eliten an den Habsburgerhöfen der österreichischen Länder 1480-1530, (Veröffentlichungen des Instituts für europäische Geschichte Mainz, Abteilung Universalgeschichte, 161, Beiträge zur Sozial- und Verfassungsgeschichte des Alten Reichs, 14) Mainz 1999.

- Die Heuser Österreich vnd Burgund. Zu den Quellen der Habsburgerhöfe um 1500 oder zu einem historiographischen Stresssyndrom, in: Frühneuzeit-Info 12/2 (2001) S. 32-48.

- Maximilian I., in:Höfe und Residenzen im spätmittelalterlichen Reich: ein dynastischtopographisches Handbuch. Teilbd. 1. Dynastien und Höfe, hg. von Werner Paravicini, Jan Hirschbiegel und Jörg Wettlaufer, (Residenzenforschung 15/1) Ostfildern 2003, S. 351-360.

- s. Burgund, Niederlande und Österreich, 2006.

The most noble Order of the Garter. 650 years, hg. von Peter J. Begent und Hubert Chesshyre, London 1999.

De orde van het Gulden Vlies te Mechelen in 1491, hg. von Raphaël de SMEDT (Handelingen van de koninklijke kring voor oudheidkunde, letteren en kunst von Mechelen 95, 2), Mecheln 1992.

La Orden del Toisón de Oro y sus soberanos (1430-2011), Ausstellungskatalog der Fundación Carlos de Amberes, hg. von Fernando Checa Cremades und MartínezCORrecher y GiL, Madrid 2011.

L'ordre de la Toison d'or de Philippe le Bon à Philippe le Beau (1430-1505): Idéal ou reflet d'une société?, hg. von Pierre Cockshaw und Christiane van BERgenPantens, Brüssel 1996.

Oosterman, Johan s. Staging the Court of Burgundy. 2013

Oosterwijk, Anne van s. Staging the Court of Burgundy. 2013

Ortega Gato, Esteban, Los Enriquez, almirantes de Castilla, in: Publicaciones de la Institución Tello Téllez de Meneses 70 (1999) S. 23-65.

Oschema, Klaus, Freundschaft und Nähe im spätmittelalterlichen Burgund. Studien zum Spannungsfeld von Emotion und Institution (Norm und Struktur, 26), Köln/ Weimar/Wien 2006.

- s. Karl der Kühne von Burgund, 2010.

- Noblesse et chevalerie comme idéologie princière, in: La cour de Bourgogne et l'Europe. Le rayonnement et les limites d'un modèle culturel. Actes du colloque international tenu à Paris les 9, 10 et 11 octobre 2007, hg. Werner PARAvicini unter 
Mitarbeit von Torsten Hiltmann und Frank Viltart, (Beihefte der Francia, 73) Ostfildern 2013, S. 229-252.

OtTner, Christine s. Außenpolitisches Handeln, 2008.

Otway-Ruthren, Annette J., The King's Secretary and the Signet Office in the Fifteenth Century, Cambridge 1939; ND Cambridge 2008.

Pachta-Reyhofen, Alexander s. Das Haus Österreich und der Orden vom Goldenen Vlies.

PAQUET, Jacques, Une ébauche de la nonciature de Flandre au $\mathrm{XV}^{\mathrm{e}}$ siècle: les missions dans les Pays-Bas de Luc de Tolentis, évêque de Sebenico (1462-1484), in: Bulletin de l'Institut historique belge de Rom 25 (1949) S. 27-144.

PAravicini, Werner, Guy de Brimeu. Der burgundische Staat und seine adlige Führungsschicht unter Karl dem Kühnen (Pariser Historische Studien, 12), Bonn 1975.

- Die zwölf »Magnificences« Karls des Kühnen, in: Formen und Funktionen öffentlicher Kommunikation im Mittelalter, hg. von Gerd Althoff (VuF, 51), Stuttgart 2001, S. 319-395.

- Soziale Schichtung und soziale Mobilität am Hof der Herzöge von Burgund, in: Francia 5 (1977) S. 127-182; erneut in: Ders., Menschen am Hof, 2002, S. 371-426.

- Peur, pratiques, intelligences: Formes de l'opposition aristocratique à Louis XI d'après les interrogatoires du connétable de Saint-Pol, in: La France de la fin du XV siècle Apogée et renouveau, hg. von Bernard Chevalier und Philippe Contamine, Paris 1985, S. 183-196; erneut in: Ders., Menschen am Hof, 2002, S. 341-356.

- Die Residenzen der Herzöge von Burgund, 1363-1477, in: Fürstliche Residenzen im spätmittelalterlichen Europa, hg. von Hans PAtze und Werner PARAvicini, (VuF, 36) Sigmaringen 1991, S. 207-263. Erneut in: Ders., Menschen am Hof, 2002, S. $445-506$.

- Kleve, Geldern und Burgund im Sommer 1473. Briefe aus einer verlorenen Korrespondenz, in: Francia 23/1 (1996) S. 53-93; erneut in: Ders., Menschen am Hof, 2002, S. 621-670.

- L'embarras de richesse: comment rendre accessibles les archives financières de la Maison de Bourgogne-Valois, in: Académie Royale de Belgique, Bulletin de Classe des Lettres et des Sciences Morales et Politiques, Serie 6, 7 (1996) S. 21-68; erneut in: Ders., Menschen am Hof, 2002, S. 65-106.

- Ordre et règle. Charles le Téméraire en ses ordonnances de l'hôtel, in: Académie des inscriptions et belles-lettres, comptes-rendus des séances de l'année 1999 (2000) S. 311-359; erneut in: Ders., Menschen am Hof, 2002, S. 671-714.

- Menschen am Hof der Herzöge von Burgund. Gesammelte Aufsätze, hg. von Klaus KRÜGER, Holger KRUSE und Andreas RANFT, Stuttgart 2002.

- Schlichtheit und Pracht: Über König Ludwig XI. von Frankreich und Herzog Karl dem Kühnen von Burgund, in: Principes. Dynastien und Höfe im späten Mittelalter, hg. von Cordula Nolte, Karl-Heinz SpIEss und Ralf-Gunnar WeRLICH (Residenzenforschung, 14), Stuttgart 2002, S. 63-86.

- Deutsche Adelskultur und der Westen im Spätmittelalter. Eine Spurensuche am Beispiel der Wittelsbacher, in: Deutschland und der Westen Europas im Mittelalter, hg. von Joachim Ehlers (VuF, 56), Stuttgart 2002, S. 457-506. 
- « Vernünftiger Wahnsinn » Karl der Kühne, Herzog von Burgund (1433-1477), in: Karl der Kühne - Kunst, Krieg und Hofkultur, 2008, S. 39-49.

- „Mon souverain seigneur“, in: Power of Persuasion. Essays on the Art of State Building in Honour of W.P. Blockmans, hg. von Peter Hoppenbrouwers, Antheum JANSE und Robert SteIn, Tournhout 2010, S. 27-48.

- Terreur royale: Louis XI et la ville d'Arras, avril 1477, in: Villes et villages: organisation et représentation de l'espace. Mélanges offertes à Jean-Marie Duvosquel à l'occasion de son soixante-cinquième annversaire, hg. von Alain Dierkens, Christophe Loir, Denis Morsa und Guy Vanthemsche, (Revue Belge de Philologie et d'Histoire 89/2) Brüssel 2011, Bd. 2, S. 551-583.

- Burgundische Kardinäle: Erfolge und Niederlagen an der römischen Kurie im 15. Jahrhundert, in: Das Ende des konziliaren Zeitalters (1440-1450). Versuch einer Bilanz, hg. von Heribert MüLler (Schriften des Historischen Kollegs, 86), München 2012, S. 253-294.

- Theatre of Death. The Transfer of the Remnants of Philip the Good and Isabel of Portugal to Dijon, November 1473-February 1474, in: Death at Court, hg. von KARLHeinz Spiess und Immo Warntjes, Wiesbaden 2012, S. 33-115.

PaszTor, Edith, Diomede Carafa, in: LexMa 2 (1983) Sp. 1495.

PAviot, Jacques, La politique navale des ducs de Bourgogne (1384-1482), Lille 1995.

- L'ordre de la Toison d'or et la croisade, in: Ordre de la Toison d'or, 1996, S. 71-74.

- Le recrutement des chevaliers de l'ordre de la Toison d'or (1430-1505), in: Ibid. S. 75-79.

- Jacques de Luxembourg. Politique et culture chez un grand seigneur du XV siècle, in: Penser le pouvoir au Moyen Age (VIII $-\mathrm{XV}^{\mathrm{e}}$ siècle). Études offertes à Françoise Autrand, hg. von Dominique Boutet u. Jacques Verger, Paris 2000, S. 327-341.

- Du nouveau sur la création de l'ordre de Toison d'or, in: Journal des savants (2002) S. 279-298.

- Emblématique de la maison de Bourgogne sous Philippe le Bon (1419-1467), in: Bulletin de Liaison des Sociétés Savantes 12 (2007) S. 11-13.

Payne, Ann und Jefferson, Lisa, Edward IV: The Garter and the Golden Fleece, in: Ordre de la Toison d'or, 1996, S. 194-197.

Peporte, Pit s. Mémoires conflictuelles et mythes, 2012.

PfeIfer, Gustav, Burg - Stadt - Landesfürstlicher Dienst. Beiträge zur Familiengeschichte der Tiroler Liechteinsteiner, in: Leifers. Vom Dorf zur Stadt. Anfänge Entwicklungen - Chancen, hg. von Georg Tengler, Liefers/Bozen 1998, S. 73-112.

Pinedo de Salazar, Julian de, Historia de la insigne orden del Toyson de Oro, 3 Bde., Madrid 1787.

Pontieri, Ernesto, Per la storia del regno di Ferrante I d'Aragona re di Napoli, Neapel ${ }^{2} 1969$.

PrAet, Joseph van, Recherches sur Louis de Bruges, seigneur de Gruthuyse, suivies de la notice des manuscrits qui lui ont appartenu, et dont la plus grade partie se conservé à la bibliothèque du Roi, Paris 1831 .

Priebatsch, Felix (Hg.), Politische Correspondenz des Kurfürsten Albrecht Achilles, Bd. 2: 1475-1480, (Publicationen aus den K. Preussischen Staatsarchiven, 67) Leipzig 1897. 
Prietzel, Malte, Guillaume Fillastre der Jüngere (1400/07-1473). Kirchenfürst und herzoglich-burgundischer Rat (Beihefte der Francia, 51), Stuttgart 2001.

- s. Fillastre, Ausgewählte Werke, 2003.

- Imitation, Inspiration und Desinteresse. Die Auseinandersetzung Maximilians I. mit den politischen Traditionen Burgunds, in: „Das kommt mir spanisch vor." Eigenes und Fremdes in den deutsch-spanischen Beziehungen des späten Mittelalters, hg. von Klaus Herbers und Nikolas JAspert, Münster 2004, S. 87-106.

- Rhetoric, Politics and Propaganda: Guillaume Fillastre's Speeches, in: The Ideology of Burgundy, 2006, S. 117-129.

- Reden als Waffen der Diplomatie. Rhetorik, Zeremoniell und Politik in den französisch-burgundischen Verhandlungen 1456-1465, in: Außenpolitisches Handeln, 2008, S. 73-96.

Prizer, William, Music and ceremonial in the Low Countries: Philip the Fair and the order of the Golden Fleece, in: Early Music History 5 (1985) S. 113-153.

- Brussels and the ceremonies of the Order of the Golden Fleece, in: Revue belge de musicologie/Belgisch tijdschrift voor muziekwetenschap 55 (2001) S. 69-90.

Die Protokollbücher des Ordens vom Goldenen Vlies, hg. von Sonja DünNEBEIL (= PB)

- Bd. 1: Herzog Philipp der Gute (1430-1467). Mit den Aufzeichnungen des Wappenkönigs Toison d'or, Regesten und dem Text der Ordensstatuten (Instrumenta, 9), Stuttgart 2002. [http://www.perspectivia.net/content/publikationen/instrumenta/ duennebeil_protokollbuecher-1]

- Bd. 2: Das Fest im Jahr 1468 unter Herzog Karl dem Kühnen. Mit einem Regestenverzeichnis (Instrumenta, 12), Ostfildern 2003. [http://www.perspectivia.net/content/ publikationen/instrumenta/duennebeil_protokollbuecher-2]

- Bd. 3: Das Fest im Jahr 1473 in Valenciennes unter Herzog Karl dem Kühnen (Instrumenta 19) Ostfildern 2009. [http://www.perspectivia.net/content/publikationen/ instrumenta/duennebeil_protokollbuecher-3]

RAPP, Francis, Maximilien d'Autriche. Souverain du Saint Empire romain germanique, bâtisseur de la maison d'Autriche (1459-1519), Paris 2007.

RApp Buri, Anna und Stucky-Schürrer, Monica, Burgundische Tapisserien, München 2001.

Rausch, Karl, Die burgundische Heirat Maximilians I., Wien 1880.

Reche Ontillera, Ablerto s. Blasco Valés/Reche Ontillera, Documentos, 2007.

« Recueil du Fay » Die Briefsammlung des Claude de Neufchâtel zur Geschichte Karls des Kühnen 1474-1477 (1505), hg. von Petra Енм-Schnocks und Harm von SEGGERN (Instrumenta, 10), Ostfildern 2003.

Redlich, Otto, Wilhelm IV., Herzog von Jülich, in: ADB 43 (1898) S. 100-106.

Regesten Kaiser Friedrichs III. (1440-1493), nach Archiven und Bibliotheken geordnet, hg. von Heinrich Koller, Paul-J. Heinig und Alois Niederstätter:

- Supplemente: Kaiser und Reich in der Regierungszeit Friedrichs III., Bd. 1: Regesten zur burgundisch-niederländischen Geschichte unter Maximilian I. bis zum Tode Friedrichs III. (1477-1493) aus den Archives Générales du Royaume/dem Algemeen 
Rijksarchief in Bruxelles/Brussel, Bestand: Manuscrits divers, bearb. von Claudia rotThoff-KraUs, Wien, Köln, Weimar 2008.

- Die Urkunden und Briefe des Österreichischen Staatsarchivs in Wien, Abt. HausHof- und Staatsarchiv, Allgemeine Urkundenreihe (1476-1479), bearb. von Kornelia Holzner-Tobisch und Anne-Katrin Kunde, Wien/Weimar/Köln (in Vorbereitung).

Ausgewählte Regesten des Kaiserreichs unter Maximilian I. 1493-1519 [= Johann Friedrich Böhmer, Regesta Imperii XIV], bearb. von Hermann Wiesflecker u.a., 4 Bde., Wien/Köln/Weimar 2002-2004.

Reiffenberg, Frédéric de, Histoire de l'Ordre de la Toison d'or depuis son institution jusqu'a la cessation des chapitres généraux; tirée des archives mêmes de cet ordre et des écrivains qui en ont traité, Brüssel 1830.

Reumont, Alfred von, Die Carafa von Maddaloni: Neapel unter spanischer Herrschaft, Berlin 1851.

Richard, Jean, Burgunder, I. Geschichte, in: LexMa 2 (1983) Sp. 1092-1095.

- Claude de Toulongeon, seigneur de la Bastie (vers 1420-vers 1504) et la résistance bourguignonne à Louis XI, in: De orde van het Gulden Vlies te Mechelen in 1491, 1992, S. 175-188.

- Philipp III., der Gute, in: LexMA 6 (1993) Sp. 2068-2070.

- Pot, in: LexMA 7 (1994), Sp. $128 \mathrm{f}$.

- s. Toison d'or, 1998.

Richert, Ernst, Die Schlacht bei Guinegate 7. August 1479. Diss. phil., Berlin 1907.

Richtlinien Handschriftenkatalogisierung, hg. von der Deutschen Forschungsgemeinschaft, 5. erweiterte Aufl., Bonn 1992.

Roo, Gerard van, Annales rerum belli domique ab Austriacis Habsburgicae gentis principibus, a Rudolpho primo, usque ad Carolum V., Innsbruck 1592.

- Annales oder Historische Chronick der durchleuchtigsten Fürsten und Herren, Ertzhertzogen zu Oesterreich, Habsburgischen Stammens, fürnehmlich von Rudolpho dem Ersten ... biß auff Carolum den Fünftten, bearb. von Conrad DiETz, Augsburg 1621.

ROTTHOFF-Kraus, Claudia s. Regesten Kaiser Friedrichs III.

Journal de Jean de Roye, connu sous le nome de Chronique scandaleuse (1460-1483), hg. von Bernard de MANDrot, 2 Bde., Paris 1894-1896.

Ruwet, Joseph, Les archives et bibliothèques de Vienne et l'histoire de Belgique, Brüssel 1956.

Saint-Christo, François de s. Colleville/Saint-Christo, Ordres, [1925].

SAint-Genois Des Mottes, Jules de s. Lettres adressées de Maximilien I.

La Sainte-Chapelle de Dijon, siège de l'ordre de la Toison d'or. Catalogue de l'exposition présentée au Musée de Dijon, Dijon ${ }^{3} 1962$.

SALET, Françis, La croix du serment de l'ordre de la Toison d'or, in: Comptes rendus de l'académie des inscriptions et belles lettres 109/1 (1965) S. 116-118.

- La croix du serment de l'ordre de la Toison d'or, in: Journal des Savants (1974) S. 73-94. 
Scheler, Dieter, Inszenierte Wirklichkeit: Spätmittelalterliche Prozessionen zwischen Obrigkeit und Volk, in: Von Aufbruch und Utopie. Perspektiven einer neuen Gesellschaftsgeschichte des Mittelalters, hg. von Bea LundT und Helma REIMÖLLER, Köln/Weimar/Wien 1992, S. 119-129.

Schätze der burgundischen Hofkunst in Wien, hg. von Sabine HAAG, Franz Kirchweger und Katja Schmitz-von Ledebur, Wien 2009.

Schmitz-von Ledebur, Katja, Der Messornat des Ordens vom Goldenen Vlies. Ein Hauptwerk der burgundischen Hofkunst, in: Karl der Kühne - Kunst, Krieg und Hofkultur, 2008, S. 62-71.

- s. Schätze der burgundischen Hofkunst, 2009.

- Textilien im Kontext höfischer Repräsentation der burgundischen Herzöge, in: Schätze der burgundischen Hofkunst, 2009, S. 81-114.

- L'ordre de la Toison d'or, in: Fastes de cour et cérémonies royales: le costume de cour en Europe (1650-1800, Ausstellungskatalog, Château de Versailles, 31 mars 28 juin 2009, hg. von Pierre Arizzoli-Clémentel, Paris 2009, S. 154-159.

- Der Messornat des Ordens vom Goldenen Vlies: Sticker im Dienste der burgundischen Herzöge, in: Reiche Bilder: Aspekte zur Produktion und Funktion von Stickereien im Spätmittelalter: Beiträge der internationalen Fachtagung des Deutschen Textilmuseums Krefeld und des Zentrums zur Erforschung Antiker und Mittelalterlicher Textilien an der Fachhochschule Köln (20. - 21. November 2008), hg. von Uta-Christiane Bergemann, Regensburg 2010, S. 25-36.

Schneider, Jean, Un conseiller des ducs de Bourgogne: Georges de Bade, évêque de Metz (1459-1484), in: Cinq-centième anniversaire de la bataille de Nancy (1477), Nancy 1979, S. 305-338.

SCHnerb, Bertrand, L'État bouguignon (1363-1477), Paris 1999.

- «La plus grande héritière du monde », in: Bruges à Beaune, 2000, S. 21-38.

Schouteet, Albert, De Vlaamse Primitieven te Brugge. Bronnen van de schilderkunst te Brugge tot de dood van Gerard David. Bd. 1: A-K, (Koninklijke Academie voor Wetenschappen, Letteren en Schone Kunsten van België. Fontes Historiae Artis Nederlandicae, 2) Brüssel, 1989.

Schubert, Ernst, König und Reich: Studien zur spätmittelalterlichen deutschen Verfassungsgeschichte, (Veröffentlichungen des Max-Planck-Instituts für Geschichte, 63) Göttingen 1979.

Schwedler, Gerald, Herrschertreffen des Spätmittelalters. Formen - Rituale Wirkungen, (Mittelalterforschungen, 21) Ostfildern 2008.

Schwennicke, Detlef s. Europäische Stammtafeln.

ScHWERDLING, Johann, Geschichte des uralten und seit Jahrhunderten um Landesfürst und Vaterland höchtst verdienten, theils fürstlich, teils gräflichen Hauses Starhemberg, Linz 1830.

Schwinger, Anna Theresa, Der Burgunder Ornat: textiler Aufbau und Stricktechniken am Burgunder Ornat, Dipl.-Arb. masch., Graz 2000.

Schwinges, Rainer C. s. Karl der Kühne von Burgund, 2010.

Scofield, Cora L., The life and reign of Edward the Fourth, 2 Bde., London 1923, ND 1967. 
SEgGern, Harm von s. Recueil du Fay.

Segnave, Paul, Le palais du Coudenberg, in: Bruxelles au XV $\mathrm{XV}^{\mathrm{me}}$ siècle, hg. von Paul Bonenfant, Brüssel 1953, S. 237-243.

SEIBRICH, Wolfgang, Johann, Markgraf von Baden, in: Die Bischöfe des Heiligen Römischen Reichs (1448-1648). Ein biographisches Lexikon, hg. von ErwiN GATZ, Berlin 1996, S. 341-343.

Serrure, Constant A., Notice sur Engelbert II comte de Nassau, lieutenant-général de Maximilien et de Philippe-le Beau aux Pays-Bas, Gent 1862.

Sicking, Louis, Ten faveure van Veere en de vorst. De heren van Veere als makelaars in macht tussen zee en vastelland, ca. 1430-1558, in: Borsele Bourgondie Oranje: heren en markiezen van Veere en Vlissingen, 1400-1700, hg. von Peter Blom u. a., (Amsterdamse historische reeks, Grote Serie 35) Hilversum 2009, S. 27-60.

Johann Siebmachers großes Wappenbuch, Bd. 27, Die Wappen des Adels von Oberösterreich, Unveränd. ND nach Nürnberg 1904, Neustadt a.d. Aisch 1984.

Silver, Larry, Marketing Maximilian. The Visual Ideology of a Holy Roman Emperor, Princeton 2008.

Simaey, Charles van s. Berings/Simaey, Abbaye de Saint-Pierre, 1988.

SLANIČKA, Simona, Krieg der Zeichen. Die visuelle Politik Johanns ohne Furcht und der armagnakisch-burgundische Bürgerkrieg (Veröffentlichungen des Max-PlanckInstituts für Geschichte, 182), Göttingen 2002.

Small, Graeme s. Court and Civic Society, 2007.

SMEDT, Raphaël de s. Orde van het Gulden Vlies te Mechelen in 1491, 1992.

- Jan heer van Lannoy, stadhouder en diplomaat (1410-1493), in: Orde van het Gulden Vlies te Mechelen in 1491, 1992, S. 55-84.

- A propos des études et commentaires relatifs aux chapitres de la Toison d'or, in: PCEEB 34 (1994) S. 145-151.

- s. Chevaliers de la Toison d'or, ${ }^{2} 2000$.

- Der Orden vom Goldenen Vlies im Lichte der burgundisch-habsburgischen Politik, in: Zwischen Habsburg und Burgund. Der Oberrhein als europäische Landschaft im 15. Jahrhundert, hg. von Konrad KRIMM und Rainer BRÜNING (Oberrheinische Studien, 21), Stuttgart 2003, S. 113-138.

Soen, Violet, La Causa Croy et les limites du mythe bourguignon: La frontière, le lignage et la mémoire (1465-1475), in: PCEEB 52 (2012) S. 81-97.

SornAy, Janine s. Sources de l'histoire.

Sources de l'histoire économique et sociale du Moyen Âge. Les états de la maison de Bourgogne, hg. von Robert-Henri Bautier und Janine Sornay, Bd. 1, Paris 2001.

Staging the Court of Burgundy. Proceedings of the Conference "The Splendour of Burgundy”, hg. von Wim Blockmans, Till.-H. Borchert, Nele GabriëLs, Johan Oosterman, Anne Van Oosterwijk, Turnhout 2013.

Stein, Henri, Etude biographique, litteraire et biblographique sur Olivier de la Marche. Position de la Thèse, Paris 1885.

- Un diplomate bourguignon du XV siècle: Antoine Haneron, in: Bibliothèque de l'école nationale des Chartes 98 (1937) S. 283-348. 
- Catalogue des Actes de Charles le Téméraires (1467-1477). Mit einem Anhang: Urkunden und Mandate Karls von Burgund, Grafen von Charolais (1433-1467), bearbeitet von Sonja DünNeBEIL, (Instrumenta, 3) Sigmaringen 1999.

STERCHI, Bernhard, Der Orden vom Goldenen Vlies und die burgundischen Überläufer von 1477 (Schriftenreihe der Eidgenössischen Militärbibliothek und des Historischen Dienstes, 4), Bern 2003.

- Über den Umgang mit Lob und Tadel. Normative Adelsliteratur und politische Kommunikation im burgundischen Hofadel, 1430-1506 (Burgundica, 10), Turnhout 2005.

- The Importance of Reputation in the Theory and Practice of Burgundian Chivalry: Jean de Lannoy, the Croys, and the Order of the Golden Fleece, in: The Ideology of Burgundy, 2006, S. 99-115.

- Rendre compte de leur honneur. Der Einfluss des Ordens auf das Verhalten seiner Mitglieder, in: Das Haus Österreich und der Orden vom Goldenen Vlies, 2007, S. $137-160$.

Stucky-Schürrer, Monica s. Rapp Buri, Stucky-SchÜrrer, Tapisserien, 2001.

Thieme, André s. Herzog Albrecht der Beherzte, 2002.

La Toison d'or ou Receuil des status et ordonnances du noble de la Toison d'or, leurs confirmations, changements, additons, cermoniens, immunitez, exemptions, prééminances, honneurs et bulles papales depuis l'instution jusques à présent, Köln 1689.

La Toison d'or à Bruges. Ausstellungskatalog, Brüssel 1907.

La Toison d'or. Cinq siècles d'art et d'histoire. Ausstellungskatalog, Brügge 1962.

La Toison d'or. Un mythe européen. Ausstellungskatalog in Schloß Malbrouck à Manderen, hg. von Jean Richard und Jean-Luc Liez, Paris 1998.

Toussaert, Jacques, Le sentiment religieux en Flandre à la fin du Moyen-Age, Paris 1963.

Trenkler, Dietlind, Maximilian I. und seine Beziehungen zu England in den Jahren 1477-1509, Diss. phil. masch., Graz 1973.

Treppo, Mario Del, Alfons II., König von Neapel, in: LexMA 1 (1980) Sp. $403 \mathrm{f}$.

Trésor de la Toison d'or. Ausstellungskatalog, Brüssel 1987.

UdinA, Frederic, Cardona, in: LexMa 2 (1983) Sp. 1506.

Ussel, Paule van, De regeering van Maria van Bourgondie over de Nederlanden.

(Univ. de Louvain. Recueil de travaux d'histoire et de philologie, 3/15) Löwen 1943.

VAESEN, Joseph s. Lettres Louis XI, 1883-1909.

VAIvre, Jean-Bérnad de, Un primitif tiré de l'oubli: le panneau de Philippe Pot de Notre-Dame de Dijon (note d'information). In: Comptes-rendus des séances de l'Académie des Inscriptions et Belles-Lettres 149/2 (2005) S. 811-858.

VAle, Malcom, War and Chivalry. Warefare and Aristocratic Culture in England, France and Burgundy at the End of the Middle Ages, Athen 1981.

Vander Linden, Herman, Itinéraires de Marie de Bourgogne et de Maximilien d'Autriche (1477-1482), Brüssel 1934.

Vaughan, Richard, Philip the Good. The Apogee of Burgundy, London 1970, Unveränd. ND mit bibliographischem Nachtrag von Graeme SMALL, Woodbrigde 2010. 
- Charles the Bold. The last Valois duke of Burgundy, London 1973; Unveränd. ND mit bibliographischem Nachtrag von Werner PARAVICINI, Woodbrigde 2011.

VeEnstra, Jan s. Ideology of Burgundy, 2006.

Verbruggen, Jan F., De slag bij Guingate, 7 augustus 1479. De verdediging van het graafschap Vlaanderen tegen de koning van Frankrijk, 1477-1480, (Centrum voor Militaire geschiedenis, Bijdragen, 27) Brüssel 1993.

Verschelde, K., De Feeste van den Toiszoene of 't Gulden Vlies, in: Archiven-Boek van Rond den Heerd 1 (1873) S. 25-29.

Vetter, Peter, Der französische Ritterorden vom heiligen Michael (1469-1830), Diss. phil., Bonn 1979.

Vielliard, Françoise, La Marche, Olivier de, in: LexMA 5 (1991) Sp. $1622 \mathrm{f}$.

Vones, Ludwig, Enriquez, in: LexMa 3 (1986) Sp. 2018-2022.

- Guevara, in: LexMa 4 (1989) Sp. 1766 f.

- Infantado, in: LexMa 5 (1991) Sp. 413.

- Velasco, in: LexMa 8 (1997) Sp. 1448.

Vones-Liebenstein, Ursula, Mendoza, in: LexMa 6 (1993) Sp. 515-517.

Vultaggio, Claudia, Friedrich I. von Aragon, in: LexMa 4 (1989) Sp. 944.

WALSH, Richard J., The coming of humanism to the Low Countries: some Italien influences at the court of Charles the Bold, in: Humanistica Lovaniensia 25 (1976) S. $146-197$.

Webern, Wilfried, Die Grafen von Nassau im Dienste Kaiser Maximilians I., Diss. phil. masch., Graz 1978.

Welzel, Barbara s. Kunst der burgundischen Niederlande, 1997.

- Anmerkungen zu Kunstproduktion und Kunsthandel, in: Kunst der burgundischen Niederlande, 1997, S. 141-157.

Wiesflecker, Hermann, Kaiser Maximilian I. Das Reich, Österreich und Europa an der Wende zur Neuzeit, 5 Bde., Wien 1971-1986.

- Guinegat(t)e, in: LexMA 4 (1989) Sp. 1785.

- s. Regesten Maximilian.

Wiesflecker-Friedhuber, Ingeborg (Hg.), Quellen zur Geschichte Maximilians I. und seiner Zeit, Darmstadt 1996.

Wijsman, Hanno s. Philippe de Clèves, 2007.

Wille, Jakob, Ludwig von Veldenz, Kf. und Herzog von der Pfalz, in: ADB 19 (1884) S. 573-575.

WIN, Paul de, Engelbert (Engelbrecht) II graaf van Nassau-Dillenburg en Vianden, heer van Breda (1451-1504), in: Orde van het Gulden Vlies te Mechelen in 1491, 1992, S. 85-116.

Wymans, Gabriel, Inventaire des archives des ducs de Croy, Brüssel 1977.

ZINGEL, Michael, Frankreich, das Reich und Burgund im Urteil burgundischer Historiographie des 15. Jahrhunderts (VuF, Sonderband 40), Sigmaringen 1995. 


\section{Wichtige Internetseiten}

In der folgenden Zusammenstellung sind einige (wissenschaftlich fundierte) Internet-Seiten zusammengestellt, die bei der Bearbeitung der Protokollbücher gute Dienste leisten, ohne jedoch einen Anspruch auf Vollständigkeit zu erheben:

BaLaT: Belgian Art Links and Tools des Royal Institute for Cultural Heritage in Brüssel: http://balat.kikirpa.be

Bibliographie zur Geschichte des Ordens vom Goldenen Vlies, zusammengestellt von Sonja Dünnebeil: http://www.oeaw.ac.at/imafo/fileadmin/mitarbeiterInnen/ sduennebeil/literatur_ogv.pdf

Bibelserver: Zusammestellung der verschiedenen Bibelfassungen: http://www. bibleserver.com

Bilddatenbank des Kunsthistorischen Museums in Wien, in dessen Bestand sich der Schatz des Ordens vom Goldenen Vlies als Depot befindet: http://bilddatenbank. khm.at/

DB Heraudica $=$ Heraudica . Base de données et collection des sources en plein texte pour la recherche sur les hérauts d'armes, éd. par Torsten Hiltmann pour l'Institut historique allemand de Paris, avec la collaboration de Franck Viltart, Henri Simonneau et Nils Bock

http://herolde.heraudica.org/fmi/iwp/cgi?-db=burgHerolde6x.fp7\&-loadframes (als Gast anmelden)

DB Prosopographia Curiae Burgundicae = Datenbank, hg. vom Deutschen Historischen Institut, 2008; auf dieser Seite sind aber auch die von Werner Paravicini verfaßten und betreuten Bücher zur burgundischen Geschichte, darunter auch PB 1-3, online gestellt: www.prosopographia-burgundica.org

Gallica Bibliothèque Numérique der Bibliothèque nationale de France: http://gallica. bnf.fr

Regesta Imperii Online der Akademie der Wissenschaft und Literatur in Mainz: Inventar aller urkundlichen und historiographischen Quellen der römischdeutschen Könige von den Karolingern bis zu Maximilian I. sowie der Päpste des frühen und hohen Mittelalters und RI-Opac, einer frei zugängliche, alle Fachdisziplinen berücksichtigende Literaturdatenbank für die mediävistische Forschung des gesamten europäischen Sprachraums:

http://www.regesta-imperii.de

\section{Wasserzeichen:}

Landesarchiv Baden-Württemberg, Stuttgart: Wasserzeichen-Informationssystem www.wasserzeichen-online.de

Institut für Mittelalterforschung der ÖAW Wien, Abteilung Schrift- und Buchwesen: WZMA - Wasserzeichen des Mittelalters http://www.ksbm.oeaw.ac.at/wz/wzma.php 


\section{Archivalienverzeichnis}

Die mit Stern (*) versehenen Bestände wurden von der Bearbeiterin durchgesehen, die übrigen Bestände wurde (lediglich) aufgrund von Erwähnungen in der Literatur aufgenommen. Vgl. dazu die Angaben in der Einleitung S. 14 mit Anm. 9.

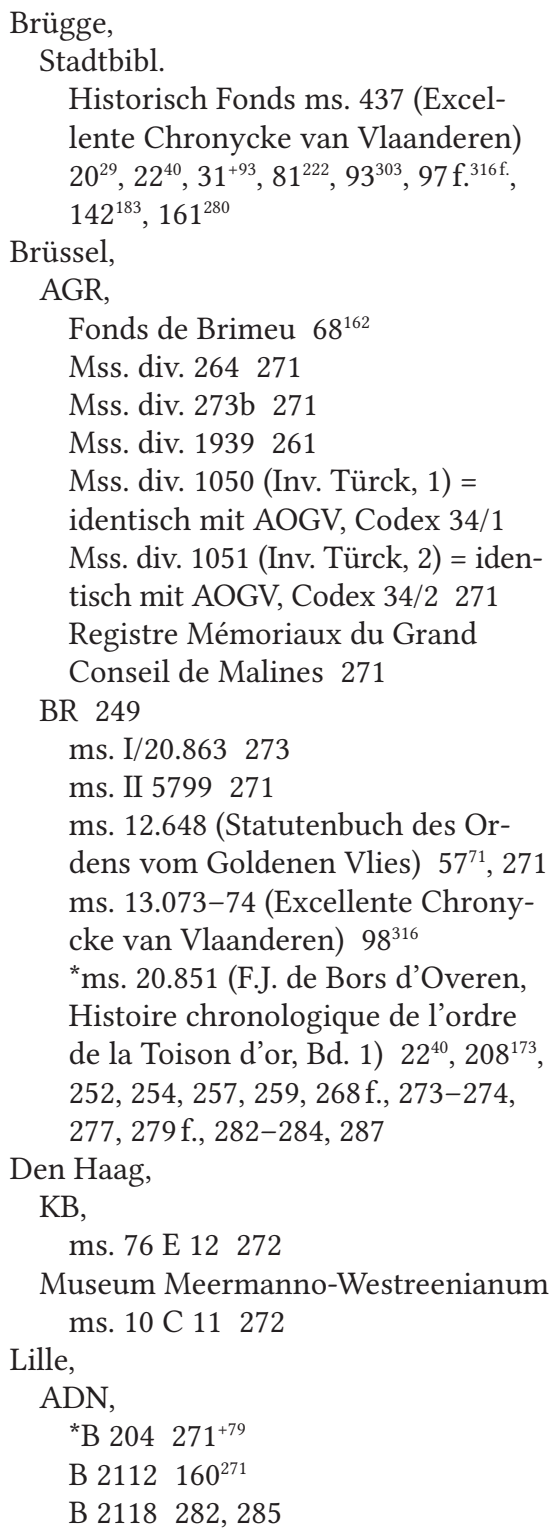

B 2121288

${ }^{*} \mathrm{~B} 1285271$

$\mathrm{BM}$, ms. 626 (Recueil) $203^{160}$

Paris,

$\mathrm{BNF}$, ${ }^{*}$ ms. 8999 = identisch mit AOGV, Codex 34/1 *ms. fr. $504622^{40}, 271$

Valenciennes,

BM, ms. $805143^{186}$

Wien,

HHStA,

${ }^{*}$ Allgemeine Urkundenreihe (AUR) $43^{3}, 48^{30}$,

*Archiv des Ordens vom Goldenen Vlies (AOGV) 35, $277^{90}$

Urkunden 255-262, 265, $268 \mathrm{f}$., 271-274, 277-279+90, 282, 287

Akten,

Karton 135

PB $113^{2}, 14^{8}, 16^{14}, 35,169^{316}$, PB $213^{2}, 29^{80}, 35,139,169^{316}$, PB $313^{2}, 35,51^{47}, 69^{166}, 102^{333}$, $158 \mathrm{f.}^{+267}, 169^{316}, 263$

PB 4 passim

PB 5 14, 27 f. ${ }^{+74}, 34$ f., 38, 71, $149^{215 f}, 160^{271}, 180^{28}, 200-$ $202^{138,149,155}, 234^{286}, 261,271$, 276, 289

PB $635^{+120}$

PB 735

Karton $457^{71}, 271^{+79}, 279$

Karton 5 (Türck'sche Systematik: 2. Partie § 2) $39^{149}, 208^{173}$, $243^{339}, 251$ f. $^{+6}, 254,275,277$, 279-284, 288

Karton $23271^{79}$

Codex $24143^{186}$ 
Codex 34/1 (Türck'sche Inventar, Bd. 1) $15^{10}, 22^{40}, 263$ f., 272 , 278-282, 289, 272, 281 f., 289

Codex 34/3 (Türck'sche Inventar, Bd. 3) 272

Codex $3735^{+123}$

Codex 42, $77^{210}$
Codex $4538^{140}, 60^{85}, 127^{105}, 185^{57}$, $190^{82}, 249-254,266$ f., 272-278, 287, 289

*Familienurkunden $17^{+20}$ *Urkundenabschriften, Collationierte Urkunden, Karton $7317^{+20}$ 


\section{Index der Orte und Personen}

Die Ordensmitglieder werden im Verzeichnis fett gesetzt. Mit Hilfe ihrer Nummer können bei Chevaliers de la Toison d'or, ${ }^{2} 2000$, die Biographie sowie Literaturangaben zu den einzelnen Mitgliedern nachgelesen werden. Zur schnelleren Orientierung wurden hier Angaben zur Geburt (*), Aufnahme in den Orden (W) sowie das Sterbedatum $(\dagger)$ aufgenommen.

A

Aachen (Nordrhein-Westfalen, D) $117^{55}$ Adam s. Isle-Adam

Adolf (von Egmond) \{58\}, Hz. von Geldern, Gf. von Zutphen (* 12.3.1438;

$\mathrm{W} 1461 ; \dagger 27.6 .1477)$ 17, 24, 26, $68 \mathrm{f} .{ }^{+166}, 74,90,116,148,190^{84}, 262,293$ Schwester s. Katharina

Sohn s. Karl

Alamaigne s. Deutsches Reich

Alba de Tormes (Prov. Salamanca, E) $256^{16}$

Hz. s. García Álvarez de Toledo

Albrecht, Hz. von Sachsen \{96\}

$\left({ }^{*} 31.7 .1443\right.$; W 1478; † 12.9.1500) $9 \mathrm{f}$., $28 \mathrm{f} ., 30 \mathrm{f}^{+90,93}, 133-135^{+141}, 146 \mathrm{f} ., 149$, $169^{+315}, 175,179,181 \mathrm{f} ., 184,201,258$, 268

Bruder s. Ernst

Albrecht Achilles, Kurfürst und Mgf. von Brandenburg (†1486) 10, 31 $1^{+93}$, $259^{+26}, 262$

Alençon, Hzt. (Hauptstadt Alençon, Dép. Orne, F) 90

Hz. s. Johann

Alexander der Große, Kg. von Makedonien $(† 323$ v. Chr.) 85

Alfons V. \{41\}, Kg. von Aragón und Sizilien (*1396, W 1445, † 27.6.1458) $90^{280}, 169^{316}, 293$

Alfons II. von Aragón († 1495), Hz. von Kalabrien, Kg. von Neapel und Jerusalem, Mitglied des Hermelinordens 256-258 $8^{+11,22}$

Vater s. Ferdinand $\{72\}$

Bruder s. Friedrich

Alsace s. Elsaß

Álvarez de Toledo s. García Álvarez de Toledo
Amance (Dép. Haute-Saône, F) 261, $279,282 \mathrm{f}$.

Amont (Dép. Haute-Saône, F) $209^{180}$

Andria (Prov. Barletta-Andria-Trani, I), Hz. s. Francesco del Balzo

Angleterre, Anglie s. England

Anteluys s. Aveluys

Antoing, Anthoing (Prov. Hennegau, B),

Herr s. Melun, Jean de

Antwerpen, Anvers (Belgien), Stadt 143, 193, 200-203, 209, 211, 213, 218, 220, 224, 238 $8^{309}, 281 \mathrm{f} ., 283$

Mgf. s. Karl; Maximilian

hzl. Residenz 193, 203

Aquin, Thomas von, Heiliger $(† 1274)$

88, 91

Aragón, Arragon (Spanien) 90

Kg. s. Alfons V.; Ferdinand; Johann

Admiral s. Folch, Juan Ramon

Aragón, Haus s. Alfons II., Alfons V.,

Ferdinand, Friedrich; Johann

Ariano (Italien), Gf. s. Guevara

Arinyo, Sekretär Ferdinands, Kg. von Kastilien 256f., 269

Aristogeiton, Tyrannenmörder $(† 514$ v. Chr.) 92

Ariston, griech. Philiosoph 90

Aristoteles, griech. Philiosoph $(† 322$

v. Chr.) 90

Arson, Jean d', frz. Pensionär 8

Arminio, Ordine della s. Hermelin-

Orden

Arnheim, Arnhem (Prov. Geldern, NL) $149^{216}$

Arras (Dép. Pas-de-Calais, F) 7, $69^{171}$

Bailli s. Crèvecœur, Philippe de

Artois (Hauptstadt Arras, Dép. Pas-deCalais, F), Gft. 9, 16, 69 $9^{171}, 78,234^{286}$, 241

Gf. s. Karl; Maximilian 
Gouverneur s. Crèvecœur, Philippe de Wappenkönig Artois $77^{212}$

Athen (Griechenland) 89, 92

Attila, Kg. der Hunen († 453) 89

Augustinus, Kirchenvater $(† 430)$ 88, 91

Aurelianum s. Orléans

Austrice s. Österreich

Auxi(-le-Château) (Dép. Pas-de-

Calais, F), Jean de $\{\mathbf{4 5}\}$, Herr

von Auxi ( ${ }^{*}$ Ende 14. Jh.; W 1445;

$+15.8 .1474) 24,68,74,115,148,262$, 293

Auxonne (Dép. Côte-d'or, F) $209^{180}$

Avallon (Dép. Yonne, F), Archidiakon s. Clugny, Guillaume de

Aveluys, Anteluys, Havelu (Auvelais, Prov. Namur, B), Nicolas d' ( $†$ um 1484), Ritter, Hz. Maximilians zweiter maistre d'hotel $84^{243}, 117^{+57}, 271$

B

Baden (Südwestdeutschland), Haus $46^{17}$

Christoph I. von $\{102\}$, Mgf., burgund. Truppenführer $\left({ }^{*} 13.11 .1453\right.$, $\mathrm{W} 1491, \dagger 19.3 .1527) 31^{+93}, 53^{+58}, 82 \mathrm{f}$., 103, 187, 259, 262, 270

Cimburga $(† 1501) \quad 121^{+76}$

Vater s. Karl

Mutter s. Österreich, Katharina von

Ehemann s. Nassau, Engelbert von

Georg von ( $†$ 1484), Bf. von Metz

$46^{+17}, 49,53,56 f ., 82 f ., 103,108,270$

s. Johann II.

Karl I. († 1475), Mgf. $121^{76}$

Bahr, Bair (Prov. Geldern, NL), Herr s.

Egmond, Willem van

Barcelona (Spanien) 260, 277

Bassée (la) (Dép. Nord, F), Herrschaft $70 \mathrm{f}$.

Bastie-sur-Serdon, La (Dép. Ain, F),

Herr s. Toulongeon

Bauffremont (Dép. Vosges, F), Pierre

de $\{20\}$, Gf. von Charny ( ${ }^{*}$ um 1397;

W 1430; † 7.8.1472) 291

Baugey s. Bugey

Baume, Guillaume de la $\{90\}$, Herr von Irlain, Kammerherr von Hz.in Margarete, Hz.in Maria und Hz. Maximilian; burgund. Gesandter in England (* um 1430; W 1481; † 1497/98) 177-179+13f.

Baux(-de Provence), Les, del Balzo (Dép. Bouches-du-Rhône, F) s. Francesco del Balzo

Bayern, Baviere (Deutschland) 10, 117 Hz. Ludwig, Hz. von Pfalz-Zweibrücken

Becan, Herr 10, 262; s. auch Buchan

Belcastro (Prov. Catanzaro, I), Gf. s. Guevara, Ferrante

Benavente (Prov. Zamora, E), Gf. s. Pimentel, Rodrigo Alfonso

Berengar II., Kg. von Italien († 966) 89 Bever, Biévène, Bievre (Prov. FlämischBrabant, B), Herr s. Rubempré, Jean de

Beveren(-Waas), Bevre (Prov. Ost-Flandern, B), Herr s. Burgund, Philipp von

Bletterans, Bleterens (Dép. Jura, F) 190

Blioul, Laurent du, Greffier des Ordens vom Goldenen Vlies (ab 1496) († 1542) $195^{103}$

Böhmen, Kgr. $133^{140}$

Boethius, spätantiker Autor $(† 524 / 526)$ 87

Bois-le-Duc, Bosleduc s. 's-Hertogenbosch

Bolin, Tristan, burgund. Wappenkönig Hennegau $62^{+98}, 65,68,77^{212}, 250,253$, 277

Borssele (Prov. Seeland, NL)

Frank van $\{42\}$, Gf. von Ostrevant ( ${ }^{*}$ um 1394/96; W 1445; † 19.11.1470) 293

Hendrik (Henri) van \{44\}, Gf. von Grandpré, Herr von Veere ( ${ }^{*}$ um 1404; $\mathrm{W} 1445$; † 15.3.1474) 24, 68, 74, 115, $148 \mathrm{f}^{+215}, 262,293$

Wolfart van $\{79\}$, Gf. von Grandpré und Buchan, Herr von Veere, Gouverneur von Holland und Seeland $\left({ }^{*}\right.$ um 1430; W 1478; † 29.4.1486) 10, $28 \mathrm{f.}^{+74}$, $32^{+100}, 140,149,171,177,179-181^{+29}$, $213,223,235,238,245,262^{+48}, 264$, 272 f., 278, 285, 294

Ehefrau s. Stuart, Maria Schwager s. Brügge, Ludwig von 
Bosleduc, Bois-le-Duc s. 's-Hertogenbosch

Bourbon, Hzt. (Hauptstadt Moulins, Dép. Allier, F) 90

s. Isabella

Jaques de $\{66\}$ (* um 1444, W 1468, † 22.5.1468) $72^{187}, 90,293$

Pierre de, frz. Pensionsempfänger 8

Bourgogne, Bourgoingne s. Burgund

Bouverien, Jan van der, Herr von Wiere, Mag., Hz. Maximilians Rat und Kammerherr, Mitglied des Parlaments von Mecheln; Präsident des Großen Rat, Kanzler von Brabant († 1493) 83 $3^{+239}$, 270

Brabant, Hzt. (Hauptstadt Brüssel, B) 43, 83 ${ }^{239}, 93-95,102 \mathrm{f} ., 117^{53}, 159,217$, 241

Hz. s. Karl; Maximilian; Philipp Hz.in s. Maria

Kanzler s. Bouverien, Jan van der Seneschal s. Nassau, Engelbert von Wappenkönig Brabant $77^{212}$

Brandenburg, Kurfürst und Mgf. s. Albrecht Achilles

Breda (Prov. Nordbrabant, NL), Herr s. Nassau, Engelbert von

Brederode (nahe Santpoort, Prov. NordHolland, NL)

Reinald (Regnault) van $\{43\}$, Herr von Brederode und Vianen (* 1415; W 1445; † 16.10.1473) 24, 68, 74, 115 , 148, 262, 293

Bretagne, Bretaigne, Britanie (Westfrankreich), Hz. s. Johann V.

Bresse (Region in Ostfrankreich mit Bourg-en-Bresse [Dép. Ain] als Zentrum, F) 274

Herr s. Savoyen, Philipp von

Brienne, Bryenne (Dép. Aube, F), Gf. s. Luxembourg

Brimeu (Dép. Pas-de-Calais, F)

Colart de $\{\mathbf{1 6}\}$, dit Florimont, Herr von Maizicourt (W 1430; † 29.7.1442) 291

David de $\{6\}$, Herr von Ligny-sur-

Canche und Briis ( ${ }^{*}$ um 1384; W 1430; † Mai/Juni 1448) 291
Guy de \{76\}, Herr von Humbercourt, Gf. von Megen, Mitglied des Regentschatsrates Hz. Karls in den Niederlanden ( ${ }^{*}$ um 1434; W 1473; $\dagger 3.4 .1477) 24,49 \mathrm{f}^{40}, 68 \mathrm{f}^{+162,167}, 74^{+195}$, $116,148,262,294$ seine Witwe $68^{162}$

Jacques de $\{\mathbf{1 8}\}$, Herr von Grigny (* um 1384; W 1430; † 18.3.1447) 291

Britanie s. Bretagne

Brouxelles s. Brüssel

Brügge, Bruges, Brugges (Prov. WestFlandern, B), Stadt (Veranstaltungsort der Ordensfeste in den Jahren 1430, 1432, 1468 und 1478), Stadt 7, 9, 11, $13,16,20-24^{+29 f ., 52}, 28-31^{+91}, 36$ f., 43 f., $63 \mathrm{f}^{+104}, 66-68^{+133,150}, 71^{183}, 74-81,88$, 105, 139, 149, 156, 162 f., 167 f., 172 , $177^{14}, 179,182,185,193,211,213 \mathrm{f}$., 216 f., 219, 227, 235-238, 245, 256-261, 263, 266, 283f., 288f., 291-294

Stadtobrigkeit 21, 84

Einwohner $84 \mathrm{f}$. ausländische Kaufleute 21, 84 Salvatorkirche, Saint Sa(u)lveur 13, 19-22, 26, 63, $72^{187}, 75$ f., 79-84, 96, $102,108 \mathrm{f}^{+24}, 112,118^{63}, 119,142-145$, 156, 161-164, 168, 172f., 260

Kirche Saint-Donas

Probst s. Haneron, Antoine de Hzl. Residenz 8, 21 f., $63^{+105}$, 77 f., 80 f., 102, 108 f., 110, 112, 118 f., 145, 161, 164 f., $172 \mathrm{f}$., 235, 238, $245 \mathrm{f}$.

Großer Saal 117

Kleiner Saal 102f., 164

Unterkunft Adolfs von Kleve 8, 173

Unterkunft des Philippe de Croy 8, $63 \mathrm{f} ., 235$

Heilig Blut-Fest $157^{+251}$

Lehen zu Brügge s. Gruuthuse

Brügge, Bruges, Familie van Johann V. von, Herr von Gruuthuse und Spiere, Sohn Ludwigs, Hz. Maximilians Kammerherr, Rat Ludwigs XI. († 1512) $123^{+85}, 153 \mathrm{f}$.

Ludwig (Loys) von $\{\mathbf{6 1}\}$, Herr von Gruuthuse, Gf. von Winchester, Hz.in Marias 1. chevalier d'honneur, 
Gouverneur von Holland und Seeland ( ${ }^{*}$ um 1427; W 1461; † 24.11.1492) 8, $17,19,23 \mathrm{f}^{+52}, 28,32^{+100}, 48 \mathrm{f.}^{+30}, 52 \mathrm{f}$., $57 \mathrm{f}$., 61, 63-67, 73+190 $, 77,81 \mathrm{f}$., 97, 100, 105, 112-115, 119, $122 \mathrm{f} .{ }^{+85}, 138$, 145, 149 f., 152-155, 161, 163 f., 167, 173, 176 f., 180 f. $^{+29}, 193,201,203,208$, 213-215, 219, 230, 235, 238, 245, 252f., 255-258, 261, 272f., 278, 282-284, 293 Schwager s. Borsele, Wolfart van Brüssel, Brouxelles (Belgien) (Veranstaltungsort der Ordensfeste im Jahr 1435) 11, 32-34, 57, 61, 68, 98, 101, 121, 159, 161, 175 f., 181, 184, 186f., 189, 191-195, 198, 199, 203-208, 211213, 216f., 219-228, 230, 238-241, 249-255, 257, 259, 261, 263, 268f., 271-278, 280-284, 286f., 292 Stadtobrigkeit 220, 224f., 281, 286 Hzl. Residenz Palais Coudenberg $11,57 \mathrm{f.}^{+75}, 61,175 \mathrm{f} ., 186,188 \mathrm{f} ., 195$, 228-230, 239

Unterkunft des Philippe de Croy 8, 181, 189

Unterkunft Ludwigs van Brügge 176

Hôtel Ravenstein 8

Kirche Saint Jacques-sur-Coudenberg, Sint-Jacob-op-de-Koudenberg 11, 228 Kirche Sainte-Gudule 11, 33, 186 f., 195, 227, 239

Dekan s. Steenberch, Martin

Bryenne s. Brienne

Buchan (Aberdeenshire, GB), Gf. 262 28 ; s. Borssele, Wolfart van

Bugey, Baugey (Dép. Ain, F), Gf. s. Savoyen, Philipp von

Bugnicourt (Dép. Nord, F), Herr s.

Lalaing, Jaques de

Burgund, Königreich $89 \mathrm{f}$.

Kg. s. Godemar; Gundioch; Hugo; Sigismund

Burgund (Gesamtstaat) 7-9, 13, 16 f. ${ }^{+16}$, $22,43-47^{+3,9,13,16}, 52,94 \mathrm{f} ., 130,209$, 214f., 216, 218, 221-225, 229 $9^{+265}, 236^{295}$, 270

Hz. s. Karl; Maximilian; Philipp
Kanzler s. Carondelet, Jean de; Hugonet, Guillaume

Präsident s. Carondelet, Jean de

Adel 21, 25, 47, 111

Amtsträger 18, 21, 25, 47, 270

Städte 18,27

Stände 18, 21

Herold Burgund $77^{212}$

Burgund, Bourgogne, Bourgoingne (pays de par-dela; Hauptstadt Dijon, Dép.

Côte d'Or, F), Hzt. 7, 9, 11, 16, 52, $69^{170}, 85,134,202^{155}, 209 f$., 216, 219 , 221, 222-225, 233 283,279

Hz. s. Karl; Maximilian; Philipp Hz.in. s. Isabella, Margarete; Maria burgund. Statthalter s. Johann II. von Chalon; Savoyen, Jakob und Philipp von

frz. grand sénéchal und „chevalier d'honneur du Parlement"s. Pot, Philippe

Burgund. Niederlande (pays de par-deça) 9, 18, 22, 27, 33, 35, $46-49^{+16,32,40}, 53^{58,61}, 59 \mathrm{f}^{+85}, 83^{238}, 134$, $133^{141}, 136,146,168,170,182,190$, 194, 200, 202f., 209-212, 215-219, 221-225, 236, $241 \mathrm{f}$., 245, 238, 263 Mitglieder des Regentschaftsrat Hz. Karls s. Brimeu, Guy de; Clugny, Guillaume de; Hugonet, Guillaume; Margarete

Gouverneur s. Savoyen, Jakob von ksl. Gesandtschaft 18

Burgund, Freigrafschaft s. FrancheComté

Burgund, Haus $8^{+4}, 55,59,79^{217}, 85,92 \mathrm{f}$., $124,130,210^{184}, 233^{+283}, 243,249^{1}, 283$

Anton von $\{54\}$, Großbastard, Gf. von La Roche-en-Ardenne, 1. Kammerherr Hz. Karls, frz. Pensionär, Mitglied des Michaelsordens ( ${ }^{*}$ um 1421; W 1456; † 5.5.1504) 7 f., 24-28, 51, 62, 68, 70 f. ${ }^{+179}, 74^{+194}, 110$ f., 116, 128, 185, 195, 197, 233, 251f., 254, 266, $270^{64}, 272 \mathrm{f}$., $285^{110}, 293$

Baudouin ( $†$ 1508), Bastard Philipps des Guten 8

s. Isabella 
Johann von $\{\mathbf{5 3}\}$ Gf. von Nevers, Étampes und Rethel (* 25.10.1415;

W 1456, Austritt 1468; † 25.9.1491) 8, $26^{+65}, 293$

s. Karl der Kühne

s. Margarete

s. Maria $(† 1463)$

s. Maria $(† 1477)$

s. Maria $(† 1482)$

s. Philipp der Kühne

s. Philipp der Gute

Philipp von $\{\mathbf{8 2}\}$, Herr von Beveren, Rat, Kammerherr und Truppenführer Hz. Maximilians, Statthalter in Namur, cappitaine generale der Picardie ( ${ }^{*}$ vor $\left.1464 ; \mathrm{W} 1478 ; \dagger 4.7 .1498\right) 10$, $28 \mathrm{f}^{+74}, 32^{+100}, 137^{+157}, 148,170^{319}, 176 \mathrm{f}$., 181, 187, 189, 209, 214, 223, 230, $233 \mathrm{f.}^{+283}, 257,262,264,267,272 \mathrm{f} ., 278$, 282, 285, 289, 294

Vater s. Anton

Buxy (Dép. Saône-et-Loire, F), Festung $250^{+5}$

C

Cabillauds s. Holland, Adelsparteien

Calais (Dép. Pas-de-Calais, F) 242

Cambrai, Cambray (Dép. Nord, F) 179 , 181, 242

Bistum $187^{73}$

Camiller, römische Patrizierfamilie 90

Canaples (Dép. Somme, F), Herr s. Créquy, Jean de

Cardona (Prov. Barcelona, E) Gf. s. Folch, Juan Ramon

Pedro de $\{49\}$, Gf. von Golisano (W 1451, † 1450) 293

Carafa, Diomede, neapolitansicher Adliger, Gf. von Maddaloni, Berater, Erzieher und Truppenführer Kg. Ferdinands $\{72\}$, Mitglied des Hermelinordens (†1487) 10, 258f. . $^{+2,34}$

Carniole s. Krain

Carondelet, Jean de, Herr von Champvans, Vorsitzender des Großen Rates und des Parlaments von Mecheln; Präsident und Kanzler von Burgund, Rat und Kammerherr unter Hz.in
Maria, Hz. Maximilian und Hz. Philipp $(† 1501 / 02) 83^{+241}, 270$

Castille s. Kastilien

Catheux (Dép. Oise, F), Herr s. Noyelle, Baudot de

Cecille s. Sizilien

Champvans(-lès-Dôle) (Dép. Jura, F),

Herr s. Carondelet, Jean de

Chalon(-sur-Saône) (Dép. Saône-et-

Loire, F), Stadt $138^{160}$

Familie von Chalon-Arlay s. Johann

Louis de \{64\}, Herr von ChâtelGuyon ( ${ }^{*} 1448$; W 1468; † 2.3.1476) $24,67^{+144}, 73,115,116,148,262,293$ Hugues de $(† 1490)$, Herr von Orbe und Châtel-Guyon, Gefangener in Frankreich $6^{4}, 28 \mathrm{f}^{+80}, 31^{93}, 137 \mathrm{f}^{+160}$, 148, 190-192, 202

Vater s. Ludwig

Ehefrau s. Savoyen. Louise von maistre d'hostel s. Jougne, Pierre de

s. Ludwig

Charny (Dép. Côte-d'Or, F), Gf. s. Bauffremont, Pierre de

Charolais, burgund. Herold $77^{212}$

Chastel Belin, burgund. Persevant $77^{212}$

Chastellain Georg ( $†$ 1475), burgund.

Geschichtsschreiber $102^{333}$

Châtel-Guyon, Chasteauguion (Dép. Jura, F), Herr s. Chalon

Châtel-sur-Moselle (Dép. Vosges, F), Herr s. Neufchâtel

Cato s. Marcus Porcius

Chesne (Dép. Ardennes, F), Jean du, Beauftragter der Witwe Guy de Brimeus $68^{162}$

Philippe du, Herr von Loupoigne, Ritter, huissier de salle Hz. Karls, maitre d'ostel Hz.in Marias, Rat Hz. Maximilians $194 \mathrm{f}^{+100}, 225,281,286$

Chimay (Prov. Hennegau, B), Gf. s. Croy

Cicero, röm. Politiker und Schriftsteller († 43 v. Chr.) 86, 90, 92 
Clairmarais, Clermares (Dép. Pas-deCalais, F), Zisterzienser-Abtei (de l'ordre Saint Bernard), Abt s. Grayben, Engelram

Clarence, Hz. s. Georg

Clessy (Dép. Saône-et-Loire, F), Herr s.

Damas, Jean

Clermares s. Clairmarais

Clèves s. Kleve

Clite (La), van der Clite, Jean de

la $\{8\}$, Herr von Comines (W 1430, $\dagger$ 13.9.1443) 291

Clugny (Dép. Sâone-et-Loire, F),

Ferry de, Rat Hz. Philipps, Hz. Karls und Hz. Maximlians, Bf. von Tournai, Vorsitzender des Parlaments von Mecheln, Kanzler des Ordens vom Goldenen Vlies (Sept. 1473-Dez. 1480),

Kardinal von S. Vitale, Hz. Maximilians Gesandter in Frankreich († 1483) Guillaume, päpstl. Protonotar und Archidiakon von Thérouanne, Mitglied des Regentschaftsrates Hz. Karls in den Niederlanden, Trésorier des Ordens vom Goldenen Vlies (1472-1477) $(\dagger 1480) 9,15,20 \mathrm{f}^{+29}, 24^{52}, 28,35$, $47-51^{+37}, 53-59,61-64,75,77,81,84 \mathrm{f}$., 95, 97, 99-103, 106-110, 112, 117, 119, 120-123, 131 f., 134, 137 f., 139, 141 f., 145, 151, 154 f., 158 f., 160 f., 163-167, 172f., 179, 181, 187, 189, 190, 193, 201, 204-206, 208, 212f., 220, 224, 227-231, 233, 238-240, 242-247+341f. $260,263^{51}$, 278, 283, 286, 289

Guillaume, Mag., päpstl. Protonotar, Archidiakon von Avallon, Mitglied des Regentschaftsrats Hz. Karls, Tresorier des Ordens vom Goldenen Vlies (1472-1477) $\left(†\right.$ 1480) 35, 49f. ${ }^{+40}$, $52,107^{11}$

Coïmbra (Portugal), Hz. s. Johann

Colonia, Johannes de, Sekretär Johanns II. \{57\}, Kg. von Aragón und Navarra $260^{+37}$

Collesano (Prov. Palermo, I), Gf. s. Cordona, Pedro de

Comminges (Südwestfrankreich, F), Gf. s. Foix, Mathieu de
Commynes, Com(m)ines, Komen

(Grenzort, teilw. Dép. Nord, F, teilw.

Prov. Hennegau, B)

Herr s. Clite, Jean de la

Philippe de, Chronist, Patenkind

Philipps des Guten (†1511) 8

Condé-en-Brie, Condet (Dép. Aisne, F) $103^{344}, 146$

Conrault, Philippe, Abt von Sankt-Peters in Gent, Rat und Beichtvater Hz. Maximilians $142^{182}, 261^{+40}, 270$

Conversano (nahe Bari, I), Gf. s. Luxembourg

Coria (span. Prov. Cáceres, E), Marques s. García Álvarez de Toledo

Corvinus s. Matthias Corvinus

Cottignies, Guillaume de, Beamter der CC Lille 271

Couches (Dép. Saône-et-Loire, F), Herr s. Montaigu, Claude de

Coustain, Pierre, Maler Hz. Maximilians $72^{187}$

Créquy (Dép. Pas-de-Calais, F), Jean V. $\{23\}$, Herr von Créquy und Canaples (* um 1400, W 1430, † 1474) 291

Crèvecœur(-le-Grand), Creveceur (Dép. Oise, F)

Jacques de $\{29\}$, Herr von Thoix (W 1433; † 10.9.1439) 292

Philippe de $\{69\}$, Herr von d'Esquerdes, Rat und Kammerherr Hz. Philipps und Hz. Karls von Burgund, Bailli von Arras, Gouverneur der Pikardie und dem Artois, Ehrenritter Hz.in Marias, Mitglied des frz. Hofes und des Michaelsordens ( ${ }^{*}$ ca. 1418 ; W 1468; † 22.4.1494) $7 \mathrm{f}$,, $24-28,51,62,66^{+137}, 69 \mathrm{f}^{+171}, 73^{+191}$, 110, 115, 128, 185, 196f., 251, 254, 266, 273, 284 $4^{110}, 293$

Pate s. Philipp der Gute Croy (Dép. Somme, F), Familie $26^{+64}$ Antoine de $\{15\}$, Gf. von Porcien, Herr von Croy ( ${ }^{*}$ um 1402; W 1430; $\dagger 21.10 .1475) 24,26,67^{+143}, 72^{187}, 73$, $109^{20}, 114,148,262,291$

Sohn s. Philippe 
Jean de $\{22\}$, Gf. von Chimay ( ${ }^{*}$ um 1403; W 1430; † 25.3.1473) 26, 291 Philippe de, Herr von Croy, Gf. von Porcien, burgund. Truppenfüher $(\dagger 1511) 10,30,109^{+20}, 118^{63}, 185 \mathrm{f}$, 191-193, 262

Philippe de $\{74\}$, Gf. von Chimay, 1. Kammerherr und Truppenführer Hz. Maximilians, Statthalter in Luxemburg ( ${ }^{*}$ Nov. 1437; W 1473; $\dagger$ 18.9.1482) 8, 10, 19, $23 \mathrm{f}^{+52}, 28,30$, $32^{+100}, 49,52$ f., 58, 61, 63-67, 73, 77, $81 \mathrm{f} ., 97,100,105,112,114,116,119$, 122, 138, 145, 152f., 155, 161 ${ }^{278}, 164$, 166-168, 172f., 181, 185-189, 191, 193, 201, 203-207, 209, 223, 230, 235, 238, 244 f., 247, 252 f., 255, 257 f., 261, 263 , 265, 272f., 278, 282, 285, 294

Cyprys. Zypern

D

Dagnum, Dagnen (Albanien), (Titular-)Bf. s. Greveray, Godefroy

Damas, Jean $\{65\}$, Herr von Clessy, Bailli, Gouverneur und frz. lieutenant général des Mâconnais, Kammerherr Kg. Ludwigs XI., frz. Amtmann in Mâcon, Mitglied des frz. Michaelsordens ( ${ }^{*}$ nach 1423; W 1468; † 1481?) 7 f. , 24-28, 51, $66 \mathrm{f.}^{+137}, 69 \mathrm{f}^{+172}, 73,110$, 125 f., 128, 185, 196 f., 252, 254, 266, 273, $284^{110}, 293$

David, alttest. Kg. 90

Demosthenes, griech. Redner $(† 322$ v. Chr.) 85

Dendermonde, Termonde, Tenremonde (Prov. Ostflandern, B) 47

Den Haag, 's-Gravenhage, La Haye (Prov. Süd-Holland, NL) (Veranstaltungsort des Ordensfestes im Jahr 1454) $62^{+101}, 260,293$

Deutsches Reich, Saint Empire, Alamaigne, Germanie 10, 21, 46 ${ }^{19}, 87,90$, 103, 170, 179, $181 \mathrm{f} ., 201$ röm.-dt. Kg. und Ks. 30; s. Friedrich III.; Maximilian I.; Karl V. Kurfürsten $133^{140}$ s. Johann II. von Baden; Friedrich I.; Philipp
Markgrafen. s. Antwerpen; Karl; Maximilian

Burgund. Gesandte s. Liechtenstein, Bartholomäus

Diego Hurtado de Mendoza († 1479), Hz. von Infantado, Marques von Santillana $256^{+15}$

Dijon (Dép. Côte d'Or, F) (Veranstaltungsort der Ordensfeste in den Jahren 1433 und 1434) 292 hzl. Residenz $69^{170}$

Dole (Dép. Jura, F) $209^{180}$

Douai, Douay (Dép. Nord, F) 9

E

Eduard IV. $\{63\}$ (Edouart) von York, Kg. von England, Herr von Irland, Souverän des Hosenbandordens $\left({ }^{*} 28.4 .1442\right.$; W 1468; † 9.4.1483) 7, 9, $17,20,24,28,46^{16}, 51,54,62,67,73^{+193}$, 91, 113, 166, $168 \mathrm{f.}^{+316}, 177 \mathrm{f}$., $200 \mathrm{f}$., $214,232,238,240,249,253,255,263$, $265-268^{+58}, 276$ f., 281f., 285, 287, 293 Geschwister s. Georg; Margarete Schwager s. Woodville, Anton Wappenkönig s. Wrythe, John Gesandte 200 f., $238^{+309}$, 281 f.; s. Montgomery, Thomas; Wrythe, John Sekretär s. King, Oliver burgund. Gesandte 9, 177 f;; s. Baume, Guillaume de la; Gobet; Quiquelberghe, Armand de; Ravenstein

Eduard I., Kg. von Portugal († 1438) $88^{263}$ Tochter s. Eleonore Schwester s. Isabella Egmond, Egmonde (Prov. Nord-Holland, NL)

s. Adolf von Geldern

Willem (Guillaume) van, Herr von Egmond und Bahr $\{78\}$ ( ${ }^{*} 26.1 .1412$; W 1478; † 19.1.1483) 9, $28 \mathrm{f.}{ }^{+74}, 140$, $149^{+216}, 171^{+321}, 193,204,209$ f., $213 \mathrm{f}$., 218-220, 223, 264f., 267, 285, 294

Bruder s. Adolf von Geldern Einsiedeln (Kanton Schwyz, CH) $48^{30}$ Eleonore von Portugal, Kaiserin $\left(†\right.$ 1467) $88^{263}$ Vater s. Eduard I. 
Ehemann s. Friedrich III.

Sohn s. Maximilian I.

Elsaß, Alsace (Ostfrankreich, F), Landgf. $43^{3}$; s. Maximilian

England, Angleterre, Anglie 11, 87, 90, $169^{313}, 177 \mathrm{f}$., 200

Kg. s. Eduard IV.

burgund. Gesandte s. Baume, Guillaume de la; Haynnau, Watelet de

Enguinegatte s. Guinegatte

Enriquez, Alfons ( $†$ 1485), Admiral von Kastilien $256^{+14}$

Ernst, Hz. von Sachsen († 1486) $258^{+24}$ Bruder s. Albrecht

Espierre, Pierre s. Spiere

Esquerdes, d'Escordes (Dép. Pas-deCalais, F), Herr s. Crèvecœur, Philippe de

Ester, Hester, alttest. Kg.in 86

Étampes (Dép. Essonne, F), Gf. s. Burgund, Johann von

Eusebius, Kirchenvater $(† 339 / 40) 88$

Eutropius, spätantiker, röm. Historiker $(† 390) 89$

Ezechiel, alttest. Priester 91

F

Fabier, römische Patrizierfamilie 89

Fabrizio, römische Patrizierfamilie 89

Ferdinand (Fernande) $\{71\}$, Kg. von Aragón, Kastilien, Leon und Sizilien, Prinz von Navarra ( ${ }^{*} 10.3 .1452$; W 1473; † 23.1.1516) 10, 24, 28, 32 , 51, 54, 62, $67 \mathrm{f}^{+153}, 72 \mathrm{f}^{+187}, 91,114$, $134,137^{157}, 147^{200}, 166,168 \mathrm{f}^{+316}, 202^{155}$, $232^{+277}, 250,253,255-257,259,263$, 267, 269, 276, 285, 288, 294

Vater s. Johann

Sekretär s. Arinyo

Ferdinand (Fernande) $\{72\}, \mathrm{Kg}$. von Neapel, Jerusalem und Sizilien, Souverän des Hermelinordens ( ${ }^{*}$ 2.6.1431; W 1473; † 25.1.1494) 10, 24, 28, 32 f., 51, 54, 62, 65 f., $72 \mathrm{f.}^{+187}, 91,108^{18}, 113 \mathrm{f}$., $134,147^{200}, 166,168 \mathrm{f}^{+316}, 187,232,249$, 253, 255-258 $8^{+11}, 263,265-269,275$,

285, 287, 294

Sohn s. Alfons II., Friedrich
Cousin s. Francesco del Balzo

sein Sekretär F.A. 258, 269

seine Gesandte am burgund. Hof 33, 187

Truppenführer s. Carafa, Diomede

Berater s. Carafa

Erzieher s. Carafa

Ferrette s. Pfirt

Ferrette, burgund. Herold 8, 11, 23, $66 \mathrm{f}^{+130}, 125-127,250-254,261^{39}, 274^{86}$; s. auch Jaspart, Gilles

Fiennes (Dép. Pas-de-Calais, F), Herr s. Luxemburg, Jacques de

Filelfio, Francesco, ital. Humanist $(† 1481) 89^{+271}$

Fillastre, Guillaume (*um 1400; † 1473), Bf. von Tournai, Abt von Saint-Bertin, Kanzler des Ordens vom Goldenen Vlies $87 f^{257,264}, 244^{347}$

Flandern, Flandres (Niederlande) 9, $18^{21}$, $9,18,21,36,43,75,153,210,233^{283}$, 236, 241

Gf. s. Karl; Maximilian

Stände 21, 47, 210 ${ }^{184}, 214,216,219$

Einwohner 210, 236

amiral de la mer s. Lalaing, Josse und Simon de

Souverän-Bailli s. Lalaing, Josse de Oberkommandierender (capitaine générale) der flämischen Truppen s. Savoyen, Jakob von grant veneur s. Brügge, Jan von; Lalaing, Josse und Simon de Anti-Habsburgische Partei $108^{18}$, $123^{85}, 233^{283}$; s. Brügge, Jan von; Kleve, Philippe von

Flandern, burgund. Wappenkönig s.

Nokerscot, Gilles

Foix, Fuxum (Dép. Ariège, F), Mathieu de $\{\mathbf{4 0}\}$, Gf. von Comminges ( ${ }^{*} \mathrm{um}$ 1389, W 1440, † Dez. 1453) 90 $0^{280}, 292$

Folch, Juan Ramon (1418-1486), Gf. von Cardona und Prades, Admiral von Aragón 256f. ${ }^{+18}$

Forlì (Prov. Forlì-Cesena, I), Herr s. Riario, Girolamo

Foûvent (Dép. Haute-Saône, F), Herr s. Vergy 
France s. Frankreich

Francesco del Balzo ( $†$ 1482), Hz. von

Andria, Cousin Kg. Ferdinands $\{72\}$,

Mitglied des Hermelinordens

$258 \mathrm{f}^{+22,35}$

Franche-Comté, Freigrafschaft Burgund (Hauptstadt Dôle, F), Gft. 9, 16, $138^{160}$, $190,202^{155}, 209^{180}, 214,221-225$

Gf. s. Karl; Maximilian

Statthalter s. Johann, Fürst von

Orange

Herold Franche-Comté s. Ysaac, Thomas

Frankreich, France 9, 17, 433, 52 f. $^{50,58,60}$, 60, 66-68, 73f., 87, 91, 115 f., 157, 179, 190, 192, 202, 204 $4^{164}, 211,221-224$, $226,229^{265}, 234-236^{+286}, 239,242,266$, 272 f., 280

Kg. s. Ludwig XI.; Karl VIII.

Dauphin s. Karl VIII.

Ritterorden s. Michaels-Orden

Konnetable s. Luxembourg, Louis de burgund. Gesandter s. Clugny, Ferry de; Fusil

Friedrich (Frédéric) III. \{94\}, röm.-dt. König und Kaiser, Hz. von Österreich $\left({ }^{*} 21.1 .1415, \mathrm{~W} 1478, \dagger 19.8 .1493\right) 7$,

$10,13,17 \mathrm{f}^{+22}, 21^{38}, 28-31^{+90,93}, 43^{3}, 45-$ $47^{+12 f ., 17,19}, 53^{60 \mathrm{f} .}, 55,59 \mathrm{f.}^{+85}, 83 \mathrm{f.}^{+238,242}$, $94,117^{55}, 121^{+76}, 131-136^{+140 \mathrm{f} .}, 146,148$, $169^{+315}, 175-177^{+5}, 179,181-183,201$, $259^{27}, 262,268,270^{64}, 277$

Ehefrau s. Eleonore

Sohn s. Maximilian

Schwester s. Österreich, Katharina von

Hof $46^{17}, 176^{5}$,

Räte s. Heßler, Georg; Keller, Johann; Liechtenstein, Bartholomäus von; Starhemberg, Bartolomäus von; Werdenberg, Haug von Kanzler s. Heßler, Georg Fiskalprokurator s. Keller, Johann Gesandte $18^{+22}, 45-47,53^{+58}, 176^{5}$; s. Johann von Baden; Heßler, Georg; Keller, Johann; Maroltinger, Wilhelm; Ludwig von Veldenz burgund. Gesandte s. Liechtenstein
Friedrich von Aragón (142-1504), Kg. von Neapel, Mitglied des Hermelinordens $258 \mathrm{f}^{+22,33}$

Vater s. Ferdinand $\{72\}$

Bruder s. Alfons II.

Friedrich I. der Siegreiche, Kurfürst und Pfalzgraf bei Rhein $(† 1476) 259^{+27}$ Neffe s. Philipp

Friesland, Frise (Norddeutschland/Niederlande), Herr s. Karl; Maximilian

Fugger, Johann Jacob $(†$ 1575) 18

Fusil, Fuzil, burgund. Herold s. Loncle Jean

Fuxum s. Foix

\section{G}

Gand s. Gent

García Álvarez de Toledo († 1488), Hz. von Alba de Tormes, Marques von Coria $256^{+16}$

Garter, Garretiere, Orden s. Hosenbandorden Wappenkönig s. Wrythe, John Geldern, Gheldres (Nordrhein-Westfalen, D/Niederlande), Hzt. 9, $43^{3}, 45^{13}$, 68f. ${ }^{166}, 83^{238}, 90,190^{+84}, 210$

Hz. s. Adolf; Karl von Burgund; Karl von Geldern; Maximilian Regentin s. Katharina Marschall und Generalstatthalter s. Nassau, Adolf von Aufständische $69^{166}, 190^{84}$, Gent, Gand (Prov. Ost-Flandern, B) (Veranstaltungsort des Ordensfestes im Jahr 1445) 18 $18^{+22}$, 34f., 46-51 $1^{+18}$, $58 \mathrm{f} ., 69^{167}, 84^{242}, 94,142,146,156,160$, 180, 208, 213-216, 219f., 222-226, 228, 230 f., 255, 261, 270 f., 283 f., 286-288, 293

Stadtobrigkeit 47

Kirche Saint-Michel 47

Sankt-Peters-Abtei, Saint Pierre Abt s. Conrault, Philippe

Hzl. Residenz Ten Walle/Prinsenhof 8, $48^{+31}, 53,55$ f., 208

Kapelle 48

Unterkunft von Ludwig von Brügge $8,49,53$ 
Genua, Genova (Prov. Ligurien, I) 89

Georg, Heiliger 96

Georg von York, Hz. von Clarence $(†$ 1478) 17

Germanie s. Deutsches Reich

Gideon, Gedeon, alttest. Richter, Patron des Ordens vom Goldenen Vlies $76^{207}$, 86,88

Gobet, Gilles, Wappenkönig Toison d'or (1468-1491) 11, 21, 24-26 $6^{+52}, 30^{90}$, $32 \mathrm{f} ., 37,49^{+39}, 51,53,56,58,61-64$, 70 f., $75,77-82^{+212,216}, 95,97,101,103$, 108-116, 118, 128 f., 138f., 142-144f., $149^{220 f}, 152,157-161^{+270}, 163-173,175$, 181, 185-191, 197, 202, 208, 214f., 220 f., 226 f., 239, 242, 245 f., 249, 253, 262-266, 268, 272 f., 275 f., 278, 283 f., $286 \mathrm{f}$.

Godomar I., Gocianus, Kg. von Burgund $(† 486) 89$

Gondeval, Nicolas de, burgund. Rat, Finanzbeamter und Hofmeister, Trésorier des Orden vom Goldenen Vlies (ab 1484) $\left(†\right.$ 1485) 35, 234 ${ }^{+288}, 271,287$

Gorinchem (Prov. Südholland, NL), burgund. Persevant $77^{212}$

Grandpré (Dép. Ardennes, F), Gf. s. Borssele

Grandson (Kanton Waadt, $\mathrm{CH}$ ), Schlacht 17, 27, 67 $7^{144}$

Gratian, Kirchenrechtler ( $†$ vor 1160) 89

's-Gravenhage s. Den Haag

Grayben, Engelram, Abt von Clairmarais $(\dagger 1484) 242^{182}, 173^{+332}$

Graz (Steiermark, A) 433, $182^{41}$

Greenwich (heute Stadtteil von London, GB) 255

Gregor I., Papst $(† 604) 86$

Greveray Godefroy, (Titular-)Bf. von Dagnum, Mitglied des Hofs Hz. Philipps des Guten $187^{+73}$

Griechenland 85

Grigny (Dép. Pas-de-Calais, F), Herr s. Brimeu, Jacques de

Gros, Jean, Mag., Trésorier des Ordens vom Goldenen Vlies (seit 1477), Hz. Karls Audenzier und Sekretär für
Finanzangelegenheiten $(\dagger 1484) 24$, $35,50^{40}, 63 \mathrm{f}^{+108,110}, 77,81,96,100 \mathrm{f}$., 103, 106-109+10f. $112,138,143,145$, 158-161, 162-165, 172f., 181, 220, $234 \mathrm{f}^{288,290}, 239,245,247,263,286 \mathrm{f}$., 289

Gruuthuse, Gruithuse, Gruythuse (Lehen zu Brügge), Herr s. Brügge, Johann und Ludwig von

Guevara (Adelsfamilie aus Kastilien) Ferrante, Gf. von Belcastro, Mitglied des Hermelinordens $258 \mathrm{f}^{+22,36}$

Iñigo de $\{48\}$, Gf. von Ariano

(W 1451, † 1462) 293

Guinegatte (heute Enguinegatte, Dép. Pas-de-Calais, F), Schlacht 9f., $123^{85}$, $229^{265}, 234^{+286}$

Gundioch, Gondigarius, König von Burgund († um 473) 89

H

Habsburg (Kanton Argau, CH) 433, Gf./Haus $30,43^{3}$, $76^{207}$; s. Friedrich III.; Maximilian

Hameçons s. Holland, Adelsparteien

Haneron, Antoine, Mag., Probst von Saint-Donas in Brügge, Finanzfachmann und Diplomat Hz. Karls von Burgund ( $†$ 1490) $84^{+242}$

Haro (Prov. La Rioja, E), Gf. s. Velasco, Pedro de

Harmodios, Tyrannenmörder $(† 514$ v. Chr.) 92

Haubourdin (Dép. Nord, F), Herr s. Luxemburg, Jean de Havelu s. Aveluys

Haye, La s. Den Haag

Haynnau s. Hennegau

Haynnau, Watelet de, burgund. Herold Ravenstein 11, 200 ${ }^{+140}, 277,281 \mathrm{f}$.

Heemsrode (Prov. West-Flandern, B), Herr s. Uutkerke, Roland d'

Heestert (Prov. West-Flandern, B), Herr s. Uutkerke, Roland d'

Hénin, Hennin (Dép. Pas-de-Calais, F), Pierre de $\{\mathbf{8 8}\} \mathbf{(}^{*} 29.9 .1433, \mathrm{~W} 1481$, $+26.6 .1490) 31^{93}$ 
Hennegau, Hainaut, Haynnau, Gft.

(Hauptstadt: Mons, B) 9, 14, 52 50 , 60, $104,108^{18}, 180,217,241,249$

Gf. s. Karl; Maximilian

Statthalter s. Kleve, Adolf von

Stellvertreter s. Kleve, Philipp von

Hennegau, burgund. Wappenkönig s.

Bolin, Tristan

Hennekart, Jean, Maler Hz. Maximilians $72^{187}$

Hermelin, Orden des Kg. von Neapel

(Ordine della Arminio) 258 22

Souverän s. Ferdinand $\{72\}$

Mitglieder s. Alfons II. und Friedrich von Aragón; Francesco del Balzo;

Carafa, Diomede; Guevera, Ferrante

Hertogenbosch ('s-), Bois-le-Duc (Prov. Nordbrabant, NL) $190^{+84}, 200,280$

Herzeele (Dép. Nord, F), Herr s. Roubaix, Jean de

Heßler, Hezeler, Georg ( $†$ 1482), Dr., päpstl. Protonotar, Kardinal, Rat, Kanzler und Gesandter Ks. Friedrichs III. $46^{+19}, 53,56$

Hester s. Ester

Hoeken s. Holland, Adelspartei

Holland, Hollande (Teil der heutigen

Niederlande), Gft. 62, 194, 215, 217

Gf. s. Karl; Maximilian

Gouverneur s. Brügge, Ludwig von;

Borsele, Wolfart van

Adelsparteien (Kabeljauwen und

Hoeken/Cabillauds et Hameçons)

$180^{29}$

Dünen $180^{29}$

Homer 86

Hollet, Fastré, burgund. controlleur de la despenses $271^{+73}$

Hongrie, Honguerie s. Ungarn

Hosenbandorden, ordre de Jarretière,

Order of Garter (Garretiere), Ritter-

orden des engl. Königshauses 8,

177-179 $9^{+12,20}, 238^{+309}$

Souverän s. Eduard IV.

Wappenkönig Garter s. Wrythe, John

Statuten 179

Mitglieder s. Karl der Kühne; Mont-

gomery, Thomas; Maximilian
Housdam, Woutre de, Hz. Maximilians garde de joyaulx $234^{+289}, 287$

Hugo von Arles, Kg. von Burgund $(† 947) 89$

Hugonet, Guillaume († 1477), Kanzler von Burgund, Mitglied des Regentschaftrates Hz. Karls in den Niederlanden $49 \mathrm{f}^{40}$

Humières (Dép. Pas-de-Calais, F), Dreux de $\{46\}$, Herr von Humières (W 1445, † 21.11.1458) 293

Humbercourt (Dép. Somme, F), Herr s. Brimeu, Guy de

\section{I}

Ieper, Ippre s. Ypern

Imola (Prov. Bologna, I), Herr s. Riario, Girolamo

Infantado, (spanischer) Hz. s. Diego Hurtado de Mendoza

Irland, Yrlande, Herr s. Eduard IV.

Irlain, Yrlain [heute: Illens] (Kanton Fribourg, CH), Herr s. Baume, Guillaume de la

Isabella von Bourbon, Hz.in von Burgund $(† 1465) 13^{2}$

Ehemann s. Karl der Kühne

Tochter s. Maria

Isabella von Portugal, Hz.in von Burgund $\left(†\right.$ 1471) $87^{+262}$

Ehemann s. Philipp der Gute Vater s. Johann von Portugal Bruder s. Eduard I.

Isle-Adam (Dép. Val-d'Oise, F), Herr s. Villiers, Jean de

Italien 89

Kg. s. Berengar II

Iuvenal, röm. Satirendichter 86

J

Jakob I., Kg. von Schottland († 1437) $262^{48}$

Tochter s. Stuart, Maria

Jarretière, Garretiere,

Orden s. Hosenbandorden

Wappenkönig s. Wrythe, John

Jaspart, Gilles, burgund. Herold Ferrette $125^{96}$ 
Jerusalem, Gherusalem (Israel), Kg. s. Alfons II.; Ferdinand

Johann II. (Jean) \{57\}, Kg. von Aragón und Navarra ( ${ }^{*}$ 29.6.1398; W 1461; † 19.1.1479) 24, 28, 32, 51, 54, 62, $65 \mathrm{f} ., 72 \mathrm{f}^{+187}, 90,113,134,166,168^{\mathrm{f}+313}$, $232^{277}, 237,250,253,255,257^{18}, 260$, 265 f., 267, 277 f. ${ }^{+90}, 285,293$

Sohn s. Ferdinand $\{71\}$

Sekretäre s. Johannes de Colonia

Johann I., Kg. von Portugal († 1433) $87^{262}$

Tochter s. Isabella

Johann II. \{39\}, Hz. von Alençon, Gf. von Perche ( ${ }^{*}$ 1404/09; W 1440; † 1476) $24,68,73,90^{280}, 114,148,262$, 292

Johann II. von Baden († 1503), Kurfürst und Erzbischof von Trier, ksl. Gesandter in Burgund $47 \mathrm{f} .^{+22}, 53$

Johann (Jean) V. \{38\}, Hz. der Bretagne $\left({ }^{*} 24.12 .1389, \mathrm{~W} 1440, \dagger 29.8 .1442\right)$ $90^{280}, 292$

Johann \{56\}, Hz. von Coïmbra, Regent von Zypern (* um 1435; W 1456; † 1457) 90, 293

Johann I. \{47\} (Jehan), Hz. von Kleve, Gf. von der Mark (* 14.1.1419;

W 1451; † 5.9.1481) 7, 9, 23 f., 28, $51 \mathrm{f}^{+49}, 62,68,74,77,90,115,127 \mathrm{f}$., 158, 185, 190-192, 197-199, 212, 230, 250, 253, 259f., 265, 267, 275f., $278^{+92}$, $282,285^{110}, 293$

Mutter s. Maria von Burgund Bruder s. Kleve, Adolf von Sohn s. Johann II.

Johann II., Hz. von Kleve ( $†$ 1521), Zögling des burgund. Hofes 17, 23, $52^{+49}, 259$

Vater s. Johann I.

Johann II. von Chalon-Arlay, Fürst von Orange, hzl. Statthalter in Burgund, Taufpate Hz.in Margaretes († 1502) 10, 202f. ${ }^{+155}, 209^{180}, 217,219,256,262$ Johanniter, Ritterorden auf Rhodos Josse NN., Mag, Sekretär Hz. Maximilians 54
Jougne (Dép. Doubs, F), Pierre de, Hofmeister von Hugues de Chalon und dessen Gesandter am burgund. Hof $202^{+138}$

Juda, alttest. Stammvater 88

Judas Makkabäus, jüd. Freiheitskämpfer $(† 160$ v. Chr) 91

Jülich (Nordrhein-Westfalen, D), Hz. s. Wilhelm IV.

K

Kabeljauwen s. Holland, Adelspartei

Kärnten, Karinthe, Hz. s. Maximilian

Kalabrien (Süditalien, I), Hz. s. Alfons II. von Aragón

Karinthe s. Kärnten

Karl V. $\{108\}$ ( ${ }^{*}$ 24.2.1500; W 1501; $\dagger$ 21.9.1558), röm.-dt. Kaiser, 5. Souverän des Ordens vom Goldenen Vlies (1506-1555) $79^{216}, 83^{239}$

Karl VIII., Dauphin, dann Kg. von Frankreich $(†$ 1498) 17

Karl (Charles) der Kühne \{34\}, Hz. von Burgund, Lothier, Brabant, Limburg und Geldern, Gf. von Flandern, Artois, der Gft. Burgund, Hennegau, Holland, Seeland, Namur und Zutphen, Mgf., des Reiches (Antwerpen), Herr von Friesland, Salins und Mecheln, Souverän des Ordens vom Goldenen Vlies, Mitglied des Hosenbandordens ( ${ }^{*} 10.11 .1433$; W 1433; † 5.1.1477) 7, 9, 11, $13 \mathrm{f.}^{+2}$, $16-18^{+20}, 21,24-27,29,31,33^{109}$, $36,43-46^{+3,9,13,16}, 50,53-56^{+61}, 58$,

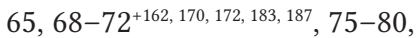
83-85 +238, 241f., 90, 93-95+309, $102^{333}, 106$, $107^{110}, 109 \mathrm{f}^{+20}, 130,133^{140}, 138 \mathrm{f}^{+160}$, 142 f., $145,147,153^{232}, 158-160^{271}, 178-$ $180^{+17,20,28}, 190^{84}, 195^{100}, 204^{164}, 209 \mathrm{f.}^{+180}$, 233 f. $^{283,288}, 241,243^{342}, 250$ f. $^{5,6}, 255$, $259^{27}, 261-263^{+44}, 269$ f. $^{+71}, 279$ f., 292 Vater s. Philipp Ehefrauen s. Isabella; Margarete Tochter s. Maria

Schwiegersohn s. Maximilian Hof 17, 21, 25, 30, $46 \mathrm{f}^{+17}, 69^{170}, 78 \mathrm{f}$., $81 \mathrm{f} ., 259^{33}$ 
Kanzler s. Hugonet, Guillaume

Rat

Räte s. Baden, Georg von; Bouverien, Jan van der; Brimeu, Guy de; Carondelet, Jean de; Clugny, Ferry und Guillaume de; Chalon, Hugues de; Crèvecœur, Philippe de; Gondeval, Nicolas de; Hugonet, Guillaume; Lalaing, Josse de; Wassenaar, Jan I. van

Finanzrat s. Haneron, Antoine Argentier s. Gondeval, Nicolas de Kammerherren s. Burgund, Anton von; Carondelet, Jean de; Chalon, Hugues de; Crèvecœur, Philippe de; Lalaing, Josse de; Luxemburg, Jacques de

grant maître de l'hôtel s. Pot, Philippe Audenzier s. Gros, Jean

huissier de salle s. Chesne, Philippe du Sekretär s. Chesne, Philippe du; Gros, Jean; Ruter, Nicolas de Wappenoffiziere s. Aliemar, Enguerrand; Bolin, Tristan; Ferrette; Flandern; Hennegau; Jaspart, Gilles; Liefkins, Jacob; Limbourg; Lothier; Namur; Peletier, Guillaume; Rose, Colinet ; Sainte Aldegonde, Jean de Pensionär s. Savoyen, Philipp von Truppenführer s. Chalon, Hugues de; Croy, Philippe de; Luxemburg, Jacques de; Neufchâtel, Jean de ; Savoyen, Jakob von Gesandte 45, $133^{140}$; s. Haneron, Antoine; Luxemburg, Jacques de

Karl, Hz. von Geldern $\left(†\right.$ 1538) $190^{84}$ Vater s. Adolf von Geldern

Karl (Charles) \{37\}, Hz. von Orléans ( $\left.{ }^{*} 24.12 .1394, \mathrm{~W} 1440, \dagger 4 . / 5.12 .1465\right)$ $90^{280}, 292$

Karneid (Prov. Bozen, I) s. Liechtenstein-Karneid

Kastilien, Castille (Spanien) 256f. ${ }^{14,17,19}$, $259^{36}$

Kg. s. Ferdinand

Adel s. Enriquez; Guevara; Pimentel; Velasco
Konstabel s. Velasco, Pedro de Admiral s. Enriquez, Alfons

Katharina, Regentin des Hzt.s Geldern $\left(†\right.$ 1497) $190^{84}$

Bruder s. Adolf von Geldern

Keller, Kelner, Johann, Ks. Friedrichs III. Rat, Gesandter und Fiskalprokurator, Hz. Maximilians Rat, valet de chambre und somelier de corps $(† 1489)$ $175-177^{+5}, 268$

King, Oliver, Sekretär Eduards IV., Kg. von England $268^{+58}$

Köln (Nordrhein-Westfalen, D), Stadt 17, 47

Kyburg, Kanont Zürich, CH), Gf. 433; s. Maximilian

Kleve, Clèves (Nordrhein-Westfalen; D) 90, 198, 278

Hz. s. Johann I.; Johann II.

Hz.in s. Maria von Burgund

Familie:

Adolf von $\{55\}$, Herr von Ravenstein, Statthalter im Hennegau ( ${ }^{*} 28.6 .1425$;

W 1456; † 18.9.1492) 8f., 19, 21, $23 \mathrm{f}^{+52}, 28,32^{100}, 51 \mathrm{f}^{+50}, 57,61,64-66$, $68,74,77,79-82^{+217}, 95-97,99,103$, 105, 108, 112 f., 115 f., 119, 124, 138, 145, 161, 163 f., 167, 172f., 181, 193, 198, 200, 204, 213 f., 218 f., 220-223 ${ }^{+236}$, 230, 238, 245, 250, 252f., 255-257, 259 f., $270^{64}, 272$ f., 276, 278, 282, 285 , 288, 293

Mutter s. Maria von Burgund

Sohn s. Philipp

Bruder s. Johann I.

s. Johann I.

s. Johann II.

Philipp von, Hz. Maximilians Rat, Kammerherr und Truppenführer, stellvertretender Statthalter im Hennegau († 1528) 17, 108 f. ${ }^{+18}, 259$ Vater s. Adolf

Krain, Carniole, Hz. s. Maximilian

L

La s. erstes Hauptwort Lalaing (Dép. Nord, F) 
Jacques de $\{\mathbf{5 1}\}$, Herr von Bugnicourt (* um 1420/22; W 1451; $+3.7 .1453) 293$

Josse de $\{\mathbf{8 0}\}$, Herr von Montignies, Souverän-Bailli und grand veneur von Flandern, des amiral de la mer und des capitaine von Sluis, Hz. Karls Rat und Kammerherr, Hz.in Marias chevalier de compaigne und chevalier d'honneur (* um 1437; W 1478; † 5.8.1483) $24^{52}, 28 \mathrm{f}^{+74}, 31 \mathrm{f}^{+93}$, $34^{113}, 123^{+84}$, 137 f., $148 \mathrm{f}$., $152-156^{232}$, 161-164, 166-168, 172, 187-189, 208, 213 f., 219, 228, 234, 262 f., 265, 267, 282-284, 288, 294

Vater s. Simon

Simon (Symon) de $\{26\}$, Herr von Montignies, grand veneur von Flandern, des amiral de la mer und des capitaine von Sluis (* um 1405; $\mathrm{W} \mathrm{1431;} \mathrm{†} \mathrm{15.3.1477)} \mathrm{24,} \mathrm{68,} \mathrm{74,} \mathrm{114,}$ $148,153^{232}, 262,292$

Langobarden 89

Lannoy (Dép. Nord, F)

Baudouin de $\{19\}$, dit le Bègue, Herr von Molenbaix ( ${ }^{*} 1389$; W 1430; † 1474) $24,68^{+162}, 74,114,148,246^{352}$, 262, 291

Neffe s. Jean (Kanzler)

Baudouin de $\{89\}$ ( ${ }^{*}$ um 1436;

W 1481; † 7.5.1501) $68^{162}$

Guilbert de $\{\mathbf{1 2}\}$, Herr von Willerval (* 1386; W 1430; † 22.4.1462) 246 ${ }^{+352}$, 291

Sohn Jean (Kanzler)

Hue de $\{7\}$, Herr von Santes $\left({ }^{*} 1384\right.$;

W 1430; † 1.5.1456) 246 2352,291

Neffe s. Jean (Kanzler)

Jean de, Abt von Saint-Bertin bei Saint-Omer, Rat Hz. Maximilians, Kanzler des Ordens vom Goldenen Vlies (seit 1480), Vorsitzender des Rats von Mecheln († 1492) 35, 39, $164^{+294}, 242^{182}, 244-248^{+347}, 289$

Vater s. Guilbert

Jean de $\{\mathbf{5 0}\}$, Herr von Lannoy (* 27.4.1410; W 1451; † 18.3.1493) 21, $23 \mathrm{f.}^{+52}, 26,28,48^{30}, 52,64 \mathrm{f} ., 68,74,77$,
$79-82^{219}, 95-99^{+319}, 105,112,114 \mathrm{f}$. , 119, 123 f., 138, 145, 151, 154, 156, 161 , 163f., 167, 172, 228, 235, 238, $245 \mathrm{f.}^{+352}$, 256, 261, 282, 285, 293

Onkel s. Croy, Antoine de

Le s. erstes Hauptwort

Leiden (Prov. Süd-Holland, NL), Burggf. s. Wassenaar, Jan van

Lembourg s. Limburg

León, Königreich (Nordwesten der iberischen Halbinsel), Kg. s. Ferdinand $\{71\}$

Leuven s. Löwen

Liechtenstein, Lichtesteyn (bei Leifers, Prov. Bozen, I), Herren von L.-Karneid Bartholomäus (Bertremy) $\{\mathbf{8 5}\}$ von Liechtenstein-Karneid, Hz. Maximilians Hofmeister, Rat Ks. Friedrichs III. und Sigmunds, Hz. von Österreich, burgund. Gesandter (*um 1415, W 1478, † 1493) 10, $24^{52}, 28 \mathrm{f.}^{+74}, 31 \mathrm{f}^{+93,100}, 37,53,57^{71}$, $83,117^{+54}, 136 \mathrm{f}^{+152}, 148-151,155 \mathrm{f}$., $161 \mathrm{f.}^{278}, 175,181-184,201,265,267$, $276 \mathrm{f} ., 284,294$

Wilhelm $(† 1432)$, Vater von Bartholomäus $136^{153}$

Ehefrau s. Wolkenstein-Trostburg, Martha von $136^{153}$

Liège s. Lüttich

Ligne (Prov. Hennegau, B), Jean de $\{87\}$, Herr von Ligne ( ${ }^{*}$ um 1435; W 1481; $\dagger$ 15.5.1491) $262^{+46}$

Ligny-en-Barrois (Dép. Meuse, F), Gf. s. Luxembourg, Jean de

Ligny(-sur-Canche) (Dép. Pas-deCalais, F), Herr s. Brimeu, David de Lille (Dép. Nord, F) (Veranstaltungsort der Ordensfeste in den Jahren 1431 und 1436) 9, 194, 212, 238-242, 268 ${ }^{57}$, 292

Cambres de Compres (CC) 271

Beamter s. Cottignies, Guillaume de

Limburg, Lembourg (heute Prov. Lüttich, B), Hz. s. Karl; Maximilian Hz.in. s. Maria Herold s. Rose, Colinet 
Loche, Guillaume de, burgund. Herold Namur $62^{100}$

Loncle, Jean, burgund. Herold Fusil 7, 11, 16 f. $^{17}, 27,77^{+212}, 143$ f., 195-197, $272 \mathrm{f} ., 279 \mathrm{f}$.

Löwen, Louvain, Leuven (Prov. fläm. Brabant, B) 208

Lorraine s. Lothringen

Louvain, Leuven s. Löwen

Lens (Dép. Pas-de-Calais, F), Herrschaft $70 \mathrm{f}$.

Lopponig s. Loupoigne

Lothier, Lothrijc, Lothrijck (Niederlothringen)

Hz. s. Karl; Maximilian

Hz.in. s. Maria

Lothier, burgund. Herold s. Sainte Aldegonde, Jean de

Lothringen, Lorraine, Hzt. (Hauptstadt Nancy, Dép. Meurthe-et-Moselle, F) $44^{+9}, 75,91,109^{20}$

Hz. s. René

Loupoigne, Lopponig (Prov. Wall. Brabant, B) $195^{100}$

Herr s. Chesne, Philippe de

Louvain s. Löwen

Lucilius, röm. Ritter 92

Ludwig XI., Kg. von Frankreich (14611483) $7-9,16 \mathrm{f}^{+17}, 20,23,25,27,29$, $44^{9}, 50^{40}, 60^{85}, 69-70^{170-172,174,179}, 103^{344}$, $109^{20}, 123^{85}, 133^{140}, 138^{160}, 146,168 \mathrm{f}$., $180^{29}, 190^{84}, 194$ f., $204^{164 \mathrm{f}}, 209^{+180}, 215$, $218,221-225,234^{286}, 236 \mathrm{f}^{+295,300}, 272$, 277, 279f. ${ }^{+95,97}, 284,286$

Schwester s. Yolande von Savoyen Mündel s. Savoyen, Louise von Hof $7,11,16^{+17}, 27,35,50^{40}, 237^{300}$, $251 \mathrm{f}$., 266, 280

Räte 280 ; s. Brügge, Jan von; Crèvecœur, Philippe de; Luxembourg, Jacques de; Pot, Philippe Kammerherren s. Damas, Jean; Luxembourg, Jacques de; Pot, Philippe Armee 14, 16, 22, 69 $9^{171}, 104,146,168$, $209^{180}, 221-225$

Ritterorden s. Michaels-Orden Pensionäre 8; s. Arson, Jean d'; Bourbon, Pierre de; Burgund, Anton von,
Baudouin und Johann; Damas, Jean; Luxembourg, Jacques de; Neufchâtel, Jean de

Gefangene 8, 25, 29, 67 f., 70 f., 110, 190, 192, 202, 204 ${ }^{164}, 279$ f. $^{+95}$; s. Burgund, Anton von; Chalon, Hugues de; Luxembourg, Jacques de burgund. Parteigänger $7 \mathrm{f}$., $16^{+16}, 25 \mathrm{f}$., 35, 70 f., $107^{11}$, 109 f., 195 f., 266, 272 f., 278; s. Burgund, Anton von; Clugny, Guillaume de; Crèvecœur, Philippe de; Damas, Jean de; Luxembourg, Jacques de; Neufchâtel, Jean de; Pot, Philippe burgund. Gesandte s. Fusil

Ludwig (von Bayern), Pfalzgraf und $\mathrm{Hz}$. von Pfalz-Zweibrücken-Veldenz, Gesandter Ks. Friedrichs III. in Burgund $(† 1489) 31^{+93}, 46^{+18}$

Ludwig de Chalon-Arlay, Fürst von Orange $(† 1463) 291^{+3}, 137 \mathrm{f}^{160}, 291^{+3}$

Sohn s. Chalon, Hugues des

Lüttich, Liège, Leodium (Belgien) 90

Luxemburg, Luxembourg, Luczembourg 241

Hzt. 209

Hz. s. Maximilian

Statthalter s. Croy, Philippe de;

Neufchâtel, Claude de

Herold Luxembourg $77^{212}$

Antiburgund. Partei $241^{+327}$; s.

Rodenmacher, Gerhard von; Virneburg, Georg von

Familie

Jacques de $\{67\}$, Herr von Richebourg, Hz. Karls Truppenführer und Gesandter, frz. Gefangener, Rat Kg. Ludwigs XI., Mitglied des Michaelordens (* um 1420; W 1468; Ausschluss 1481 ; † 20.8.1487) $7 \mathrm{f} ., 17^{17}, 24-28$, 51, 62, $66 \mathrm{f}^{+137}, 70 \mathrm{f.}^{+178}, 73,110 \mathrm{f} ., 115$, 128, 185, 195-197, 251f., 254, 266, 273 , $279 \mathrm{f}^{+}{ }^{+95}, 284^{110}, 293$

Ehefrau 8

Bruder s. Louis

Jacques de $\{\mathbf{8 1}\}$, Herr von Fiennes, Rat, Kammerherr und Truppenführer Hz. Maximilians ( ${ }^{*}$ nach 1441; W 1478; 
$\dagger$ 1.2.1488) 28f., $140^{+169}, 148,170^{319}$, 187, 189, 193f., 204, 209, 214f., 223, 228 , 230, 234, 262, 264f., 267, 282, 284f., 294

Jean de $\{13\}$, Gf. von Ligny-en-Barrois (* um 1390; W 1430; † 5.1.1441) 291

Jean de $\{33\}$, Bastard von Saint-Pol, Herr von Haubourdin (* um 1400; W 1433; † 28.7.1466) 292

Jean de $\{75\}$, Gf. von Marle (* um 1436; W 1473; † 22.6.1476) 24, 67 ${ }^{+146}$, 73, 116, 148, 262, 294

Louis I de, Gf. von Saint-Pol, Konnetabel von Frankreich $\left(†\right.$ 1475) $71^{178}$, $204^{164}$

Pierre de $\{\mathbf{1 0}\}$, Gf. von Saint-Pol (* 1390; W 1430; † 31.8.1433) 291

Pierre de $\{83\}$, Gf. von Saint-Pol, Conversano und Brienne (* um 1440, $\mathrm{W} 1478, \dagger 25.10 .1482) 6,10,24^{52}$, $28 \mathrm{f.}^{+74}, 31 \mathrm{f.}^{+93}, 82 \mathrm{f}^{+237}, 103,108 \mathrm{f} ., 118$, 137 f., 148 f., 152, 155 f., 161-164, 167, 173, $176 f$., 187, 189, 193f., 203-208, 213 f., 219, 228, 230, 235, 239, 262, 267, 272f., 276, 278, 282-284, 294

\section{M}

Maastricht, Trecht sur Meuse (Prov. Limburg, NL) $210^{+185}, 255$

Mâcon (Dép. Saône-et-Loire, F) 8, 23, 66f., 250, 252, 254

frz. Amtmann s. Damas, Jean de

Mâconnais (Region um Mâcon, Dép. Saône-et-Loire, F) 69 $69^{171}, 126$

Bailli, Gouverneur und frz. lieutenant général des Mâconnais s. Damas, Jean

Macrobius, spätantiker Philosoph († um 385/390) 87

Maddaloni (Prov. Caserata, I), Gf. s. Carafa, Diomede

Madrid (Spanien) 255-257

Maizicourt (Dép. Somme, F), Herr s. Brimeu, Colart de

Makedonien, Kg. s. Alexander der Große; Philipp II.

Malet, Thomas $103^{333}$

Malines s. Mecheln

Manrique (Adelsfamilie aus Kastilien) s. Pedro
Marche, La (bei Villegaudin, Dép. Saône-et-Loire, F) Olivier de, maitre d'ostel Hz. Maximilians († 1502) 11, $20^{29}, 32,63^{+105}, 84^{243}, 194$ f., 260, 271 , 281

Marcus Porcius Cato Censorius, genannt Cato der Ältere, († 149 v. Chr.), röm. Staatsmann und Schriftsteller 92

Margarete von Burgund (1480-1530) $46^{16}, 202^{155}, 287 \mathrm{f}^{+114}$

Eltern s. Maximilian und Maria Taufpate s. Johann von Chalon-Arlay Margarete von York, Hz.in von Burgund (madame la grant) (1446-1503) 11, $18^{+22}, 20,46-48^{+16,20}, 76,82,177 \mathrm{f}^{+13}$, 287

Brüder s. Eduard IV.; Georg Ehemann s. Karl der Kühne Stieftochter s. Maria Schwiegersohn s. Maximilian Enkel s. Margarete; Philipp der Schöne Hof 47, 76, $177^{13}$

Kammerherr s. Baume, Guillaume de la

fremde Gesandte 46; s. Georg von Baden; Heßler, Georg; Ludwig von Veldenz

Maria, Hz.in von Burgund, Österreich, Brabant, Lothier, Limburg usw. (1455-1482) $7 \mathrm{f}^{+2}, 13^{+2}, 15-20^{+16,18,21}$, $23,33,36,43-48^{+3,13,16,18,28,30}, 50,52^{+49}$, 54-56, 58, 69 ${ }^{170 f .}, 71,75$ f., 82, 85, $91 \mathrm{f}$., 93, $94 \mathrm{f} ., 108^{18}, 124,138^{160}, 139,153^{232}$, 173, 177 f. ${ }^{13 f}, 180^{28}, 187,195^{+100}, 204^{+166}$, 209 f. $^{+184}, 216^{215}, 225,236^{297}, 250-252$, $259^{29,33}, 269 \mathrm{f}^{+71}, 286$

Eltern s. Karl; Isabella Großvater s. Philipp Stiefmutter s. Margarete Ehemann s. Maximilian I. Kinder s. Margarete; Philipp der Schöne

Onkel s. Kleve, Adolf von

Hof 47, 76, 173, 187

Rat s. Carondelet, Jean de; Tolentis, Lucas de 
chevalier de compaigne s. Lalaing, Josse de

Kammerherren, chevalier d'honneur

s. Baume, Guillaume de la; Carondelet, Jean de; Crèvecœur, Philippe de; Lalaing, Josse de; Brügge, Ludwig von; Wassenaar, Jan I. van maistre de requestes $\mathrm{s}$. Tolentis, Lucas de maistre d'ostel s. Chesne, Philippe du Sekretär s. Ruter, Nicolas de

Maria von Burgund, Hz.in von Kleve $\left(†\right.$ 1463) $79^{217}$

Bruder s. Philipp der Gute

Söhne s. Kleve, Adolf und Johann

Maria von Burgund ( $†$ 1422), Hz.in von Savoyen $233^{283}$

Vater s. Philipp der Kühne

Enkel s. Savoyen, Jakob von

Mark (von der), de la Marke, Marque (Nordrhein-Westfalen, D), Gf. s. Johann

Marle (Dép. Aisne, F), Gf. s. Luxemburg, Jean

Maroltinger, Wilhelm, Dr., Gesandter Ks. Friedrichs III., Rat Hz. Maximilians $(† 1482) 15,53^{+58}, 55 \mathrm{f}$.

Martelli, römische Patrizierfamilie 89, 92

Masmines, Massemen (Oost-Vlaanderen), Robert de $\{\mathbf{1 7}\}$, Herr von Masmines $\left({ }^{*} 1385 / 90, \mathrm{~W} 1430, \dagger 9.1430\right)$ 291

Matthias Corvinus, Kg. von Ungarn $(† 1490) 10,28-30^{+90,93}, 133-135^{+140}$, 146 f., 149, 169+315 $175,179,181$ f., 184, 201, 256, 258, 268

Maximilian I. $\{77 b\}\left({ }^{*} 22.3 .1459\right.$; † 12.1.1519), Erzhzg. von Österreich, Hz. von Burgund, Lothier, Brabant, Steyer, Kärnten, Krain, Limburg, Luxembourg, Geldern, Gf. von Flandern, Tirol, Habsburg, Pfirt, Kyburg, Artois, der Gft. Burgund, Hennegau, Holland, Seeland, Elsass, Namur und Zutphen, Mgf., des Reiches (Antwerpen), Herr von Friesland, Salins, Mecheln, der Windischen Mark und Portenau, spä- terer röm.-dt. Kg. und Ks, 3. Souverän des Ordens vom Goldenen Vlies (ab 1478) passim

Eltern s. Friedrich III.; Eleonore Ehefrau s. Maria

Kinder s. Margarete; Philipp der Schöne

Schwiegervater s. Karl

Schwiegermutter s. Margarete

Onkel s. Sigmund von Österreich Feinde s. Ludwig XI.

Vertraute s. Nassau, Adolf von Statthalter (für diverse Herrschaften) s. Burgund, Philipp von; Starhemberg, Bartolomäus von Hof $6^{2}, 20-22,28,30,33,49,53^{+58}$, 71 ${ }^{179}, 78 \mathrm{f}$., 81-84, 108f., 111, 118, 173, $187,206,238^{309}, 246,249,251,259^{29}$, 269-271

Hofrat (conseil privé) 53-55, 59 Präsident s. Bouverien, Jan van der

Großer Rat (Grand Conseil) 94, 219, 270

Präsident s. Bouverien, Jan van der

Räte 15; s. auch Bouverien, Jan van der; Burgund, Philipp von; Carondelet, Jean de; Chesne, Philippe du; Clugny, Ferry de; Conrault, Philippe; Gondeval, Nicolas de; Keller, Johann; Kleve, Philipp von; Lannoy, Jean de; Luxemburg, Jacques de; Maroltinger, Willhelm; Melun, Jean de; Starhemberg, Bartolomäus von; Tolentis, Lucas de; Wassenaar, Jan I. van; Werdenberg, Haug von Kammerherren s. Baume, Guillaume de la; Bouverien, Jan van der; Brügge, Jan von; Burgund, Philipp von; Carondelet, Jean de; Croy, Philippe de; Kleve, Philipp von; Luxemburg, Jacques de; Melun, Jean de; Wassenaar, Jan I. van Rechnungskammer (Chambre des Comptes) 274, 282, 288

Finanzbeamte 271 
maistre de requestes $\mathrm{s}$. Tolentis,

Lucas de controlleur de la despenses s. Hollet, Fastré

Trésorier s. Gondeval, Nicolas de Hofmeister, maistre d'hostel s. Aveluys, Nicolas d'; Gondeval, Nicolas de; Liechtenstein, Bartholomäus von; Marche, Olivier de la; Nassau, Adolf von

Hofmaler s. Coustain, Pierre; Hennekart, Jean

Marschall s. Nassau, Adolf von

Armee 103, 210, 212, 214, 217, 219-225, 234 $4^{286}, 238$

Truppenführer s. Baden, Christoph von; Burgund, Philipp von; Chalon, Hugues de; Croy, Philippe de; Kleve, Philipp von; Nassau, Engelbert von; Luxembourg, Jacques de; Savoyen, Jakob von

Sekretäre s. Josse; Steenberch, Martin; Ruter, Nicolas de Wappenkönige, Herolde usw. $62^{+100}, 84$, 108, 118, 214; s. Artois; Brabant; Burgund; Charolais; Chasteu Belin; Ferrette; Flandern; Franche-Comté; Fusil; Gobet, Gilles; Gorinchem; Hennegau; Limburg; Loche, Guillaume de; Loncle, Jean; Limbourg; Lothier; Luxembourg; Namur; Nokerscot, Gilles; Orscamp; Peletier, Guillaume; Quesnoy; Quiquelberghe, Armand de; Ravenstein; Rupelmonde; SaintGeorge; Salins; Toison d'or Beichtvater s. Conrault, Philippe valet de chambre und somelier de corps s. Keller, Johann garde de ses joyaulx s. Housdam, Woutre

Gesandte s. Baume, Guillaume de la; Clugny, Ferry de; Fusil; Lannoy, Jean de; Liechtenstein, Bartholomäus; Ravenstein; Rupelmonde Fremde Gesandte 33, 187; s. Ferdinand \{72\}; Chalon, Hugues de; Eduard IV.; Jougne, Pierre de; Maroltin- ger, Wilhelm; Montgomery, Thomas;

Tolentis, Lucas de; Wrythe, John

Mecheln, Malines, Mechelen (Prov. Brabant, B), Stadt $18^{22}, 230 \mathrm{f}^{+266}$

Herr s. Karl; Maximilian

Rat

Vorsitzende s. Carondelet, Jean de;

Lannoy, Jean de

Parlament $83^{239,241}, 243 \mathrm{f}^{342,347}$

Vorsitzender s. Carondelet, Jean de;

Clugny, Ferry de

Mitglieder s. Bouverien, Jan van der

Megen, Meghen (Prov. Nordbrabant,

NL), Gf s. Brimeu, Guy de

Melun (Dép. Seine-et-Marne, F), Jean de $\{\mathbf{2 8}\}$, Herr von Antoing, Rat und Kammerherr Hz. Maximilians (* um 1397; W 1432; † 15.2.1484) 10, $23 \mathrm{f}$., $28,49,52$ f., 65 f., $73,80^{219}, 109^{20}, 114$, $132^{137}, 137^{157}, 202^{155}, 208,213 \mathrm{f} ., 219$, 228, 257 f., 260-262, 266, 283 f., 292

Mendoza s. Diego Hurtado de Mendoza Metz (Dép. Moselle, F) 46 ${ }^{17}$, Bischof s. Baden, Georg von

Michaels-Orden, ordre de Saint-Michel, Ritterorden Ludwigs XI., Kg. von Frankreich 8, 25 $5^{+59}, 70$ f. $^{+174}, 110 \mathrm{f} ., 128$, $236 \mathrm{f}^{+300}, 279 \mathrm{f}$.

Souverän s. Ludwig XI.

Mitglieder s. Crèvecour, Philippe de; Damas, Jean; Neufchâtel, Jean de; Pot, Philippe; Luxembourg, Jacques de

Moers, Meurs (Nordrhein-Westfalen, D), Gf. Friedrich von $\{25\}\left({ }^{*} 1392\right.$, $\mathrm{W} 1431, \dagger$ 11.7. 1448) 292

Molenbaix, Molembais (Prov. Hennegau, B), Herr s. Lannoy, Baudouin de

Mons (Prov. Henngau, B), Stadt (Versammlungsort des Ordens im Jahr 1451) $20,60,67 \mathrm{f} ., 80^{219}, 123-125$, 127, 152, 194, 219, 233, 249, 265-267, 293

Montaigu, Claude de $\{\mathbf{7 0}\}$, Herr von Couches ( ${ }^{*}$ um 1406; W 1468; $\dagger$ 14.3.1471) $72^{187}, 293$

Montaigu, Montagu (bei Vesoul, Dép. Haute-Saône, F), Herr s. Neufchâtel 
Montgomery, Thomas ( $†$ 1494), Mitglied des Hosenbandordens und Gesandter Kg. Eduards IV. von England 201 ${ }^{144}$, $238^{+309}, 281$

Montignies, Montigny (Dép. Nord, F), Herr s. Lalaing

Mornay (Dép. Ain, F), Herr s. Toulongeon, André de

Murten (Kanton Fribourg, CH), Schlacht $27,67^{146}$

$\mathbf{N}$

Najera (Prov. La Rioja, E), Hz. s. Pedro Manrique

Namur (Belgien), Gft. $137^{157}$

Gf. s. Karl; Maximilian

Statthalter s. Burgund, Philipp von

Herold $62^{+100}, 70,77^{212}, 251 \mathrm{f}$., 254;

s. Loche, Guillaume de; Peletier,

Guillaume le

Nancy, Nancey (Dép. Meurthe-et-Moselles, F), Schlacht $13,18,27,44^{+9}, 67^{145}$, $71^{178}, 75,109^{20}$

Naples s. Neapel

Nassau, Nassow (Rheinland-Pfalz, D), Gf.: Adolf (1443-1511), Gf. von NassauWiesbaden, Hz. Maximilians Marschall, Hofmeister und Vertrauter, Marschall und Generalstatthalter von Geldern und Zutphen $83^{+238}$, 96 f., $103,190 \mathrm{f}^{84}$

Engelbert von $\{77\}$, Gf. von Vianden, Herr von Breda, Seneschal von Brabant, Truppenführer Hz. Maximilians (* 17.5.1451; W 1473; $+31.5 .1504) 10,23 \mathrm{f}^{+52}, 28,32^{100}, 49$, 53, 61, 64 f., 67 f., 74, 77, 81 f., 97, 100, $105,108,112,116,119-122,138,145$, $150,161^{278} 164$, $176 \mathrm{f}$., 181, 209, $213 \mathrm{f}$., 218-220, 223, 230, 234 f., 238, 245 , 272f., 278, 285, 289, 294

Ehefrau s. Baden, Cimburga von

Navarra, Navarre (Spanien) 90

Kg. s. Johann

Prinz s. Ferdinand $\{71\}$

Neapel, Naples (Italien) 257-259, 269

Kg. s. Alfons II., Ferdinand, Friedrich

Adliger s. Carafa, Diomede
Nestor, griech. Held 86

Neufchâtel, Neufchastel (heute Neuchâtel-Urtière, südlich Montbéliard, Dép. Doubs, F), Familie $250^{+5}$

Claude de $\{100\}$, Gouverneur von Luxemburg ( ${ }^{*} 1449 / 50$; W 1491;

$+24.2 .1505) 241^{327}$

Jean de $\{24\}$, Herr von Montaigu

( ${ }^{*}$ 1375; W 1430, Ausschluss 1431;

† 1433) 291

Jean de $\{52\}$, Herr von Montaigu, burgund. Truppenführer, Parteigänger Kg. Ludwigs XI., Mitglied des Michaelsordens ( ${ }^{*}$ 1419; W 1451; † 7.1489) 5f., 24, 27 f., 33, 52, $59^{83}$, $66 f^{+133}, 73,114,125$ f., 196, 212, $237,250^{+5}, 252$ f., $255,261,266,274$, 279-283, 285 f.+ ${ }^{+110 f .}, 293$

Thiébaut VIII de $\{36\}$, Herr von Neufchâtel (* 1387; W 1433; † 21.5.1459) 292

Thiébaut IX de $\{\mathbf{5 9}\}$, Herr von Neufchâtel und Châtel-sur-Moselle (* 1417; W 1461; † 4.12.1469) 293

Neuss (Nordrhein-Westfalen, D), Lager vor $68^{162}$

Nevers (Dép. Nièvre, F), Gf. s. Burgund, Johann von

Niclolai, Nicolas, Greffier des Ordens vom Goldenen Vlies (1542-1571) 271 79

Niederlande 9f., 13, 15; s. auch Burgund. Niederlande

Niederösterreich $117^{55 f}$; s. auch Österreich

Hz. s. Maximilian

Statthalter s. Starhemberg, Bartolomäus von

Verwalter der Hauptmannschaft s. Traun, Michael von

Nokerscot, Gilles, burgund. Wappenkönig Flandern $62^{+97}, 78^{+212}, 249,253$, 258, 266, $268 \mathrm{f}$.

Notre-Dame-lez-Douai (Dép. Nord, F) $236^{295}$

Noyelle-Vion (Dép. Pas-de-Calais, F), Baudot de \{32\}, Herr von Catheux (W 1433, † 1461) 292

Nürnberg (Bayern, D) $175^{5}$ 
O

Österreich, Austrice, Ostrice 47, $133^{140}$; s. auch Niederösterreich

Hz./Ehz. s. Friedrich III.; Maximilian; Philipp der Schöne; Sigmund

Hz.in s. Maria

Marschall s. Nassau, Adolf von

Haus

s. Friedrich III.

s. Maximilian

Katharina $(† 1493) 121^{76}$

Bruder s. Friedrich III.

Ehemann s. Baden, Karl von

Oostrevant s. Ostrevant

Orange, Orenges (Dép. Vaucluse, F),

Fürst (prince) s. Johann II. und Ludwig von Chalon

Orden s. Hermelinorden; Hosenbandorden; Michaelsorden; Vlies, goldenes

Orléans, Aurelianum (Dép. Loiret, F), 90 Hz. s. Karl

Orscamp, burgund. Poursuivant s. Quiquelberghe, Armand de

Ostia, Julianus von, päpst. Legat $48^{32}$

Ostrevant, Oostrevant (Teil des Hennegaus), Gf. s. Borselen, Frank van

Ostrice s. Österreich

Ostriche, Herold 277

Ovid, röm. Dichter († um 17 n.Chr.) 86

$\mathbf{P}$

Pallas Athene, griech. Göttin 86

Papst 30; s. Gregor I.; Sixtus IV.

Paris (F), Parlament 16

Pedro Manrique († 1515), Hz. von Najera, Gf. von Trevino $257^{+20}$

Peletier, Guillaume, burgund. Herold Namur $62^{100}, 288$

Perche (Le) (Region in der südl. Normandie, F), Gf. s. Johann

Petrus, Apostel 92

Pfalz bei Rhein (D), Pfalzgraf (comes palatinus), s. Friedrich I.; Philipp

Philibert, Hz. von Savoyen (1465-1482) $259^{+32}$

Philipp II., Kg. von Makedonien ( $† 336$ v. Chr.) 86
Philipp II. \{172\}, Kg. von Spanien (1527-1598), 6. Souverän des Ordens vom Goldenen Vlies (seit 1555) 271

Philipp der Gute $\{01\}$, Hz. von Burgund und Brabant, Gründer und 1. Souverän des Ordens vom Goldenen Vlies $\left({ }^{*} 21.7 .1396\right.$; † 15.6.1467) 7 , 31, 54 f., 59, $69^{170 f}, 71$ f. ${ }^{183}, 76^{207}, 79^{217}$, $87-94^{+262}, 130$ f., $139,145,158,187^{+73}$, $233^{283}, 241,243^{342}, 269,291^{+2}$

Söhne s. Karl der Kühne sowie Burgund, Anton und Baudouin Schwester s. Burgund, Maria von Enkel s. Maria; Burgund, Philipp von Patenkinder s. Commynes, Philippe de; Crèvecœur, Philippe de; Pot, Philippe

Räte s. Clugny, Ferry de; Crèvecœur, Philippe de; Greveray Godefroy Kammerherr s. Crèvecœur, Philippe de

Wappenoffiziere s. Aliemar, Enguerrand; Hennegau; Rupelmonde

Philipp der Kühne († 1404), Hz. von

Burgund $233^{283}$

Tochter s. Maria von Burgund

Philipp der Schöne \{86\}, Erzhz. von Österreich, späterer Hz. von Burgund ( $\left.{ }^{*} 22.6 .1478, \mathrm{~W} 1481, \dagger 25.9 .1506\right)$, 4. Souverän des Ordens vom Goldenen Vlies $46^{16}, 71^{179}, 83^{+241}$

Eltern s. Maximilian I. und Maria von Burgund

Hof $8^{2}$

Räte s. Burgund, Anton von; Carondelet, Jean de

Kammerherr s. Carondelet, Jean de Philipp, Kurfürst und Pfalzgraf bei

Rhein $(† 1508) 31^{+93}, 259^{+27}$

Onkel s. Friedrich I.

Pfirt, Ferrette (Dép. Haut-Rhin, F) $43^{3}$

Gf. s. Maximilian

Picardie, Piccardie s. Pikardie

Pierre, Herr s. Spiere, Espierre

Pikardie, Picardie, Piccardie (nordfrz. Region mit Amiens als Zentrum) 16, $69^{171}$

Gouverneur s. Crèvecœur, Philippe de 
cappitaine generale s. Burgund, Philipp von

Pimentel (Adelsfamilie aus Kastilien), Rodrigo Alfonso († 1499), Gf. von Benavente $257^{+19}$

Plato, antiker Philosoph $(† 348 / 347$ v. Chr.) $89 \mathrm{f}$.

Poitiers (Dép. Vienne, F) 7, 280

Pont-à-Vendin (Dép. Pas-de-Calais, F) $267 f^{55 f}$

Pontailler (Dép. Côte-d'Or, F), Guy de $\{\mathbf{3 1}\}$, Herr von Talmay $\left({ }^{*} 1392\right.$; W 1433; † 1437) 292

Porcien (Dép. Ardennes, F), Gf. s. Croy

Portenau, Pordenone (Venetien, I), Herr $43^{3}$; s. Maximilian

Portugal

Familie s. Eleonore; Isabella; Johann Kg. s. Eduard I.; Johann

Pot:

Philippe $\{\mathbf{6 0}\}$, Herr von la RocheNolay, grant maître de l'hôtel Hz. Karls, frz. grand sénéchal und „chevalier d'honneur du Parlement" von Burgund, Rat und Kammerherr Kg. Ludwigs XI., Mitglied des frz. Michaelsordens ( ${ }^{*}$ um 1428; W 1461; Ausschluss 1481; † 16.9.1493) $7 \mathrm{f}$., 24-28, 51, 62, 66, 69f. ${ }^{+170}, 73,110,115$, 128, 185, 196 f., 250-252 $2^{+5}, 254,266$, 273f., $284^{110}, 293$

Pate s. Philipp der Gute

Renier $\{2\}$, Herr von la Prugne und la Roche-Nolay ( ${ }^{*}$ um 1362; W 1430; † 30.10.1432) 291

Prüschenk, Sigmund, Vertrauter Maximilians $236^{297}$

Prugne (La) (Dép. Allier, F), Herr s. Pot, Renier

Pubilus Rutilius Rufus, röm. Politiker († 78 v. Chr.) 92

Q

Quesnoy (Dép. Nord, F), burgund. Persevant $77^{212}$

Quiquelberghe, Armand de, burgund. Poursuivant Orscamp 11, 282
$\mathbf{R}$

Ravenstein, Ravestain, Ravensteyn (Prov. Nordbrabant, NL), Herr s. Kleve, Adolf von

Ravenstein, burgund. Herold s. Haynnau, Watelet de

Rebecque, Gilles de, burgund. Herold Rupelmonde 11, $196 \mathrm{f}^{+109}, 274 \mathrm{f}$., $279-281^{+98}$

René, Hz. von Lothringen († 1508) 449, $71^{178}$

Rethel (Dép. Ardennes, F), Gf. s. Burgund, Johann von

Reubempré s. Rubempré

Rhodos (Insel in der Ägäis, GR) 89

Riario della Rovere (ital. Adelsfamilie aus Savona), Girolamo (Incluytus $\mathrm{Hi}$ eronimus), Vizegraf von Riario, Neffe und militiärischer Befehlshaber Papst Sixtus IV., Herr von Imola und Forlì $\left(†\right.$ 1488) $10,256^{+13}$

Richebourg (Dép. Pas-de-Calais, F), Herr s. Luxemburg, Jacques de Riplemonde s. Rupelmonde

Roche-en-Ardenne (La), La Roiche (Prov. Luxemburg, B), Gf. s. Burgund, Antoine von

Roche-Nolay (La), Roiche de Nolay (heute: La Roche-Pot) (Dép. Côte-d'Or, F), Herr s. Pot

Rochefort(-sur-Nenon) (Dép. Jura, F) $209^{180}$

Rodemack, Rodemacher, Rodemach (Dép. Moselle, F), Gerhard von, Anführer der antiburgund. Partei in Luxemburg († 1492) $241^{+327}$

Roich... s. Roch...

Rom, Rome (Italien) 93, 242

Empereur s. Deutsches Reich

Kurie, Apostolische Stuhl 243-245 s. auch Papst

Kardinal s. Clugny Ferry de Nuntius s. Tolentis, Lucas de Gesandte 21

Protonotare s. Clugny, Guillaume de; Hesseler, Georg 
Patrizierfamilien s. Camiller; Fabier; Fabrizio; Martelli; Scipio

S. Vitale, Kardinal s. Clugny, Ferry de

Romanus, Aegidius († 1316) 92

Romont (Kanton Freiburg, CH), Gf. s. Savoyen, Jakob von

Rose, Colinet, burgund. Herold Limburg $62^{+99}, 68,77^{212}, 127 \mathrm{f} ., 250,253,260,285$

Roubaix, Robais (Dép. Nord, F), Jean de $\{3\}$, Herr von Roubaix und Herzeele ( ${ }^{*}$ um Juni 1369, W 1430, † 7.6.1449) 291

Rovere della (ital. Adelsfamilie) s. Riario Roye (Dép. Somme, F), Guy de $\{\mathbf{6 2}\}$, Herr von Roye (W 1461, † 1463) 293

Rubempré, Reubempré (Dép. Somme, F), Jean de $\{73\}$, Herr von Bever (* nach 1430; W 1473; † 5.1.1477) 24, 67 $7^{+145}$, 73, 116, 148, 262, 294

Rupelmonde, Riplemonde, Ripremonde (Ostflandern), burgund. Herold s. Rebecque, Gilles de

Ruter, Nicolas de, burgund. Sekretär $270^{+71}$

\section{S}

Saba, alttest. Kg.in 91

Sabaudia s. Savoyen

Sachsen, Saxe (Ostdeutschland)

Hz. s. Albrecht und Ernst

Räte $46^{18}$

Saint-Bertin, Abtei s. Saint-Omer

Sainte Aldegonde, Jean de, burgund. Herold Lothier $78^{+212}, 267^{+53}, 269$

Sainte-Croix (Dép. Saône-et-Loire, F), Herr s. Vienne, Guillaume de

Saint Empire s. Deutsches Reich

Saint-George (Dép. Côte d'Or, F), Herr s. Vienne, Guillaume de

Saint-George, burgund. Herold $78^{+212}$

Saint-Omer (Dép. Pas-de-Calais, F) (Veranstaltungsort der Ordensfeste in den Jahren 1440 und 1461) 9, 160, 173 332 , 238, 240-242, 263, $292 \mathrm{f}$.

Abtei Saint-Bertin

Äbte $244^{347}$; s. Fillastre, Guillaume;

Lannoy, Jean de
Saint-Pol(-sur-Ternoise) (Dép. Pas-de-

Calais, F) s. Luxemburg

Saint Vitale s. Rom

Salins(-les-Bains) (Dép. Jura, F)

Herr s. Karl; Maximilian

Herold Salins $77^{212}$

Saline $138^{160}$

Salomon, alttest. Kg. 90

Santes (Dép. Nord, F), Herr s. Lannoy, Guilbert de

Santillana (del Mar) (Prov. Kantabrien, E), Marques s. Diego Hurtado de Mendoza

Savoyen, Savoie, Savoye, Sabaudia

(Westalpenraum) 52, 90

Hz. s. Philibert

Hz.in s. Maria; Yolande

Haus

Jakob von $\{84\}$, Gf. von Romont, Heerführer Hz. Karls, Gouverneur von Burgund, Oberkommandierender (capitaine générale) der flämischen Truppen (* 1447-1452; W 1478; $\dagger 30.1 .1486) 9 \mathrm{f} ., 24^{52}, 28 \mathrm{f} ., 31 \mathrm{f} .{ }^{+93}, 108$, 118, $140 \mathrm{f} ., 149,152,155 \mathrm{f} ., 161 \mathrm{f}{ }^{278}$, 177, 181, 193, 204, 209, $213 \mathrm{f} ., 221 \mathrm{f.}^{+236}$, $228,230,233 \mathrm{f}^{+283}, 238,262,265,267$, $282 \mathrm{f} ., 285,294$

Großmutter s. Maria von Burgund Louise von, Tochter Yolandes, Mündel Kg. Ludwigs XI. († 1503) 29, $138^{160}$ Ehemann s. Chalon, Hugues de s. Maria von Burgund Philipp von $\{68\}$, Gf. von Bugey, Herr von Bresse, Hz. Karls Stellvertreter in Burgund, burgund. Pensionär ( ${ }^{*}$ 15.11.1443; W 1468; $\uparrow 7.11 .1497)$ 9, 23 f., $28^{+74}, 52,59$, $67,73^{+192}, 90,116,125-127,134,185$, 196f., 212, 251-254 ${ }^{+6}, 266,274^{+86}$, 280 f., $285^{110}, 293$

Sekretär s. Saynage, Jean

s. Yolande

Saxe s. Sachsen

Saynage, Jean, Sekretär Philipps von

Savoyen 281

Schottland, Kg. s. Jakob I.

Schweiz $210^{184}$ 
Scipio, römische Patrizierfamilie $90^{278}$, 92

Scipio Africanus († 183 v. Chr.), röm. Feldherr und Staatsmann 92

Secille s. Sizilien

Seeland, Zeeland (Niederlande), Gft. 217

Gf. s. Karl; Maximilian

Gouverneur s. Brügge, Ludwig von;

Borsele, Wolfart van

Sellier, Philippe, Händler in Brügge $177^{14}$

Seneca, röm. Philosoph († 65 n.Chr.) 91

Sevilla (Südspanien) 269

Šibenik, Sebenico, Sibinicensis (Kroati-

en), Bischof s. Tolentis, Lucas de

Sicilia, Sicilie s. Sizilien

Sigismund, Kg. von Burgund († 524) 89

Sigmund, Hz. von Österreich und Tirol

$(† 1496) 53^{60}, 259^{+31}$

Neffe s. Maximilian

Rat s. Liechtenstein, Bartholomäus von

Sixtus IV., Papst (1471-1484) 21, $48 \mathrm{f}^{+32 \mathrm{f}}, 243^{339}, 256^{13}$

Neffe/Nepot s. Riario, Girolamo

Gesandte am burgund. Hof s. Tolen-

tis, Lucas de; Ostia, Julianus von militär. Befehlshaber s. Riario, Girolamo

Sizilien, Sicilia, Secille, Cecille (Italien),

Kg. s. Alfons V., Ferdinand

Sluis (Prov. Seeland, NL), capitaine s.

Lalaing, Josse und Simon

Sokrates, griech. Philosoph $(† 399$

v. Chr.) 90

Spanien (Hauptstadt Madrid, E) $169^{313}$

Kg. s. Phillip II

Spiere(-Helkijn), Espierre(-Helchin), de

la Pierre (Prov. Westflandern, B), Herr s. Brügge, Jan von

Starhemberg, Starnberg, Traembourg (in Eferding, Oberösterreich), Bartolomäus von, Rat Ks. Friedrichs III. und Maximilians, Statthalter von Niederösterreich († 1531) $117^{+55}$

Steenberch, Martin, Magister, Dekan in Sainte-Goudule in Brüssel, Hz. Maximilians Sekretär (seit 1461) Greffier des Ordens vom Goldenen
Vlies († 1491) 11, 24 $4^{+52}, 36$ f., 39, 49 $9^{+38}$, 53-58 ${ }^{+62,66,70 f .}, 61-64,77,81,86,96$, 101-103, 106, 108 f., 112, 117, 126, 130, $136 \mathrm{f} ., 138,143,144 \mathrm{f}^{192}, 158-161^{+272,274}$, 163-166, 169+313 $, 172-177,179,181$, 184, 186 f., 189, 191, 193, 195 f., 207 f., 215 f., 220, 225-227, 230, 239, $241 \mathrm{f}$., 245-249, 252, 254-256, 261, 263-265, 268-273, 275, 278, 280-283, 286, $288 \mathrm{f}$.

Steyer, Stire, Hz. s. Maximilian

Stire s. Steyer

Stuart, Maria († 1465), Tochter Jakobs I., Kg. von Schottland $262^{48}$

Ehemann s. Borssele, Wolfart van

\section{$\mathbf{T}$}

Talmay (Dép. Côte-d’Or, F), Herr s. Pontailler, Guy de

Termonde, Tenremonde s. Dendermonde

Ternant (Dép. Côte-d'Or, F), Philippe de $\{\mathbf{2 1}\}$, Herr von Ternant (W 1430, † 1456) 291

Thérouanne, Therouenne (Dép. Pas-deCalais, F) 9, 234 ${ }^{+286}, 289$

Archidiakon s. Clugny, Guillaume de Schlacht bei s. Guinegatte

Thoix, Thois (Dép. Somme, F), Herr s. Crèvecœur, Jacques de

Thomas, Hl. s. Aquin, Thomas von

Toison (Thoison) d'or s. Vlies, Goldenes

Toledo (Spanien) s. García Álvarez de Toledo

Tolentis, Lucas de, Bf. von Šibenik (1470-1491), päpstl. Nuntius, Gesandter Papst Sixtus IV. am burgund. Hof, Hz. Maximilians und Hz.in Marias Rat und maistre de requestes ( $†$ 1491) 21, 48 $8^{\text {+32f. }}, 82 \mathrm{f} ., 108$

Toulongeon (Dép. Saône-et-Loire, F) André de \{27\}, Herr von Mornay (W 1432; † nach 30.11. 1432) 292 Antoine de $\{9\}$, Herr von Traves und La Bastie-sur-Serdon (W 1430; † 29.9.1432) 291

Claude de $\{\mathbf{9 3}\}$, Herr von La Bastie-sur-Serdon ( ${ }^{*}$ 1421/22; W 1481; † 1503) 29, $140 \mathrm{f}^{+174}$ 
Toulouse (Dép. Haute-Garonne, F), Sénéschal, frz. Truppenführer $138^{160}$

Tournai, Tournay (Prov. Hennegau, B) 242

Bistum/Diozöse 163

Bf. s. Clugny, Ferry de, Fillastre, Guillaume

Tours (Dép. Indre-et-Loire, F) 8, 279

Tirol, Tyroll (Hauptstadt Innsbruck, A), Hz. s. Maximilian; Sigmund

Traves (Dép. Haute-Saône, F), Herr s. Toulongeon, Antoine de

Traun, Traon, Train (Oberösterreich), Michael von († ca. 1522), Maximilians Verwalter der niederösterr. Hauptmannschaft $117^{+56}$

Trecht sur Meuse s. Maastricht

Trémoïlle (La), (heute: Tremouille, Dép. Vienne, F), Jean de la $\{\mathbf{1 1}\}$, Herr von Jonvelle (W 1430, † nach 1449) 291

Trevino (Prov. Burgos, E), Gf. s. Pedro Manrique

Trostburg (bei Waidbruck, Prov. Bozen, I), Familie s. WolkensteinTrostburg

Trier, Treves (Rheinland-Pfalz, D) Erzbischof s. Johann II. von Baden Treffen $17 f$., $45^{+13}, 53^{60}, 68 f^{166}, 84^{242}$

Türken $45^{13}, 48^{32}$

Tyroll s. Tirol

U

Ungarn, Hongrie, Honguerie $133^{140 \mathrm{f}}$

Kg. s. Ladislaus; Friedrich III.; Matthias Corvinus

Uutkerke (Prov. West-Flandern, B),

Roland d' $\{4\}$, Herr von Heemsrode und Heestert ( ${ }^{*}$ Ende 14. Jh.; W 1430; † 22.3.1442) 291

\section{V}

Valenciennes (Dép. Nord, F), Veranstaltungsort des Festes des Orden vom Goldenen Vlies (1473) 7, 9, 48 $8^{32}, 51^{47}$, 58, 69, 72, 147, 157-159, 162, 173, 185 , 241, 26754, 269, 294

Valerius Maximius, lat. Schriftsteller 89,92
Veere, La Vere (Prov. Seeland, NL) $149^{215}$ Herr s. Borssele

Velasco, Pedro de († 1492), Gf. von

Haro, Konstabel von Kastilien $256^{+17}$

Veldenz (Rheinland-Pfalz, D), Hz. s.

Ludwig, Hz. von Pfalz-ZweibrückenVeldenz

Vere, la s. Veere

Vergy (Dép. Côte-d'Or, F)

Antoine de \{5\}, Gf. von Dammartin

(W 1430; †29.10.1439) 291

Jean de $\{\mathbf{3 0}\}$, Herr von Fouvent (W 1433; † 1460) 292

Vergil, lat. Dichter († 19 v. Chr.) 87, 92

Vernembourg s. Virneburg

Vesoul (Dép. Haute-Saône, F) $209^{180}$

Vianden (Großhzt. Luxembourg), Gf. s.

Nassau, Engelbert von

Vianen, Vyane (Prov. Süd-Holland, NL),

Herr s. Brederode, Reinald van

Vienne (Dép. Isère, F), Guillaume de $\{1\}$, Herr von Saint-George und Sainte-Croix (W 1430; † 1434) 291

Vieville lez Therouenne s. Thérouanne Schlacht s. Guinegatte

Villiers, Villers (Dép. Val-d'Oise, F), Jean de $\{\mathbf{1 4}\}$, Herr von L'Isle-Adam

(* um 1384, W 1430, † 22.5.1437) 291

Virneburg, Vernembourg (RheinlandPfalz, D)

Gf. Ruprecht IV. $\{35\}$ (W 1433;

$+4.10 .1444) 292$

Georg, Anführer der antiburgund.

Partei in Luxemburg $241^{+327}$

Vlies, Orden vom goldenen, Toison d'or,

Thoison d'or, ordo Velleris Aurei

Gründung 54, 56, 58f., 76 $6^{207}, 88,94,144$

Gründer s. Philipp der Gute

Souveräne 15; s. Philipp der Gute;

Karl der Kühne; Maximilian I.; Phillip der Schöne; Karl V.; Phillip II.

Inaugruation 7, 15 f., 19-22, 37, 56, 59f., 63-65, 72 ${ }^{183}, 75-102,168,261$, 263, 266, 268f., 277, 281

Nachfolgeregelung $15,17^{17}, 21$, 44 f., 50 f., 54 f., 58, 75, 249

Ordenseid 21, 63, 97-99+315, 318

Stellvertreter 15, 44, 163 ${ }^{+289}, 218$ 
Mitglieder 7, 24, 28, 47, 50 f., 54, 56, 59, 72-74, 79, 159, 269f., 281, 284, 287, 291-294

Neuwahl 10, 14, 23f., 27-31, 34, $53^{58,61}, 56,108^{17}, 111,123^{84}, 131-138$, 140 f., 146-149, 162, 166, 168-170, 175, 179, $181 \mathrm{f} ., 184 \mathrm{f} ., 190,192 \mathrm{f}$., $201 \mathrm{f} ., 237,239,256^{10}, 263,266-268$, 277

Wahlvorschläge 10, $19 \mathrm{f} ., 27,29$, $53^{58}, 58,108^{18,20}, 111,125,132$, $137 \mathrm{f}^{157,160}, 147^{200}, 180^{28}, 202^{+155}$, 237 $7^{302}$, 249f., 256-259, 262 f., 276 Ersatzkandidaten $29^{+80}, 140$ Aufnahme 10, 29f. ${ }^{+91}, 149-152$, $155 \mathrm{f} ., 162,166,168-171,175$, $178 \mathrm{f}^{+20}, 182-184,190,201 \mathrm{f}$, 263-265, 267 f., 277

Aufnahmeeid 10, 30, 51, 70 $0^{+175}$, $97 \mathrm{f}^{+315}, 111,119$ f., $128,151^{+229}$, 154-156, 170 f., 182-184, 190, 199, 202, 207, 265, 276

Treueeid gegenüber dem Souverän $21 \mathrm{f} ., 99 \mathrm{f}$.

Sitzordnung, Rangfolge 24, $28^{+74}$, $33,65-69^{+120}, 72-74,80 \mathrm{f}^{218,}{ }^{222}, 109$, 162-164

correction $23^{+49}$, $111 \mathrm{f}$., 119-128, 157, $166,168,171,199 \mathrm{f}^{+138}, 205,250 \mathrm{f} \mathrm{f}^{+5 f}$, 266, $274 \mathrm{f}$.

Ausschluss $26 \mathrm{f}^{+67}, 71^{178}, 128 \mathrm{f}^{+113}$, $237^{300}$

Ablehnung der Mitgliedschaft 30, $182^{+40}, 202$

Exklusivität der Mitgliedschaft $25^{+59}, 27,70^{+175}, 236$ verstorbene Mitglieder 7, 23, $26 \mathrm{f}$,, 34, 51, 58, 65, 67f., 71-74, 79, 85, 111, 144 f., 147 f., 158, 162, 237, 262 abtrünnige Mitglieder $7,11,16^{16}$, 23, 25-27, 51, 59, 66-71, 73f., $110 \mathrm{f} ., 128 \mathrm{f} ., 144,157,171 \mathrm{f} ., 185$, 195f., 211, 214, 226-228, 236, 242, 251 f., 272 f., 278, 280; s. Burgund, Anton von; Crèvecœur, Philippe de; Damas, Jean de; Luxembourg, Jacques de; Neufchâtel, Jean de; Pot, Philippe;
Amtsträger 15, 21 f., 24, 34f., 99-101, 159, 269 f., 281, 284

Kanzler 11, 35 ; s. Fillastre, Guillaume; Clugny, Ferry de; Lannoy, Jean de

Neuwahl 35, 242-248 ${ }^{+345}, 289$

Einkünfte 289

Greffier 11; s. Blioul, Laurent du; Niclolai, Nicolas; Steenberch, Martin

Einkünfte 24, 159, 263

Trésorier 11, 35, 106-108; s.

Clugny, Guillaume de; Gondeval,

Nicolas de; Gros, Jean

Neuwahl 35, 106-108, 263

Wappenkönig Toison d'or 11; s.

Gobet, Gilles; Ysaac, Thomas

Einkünfte 24, 263

Im Auftrag des Ordens tätige

Wappenkönige, Herolde u.a. 11, 21, 27, 62, $77 \mathrm{f}^{+212}, 80-82,84,108$, 128, 195 f., 200 f., 212, 226-228, 242, 249f., 272, 275, 281; s. auch Charolais, Limburg, Flandern; Fusil, Gobet, Gilles de; Hennegau; Lothier; Namur; Nokerscot, Gilles; Orscamp; Peletier, Guillaume; Quiquelberghe, Armand de

Gesandtschaften des Ordens 25, 29f., 166 f., 169 f., 175, 177, 179, 181-184, 201, 214, 268, 277; s. Gobet, Gilles; Liechtenstein, Bartholomäus; Ravenstein; Rupelmonde

Instruktionen 166-172, 175, 177, 182, 184, 216, 227, 268, 277

Ordensfeste 22-25, 32-34, 37

Einladungsschreiben $7,14,16$, $19 \mathrm{f}^{+27}, 23,32,34 \mathrm{f} ., 58-61^{+90}, 65-69$, 75, 95, 125-127, 172, 184 f., 190, 193f., 196, 198-200, 210-212, $220,237^{302}, 241 \mathrm{f} ., 247-250,252 \mathrm{f}$., 255-258, 260 f., 263, 275-279, 281 f., $287 \mathrm{f}$.

Vorladungen $7,16^{16}, 25-27,34 \mathrm{f}$., $59-62^{+83}, 66-70,125-129,157,171$, 184f., 194-197, 211f., 226, $237^{300}$, 242, 249-252, 254f., 261, 272-276, 278-280, 288 
Zusage (der Teilnahme) 279

Absage (der Teilnahme) 19f., 23, 32 f., 58, 66, 126, 128, 166, 182,

196f., 212, 221, 227, 249, 255-261, $274 \mathrm{f}^{+84,86}, 276,282$

Stellvertreter/procuracion 20, 26, 65-68, 202, 232, 241 $1^{330}, 249 \mathrm{f}^{+5}$, 255-258, 261, 266, 276, 281-283, 286

Vollmachten 32, 58, 65f., 185, 212, 249, 255-257, 261, 283, 286

Fehlende Entschuldigungsschreiben 23, 65-67, 125, 128, 166, 190, $237^{300}, 251^{6}, 255,281 \mathrm{f}$.

Ausschluss (der Teilnahme) 26, $70 \mathrm{f} ., 110 \mathrm{f}$.

Festsaal $102 \mathrm{f} ., 117 \mathrm{f}$.

Festmahl 22, $102 \mathrm{f} ., 110,117 \mathrm{f}^{+63}$, 145,164

Schweigegebot 10, 30, 119, $175-177^{+4}, 268$

Beschlussfähigkeit 51f., 231, 288

Absage (des Festes) 32, 34,

207-226, 283-287

Absageschreiben 221-225, 230+266 Schiedsgericht 10, $31 \mathrm{f} ., 123 \mathrm{f}^{+86}$, 152-155, 180 f., 203-207, $233 \mathrm{f}$.

Gottesdienste 14, 20, 22-24, 26, 162 , 261

Prozessionen $21 \mathrm{f} ., 80 \mathrm{f}^{+222}, 102,108-$ $110^{+21}, 112,117,141,157,164,187$ Gottesdienst zur Erhebung Maximilian zum Souverän 13, 20-22, 63-65

Verspergottesdienst 105f., $108 \mathrm{f}$. Große Messe (zu Ehren St. Andreas) $22,33,53^{61}, 65,110,112-117$, 119, $136^{153}, 139$

Münzopfer (offrande) 26, 112-117, 142

Totenvigil 22, $118 \mathrm{f}^{+64}$

Totenmesse $22,65,72^{183}, 129 \mathrm{f}^{+121}$, 139, 141-145

Kerzen-Opfer 26, 139

Marienmesse 25, $156 \mathrm{f} ., 161 \mathrm{f}+{ }^{+280}$, 164, 172

Hl. Geist-Messe 25, 156 f., 162, $172 \mathrm{f}^{+330}$
Andreas-Messe (30. Nov.) 33f., $186-188^{+74}$

Ordenstreffen zum St. Andreas-Tag

33f., 36, 186-193, 288

Außerordentliche Sitzungen 14, 25, 29, 32-35, 48, 63, 175-181, 181-186, 193-207, 208-221, 228-230, 230-235, 235-238, 238-248, 281, 284, 287

Archiv, graffe 32, 35, 60, $107 \mathrm{f} .$, 196, 198, $277 \mathrm{f.}^{+90}$

Protokollbücher 35, 60, 62, 158, 211, 221, 230, 245; s. auch Archivalienverzeichnis

Statuten $10,15,16^{+14}, 26^{67}, 29-31$, $33^{+108}, 44$ f., $50 \mathrm{f}^{+44}, 54-59^{+71}, 70^{+175}, 75$, $77,80^{218}, 85,88^{268}, 94-96,99 \mathrm{f}^{+326}, 104$, $107 \mathrm{f}^{+11}, 111 \mathrm{f} ., 118-120^{+71,74}, 128 \mathrm{f}^{+121}$, $131-133^{+132}, 135,137,140,145$ f. $^{192}$, 150 f., $154-156,161,163^{+289}, 166,168$, $170 \mathrm{ff}^{+323}, 173,178 \mathrm{f} ., 181-183^{+40}, 190$, $197,199,218,220^{+222}, 232-234^{+278,287}$, 236, 239-241 ${ }^{+330}, 244$ f. $^{+345}, 247$, 249-252, 269, 271f., 274f., 277

Revision 1445/46 33, $101^{326}, 171^{323}$ Übersetzungen $10,15,56 \mathrm{f}$ $^{+71}$, 151, 171

Chronik über die Taten verstorbener Mitglieder $145^{192}$

Meßbuch 30, 97-101+315, 151, 155, 247

Privilegien 24f., $158 \mathrm{f}^{+263}, 269-272$

Besitzungen 35

Siegel 35, 60-62+88, 108, 129, 158, 159, 195, 244, 248, 252, 272 f., 275 , $278^{+92}, 286,288 \mathrm{f}$.

Kerzenständer (harce) 129, $143 \mathrm{f}^{+186}$, Schwurkreuz 30, 97-101+315, 151, 155, 183, 247

Tapisserien $20,75 \mathrm{f}^{+207}$

liturgisches Gewänder 35, $109^{+22}$, 142, 145

Wappenschilde $20^{+29}, 26,65 \mathrm{f}^{120,136}$, 71-74 ${ }^{+187}$, 109f., 112 f., 139, 142, 143f., 162-164, 173, 182, 195

Ordensornat 21, 35, 77210, 96, 145, 173 Ordenskette/Kollane, collier 7, $9 \mathrm{f}$., 21, 27, 54, 56, 68 $8^{162}, 70,75,78-82^{+215}$, 91, 95 f., 111, 128, 134 f., 140 f., 156, 
$166,168-171,178^{+15}, 182,184,187$, $190,202,234-236^{+287}, 251^{6}, 265,277$, 286, 289

Tragepflicht 7, 9, 178 ${ }^{+15}, 238$

Kleine Ordenskette am Seidenband $251^{6}$

Große Ordenskette des Herolds (Potence) 79f. ${ }^{216}, 96,109$

Mäntel 21, 77-79 $9^{+210}, 96 \mathrm{f}^{+309}, 102$, 112, 118 f., 141, 152f., 161, 173

Kappen (chapperons) $77 \mathrm{f}^{+210}, 96^{+309}$, 112, 118 f., 141, 161, 173

Wassenaar (Prov. Süd-Holland, NL), Jan I. van, Burggf. von Leiden († 1496), Rat und Kammerherr unter Hz. Karl, Hz.in Maria und Hz. Maximilian, Verbündeter der hollandischen Partei der Kabeljauwen 32, $180 \mathrm{f}^{+28 f}$.

Werdenberg, Werdemberch (Burg in Grabs, Kanton St. Gallen, CH), Gf. Haug († 1508), Rat Ks. Friedrichs III. und Maximilians $270^{+67}$

Wiere(-au-Bois), Wierre (Dép. Pas-deCalais, F), Herr s. Bouverien, Jan van der

Wiesbaden (Hessen, D), Gf. s. Nassau, Adolf von

Wilhelm IV., Hz. von Jülich $(†$ 1511) $262^{+44}$

Willerval (Dép. Pas-de-Calais, F), Herr. s. Lannoy

Winchester, Wyncestre (Gft. Hampshire, GB), Gf. s. Brügge, Ludwig von

Windischen Mark (Slowenien), Herr $43^{3}$; s. Maximilian

Windsor (Gft. Berkshire, GB) 268

Wolkenstein-Trostburg (Prov. Bozen, I), Martha von, Ehefrau von Wilhelm von Liechtenstein-Karneid
Woodville, Anton, Schwager Kg. Eduards IV. $(†$ 1483) 17

Wrythe, John, engl. Wappenkönig Garter und Gesandter am burgund. Hof $200^{+143}$

X

Xenophon, griech. Feldherr $(† 429$

v. Chr.) 90

Y

Yolande von Frankreich, Hz.in und Regentin von Savoyen $(† 1478)$ $138^{160}$

Bruder s. Ludwig XI.

Tochter s. Savoyen, Louise von

York (England), Haus $46^{16}$

s. Eduard

s. Georg

s. Margarete

Ypern, Ieper, Ypres, Ippre (Prov. Westflandern, B) 9, $240 \mathrm{f}$.

Yrlain s. Irlain

Yrlande s. Irland

Ysaac, Thomas $77^{212}$

$\mathbf{Z}$

Zeeland s. Seeland

Zenon, oström. Kaiser († 491) $91 \mathrm{f}$.

Zutphen (Prov. Geldern, NL) 433, 69166, $83^{238}$

Gf. s. Adolf; Karl; Maximilian

Marschall und Generalstatthalter s.

Nassau, Adolf von

Zweibrücken (Rheinland-Pfalz, D), Hz. s. Ludwig, Hz. von Pfalz-Zweibrücken-Veldenz

Zypern, Cyry (Insel im Mittelmeer), Regent s. Johann von Coïmbra 90 


\section{KIELER WERKSTÜCKE}

\section{Reihe A: Beiträge zur schleswig-holsteinischen und skandinavischen Geschichte}

Hrsg. von Oliver Auge

Band 1 Kai Fuhrmann: Die Auseinandersetzung zwischen königlicher und gottorfischer Linie in den Herzogtümern Schleswig und Holstein in der zweiten Hälfte des 17. Jahrhunderts. 1990.

Band 2 Ralph Uhlig (Hrsg.): Vertriebene Wissenschaftler der Christian-Albrechts-Universität zu Kiel (CAU) nach 1933. Zur Geschichte der CAU im Nationalsozialismus. Eine Dokumentation, bearbeitet von Uta Cornelia Schmatzler und Matthias Wieben. 1991.

Band 3 Carsten Obst: Der demokratische Neubeginn in Neumünster 1947 bis 1950 anhand der Arbeit und Entwicklung des Neumünsteraner Rates. 1992.

Band 4 Thomas Hill: Könige, Fürsten und Klöster. Studien zu den dänischen Klostergründungen des 12. Jahrhunderts. 1992.

Band 5 Rüdiger Wurr / Udo Gerigk / Uwe Törper / Alfred Sielken: Türkische Kolonie im Wandel. Ausländersozialarbeit und Ausländerpädagogik in Schleswig-Holstein (Bandhrsg.: Kai Fuhrmann und Ralph Uhlig). 1992.

Band 6 Torsten Mußdorf: Die Verdrängung jüdischen Lebens in Bad Segeberg im Zuge der Gleichschaltung 1933-1939 (Bandhrsg.: Kai Fuhrmann und Ralph Uhlig).1992.

Band 7 Thorsten Afflerbach: Der berufliche Alltag eines spätmittelalterlichen Hansekaufmanns. Betrachtungen zur Abwicklung von Handelsgeschäften. 1993.

Band 8 Ralph Uhlig: Confidential Reports des Britischen Verbindungsstabes zum Zonenbeirat der britischen Besatzungszone in Hamburg (1946-1948). Demokratisierung aus britischer Sicht. 1993.

Band 9 Broder Schwensen: Der Schleswig-Holsteiner-Bund 1919-1933. Ein Beitrag zur Geschichte der nationalpolitischen Verbände im deutsch-dänischen Grenzland. 1993.

Band 10 Matthias Wieben: Studenten der Christian-Albrechts-Universität im Dritten Reich. Zum Verhaltensmuster der Studenten in den ersten Herrschaftsjahren des Nationalsozialismus. 1994.

Band 11 Volker Henn / Arnved Nedkvitne (Hrsg.): Norwegen und die Hanse. Wirtschaftliche und kulturelle Aspekte im europäischen Vergleich. 1994.

Band 12 Jürgen Hartwig Ibs: Die Pest in Schleswig-Holstein von 1350 bis 1547/48. Eine sozialgeschichtliche Studie über eine wiederkehrende Katastrophe. 1994.

Band 13 Martin Höffken: Die "Kieler Erklärung" vom 26. September 1949 und die "Bonn-Kopenhagener Erklärungen" vom 29. März 1955 im Spiegel deutscher und dänischer Zeitungen. Regierungserklärungen zur rechtlichen Stellung der dänischen Minderheit in Schleswig- Holstein in der öffentlichen Diskussion. 1994.

Band 14 Erich Hoffmann / Frank Lubowitz (Hrsg.): Die Stadt im westlichen Ostseeraum. Vorträge zur Stadtgründung und Stadterweiterung im Hohen Mittelalter. Teil 1 und 2. 1995.

Band 15 Claus Ove Struck: Die Politik der Landesregierung Friedrich Wilhelm Lübke in SchleswigHolstein (1951-1954). 1997.

Band 16 Hannes Harding: Displaced Persons (DPs) in Schleswig-Holstein 1945-1953. 1997.

Band 17 Olav Vollstedt: Maschinen für das Land. Agrartechnik und produzierendes Gewerbe Schleswig-Holsteins im Umbruch (um 1800-1867). 1997.

Band 18 Jörg Philipp Lengeler: Das Ringen um die Ruhe des Nordens. Großbritanniens Nordeuropa-Politik und Dänemark zu Beginn des 18. Jahrhunderts. 1998.

Band 19 Thomas Riis (Hrsg.): Tisch und Bett. Die Hochzeit im Ostseeraum seit dem 13. Jahrhundert. 1998. 
Band 20 Alf R. Bjercke: Norwegische Kätnersöhne als königliche Dragoner. Eine Abhandlung über den Dragonerdienst in Norwegen und die Grenzwache in Schleswig-Holstein 1758-1762. 1999.

Band 21 Niels Bracke: Die Regierung Waldemars IV. Eine Untersuchung zum Wandel von Herrschaftsstrukturen im spätmittelalterlichen Dänemark. 1999.

Band 22 Lutz Sellmer: Albrecht VII. von Mecklenburg und die Grafenfehde (1534-1536). 1999.

Band 23 Ernst-Erich Marhencke: Hans Reimer Claussen (1804-1894). Kämpfer für Freiheit und Recht in zwei Welten. Ein Beitrag zu Herkunft und Wirken der "Achtundvierziger". 1999.

Band 24 Hans-Otto Gaethke: Herzog Heinrich der Löwe und die Slawen nordöstlich der unteren Elbe. 1999.

Band 25 Henning Unverhau: Gesang, Feste und Politik. Deutsche Liedertafeln, Sängerfeste, Volksfeste und Festmähler und ihre Bedeutung für das Entstehen eines nationalen und politischen Bewußtseins in Schleswig-Holstein 1840-1848. 2000.

Band 26 Joseph Ben Brith: Die Odyssee der Henrique-Familie (Bandhrsg.: Björn Marnau und Ralph Uhlig). 2001.

Band 27 Karl-Otto Hagelstein: Die Erbansprüche auf die Herzogtümer Schleswig und Holstein 1863/64. 2003.

Band 28 Annegret Wittram: Fragmenta. Felix Jacoby und Kiel. Ein Beitrag zur Geschichte der Kieler Christian-Albrechts-Universität. 2004.

Band 29 Sönke Loebert: Die dänische Vergangenheit Schleswigs und Holsteins in preußischen Geschichtsbüchern. 2008.

Band 30 Hans Gerhard Risch: Der holsteinische Adel im Hochmittelalter. Eine quantitative Untersuchung. 2010.

Band 31 Silke Hinz: Hochzeit in Kiel. Wandel im Hochzeitsgeschehen von 1965 bis 2005. 2011.

Band 32 Sönke Loebert / Okko Meiburg / Thomas Riis: Die Entstehung der Verfassungen der dänischen Monarchie (1848-1849). 2012.

Band 33 Franziska Nehring: Graf Gerhard der Mutige von Oldenburg und Delmenhorst (14301500). 2012.

Band 34 Simon Huemer: Studienstiftungen an der Christian-Albrechts-Universität zu Kiel. Private Bildungsförderung zwischen Stiftungsnorm und Stiftungswirklichkeit. 2013.

Band 35 Marina Loer: Die Reformen von Windesheim und Bursfelde im Norden. Einflüsse und Auswirkungen auf die Klöster in Holstein und den Hansestädten Lübeck und Hamburg. 2013.

Band 36 Alexander Otto-Morris: Rebellion in the Province: The Landvolkbewegung and the Rise of National Socialism in Schleswig-Holstein. 2013.

Band 37 Oliver Auge (Hrsg.): Hansegeschichte als Regionalgeschichte. Beiträge einer internationalen und interdisziplinären Winterschule in Greifswald vom 20. bis 24. Februar 2012. 2014.

Band 38 Julian Freche: Die Eingemeindungen in die Stadt Kiel (1869-1970). Gründe, Probleme und Kontroversen. 2014.

Band 39 Martin Göllnitz: Karrieren zwischen Diktatur und Demokratie. Die Berufungspolitik in der Kieler Theologischen Fakultät 1936 bis 1946. 2014.

Band 40 Jelena Steigerwald: Denkmalschutz im Grenzgebiet. Eine Analyse der Wissensproduktion und der Praktiken des Denkmalschutzes in der deutsch-dänischen Grenzregion im 19. Jahrhundert. 2015.

Band 41 Caroline Elisabeth Weber: Der Wiener Frieden von 1864. Wahrnehmungen durch die Zeitgenossen in den Herzogtümern Schleswig und Holstein bis 1871. 2015. 
Band 42 Oliver Auge (Hrsg.): Vergessenes Burgenland Schleswig-Holstein. Die Burgenlandschaft zwischen Elbe und Königsau im Hoch- und Spätmittelalter. Beiträge einer interdisziplinären Tagung in Kiel vom 20. bis 22. September 2013. 2015.

\section{Reihe B: Beiträge zur nordischen und baltischen Geschichte} Hrsg. von Hain Rebas

Band 1 Rainer Plappert: Zwischen Zwangsclearing und Entschädigung. Die politischen Beziehungen zwischen der Bundesrepublik Deutschland und Schweden im Schatten der Kriegsfolgefragen 1949-1956. 1996.

Band 2 Volker Seresse: Des Königs "arme weit abgelegenne Vntterthanen". Oesel unter dänischer Herrschaft 1559/84-1613. 1996.

Band 3 Ingrid Bohn: Zwischen Anpassung und Verweigerung. Die deutsche St. Gertruds Gemeinde in Stockholm zur Zeit des Nationalsozialismus. 1997.

Band 4 Saskia Pagell: Souveränität oder Integration? Die Europapolitik Dänemarks und Norwegens von 1945 bis 1995. 2000.

Band 5 Ulrike Hanssen-Decker: Von Madrid nach Göteborg. Schweden und der EU-Beitritt Estlands, Lettlands und Litauens, 1995-2001. 2008.

Reihe C: Beiträge zur europäischen Geschichte des frühen und hohen Mittelalters Hrsg. von Hans Eberhard Mayer

Band 1 Martin Rheinheimer: Das Kreuzfahrerfürstentum Galiläa. 1990.

Band 2 Oliver Berggötz: Der Bericht des Marsilio Zorzi. Codex Querini-Stampalia IV 3 (1064). 1990.

Band 3 Thomas Eck: Die Kreuzfahrerbistümer Beirut und Sidon im 12. und 13. Jahrhundert auf prosopographischer Grundlage. 2000.

Reihe D: Beiträge zur europäischen Geschichte des späten Mittelalters

Hrsg. von Werner Paravicini

Band 1 Holger Kruse, Werner Paravicini, Andreas Ranft (Hrsg.): Ritterorden und Adelsgesellschaften im spätmittelalterlichen Deutschland. Ein systematisches Verzeichnis. 1991.

Band 2 Werner Paravicini (Hrsg.): Hansekaufleute in Brügge. Teil 1: Die Brügger Steuerlisten 1360-1390, hrsg. von Klaus Krüger. 1992.

Band 3 Les Chevaliers de l'Ordre de la Toison d'or au $\mathrm{XV}^{\mathrm{e}}$ siècle. Notices bio-bibliographiques publiées sous la direction de Raphaël de Smedt. 1994. 2. Auflage 2000.

Band 4 Werner Paravicini (Hrsg.): Der Briefwechsel Karls des Kühnen (1433-1477). Inventar. Redigiert von Sonja Dünnebeil und Holger Kruse. Bearbeitet von Susanne Baus u.a. Teil 1 und 2. 1995.

Band 5 Werner Paravicini (Hrsg.): Europäische Reiseberichte des späten Mittelalters. Eine analytische Bibliographie. Teil 1: Deutsche Reiseberichte, bearb. von Christian Halm. 1994. 2., durchgesehene und um einen Nachtrag ergänzte Auflage 2001.

Band 6 Rainer Demski: Adel und Lübeck. Studien zum Verhältnis zwischen adliger und bürgerlicher Kultur im 13. und 14. Jahrhundert. 1996.

Band 7 Anne Chevalier-de Gottal: Les Fêtes et les Arts à la Cour de Brabant à l'aube du XV siècle. 1996.

Band 8 Stephan Selzer: Artushöfe im Ostseeraum. Ritterlich-höfische Kultur in den Städten des Preußenlandes im 14. und 15. Jahrhundert. 1996.

Band 9 Werner Paravicini (Hrsg.): Hansekaufleute in Brügge. Teil 2. Georg Asmussen: Die Lübecker Flandernfahrer in der zweiten Hälfte des 14. Jahrhunderts (1358-1408). 1999. 
Band 10 Jean Marie Maillefer: Chevaliers et princes allemands en Suède et en Finlande à l'époque des Folkungar (1250-1363). Le premier établissement d'une noblesse allemande sur la rive septentrionale de la Baltique. 1999.

Band 11 Werner Paravicini, Horst Wernicke (Hrsg.): Hansekaufleute in Brügge. Teil 3. Prosopographischer Katalog zu den Brügger Steuerlisten 1360-1390. Bearbeitet von Ingo Dierck, Sonja Dünnebeil und Renée Rößner. 1999.

Band 12 Werner Paravicini (Hrsg.): Europäische Reiseberichte des späten Mittelalters. Eine analytische Bibliographie. Teil 2: Französische Reiseberichte, bearbeitet von Jörg Wettlaufer in Zusammenarbeit mit Jacques Paviot. 1999.

Band 13 Nils Jörn, Werner Paravicini, Horst Wernicke (Hrsg.): Hansekaufleute in Brügge. Teil 4. Beiträge der Internationalen Tagung in Brügge April 1996. 2000.

Band 14 Werner Paravicini (Hrsg.): Europäische Reiseberichte des späten Mittelalters. Eine analytische Bibliographie. Teil 3. Niederländische Reiseberichte. Nach Vorarbeiten von Detlev Kraack bearbeitet von Jan Hirschbiegel. 2000.

Band 15 Werner Paravicini (Hrsg.): Hansekaufleute in Brügge. Teil 5. Renée Rößner: Hansische Memoria in Flandern. Alltagsleben und Totengedenken der Osterlinge in Brügge und Antwerpen (13. bis 16. Jahrhundert). 2001.

Band 16 Werner Paravicini (Hrsg.): Hansekaufleute in Brügge. Teil 6. Anke Greve: Hansische Kaufleute, Hosteliers und Herbergen im Brügge des 14. und 15. Jahrhunderts. 2011.

Band 17 Sonja Dünnebeil (Hrsg.): Die Protokollbücher des Ordens vom Goldenen Vlies. Teil 4: Der Übergang an das Haus Habsburg (1477 bis 1480). Vorwort von Werner Paravicini. 2016.

\section{Reihe E: Beiträge zur Sozial- und Wirtschaftsgeschichte}

Hrsg. von Gerhard Fouquet

Band 1 Thomas Hill / Dietrich W. Poeck (Hrsg.): Gemeinschaft und Geschichtsbilder im Hanseraum. 2000.

Band 2 Gabriel Zeilinger: Die Uracher Hochzeit 1474. Form und Funktion eines höfischen Festes im 15. Jahrhundert. 2002.

Band 3 Sascha Taetz: Richtung Mitternacht. Wahrnehmung und Darstellung Skandinaviens in Reiseberichten städtischer Bürger des 16. und 17. Jahrhunderts. 2004.

Band 4 Harm von Seggern / Gerhard Fouquet / Hans-Jörg Gilomen (Hrsg.): Städtische Finanzwirtschaft am Übergang vom Mittelalter zur Frühen Neuzeit. 2007.

Band 5 Gerhard Fouquet (Hrsg.): Die Reise eines niederadeligen Anonymus ins Heilige Land im Jahre 1494. 2007.

Band 6 Sven Rabeler: Das Familienbuch Michels von Ehenheim (um 1462/63-1518). Ein niederadliges Selbstzeugnis des späten Mittelalters. Edition, Kommentar, Untersuchung. 2007.

Band 7 Gerhard Fouquet / Gabriel Zeilinger (Hrsg.): Die Urbanisierung Europas von der Antike bis in die Moderne. 2009.

Band 8 Dietrich W. Poeck: Die Herren der Hanse. Delegierte und Netzwerke. 2010.

Band 9 Carsten Stühring: Der Seuche begegnen. Deutung und Bewältigung von Rinderseuchen im Kurfürstentum Bayern des 18. Jahrhunderts. 2011.

Band 10 Sina Westphal: Die Korrespondenz zwischen Kurfürst Friedrich dem Weisen von Sachsen und der Reichsstadt Nürnberg. Analyse und Edition. 2011.

Band 11 Ulf Dirlmeier: Menschen und Städte. Ausgewählte Aufsätze. Herausgegeben von Rainer S. Elkar, Gerhard Fouquet und Bernd Fuhrmann. 2012. 
Reihe F: Beiträge zur osteuropäischen Geschichte

Hrsg. von Ludwig Steindorff und Martina Thomsen

Band 1 Peter Nitsche (Hrsg.), unter Mitarbeit von Ekkehard Klug: Preußen in der Provinz. Beiträge zum 1. deutsch-polnischen Historikerkolloquium im Rahmen des Kooperationsvertrages zwischen der Adam-Mickiewicz-Universität Poznań und der Christian-AlbrechtsUniversität zu Kiel. 1991.

Band 2 Rudolf Jaworski (Hrsg.): Nationale und internationale Aspekte der polnischen Verfassung vom 3. Mai 1791. Beiträge zum 3. deutsch-polnischen Historikerkolloquium im Rahmen des Kooperationsvertrages zwischen der Adam-Mickiewicz-Universität Poznań und der Christian-Albrechts-Universität zu Kiel, unter Mitarbeit von Eckhard Hübner. 1993.

Band 3 Peter Nitsche (Hrsg.): Die Nachfolgestaaten der Sowjetunion. Beiträge zur Geschichte, Wirtschaft und Politik. Herausgegeben unter Mitarbeit von Jan Kusber. 1994.

Band 4 Stephan Conermann / Jan Kusber (Hrsg.): Die Mongolen in Asien und Europa. 1997.

Band 5 Randolf Oberschmidt: Rußland und die schleswig-holsteinische Frage 1839-1853. 1997.

Band 6 Rudolf Jaworski / Jan Kusber / Ludwig Steindorff (Hrsg.): Gedächtnisorte in Osteuropa. Vergangenheiten auf dem Prüfstand. 2003.

Band 7 Ulrich Kaiser: Realpolitik oder antibolschewistischer Kreuzzug? Zum Zusammenhang von Rußlandbild und Rußlandpolitik der deutschen Zentrumspartei 1917-1933. 2005.

Band 8 Annelore Engel-Braunschmidt / Eckhard Hübner (Hrsg.): Jüdische Welten in Osteuropa. 2005.

Band 9 Martin Aust / Ludwig Steindorff (Hrsg.): Russland 1905. Perspektiven auf die erste Russische Revolution. 2007.

Band 10 Sven Freitag: Ortsumbenennungen im sowjetischen Russland. Mit einem Schwerpunkt auf dem Kaliningrader Gebiet. 2014.

Reihe G: Beiträge zur Frühen Neuzeit

Hrsg. von Olaf Mörke

Band 1 Rolf Schulte: Hexenmeister. Die Verfolgung von Männern im Rahmen der Hexenverfolgung von 1530-1730 im Alten Reich. 2000. 2., ergänzte Auflage 2001.

Band 2 Jan Klußmann: Lebenswelten und Identitäten adliger Gutsuntertanen. Das Beispiel des östlichen Schleswig-Holsteins im 18. Jahrhundert. 2002.

Band 3 Daniel Höffker / Gabriel Zeilinger (Hrsg.): Fremde Herrscher. Elitentransfer und politische Integration im Ostseeraum (15.-18. Jahrhundert). 2006.

Band 4 Volker Seresse (Hrsg.): Schlüsselbegriffe der politischen Kommunikation in Mitteleuropa während der frühen Neuzeit. 2009.

Band 5 Björn Aewerdieck: Register zu den Wunderzeichenbüchern Job Fincels. 2010.

Band 6 Tatjana Niemsch: Reval im 16. Jahrhundert. Erfahrungsräumliche Deutungsmuster städtischer Konflikte. 2013.

Band 7 Martin Pabst: Die Typologisierbarkeit von Städtereformation und die Stadt Riga als Beispiel. 2015.

Reihe H: Beiträge zur Neueren und Neuesten Geschichte Hrsg. von Christoph Cornelißen

Band 1 Lena Cordes: Regionalgeschichte im Zeichen politischen Wandels. Die Gesellschaft für Schleswig-Holsteinische Geschichte zwischen 1918 und 1945. 2011.

Band 2 Birte Meinschien: Michael Freund. Wissenschaft und Politik (1945-1965). 2012. 
Band 3 Stefan Bichow: Die Universität Kiel in den 1960er Jahren. Ordnungen einer akademischen Institution in der Krise. 2013.

www.peterlang.com 